\title{
DEL RURAL AGRARIO AL RURAL PERIURBANO: INSTRUMENTOS DE DESARROLLO RURAL EN LA COMARCA DE TORRIJOS (TOLEDO)
}

TESIS DOCTORAL

Aránzazu Martín Pérez

Ingeniero Agrónomo

MADRID, 2016 



\section{DEL RURAL AGRARIO AL RURAL PERIURBANO: INSTRUMENTOS DE DESARROLLO RURAL EN LA COMARCA DE TORRIJOS (TOLEDO)}

TESIS DOCTORAL

Aránzazu Martín Pérez

Ingeniero Agrónomo

Directora

Dª Ana Velasco Arranz

Ingeniero Agrónomo

Doctora en Sociología

MADRID, 2016 

Tribunal 

DEDICATORIA

A mi padre, por enseñarme con su ejemplo el valor del esfuerzo, de la superación y de la lucha por alcanzar aquello en lo que uno cree. 



\section{AGRADECIMIENTOS}

Son muchas las personas que han supuesto un indudable apoyo para poder realizar y terminar a tiempo esta Tesis Doctoral. Desde estas líneas quisiera agradecer a todas ellas el tiempo que han dedicado a escucharme, a compartir reflexiones comunes tratando de aclarar ideas y centrar el camino en momentos decisivos, a través de sus opiniones, y conocimientos.

En primer lugar dar las gracias a Ana Velasco, mi directora de Tesis, por el esfuerzo, el compromiso, el apoyo, la paciencia y la dedicación en todo momento y situación, con aportaciones y revisiones continuas, siempre con buen ánimo y espíritu colaborador, sin la que hubiera sido imposible llegar a buen término esta investigación. Gracias Ana por tu implicación y generosidad.

Quiero dar las gracias también a mi profesora de Derecho Agrario Enedina Calatayud, impulsora de la idea de convertirme en Doctor, y recoger en ella mis agradecimientos hacia todos los profesores que a lo largo de mi vida, han forjado mi persona y han hecho posible llegar hasta aquí.

Quisiera agradecer asimismo a los funcionarios de la Consejería de Agricultura, Medio Ambiente y Desarrollo Rural de la Junta de Comunidades de Castilla la Mancha, por su disponibilidad y atención en las numerosas ocasiones que he dispuesto de su tiempo para enriquecer esta investigación.

Para terminar quisiera dar las gracias a toda mi familia, a mis padres, esposo y a mis tres hijos que en la medida de sus posibilidades han aportado su granito de arena en la realización de esta Tesis. 



\section{INDICE}

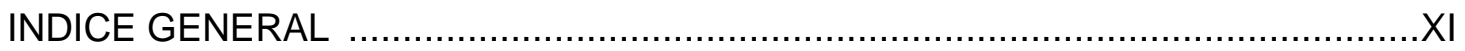

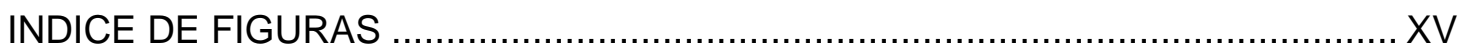

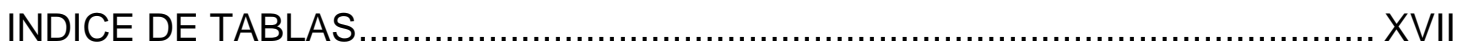

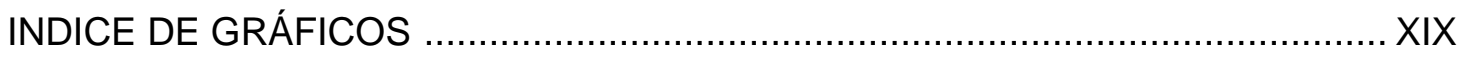

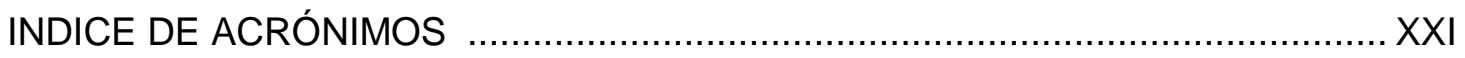

RESUMEN

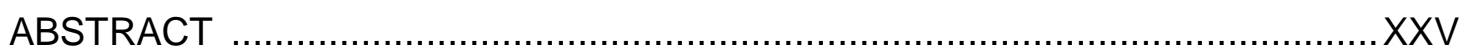

\section{BLOQUE I: INTRODUCCION Y ANTECEDENTES}

\section{CAPITULO1:INTRODUCCIÓN, OBJETIVOS, METODOLOGÍA Y ESTRUCTURA ...1}

1.1 Antecedentes y justificación de la investigación................................................

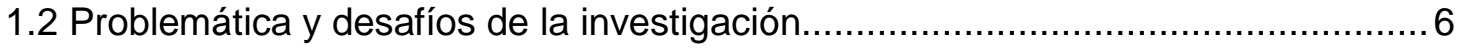

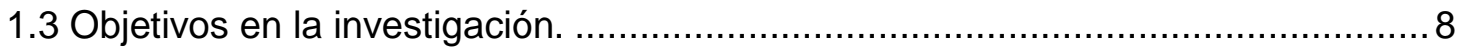

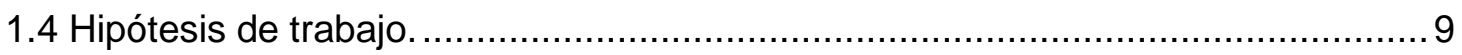

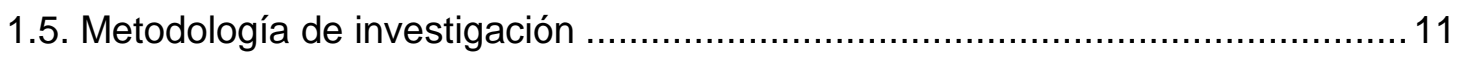

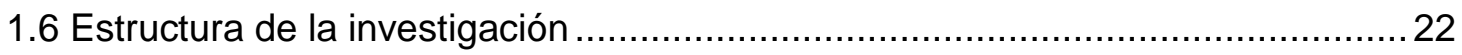

BLOQUE II: MARCO TEORICO

CAPITULO 2: DESARROLLO RURAL: CONCEPTOS A CONSIDERAR................23

2.1 Territorio, un espacio de múltiples miradas............................................... 25

2.2 Ruralidad: Un concepto con múltiples acepciones ....................................... 30

2.2.1 Dinámica gradual entre lo Rural y lo Urbano: lo Periurbano....................41

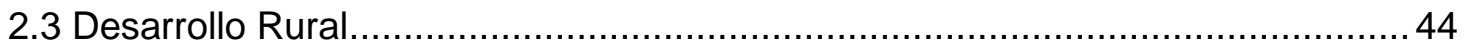

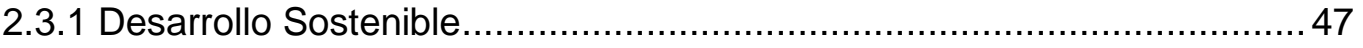

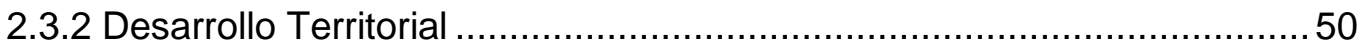


2.4. Grupos de Desarrollo Rural . .53

2.4.1 Proyectos dentro de los Grupos de Desarrollo Rural. 61

\section{CAPITULO 3: EVOLUCIÓN HISTÓRICA DE LA POLÍTICA DE DESARROLLO} RURAL EN EUROPA .......................................................................67

3.1 Breve recordatorio de los hitos que han acompañado esta política ...................69

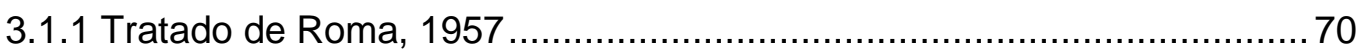

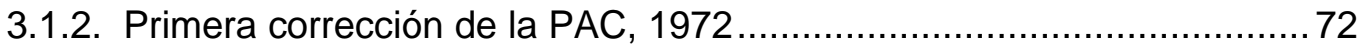

3.1.3 FEDER. Origen Política Regional Europea (1975-1986).......................73

3.2 Cimientos de la Política de Desarrollo Rural: ........................................... 75

3.2.1 La reforma de los fondos estructurales en $1988 \ldots \ldots \ldots \ldots \ldots \ldots \ldots \ldots \ldots \ldots . . . . . . \ldots \ldots$

3.2.2 Aparición de LEADER (1991), basada en "El futuro del mundo rural",

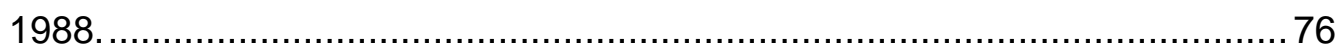

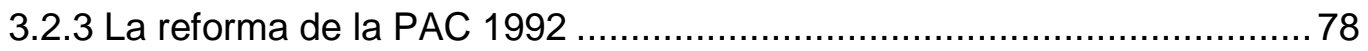

3.4 Nueva Reforma de la PAC y nuevo Reglamento de Desarrollo Rural.................. 84

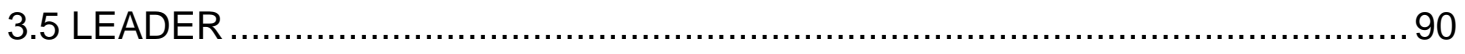

3.5.1 Primer Período 1991-1993: LEADER I............................................. 90

3.5.2 Segundo Período 1994-1999: LEADER II y PRODER.......................... 93

3.5.3 Tercer Período 2000-2006: LEADER + y PRODER II ........................... 96

3.6 Politica Europea de Desarrollo Rural (2007-2013) ....................................... 102

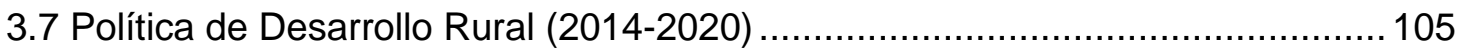

CAPITULO 4: ESPACIO RURAL PERIURBANO ............................................. 113

4.1 Espacios Periurbanos: Definiciones y funciones...................................... 115

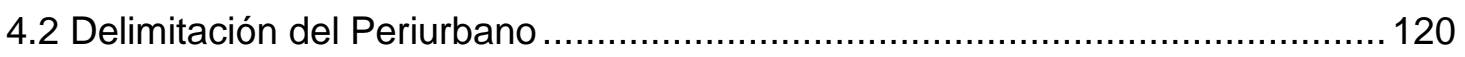


4.3 Clasificaciones de Periurbano: Dificultad para su identificación y

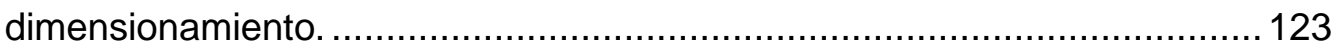

4.4 Procesos comunes en espacios periurbanos............................................. 128

4.5 Conflictos-tensiones en el rural periurbano.................................................... 132

4.6 Periurbano en diferentes países .................................................................... 135

BLOQUE III: COMARCA TORRIJOS

CAPITULO 5: PROGRAMA DE DESARROLLO RURAL DE CASTILLA LA MANCHA 2007-2013 .............................................................................. 139

5.1 Características Generales de Castilla la Mancha......................................... 141

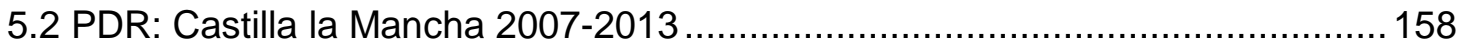

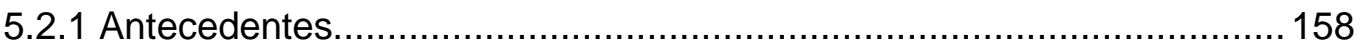

5.2.2 Descripción del Programa............................................................. 160

5.2.3 Ejes y Medidas del PDR ................................................................ 176

5.2.4 Cuadro Financiero del Programa ................................................... 179

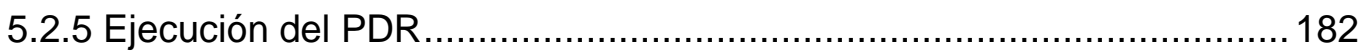

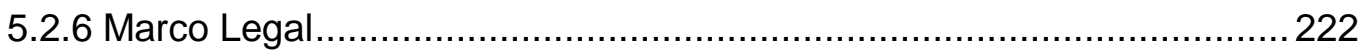

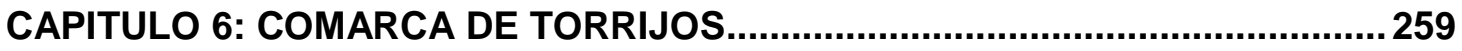

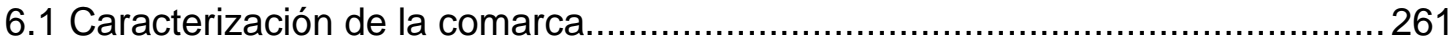

6.2 Sistema Económico-Social: Recursos Humanos y Actividades ...................... 278

6.2.1 Características Demográficas ....................................................... 278

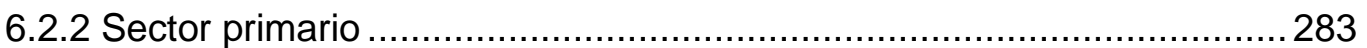

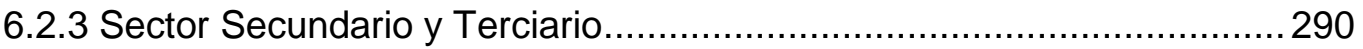

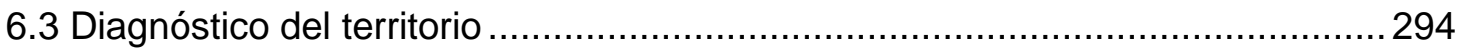

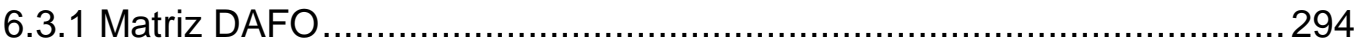


6.4 Desarrollo rural y local dentro del proceso de cambio. 295

6.4.1 PDR 295

6.4.2 GDR Castillos del Medio Tajo. 297

CAPITULO 7: DISCUSION Y CONTRASTACION DE HIPOTESIS 325

CAPITULO 8: CONCLUSIONES 333

CAPITULO 9: BIBLIOGRAFIA 343

BLOQUE IV: ANEXOS

ANEXO I: MARCO LEGAL 359

ANEXO II: ENTREVISTAS 375 


\section{INDICE DE FIGURAS}

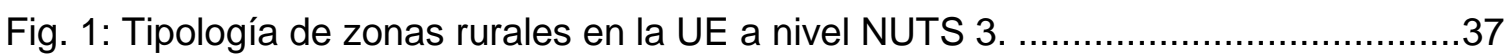

Fig. 2: Clasificación de las zonas rurales en España..................................................39

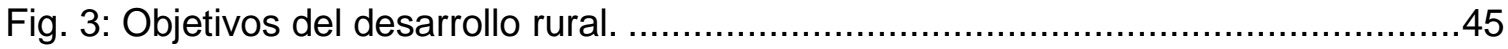

Fig. 4: Composición tipo más frecuente de un GAL..................................................58

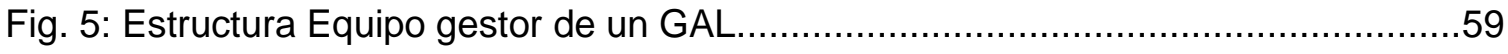

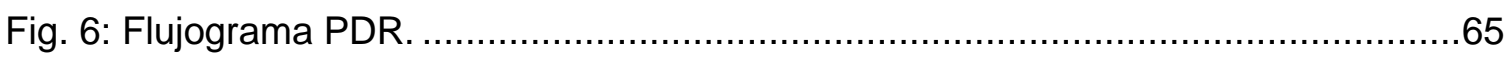

Fig. 7: Evolución de la política del Desarrollo Rural en la Unión Europea......................69

Fig. 8: Cuadro Decálogo Declaración De Cork. ....................................................... 80

Fig. 9: Enfoque Estratégico Política Rural Europea 2007-2013................................86

Fig. 10: Grupos de Desarrollo Rural LEADER + en Castilla la Mancha..........................99

Fig. 11: Localización GAL PRODER 2 Castilla La Mancha.......................................101

Fig. 12: Distribución Grupos Desarrollo Rural Castilla La Mancha 2007-2013............103

Fig. 13 : Estrategia Europa 2020 ….................................................................... 110

Fig. 14: Organización de las coronas periurbanas según Bryant y Russwurm.............121

Fig. 15: De la oposición campo-ciudad a la interfase rural urbana.............................122

Fig. 16: Áreas rurales y su clasificación según ESPON........................................127

Fig. 17: Área Geográfica cubierta por el Programa de Desarrollo Rural. .....................141

Fig. 18: Densidad de población por municipios Castilla la Mancha.............................145

Fig. 19: Tipología de Zonas Rurales en Castilla-la Mancha: Rurales a revitalizar, rurales intermedias, Rurales periurbanas. ............................................................149

Fig. 20: Resumen de las directrices estratégicas de Desarrollo Rural. .......................158

Fig. 21: Distribución por comarcas de la provincia de Toledo. ...................................262

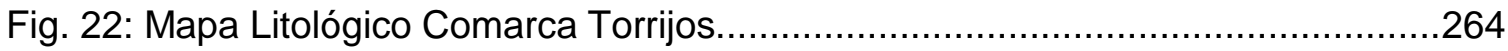

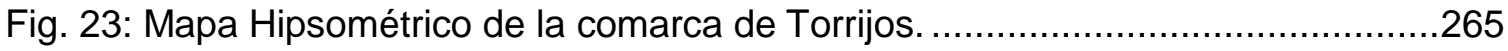

Fig. 24: Área esteparia del Margen derecha del río Guadarrama. ............................268 


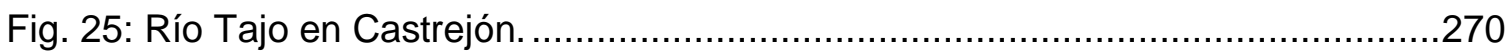

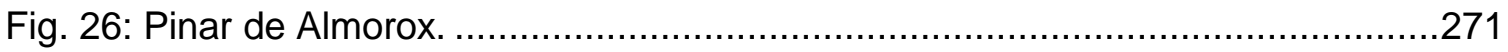

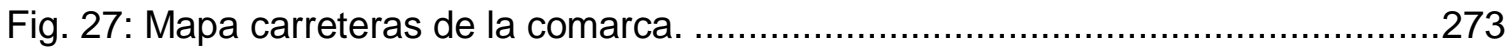

Fig. 28: Ocupados por sector de actividad año 1989.........................................291

Fig. 29: Peso de las medidas del eje 3 ejecutadas a través del eje LEADER en relación al presupuesto, el gasto y la relación con la ejecución física de medida 413..304 Fig. 30: Proyectos ejecutados por el grupo en relación a su estrategia. 308 


\section{INDICE DE TABLAS}

Tabla 1: Definiciones de Ruralidad. 40

Tabla 2: Puntuación para obtener Ruralidad. 64

Tabla 3: Distribución Gasto Agrario entre los 2 Pilares PAC.......................................83

Tabla 4: Ejes y Medidas de Actuación Política Desarrollo Rural 2007-2013.................87

Tabla 5: Directrices Estratégicas Comunitarias de Desarrollo Rural 2007-2013. ...........88

Tabla 6. Principales características de las 3 tipologías de zonas rurales CM. 149

Tabla 7: Distribución de cabezas de ganado según especie y peso en el total nacional 156

Tabla 8: Árbol de objetivos del PDR Castilla la Mancha. 178

Tabla 9: Cuadro financiero del PDR a 31de diciembre de 2014. 180

Tabla 10: Ejecución financiera de las operaciones relacionadas con nuevos retos a

31 de diciembre de 2014. 180

Tabla 11: Análisis del cumplimiento de la regla $n+2$. 182

Tabla 12: Variación de la población en los 11 pueblos de mayor población comarcal. 279

Tabla 13: Municipios de mayor población de la comarca. 280

Tabla 14: Tasas demográficas de la comarca 2009. 281

Tabla 15: Población en edad de trabajar y paro en la comarca. 283

Tabla 16: Distribución de la población sector primario en años 1989 y 2009. 285

Tabla 17: Distribución de las tierras labradas y la SAU en los años 1989 y 2009. 286

Tabla 18: Distribución de cultivos en las tierras labradas años 1989 y 2009. .287

Tabla 19: Evolución de la cabaña ganadera en la comarca de Torrijos. 290

Tabla 20: Industrias de la comarca de Torrijos año 1989. 292

Tabla 21: Cuadro financiero 2011 GDR Castillos del Medio Tajo. 311

Tabla 22: Cuadro financiero 2012 GDR Castillos del Medio Tajo. 318

Tabla 23: Cuadro financiero 2013 GDR Castillos del Medio Tajo. 323 


\section{INDICE DE GRÁFICOS}

Gráfico 1: Estructura productiva en 2013...................................................... 154

Gráfico 2: Evolución por trimestres y años del Gasto FEADER...............................182

Grafico 3: Distribución del gasto público ejecutado para todo el PDR en valores acumulados 2007-2014.

Grafico 4: Grado de ejecución del gasto público, valores acumulados 2007-2014......184

Gráfico 5: Distribución del gasto del eje 1 por medidas. ............................................185

Gráfico 6: Distribución del gasto del Eje 2 por medidas........................................185

Gráfico 7: Distribución del gasto del Eje 4 por medidas........................................186

Gráfico 8: Porcentaje de ejecución de Nuevos Retos 2007-2014..............................187

Gráfico 9: Evolución del gasto público total acumulado 2007-2014.Medida 111.........189

Grafico 10: Evolución del número de jóvenes agricultores beneficiarios 2007-2014 ...190

Gráfico 11: Evolución del volumen de la inversión. 2007-2014.................................191

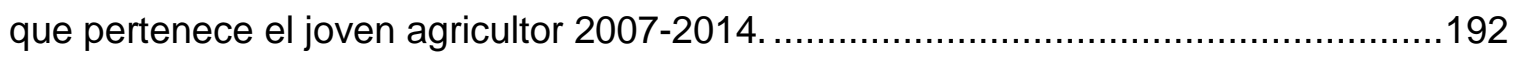

Grafico 13: Evolución del gasto público total 2007-2014.......................................193

Gráfico 14: Resumen de la evolución de los principales indicadores de ejecución

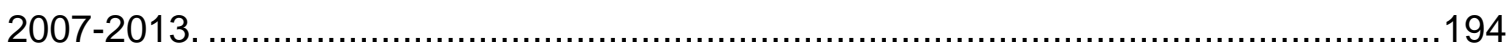

Gráfico 15: Evolución del número de beneficiarios 2007-2014................................195

Gráfico 16: Evolución del gasto público total 2007-2014..........................................196

Gráfico 17: Distribución de las solicitudes de ayuda aprobadas en relación al tipo de

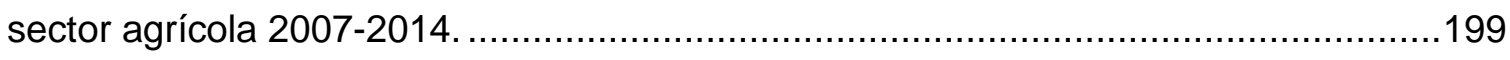

Gráfico 18: Evolución del gasto público total 2007-2014.......................................201

Gráfico 19: Evolución del Gasto Público 2007-2013.............................................202

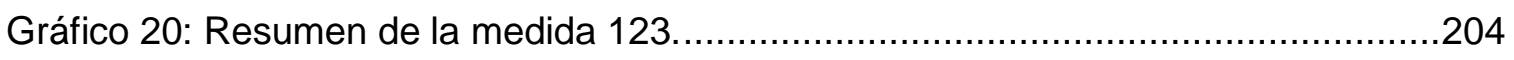

Gráfico 21: Evolución del gasto público total 2007-2014. Medida 125 y submedidas. .206 
Gráfico 22: Distribución de las explotaciones beneficiarias según la categoría de su producción 2007-2014.

Gráfico 23: Distribución de las solicitudes de ayuda presentadas según la categoría

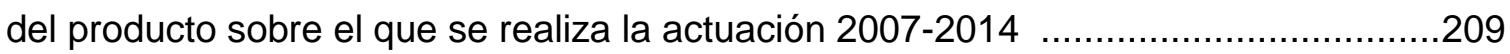

Grafico 24: distribución del número de explotaciones por submedidas......................210

Gráfico 25: Evolución del volumen total de la inversión 2007-2014 ..........................215

Gráfico 26: Distribución del gasto público total según la medida. ...............................217

Gráfico 27: Distribución de los proyectos financiados por los GDR en función de las medidas

Gráfico 28: Distribución de beneficiarios en función del tipo de propiedad y medida. ..219 Gráfico 29: Resumen de la evolución de los principales indicadores de ejecución. .....220

Gráfico 30: Evolución superficie. 276

Gráfico 31: Pirámide de población de la comarca de Torrijos. 281

Gráfico 32: Distribución de las tierras labradas en al año 1989. 287

Gráfico 33: Distribución de las tierras labradas en al año 2009. 288

Gráfico 34: Trabajadores por sector de actividad 2009 293

Gráfico 35: Empresas por sector de actividad 2009. 294

Gráfico 36: Esquema de funcionamiento Grupo de Acción Local Castillos de Medio Tajo.

Gráfico 37: Comparación de los pesos previstos y ejecutados de las medidas del eje 3 gestionadas a través del eje LEADER por nuestro GDR. 306 


\section{LISTA DE ACRÓNIMOS}

\begin{tabular}{|c|c|}
\hline CEDER & Centro de Desarrollo Rural \\
\hline CEDERCAM & Red de Grupos de Desarrollo Rural de Castilla-La Mancha \\
\hline CEPAL & Comisión Económica de las Naciones Unidas para América Latina \\
\hline CNASEA & Centro Nacional Ordenación de Estructuras Explotaciones Agrícolas \\
\hline DAFO & Debilidades, Amenazas, Fortalezas y Oportunidades \\
\hline DRT ETE & Desarrollo Rural Territorial Estrategia Territorial Europea \\
\hline EUROSTAT & Oficina Estadística de la Unión Europea \\
\hline FEADER & Fondo Europea Agrícola de Desarrollo Rural \\
\hline FEDER & Fondo Europeo de Desarrollo Regional \\
\hline FSE & Fondo Social Europeo \\
\hline GAEC & Grupos Agrícolas de Explotación Común (Francia) \\
\hline GAL & Grupo de Acción Local \\
\hline GDR & Grupo de Desarrollo Rural \\
\hline IC & Indemnización Compensatoria \\
\hline IE & Instituto de Estadística \\
\hline IESA & Instituto de Estudios Sociales Avanzados \\
\hline ILO & International Labour Office \\
\hline JCCM & Junta de Comunidades de Castilla-La Mancha \\
\hline LDSMR & Ley 45/1997, 13 de diciembre, de Desarrollo Sostenible Medio Rural \\
\hline LEADER & Relaciones entre acciones de Desarrollo de la Economía Rural \\
\hline LEADER + & LEADER en el periodo 2000-2006 \\
\hline LEADER I & LEADER en el periodo 1991-1993 \\
\hline LEADER II & LEADER en el periodo 1994-1999 \\
\hline MAPA & Ministerio de Agricultura, Pesca y Alimentación \\
\hline MARM & Ministerio de Medio Ambiente, Rural y Medio Marino \\
\hline MCA & Marco Comunitario de Apoyo \\
\hline ONG & Organización No Gubernamental \\
\hline PAC & Política Agraria Comunitaria \\
\hline PDI & Programas de Desarrollo Integrado \\
\hline PEDSMRCLM & $\begin{array}{l}\text { Plan Estratégico Desarrollo Sostenible del Medio Rural de Castilla-La } \\
\text { Mancha }\end{array}$ \\
\hline PNDR & Plan Nacional de Desarrollo Rural (Francia) \\
\hline $\mathrm{PO}$ & Programa Operativo \\
\hline POI & Programas Operativos Integrados \\
\hline POT & Plan de Ordenación Territorial de Castilla-La Mancha \\
\hline PRODER & $\begin{array}{l}\text { Programa Operativo de Desarrollo y } \\
\text { Diversificación Económica de Zonas Rurales }\end{array}$ \\
\hline
\end{tabular}


PRODER 1

PRODER 2

PROPOM

RECAMDER

RIGE

RNN

SAU

SGAR

SIG

SIT

SS

UCLM

UE

UPM

VAB
PRODER en el periodo 1994-1999

PRODER en el periodo 2000-2006

Programas de Ordenación y Promoción de los Recursos Agrarios de Alta Montaña

Red Castellano-Manchega de Desarrollo Rural

Red de Carreteras de Interés General del Estado

Red Rural Nacional

Superficie Agraria Útil

Secretaria General para los Asuntos Regionales (Francia)

Sistema de Información Geográfica

Sistema de Información Territorial

Seguridad Social

Universidad de Castilla-La Mancha

Unión Europea

Universidad Politécnica de Madrid

Valor Añadido Bruto 


\section{RESUMEN}

En los últimos años, una de las líneas de investigación que ha suscitado interés en las ciencias sociales es el estudio de la transformación de los territorios. La presente Tesis Doctoral se enmarca dentro de este campo de investigación, utilizando en el análisis los Programas de Desarrollo Rural fruto de la política europea y su aplicación sobre un territorio específico como es la comarca de Torrijos en la provincia de Toledo (España). El objeto de estudio es el proceso de transformación que ha tenido lugar en su ruralidad desde los años noventa del pasado siglo hasta ahora, de manera a aportar elementos al proceso de periurbanización que ha acontecido.

Se toma como punto de partida el estudio de la caracterización del medio rural, y de la periurbanización, se repasa la evolución histórica de la política comunitaria de desarrollo rural en un marco teórico, para a continuación centrarnos en el análisis del PDR de Castilla la Mancha 2007-2013 y analizar por un lado, las medidas que se están aplicando en la comarca objeto de estudio, así como el papel específico del Grupo de Desarrollo Rural Castillos de Medio Tajo más focalizado en lo local, por otro.

Para el desarrollo de esta tesis, la metodología de investigación empleada ha sido mixta, además del análisis estadístico documental en una primera etapa junto con el estudio minucioso de las medidas del PDR 2007-2013, se ha realizado una investigación empírica basada en entrevistas a diferentes agentes conocedores de la realidad de la comarca, ampliando la recogida de datos primarios con la observación participante, por la vinculación directa con este territorio. El análisis de todo el material recogido nos ha permitido contrastar una serie de hipótesis planteadas y obtener resultados para comprender el proceso de transformación. Así, si bien la proximidad al gran núcleo urbano de Madrid ha conseguido una mejora en la calidad 
de vida de sus habitantes, la aplicación de las políticas de desarrollo rural no ha conseguido diversificar la economía de esta comarca, por un lado los PDR son demasiado genéricos para responder a especificidades y realidades locales tan diferentes en la Comunidad de Castilla la Mancha, por otro son Programas atemporales que si bien obedecen a una programación dentro de un período, los efectos en la economía adquieren visibilidad (positiva o negativa) en una etapa posterior. En cuando a la acción de los GDR como herramientas de participación local, se observa que su actividad está relacionada con las prioridades de las corporaciones locales, manteniendo la mirada más sobre el rural agrario que fue que en el rural periurbano que acontece.

Palabras clave: desarrollo rural, territorio, periurbano, diversificación, PDR, GDR, Torrijos. 


\section{ABSTRACT}

In the last years one of the lines of research that has caused interest in the social sciences is the study of the transformation of the territories. The present Doctoral Thesis stands within this field of investigation, using in its analysis the Programs of Rural Development product of the European Politics and their application on a specific territory such as the region of Torrijos in the province of Toledo (Spain).The object of the study is the process of transformation that its rural area has undergone since the 1990s until now, so that it adds elements to the development that has taken place there.

The study of the characteristics and development of the rural area is taken as a starting point and the historical evolution of the community politics of rural development in a theoretical framework revised, to focus later on the analyses of the PDR of Castilla la Mancha.2007-2013 and to analyze on the one hand the measures that are being applied in the region object of study and on the other hand the specific paper of the Group of Rural Development "Castillos de Medio Tajo", more focused on the local aspects.

For the development of this thesis, the methodology of investigation that has been used has considered two aspects, besides the statistical documentary analyses in a first stage together with the meticulous study of the measures of the PDR 20072013, an empirical investigation based on interviews to different agents who know the reality of the region has been done extending the collection of primary information to the observation of those who participate directly in this investigation. The analysis of all the material has allowed us to confirm a series of raised hypotheses and to obtain results to understand the process of transformation. Thus, although the proximity to the great urban core of Madrid has given an improvement in the quality of life of its habitants, the application of the policies of rural development has not managed to 
diversify the economy of this area. On the one hand, the PDR is too generic to answer to specifities and local realities so different in the community of Castilla la Mancha, on the other hand they are atemporal programmes that although they obey a programming within a period, their effects in the economy acquire visibility (positive or negative) in a later stage .As for the action of the GDR as tools of local participation, it is observed that their activity is related to the priorities of the local corporations, focusing more on the agrarian rural aspect than on the peri-urban rural it is now.

KEY WORDS: rural development, territory, peri-urban, diversification, PDR, GDR, Torrijos. 
CAPITULO I: INTRODUCCIÓN, OBJETIVOS, METODOLOGÍA Y ESTRUCTURA 


\section{CAPITULO I: INTRODUCCIÓN, OBJETIVOS, METODOLOGÍA Y ESTRUCTURA}

\subsection{Antecedentes y justificación de la investigación.}

El punto de partida de esta Tesis Doctoral podríamos situarlo coincidiendo con la finalización de mi Tesis de Máster defendida en 1999 con el fin de obtener el título de Master of Science en el Centro Internacional de Estudios Agronómicos Mediterráneos de Montpellier (C.I.H.E.A.M) y que llevaba por título "Proyecto de una Central de Biomasa en una perspectiva de Desarrollo Local".

Se trataba entonces de un proyecto de investigación cuyo objetivo principal era analizar si la creación de una central de biomasa, usando Cardo (cynara cardunculus) como combustible podía contribuir al Desarrollo Local de la comarca de Torrijos (Toledo), aprovechando el conjunto de elementos naturales del territorio y las grandes oportunidades que parecían ofrecer en ese momento las energías renovables. Así, éstas se presentaban como un recurso valioso para acceder a mejorar las condiciones de desarrollo, crear empleo y resolver algunos de los problemas desarrollo económico y social que presentaba el entorno.

Además, la propuesta de usar Cynara como combustible se ampliaba al uso de residuos de poda tanto de olivar como de viña, cultivos que junto al cereal son predominantes de esta comarca.

En aquel momento, en 1999, la energía eléctrica producida proveniente de energías renovables tenía asegurada su compra por parte de las compañías eléctricas ${ }^{1}$, es decir la comercialización del producto final estaba garantizada.

Nuestra propuesta del proyecto:"Central de biomasa" encajaba perfectamente

\footnotetext{
${ }^{1}$ Ministerio de Ciencia y Tecnología (1999), Plan de Fomento de las Energías Renovables en España. Secretaría de Estado de Industria y Energía, p. 13. Este Plan se elabora como respuesta al compromiso que emana de la Ley 54/1997, de 27 de noviembre, del Sector Eléctrico, y que define el objetivo de desarrollo a alcanzar por las Energías Renovables.
} 
con las características de la Comarca objeto de estudio, pero no se contaba con la representación de los agricultores al respecto: lo que manifestaba el agricultor ante el hecho de sembrar "cardos", era que "toda la vida quitándolos de nuestros campos, y ahora quieren ustedes que los sembremos", era los comentarios y reacciones más comunes. Condicionando el rechazo al proyecto.

La propuesta de dicho proyecto conllevaba también una iniciativa en relación a la reactivación económica de la Comarca, de forma que los agricultores accedieran a diversificar sus rentas y las subvenciones provenientes de la Unión Europea. Recordemos que el escenario del momento era que las ayudas directas tenían un peso notable en los resultados económicos de las explotaciones es decir, sin ellas cultivar las tierras no era rentable, y la pregunta que se hacían los agricultores era hasta cuándo Europa les iba a seguir ayudando (Velasco, 2002).

Estamos ante el escenario de la Agenda 2000 donde se presenta como evidente la necesidad de disponer de una estrategia eficiente para ayudar al mundo rural. Se trata de "motivar" a los agricultores hacia una multifuncionalidad que vaya desde la conservación del suelo y la preservación de la biodiversidad hasta desarrollar actividades económicas complementarias, pero también de mejorar las infraestructuras, las comunicaciones, en definitiva su entorno. Aspecto sobre los que podemos encontrar una extensa bibliografía, entre ellos (Massot, 2000; Atance y Tió, 2000, Moyano y Garrido, 2007). Y es que, como señala la propia Agenda 2000, la Política Agraria Común nacida con los objetivos del Tratado de Roma, había estado incentivando la productividad, poniendo en entredicho el modelo de subvenciones directas, obligando así a una nueva reorientación de las políticas hacia actividades de carácter agroambiental y territorial, no basadas exclusivamente en el volumen de producción agrícola. 
Así, el llamado «segundo pilar de la Política Agrícola Común», viene a responder a las inquietudes suscitadas en diversos ámbitos de la sociedad, e intenta ser una herramienta fundamental en el denominado «Modelo agrario europeo», buscando un marco coherente y sostenible a fin de garantizar el futuro de las zonas rurales, contribuyendo al tiempo a la creación y mantenimiento de empleo.

El escenario que abría ese momento era que junto a las limitaciones estructurales y sociales coexistentes en la política productivista del modelo europeo, el proceso de la globalización obligaba a los agricultores a ser competitivos y a realizar más esfuerzos para hacerse sitio en los mercados mundiales. Aquellos que no pudieran seguir a los mercados y a la distribución se enfrentan a un futuro incierto, pues las ayudas institucionales no servirán para garantizar su renta (Delorme, 2004).

La política de desarrollo rural europea, que se plantea a partir de la Agenda 2000 , intenta crear un marco coherente y sostenible que garantice el futuro de las zonas rurales y contribuya al mantenimiento y la creación de empleo, sin obviar los desequilibrios existentes a nivel territorial ${ }^{2}$.

Es sobre esta inferencia que vamos a seguir el hilo conductor de nuestra indagación, ya que al haber constatado que el proyecto de biomasa no tenía continuidad nos pareció más interesante ahondar en los Programas de Desarrollo Rural como herramienta para acompañar el cambio de la comarca objeto de estudio hacía una ruralidad adaptada al nuevo marco europeo propuesto como Segundo Pilar de la PAC.

Hasta comienzo del siglo XXI, la Comarca de Torrijos había apostado por la agricultura como factor de desarrollo endógeno, la iniciativa que se proponía con el

\footnotetext{
${ }^{2}$ Cork Declaration (1996), A Living Countryside, 9/XI/1996.
} 
proyecto de biomasa es posible que se adelantaran al momento, puesto que las energías renovables empiezan a desarrollarse en el medio rural español a partir de 2006, pero la comarca ya estaba cambiando, el sector agrario perdía fuelle a favor de actividades y servicios relacionados con el sector de la construcción y el impacto de la gran ciudad de Madrid, que por su influencia limítrofe se acusa en las provincias de Castilla la Mancha

\subsection{Problemática y desafíos de la investigación.}

La falta de continuidad con el proyecto de Tesis de Master of Science fue un punto de inflexión en la intención de mi investigación. Con todo, seguíamos interesados en profundizar en lo que estaba ocurriendo en esa comarca. Puesto que esa primera investigación nos había familiarizado con la situación socio-económica y la realidad existente en aquel momento. Insistimos en seguir trabajando sobre este territorio para intentar conocer qué procesos de transformación estaban ocurriendo en el contexto de la Ruralidad, y que papel tenía el desarrollo local, las iniciativa LEADER y PRODER, el Grupo de Acción Local que trabaja en esta zona "Castillos de Medio Tajo", etc. Surgiendo de ahí un nuevo cuestionamiento que nos ha llevado hasta la presente investigación.

Partiendo del hecho de que hasta hace dos décadas la Comarca de Torrijos era un territorio agrario y que en la actualidad ha perdido esta identidad nos preguntamos:

¿Qué evoluciones se están produciendo en este territorio y qué transformaciones las acompañan?

¿Cómo se ha aplicado el segundo pilar de la PAC en esta comarca? Es decir, ¿Qué medidas del desarrollo rural han priorizado los PDR? 
¿Han dotado de medios a este territorio para hacerle más atractivo y conseguir un desarrollo adaptado a las nuevas circunstancias económicas y sociales? O dicho de otro modo: ¿Qué nuevas oportunidades han proporcionado a esta Comarca los Programas de Desarrollo Rural (PDR)?

¿Qué papel han tenido las iniciativas comunitarias LEADER y PRODER en esos cambios? Y en particular los proyectos del Grupo de Desarrollo Rural, que actúa en la comarca

¿Qué papel tiene los agricultores en dicho proceso de transformación rural? Es decir si sus estrategias de producción agraria son convergentes o contrarias a las iniciativas de procesos de desarrollo local.

$Y$ finalmente, ¿Qué factores intervienen en la transformación de un territorio agrario a un territorio periurbano?

Los espacios rurales localizados en torno a grandes ciudades llevan algún tiempo sintiendo los efectos de los procesos de expansión y dispersión de usos urbanos. Entre ellos, que los espacios agrarios están sometidos a una notable influencia urbanizadora. Si bien algunos de los factores que explican ambos procesos se pueden relacionar con el desarrollo y mejora de las infraestructuras viarias, el uso del suelo, el tipo de empleos creados, etc. El proceso de dispersión de actividades económicas y de población somete a los espacios periurbanos a intensos conflictos y tensiones (entre usos del suelo, entre la población autóctona y los nuevos habitantes, conflictos por la necesidad de nuevas infraestructuras y de nuevos equipamientos y servicios, etc.), que en muchos casos desbordan la escala administrativa municipal y requieren de nuevas formas de gobierno y gestión del 
territorio, que permitan abordar la creciente complejidad de estos espacios (Tchekemian, 2007).

En este sentido, la proximidad de nuestra comarca a un núcleo urbano como es Madrid, nos hace reflexionar sobre los impactos que se derivan de este contexto e incluso ponernos ante la hipótesis de que las actuaciones de la política de Desarrollo Rural tras la aplicación de la Agenda 2000, unido al hecho de la influencia que ejerce la proximidad a la gran ciudad de Madrid han originado una transformación del territorio, pasando de ser un "rural agrario", a un "rural periurbano".

\subsection{Objetivos en la investigación.}

El objetivo principal de la investigación es analizar los cambios que se han producido durante los últimos 20 años en la comarca de Torrijos y en el ámbito rural y observar de qué manera estas transformaciones han sido acompañadas por las medidas del desarrollo rural. Es decir, en qué medida los PDR han incorporado otra ruralidad en esta comarca.

Este objetivo general irá acompañado de otros objetivos específicos:

* Analizar los PDR y ver las Políticas de Desarrollo Rural que han supuestos cambios en el territorio y qué tipo de cambios.

* Observar si los PDR aplicados a la Comarca han intervenido en la desagrarización del medio promoviendo otras actividades y acercando así la ciudad al campo; o si bien ha sido la influencia exterior la que ha hecho que los PDR se adapten a esta situación. 
* Establecer qué y cómo las acciones de los Grupos de Acción Local han inducido una ruralidad menos agraria, es decir si las iniciativas LEADER, han sido árbitros entre un rural agrario y rural urbano.

* Observar de qué manera, en este territorio el impulso que recibe para su desarrollo depende de los factores endógenos al mismo y de la existencia de una capital social e institucional proactivo. Entre otros actores la Unión Europea se ha convertido en el actor principal de "desarrollo territorial".

\section{* Aporte al campo científico}

La aportación de esta investigación al campo científico, es poner un grano de arena más en la creación de conocimiento mediante el análisis de cómo los Instrumentos Políticos de Desarrollo Rural acompañan el cambio de identidad en la ruralidad, centrándonos en un determinado territorio, la Comarca de Torrijos (Toledo). Lo que se acompaña de la observación social de la producción del cambio de un Rural Agrario a un Rural Periurbano, integrando en este proceso las actuaciones y el papel específico del Grupo de Desarrollo Rural ubicado en la Comarca.

\subsection{Hipótesis de trabajo.}

- HIPOTESIS 1: Como hipótesis principal formulamos que los Programas de Desarrollo Rural son herramientas que han servido a orientar el desarrollo de la Comarca de Torrijos en el ámbito del rural agrario, no así en el rural periurbano. 
Este supuesto se acompaña de tres hipótesis específicas:

- HIPOTESIS 2: Que las actuaciones de los Programas de Desarrollo Rural para Castilla La Mancha y consecuentemente para la Comarca de Torrijos han buscado fijar población y crear un entorno más sostenible incorporando una red de relaciones multidisciplinares en la coordinación de las acciones a realizar.

- HIPOTESIS 3: Los Grupos de Desarrollo Rural lideran iniciativas que responden a una realidad de proximidad inserta en la concepción tradicional de las políticas públicas.

- HIPOTESIS 4: Los Programas de Desarrollo rural son atemporales a los resultados que se pretenden alcanzar, se van mostrando unas tendencias sin resultados finales. 


\section{5.- Metodología de investigación}

La ejecución de un determinado aparato metodológico para la realización de este tipo de investigación exige, la adecuación entre los objetivos planteados, las características del objeto de estudio y las técnicas de investigación a desarrollar. De este modo, a la hora de establecer la metodología para nuestra Tesis, se ha tenido en cuenta fundamentalmente el marco teórico en que nos íbamos a desenvolver, establecido fundamentalmente en el ámbito de las Ciencias Sociales.

Por otro lado, tenemos que estas ciencias, como toda ciencia, trabajan con hechos, y éstos, naturalmente, han de ser aislados y tratados de manera que se conviertan en datos. Después procederemos a analizar y diagnosticar dichos datos, informes y estudios hasta la situación actual, comprometiéndonos a un análisis cuidadoso y meticuloso de dichos datos objeto de estudio a través de los diferentes Censos Agrarios, estadísticas poblacionales y económicas, desarrolladas por diferentes organismos ${ }^{3}$, así como de un intenso trabajo de campo consistente en la observación directa y la observación participante fruto del trato directo con las diferentes personas que están siendo actores de este proceso de cambio, para de este modo distinguir entre lo que parece ser y lo que realmente es.

Toda investigación nace de la observación de algún fenómeno que nos sorprende, de alguna experiencia que frustra una expectativa o que rompe con el hábito de la expectativa, pasando de la duda a la creencia, de resolución de una duda genuina y el consecuente establecimiento de un hábito de pensamiento estable al que Peirce llamó investigación (Droguett, 2001).

La observación que nos sorprende y que motiva este trabajo es la transformación que ha seguido un territorio en el que hasta hace dos décadas la

\footnotetext{
${ }^{3}$ Fundamentalmente los datos procederán del INE, y de la Junta de Comunidades de CastillaLa Mancha.
} 
importancia de su sector primario lo enmarcaba en un rural agrario y en la actualidad, la influencia de la modernización agraria, la falta de empleo en este sector y sobretodo el impacto que ejerce la proximidad de un gran núcleo urbano como Madrid, han transformado esa sociedad: hábitos, actividades, movilidad, hábitat, etc. Se quería observar este proceso desde la proximidad, considerando que es necesario comprender estos cambios, pues aunque nuestra investigación está basada en el estudio particular de la Comarca de Torrijos, no son fenómenos aislados, son cambios que forman parte de la evolución de una sociedad más amplia como es la Castellano manchega, pero también podría elevarse a nivelas administrativos mayores.

La metodología utilizada ha variado en función de los datos obtenidos necesarios para responder a los objetivos y a la contrastación de las hipótesis planteadas en este Trabajo de investigación. Por tanto, al igual que existe una gran diversidad en cuanto a las fuentes de datos y a los datos en sí, igualmente nos encontramos con un pluralismo metodológico, que pasaremos a explicar a continuación.

\section{* ¿Cómo he procedido para llevar a cabo la investigación?}

En este sentido, señalar que ya había tomado contacto con la zona desde el estudio de la tesis de Master of Science en el Centro Internacional de Estudios Agronómicos Mediterráneos de Montpellier, y conocía la zona por residencia de familiares.

Al plantearse la problemática y los objetivos a trabajar, primero empiezo a consultar por un lado el Análisis documental, estadísticas, artículos que hacen 
referencia a la cuestión del rural periurbano y por otro lado a los Programas de desarrollo rural y su relación con el proceso de cambio, en la identidad de la ruralidad (rural-urbano, rural-agrario), al tiempo que, tomo contacto con representantes locales relacionados con las Políticas que se llevan a cabo en el territorio: Alcaldes, Grupo de Desarrollo rural, Presidentes de cooperativas, etc. En un principio he ido hablando con ellos para ver cómo veían el cambio en el territorio, entrando en una fase de investigación exploratoria que reafirmará el cuestionamiento de nuestra problemática. En una segunda fase, empiezo a analizar y a trabajar con los Programas de desarrollo rural y sus análisis, tarea que no ha sido nada fácil por los distintos cambios en los mismos, que me han llevado a trabajar con 7 versiones diferentes del PDR 2007-2013.

En paralelo, seguía recogiendo información de lo que ocurría en el territorio a través de la técnica de la observación participante, esta técnica cualitativa, en la que el objeto de conocimiento se ofrece directamente al investigador, el cuál permanece en mayor o menor grado integrado profunda y activamente en el proceso que se pretende investigar.

Esta técnica metodológica aprehende directamente el fenómeno, la observación de la realidad social, con la mirada, con la interacción entre el observador y los habitantes, y se va recabando información relevante que responda a los objetivos planteados, permite una adecuada comprensión holística de las interacciones sociales producidas en el contexto de cambio. La lógica que la guía, a diferencia de otras técnicas de investigación social, se basa fundamentalmente en un proceso de indagación abierto y flexible que requiere un esfuerzo de redefinición constante de feedback con nuestro objeto de estudio, a partir de hechos recogidos en entornos concretos. 
Este tipo de observación es la técnica que mejor permite conocer la vida de un grupo, de una comunidad o realidad social desde su interior, porque no solo permite captar los fenómenos objetivos o manifiestos, sino también los subjetivos o latentes, es decir permite llegar a comportamientos sociales imposibles de conocer por otras vías.

En esta técnica es importante es lugar desde donde se mira y la manera en qué miramos. Esta observación exige la construcción de una objetividad desde la mirada del investigador.

El hecho de investigar sobre dinámicas sociales en una comarca conocida, implica hacer un esfuerzo por parte del sujeto investigador, para separarse del objeto de estudio y construir su objeto desde una percepción objetiva, vinculada a lo académico, dejando de lado los afectos personales.

Al mismo tiempo, esta imbricación con el territorio, nos brinda la oportunidad de una mayor cercanía en nuestra labor investigadora con la historia compartida con los habitantes del territorio (paisanos), compartiendo sensibilidades específicas. Estas personas te hablan de lo que ocurre en su entorno día a día, de cómo ha cambiado la sociedad en los últimos años etc. Son interacciones que llegan desde la puerta de una frutería, mientras tomas una cerveza, vigilando a los niños en un parque público, en todo momento estás recibiendo información.

Es decir, en esta observación participante, hablamos de compartir espacios comunes, reteniendo percepciones particulares de los cambios sociales sobre este espacio rural, cada día más influenciado (penetrado) por los modos de vida urbanos procedentes de la gran ciudad, Madrid, cuya periferia alcanza casi al territorio.

Cada fin de semana compartido con los lugareños, mi cuaderno de notas venía repleto de información referente a las conversaciones y vivencias mantenida con ellos. Notas que han ido incorporándose a nuestra observación, a lo largo de 
todo el proceso de la Tesis Doctoral. En cierta medida, me sentía "adoptada" por los lugareños, llegando incluso a situaciones en las que estos actores, buscaban un encuentro para contarme tal o cual cosa que creían debería saber, aceptaban mi presencia "indagadora" en el terreno, lo que me hacía sentir cercana a ellos.

Como expresó Whyte en uno de los estudios de observación participante más conocidos, Street Corner Society, "lo que la gente me dijo me ayudó a explicar lo que había sucedido, y lo que yo observé me ayudó a explicar lo que la gente me dijo" (Whyte, 1961)

También se realiza una parte de comunicación que no aparece en forma de entrevista, y que consiste en hablar con las poblaciones locales, agentes turísticos, comerciantes etc para determinar si existe una puesta en valor de estos servicios, coincidente con la demanda que proviene del exterior principalmente de Madrid

La tercera fase ha sido la de la realización en paralelo de entrevistas abiertas a distintos agentes de la comarca, lo que ha servido para contrastar información relevante y necesaria para la comprensión del objeto de estudio. La muestra empleada en estas entrevistas ha sido representativa, ya que se ha elegido a un grupo de personas conocedoras del territorio y de la realidad que allí se estaba produciendo, y en algunos casos incluso agentes relacionados con el desarrollo regional, local: Consejero de Agricultura, Medio ambiente y Desarrollo Rural de la JCCM, Alcaldes, Presidente del GDR, Gerente del GDR, etc. Por solicitud expresa de alguno de los entrevistados, se mantienen algunos de estos agentes en el anonimato, refriéndonos sólo al cargo representativo que ostentaban en ese momento.

Se han realizado 10 entrevistas, distintas en función del perfil del entrevistado, cuyas guías se adjuntan a continuación: 
GUIA DE ENTREVISTA TIPO 1: CONSEJERO AGRICULTURA, MEDIO AMBIENTE Y DESARROLLO RURAL DE LA JCCLM

Previa presentación de cada entrevistado, y abriendo la conversación sobre la influencia que la periferia de Madrid ejerce en el territorio, se han formulado las siguientes preguntas:

1. Globalmente ¿Qué opinión tiene de los proyectos LEADER?

2. En cuanto a los Grupos de Desarrollo Rural o de Acción Local (GAL) ¿según Ud que papel han tenido y como han contribuido al desarrollo rural regional?

3. Estos grupos como conocedores del territorio, ¿deberían ser más activos? ¿Habría que redefinir a estos grupos? ¿Más autonomía?

4. ¿Cuál es su percepción del PDR 2007-2013 de Castilla la Mancha?

5. ¿Son suficientes las Políticas de Desarrollo Rural europeas para conseguir el desarrollo del medio rural?

6. ¿Cuál es el problema en la falta de estimulación en la incorporación de jóvenes a la agricultura?

7. ¿Por qué resulta tan complicado que los agricultores, empresarios agrícolas, etc consigan asociarse bien en cooperativas o en otro tipo de estructuras para aumentar su competitividad como ocurre en otros países cercanos?

8. Punto de vista sobre el futuro de la agricultura y las actividades agroindustriales en la región.

GUIA DE ENTREVISTA TIPO 2: AGRICULTOR; EMPRESARIO LOCAL 
Previa presentación de cada entrevistado, y abriendo la conversación sobre la influencia que la periferia de Madrid ejerce en el territorio, se han formulado las siguientes preguntas:

1. ¿Cuáles son los elementos que han contribuido a este cambio del rural agrario a rural periurbano?

2. ¿Por qué? ¿A qué se debe según usted? ¿En qué se ha traducido?

3. Importancia de la agricultura a tiempo parcial. ¿Qué \%?

4. ¿Esos agricultores a que se dedican en su otra actividad? ¿Han heredado la SAU? ¿Realizan la actividad agraria los fines de semana?

5. ¿Ha oído hablar de los Programas de Desarrollo Rural (PDR)?

6. Dentro de la comarca, en los últimos PDR ¿Según usted. qué ejes se han intentado priorizar? ¿Por qué esos?

7. ¿Cuál es el problema en la falta de instalación de jóvenes en la agricultura?

8. ¿Hay continuidad intergeneracional? Si no existe continuidad ¿por qué?, ¿a qué se debe?

\section{GUIA DE ENTREVISTA TIPO 3: ALCALDE, GERENTE DE GDR, ETC}

Previa presentación de cada entrevistado, y abriendo la conversación sobre la influencia que la periferia de Madrid ejerce en el territorio, se han formula las siguientes preguntas:

1. ¿Cuáles son los elementos que han contribuido a este cambio?

2. ¿Qué tipo de cambios principales se han producido en el municipio en estos 1520 años?

3. ¿Cómo ha cambiado la agricultura? ¿Ha emigrado mucha gente del pueblo? ¿ha venido mucha gente extranjera? ¿en qué actividad se reubican? 
4. ¿Es un municipio con gente joven, mayor, desempleados?

5. ¿Qué piensa de los proyectos LEADER? ¿conoce los GAL? ¿Qué opina de ellos? ¿Han hecho mucho por el desarrollo del Medio Rural?

6. ¿Cuántos agricultores hay? ¿son a tiempo completo? ¿parcial? ¿son jóvenes? ¿Viven en el pueblo? ¿Las tierras son suyas? ¿Propietarios 0 arrendatarios?

\section{* Etapas de la investigación}

Podemos resumir las etapas varias a lo largo de la investigación:

Una primera etapa de búsqueda de datos secundarios en la que se ha analizado documentación estadística procedente de la Administración General del Estado (INE, ICEX, MAGRAMA, fundamentalmente), de la Administración Regional (Junta de Comunidades de Castilla la Mancha), revistas y documentaciones científicas para definir el marco teórico (conceptos y nociones que se incorporan a lo largo del trabajo: Territorio, Espacio, Rural, Territorio Rural, Desarrollo Rural, Periurbano etc.).

El análisis documental nos ha permitido crear tanto el Marco teórico, como la obtención de las hipótesis.

Los Censos Agrarios nos han permitido determinar la evolución de la sociedad agraria hacia una sociedad periurbana, los cambios en los servicios, un análisis de la situación socioeconómica de la comarca y de su sistema agrario utilizando en todo momento una situación comparativa entre los años 80 (Censo Agrario de 1989) y la situación actual (Censo Agrario 2009). La Encuesta de Población Activa (EPA) se ha utilizado para determinar la estructura de población de la población agraria. Siempre con el trabajo posterior de acotar siempre los datos a 
nivel tanto de la comarca de Torrijos, como de los distintos términos municipales que la componen y así poder determinar las perspectivas futuras de este territorio.

Dentro de la dimensión teórica se han consultado documentación científica principalmente en español y en francés, aunque no hemos prescindido de algunas referencias anglófonas. Estos documentos constituyen el eje central de nuestra Tesis.

Otra etapa relevante del análisis documental ha sido la referente a la Evolución de la Política de Desarrollo Rural Europea, en particular su evolución desde 1999. Se ha puesto un especial interés en las iniciativas LEADER, marco legal en el que se apoya muestro Grupo de Desarrollo Rural.

El análisis del Programa de Desarrollo Rural (PDR) 2007-2013 de Castilla la Mancha, profundizado en los ejes y medidas que el desarrollo rural ha aplicado en la Región y en la Comarca de Torrijos, y de qué manera han tenido incidencia en el proceso de cambio que se intenta analizar ha sido central en esta investigación.

También se ha utilizado la técnica de la observación participante en estudios sociológicos, a lo largo de todo el proceso de recogida de información, una herramienta que permite valorar aquellos aspectos que se reproducen en el contexto y entorno, que en numerosas ocasiones no se tienen en cuenta y son importantes para el enjuiciamiento de las cuestiones de evaluación.

También se han analizado las Memorias del Grupo de Desarrollo Rural, "Castillos de Medio Tajo" sus programas y la aplicación de la financiación, proyectos etc. Ahondando en las acciones de este grupo, se han podido Identificar otros actores e instituciones que sin estar dentro del GDR, han aportado información relevante sobre el proceso que está ocurriendo en esta comarca. 
Para finalizar se han realizado entrevistas, en una tercera fase, de manera que obtenemos datos primarios a través de la interrogación a representantes específicos de la comarca. Se ha realizado una decena entrevistas directas a responsables del Grupo de Acción Local y a diversos "agentes" que han intervenido en el proceso: Presidentes de Cooperativas, Promotores, Agricultores, Alcaldes de varios municipios, empresarios, etc., De esta manera, los entrevistados han podido expresarse de una forma abierta sobre aquellas cuestiones que eran útiles en nuestra investigación, convirtiéndose en "actores principales", y una fuente principal para poder comprender parte substancial del proceso objeto de estudio.

Está recogida de datos primarios ha ido profundizándose y completándose con llamadas telefónicas, a medida que el propio proceso de investigación avanzaba.

Los métodos empíricos cuantitativos y cualitativos son, cada uno de ellos, necesario in sua esfera, in suo ordine, para dar razón de aspectos, componentes o planos específicos del objeto del conocimiento. No sólo no se excluyen mutuamente, sino que se requieren y complementan, tanto más cuanto que el propósito de abarcar la totalidad del objeto sea más decidido (Beltrán, M 2003).

\section{* Limitaciones en el proceso metodológico.}

No queremos dejar de mencionar la dificultad que ha existido a la hora de comparar las diferentes medidas del PDR 2007-2013, al existir 7 versiones del mismo, e irse modificando a medida que avanzaba con el trabajo. Así, las medidas que aparecían en el primer PDR con unos importes, se iban modificando en el segundo PDR con un nuevo cuadro financiero. Esto ha significado recurrir a numerosas llamadas por teléfono y visitar a diversos funcionarios de la Consejería de 
Agricultura, Medio Ambiente y Desarrollo Rural para que nos explicasen los datos, dudas etc, y siempre con una total y buena disposición para ello.

Reflejar también el trabajo que ha supuesto para desagregar los datos del PDR a nivel comarcal, ya que las medidas se procesan estadísticamente a nivel provincial. En algunos casos ha habido incluso que realizar aproximaciones, o proporciones para obtener los resultados ante la imposibilidad de poderlos obtener por comarcas.

Indicar también que la coincidencia de la fase de redacción y obtención de últimos datos con las elecciones autonómicas no ha sido beneficioso en el proceso metodológico, ya que ha habido un impase sin directrices políticas, en el que nadie quería asumir riesgos y me pedían esperar a "tener jefes" y poder consultar instrucciones para ofrecer los datos. Esta coincidencia del periodo electoral, también ha tenido repercusión en la entrevista a algunos Alcaldes, ya que se produjeron bastantes cambios a nivel municipal, y entrevistas programadas de antemano fueron anuladas al no ostentar ellos esos cargos. 


\subsection{Estructura de la investigación}

La tesis doctoral se ha estructurado en nueve capítulos organizados entorno a 4 bloques.

El primer bloque está compuesto por el Capitulo 1 de Introducción, en el que se han abordado cuestiones relacionadas con los antecedentes y la justificación de la investigación, con el planteamiento de las preguntas iniciales; la definición de los objetivos e hipótesis, así como la metodología empleada en la investigación.

El segundo bloque trata el Marco Teórico sobre el que se apoya la Tesis. Se ha estructurado en 3 capítulos (2, 3, y 4). En el capítulo 2 se abordan conceptos sobre el desarrollo rural, territorio, ruralidad etc....en el capítulo 3 se hace una exposición sobre la Evolución de las Políticas de Desarrollo Rural en Europa, remarcando nuestra atención sobre la iniciativa comunitaria LEADER, y su incidencia. En el Capítulo 4 trata de recoger distintos enfoques del periurbano, clasificaciones, periurbano en diferentes países, etc.

El bloque III, se ha realizado la contextualización de la comarca objeto de estudio, así en un capítulo 5 se analiza el PDR de Castilla la Mancha, así como las memorias de los GDR y sus programas de inversión, en el capítulo 6 describimos la realidad administrativa analizando su evolución socio económica y realizamos un diagnóstico. En el Capitulo 7 se realiza la contrastación de las hipótesis planteadas, para en el Capítulo 8 resumir las principales conclusiones, señalando los principales resultados obtenidos en la presente investigación.

Se termina el documento con el Capítulo 9 sobre la Bibliografía consultada y el Bloque 4 que ilointegran los Anexos I, Marco Legal y Anexo II entrevistas realizadas. 
CAPITULO 2: DESARROLLO RURAL: CONCEPTOS A CONSIDERAR. 


\section{CAPITULO 2: DESARROLLO RURAL: CONCEPTOS A CONSIDERAR.}

\subsection{Territorio, un espacio de múltiples miradas.}

Según el Diccionario de la RAE la definición semántica de territorio es la de "un espacio geográfico cualificado por una pertenencia jurídica o por una especificidad natural o cultural ". Esta definición implica el reconocimiento de límites, haciendo referencia a una entidad limitada, circundado, donde la noción de territorio iría asociado con el de frontera.

No obstante el término territorio ha sido objeto de numerosas reflexiones que en el curso del tiempo han hecho evolucionar su significado. De tal manera que si en un primer tiempo, el termino territorio era utilizado para definir un espacio sobre el cual se ejercitaba una autoridad o una jurisdicción. Es a partir de los años 1980, cuando las diversas disciplinas aumentaron su campo semántico. incorporándose a la literatura bajo diversos enfoques (biología, geografía, antropología, política, sociológico, etc.), hasta el punto de que exista hoy una multitud de definiciones según el dominio estudiado (Levy et Lussault, 2003).

Si bien la idea de territorio está enlazada con la noción de espacio geográfico, no son sinónimos para Le Berre, M (1992), el "territorio" es la porción de la superficie terrestre apropiada por un grupo social para asegurarse su producción y la satisfacción de sus necesidades vitales", en definitiva genera identidad mediante un proceso de construcción que se desarrolla y evoluciona a lo largo del tiempo sobre un espacio geográfico.

En un enfoque de ordenación territorial tradicional el territorio remite a la planificación del estado sobre un espacio donde ejerce sus competencias (Fourny, 1995) pero a menudo distanciado del desarrollo local, estableciendo así un espacio 
multinivel en la lógica de aplicación de las políticas. Para el enfoque sociológico el territorio es un espacio de representaciones y de interrelaciones múltiples en el que se desarrollan un conjunto de acciones que pueden ser fruto de encuentros y oposiciones entre actores, acciones que se articulan en función de unas reglas o normativas que definen un proyecto político.

El concepto de territorio y su polisemia resurge en un periodo de profundo cambio institucional en la organización europea: las estructuras que hasta entonces habían dominado las relaciones sociales, económicas y políticas se habían visto cuestionadas, y se buscaban nuevos encajes para la realidad presente considerando la necesidad de articular los sectores productivos con los actores territoriales produciendo una mayor cohesión (Koolman, 1993)

Además a lo largo de estas últimas décadas se ha asistido a un gran cambio en la apertura de la economía a nivel global, que junto a los grandes avances tecnológicos, han aumentado el movimiento de mercancías, de personas, de información dando lugar a un espacio abstracto de flujos que se organiza a partir de redes de relaciones (Sassen ,2013).

De esta manera el espacio concreto de los lugares convive con este espacio abstracto, interactuando a través de los territorios locales, estableciendo unos vínculos que como recuerdan Brugué, Gomá y Subirats (2002), obligan a los territorios a un doble movimiento: por un lado les impulsa a generar estrategias que les conecten a la red global y por otro han de poner en valor todos sus recursos y capacidades para ser influyentes dentro de la red.

Según Castells (2001), "los sectores valiosos de los territorios y de la población se vinculan a las redes globales de creación de valor y apropiación de riqueza", mientras que "todos aquellos que carecen de valor o que dejan de tener valor, se desconectan de la red y en última instancia se descartan”. Es decir, las 
desigualdades existentes entre los territorios ya no vienen causadas por la distancia, sino por la capacidad para conectarse a los flujos de información, tecnología etc., y de esta manera poder acceder a las redes, a otros espacios, a otras personas; lo importante no es la localización sino tener algo que ofrecer y que sea interesante. Esta realidad tiene grandes repercusiones en el espacio, recobrando importancia la escala local, llegando a ser el verdadero protagonista de cambio el territorio.

En este sentido, el territorio emerge como elemento capaz de sustituir al mercado en la mediación entre las relaciones sociales, económicas y políticas. De qué forma se organicen los agentes locales y se coordinen va depender en gran medida el desarrollo de sus territorios.

Desde una mirada de sistema endógeno, el territorio es un actor capaz de generar sus propios recursos específicos, que por su naturaleza son difíciles de encontrar en otros lugares con la misma calidad, y que por tanto ofrece ventajas comparativas a los territorios que saben poner en valor estos recursos (Vázquez Vaquero, 1996). En la teoría de desarrollo endógeno se sostiene que la política de desarrollo local permite alcanzar de forma eficiente la respuesta local a los desafíos de la globalización, lo que convierte a la teoría del desarrollo endógeno en una interpretación para la acción. Este proceso de construcción remite al concepto de territorialidad. definido por Aldhuy (2009) desde un enfoque antropológico como "conjunto de relaciones existenciales y sociales que los individuos en grupo mantienen con el espacio que producen y reproducen cotidianamente, a través de las representaciones, las imágenes, las categorías y los objetos geográficos que movilizan en un proyecto de producción de la sociedad más o menos intencional y explicito".

Para Pecquer (2000), el territorio es una concurrencia de actores dentro de un espacio geográfico delimitado, (aunque la frontera del territorio pueda ser difusa o 
provisional) que tiene como objetivo identificar y luego tratar de resolver un problema productivo compartido por estos actores.

Según Raffestin (1986), el territorio es analizado "como la proyección de un sistema de intenciones humanas sobre una porción de la superficie terrestre", es decir para él la territorialidad es "un proceso de construcción de un comportamiento".

El geógrafo Marcelo Lopes de Souza (1995) parece haber elaborado una definición bastante interesante del concepto de territorio que es, al mismo tiempo, restrictiva (por su énfasis en la idea de poder) y amplia (por la posibilidad de considerar las diversas dimensiones como la social, política, cultural y económica).Para Souza, el territorio es el espacio determinado y delimitado por y a partir de relaciones de poder, que define, así, un límite y que opera sobre un sustrato referencial, en definitiva, el territorio es definido por relaciones sociales.

También aparece como un factor estratégico de oportunidades a partir de la interacción dinámica entre el sistema económico y la formación social local. (Garofoli, 1986).

Para Manzanal (Manzanal, 2006) hace más bien referencia a un espacio determinado por relaciones de poder y que posee como referencia el lugar; es decir, el espacio de la vivencia, de la convivencia. $Y$ considerando el establecimiento de relaciones internas o externas entre los respectivos espacios con otros actores sociales, instituciones y territorios.

Hay otros autores como Romain Lajarge (2012), que considera esta palabra limitada, prefiriendo el proceso en términos de " territorialidad".

En estas diferentes definiciones, podemos retener algunas palabras claves para la definición de territorio: 
- puede ser comprendido como un espacio, es decir una extensión, definida eventualmente fuera de la presencia de los hombres, a partir de características objetivas que describen el espacio en cuestión.

- puede ser también el espacio controlado limitado por los Estados del siglo XIX, como una metáfora del Estado en la ciencia política. En este caso, la construcción territorial viene del exterior;

- puede también ser adaptado por los actores y provenir de procesos colectivos de reconocimiento y de acción por los actores. En este caso, los actores están presentes para construir un territorio;

En fin, la dimensión de la historicidad debe estar presente, porque representa la acción implícita de los actores, que demuestra que cada lugar es tributario de su propia historia.

Desde los años ochenta, el término territorio va a estar presente en los debates sobre la ruralidad y el futuro del mundo rural. Y más recientemente, desde 2005 el Reglamento de Desarrollo Rural 1698/2005 otorga un enfoque integral entre lo agrario el territorio y el medio ambiente, signifiando a los territorios una cohesión social, económica y medioambiental y articulando lo rural con lo urbano (Foro IESA, 2009). En esta investigación se relaciona con un espacio complejo e integrador en un contexto de cambio de identidad al pasar de agrario a periurbano, en el que se articulan unas políticas locales.

Finalmente y desde esta diversidad de miradas que integra esta noción, los territorios son una construcción social y humana, aparecen en la medida en que las personas los habitan y se relacionan (Nelson, 2011), es decir, se dan a partir de la existencia de las sociedades, cuando estas transforman las geografías en sus hábitats. Así, los actores públicos y privados tienen posibilidades de organizar sus comunicaciones, interacciones y conflictos en la pretensión de resolver sus 
necesidades y deseos. A ello concurren con conceptos generales de las ciencias sociales, la gobernabilidad y gobernanza como escenario de las decisiones públicas, la productividad y competitividad como variables fundamentales del accionar privado

y las acciones públicas deliberadas, las cuales generalmente se convierten en políticas para el desarrollo, consensos de los agentes y agencias públicas y privadas en busca de un objetivo común.

El territorio es pues el resultado de un proceso de construcción, apoyado en la interacción entre los individuos y los grupos sociales existentes, cuyas acciones, relaciones, movimientos etc van a generar nuevas potencialidades y nuevas oportunidades. Para nosotros el territorio de estudio es la Comarca de Torrijos, y nuestro objetivo es intentar comprender su evolución analizando la transformación que ha sufrido esa comarca durante los últimos años

\subsection{Ruralidad: Un concepto con múltiples acepciones}

Globalmente, la emergencia del concepto de "rural "se ha ido perfilando estos treinta últimos años. La definición de espacio rural no es fácil, ya que los propios límites entre lo urbano y lo rural son difusos; tradicionalmente se ha relacionado rural con lo agrario, visión que ha quedado obsoleta por los nuevos procesos y actividades que se desarrollan en los espacios rurales (Esparcia y Noguera, 2001).

Según J. Diry: «el espacio rural se diferencia del espacio urbano por dos criterios: la construcción discontinua, dejando un espacio más o menos grande a los campos, presencia de los espacios forestales y densidades de población reducidas». Aunque el autor la completa indicando la necesidad de analizar tres variables: el 
medio natural, las herencias históricas y la influencia de los actores económicos y sociales, tanto internos como externos (Diry, 2002)

Las primeras aproximaciones al concepto de ruralidad tienen su origen en la sociología urbana de la Escuela de Chicago, para quien las nociones de urbano y rural no representaban modelos absolutos prefiriendo hablar de un continuum entre ambos espacios. El antropólogo Redfield establecerá el binomio Folk-Urban como continum entre sociedades tradicionales y urbanizadas, en el que existen flujos de ida y vuelta: el campo conserva hábitos y actitudes tradicionales y la ciudad le incorpora la modernidad urbana. En el ámbito de la sociología rural Sorokin y Zimmerman desarrollan la teoría del continuum Rural-urbano apoyándose en la idea de un cambio gradual entre ambas sociedades. Entre los dos extremos rural, urbano tenemos como dirá Henrí Mendrás (1959) “... diferencias de intensidad entre los contrastes de esas dos sociedades".

Pahl se avanzará en la idea de que el estilo de vida de los individuos no tiene que ver con su localización, rural o urbana, sino con tres factores que por orden de importancia son: la clase social a la que pertenecen, la edad o posición en el ciclo familiar y el grupo local o nacional de los que forman parte (Pahl, 1968). Recogiendo la idea de Palh, Lewis y Maund, (1976) señala el proceso de urbanización es un fenómeno global que incluye a toda la sociedad, con independencia de la ubicación geográfica, y que son los rasgos sociales y de estilo de vida los que caracterizan los lugares.

Señala Bernard Kayser que la ruralidad está caracterizada por el modo específico de relación que la sociedad rural mantiene con su entorno, con su localidad. En este sentido nos dice que en los años ochenta desde el Consejo de Europa ya se anunciaba que «Los términos rural y urbano designan modos de utilización del territorio y se aplican tanto a la tierra como al hombre. Juntos 
constituyen lo que se considera hoy como un sistema continuo "rural-urbano" dentro del cual no hay una ruptura o distinción neta, habiendo diversos niveles de actividad social y económica, más altos en el extremo urbano y más bajos en el extremo rural. Hacia el urbano la actividad humana y la producción de manufacturas predominan y se intensifican, y hacia el rural son los procesos ecológicos y los recursos naturales los que lo hacen (Kayser, 1990).

Este mismo autor en su obra Pour une ruralité choisie (Kayser, 1994) (Por una ruralidad elegida) señala que la ruralidad es una noción cualitativa asociada al desarrollo económico del " rural productivo" donde se deben aplicar las políticas públicas. Distinguiendo tres grandes categorías: periurbano, rural aislado, rural "productivo", es decir el que comprende, según el autor, las comunas rurales más dinámicas sobre los planes sociales y económicos.

El espacio rural es un tejido económico y social que comprende un conjunto de personas, territorio, culturas y actividades diversas: agricultura, selvicultura, artesanía, pequeñas y medianas industrias, comercio y servicios, sirviendo además de amortiguador y de espacio regenerador indispensable para el equilibrio ecológico (Comisión Europea, 1988). Un territorio ideal de observación del cambio, las adaptaciones y las evoluciones sociales, económicas, técnicas frente a las agresiones externas de toda índole, presión territorial, baldíos agrícolas, degradación del paisaje, éxodo, emigración, etc.

El proceso para identificar estos espacios rurales, arranca en un primer momento, de la concepción del espacio social como resultado del sistema de relaciones personales y de producción, así como de la asignación de funciones desde el conjunto de la sociedad, que en la medida que ocupan un territorio en concreto lo definen e identifican con aspectos que lo diferencian hacia fuera, configurando la percepción que desde el medio rural se tiene del espacio urbano, y lo 
homogeneízan hacia dentro, conformando la identidad de lo rural. (Pereira, D et al, 2004).

Además como señala Sumpsi, 1994, este medio rural hay que conservarlo, pues presenta un patrimonio económico, ambiental, humano e histórico que sostiene una forma de entender la vida, una cultura y un paisaje milenario que son señas de identidad de la vieja Europa.

Si bien la identificación tradicional entre medio rural y producción agraria ha sido una constante durante los pasados años, el sistema productivo se ha reestructurado y lo rural ya no es sinónimo de agrario, lo que no implica negar las relaciones genéticas entre ambos conceptos, ni ignorar su importancia para el mantenimiento de muchas zonas de monofuncionalidad agraria. Por otro lado el peso del sector agrario ha perdido valor en el PIB y el sector agrario ha dejado de ser el más importante por participación en el empleo y la riqueza, es lo que Lamo de Espinosa (2004) denomina desagrarización.

Actualmente, el desarrollo de un sector económico no se puede considerar independiente de la evolución económica general del sistema al que pertenece, más bien al contrario, supone un proceso que afecta a todo el territorio, a los elementos productivos y a su población. (Larrubia, R 1998).

En este sentido la globalización nos impone que a partir de ahora nada de lo que ocurre a nuestro alrededor es un suceso delimitado, sino que todos tenemos que organizarnos a lo largo del eje "global-local".

Así entendida la globalidad ofrece una situación que es a veces descrita como "segunda modernidad". En este proceso "lo rural" adquiere nuevas connotaciones y funciones mas relacionadas con la demanda de servicios para el ocio y vinculadas a la preservación y protección de los espacios naturales. 
Desde el punto de vista de organización del territorio hemos visto en páginas anteriores que también se ha mantenido una estructura dual y polarizada, considerando que las ciudades, lo urbano, funcionaban como centros de economía regionales especializadas, mientras las áreas agrícolas, lo rural, eran consideradas periferias dependientes de los núcleos urbanos. (Lowe, Murdoch, Ward, 1997). Así, en la identificación del mundo rural con las actividades agrarias, se explica que los responsables de las políticas dirigidas a zonas rurales fueran elaboradas en base a su fundamento agrario, siendo motores de una agricultura productivista.

El crecimiento de la mecanización en la agricultura y los avances en biotecnología etc. han aumentado la productividad y rentabilidad agraria, sin embargo cada vez menos habitantes obtienen su fuente de ingresos exclusivamente de la actividad agrícola, (incluso en las zonas de agricultura extensiva), habiendo pasado la agricultura en muchos territorios, de tener un papel central y prioritario a un papel complementario e incluso en muchos casos marginal (Hervieu, 1995).

Por otro lado, para dar operacionalidad al concepto de rural se ha mantenido hasta recientemente que la dicotomía rural asociada a la actividad agraria en contraposición a lo urbano. Así, se establece de modo simplista la diferenciación en el que se apoyan los criterios estadísticos que clasifican los núcleos de población o las unidades territoriales menores en relación con su tamaño demográfico ${ }^{4}$, ha demostrado ser poco eficaz a la hora de hacer coincidir ambos conceptos con la realidad, fundamentalmente porque la agricultura no es ya la única actividad de esas zonas, y porque, los modos de vida, los comportamientos y las aspiraciones de los

\footnotetext{
${ }^{4}$ Por ejemplo, en la definición utilizada por el INE los núcleos con población menor de 2000 hab, se denominan rurales y los núcleos con más de 10.000 hab, como urbano. Entre ambos están los núcleos semi-rurales o semi-urbanos.
} 
residentes en ambos espacios, especialmente en los países desarrollados, se acercan cada día más.

Otra propuesta de diferenciación de los espacios rurales es la realizada por Gómez Orea (1985), a partir de la incidencia de una serie de factores que han transformado el concepto tradicional del medio rural. La aparición de nuevas actividades no agrarias en el medio rural, las degradaciones naturales y la utilización de los propios recursos naturales en el espacio rural, serían los elementos a tener en cuenta.

Distingue entre:

- $\quad$ Zonas del entorno rural de las ciudades en expansión, con problemas por el cambio del uso del suelo rural a urbano. Fuerte especulación urbana con degradación de espacios rurales

- $\quad$ Zonas dinámicas pero que se ven afectadas por el cambio de función, pasando de agraria a secundaria y terciaria. Problemas muy parecidos al caso anterior

- Zonas donde las condiciones naturales y culturales son propicias a un desarrollo basado en la agricultura, a pesar de los problemas de contaminación por uso de pesticidas y fertilizantes

- Zonas rurales de condiciones difíciles para la agricultura. Suelen ser áreas remotas o/y de montaña

La Comisión Europea ${ }^{5}$ ha utilizado en gran medida, la metodología de la OCDE basada en la densidad de población, con un planteamiento en dos fases:

En primer lugar las unidades locales (por ejemplo las municipales) se definen como rurales si su densidad de población es inferior a $150 \mathrm{hab} / \mathrm{km}^{2}$.

\footnotetext{
${ }^{5}$ Acuerdo 2006/144/CE
} 
Y las regiones se clasifican en tres categorías:

Región predominantemente rural (PR): más del $50 \%$ de la población vive en municipios rurales, con menos de $150 \mathrm{hab} / \mathrm{Km}^{2}$.

Región intermedia (RI): entre un $15 \%$ y un $50 \%$ de la población vive en municipios rurales.

Región predominantemente urbana (PU): menos del 15\% de la población vive en municipios rurales.

Para Gallego (2005), el criterio es razonable, pero tiene algunas limitaciones y puede producir resultados inesperados que dependen de la delimitación de las fronteras comunes, en particular para las unidades estadísticas grandes y heterogéneas como las NUTS3 (Unidades Territoriales de Estadística), cuyo territorio en su conjunto se puede clasificar con la etiqueta de rural, cometiendo probablemente un error porque incluya zonas que no sean consideradas rurales.

Otra clasificación, es la realizada por la Agencia de Estadística de la Unión Europea (EUROSTAT) con una metodología de clasificación urbano-rural que es una adaptación de la metodología propuesta por la OCDE (descrita con anterioridad), con pequeñas variaciones, en regiones NUTS3 (que en España son las provincias), a la vez que subraya el error metodológico de aplicar esta clasificación a regiones de mayor tamaño como las comunidades autónomas (NUT2). 
Fig. 1: Tipología de zonas rurales en la UE a nivel NUTS 3.

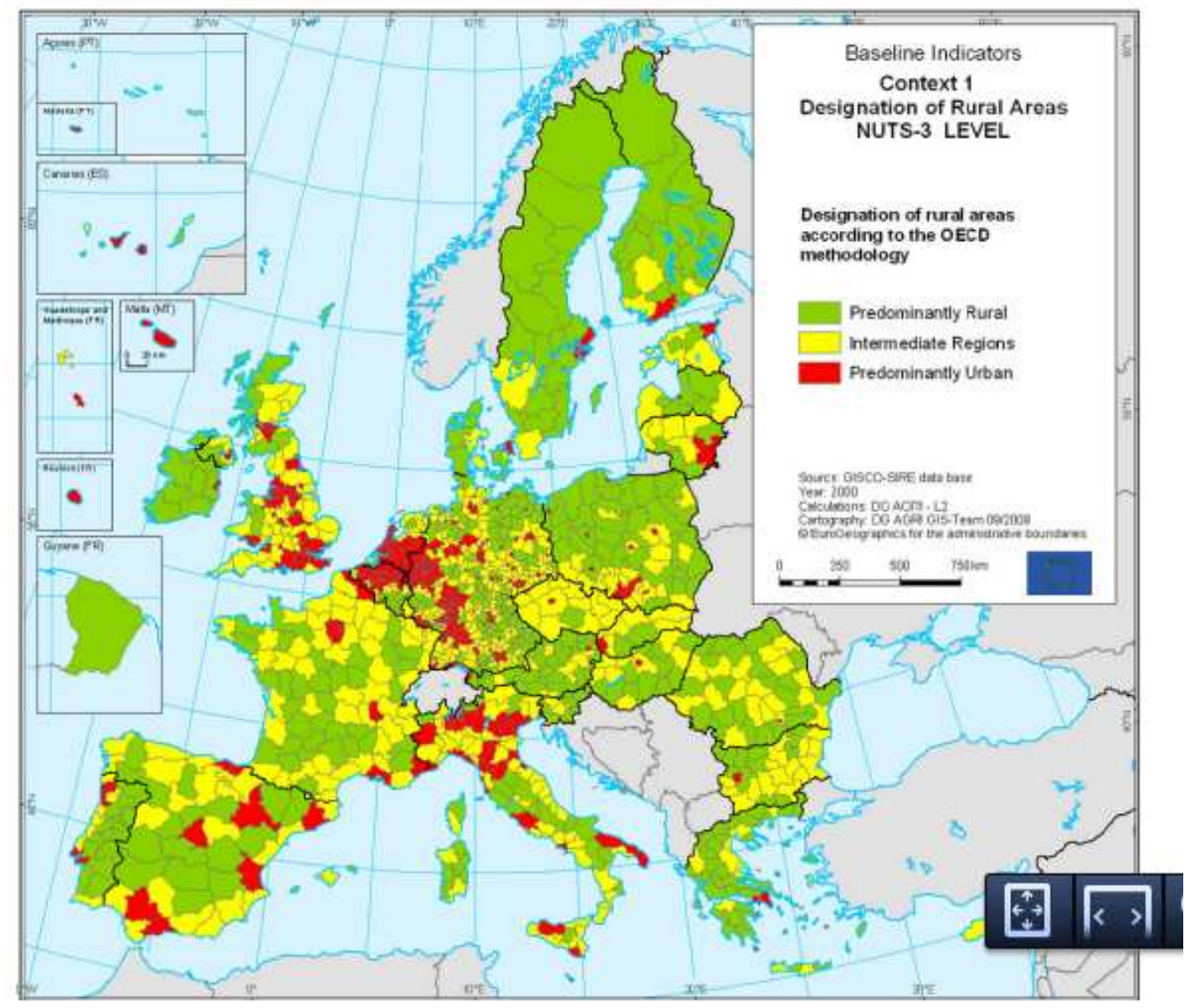

Fuente: ESPON ATLAS Mapping the structure of the European territory 2010

Recordemos que la clasificación NUTS ${ }^{6}$ (nomenclatura de Unidades Territoriales de Estadística), es un sistema jerárquico para dividir el territorio económico de la UE con el fin de, la recopilación, el desarrollo y la armonización de las estadísticas regionales de la UE. y los análisis socioeconómicos de las regiones.

\footnotetext{
${ }^{6}$ El resultado de la delimitación regional, en el caso de España, es muy similar al que se obtiene con la aplicación de la tipología original de la OCDE; así, utilizando el mismo año con el fin de hacer comparables los resultados sólo se producen dos cambios: Palencia pasa de ser considerada «predominantemente rural» en la metodología original a «intermedia», y la provincia de Guadalajara pasa de «intermedia» a «predominantemente rural».
} 
La Ley 45/1997, de 13 de diciembre, de Desarrollo Sostenible del Medio Rural define como medio rural el espacio geográfico formado por la agregación de municipios o entidades locales menores definido por las administraciones competentes que posean una población inferior a 30.000 habitantes y una densidad de población inferior a 100 hab/ $\mathrm{km}^{2}$. Además, esta Ley define "municipio rural de pequeño tamaño" el que posea una población residente inferior a los 5.000 habitantes y esté integrado en el medio rural.

Esta Ley distingue tres tipos de zonas rurales, según su tipología:

Zonas rurales a revitalizar (color rojo Fig. 2): aquellas con escasa densidad de población, elevada significación de la actividad agraria, bajos niveles de renta y un importante aislamiento geográfico o dificultades de vertebración territorial.

Zonas rurales intermedias (color amarillo Fig2): aquellas de baja o media densidad de población, con un empleo diversificado entre el sector primario, secundario y terciario, bajos o medios niveles de renta y distantes del área directa de influencia de los grandes núcleos urbanos.

Zonas rurales periurbanas (color verde Fig.2): aquellas de población creciente, con predominio del empleo en el sector terciario, niveles medios o altos de renta y situadas en el entorno de áreas urbanas o áreas densamente pobladas. 
Fig. 2: Clasificación de las zonas rurales en España.

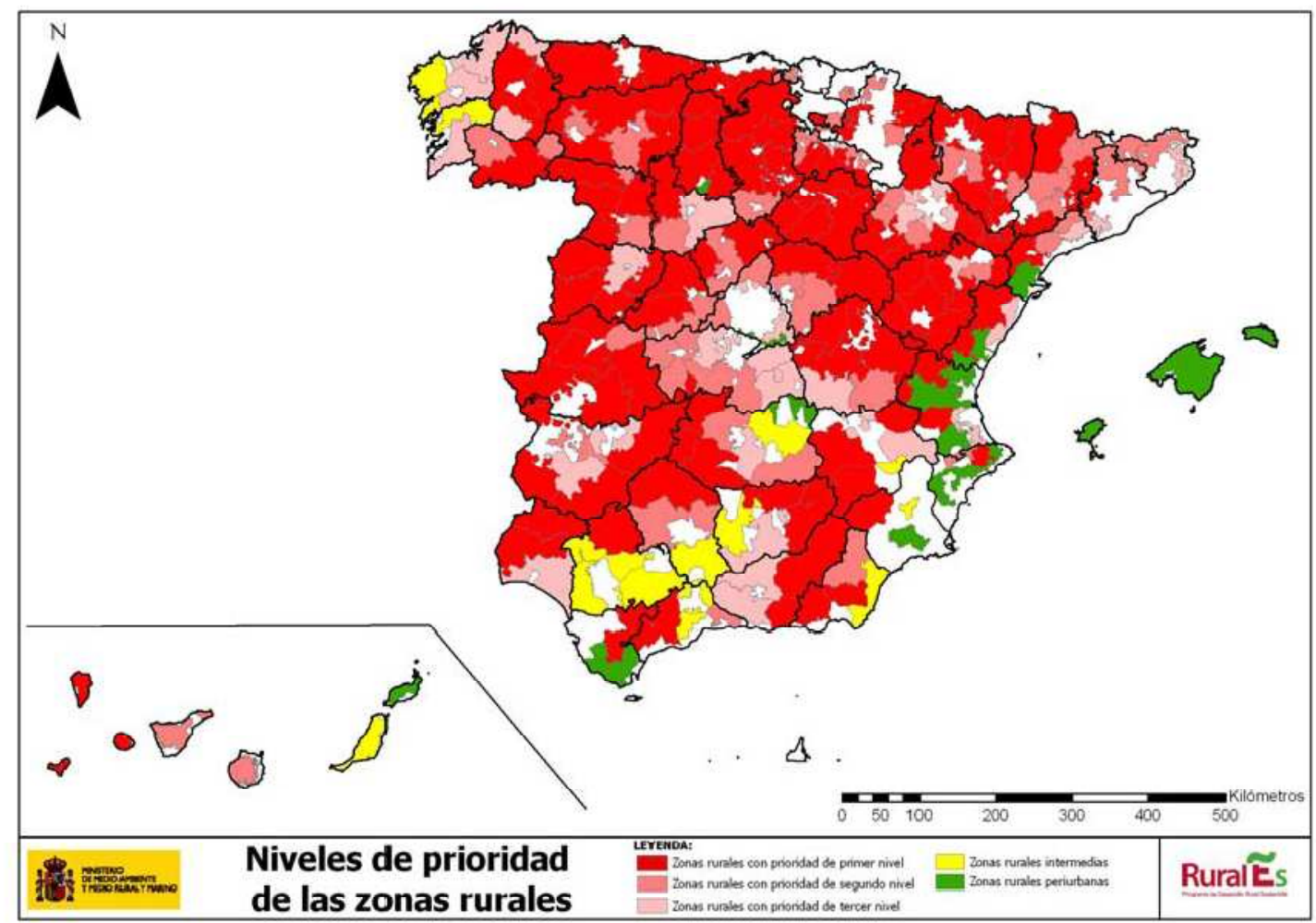

Fuente: PDRS, MAGRAMA (2010)

Las zonas rurales a revitalizar, así como las áreas integradas en la Red Natura 2000 y los municipios menores de 5.000 habitantes de las zonas intermedias y periurbanas tienen las consideración de zonas rurales prioritarias a efectos de la aplicación del Programa de Desarrollo Rural Sostenible. 


\section{Tabla 1: Definiciones de Ruralidad.}

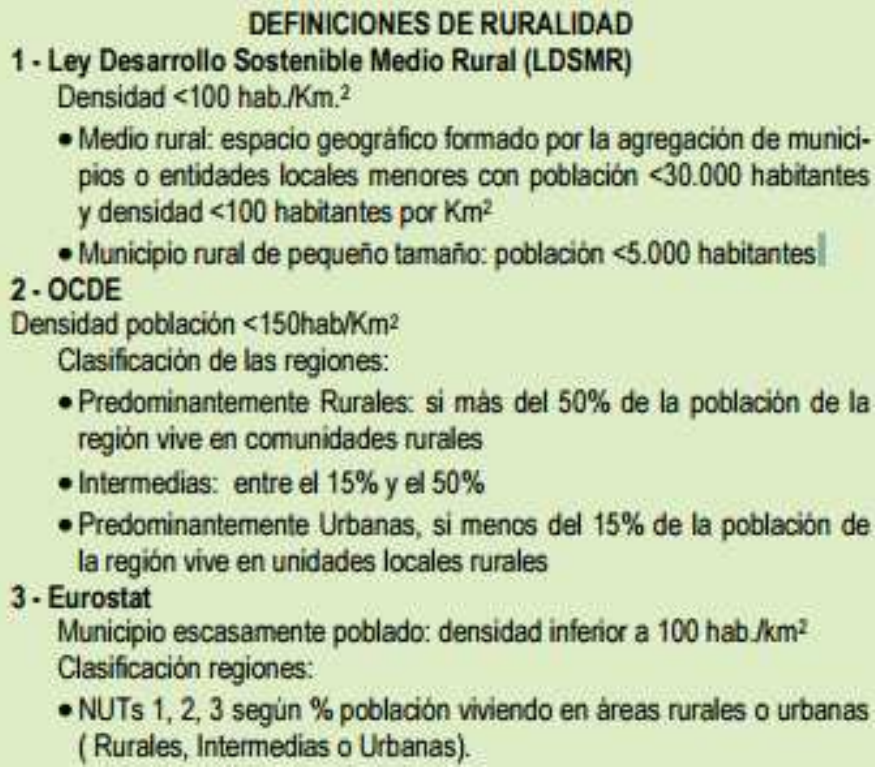

Fuente: MAGRAMA, 2009

Para conseguir un medio rural más equilibrado, tratando de equiparar las desigualdades de índole económica y social existentes, aumentado la calidad de vida de sus habitantes y respetando el medioambiente como dictamina la LDRS es necesario dar contenido al término el Desarrollo Rural en cada caso (tal como veremos en el siguiente apartado).

La Comunidad de Castilla la Mancha, tiene un 99\% de los municipios que conforman la región, con una población inferior a 30.000 habitantes y una densidad de población menor de 100 hab/km2 (criterio que define medio rural en la LDSMR), por lo que se realizó como veremos en el BLOQUE III, una clasificación tipológica de las zonas rurales de la región atendiendo a los criterios recogidos en el artículo 10.1 de la Ley para el Desarrollo Sostenible del Medio Rural, particularizando los tres tipos de zona que establece en virtud de las particularidades regionales. 
El objetivo central perseguido con la zonificación a escala local es detectar características homogéneas que articulen los espacios comarcales en aras a una actuación diferenciada en materia de desarrollo rural, propiciando estrategias que, en función de su diversidad y adecuación, permitan alcanzar un mayor grado de eficiencia en el resultado de las actuaciones públicas articuladas en torno a políticas de desarrollo territorial. (Plan Estratégico Sostenible del Medio Rural de Castilla la Mancha, 2007).

\subsubsection{Dinámica gradual entre lo Rural y lo Urbano: lo Periurbano}

Aquí vamos a introducir una nueva escala en la relación entre lo rural y lo urbano, que lo lleva hacia un estatus intermedio, ver "periurbano"7.

El concepto 'periurbano' se utiliza con un carácter genérico de envolvente por una graduación urbana imprecisa, debido a la falta de un acuerdo en el establecimiento de unos marcos conceptuales y analíticos comunes que determinen una definición concreta del término y una metodología de delimitación geográfica.

El primer intento de delimitación de las áreas periurbanas fue la definición que el año 1979 proporcionó la OCDE según la cual, desde una perspectiva territorial y de los habitantes, una zona periurbana es aquella que comprende en un radio de 20 km alrededor de los núcleos urbanos de más de 200.000 habitantes, en un radio de $15 \mathrm{~km}$ alrededor de núcleos urbanos de entre 100.000-200.000 habitantes y en un radio de $10 \mathrm{~km}$ alrededor de núcleos urbanos de entre 50.000-100.00.

Desde entonces han surgido muchas definiciones que no han llegado a aportar una aproximación en la delimitación de este ámbito.

\footnotetext{
${ }^{7}$ El Periurbano se desarrollará ampliamente en el Capítulo 4.
} 
Las características específicas de los espacios periurbanos son la indeterminación de sus límites, tanto con el espacio urbano difuso como con el espacio rural impreciso, su dinamismo, la heterogeneidad de usos que acoge y la precariedad territorial, ambiental y social configurada en la periferia de las aglomeraciones urbanas.

Este último es, en su denominación, una extensión del urbano hacia el rural. Entonces un análisis simple de los flujos de rentas y de los movimientos pendulares, así como de la circulación aparente de las riquezas (teniendo como base los gastos efectivos por territorio) muestra, como lo describió bien Laurent Davezies (2008), que las transferencias de valores no se hacen más mecánicamente en el sentido campo hacia las ciudades.

Existe una cambio de las relaciones, donde lo urbano produce el valor económico (bienes y servicios), (Pecquer, 2007) y lo rural es el lugar de absorción de este valor, por un lado a través de servicios específicos y por otro lado por una revalorización de la imagen de la naturaleza que ofrece una nueva especificidad.

Por otro lado, se reconoce un agotamiento conceptual de los términos urbano-rural basados en la oposición tradicional campo-ciudad, la epistemología trabaja más desde la interfase entre ambos términos.

Lo urbano, ya no hace referencia a un espacio que circunscribe, sinoa una yuxtaposición de elementos urbanos y rurales.

Para Bonzo (2005), revisando la cuestión del perourbano en Francia y España, destaca 3 enfoques:

- La percepción de lo periurbano no sólo como territorio, sino como forma de vida.

- La difusión urbana sobre el periurbano

- La apuesta que la periurbanización representa para los políticos 
Todos estos cambios son producidos por una competitividad dentro de un entorno globalizado. El territorio aparece como una entidad activa que saca su potencial de desarrollo de sus recursos locales, sus actividades, sus actores, sus redes. La coordinación de actores a la escala territorial provoca un cambio: la decisión se autonomiza en parte con relación al poder central público.

Surge el término gobernanza, con una perspectiva más bien económica, como proceso de coordinación de los actores para organizar la actividad económica. Se trata de comprobar más bien que las coordinaciones y las organizaciones alrededor de este proceso no sólo varían de un territorio al otro, sino que dependen de la configuración específica de cada territorio.

Una posible definición, podría ser el proceso a través del cual las sociedades e instituciones locales, junto con instituciones y agentes que intervienen sobre su territorio desde diferentes niveles de decisión (gobernanza multinivel), pueden influir en la trayectoria, en la cohesión social interna y en la capacidad competitiva del mismo actuando de una manera cooperativa y coordinada. (Abad, 2013).

La gobernanza territorial se entiende, por tanto, como el proceso a través del cual se organizan y coordinan las múltiples relaciones e interacciones establecidas entre actores y niveles de gobierno diversos que, operando a diferentes escalas, están presentes en un territorio.

Este proceso es un nuevo modo de articular y de regular la compleja arquitectura derivada del encajamiento de diferentes escalas de decisión, al mismo tiempo que como ámbito de reflexión y de acción para generar nuevas formas de desarrollo que conduzcan hacia la consecución de una cohesión territorial sostenible.

En esta dinámica rural-urbano, no puede dejarse de lado, el significante del mercado de trabajo. En el campo se quedaban tradicionalmente jóvenes sin estudios, 
los que querían profesiones liberales con otras ambiciones solían ir a estudiar a la ciudad. Cuando el sector primario pierde empleo, los jóvenes se van a la construcción, manteniendo un mercado de trabajo de baja cualificación.

Pero la penetración de la ciudad en este medio rural, con un sentido inverso, está incorporando otro mercado, aunque sea emergente (emprendedores vitivinícolas, recuperación de la industria del calzado, manufacturas, fabricación de muebles auxiliares, etc) más cualificado.

En esta dinámica la agricultura deja de ser un sector refugio, la mano de obra se desplaza entre sectores, es la cualificación y el modo de vida buscado los que designan las ubicaciones del trabajador.

\subsection{Desarrollo Rural}

El concepto de desarrollo rural se acuña en los años setenta, después de dos décadas de desarrollo, no para designar un modelo especifico para las zonas rurales, sino como estrategia para contrarrestar los efectos negativos del modelo de desarrollo dominante sobre los países de desarrollo durante las décadas de los cincuenta y sesenta (Ceña, 1994). A este respecto dos hechos se manifestaron con gran nitidez: la pobreza había aumentado y se encontraba principalmente en las zonas rurales, y la agricultura podía ser o cuello de botella o motor de desarrollo global en función de la estrategia seguida.

Existen distintas aproximaciones en el concepto de desarrollo rural, para Jansma, desarrollo rural es una mejora general en el bienestar económico y social de los residentes rurales y en el entorno institucional y físico en el que viven. (Jansma et al, 1981). 
El desarrollo rural es un proceso localizado de cambio social y crecimiento económico sostenible, que tiene por finalidad el progreso permanente de la comunidad rural y de cada individuo integrado en ella (Valcárcel-Resalts 1992).

Para Gomez Orea, 2002, puede entenderse en un sentido básico como la mejora de las condiciones de vida de los habitantes de los espacios rurales fijando como objetivos la mejora de la calidad de vida de los habitantes del medio rural, que a su vez implica el incremento de los niveles de renta, la mejora en las condiciones de vida y de trabajo y la conservación del medio ambiente.

Fig. 3: Objetivos del desarrollo rural.

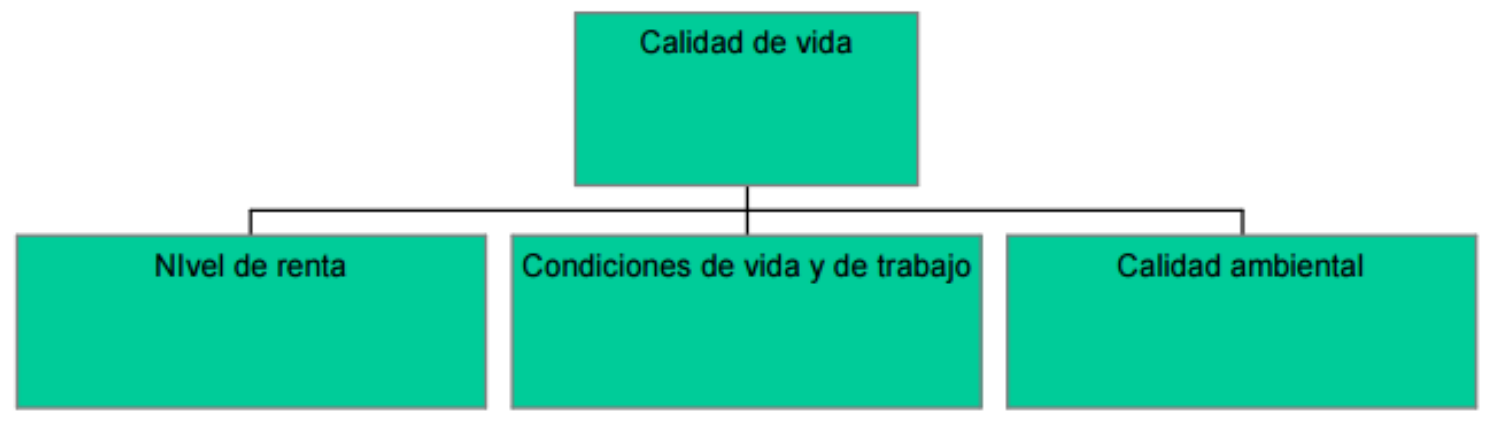

Fuente: Gómez Orea 2002

Quintana et al, 1999, conciben el desarrollo rural como "un proceso de revitalización equilibrado y autosostenible del mundo rural basado en su potencial económico, social y medioambiental mediante una política regional y una aplicación integrada de medidas con base territorial por parte de organizaciones participativas". Explicando cada uno de sus términos:

- Proceso de revitalización: mejora en el bienestar económico y social de los residentes rurales (Etxezarreta et al, 1987)

- Equilibrado y autosostenible: una búsqueda autónoma de las propias vías de desarrollo (Arrandis, 1996) 
- Desarrollo integrado: no se trata de medidas sectoriales aisladas, sino que existe un planteamiento y unos objetivos de desarrollo de cada área.

- Política Regional: va a ser la base para el desarrollo rural, por la territorializacion que hace del espacio y la posibilidad que tiene de aplicar medidas de desarrollo rural de carácter integrado.

- Base Territorial: el espacio de la UE se divide por la aplicación de la política regional.

- Organización Participativa: Las responsables de promover estrategias de desarrollo en zonas rurales.

Para Sancho Comins et al (2002) y Gonzalez de Canales (2003) el desarrollo rural es el proceso endógeno que se genera en el territorio de forma global e intersectorial y que exige la participación activa de la propia población en un progreso apoyado en la acción subsidiaria de las administraciones y de otros agentes externos. Mediante este proceso se pretende una mejora de las condiciones de vida y trabajo que lleve consigo la creación de empleo y riqueza, compatible con la preservación del medio y uso sostenible de los recursos naturales.

El desarrollo rural pretende reestructurar el sistema económico rural mediante estrategias de desarrollo empresarial basado en las capacidades del territorio. González de Canales (2004) lo concibe como la capacidad que tienen las personas en un territorio de movilizarse asumiendo el protagonismo de asegurar su futuro, procurando la máxima integración de los actores locales, organizándose en partenariado local capaz de asumir acciones de desarrollo de forma corresponsable con las administraciones públicas, capitales e iniciativas de I+D+l innovadoras.

El Desarrollo Rural tiene por objetivo la corrección de desequilibrios en el medio rural. Así, se siguen contemplando por las autoridades comunitarias en las medidas de política rural para el nuevo período 2014-2020, y así, la Comisión 
propone los tres objetivos estratégicos siguientes para la próxima reforma de la PAC: 1) Producción alimentaria viable; 2) Gestión sostenible de los recursos naturales y acción por el clima; y 3) Desarrollo territorial equilibrado (Ramos, 2011).

\subsubsection{Desarrollo Sostenible}

El concepto de desarrollo sostenible, aparece por primera vez, en el documento "Nuestro Futuro Común", también llamado Informe Brundtland, elaborado por la Comisión Mundial sobre Medio Ambiente y Desarrollo de las Naciones Unidas, en el año 1987. Posteriormente, diversas cumbres mundiales desarrollan y profundizan el concepto, entre estas, la Conferencia de las Naciones Unidas sobre el Medio Ambiente y el Desarrollo, o Cumbre de la Tierra, celebrada en Rio de Janeiro en 1992.

Anteriormente otras expresiones como "desarrollo verde, "ecodesarrollo", habían sido utilizadas para referirse a un modo de producción que fomenta la equidad entre los diferentes grupos sociales y fuera más respetuoso con el medio ambiente.

Desarrollo Sostenible es el desarrollo que satisface las necesidades de la generación presente sin comprometer las capacidades de las generaciones futuras de satisfacer sus propias necesidades. Implica pasar de un desarrollo pensado en términos cuantitativos basado en el crecimiento económico a uno de tipo cualitativo donde se establecen estrechas vinculaciones entre aspectos económicos, sociales y ambientales, sin que el avance sobre uno de estos tres aspectos signifique ir en deterioro del otro.

Sin embargo, en la mayoría de los casos, la reflexión sigue estando fundamentalmente enfocada sobre las formas concretas para conciliar a largo plazo, 
las dinámicas de desarrollo con la protección de los recursos y del medio natural. Incorpora un principio de responsabilidad, que establece que todo el mundo está involucrado en su nivel de acción en la consecución de estos objetivos.

La política agrícola es un "lugar privilegiado" de aplicación, debido a la importancia de los impactos ambientales de la agricultura y la silvicultura en todo el mundo, su aplicación a la tierra, su papel en la calidad y la seguridad alimentaria (Martin, A 1990), en este sentido, para la Unión Europea, la Declaración de Cork (noviembre de 1996) supuso hacer del concepto de desarrollo sostenible, uno de los pilares de reflexión sobre el desarrollo rural para los próximos años.

En esta Declaración, aparece la necesidad de integrar en la política regional europea los dos conceptos de desarrollo rural y de sostenibilidad: "el desarrollo rural sostenible debe ponerse en el primer lugar de la agenda de la UE y convertirse en el principio fundamental que guie toda la política rural en el futuro inmediato y después de la ampliación. El objetivo es invertir la tendencia al éxodo rural, combatir la pobreza, fomentar el empleo y la igualdad de oportunidades, anticiparse a las crecientes exigencias de mejora en materia de calidad, salud, seguridad, desarrollo personal y actividades en tiempo libre, así como aumentar el bienestar en el espacio rural. El requisito de preservación y mejora de la calidad del medioambiente rural debe integrarse en todos los trabajos de la política comunitaria relacionados con el desarrollo rural. Los gastos públicos, las mejoras infraestructurales y los bienes de equipo en materia de educación, sanidad y telecomunicaciones deben tener un reparto más justo entre el espacio rural y las zonas urbanas. Los fondos disponibles deben utilizarse en mayor proporción para fomentar el desarrollo rural y garantizar la realización de los objetivos fundamentales".

Desde la OCDE se ha puesto de manifiesto que el desarrollo sostenible es algo más que la adecuada gestión medioambiental, y que además de impulsar 
determinadas transformaciones en el sistema económico que reduzcan el impacto negativo en el medio ambiente y/o que favorezcan su restauración, se debiera incorporar variables socioculturales, especialmente aquellas que inciden en el desarrollo de actividades que mejoran la capacidad de la ciudadanía para comprender y emprender políticas de desarrollo sostenible, que favorecen la formulación de alternativas tendentes a formar comunidades sostenibles.

Por otro lado, la Unión Europea, en consonancia con los compromisos adquiridos por las partes firmantes de la Declaración de Rio, presenta en junio de 2001, en el marco de la reunión del Consejo Europeo de Gotemburgo, la Estrategia Europea de Desarrollo Sostenible, cuyos objetivos y prioridades son coherentes con el VI Programa de Acción Comunitaria en Materia de Medio Ambiente (2001-2010), "Medio ambiente 2010: El futuro está en nuestras manos".

En el caso de la Unión Europea es claro que el futuro de la región está estrechamente ligado al desarrollo equilibrado y sostenible de los territorios rurales, que ocupan un $92 \%$ del territorio de laUE-27, y donde vive más de la mitad de su población

España se suma al esfuerzo comunitario e inicia la Estrategia Española de Desarrollo sostenible en el año 2001, que se enmarca dentro de la Estrategia d Desarrollo Sostenible de la UE con un principio general consistente en determinar y elaborar medidas que permitan la creación de comunidades sostenibles capaces de gestionar y utilizar los recursos de forma eficiente, para aprovechar el potencial de innovación ecológica y social que ofrece la economía garantizando la prosperidad, la protección del medio ambiente y la cohesión social.

De forma simultánea es aprobada la Ley de Desarrollo Rural del Medio Sostenible (2007), que trata como objetivo de la política de desarrollo rural la de hacer de las zonas rurales un lugar más atractivo en donde vivir y trabajar en un 
escenario en donde puedan encontrar una vida mejor gentes cada vez más diversas de todas las edades invirtiendo el proceso de envejecimiento y despoblación de las mismas, dotándolas de medios par que generen su propio desarrollo, se adapten a las nuevas circunstancias económicas y sean valoradas como merecen por el conjunto de la sociedad.

El Gobierno de Castilla la Mancha a su vez elabora un Plan Estratégico de Desarrollo Sostenible del Medio Rural 2008-2013, abriendo una puerta al futuro del desarrollo rural de la región.

El modelo de desarrollo que se propone no puede ser otro que el que, respetando los recursos naturales, sea capaz de proporcionar a todos los ciudadanos las mismas oportunidades con independencia de su lugar de residencia. Un Plan que conjuga a la perfección el concepto de desarrollo sostenible con el de desarrollo equilibrado, respetuoso con el entorno, adaptado a la realidad presente y planificando el desarrollo futuro.

\subsubsection{Desarrollo Territorial}

El desarrollo local es un proceso a lo largo del cual se busca organizar los recursos locales (territorio, población, instituciones...) y articularlas con los recursos exteriores (mercados, políticas, tecnología, capital, servicio, etc (Mendes, 1997).

Para Pecquer (1989), el desarrollo local es una dinámica que pone en evidencia la eficacia de las relaciones entre los hombres para poner en valor las riquezas de las que disponen. Cuando existe un medio denso de producción, los emprendedores intercambian la información sobre sus respectivas materias, la evolución de sus técnicas, la forma de gestión del personal etc, es decir existe una cultura emprendedora que enriquece la capacidad de ese medio de adaptarse a las 
dificultades del exterior. Es entonces cuando los territorios alcanzan sinergias y se crean lugares donde se desarrolla una toma de conciencia colectiva de esa unidad.

El desarrollo local constituye une interpretación de los procesos de desarrollo en función de los tiempos actuales, es una modalidad de desarrollo que puede tomar forma en territorios de diversos tamaños, pero no en todos, dada la complejidad del proceso de desarrollo (Boisier ,2001).

Es un método que pretende la evolución del territorio por medio de un proceso de movilización de los recursos endógenos (los propios de un territorio) al servicio de la promoción social y personal de la comunidad local. Su consecución se logra asumiendo iniciativas de empleo y desarrollo compatibles con la conservación de su patrimonio cultural y natural.

En definitiva, el desarrollo local representa un conjunto de ideas teóricas que tratan de explicar la creciente complejidad de la economía en un contexto territorial y los procesos de desarrollo entendidos como dinámicas de cambio social, basándose en elementos económicos y extraeconómicos (Peña, 2006)

A fines de los 80, la emergencia de los procesos de desarrollo local en Europa y al Sur del Mediterráneo tienen que ver con tres acontecimientos que una inflexión en el marco de las políticas europeas:

El primero fue la reforma MacSharry de la PAC que empezó en el famoso Consejo de ministros de la Unión Europea de 1986, en Dublín.

El segundo es el de la creación del segundo pilar del PAC, dedicado al desarrollo rural. Este segundo pilar es una elección política de la presidencia de la Comisión Europea que decreta como inaceptable, en nombre de la " cohesión económica y social " de la Unión, que el 80 \% del territorio agrícola este "marginado". Una comunicación oficial de la Comisión Europea resume esta nueva orientación en "L'avenir du monde rural". 
El tercer estará constituido por el programa de desarrollo rural destinado a crear las iniciativas LEADER. Este programa, que se presentará en 1989, interesará a 217 zonas rurales en la Unión. Esta iniciativa, totalmente original para la época, establece una relación directo entre el grupo de actores locales que administra el desarrollo de la zona y la Comisión Europea va, en Europa, a ser una de las manifestaciones mayores de la emergencia progresiva de un desarrollo territorial.

Por otro lado, el término desarrollo territorial hace referencia a un proceso bien establecido y refiere a la escala geográfica en la que coexisten y se pueden reconocer diferentes niveles (nacionales, supranacionales etc).

Para lograr una versión comprensiva del desarrollo territorial, se asume que la actual cultura propia de los centros urbanos, posterior a la emergencia de las telecomunicaciones, se constituye en una de las formas más avanzadas de la evolución de la especie humana, y que esta se asienta sobre los siglos de historias y tradiciones geográficamente delimitadas. Esta cultura se expresa con mayor claridad a través de los servicios y, en especial, lo referido a las tecnologías de información y comunicaciones y los temas empresariales avanzados, sentando las bases de lo que son actualmente las redes y las ciudades-red (Castells, 2001).

La historia y la geografía nos muestran que muchos espacios rurales podrían tener desde hace tiempo la calificación de "territorios" por sus límites bien definidos y de su denominación bien articulada. Además cuando hablamos de una emergencia reciente, se trata de lo que habría que llamar más bien unos "territorios de desarrollo". Así, para simplificar, podríamos decir que el término más tradicional es "territorio" y lo que es reciente es la "territorialidad" de ciertos espacios como portadores de desarrollo, lo que nos lleva a hablar de desarrollo territorial. (Campagne, P 2014). 
Para este autor, el desarrollo territorial es un proceso dinámico de actividades basado en la puesta en valor de los recursos locales de los territorios, mejorando los ingresos, satisfaciendo las necesidades, creando territorios autosuficientes, que puedan crear puestos de trabajo y valor económico para volver a invertir y expandir este proceso.

El desarrollo territorial no está solamente determinado por lo atractivo del territorio para las empresas y para los individuos. Otros conceptos son interesantes tener en cuenta para el análisis de la atracción hacia este territorio: polo de empleo, zona comercial, grandes equipamientos, estilo de vida etc.

El proceso que tratamos aquí enfocado sobre un territorio es el fruto de fases las políticas agrarias y las condiciones socioeconómicas que se han venido sucedieron durante casi treinta años, para dar lugar a nuevas ruralidades. Garrido y Moyano 2013 señalan que la definición de rural a nivel europeo se refugia en un enfoque unidimensional que ha debilitado los objetivos de cohesión territorial debido a la dispersión de políticas de las políticas y a la falta de coordinación entre los territorios de la UE.

\subsection{Grupos de Desarrollo Rural}

Los Grupos de Desarrollo Rural o Grupos de Acción Local, son asociaciones sin ánimo de lucro, con una participación pública (máx. 50\%) y privada, cuales quiera que sea su forma jurídica y que en su organización interna se encuentren representados los interlocutores públicos y privados de un territorio determinado, siendo su objetivo el de la aplicación de un programa regional de Desarrollo Rural (MAGRAMA, 2001). 
En el capítulo 3 abordamos la evolución de las políticas de desarrollo rural, y explicamos ampliamente la iniciativa comunitaria LEADER ${ }^{8}$. Pués bien, los Grupos de Acción Local son sus "protagonistas operativos".

La metodología LEADER representa una formula de trabajo que ha permitido promover la innovación en las actividades del mundo rural y que ha propiciado la posibilidad de que las zonas rurales más necesitadas encuentren métodos novedosos, que les permitan cambios interesantes en la manera de afrontar los nuevos retos a los que se enfrentan las poblaciones rurales, permitiendo que se constituyan Grupos que sean los catalizadores de la cooperación pública y privada (Carmona, 2013).

Las iniciativas Leader han de entenderse como respuesta de la Unión a la crisis vivida por sus espacios rurales desde los años setenta. Leader ha sido por tanto una herramienta de exploración de nuevos argumentos para territorios que, a través de la experimentación a escala real de métodos y enfoques del desarrollo rural novedosos e innovadores ha conseguido articular un nuevo discurso para los territorios rurales europeos (De los Ríos, 2002).

La importancia y el éxito de dichas iniciativas se ha plasmado en una metodología de desarrollo rural basada en el protagonismo, autónomo y responsable, de la población rural en su propio desarrollo, en tanto en cuanto es la propia población rural la que, organizada en Grupos de Acción Local, analiza la situación de su territorio o comarca, identifica y valora los problemas que le afectan, los prioriza, estudia las posibles soluciones, elige las que puede abordar con los recursos de que dispone o pueda recabar de los poderes públicos, diseña una estrategia para aplicarlas, ejecuta el programa estratégico y, finalmente, lo evalúa y emprende nuevos retos (Red Rural Nacional, 2011).

${ }^{8}$ La iniciática LEADER arranca con una Comunicación de la Comisión a los Estados 91/C/73/14, adoptada al amparo del artículo 11 Reglamento (CEE) 4253/88 
El escaso desarrollo o implantación de otras estructuras, o simplemente su inexistencia, permitió que LEADER contribuyera a esa identidad territorial, a «hacer comarca», y con ello también ha fomentado la vertebración del territorio rural, tan importante para afrontar con ciertas garantías la puesta en marcha de estrategias e intervenciones que han de tener una perspectiva necesariamente supramunicipal (Esparcia, J 2011).

En la Comunidad Autónoma de Castilla-La Mancha y enmarcado dentro del Programa de Desarrollo Rural 2007-2013, el enfoque LEADER persigue el desarrollo del medio rural a través de proyectos que reactiven su estructura social y demográfica, derivándose de este hecho la relevancia de los Grupos de Acción Local en esta comunidad.

El objetivo no es relegar a la población rural a un papel de mero receptor de ayudas, sino que ésta se involucre, a través de sus representantes locales, en la gestión del programa y sea verdaderamente responsable del camino que hayan decidido emprender. El enfoque ascendente ${ }^{9}$ que lleva asociado el programa LEADER supone el compromiso y la movilización de los agentes económicos sociales de cada territorio con el fin de que las intervenciones sean verdaderamente participativas y representativas.

Estos GAL dinamizan su territorio informando y animando a posibles promotores de actuaciones que se pueden acoger del programa comarcal LEADER, que cada GAL elabora en su territorio de actuación.

9 en cuanto es la población la que, afectada por problemas y carencias, posee toda la legitimidad para estudiar las posibles soluciones, diseñar estrategias de desarrollo y, con el apoyo de las instituciones y bajo el principio de subsidiariedad, ponerlas en práctica y responsabilizarse de sus resultados. 
La composición de los GAL, es variada ${ }^{10}$. El requisito marcado por el programa es que sus socios tengan una implantación efectiva en la comarca y que represente a la población bien de forma directa o bien a través de colectivos social, económico, cultural, político, institucional, profesional o sindical.

Esta composición de los Grupos de Desarrollo Rural cuenta intrínsecamente con capacidades, habilidades y orientaciones que maximizan el acercamiento de la población rural a la toma de decisiones, generando un proceso más participativo entre todos los agentes implicados. De la naturaleza de esas coaliciones ha dependido en gran medida que las comarcas LEADER hayan evolucionado por unas trayectorias del desarrollo o por otras.

El conocimiento del territorio y el trabajo en contacto directo y permanente con la población y los sectores económicos del territorio, les permite una gran capacidad de respuesta y adaptación a los cambios. Lo que es cierto es que detrás de un GAL que funciona correctamente y que está desarrollando una buena labor en su territorio, suele tener detrás un buen equipo técnico.

Estos Grupos han de actuar como gestores de dotaciones económicas globales coordinadas por el organismo nacional, asignadas en función de un programa de desarrollo rural. El objetivo no es otro que el de tener a toda la población de ese territorio interesada en cómo se desarrolla el programa y buscar una permanencia en el tiempo.

Han de ser capaces de definir con cierta precisión tanto las necesidades como las fortalezas y oportunidades con las que cuenta el territorio. Éstos son aspectos básicos a la hora de definir los objetivos y acciones a poner en marcha, es decir, a la hora de diseñar y ejecutar una estrategia de desarrollo que responda a esas necesidades y que permita maximizar las oportunidades que se deriven de los

\footnotetext{
${ }^{10}$ En la página siguiente representamos un esquema tipo de composición de un GAL
} 
recursos internos, físicos, humanos e institucionales, así como del entorno exterior (Esparcia, 2011).

Las actuaciones de este grupo si bien se desarrollan conforme a un programa comarcal, pero que es diseñado por el Grupo, siendo más tarde aprobado por el Organismo Intermedio mediante la firma de un Convenio de colaboración. En este convenio se fija el Cuadro financiero, por medidas de actuación para el periodo de aplicación de los Programas.

Además estos Grupos tienen unos requisitos legales y administrativos, tales como tener sede física en un municipio de la comarca de actuación, tienen unos Estatutos, y están sujetos a controles por el Organismo Intermedio.

La selección de Grupos se realiza mediante convocatorias autonómicas, con representación de las administraciones cofinanciadoras (General del Estado, Autonómica y, en su caso, Local). 
Fig. 4: Composición tipo más frecuente de un GAL.

\begin{tabular}{|l|l|}
\hline ENTIDAD & \multirow{2}{*}{ CARÁBLCTER } \\
(máximo 50\%)
\end{tabular}

Fuente: Carmona, G 2013 
Fig. 5: Estructura Equipo gestor de un GAL

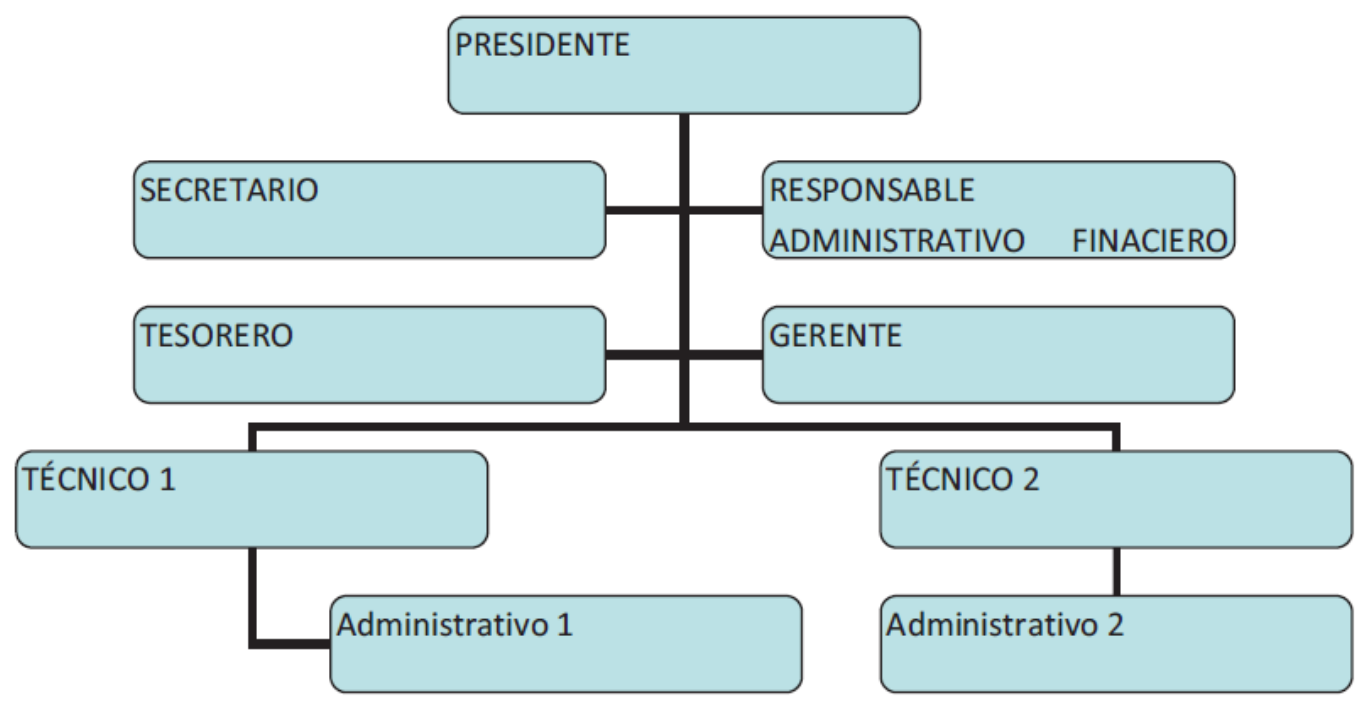

Fuente: Carmona, G 2013

En los 10 primeros años de vida de la metodología LEADER, (desde su creación hasta LEADER+), el protagonismo de estos Grupos de Acción Local, se fue consolidando en la gestión de los programas de desarrollo rural. Además el reconocimiento que tienen en el entorno institucional, ha contribuido a esa legitimación que tienen hoy en día, como algo que ya está consolidado en la mayor parte de los casos.

En Castilla la Mancha esos grupos de Desarrollo rural se ajustan a las comarcas naturales e históricas, o bien a parte de las mismas cuando se inter ponen límites provinciales o cuando la extensión geográfica a gestionar es demasiado extensa.

Para el período 2000-2006, en nuestra región, la Orden 18 de Octubre de 2001, de la Consejería de Medio Ambiente, establece las normas de presentación, selección y aplicación de programas de desarrollo rural con ámbito territorial en Castilla la Mancha, en el marco de la iniciativa comunitaria LEADER+ y el programa de desarrollo PRODER II, fueron seleccionados un total de 29 programas de 
desarrollo rural (13 LEADER+ y 16 PRODER), firmándose los convenios entre los GAL y el Organismo Intermedio en noviembre 2002.

Para el período 2007-2013 ${ }^{11}$, en Castilla la Mancha el Programa de Desarrollo rural LEADER es aplicado por los 29 Grupos de Acción Local, que se pasaron a nombrar Grupos de Desarrollo Rural $(G D R)^{12,}$ según la Orden 6 Junio 2008 de la Consejería de Medio Ambiente y Desarrollo Rural de Castilla la Mancha, en la que se establece el procedimiento de selección de territorios y las disposiciones de aplicación del Eje LEADER en el marco del Programa de Desarrollo Rural de Castilla la Mancha 2007-2013.

Pero no fue este el nuevo cambio introducido, por citar los más relevantes:

- $\quad$ En municipios con más de 10.000 habitantes el PDR de Castilla la Mancha obliga la creación de al menos tres puestos de trabajo incluyendo mujeres o discapacitados para poder aprobar un proyecto.

- Los gastos de funcionamiento del propio GDR (gerente, Técnico y Administrativo), están limitados a un $20 \%$ del total del cuadro financiero.

- Se suprime la posibilidad de ayuda para las cooperativas y empresas agroalimentarias a través de los GDR bajo enfoque LEADER $^{13}$

En cualquier caso, los GAL- GDR han adquirido hoy un peso específico en la nueva política rural, demostrando ser unos interlocutores útiles, necesarios y capaces de asumir la responsabilidad compartida en el diseño y la gestión del desarrollo rural. Es

\footnotetext{
${ }^{11}$ Eje Leader del PDR 2007-2013

${ }^{12}$ Los dos términos se aplican en función del momento histórico al que se refiera el texto, pero con la consideración que es la misma entidad nombrada de diferente manera.

${ }^{13}$ Este tipo de ayudas se enmarcan el Eje 1 "Aumento de la competitividad del sector agrícola y forestal".
} 
previsible que su importancia crezca en el futuro, por lo que conocer su estructura interna, sus relaciones externas y su funcionamiento actual nos ayudará a corregir las deficiencias que puedan presentar y potenciar sus aspectos positivos, para de esta manera construir grupos más sólidos en los que pueda apoyarse el desarrollo rural.

\subsubsection{Proyectos dentro de los Grupos de Desarrollo Rural.}

Los Grupos de Acción Local deben basarse en el partenariado y la colaboración de los distintos agentes que forman parte del mismo a la hora de definir la estrategia que mejor se adapte a cada uno de los territorios. La composición de los Grupos ha ido variando a lo largo del tiempo y se han ido incluyendo nuevas exigencias y limitaciones en cuanto a su composición y los mecanismos que deben seguir en la toma de las decisiones relativas a la aplicación de sus programas. Estas exigencias persiguen el que no exista una predominancia clara de ningún sector a la hora de tomar decisiones, para que en el ámbito de una mayor diversidad de opiniones, se puedan conseguir mejores resultados.

Haciendo un repaso sucinto sobre los proyectos en los Programas de Desarrollo Rural, empezaremos hablando sobre los pasos iniciales hasta la materialización de un proyecto. El punto de partida de un proyecto consiste en la búsqueda de promotores que estén dispuestos a emprender un proyecto por parte del equipo técnico del GAL, que tiene que transmitir las condiciones y posibilidades existentes de realizar un proyecto dentro del Programa LEADER (en alguna de su líneas o ejes estratégicos), para ser mas tarde aprobado por el equipo del GAL. 
Los proyectos tienen que cumplir con una serie de requisitos transversales:

- Respeto y cuidado del Medio ambiente y el Paisaje comarcal, de acuerdo a los principios establecidos por el Grupo.

- Integrar la igualdad de oportunidades.

- Incorporar las nuevas tecnologías.

- Mantener durante 5 años como mínimo la actividad de ese proyecto.

Y además, los proyectos LEADER tienen que cumplir las siguientes condiciones:

- Ubicarse en un municipio de la comarca de hasta 10.000 habitantes

- Viabilidad económica y técnica del proyecto

- Ser un proyecto piloto o que tenga carácter innovador

- Cumplir con las valoraciones en materia del Paisaje del Programa comarcal.

- Comprometerse a proteger la Red de Áreas Protegidas de Castilla la Mancha, y otros espacios naturales de la Sierra del Segura no incluidos en esta Red, y a no deteriorarlos con la realización del proyecto.

- Asentar y fijar la población con la creación d empleo.

- Contribuir a la puesta en valor del patrimonio rural, bien sea natural, histórico o cultural o a la mejora económica del entorno económico.

- Pasar el procedimiento de Evaluación de Impacto Ambiental en caso necesario.

- Cumplir con la normativa municipal, regional y estatal que sea aplicable a la actividad a desarrollar.

Los proyectos se clasifican en productivos y no productivos:

- Productivos: son aquellos en los que se obtiene algún beneficio. Los promotores son particulares o empresas. 
- No productivos ${ }^{14}$ : no tienen beneficio alguno. Los promotores son asociaciones sin ánimo de lucro, ayuntamientos o mancomunidades.

En cualquier caso respecto a los proyectos subvencionables, tienen que estar dentro de una de las siguientes medidas recogidas en el Programa comarcal LEADER:

311. Diversificación hacia actividades no agrícolas

312. Creación y el desarrollo de empresas

313. Fomento de Actividades Turísticas

321. Servicios básicos para la economía y la población rural

322. Renovación y desarrollo de poblaciones rurales

323. Conservación y mejora del patrimonio rural

331. Formación e Información

341. Adquisición de capacidades

421. Cooperación

431. Gastos de funcionamiento, adquisición de capacidades y animación

La baremación de los proyectos también ha cambiado a lo largo de los años, así en el período 2000-2006, los proyectos se puntuaban directamente por el GAL con un máximo de ayuda sobre el presupuesto aprobado con independencia del montante de la inversión, diferenciando entre proyectos productivos (máximo 50 \% de ayuda sobre el presupuesto aprobado), y no productivos a definir por el GAL pero con un máximo del $100 \%$ de la inversión aprobada.

\footnotetext{
${ }^{14}$ Aquellas que no generan ingresos o, en el caso de que los tuviera, estos proceden de tasas, precios públicos o tarifas, en el caso de gestión indirecta de servicios públicos. Si dichos ingresos proceden de precios públicos, para su consideración como proyecto no productivo, el beneficio neto debe ser inferior al valor de la capitalización de la inversión al interés legal del dinero.
} 
En el período 2007-2013, hay un máximo de ayuda del $40 \%$ sobre el presupuesto aprobado y se aplica además la regla de Minimis, según la cual el importe de la ayuda es la suma de 2 tramos, un primer tramo que depende de las características del proyecto: creación de empleo, innovación, mujer joven, viabilidad, calidad, garantía y solvencia del promotor con un máximo $28 \%$.

Y un segundo tramo, con un máximo de un 12\% en aplicación del principio de ruralidad, según el cuadro nำ a continuación, una discriminación positiva para los proyectos que se emprendan en los núcleos de población más pequeños, que contempla el PDR de Castilla la Mancha.

Tabla 2: Puntuación para obtener Ruralidad.

\begin{tabular}{|c|c|c|c|c|c|}
\hline PORCENTAJE ADICIONAL & \multicolumn{5}{|c|}{ HABITANTES DEL NUCLEO DEPOBLACION } \\
\hline TIPO DE ZONA & $<500$ & $\begin{array}{l}500- \\
1000\end{array}$ & $\begin{array}{l}1000- \\
2000\end{array}$ & $\begin{array}{l}2000- \\
5000\end{array}$ & $\begin{array}{l}5000- \\
10000\end{array}$ \\
\hline $\begin{array}{l}\text { ZONA A REVITALIZAR O NUCLEO CON } \\
\text { PERDIDA POBLACION }\end{array}$ & 10 & 9 & 8 & 7 & 6 \\
\hline ZONA INTERMEDIA & 8 & 7 & 6 & 5 & 4 \\
\hline ZONA PERIURBANA & 6 & 5 & 4 & 3 & 2 \\
\hline $\begin{array}{lc}\text { PORCENTAJE } & \text { ACUMULABLEPOR } \\
\text { PERTENENCIA A RED NATURA } 2000\end{array}$ & \multicolumn{5}{|c|}{2} \\
\hline
\end{tabular}

Fuente: Elaboración propia a partir datos PDR Castilla la Mancha. 
Para resumir la trayectoria de un expediente desde el origen, hasta que es abonado, pasa por una serie de etapas reflejadas en el cuadro adjunto:

Fig. 6: Flujograma PDR.

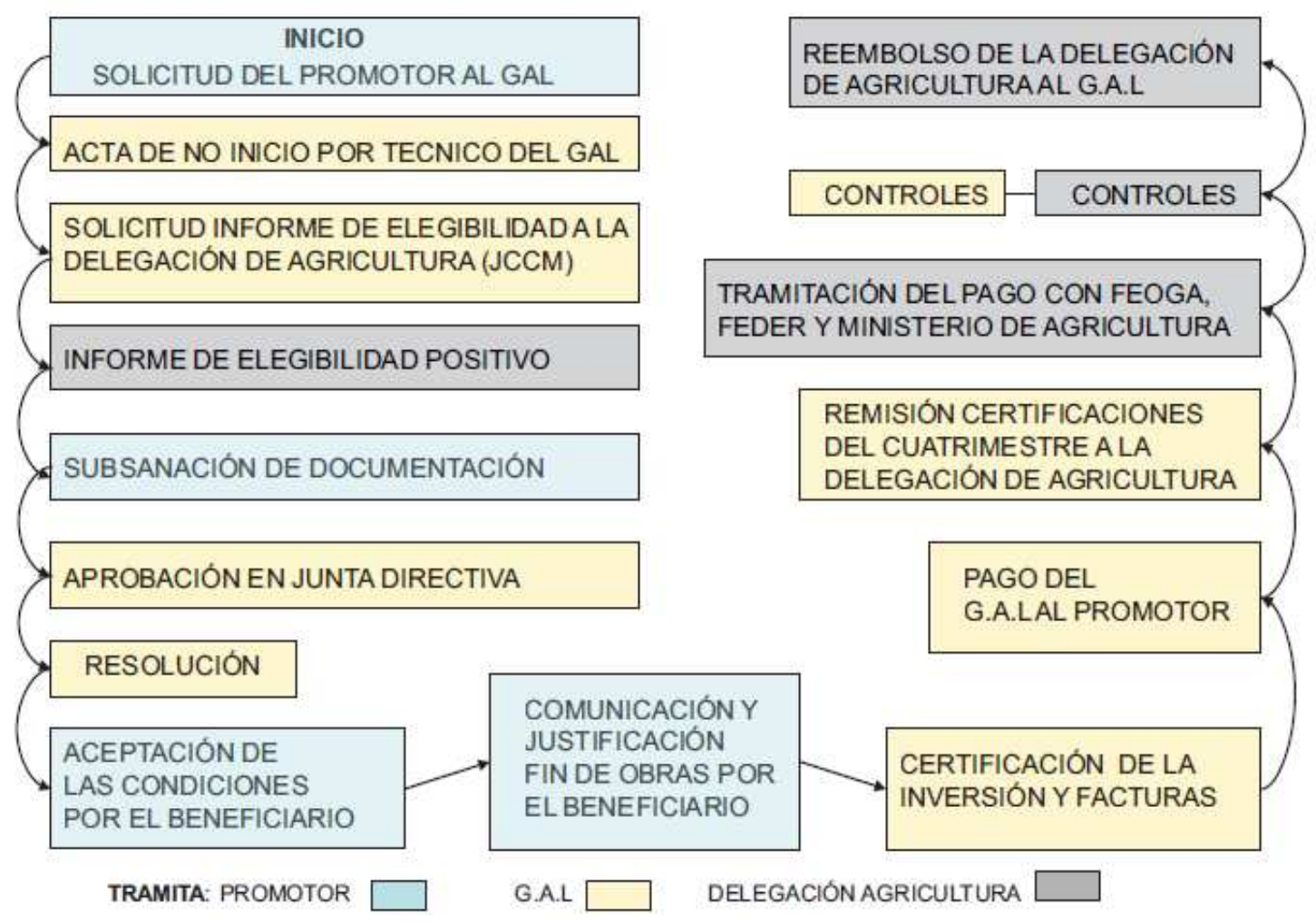

Fuente: PDR 2007-2013 Castilla la Mancha 
CAPITULO 3: EVOLUCIÓN HISTÓRICA DE LA POLÍTICA DE DESARROLLO RURAL EN EUROPA 


\section{CAPITULO 3: EVOLUCIÓN HISTÓRICA DE LA POLÍTICA DE DESARROLLO RURAL ENEUROPA}

\subsection{Breve recordatorio de los hitos que han acompañado esta política}

Desde su constitución la UE ha intentado potenciar el desarrollo de las zonas rurales para poder lograr un desarrollo económico equilibrado. En este apartado se va a tratar de hacer un recordatorio sobre la evolución histórica de la Política Europea de Desarrollo Rural, desde los inicios de la Comunidad Económica Europea (CEE) en 1957 hasta la actualidad, resaltando los aspectos de mayor importancia y la evolución y los cambios que ha ido teniendo la idea de Desarrollo Rural.

Fig. 7: Evolución de la política del Desarrollo Rural en la Unión Europea.

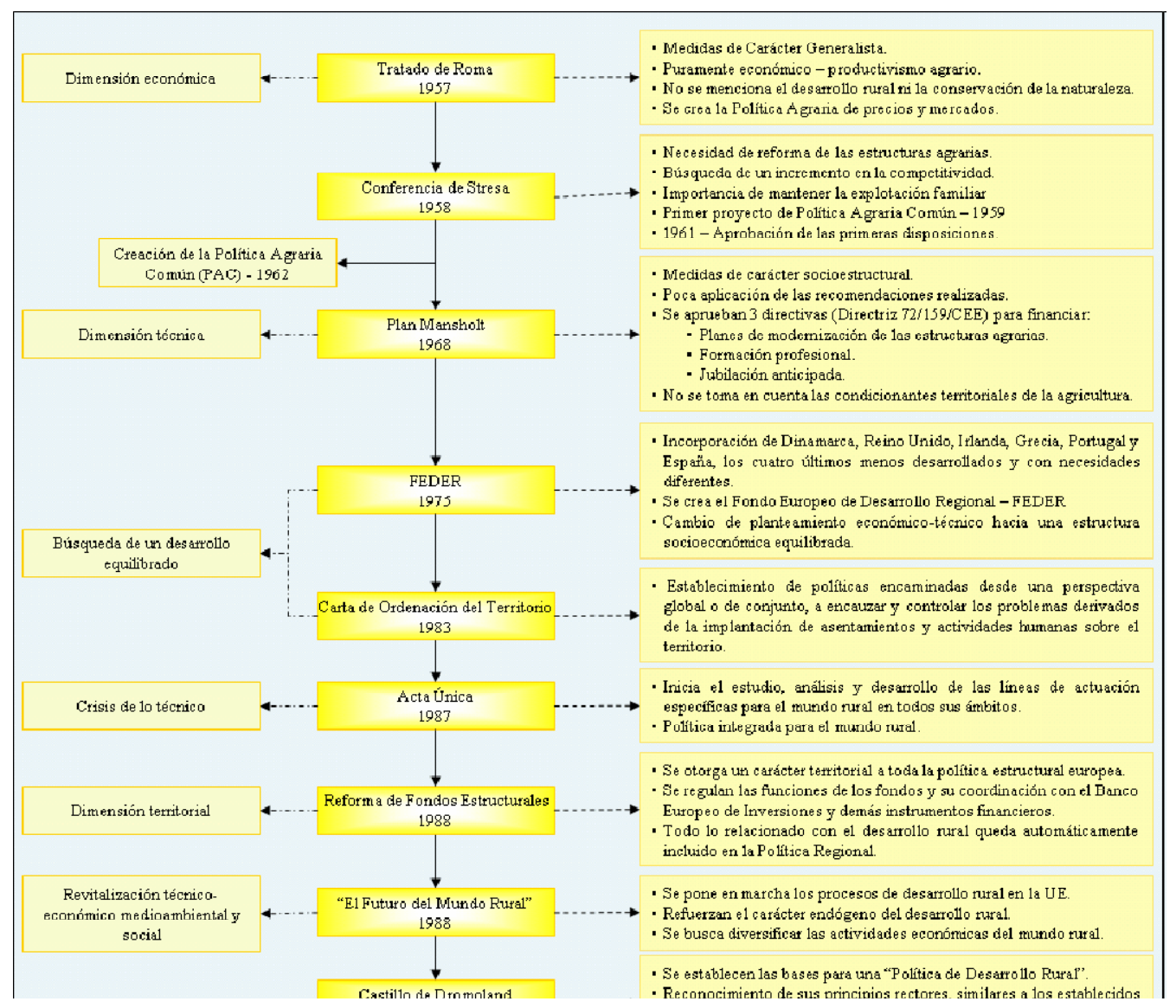




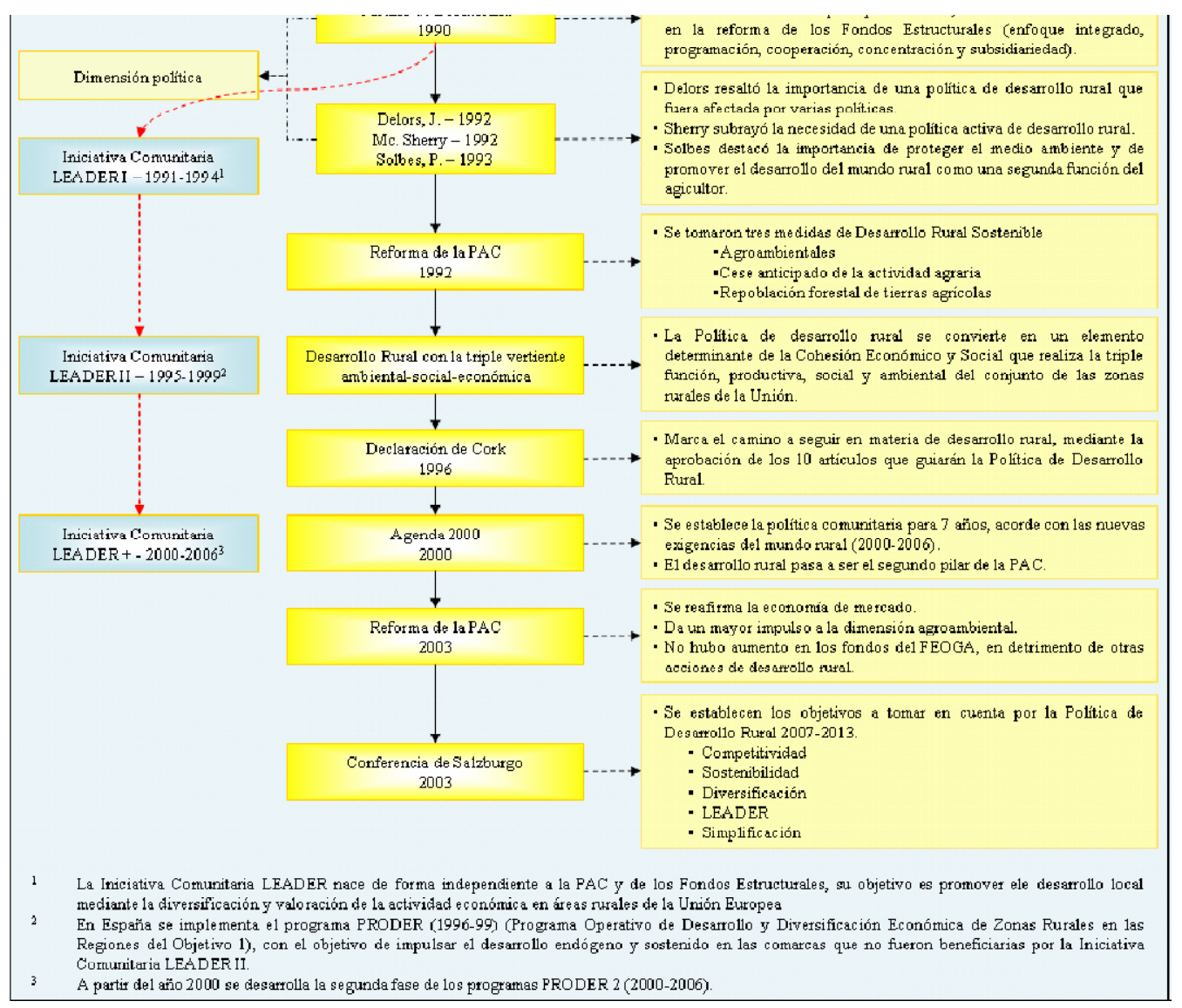

Fuente: Tolón, A 2008

\subsubsection{Tratado de Roma, 1957}

En 1957 se firma el Tratado de Roma, por entonces y como consecuencia de la II G.M sufrida en Europa, había un déficit generalizado de productos agrícolas, unas rentas agrícolas y un nivel de vida mucho más bajos que en otros sectores y una gran diferencia estructural entre regiones. Ello llevó a que un Título entero del Tratado (el Título II), fuese dedicado a la agricultura. En este Título II, el artículo 39.1 ya estableció los 5 grandes objetivos que debía perseguir la Política Agraria Común (PAC):

- Incrementar la productividad agrícola fomentando el progreso técnico y asegurando el desarrollo racional de la producción agraria, así como un empleo 
óptimo de los factores de producción, en especial, la mano de obra.

- Garantizar así un nivel de vida equitativo al resto de los sectores a la población agraria, en especial mediante el aumento de la renta individual de los que trabajan en la agricultura.

- Estabilizar los mercados.

- Garantizar la seguridad de los abastecimientos y productos básicos alimentarios

- Asegurar al consumidor suministros a unos precios razonables.

A finales de los años sesenta, el análisis de la situación de agricultura dejaba claro que la seguridad de los abastecimientos estaba garantizada, se aseguraba el suministro de alimentos al consumidor a precios razonables y los mercados habían alcanzado una cierta estabilidad.

No obstante, los dos objetivos iniciales no se estaban alcanzando, por un lado no se había producido un desarrollo racional de la producción ni una asignación óptima de los factores de producción, y la demanda crecía más lentamente que la oferta con lo que se estaban produciendo costosos excedentes. Además, la renta de los agricultores no había conseguido igualar a la del resto de los sectores.

En un intento de corregir estos problemas estructurales, en 1964 se dividió el FEOGA en dos secciones:

- la Sección Orientación, con objetivo de fomentar las reformas agrícolas estructurales.

- la Sección Garantía para financiar los gastos de las organizaciones comunes de mercado, que absorberá la gran mayoría del presupuesto de este fondo en detrimento de las necesarias correcciones estructurales de las distintas regiones agrarias.

Además los 2 problemas mencionados con anterioridad, fueron recogidos en 
el Memorándum sobre la Reforma de la Agricultura en la Comunidad Económica Europea, más conocido como Informe o Plan Mansholt (Comisión Europea, 1969), en el que además se señalaban dos aspectos interesantes en relación al futuro de la PAC y del discurso regional:

- Se hace mención a la incapacidad de la política de precios y mercados de aportar, por sí sola, soluciones a las dificultades estructurales y coyunturales a las que se enfrentaba el sector agrario; poniendo de relieve la necesaria la contribución de la Política de Estructuras Agrarias en estos desafíos.

- El informe insistía en la necesidad de reconocer la diversidad regional de las estructuras agrarias europeas ${ }^{15}$ como paso previo a la concentración de las ayudas financieras procedentes del FEOGA-Orientación y del Fondo Social Europeo (FSE) en aquellos territorios más desfavorecidos. Se pensaba que mediante la concentración territorial de esfuerzos se solucionarían las disparidades regionales en la Comunidad.

\subsubsection{Primera corrección de la PAC, 1972}

En 1972 el Consejo de Ministros adoptó un paquete de decisiones para alcanzar los objetivos señalados en el Informe Mansholt, que se tradujeron en las 3 directivas de carácter estructural:

- Directiva de modernización de las explotaciones agrarias (159/72/CEE).

- Directiva para incentivar el cese de la actividad agraria (160/72/CEE).

- Directiva sobre cualificación profesional de los agricultores (161/72/CEE).

A pesar de estas medidas anteriores, y agudizado además por la

\footnotetext{
${ }^{15}$ Establecía tres categorías-tipo de regiones (industriales, semiagrícolas y esencialmente agrícolas) según el peso que el sector agrario tenía en sus sistemas socio-productivos.
} 
incorporación en 1973 a la CEE de Dinamarca, Reino Unido e Irlanda, los excedentes agrarios continuaban creciendo en Europa y la evolución de precios en los mercados mundiales provocó un rápido incremento del gasto de la PAC generando fuertes tensiones presupuestarias en la CEE.

En consecuencia, a finales de los años sesenta los gobiernos nacionales europeos giraron hacia posturas políticas más intervencionistas y favorables a la creación de una Política Regional Comunitaria, tal y como se puso de manifiesto en las Cumbres de Jefes de Estado y de Gobierno celebradas en París en 1972 y 1974, dónde se acordó elaborar un Reglamento por el que se creaba el Fondo Europeo de Desarrollo Regional (FEDER) ${ }^{16}$.

Con la aparición de FEDER se abre una nueva etapa, los organismos comunitarios reconocen no sólo la existencia de desequilibrios, sino que expresan la voluntad de actuar sobre ellos. A partir de este momento teoría y práctica irán configurando una política europea regional (finalmente promulgada en 1986 con el Acta Única Europea).

\subsubsection{FEDER. Origen Política Regional Europea (1975-1986)}

Las autoridades europeas, y en especial la Comisión, perciben que mientras el papel de los FEDER se viese reducido a complementar los programas de desarrollo llevadas a cabo por cada Estado miembro, la reducción de las disparidades territoriales en el conjunto de la Comunidad no se produciría.

Progresivamente irán adquiriendo una mayor autonomía y capacidad financiera y de actuación a través de las sucesivas modificaciones llevadas a cabo

${ }^{16}$ Règlement (CEE) № 724/75 du Conseil, du 18 mars, portant création d'un Fonds Européen de Développemment Regional (Consejo de las Comunidades Europeas, 1975 
en los Reglamentos reguladores del FEDER, así como mediante la regionalización de las distintas políticas estructurales, entre ellas la política agraria de estructuras.

Esta regionalización de la política agraria tuvo dos de sus exponentes en la Directiva 268/75/CEE sobre la agricultura de montaña y determinadas zonas desfavorecidas, y en los Programas de Desarrollo Integrado y los posteriores Programas Mediterráneos Integrados.

En esta Directica se reconoce la dimensión regional de la política agraria comunitaria, al considerar las limitaciones estructurales de algunos de sus territorios para la actividad agrícola (escasa productividad de los suelos, escasez de agua, orografía etc). Se autoriza por primera vez las ayudas directas bajo la fórmula de "Indemnizaciones Compensatorias", con el objetivo de parar el abandono y la despoblación que padecían estas zonas, así como ayudar a conservar el medio natural y su entorno.

Además esta directiva daba un papel destacado a los estados miembros, que debían adaptar sus legislaciones a los criterios y métodos establecidos por la Comisión y de este modo podrían hacer delimitaciones en sus territorios para definir qué zonas incluir como zonas desfavorecidas en la lista comunitaria.

Con respecto a los Programas de Desarrollo Integrado: se iniciaron en 1981, y en 1985 se ampliarán hacia regiones mediterráneas de Italia, Francia y Grecia bajo el nombre de Programas Mediterráneos Integrados. Se aplican por primera vez el enfoque integrado del desarrollo, es decir partiendo de la elaboración de un programa estructurado por parte del Estado beneficiario. De este modo, se buscaba la coordinación entre acciones financiadas mediante los tres fondos estructurales (Fondo Social Europeo, FEOGA -Orientación y FEDER). Estas acciones irían dirigidas a mejorar la transformación y comercialización, así como a activar otros 
sectores económicos como la artesanía, turismo etc con el fin de mejorar la situación socioeconómica de las regiones afectadas.

La incorporación de Grecia, Portugal y España aumentó las diferencias interregionales ya existentes, obligando al Consejo de Europa a plantear una revisión del tratado de Roma, que acabo por materializarse con la aprobación del Acta Única Europa en 1986. Desde los organismos comunitarios se optará por poner en marcha nuevos mecanismos que logren hacer funcionar a la Comunidad como un todo, y no como un conjunto de regiones con distintos niveles de desarrollo. Además en este AUE, se indica la necesidad de reformar la estructura y el funcionamiento de los fondos estructurales con el objetivo de reforzar su eficacia y la coordinación entre ellos y el resto de instrumentos financieros existentes.

\subsection{Cimientos de la Política de Desarrollo Rural:}

Tres procesos van a fijar las bases para esta Política de Desarrollo Rural:

\subsubsection{La reforma de los fondos estructurales en 1988.}

Se basa en el Reglamento 2052/88 (Consejo de las Comunidades Europeas, 1988), donde se recogen las principales directrices y principios sobre los que se va a apoyar la reforma de los fondos estructurales.

Surge la idea de que toda la política de ayudas debe seguir un planteamiento estratégico y un fin común para el desarrollo integral de las regiones. Así, aparecen definidos 5 objetivos territoriales para distinguir las regiones con características homogéneas:

Objetivo 1: Fomentar el desarrollo y el ajuste estructural en las regiones menos desarrolladas (FEDER, FSE y FEOGA-O) 
Objetivo 2: Reconvertir las regiones o parte de la regiones gravemente afectadas por el declive industrial (FEDER y FSE)

Objetivo 3: Combatir el paro de larga duración (FSE)

Objetivo 4: Facilitar la inserción profesional de los jóvenes (FSE)

Objetivo 5: en la perspectiva de la Reforma de la PAC

5a: Acelerar la adaptación de las estructuras agrarias (FEOGA-O)

5b: Fomentar el desarrollo de las zonas rurales (FEDER, FSE y

FEOGA-O).

Además esta reforma de los fondos estructurales, planteó un cambio en la coordinación de las inversiones de estos fondos y el resto de instrumentos financieros comunitarios, dotando a la Comisión la potestad de poder actuar de manera independiente a través de iniciativas comunitarias.

\subsubsection{Aparición de LEADER (1991), basada en "El futuro del mundo rural", 1988.}

Con la reforma de la PAC a mediados de los años 80, comenzó un proceso de reducción del proteccionismo agrario. Las medidas que se adoptaron fueron fundamentalmente en dos direcciones, en primer lugar, se sustituyeron las ayudas a la producción por ayudas directas a la renta para reducir los excedentes y disminuir de esta manera el coste financiero de la PAC; y en segundo lugar, se pusieron en marcha medidas de acompañamiento que pretendían, el mantenimiento de la población agraria con fines productivos, pero también y mantenimiento y de protección de los espacios rurales.

Dichas medidas se agrupaban en tres capítulos: 
- Protección del medioambiente: medidas destinadas a reducir el impacto ecológico de las actividades agrarias y a fomentar la agricultura ecológica.

- Forestación de tierras agrícolas: conversión de tierras agrícolas marginales en explotaciones forestales.

- Jubilación anticipada: reducción de mano de obra activa, pero no de población con renta en espacios rurales.

El despoblamiento de las zonas agrícolas en las zonas rurales más desfavorecidas ocasionado por el abandono de la actividad agraria, originó una preocupación de la Comisión Europea por el futuro del mundo rural, que se materializó en una comunicación de la Comisión al Consejo y al Parlamento europeo en 1988 sobre el futuro del mundo rural: (L'avenir du monde rurale), dando un gran impulso a la política de Desarrollo Rural Europea.

Las zonas rurales se clasificaron en tres tipos diferentes según su problemática: regiones rurales sometidas a la presión de la evolución moderna, regiones en "declive rural" y zonas especialmente marginalizadas.

La Comisión recomendaba específicamente medidas para cada una de estas problemáticas, pero las globaliza dentro de una metodología común, por lo que todas las acciones de desarrollo rural deben ser concebidas a partir de las realidades locales, mediante acciones estructurales de diversificación de las actividades económicas en el medio rural.

Así entre los años 1989 y 1991, se aprobaron 14 iniciativas, cada una de las cuales contaría con la financiación de uno o varios fondos estructurales.

Es en este contexto donde se aprueba la iniciativa comunitaria LEADER (Liaison Entre Actions de Développement de l'Ėconomie Rurale), ampliamente inspirada en la comunicación "l'avenir du monde rural", primera actuación europea 
para llevar a cabo una política de desarrollo rural de carácter territorial, integrada y participativa.

\subsubsection{La reforma de la PAC 1992}

Al empezar a considerar las políticas estructurales, se aprueban un conjunto de medidas llamadas DELORS II, que comprendía la creación de los fondos de cohesión, la duplicación de los fondos Estructurales en 1988, y la reforma de la PAC en 1992.

Esta reforma ya resaltaba la triple función que debían cumplir las zonas rurales, ambientales, productivas y sociales, estaba basada en la compensación de la pérdida de ingresos experimentada por los agricultores, en la protección del medio ambiente y en la reducción de los precios agrícolas para aumentar la competitividad del mercado interior. En 1992 aparecen las Medidas de Acompañamiento de la PAC: Cese anticipado de la Actividad agraria, indemnización compensatoria de zonas desfavorecidas y forestación de tierras agrícolas.

\subsection{Declaración de Cork a la Agenda 2000 (1996-1999)}

El Comisario de Agricultura y Desarrollo Rural Fischler en noviembre de 1996 organizó la I Conferencia Europea sobre Desarrollo Rural en la ciudad irlandesa de Cork, con la intención de impulsar el debate sobre la necesidad de una Política de Desarrollo Rural Integrada en la Comunidad Europea.

Como resultado de la misma se hizo pública, "La declaración de Cork: por un paisaje rural vivo", donde se recogían los fundamentos para sostener dicha política en 10 puntos, entre los cuales se encontraba la apuesta por un enfoque integrado, 
por la sostenibilidad medioambiental en los espacios rurales, por la subsidiariedad como medio para la descentralización de la política rural o la apuesta por las redes como fórmula de gestión más eficaz.

Se constata que las zonas rurales albergan a una cuarta parte de la población europea y constituyen el $80 \%$ del territorio de la Unión Europea, que están caracterizadas por una estructura cultural, económica y social diferenciada que constituye una autentica reserva de diversidad frente a la tendencia homogeneizadora de las culturas urbanas, que albergan una gran variedad de actividades y paisajes de gran interés.

Además, se declararon convencidos de que las zonas rurales y sus habitantes representan un activo real para la Unión Europea y tienen a su alcance la posibilidad de ser jugar un papel muy importante en los diferentes aspectos de la sociedad actual y de que la agricultura es y debe seguir siendo un punto de encuentro privilegiado entre el hombre y el medio ambiente.

Por otra parte se declaran conscientes de que el peso económico de la agricultura en las economías europeas ha dejado de ser predominante y sigue descendiendo, por este motivo, el desarrollo rural debe movilizar todos los sectores socioeconómicos del medio rural, de que los ciudadanos europeos dan cada vez más importancia a su calidad de vida y de que las zonas rurales ocupan una posición privilegiada para responder a esta demanda y ofrecen un escenario para el desarrollo de un modelo moderno del concepto de calidad.

Reconocen que la PAC ha de cambiar su curso como consecuencia de los cambios habidos en el comercio internacional y que los agricultores han de ser ayudados en el proceso de ajustes que se está viviendo sustituyendo los pagos compensatorios a la producción por ayudas directas. 
Todo ello, reconociendo la importancia del sector agrario como pilar fundamental para el desarrollo rural. Como colofón se aprobó un decálogo con los objetivos que debería marcarse la futura política de desarrollo rural.

Fig. 8: Cuadro Decálogo Declaración De Cork.

\begin{tabular}{|c|c|}
\hline 1. Prioridad rural & $\begin{array}{l}\text { El desanollo rural sostenible debe constituir en principio } \\
\text { fundamental de toda PRE }\end{array}$ \\
\hline 2. Enfoque integrado & $\begin{array}{l}\text { La politica de desamollo rural, además de presentar una } \\
\text { dimension temirorial, debe basarse en un enfogue inregrado }\end{array}$ \\
\hline 3. Diversificación & $\begin{array}{l}\text { La diversificación económica y social del mudo rumal debe } \\
\text { fortalecer las ciudades pequeñas como nodos de desarrollo en } \\
\text { zonas rurales, difundir avances de } T I C \text { 's, etc. }\end{array}$ \\
\hline 4. Sostenibilidad & $\begin{array}{l}\text { La PRE debe procurar el manteniniento de la calidad y la } \\
\text { función de los paisajes rurales de Europa }\end{array}$ \\
\hline 5. Subsidiariedad & $\begin{array}{l}\text { La PRE debe respetar el principio de subsidianiedad. El } \\
\text { desarrollo nural tiene que nacer en el ambiro local y ser } \\
\text { dinigido por las comunidades nurales }\end{array}$ \\
\hline 6. Simplificación & $\begin{array}{l}\text { La PRE debe someterse a un proceso de simplificación } \\
\text { legislativa que lleve a: mayor subsidiariedad en las decisiones } \\
\text { va aplicación politica mas descentralisada }\end{array}$ \\
\hline 7. Programación & $\begin{array}{l}\text { Los programas de desarrollo rural deben segui } \\
\text { procedinientos mansparentes e integrarse on un programa } \\
\text { unico de desamollo rural para cada region }\end{array}$ \\
\hline 8. Financiación & $\begin{array}{l}\text { Debe estrimularse el uso de los recursos financieros locales } \\
\text { para promover proyectos locales de desarrollo rural }\end{array}$ \\
\hline 9. Gestión & $\begin{array}{l}\text { PRE debe impulsar la capacidad y eficacia de las. } \\
\text { administraciones regionales y locales y de los grupos } \\
\text { commitarios de base favoreciendo la creacion de redes de } \\
\text { intercambio }\end{array}$ \\
\hline 10. Evaluación & $\begin{array}{l}\text { Refuerzo de los procedimientos de seguimiento, evaluacion y } \\
\text { analisis de los resultados para garantizar la transparencia y el } \\
\text { buen uso del dinero público }\end{array}$ \\
\hline
\end{tabular}

PRE: Politica Rural Europea

Fuente: Observatorio Europeo LEADER (2001)

Esta conferencia, para muchos, marcó una nueva y decisiva etapa para la política rural europea, sin embargo, fue ampliamente criticada, principalmente por los sectores más agraristas que entendieron que la misma era una potenciación de lo rural frente a lo agrario que derivaría en un trasvase de recursos económicos del FEOGA-Garantía hacia los programas de desarrollo rural y el FEOGA-Orientación, y disminuiría sustancialmente las rentas directas percibidas por los agricultores. 
La diferencia de posiciones entre como debería ser el marco de actuación entre la política agraria y la política rural y las presiones del lobby agrario hicieron que el Consejo de Dublín, no respaldara las tesis de transformación de la política agraria en una política rural, capaz de incluir a todos los sectores presentes en el mundo rural.

La futura Adhesión de diez nuevos países plantea la necesidad de revisar el marco financiero de la UE. Con la aprobación del documento "Agenda 2000: por una Unión más fuerte y más amplia", se establece el marco financiero para el período 2000-2006, y se reconoció institucionalmente el desarrollo rural como una política oficial de la UE, quedando así recogido el espíritu de Cork (se defendía un desarrollo rural integrado, multisectorial y sostenible) y permitió que algunos de los planteamientos no aceptados en ese momento se recuperaran y formaran parte de los planteamientos del segundo pilar de la PAC.

Es un reconocimiento de que la PAC tal y como está diseñada no resuelve la problemática de las zonas europeas rurales, y hay que buscar otras fuentes alternativas y complementarias de ingresos y de actividad económica.

Como refleja el artículo 2 del Reglamento (CE) 1257/99, las medidas de desarrollo rural propuestas servirán de acompañamiento y de complemento a otros instrumentos de la PAC, con lo que, bajo este enfoque, el desarrollo rural ocupa una posición secundaria respecto a la política de mercados, perdiendo el protagonismo que la perspectiva territorial le otorgaba en Cork.

Entre las propuestas de la Comisión, se encuentra la de consolidar los esfuerzos presupuestarios de los fondos Estructurales, reduciendo el número de objetivos de 7 a 3 , dos regionales y uno de carácter horizontal: 
№ 1. Promoción del desarrollo y el ajuste estructural de las regiones menos desarrolladas (PIB pc $<75 \%$ media de la UE)

№ 2. id económica y social de las demás regiones con dificultades estructurales.

№ 3. Desarrollo de principios fundamentales sobre los que se asienta la nueva política rural:

- $\quad$ Multifuncionalidad de la agricultura es decir, de las diversas funciones que desempeña esta actividad además de la de producción de alimentos. Ello implica el reconocimiento de la amplia gama de servicios prestada por los agricultores y el fomento de tales actividades en su diversificación de rentas.

- Enfoque multisectorial e integrado de la economía rural a fin de diversificar las actividades, crear nuevas fuentes de ingresos y empleo y proteger el patrimonio rural.

- $\quad$ Flexibilización de las ayudas al desarrollo rural basándose en el principio de subsidiariedad para favorecer la descentralización de las decisiones, la consulta con las regiones y la concertación con ellas como método de trabajo.

- $\quad$ Transparencia en la elaboración y gestión de los programas.

Las medidas previstas que, en todos los casos, contarán con la cofinanciación de los Estados miembros y que servirán de acompañamiento y complemento de otros instrumentos de la PAC, pueden agruparse en dos bloques:

Medidas de acompañamiento de la PAC: recogen las tres medidas de 1992 (agroambientales, cese anticipado de la actividad y forestación de tierras) y las indemnizaciones compensatorias en las zonas desfavorecidas o sujetas a limitaciones medioambientales. Serán cofinanciadas por la sección Garantía del FEOGA en todo el territorio y la única novedad respecto a la normativa anterior es 
que las medidas agroambientales pasan a ser las únicas de obligado cumplimiento por los Estados miembros.

Medidas de modernización y diversificación de las explotaciones agrícolas: inversiones en las explotaciones, instalación de jóvenes agricultores, formación profesional, mejora de la transformación y comercialización de los productos agrícolas, silvicultura y fomento de la adaptación y desarrollo de las zonas rurales. Estas medidas serán financiadas por la sección Garantía del FEOGA, salvo en las zonas cubiertas por el objetivo nํํ 1 que correrán a cargo de la sección Orientación.

Tabla 3: Distribución Gasto Agrario entre los 2 Pilares PAC.

\begin{tabular}{|c|c|c|c|c|}
\hline \multicolumn{5}{|c|}{$\begin{array}{l}\text { DISTRIBUCIÓN DEL GASTO AGRARIO ENTRE LOS DOS PILARES DE LA PAC. } \\
\text { Millones de } €\end{array}$} \\
\hline & \multicolumn{2}{|c|}{1995} & \multicolumn{2}{|c|}{2001} \\
\hline & España & UE- 15 & España & UE-15 \\
\hline Precios y mercados & 4.482 & 33.670 & 5.635 & 37.137 \\
\hline Desarrollo rural & 680 & 3.529 & 1.160 & 6.509 \\
\hline Total & 5.162 & 37.199 & 6.795 & 43.646 \\
\hline
\end{tabular}

Fuente: MAGRAMA

Como se refleja en el cuadro anterior, la financiación de la política de precios y mercado ha seguido teniendo una prioridad absoluta, así en 2001 el $85 \%$ del gasto se orientó a la financiación del primer pilar y el 15\% al segundo.

\subsection{Nueva Reforma de la PAC y nuevo Reglamento de Desarrollo Rural.}


En 1999 se acuerda la Estrategia Territorial Europea (ETE), que se define como:"Marco político para mejorar la cooperación entre distintas políticas comunitarias que tienen efectos territoriales importantes" (Consejo de Europa, 1999), con el objetivo de lograr un desarrollo equilibrado y sostenible de los territorios europeos.

Los principios del desarrollo territorial y los modelos de gestión nuevos contenidos en la ETE, se fueron desarrollando a partir de 3 acontecimientos:

- $\quad$ Estrategia de Lisboa: aprobada en 2000, tenía como objetivo convertir a la UE antes de 2010 en la economía del conocimiento más competitiva y más dinámica del mundo, capaz de un crecimiento económico sostenible con más y mejor empleo y una mayor cohesión social.

- Estrategia de Gotemburgo: Aprobada inicialmente en 2001 y revisada en 2005 (Comisión Europea, 2005a), añade la dimensión medioambiental a la estrategia propuesta en Lisboa, convirtiéndose así en el tercer pilar de esta última, junto al crecimiento económico y a la cohesión social (Comisión Europea, 2003b). Se reconoce que para hacer efectivo el desarrollo sostenible en la UE es necesario que ambas estrategias se refuercen mutuamente.

- Libro Blanco de la Gobernanza: Aprobado en 2001 (Comisión Europea, 2001), pone en debate la cuestión del modelo de organización y decisión política de la UE, proponiendo renovar el método comunitario basado en la relación vertical entre los Estados y la UE, reforzando la interacción con los organismos regionales y locales y la sociedad civil.

En 2003, se inicia la reforma de la PAC, con la intención de adaptar la política de Desarrollo Rural a los principios de la ETE, y de las Estrategias de Lisboa y Gotemburgo. De esta forma la PAC conseguiría una mayor coherencia interna, así 
como ser un mayor complemento con otras políticas europeas con incidencia territorial como lo son la política de cohesión y medioambiental.

Este proceso de adaptación de la PAC iniciado en 2003, continua en 2005 con la aprobación de un nuevo marco financiero de la política agraria, partir del cual se crean el FEAGA (Fondo Europeo de Garantía Agrícola), para financiar el primer pilar y el Fondo Europeo de Desarrollo Rural (FEADER), para financiar el segundo pilar, así como con la aprobación de la nueva política de desarrollo rural. (Reglamento (CE) 1698/2005.

Cabe mencionar que otro de los acontecimientos que marcó las directrices de este Reglamento fue sin duda alguna la Conferencia de Salzburgo en 2003, donde el comisario Fischler vuelve a ser protagonista y realizara 3 propuestas que fueron recogidas en este Reglamento:

- aumentar la competitividad de la agricultura y la silvicultura mediante la ayuda a la reestructuración, el desarrollo y la innovación.

- mejorar el medio ambiente y el medio rural mediante ayudas a la gestión de las tierras.

- mejorar la calidad de vida en las zonas rurales y fomentar la diversificación de la actividad económica.

El diseño de esta nueva política parte de la aplicación de un enfoque estratégico, a partir del cual se definen las prioridades políticas comunitarias en materia de desarrollo rural, que se materializan mediante un conjunto de objetivos y de ejes y medidas de actuación. Junto a esas prioridades se establecen también el marco institucional que va a determinar los instrumentos a utilizar, el procedimiento a seguir, las competencias y responsabilidades de los distintos agentes implicados en su implementación, así como el esquema presupuestario que sostiene financieramente la estrategia propuesta. (Comisión Europea, 2006). 
Fig. 9: Enfoque Estratégico Política Rural Europea 2007-2013.

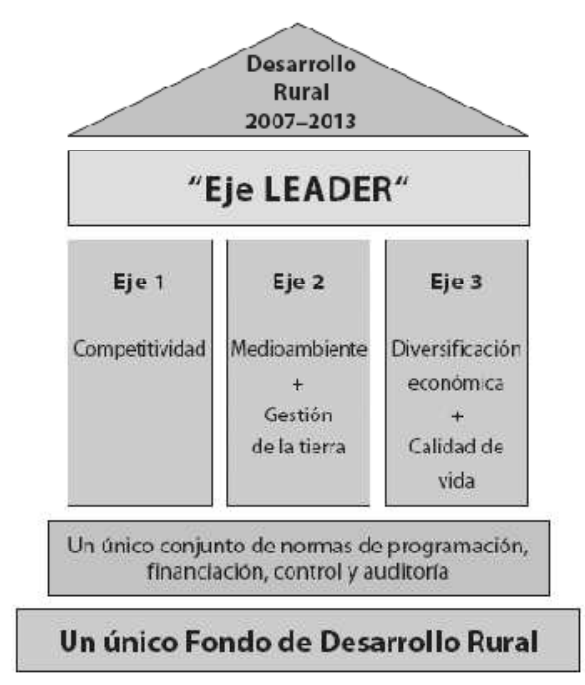

Fuente: Comisión Europea, 2006

Para la consecución de cada uno de estos objetivos generales se establece un eje temático, eje que a su vez se articula en torno a unos objetivos específicos, y asociados a esos objetivos específicos se establecen conjuntos de medidas de actuación Por otra parte, los tres ejes temáticos se complementan con un cuarto eje transversal de carácter metodológico dedicado al enfoque Leader. 
Tabla 4: Ejes y Medidas de Actuación Política Desarrollo Rural 2007-2013.

\begin{tabular}{|c|c|c|}
\hline \multicolumn{2}{|c|}{ Fijación de objetivos } & \multirow[b]{2}{*}{ 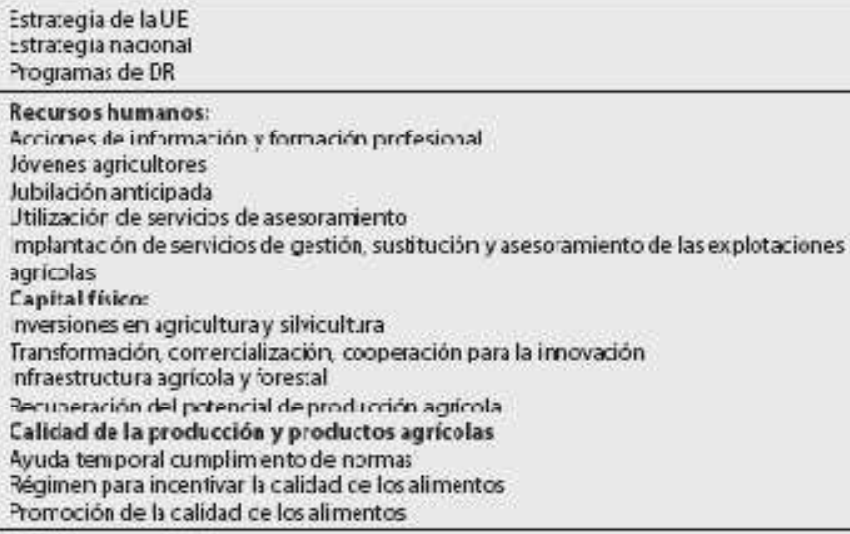 } \\
\hline \multirow[t]{5}{*}{ competitividad } & \multirow[t]{2}{*}{ medidas } & \\
\hline & & $\begin{array}{l}\text { Medidas transitorias: } \\
\text { jernisulusistencid } \\
\text { Creación ce agrupaciones de froductores }\end{array}$ \\
\hline & porc de fnandación & nínimo $10 \%$ \\
\hline & porc, sofinemeiadson UL & nóxino $50-75 \%$ \\
\hline & aplicación territorial & todas las zonas rurales \\
\hline \multirow[t]{4}{*}{$\begin{array}{c}\text { Eje } n^{\circ} \cdot 2 \\
\text { gestión de las } \\
\text { tierras }\end{array}$} & medidas & 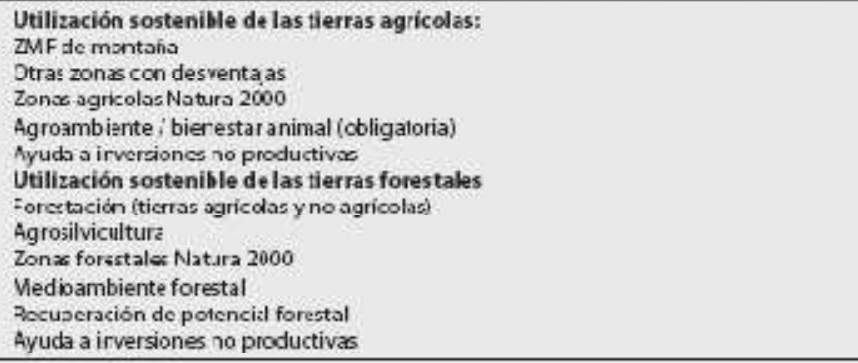 \\
\hline & base de ret. (agnic) & sondaonahidad \\
\hline & porc de financiación & ninimo $25 \%$ \\
\hline & $\begin{array}{l}\text { porci sofinénciajón UE } \\
\text { aplicación terrtorial }\end{array}$ & $\begin{array}{l}\text { náximo } 55 / 800^{*} \\
\text { todas las zonasrurales }\end{array}$ \\
\hline \multirow[t]{4}{*}{$\begin{array}{c}\text { Eje } n^{\circ} 3 \\
\text { Desarrollo } \\
\text { rural an } \\
\text { sentido amplio }\end{array}$} & medidas & 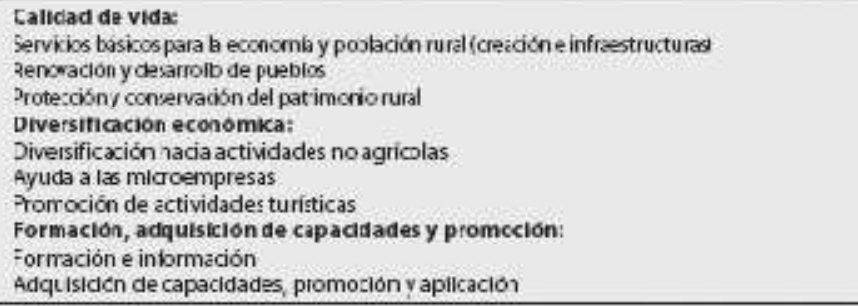 \\
\hline & porc de franciación & nínimo $10 \%$ \\
\hline & porc. sofinenciadón UE & nàxino $50 / 75 \%$ \\
\hline & aplicación territorial & todas las zonas rurales \\
\hline \multirow[t]{4}{*}{ Eje Leader } & aplicación & 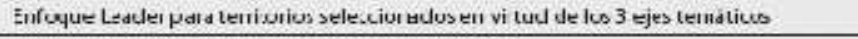 \\
\hline & porc de franciación & nínimo $5 \% 0.5 \%$ en los nuevos Estados miembrosi \\
\hline & sorc. sofinemciadśn UE & náxino $55 / 80 \% *$ \\
\hline & aplicación terrìorial & todas las zonas rurales, territor os seleccionados \\
\hline
\end{tabular}

Fuente: Comisión Europea, 2006 


\section{Tabla 5: Directrices Estratégicas Comunitarias de Desarrollo Rural 2007-2013.}

1. Mejora de la competitividad de los sectores agricola y silvicola. Los recursos asignados al eje 1 deberán contribuir a que el sector agroalimentario europeo sea un sector fuerte y dinámico, centrándose en las prioridades de transferencia de conocimientos, modemización, innovación y calidad de la cadena alimentaria y en los sectores prioritarios de inversión en capital físico y humano.

2. Mejora del medio ambiente y del paisaje rural. Con el fin de proteger y mejorar los recursos naturales y paisajisticos de las zonas rurales de la UE, los recursos asignados al eje 2 deberán contribuir a los tres ámbitos prioritarios de la UE: La biodiversidad y la preservación y desarrollo de los sistemas agricolas y silvicolas de elevado valor natural y de los paisajes agricolas tradicionales; el régimen hidrológico y el cambio climático.

3. Mejora de la calidad de vida en las zonas rurales y fomento de la diversificación. Los recursos asignados al eje 3 deberán contribuir a la prioridad absoluta de creación de oportunidades de empleo y de condiciones de crecimiento. El abanico de medidas disponibles en virtud de este eje deberá ir encaminado principalmente a fomentar la capacitación, la adquisición de competencias y la organización, con miras a la aplicación de estrategias locales de desarrollo, $y$ a conseguir que las zonas rurales sigan siendo atractivas para las generaciones futuras. Cuando se promueva la formación, la información y el espíritu empresarial, deberá prestarse especial atención a las necesidades especificas de las mujeres, los jóvenes y los trabajadores de más edad.
4. Desarrollo de la capacidad local de creación de empleo y diversificación. Los recursos asignados al eje 4 (Leader) deberán contribuir a la consecución de los objetivos prioritarios de los ejes 1, 2 y, sobre todo, 3, pero también a la prioridad horizontal de mejorar la gobernanza y de aprovechar el potencial de desarrollo endógeno de las zonas rurales.

5. Transposición de las prioridades en programas. Cuando elaboren su estrategia nacional, los Estados miembros deberán velar por que exista la máxima sinergia posible entre los diferentes ejes y dentro de estos y evitar potenciales contradicciones. Igualmente, deberán considerar la forma de tener en cuenta otras estrategias al nivel de la UE, en particular en el ámbito del medio ambiente.

6. Complementariedad entre instrumentos comunitarios. Debe fomentarse la sinergia entre las políticas estructurales, de empleo y de desarrollo rural. Los Estados miembros deberán velar por la complementariedad y coherencia de las acciones que vayan a financiar el Fondo Europeo de Desarrollo Regional, el Fondo de Cohesión, el Fondo Social Europeo, el Fondo Europeo de la Pesca y el FEADER, en un territorio concreto y en un ámbito de actividad determinado. Los principios rectores esenciales para trazar la línea de demarcación y los mecanismos de coordinación entre las acciones financiadas por los diferentes Fondos deberán definirse en el marco estratégico nacional de referencia (documento estratégico nacional sobre política de cohesión) y en el plan estratégico nacional sobre desarrollo rural.

Fuente: Comisión Europea, 2006

A partir de este momento la aplicación sobre cada territorio de la estrategia nacional de cada Estado debía realizarse mediante Programas de Desarrollo Rural (PDR), en los que tendrían que aparecer las medidas y actuaciones concretas para cada Eje.

En el Reglamento (CE91698/2005), señala que los Estados miembros pueden elegir entre dos opciones, bien presentar un único programa estatal de desarrollo rural o bien un conjunto de programas regionales. Además si se eligiese esta opción se tendría que presentar un Marco Nacional que tuviera elementos comunes para esos programas regionales. 
En nuestro país han sido las Comunidades Autónomas quienes han redactado su propio PDR. No obstante, previamente se aprobó un Marco Nacional de Desarrollo Rural que recogía las medidas horizontales obligatorias en los programas regionales. Así, las Comunidades Autónomas diseñaron actuaciones concretas para cada una de las medidas que componen los cuatro ejes propuestos en el Reglamento Europeo, así como los planes de financiación prevista para su cumplimiento. El conjunto de los 17 PDR regionales configuran el PDR estatal español.

\subsection{LEADER.}

La iniciativa comunitaria17 LEADER corresponde a las siglas en francés, Liasions entre Activités de Développement de L’Economie Rural o relaciones entre actividades de Desarrollo de la Economía Rural y supuso un importante avance en la evolución del Desarrollo Rural en la Unión europea.

Esta iniciativa que como ya hemos señalado comienza en 1991 y finaliza en 2007, se puede dividir en tres fases:

$$
\begin{array}{ll}
\text { - } & \text { Primer Período 1991-1993: LEADER I } \\
\text { - } \quad \text { Segundo Período 1994-1999:LEADER II y PRODER } \\
\text { - } \quad \text { Tercer Período 2000-2006:LEADER + y PRODER II }
\end{array}
$$

\subsubsection{Primer Período 1991-1993: LEADER I}

\footnotetext{
$17 \quad$ El término Iniciativa Comunitaria significa que fue un programa de la Comisión diseñado desde la perspectiva de los interesas europeos y por encima de los de cualquier Estado miembro.
} 
Esta iniciativa comunitaria se inicia en 1991, como consecuencia de la reforma de los fondos estructurales, se adopta una iniciativa destinada a dar respuesta a los cambios estructurales con soluciones innovadoras (ver pto 3). El programa comunitario Leader constituye el primer intento de poner en práctica el nuevo enfoque territorial, integrado y ascendente de desarrollo rural. Con base en la identificación de los problemas (envejecimiento de la población y el éxodo rural, que aún persisten en algunas regiones, o la pérdida de empleos) y las potencialidades de zonas rurales específicas, se formulan planes y promueven inversiones prioritarias (Cazorla, 1994)

En esta primera fase de aplicación de LEADER se consideró que las zonas objeto de aplicación deberían tener una dimensión comarcal y contar con una población entre 5.000 y 10.000 habitantes. Además estas zonas rurales, tiene que estar incluidos en las regiones Objetivo 1(retraso en el desarrollo) y en regiones Objetivo 5b (zonas rurales frágiles) de los fondos estructurales. De esta manera se impulsa el desarrollo local de estas zonas, intentando reflexionar sobre las potencialidades que ofrece el territorio para mejorar su organización y crear empleo, promoviendo acciones integradas, innovadoras y multisectoriales. Estas acciones se dirigen principalmente al aprovechamiento de las ventajas comparativas y peculiaridades del territorio.

Las comarcas participantes constituyen sus propios Grupos de Acción Local (GAL), constituidos por agentes públicos y privados de la economía y sociedad del territorio: ayuntamientos, asociaciones de productores y comerciantes, cooperativas, sindicatos, empresarios, ONG, bancos/cajas rurales, y grupos de la sociedad civil, interesados en el proceso, convirtiéndose así en un órgano gestor del programa.

EI GAL, con ayuda de un pequeño equipo técnico: 
- $\quad$ Prepara un plan estratégico y de inversiones para la comarca, con recursos y financiamiento de diversos orígenes, no sólo del LEADER, en el marco del programa operativo o de desarrollo rural de la región.

- $\quad$ Formula un plan de acción específico para los cinco o seis años de funcionamiento del Programa.

- Estudia, aprueba y supervisa la ejecución de los proyectos presentados por los postulantes al financiamiento del Programa. Dentro de las normas establecidas los GAL disponen de un amplio margen de maniobra.

En España esta iniciativa comenzó a ser aplicada a nivel nacional a partir de enero de 1992 a través de 53 grupos de acción local. En Europa se constituyeron 217 grupos, es decir los GAL españoles representaron el 24,4\%. En Castilla la Mancha se constituyeron $6 \mathrm{GAL}$.

En la financiación de Leader I participaron tres fondos estructurales: el Fondo Europeo de Orientación y Garantía Agrícola (FEOGA-Orientación), el Fondo Europeo de Desarrollo Regional (FEDER) y el Fondo Social Europeo (FSE), bajo la forma de intervención de subvenciones globales y a través de un Organismo intermediario nacional que en el caso de España correspondió al antiguo Instituto Nacional de Reforma y Desarrollo Agrario (IRYDA).

Los programas comarcales Leader en España contaron con 7 medidas que agruparon los 4.359 proyectos llevados a cabo:

- Apoyo Técnico al desarrollo rural.

- $\quad$ Formación profesional y ayuda al empleo.

- $\quad$ Apoyo al Turismo Rural.

- $\quad$ Apoyo a pequeñas y medianas empresas, artesanía y servicios locales.

- Valorización y comercialización de productos agrarios locales. 
- $\quad$ Promoción cultural y apoyo al asociacionismo.

- $\quad$ Equipamiento y funcionamiento de los grupos.

\subsubsection{Segundo Período 1994-1999: LEADER II y PRODER.}

\section{LEADERII}

La iniciativa era aplicable con unos recursos financieros limitados en las zonas menos desarrolladas (regiones de objetivo 1), en las zonas con deficiencias estructurales (objetivo 5b) y en las zonas con baja densidad de población del norte de Europa (objetivo 6). Además del objetivo inicial de la iniciativa comunitaria en cuanto a seguir prestando apoyo a proyectos impulsados por agentes locales, en este segundo periodo de programación se dio más énfasis al carácter innovador y de demostración de los proyectos, al intercambio de experiencias y puesta en red, y a la cooperación transnacional.

Estas características innovadoras podían afectar a cuestiones puramente económicas, culturales, medioambientales o de integración social en estrecha colaboración con el desarrollo rural.

En este período, se puso en marcha el Observatorio Europeo Leader, dependiente de la comisión europea, cuyo cometido se centró en el trabajo en red. En España esta iniciativa se articuló a través de 17 programas regionales, uno por comunidad autónoma que se desarrollan a través de 133 programas comarcales, gestionados por $133 \mathrm{GAL}$, que comparados con el ámbito europeo supusieron un $13,2 \%$.

En Castilla la Mancha se constituyeron $13 \mathrm{GAL}$. 
Si comparamos estos datos con los de LEADER I se confirma que aumentaron el número de GAL y el número de proyectos se expandieron en el territorio, por consiguiente también creció el número de beneficiarios.

LEADER II se financia a través de FEOGA-O, FEDER, y FSE, además de abrirse a la financiación de las 3 administraciones. Central, autonómica y local, así como a la inversión privada. Otra de las diferencias con Leader I, es que los beneficiarios de este programa pueden ser Gal o los agentes colectivos públicos o privados del medio rural: cámaras de agricultura, cooperativas, agrupaciones de empresas, etc.

En cuanto a las medidas subvencionables en el marco de Leader II, se partió de medidas análogas a Leader I para pasar a estructurarlas en cuatro categorías:

- MEDIDA A: «Adquisición de competencias», se enfocó en la preparación de los agentes locales para desempeñar un papel responsable en la distribución de los programas locales y mejorar el flujo de información.

- MEDIDA B: «Programas de innovación rural», donde se debía dar prioridad a los programas de inversión y acción local que resultasen innovadores en el contexto local, pudiesen funcionar como modelos y fuesen transferibles.

- $\quad$ Apoyo técnico al desarrollo rural.

- $\quad$ Formación y ayudas a la contratación.

- Turismo rural.

- $\quad$ Pequeñas empresas, artesanía y servicios.

- Valorización y comercialización de productos agrarios.

- $\quad$ Conservación y mejora del medio ambiente y su entorno.

- MEDIDA C: «Cooperación transnacional», era facultativa. Se refería a la cooperación entre zonas Leader de dos o más Estados miembros. 
- MEDIDA D: «Redes de colaboración», implicaba el desarrollo de la solidaridad activa entre zonas rurales y el intercambio de logros, experiencia y conocimientos.

\section{PRODER I}

La iniciativa LEADER tuvo gran aceptación entre las zonas rurales de toda España, sin embargo los fondos que nuestro país tenía asignados eran insuficientes, por lo que el Ministerio de Agricultura, Pesca y Alimentación (MAPA), y las Comunidades Autónomas acordaron destinar parte de los recursos presupuestarios previstos en el Marco Comunitario de apoyo de los fondos estructurales a un programa conocido como PRODER (Programa Operativo de Desarrollo y Diversificación Económica de Zonas Rurales) y que fue aprobado por la Comisión Europea en la Decisión C96/ 1454, como un programa plurirregional de aplicación solo en España, con objetivos similares a LEADER II.

Los beneficiarios de estas medidas eran territorios rurales de las regiones Objetivo 1, que no pudieron acceder a la medida B de la iniciativa LEADER II, con unos objetivos similares a LEADER, "impulsar el desarrollo endógeno y sostenido de las zonas de aplicación, a través de la diversificación de la economía rural, persiguiendo el mantenimiento de la población, frenando la regresión demográfica y elevando las rentas y el bienestar social de sus habitantes a niveles más próximos o equiparables a otras zonas más desarrolladas, asegurando la conservación del espacio y de los recursos naturales» (MAPA ,1996).

Para cumplir estos objetivos, el programa PRODER se articulo entorno a estas 8 medidas: 
- Valorización del patrimonio rural. Renovación y desarrollo de núcleos de población con predominio de la actividad agraria (FEOGA-O).

- Valorización del patrimonio local. Renovación y desarrollo de núcleos de población sin predominio de actividad agraria (FEDER).

- Fomento de las inversiones turísticas en el espacio rural: Agroturismo (FEOGA-O).

- Fomento de las inversiones turísticas en el espacio rural: Turismo local (FEDER).

- $\quad$ Fomento de pequeñas empresas, actividades de artesanía y de servicios (FEDER).

- $\quad$ Servicios a las empresas en el medio rural (FEOGA-O).

- $\quad$ Revalorización del potencial productivo agrario y forestal (FEOGA-O).

- $\quad$ Mejora de la extensión agraria y forestal (FEOGA-O)

En España se gestionaron 101 programas, 14 en la comunidad de Castilla la Mancha. Esta primara fase tuvo un presupuesto de 619 Millones de $€$, de los que 279 $(45,2 \%)$ correspondieron a financiación comunitaria (FEDER y FEOGA-O), 214 de la inversión privada $(34,6 \%)$ y el resto $(20,2 \%)$ de las diferentes administraciones.

\subsubsection{Tercer Período 2000-2006: LEADER + y PRODER II}

\section{LEADER +}

La tercera fase de la iniciativa LEADER, abarcó el periodo 2000-2006, se estableció en el Reglamento CE 1260/1999, en el marco que origino la Agenda 2000. 
Así se estableció como gran diferencia con Leader I y II, que las estrategias generales de la iniciativa las iban a realizar los Estados miembros, las comunidades autónomas en nuestro país. Estableciéndose 3 objetivos generales:

- Fomentar estrategias de desarrollo sostenible, integradas y destinadas a producir nuevas formas de valorización del patrimonio natural y cultural, mejorar el entorno económico y la capacidad de organización de las comunidades locales.

- Incitar y ayudar a los agentes del mundo rural para hacer una reflexión sobre el potencial de su territorio a largo plazo.

- Impulsar las actividades integradas realizadas por grupos de cooperación a escala local.

Si bien LEADER I se centró en la diversificación, LEADER II en la innovación, LEADER + está dirigido a fomentar la cooperación entre territorios y entre actores locales (MARQUEZ et al., 2006).

Se pretendía fomentar el trabajo en red para dar a conocer nuevos modelos de desarrollo rural, obtener resultados transferibles, intercambiar logros, experiencias y conocimientos entre los agentes de Leader.

Para cumplir estos objetivos generales la Comisión planteó una estrategia articulada en torno a 3 ejes o capítulos:

- Eje o Capítulo 1: apoyo a las estrategias de desarrollo rural territoriales, integradas e innovadoras.

- Eje o Capítulo 2: apoyo de la cooperación interterritorial y transnacional de los espacios rurales.

- Eje o Capítulo 3: integración en una red de todos los territorios rurales, tengan o no acceso a Leader Plus, así como de los agentes de desarrollo rural 
En nuestro país dos características importantes respecto de este período respecto al período anterior fueron.

- $\quad$ Recuperación de la población del éxodo rural desde los pueblos a las ciudades por la llegada de los "nuevos vecinos" (inmigrantes).

- $\quad$ El descenso del sector primario, pasando a ser menor del $5 \%$ en España y menor del 10\% en nuestra región.

En España todos los territorios rurales se podían beneficiar de esta iniciativa, y para desarrollar estos 3 ejes se establecieron una serie de medidas (en nuestro país lo hicieron las CCAA):

- Eje 1. Estrategias de desarrollo.

101. Adquisición de competencias.

102. Gastos de gestión, funcionamiento administrativo y asistencia técnica.

103. Servicios a la población.

104. Patrimonio.

105. Valorización de los productos locales y agrarios.

106. PYMES y servicios.

107. Valorización del patrimonio natural y arquitectónico.

108. Turismo.

109. Otras inversiones.

110. Formación y empleo.

- Eje 2. Cooperación

201. Interterritorial

202 Transnacional).

- Eje 3. Puesta en red (todos los grupos Leader Plus y otros agentes locales).

- Eje 4. Gestión, seguimiento y evaluación 
Se puso en marcha a través de un programa nacional gestionado por el MAPA y 17 programas regionales de desarrollo rural (uno por cada comunidad autónoma), que se articularon en los ejes 1,2, y 4, no así el eje 3 Puesta en Red que se articuló en el Programa Nacional.

Se aprobaron 145 Grupos de Acción Local de los que 13 se encontraban en Castilla la Mancha.

Además Las aportaciones comunitarias procedieron de un único fondo, el FEOGA- Orientación (recomendación de la Agenda 2000).

Para el conjunto de la UE la contribución del FEOGA-O, fue de 2020 millones de $€$, de los que 466 repercutieron en España. 
Fig. 10: Grupos de Desarrollo Rural LEADER + en Castilla la Mancha.

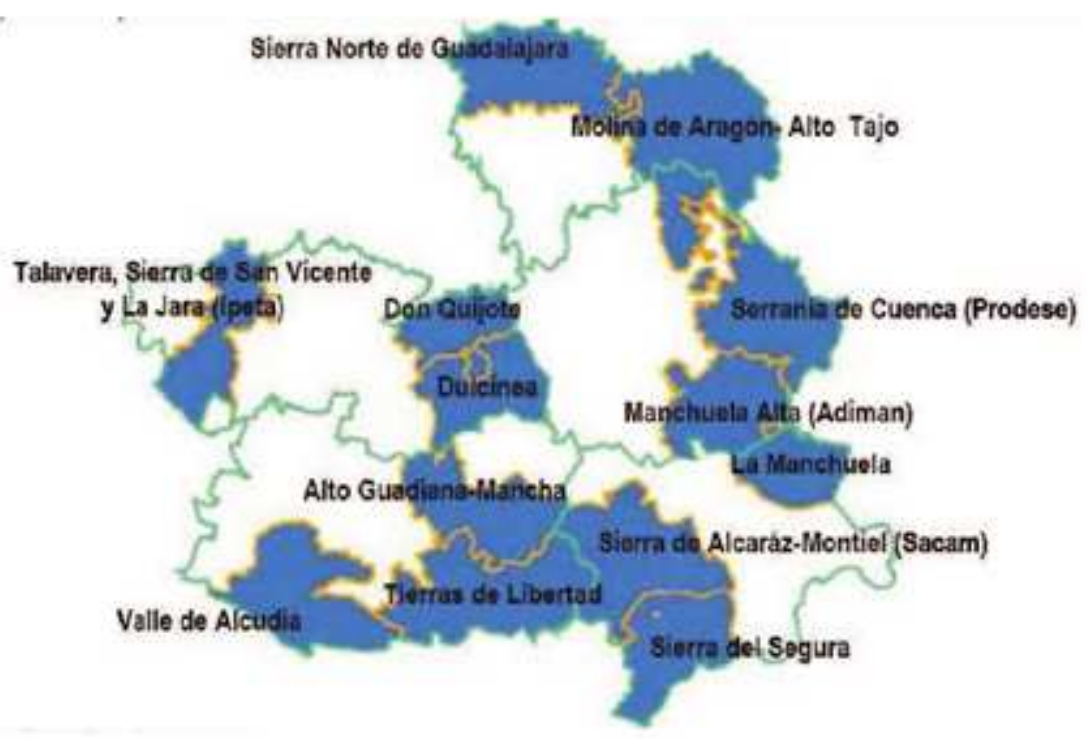

Fuente: PDR Castilla la Mancha 2007-2013

\section{PRODER II}

Este programa fue una segunda programación de PRODER I paralelo a LEADER + .

PRODER pasó de ser un Programa Operativo limitado a las zonas rurales de objetivo 1 en el periodo 1994-1999, para convertirse en este periodo 2000-2006 en un paquete de medidas aplicables en todo el territorio nacional y desarrolladas a través de los Programas Operativos Integrados de regiones de objetivo 1 y de los PDR de fuera de objetivo 1.

Cada comunidad decidió el presupuesto aplicable, las medidas y acciones a desarrollar, los métodos de gestión a implantar y las condiciones específicas para la concesión de ayudas. 
12 comunidades autónomas decidieron implantar este Programa, 8 en objetivo 1 (entre las que se encuentra Castilla la Mancha), 3 fuera de objetivo 1 y 1 en Objetivo 1 en transición.

En PRODER II se contó con un total de $162 \mathrm{GAL}$, siendo 16 los correspondientes a Castilla la Mancha. Las medidas en las que se articuló este programa eran similares a los objetivos planteados en LEADER +.

PRODER II fue cofinanciado por FEOGA-O y FEDER en las regiones de objetivo 1 y FEOGA-G en las regiones fuera de objetivo 1, además de contar con fondos nacionales, autonómicos y locales, además de recibir financiación privada.

Las medidas en las que se articuló este programa respondieron a similares objetivos a los planteados en LEADER+.

En nuestra comarca Torrijos empezaría la actuación en este período del Grupo de Acción Local (GAL) Castillos de Medio Tajo.

Estos GAL son Asociaciones sin ánimo de lucro con participación pública (máximo 50\%) y privada, que tienen por objeto la dinamización rural del territorio en el que actúan. Sus actuaciones se desarrollan conforme a un Programa Comarcal (LEADER o PRODER), que el propio grupo diseña (en este caso PRODER) y que luego es aprobado por el Organismo Intermediario mediante la firma de un Convenio de Colaboración. En este Convenio se fija un Cuadro Financiero, por medidas de actuación, para el periodo de actuación de estos Programas, en este caso nuestro GAL para el periodo 2000-2006, ha contado con un presupuesto de 4.674.215€. 
Fig. 11: Localización GAL PRODER 2 Castilla La Mancha.

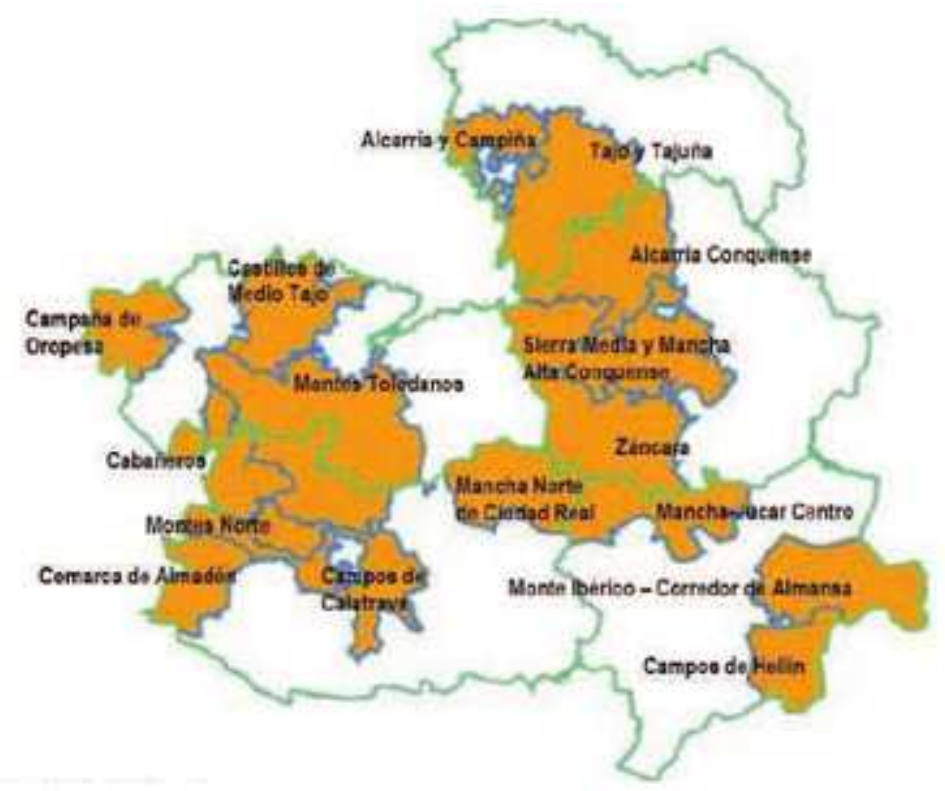

Fuente: PDR Castilla la Mancha 2007-2013 


\subsection{Política Europea de Desarrollo Rural (2007-2013)}

En este período LEADER deja de ser una iniciativa después de 15 años de aplicación y se integra en los programas nacionales o regionales como un cuarto Eje de desarrollo.

Las instituciones comunitarias estiman que esta iniciativa tiene la suficiente madurez como para aplicar el enfoque propio LEADER, en la programación general del desarrollo rural.

Así tenemos:

Eje 1: Aumento de la competitividad del sector agrícola y forestal.

Eje 2: Mejora del medio ambiente y del entorno rural.

Eje 3: Calidad de vida en las zonas rurales y diversificación rural.

Eje 4: LEADER, con las siguientes medidas:

41. Estrategias de desarrollo local

411. Competitividad

412. Medio ambiente

413. Diversificación /calidad de vida

421. Cooperación

431. Costes de funcionamiento, adquisición de competencias y promoción territorial.

Este Eje 4 dentro del Reglamento 1698/2005 FEADER, releva a LEADER+y supone la continuidad de esta metodología para el desarrollo rural hasta 2013, aplicándose también a los territorios PRODER II.

En España se constituyeron 315 GAL, en este período.

En Castilla la Mancha, el programa de Desarrollo Rural LEADER se aplica por los 29 Grupos de Acción Local, que ahora pasan a denominarse GDR. El GDR de 
nuestra comarca Castillos de Medio Tajo cuenta para este período con un presupuesto de $3.229 .330 €$.

Los Grupos de Acción Local en este momento además de gestionar medidas agrarias y agroambientales, aumentan sus responsabilidades, convirtiéndose en un elemento imprescindible para avanzar en el nuevo camino abierto en la política rural.

Fig. 12: Distribución Grupos Desarrollo Rural Castilla La Mancha 20072013.

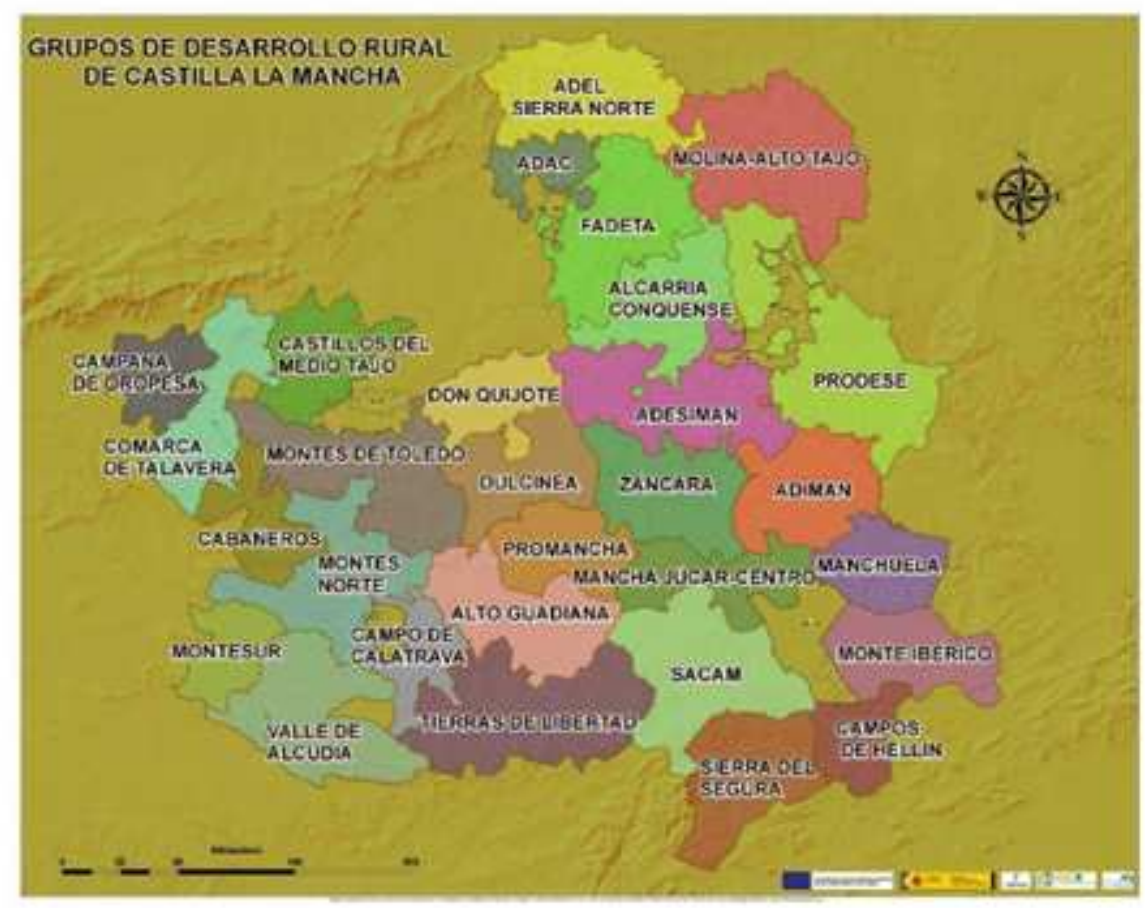

Fuente. MAGRAMA

En España, la estructura de la programación 2007-2013 se basa en un Plan Estratégico Nacional de Desarrollo Rural, que se elabora para llevar a cabo una programación acorde a su marco competencial y el Marco Nacional de Desarrollo Rural traduce las Directrices Comunitarias de Desarrollo Rural y definen las Medidas Horizontales comunes para los 17 Programas de Desarrollo Rural Autonómicos 
(PDR). Se crea la Red Rural Nacional (RRN), plataforma integrada por los principales actores del medio rural destinada a fortalecer alianzas, divulgar experiencias y conformar un escenario común con todos los actores implicados en el desarrollo sostenible del medio rural español (MAGRAMA, 2012).

De forma paralela, se consensua la Ley de Desarrollo Sostenible del Medio Rural, (45/2007) aprobada por las Cortes en 2007 , (reforzando la vía comunitaria de desarrollo rural) una ley que busca: " favorecer el desarrollo de una actividad económica sostenible y diversificada, que frene el deterioro medioambiental, y promueva el mantenimiento y recuperación de los recursos naturales y de la riqueza cultural del territorio rural español, así como la mejora de las condiciones de vida de las comunidades rurales y la revitalización del campo como espacio de desarrollo humano". Además esta Ley pone especial énfasis en el desarrollo de colectivos considerados prioritarios, propiciando la incorporación de activos rurales jóvenes que permitan el mantenimiento de la población, a la vez que fomenta la igualdad y la promoción de la mujer.

En nuestra región, la Consejería de Medio Ambiente y Desarrollo Rural de Castilla la Mancha tuvo la decisión de elaborar un Plan Estratégico de Desarrollo Sostenible del Medio Rural para el periodo 2007-2013.

El modelo de desarrollo que se propone es el de respetando los recursos naturales, ser capaz de proporcionar a todos los ciudadanos las mismas oportunidades con independencia del lugar de residencia (medio rural o urbano).

\subsection{Política de Desarrollo Rural (2014-2020) ${ }^{18}$}

\footnotetext{
${ }^{18}$ Basado en Gallardo, 2014
} 
La nueva Política de desarrollo rural europea se ha plasmado principalmente en dos reglamentos: Reglamento (UE) №. 1303/2013, de disposiciones comunes a los fondos estructurales, el FEADER y el Fondo de Cohesión y Reglamento (UE) ㄲo. 1305/2013, de desarrollo rural.

La estrategia de crecimiento de la Unión Europea para esta década "Europa 2020", constituye el marco para la acción de las administraciones públicas en el horizonte 2020.

Su eje principal es el crecimiento económico sustentado en tres prioridades:

- Apoyo al conocimiento y la innovación

- Sostenibilidad

- Integrador, lo que lleva implícito una economía con elevado nivel de empleo (objetivo último sea la cohesión económica, social y territorial).

Podemos ver así como la articulación territorial constituye un factor estratégico en la senda de ese crecimiento integrador.

En este contexto, la Unión Europea se plantea nuevos retos, desafíos e instrumentos para impulsar el desarrollo de los territorios rurales. Se reconoce que la agricultura y el mundo rural han sido y siguen siendo fundamentales para la sociedad y para la construcción del espacio europeo considerando sus distintas dimensiones: institucional, cultural, social, económica o ambiental (Gallardo, 2013).

La Comisión Europea ha presentado su documento de trabajo (SWD, 2012), dentro del Marco Estratégico Común (MEC), que tiene como misión establecer las prioridades de inversión de los Estados miembros en consonancia con esta Estrategia 2020.

Este documento proporcionara una estrategia a la vez que coordinara las actuaciones de los 5 Fondos que intervienen en la financiación: FEDER, FSE, FC, 
FEADER, FEMP. Así mismo, prevé establecer unos Contratos de Asociación que recojan los compromisos de los socios a nivel nacional y regional.

Un nuevo reto es planteado, la integración de la dimensión territorial del desarrollo rural en el marco de la cohesión, considerando conjuntamente recursos, fondos y políticas, para así aumentar la eficacia de las acciones encaminadas tanto a mejorar la calidad de vida de los habitantes del medio rural y la eficiencia en el uso de los recursos que posibilitan esas políticas.

Así se ha elaborado un Reglamento ${ }^{19}$ de disposiciones comunes para los cinco fondos anteriormente citados y 11 objetivos temáticos, con el fin de alcanzar una mayor eficacia:

1. Promover la investigación, el desarrollo tecnológico y la innovación.

2. Mejorar el uso y la calidad de las tecnologías de la información y la comunicación y el acceso a las mismas.

3. Mejorar la competitividad de las pymes, del sector agrícola (FEADER) y del sector de la pesca y la acuicultura (FEMP).

4. Favorecer la transición a una economía baja en carbón en todos los sectores.

5. Promover la adaptación al cambio climático y la prevención y gestión de riesgos.

6. Proteger el medioambiente y promover la eficiencia en cuanto a los recursos.

7. Promover el transporte sostenible y eliminar los estrangulamientos en las infraestructuras de red fundamentales.

8. Promover el empleo y favorecer la movilidad laboral.

\footnotetext{
${ }^{19}$ Reglamento (UE) núm. 1303/2013 del Parlamento Europeo y del Consejo de 17 de diciembre de 2013 por el que se establecen disposiciones comunes relativas al Fondo Europeo de Desarrollo Regional, al Fondo Social Europeo, al Fondo de Cohesión, al Fondo Europeo Agrícola de Desarrollo Rural y al Fondo Europeo Marítimo y de la Pesca, y por el que se establecen disposiciones generales relativas al Fondo Europeo de Desarrollo Regional, al Fondo Social Europeo, al Fondo de Cohesión y al Fondo Europeo Marítimo y de la Pesca, y se deroga el Reglamento (CE) 1083/2006 del Consejo.
} 
9. Promover la inclusión social y luchar contra la pobreza.

10. Invertir en la educación, el desarrollo de capacidades y el aprendizaje permanente.

11. Mejorar la capacidad institucional y garantizar una administración pública eficiente.

Se formula un nuevo escenario donde adquieren relevancia cuestiones como la participación público- privada, la focalización territorial, la innovación, o la gobernanza de los fondos.

FEADER contribuirá a la Estrategia Europa 2020 fomentando un desarrollo rural sostenible en toda la Unión complementario a los demás instrumentos de la PAC, la Política de Cohesión y la Política Pesquera Común.

De esta manera intentará llegar a un desarrollo del sector agrícola más equilibrado desde el punto de vista territorial y medioambiental, más respetuoso con la problemática del cambio climático, más competitivo y más innovador.

A su vez el marco general de la PAC en la ayuda al desarrollo rural contribuirá a lograr 3 objetivos:

- Fomentar la competitividad de la agricultura

- Garantizar la gestión sostenible de los recursos naturales y la acción por el clima

- Lograr un desarrollo territorial equilibrado de las economías rurales, incluyendo la creación y conservación del empleo.

Los objetivos de desarrollo rural se traducen en 6 prioridades que tendrán que tratarse en las correspondientes medidas de desarrollo rural:

1. Fomentar la transferencia de conocimientos y la innovación en la agricultura, la silvicultura y las zonas rurales: 
- Promover la innovación y la base de conocimientos en las zonas rurales.

- Reforzar los vínculos entre la investigación y la innovación en la agricultura y la silvicultura.

- Promover el aprendizaje permanente y la formación profesional en los sectores agrícola y forestal.

2. Mejorar la competitividad de todos los tipos de agricultura y la viabilidad de las explotaciones:

- Facilitar la reestructuración de las explotaciones que se enfrentan a importantes problemas estructurales (en particular las que tienen una baja participación en el mercado, las que se orientan al mercado y operan en sectores particulares o las que necesitan una diversificación agrícola).

- Facilitar una estructura de edad equilibrada en el sector agrario.

3. Fomentar la organización de la cadena de distribución de alimentos y la gestión de riesgos en agricultura:

- Integrar mejor a los productores primarios en la cadena alimentaria a través de programas de calidad, promoción de mercados locales y cadenas de distribución cortas, agrupaciones de productores y organizaciones interprofesionales.

- Prestar apoyo a la gestión de riesgos en las explotaciones agrarias.

4. Restaurar, preservar y mejorar los ecosistemas dependientes de la agricultura y la silvicultura: 
- Restaurar y conservar la biodiversidad (incluso en los espacios de la Red Natura 2000 y zonas de agricultura de alto valor natural) y el estado de los paisajes europeos.

- Mejorar la gestión del agua.

- Mejorar la gestión del suelo.

5. Promover la eficiencia en el uso de los recursos y alentar la transición a una economía hipocarbónica en la agricultura y los sectores alimentario y forestal:

- Aumentar la eficiencia en el uso del agua por parte de la agricultura.

- Aumentar la eficiencia en el uso de la energía en la agricultura y la transformación de alimentos.

- Facilitar el suministro y uso de fuentes renovables de energía,

- subproductos, desechos, residuos y otras materias primas no alimentarias para la bioeconomía.

- Reducir las emisiones de óxido nitroso y metano procedentes de la agricultura.

- Promover la captura de carbono en la agricultura y la silvicultura.

6. Fomentar la inclusión social, la reducción de la pobreza y el desarrollo de las zonas rurales.

- Facilitar la diversificación y la creación de nuevas pequeñas empresas y de empleo.

- Promover el desarrollo local en las zonas rurales.

- Mejorar el acceso, uso y calidad de las tecnologías de la información y la comunicación (TIC) en las zonas rurales. 
Fig. 13 : Estrategia Europa 2020.

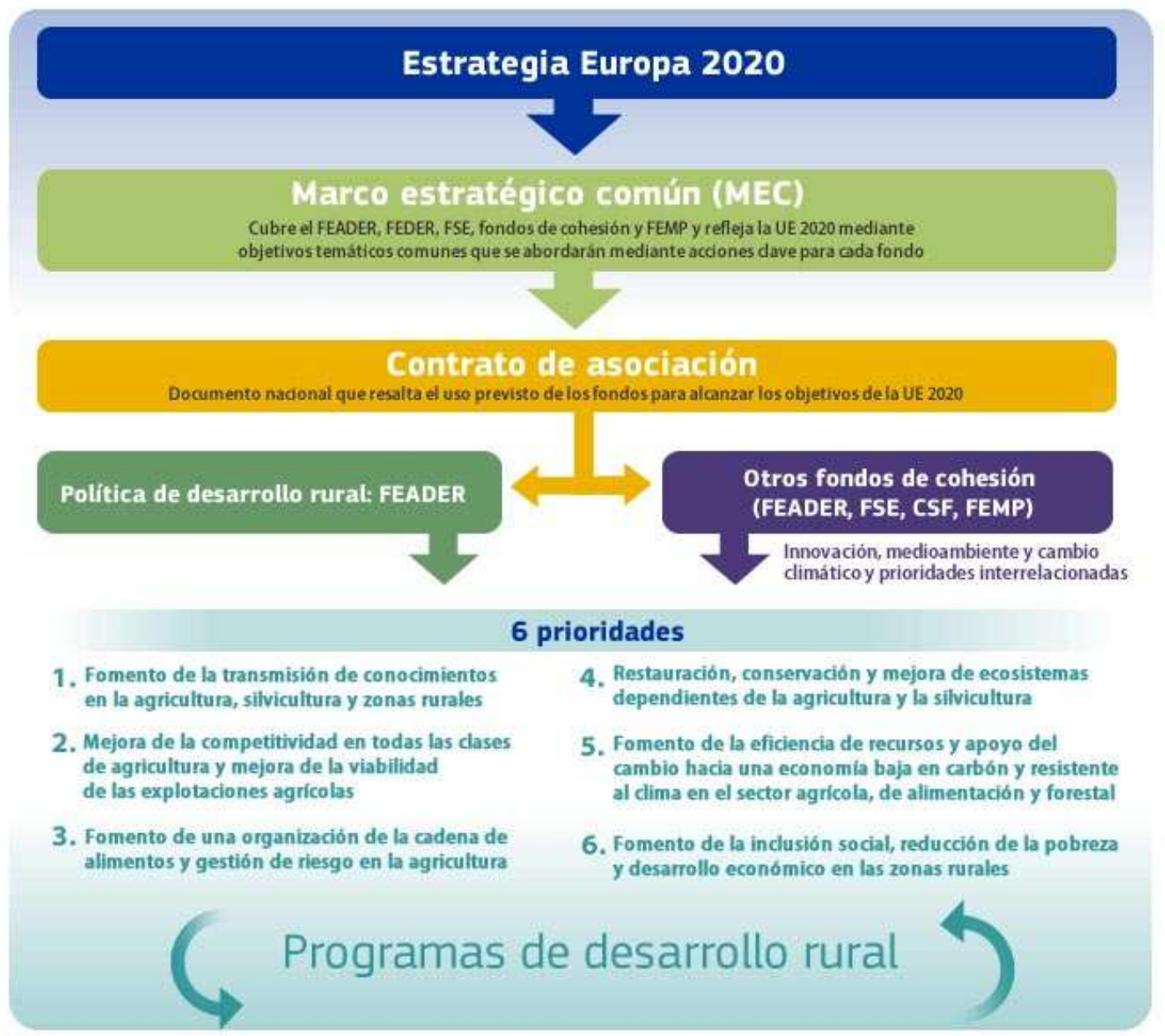

Fuente: European Network For Rural Development (ENRD), 2015.

Para su consecución, los Estados miembros y las regiones elaboran Programas de Desarrollo Rural (PDR) basándose en, al menos 4, de las 6 prioridades citadas. Entre las medidas especificas que la Comisión Europea propone, cabe destacar:

1. Servicios de asesoramiento, gestión y sustitución de explotaciones agrarias

2. Agroambiente y clima;

3. Agricultura ecológica, 
4. Zonas con limitaciones naturales y otras limitaciones específicas;

5. Medidas forestales;

6. Inversiones de mejora de las explotaciones agrarias,

7. Infraestructuras públicas de regadío

8. Transformación y comercialización de productos agrarios;

9. Instalación de jóvenes agricultores;

10. Innovación;

11. Estrategia LEADER

Debe señalarse que a las medidas que tengan que ver con agroambiente y clima se destinará un $30 \%$ del presupuesto asignado, incluyendo en este paquete nuevas medidas como son las forestales, la Directiva Marco de Agua, zonas Natura 2000, biodiversidad y las zonas con limitaciones naturales.

Por su parte, el $5 \%$ del presupuesto del FEADER se dedicará a las medidas asociadas al enfoque LEADER. En el caso de las inversiones en regadío, se permitirá la financiación de las que garanticen un ahorro de, al menos, el $5 \%$, así como las balsas de regulación, la mejora de la eficiencia energética, la utilización de aguas regeneradas y los nuevos regadíos.

Es decir, los PDR deben incluir los elementos que establece el Reglamento de disposiciones comunes del MEC y, además, otros más específicamente relacionados con el desarrollo rural:

- $\quad$ un informe previo de evaluación

- un análisis de situación (utilizando la matriz DAFO) donde se expongan las necesidades de los territorios que serán objeto de aplicación del programa o subprograma temático(de acuerdo con las prioridades generales de la UE) 
- una descripción de la estrategia de desarrollo rural (fijando los objetivos a alcanzar y definiendo las medidas que de forma coordinada se piensan aplicar para alcanzarlos y los recursos que se les asignarán)

- $\quad$ una descripción de la estrategia que se piensa adoptar para hacer efectiva la aplicación de la AEI en el sector agroalimentario;

- $\quad$ un plan de financiación donde se especifique tanto la contribución total del FEADER al conjunto del PDR como su contribución a cada una de las medidas que componen los distintos subprogramas temáticos, así como la parte de cofinanciación que le correspondería al Estado miembro o, en su caso, al gobierno regional

- $\quad$ un sistema de indicadores para poder evaluar a posteriori la eficacia del programa y de cada uno de los subprogramas.

Para financiar esta política de desarrollo rural en el período 2014.2020, a España le corresponden 8.291 M€, 8.053 para FEADER y 238M€ para el Programa Nacional

En cuanto a las tasas de cofinanciación permitida y dado que Castilla laMancha se ha calificado como región en transición, dispondrá de una tasa del 75\% que puede incrementarse para algunas medidas como LEADER, agroambientales, agrupaciones de productores, cooperación etc. Nuestra Región recibirá 1.147 M€ un $14,2 \%$ del total. 


\section{CAPITULO 4: ESPACIO RURAL PERIURBANO}




\section{ESPACIO RURAL PERIURBANO}

\subsection{Espacios Periurbanos: Definiciones y funciones.}

El concepto de Espacio Periurbano surge a finales de los años setenta, para intentar comprender y explicar los procesos de reestructuración y de expansión urbana hacia el espacio rural próximo.

Desde entonces se pone en evidencia las transformaciones territoriales, las desigualdades entre territorios y que la dicotomía rural-urbano era limitada para explicar este proceso. Es así como se pone de manifiesto el concepto de periurbano refiriéndose a una extensión continua de la ciudad hacia la progresiva absorción del espacio rural que la rodea.

Emerge así el término de periurbanizacion para describir un proceso que se va a desarrollar en la periferia de las ciudades y en espacios con baja densidad sin una continuidad del hábitat, bajo la imagen de una población dispersa en construcción.

En España, algunos sociólogos como Gaviria, y Baigorri, entre 1982 y 1984 empiezan a incorporar estas investigaciones en el área Metropolitana de Madrid $^{20}$. Remitiendo a un espacio que se desarrolla en la periferia de las ciudades con una urbanización débil, donde es difícil designar las fronteras.

En estos momentos se habla también de un tejido compuesto y se califica de muy diversas maneras: "exurbano", "naturbano", "suburbano" siempre manifestando un carácter de composición, de mezcla. Así, Jaillet (2004) entiende el término periurbano como simples extensiones (espacios), se encuentran alrededor de la

\footnotetext{
${ }^{20}$ Los autores citados, realizaron una investigación "Posibilidades de desarrollo de la agricultura periurbana en el área Metropolitana de Madrid", por encargo de la COPLACO, antecedente de la actual Consejería de Medio Ambiente y Ordenación del Territorio de la Comunidad de Madrid.
} 
ciudad apelando a "exurbano", sin embargo para Steinberg (2001), la periurbanizacion son extensiones densas y continuas de la ciudad sobre el campo más allá de las "afueras" (la banlieu), remitiendo a espacios discontinuo y frecuentemente unidos al desarrollo de núcleos rurales preexistentes.

Esta definición, se corresponde con un enfoque de la periurbanizacion próximo a la ruurbanización, concepto iniciado por G. Bauer y J.M Roux en 1976, para definir una zona rural próxima a centros urbanos que experimenta el aporte residencial de una población de origen principalmente urbano, caracterizada sin embargo por la subsistencia de un espacio no urbanizado ampliamente dominante.

La ruurbanización es una etapa en un proceso más largo que conduciría al periurbanizacion (Berger, M, 1981). Así este proceso llevaría asociado una migración positiva de habitantes, una disminución de los agricultores, y una transformación del mercado del suelo, al originarse construcciones de casas individuales en municipios rurales próximos a una aglomeración metropolitana.

Al irse extendiendo la ciudad e ir absorbiendo los espacios rurales que la rodean, el periurbano se vuelve un ámbito difuso entre lo urbano y lo rural ya que por un lado se desarrollan actividades económicas y sociales que se encuentran ligadas a la dinámica de la ciudad pero que al mismo tiempo, incorpora actividades propias del campo, constituyendo un territorio resbaladizo, en permanente transformación, frágil y susceptible de nuevas intervenciones (Barsky, 2005). Así el mismo autor, subraya la periurbanizacion como un espacio que se define por su indefinición: no es campo ni es ciudad (Barsky, A 2013), lo presenta como una tercera corona, donde los procesos de urbanización confrontan una sociedad agraria a una sociedad mesorural en funcionamiento que participa de la desaparición del espacio rural tradicional. 
Estos espacios periurbanos están desde su inicio en continua crisis y deben responder a numerosas funciones. Por lo general, reciben todo aquello que arroja la ciudad o no tiene cabida en ella y absorben funciones que, en determinados casos, requieren condiciones de cierto alejamiento, tamaño suficiente y menor precio del suelo (Sancho Martí, 1989)

Según Banzo, 2005, la periurbanización remite a un espacio donde se mezclan dos mundos con valores y objetivos distintos: una población rural vinculada a las actividades agropecuarias y una población urbana ligada a actividades y funciones de servicios propios de la ciudad. Esta idea ha sido cuestionada por los ruralistas, que defienden la existencia de procesos específicos como la rurbanización o la periruralidad y que consideran al espacio rural con impulsos y dinámicas propias.

En todo caso, el término periurbano significa un proceso de mutación de un territorio en consolidación, y con una gran heterogeneidad en los usos del suelo y el espacio: terrenos construidos con alta densidad, dedicados a industrias, vertederos, campos de cultivo y espacios naturales, etc (Capel, 1994). Este mismo autor explica que la localización de villas alrededor de los centros urbanos no es un fenómeno reciente en el tiempo, sino que ya las ciudades romanas y posteriormente las medievales se configuraban con este tipo de estructura.

Para Verdaguer (2010), el suelo periurbano, espacio de transición por excelencia, suele convertirse en la franja "descosida" de la ciudad y en el escenario residual de aquellas actividades que no encuentran su acomodo en el tejido consolidado, ya sea por su impacto, por su carácter irregular, o por su insuficiente valor añadido. Además las expectativas de lucro los convierten también en suelos en "espera" de ser urbanizados y por tanto en material privilegiado para las políticas que han caracterizado el desarrollo de muchas ciudades españolas durante décadas. 
En definitiva, en la medida en que la urbanización avanza sobre el ámbito rural, origina conceptos nuevos que dan cuenta de nuevas formas de cómo se están ocupando estos espacios, que en realidad no son nuevos, lo que sí lo son los procesos sociales que se desarrollan (Puebla, 2004)

Es decir, la periurbanizacion sería una mutación territorial en la que la función residencial de los espacios rurales, cambia de caracteres, perdiendo los aspectos agrarios o rurales en beneficio de los caracteres urbanos. El análisis del desarrollo de estas nuevas formas de residencia que afectan al espacio que rodea las ciudades aparece así como una etapa importante del conocimiento de la periurbanizacion y de la recalificación territorial que conlleva.

Pero la periurbanizacion no se detiene en esta transformación residencial, lleva acompañada la implantación de equipamientos y de actividades que no están ligadas al mundo rural, y que provienen del sistema urbano. A lo largo de esta mutación, el crecimiento demográfico puede ser importante, pero no es obligatorio, además los orígenes del proceso pueden ser endógenos o exógenos, urbanos 0 regionales (Prost, B 1991). Este mismo autor señala que no hay coincidencia entre los procesos de ruurbanización y periurbanizacion, sino un "décalage" o desplazamiento cronológico y casi siempre espacial que procede del propio fenómeno.

Desde la óptica del desarrollo rural, la periurbanización representa una solución de continuidad entre la vida rural y la de la gran concentración urbana, donde se difunde una nueva manera de vivir marcada por los ritmos de la ciudad, sus expresiones políticas y culturales, y las actividades productivas de corte urbano. Dicha difusión descansa en la integración de los elementos espaciales y sociales del mundo rural, alterando profundamente su organización socioeconómica (Prost, B 1991). Para este autor, hace falta tiempo para que el mundo rural desaparezca por 
completo a favor los nuevos espacios donde el cambio social va dando paso a un nuevo territorio creado sobre fragmentos de un espacio reinventado, y apropiado por nuevos actores (Prost, B 1991).

Más recientemente Ávila Sánchez, (2009) manifiesta que el periurbano es el ámbito de difusión urbano-rural, e incluso rural, donde se desarrollan prácticas económicas y sociales ligadas a la dinámica de las ciudades pero que contiene también características rurales. Es decir, el elemento central en cuanto a la existencia del fenómeno lo constituyen las relaciones que se establecen por cercanías y proximidad con el entorno urbano.

También Berroir (2005) nos dice que los espacios periurbanos ya no pueden considerarse espacios residuales o intersticiales de la expansión urbana sino que son una categoría espacial asociada a un modelo emergente.

Funciones del área Periurbana:

- Reserva de zonas verdes: por ser un espacio urbanizado parcialmente tiene disponibilidad de suelo

- Residencial: suelo más accesible, mayor proximidad con espacios abiertos, está, siendo dotado de mayores servicios

- Filtro o amortiguamiento: de los excedentes que genera la gran ciudad. Reduce los niveles de contaminación y modera los efectos nocivos de la gran ciudad

- Zonas recreativas y ocio: solución ante el aumento de la demanda de suelo para estos usos

- Especulación inmobiliaria: dinámica por la disponibilidad de suelo y la cercanía con la gran ciudad. Usos inactivos esperando la posibilidad de urbanización

- Acercamiento al espacio rural y a la naturaleza: presencia de formaciones naturales. Es un escaparate de lo rural y de lo natural. 
- Asentamientos industriales: Espacio óptimo para la instalación de grandes superficies industriales y comerciales.

- Absorción de excedentes: Se convierte en receptor de muchos excedentes. Aunque a veces se realiza sin control y no es capaz de absorber.

El uso tradicional de los espacios periurbanos ha experimentado en la generalidad de los países europeos drásticos cambios, debido a la desvalorización en términos económicos de las actividades agrícolas, a la fuerte demanda de tierra para una expansión urbana altamente consumidora de suelo: extensas urbanizaciones de desarrollo horizontal, segundas residencias, equipamientos e infraestructuras diversas, vías de comunicación y transporte, etc.), a la gran capacidad técnica existente hoy para la transformación de tales espacios (encauzamientos, puentes, grandes infraestructuras...), a la enorme producción de desechos, a la demanda masiva de materiales para la construcción, y a la presión de los ciudadanos, que reclaman lugares de ocio y de esparcimiento públicos y privados (Sancho Martí, 1989).

\subsection{Delimitación del Periurbano}

Para su delimitación se han propuesto diferentes marcos espaciales:

Kayser, 1990, establece tres coronas periurbanas:

- $1^{a}$, la que se corresponde con la suburbanización, funcionalmente unida a la ciudad

- $\quad 2^{a}$, en la que los procesos de transformación ya han comenzado, parcelaciones generalizadas 
- $\quad 3^{a}$, carácter rural en la que los procesos de urbanización compiten con una sociedad y unas actividades rurales que todavía presentan cierta resistencia al cambio. Proceso de periurbanización reciente.

La frontera entre la $2^{\underline{a}}$ y la $3^{\underline{a}}$ es difícil y se recurre a tres tipos de variables:

- Según la situación y las características de la agricultura, el tipo de poblamiento y el equipamiento básico

- Según el grado de urbanización, el volumen de las nuevas edificaciones, características del mercado del suelo

- Según el papel de los agricultores y de los otros grupos sociales en la gestión municipal, medidas de planificación

Bryant, et al (1982), amplían el modelo iniciado por Pryor, 1968, basado en un modelo de franja rural-urbana, utilizando criterios demográficos y usos del suelo. Pero para ambos los procesos de periurbanizacion han expandido los límites de la ciudad sobre el entorno rural, hablan de una "ciudad regional".

Fig. 14: Organización de las coronas periurbanas según Bryant y Russwurm.

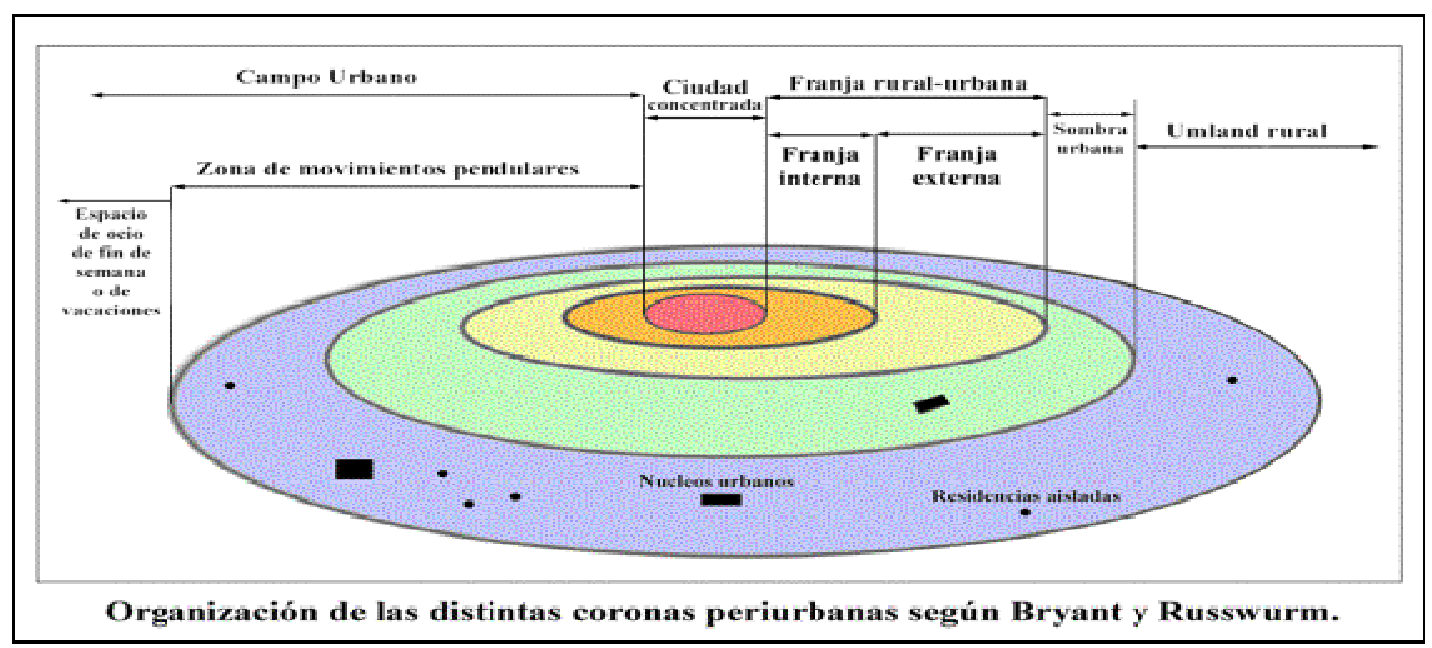

Fuente: Bryant, Russwurm et Al (1982). 
Así para estos autores la ciudad concentrada, acoge entre el $75 \%$ y el $90 \%$ de la población en apenas un $5 \%$ del territorio y la ciudad dispersa o campo urbano es aquella, donde el 95\% del espacio alberga entre el 10\% y el $25 \%$ de la población.

Más recientemente, Galindo (2006) propone una metodología alterna al proceso de urbanización difusa donde se articula lo urbano con lo regional. Para lo cual propone pasar de un enfoque bipolar campo-ciudad, a uno donde la bipolaridad se difumine y ocurra un proceso de incorporación a la red urbano-regional.

Es decir, pasar de los sistemas de ciudades unidas por distintos flujos a una franja periurbana que deviene un espacio de interfase cuando lo urbano interactúa con lo rural. Y, si bien todo el espacio que rodea la ciudad es, por definición periurbano, solo habría interface donde existe una interacción rural-urbano.

Fig. 15: De la oposición campo-ciudad a la interfase rural urbana.

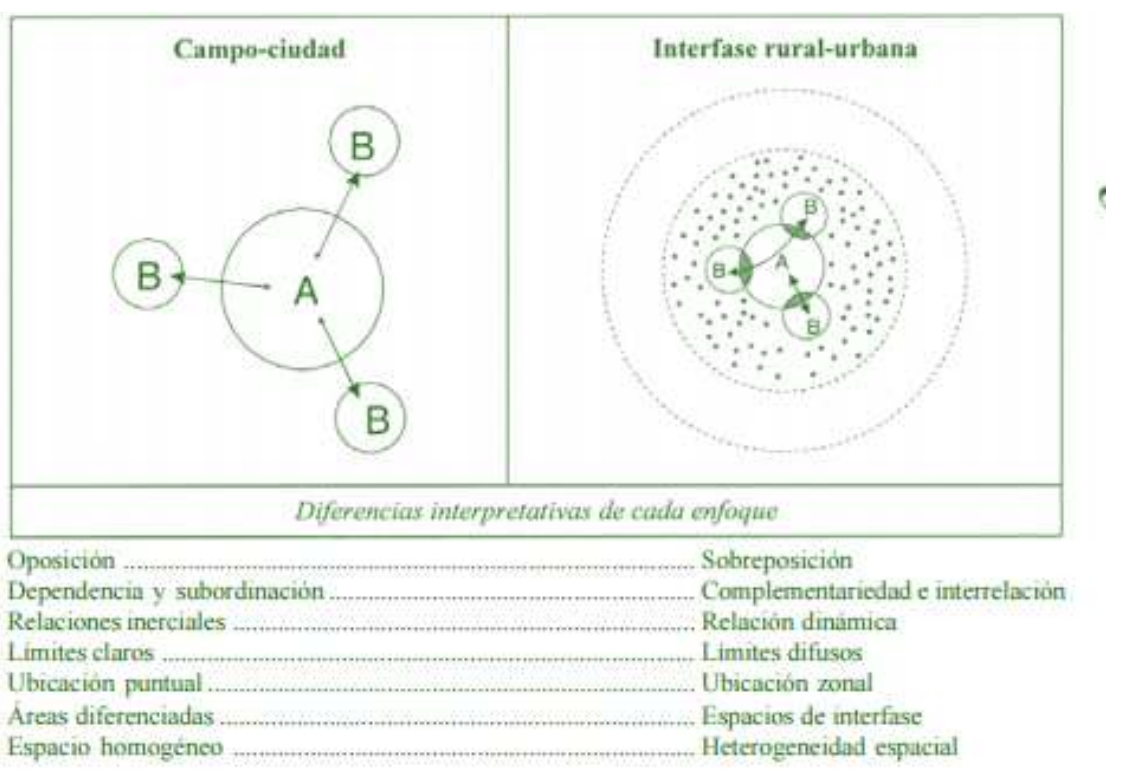

Fuente: Galindo, Delgado (2006)

Para Banzo, M (2001), plantear la cuestión de la existencia de un territorio periurbano, obliga a dirigir la mirada a la relación de la población con este espacio, 
por tanto lleva a orientar la reflexión a entender cómo se vive en este espacio, más que cómo se construye, es decir es más interesante fijarse en el proceso de periurbanizacion que en el espacio urbano.

Este hecho de considerar la periurbanizacion como proceso espacial y modo de vida, permite rebasar ciertos problemas:

- Evita el cuestionamiento sobre los límites, porque se trata de entender el funcionamiento de un sistema más que su extensión espacial. La distancia a la ciudad ya no tiene mucho sentido: existe una diversidad y una diversificación de los procesos dentro de la corona periurbana, mientras que la mejoría de los modos de comunicación difunde la periurbanización a distancias muy lejanas del núcleo urbano.

- Permite conocer la dinámica y no sólo su resultado, lo que parece particularmente importante cuando nos interesamos en los espacios en constante transformación.

- Facilita las comparaciones, la forma en que se caracteriza el espacio periurbano puede cambiar, aunque los elementos que favorecen esta discontinuidad son muy parecidos de un país a otro y resultan en primer lugar de un acceso mayor de la población a la movilidad.

\subsection{Clasificaciones de Periurbano: Dificultad para su identificación y dimensionamiento.}

La gran cantidad de definiciones estadísticas en los países europeos nos ayudan a afirmar que no existe una categoría y una nomenclatura común para denominar a este fenómeno. Parece pués evidente que es muy difícil, decir con precisión qué representa en realidad el periurbano (Louargant et al, 2011). 
Según Caruso (2002), en Bélgica este espacio atañería a un 24\% del territorio belga y a un $20 \%$ de su población, en Gran Bretaña a un $36 \%$ del territorio y a un $26 \%$ de su población; en los Países Bajos a un $40 \%$ de su territorio y un $23 \%$ de su población. Si estos resultados ya nos dan una idea de estar hablando de unas magnitudes importantes, además tendríamos que tener en consideración la terminología específica de cada país: espacio suburbano y suburbano-rural, "rings" en Reino Unido, "banlieu" en Bélgica etc. Este autor considera además que países mediterráneos como Italia, España y Grecia no parece que tengan una definición estadística ni un enfoque político del espacio periurbano, si bien como veremos en el punto seis se tiende a una homogeneización. En efecto, en España no existe una delimitación oficial del hecho urbano ni del fenómeno periurbano en el INE (Instituto Nacional de Estadística). La definición espacial de la ciudad esta propuesta a nivel regional por las Consejerías de Ordenación del Territorio y por las estadísticas locales a nivel autonómico.

Sin embargo, el Instituto Nacional de la Estadística y de los Estudios Económicos (INSEE) francés da una definición precisa del periurbano, para describir los pueblos que ni pertenecen a una aglomeración, en sentido de continuidad de edificaciones y que contienen al menos un $40 \%$ de sus población activa trabajando en un "área urbana" ${ }^{21}$. En este caso la definición de "áreas urbanas" se basa en las migraciones de activos con empleo y no directamente en las dinámicas demográficas.

Así las categorías establecidas muestran que se trata de un fenómeno plural, relacionado principalmente con los vínculos funcionales con la ciudad, y/o a veces

${ }^{21}$ En 1997, el INSEE describe el área urbana como sustitución de las llamadas zonas ZPIU (Zonas de Población Industrial y Urbana) y hace referencias a un espacio agregado a un polo urbano que ofrece al menos 5000 empleos y una corona periurbana (compuesta de pueblos rurales o unidades urbanas donde al menos el $40 \%$ de la población residente activa trabaja en el resto del aire urbano. 
teniendo en cuenta la parte de los activos agrícolas, y según los países la densidad de población "intermedias".

EUROSTAT habla de "espacios intermedios" y la OCDE de espacios densos "significativamente rurales". Además, el observatorio europeo ESPON (2006) ${ }^{22}$, ha definido una tipología europea de relaciones urbano-rurales ${ }^{23}$, con la finalidad de proporcionar una mejor compresión de la diversidad de las regiones europeas. a nivel NUTS3 (nuestras provincias). La tipología utilizó dos dimensiones básicas: el grado de influencia urbana y el grado de intervención humana.

El grado de influencia urbana viene determinado por la densidad de población, así como por el status del centro urbano principal de cada NUTS 3.

El grado de intervención humana refleja la ocupación relativa de la superficie terrestre, de acuerdo con las 3 coberturas establecidas: usos artificiales, uso agrícola, uso residual.

ESPON a partir del grado de influencia urbana, ha considerado dos clases de territorio:

- $\quad$ Alta influencia urbana. zonas con densidad de población por encima de la media europea y/o zona NUTS 3 con su centro urbano principal calificado como Área Metropolitana de Crecimiento Europeo.

De débil influencia urbana: el resto de regiones NUTS 3.

\footnotetext{
${ }^{22}$ A nivel europeo, como ya vimos en el capítulo 2, que el observatorio europeo ESPON propone una clasificación basada en la densidad de población (OCDE, 1994).

23 Entendemos por tipologías, las clasificaciones territoriales basadas en la aplicación de indicadores científicamente sólidos y políticamente relevantes.
} 
ESPON a partir del grado de intervención humana, establece 3 categorías principales de territorios según la mayor o menor superficie ocupada por los usos artificiales, agrícolas o residuales:

- $\quad$ Alta intervención humana: zonas con un \% de suelo artificial por encima de la media europea.

- $\quad$ De intervención humana media: zonas con un \% de superficie agrícola por encima de la media europea.

- $\quad$ De débil intervención humana: zonas con \% de suelos residuales por encima de la media europea.

Las dos clases de influencia urbana y las tres clases de intervención humana, se combinaron en un modelo de seis tipos, dinámico y flexible que permite considerar la evolución temporal de las variables utilizadas, dado que se emplean series estadísticas cronológicas, densidad de población, variación usos suelos, al mismo tiempo que puede ser aplicado a diferentes escalas geográficas. 
Fig. 16: Áreas rurales y su clasificación según ESPON.

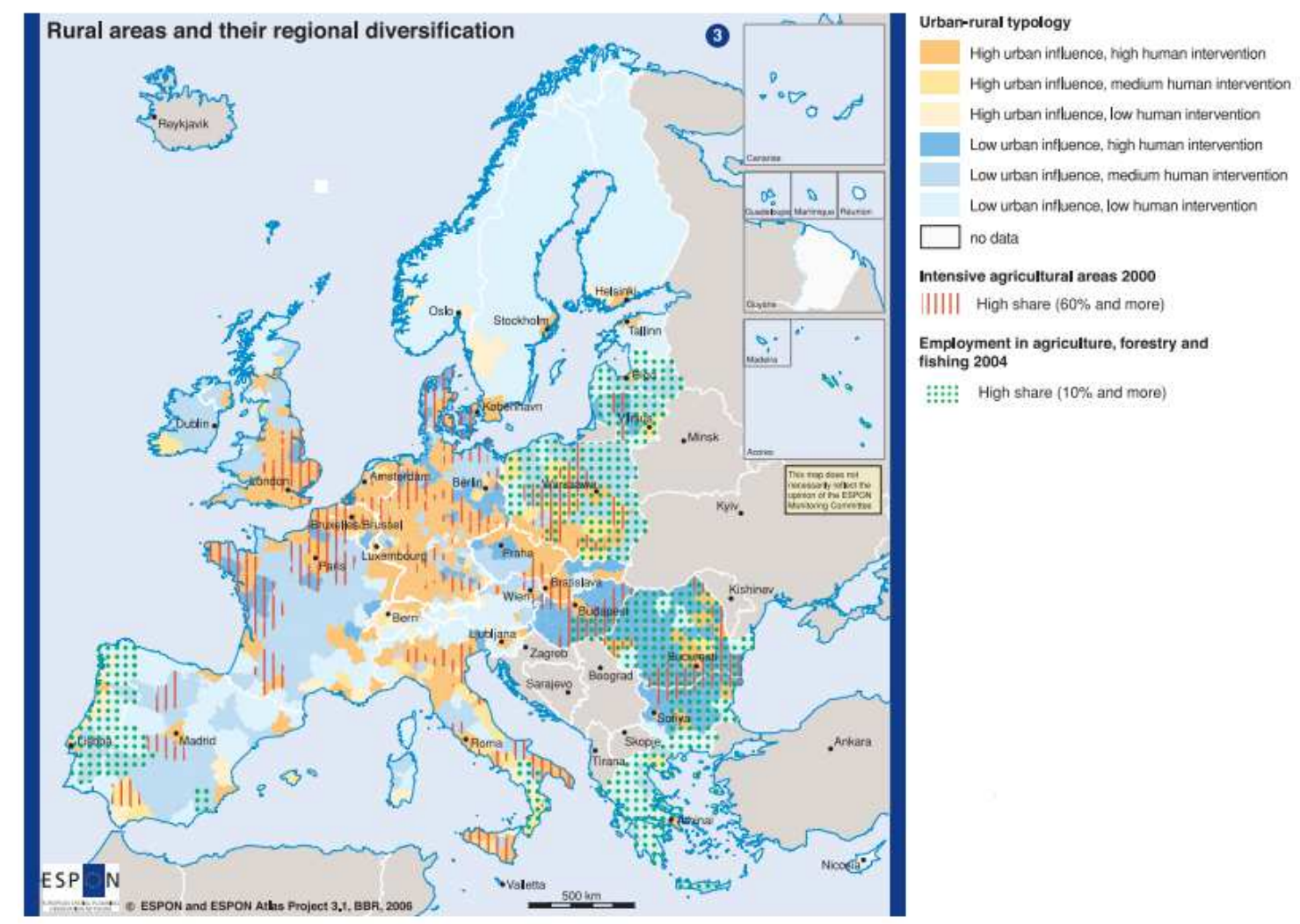

Fuente: ESPON ATLAS 2006

Posteriormente otro intento de clasificación vino de la mano de Dijkstra, L y Poelman, H, (2008), combinando la clasificación de la OCDE con unos indicadores de distancia. Este nuevo enfoque combinaba una nueva clasificación de lejanía, basada en el tiempo de conducción a la ciudad más cercana (cercanía a una ciudad implica que la menos el 50\% de la población vive a menos de 45 minutos en coche de una ciudad con más de 50,000 habitantes), con la clasificación de la OCDE según regiones predominantemente urbanas, intermedias y predominantemente rurales.

Estos son sólo, algunos de los modelos que con diversos criterios han intentado delimitar el proceso de dispersión urbana en los últimos años. No obstante, una constatación es clara, el proceso de periurbanizacion es diverso y complejo, lo 
que dificulta el establecimiento de unos límites aceptados y establecidos universalmente (a nivel europeo).

En nuestro caso de estudio vamos a analizar la clasificación que hace el Programa de Desarrollo Rural de Castilla la Mancha 2007-2013 de nuestra región Castilla la Mancha y nuestra comarca de estudio, Torrijos.

\subsection{Procesos comunes en espacios periurbanos.}

Este espacio cambiante, envidiado, atractivo, dinámico y difícil de limitar (que no ilimitado), responde a una serie de procesos:

\section{$>\quad$ Desarrollo tecnológico}

El desarrollo tecnológico ha posibilitado la segmentación del proceso productivo y la reorganización territorial de las actividades económicas, de manera que los sectores industriales y comerciales se han ido hacia la periferia de las ciudades e incluso en el ámbito rural inmediato a la urbe. A partir de este hecho, las regiones urbanas mejor comunicadas han desarrollado su actividad empresarial, dando lugar a polígonos industriales y logísticos.

$>\quad$ Desarrollo de la red de infraestructuras.

Las redes viarias articulan el territorio, permitiendo una mayor movilidad de la población, además dada su capilaridad frente a otras infraestructuras, permiten un mayor acercamiento entre consumidores y productores, y a su vez a éstos con las fuentes de materias primas.

Mencionar también el desarrollo de otras redes, como la energética (luz, gas..), saneamiento, depuración, digitales, etc.

Cambios en la sociedad 
Como ya se ha comentado a lo largo de la investigación, se produce un cambio en la percepción de espacio marginal y atrasado que las clases medias urbanas tienen de las periferias rurales. Más bien al contrario, ven a este espacio como un territorio que les ofrece la posibilidad de vivir en una vivienda unifamiliar en un entorno de mayor de mayor calidad de vida.

Es un espacio donde los extremos socio-demográficos están ausentes: no hay muy ricos, ni muy pobres, no hay familias muy numerosas, ni de familias mono parentales.

Este escenario lo suele elegir parejas jóvenes, de clase media con hijos menores donde trabajan los dos: buscan un alojamiento adaptado a su tamaño y a sus comodidades de la vida familiar, que no encuentran en la ciudad. Esto conlleva a su vez un cambio en la movilidad de estas familias, al necesitar un vehículo para desplazarse al trabajo, ocio etc. y no existir en estos territorios un desarrollo adecuado de los transportes públicos.

El periurbano les asegura así un acceso a la totalidad de la parte atractiva y amena de las ciudades, a una buena distancia de los perjuicios de la ciudad, o que ellos consideran como tales: su gran densidad, su incomodidad, su congestión etc, próximo al campo (Jaillet, MC 2004).

Son espacios que constituyen en cierta manera, el ideal, caracterizado por una búsqueda de confort (espacial al menos), de acceso a la propiedad individual, próxima al campo (un campo habitado), a la montaña (espacio de esparcimiento), con vías de comunicación para acceder al trabajo y a la ciudad. Si además tienen una oferta de servicios d equipamientos adecuados reúnen condiciones más favorables a la vida en familia que otros espacios

Aparición de zonas de equipamientos y servicios. 
Tradicionalmente se situaban en las zonas centrales de las regiones urbanas, al instalarse población en el periurbano, estos equipamientos se han ido desplazando también hacia este espacio. Es decir, se produce un desarrollo de las actividades recreativas o de esparcimiento.

El perfil de los habitantes de las zonas periurbanas no es ajeno a las características de los equipamientos que nos encontramos. La llegada de una población nueva, con unos hábitos culturales urbanos, contribuye a la instalación de equipamientos socio-culturales y deportivos, así como estructuras de acogida para los más pequeños. Un buen nivel de equipamiento en estas zonas facilita el acceso de los habitantes a estos servicios. (Jaillet, MC 2005)

$>\quad$ Presión de sector financiero- inmobiliario.

Son los encargados de promover, diseñar y dar forma a la expansión urbana actual sobre el entorno rural circundante. Aparece un modelo urbanístico de carácter especulativo, apoyado en la construcción de una red de infraestructuras viarias.

El periurbano representa en sí mismo un "mercado" en el que, promotores, constructores, bancos, empresas, grandes distribuidores están interesados. La periurbanizacion es en lo sucesivo un fenómeno frente a cual las empresas y las actividades privadas o públicas son unos actores por lo menos tan decisivos como los hogares (Lourgant, S, 2011).

En definitiva, el territorio rural periurbano se recalifica porque pierde su rol de organizador de la vida local. Este rol será asignado en lo sucesivo a nuevos actores y a nuevas fuerzas; el espacio, diversamente apropiado, se modifica profunda pero desigualmente; se organizan nuevos territorios y actúan nuevas fuerzas. Este ámbito de interacciones urbano-rurales, al formar parte del sistema de la economía urbana, recalifica las actividades humanas y a las fuerzas económicas regionales; su efecto en las redes de equipamientos e infraestructuras; en la movilización de los actores 
locales y en puesta en marcha de iniciativas endógenas y exógenas en torno a proyectos colectivos (RITMA, 2001).

En la mayoría de los casos la presión urbanizadora se intensifica sobre los espacios agrarios, como ha ocurrido en la Comarca de Torrijos. Esta transformación supone la pérdida irreversible de un suelo que antes era agrario y ahora ocupa otro valor estratégico, que se presta a una compleja red de servicios: de soporte, de biodiversidad, de abastecimiento, de regulación y culturales.

La adecuada consideración y comunicación de esta pluralidad contribuye a mejorar la percepción que se tiene de estos ecosistemas. Para ello es necesario comprender el uso urbano de lo rural y de las interacciones de las actividades agrarias periurbanas con la ciudad. $\mathrm{Y}$ ante la transformación de los ecosistemas agrarios debería primar el principio de precaución (Riechmann, 2007). Pues en ocasiones, en opinión de Poulot, M (2008), los habitantes del periurbano justifican su elección residencial como un idilio paisajístico, en lugar de poner por delante el deseo de vivir en los pueblos por tratarse de un espacio más "amigable" y con una mayor solidaridad, de manera que este proceso desemboque en el intercambio de servicios. Sin embargo, la exaltación de tales valores parece a priori bastante alejada de la realidad tal como aparece en diferentes trabajos llevados sobre el habitante periurbano (Charmes, 2005), cuestionando si ser rural o hacer rural es en realidad una moda, un sesgo de modernidad o bien lleva asociado otras consideraciones más solidarias o interesadas. 


\subsection{Conflictos-tensiones en el rural periurbano.}

La dimensión conflictiva siempre se presenta como esencial en los procesos de ordenación del territorio y de desarrollo regional que conciernen a actividades ligadas a la agricultura los recursos naturales: la distribución del agua y suelo para diversos usos, la puesta en marcha de infraestructuras públicas, la gestión de la contaminación y residuos junto con sus consecuencias, y como no, los problemas de economía residencial suelen ser los más frecuentes en el proceso de periurbanizacion. La toma en consideración y el manejo de las tensiones y de las controversias que emanan del desarrollo de estas diferentes actividades, están considerados hoy en día como primordiales.

En este sentido, los espacios rurales y naturales y periurbanos son receptáculos importantes de tensiones y conflictos debido a su carácter multifuncional (Hervieu, B 2001). En efecto, a menudo consideramos que sirven de soporte a tres tipos de funciones que inducen usos competenciales y por lo tanto divergencias y oposiciones entre los actores locales económicos y sociales: una función económica o de producción, una función residencial y recreativa (el campo como entorno de vida, bien se trate de un hábitat permanente o temporal) y una función de conservación (protección de la biodiversidad, del patrimonio natural, cultural y paisajístico).

Los fuertes antagonismos existentes entre los habitantes autóctonos y los recién llegados, son causa en ocasiones de situaciones conflictivas aunque pueden suponer asimismo oportunidades para el desarrollo de estos espacios, es más, son parte integrante del proceso en la dinámica de desarrollo local (André, T et al., 2006).

Entre los 9 tipos de usos principales de los espacios rurales y periurbanos: actividad agrícola, actividad industrial (incluido industria agroalimentaria), actividad 
terciario, producción de energía, construcción de infraestructuras, gestión de los residuos y los problemas de depuración, protección y reserva de la naturaleza, las actividades recreativas, la actividad residencial, tres son principalmente dados a conflictos o a relaciones conflictivas. Se trata de:

- del uso industrial,

- $\quad$ del uso residencial (que a menudo se opone al precedente),

- $\quad$ del uso de protección y de gestión de la naturaleza (ídem).

El uso industrial es a menudo señalado con el dedo debido al externalidades negativo que provoca (contaminaciones difusas, perjuicios olfativos, ruidos ambientales) y que incomoda a los vecinos. Los conflictos que emergen están ligados a la instalación de nuevas fábricas o edificios para ganadería, a las contaminaciones de naturaleza diversas emitidas por estas actividades, así como a riesgos industriales procedentes de esas industrias.

Los dos otros usos, residencial y de protección y de gestión de la naturaleza, a menudo se oponen, de manera bastante previsible, al uso industrial. Los actores que se encuentran en situaciones de conflicto a propósito de su actividad residencial pretenden defender su entorno de vida y se encuentran en desacuerdo con la instalación de edificios industriales o los perjuicios que provienen de fábricas o de empresas ya instaladas. Los que movilizan argumentos a favor de los usos de protección y de gestión de la naturaleza se erigen defensores del patrimonio natural y de la calidad de los medios (agua, aire, suelos), que consideran en peligro por actividades de naturaleza industrial.

No obstante, estos dos últimos usos (residencial y de protección de la naturaleza) no se oponen tan solo a los cambios provocados por el crecimiento de la actividad industrial en las zonas rurales y periurbanas, no es raro verlos oponerse a 
innovaciones nacidas de políticas de Estado, en particular en materia de gestión de los residuos, de la producción o el transporte de energía, y de infraestructuras de transporte.

Podemos decir que la relación de proximidad geográfica entre los actores es a menudo presentada como ventaja, es un factor de oposición-conflictividad entre los actores locales. Los conflictos saltan entre los agentes que se encuentran en situaciones de superposición, de contigüidad, de conexión, de vecindad próxima, o que pretenden usos diferentes del mismo espacio o el mismo lugar (Bonin, M 2004). Si la proximidad geográfica es portadora de tensiones, es porque impone una superposición, una contigüidad o una vecindad de los espacios sobre los cuales los agentes tienen proyectos de uso o de acciones diferentes.

A veces se confunde usos con usuarios del espacio, dando lugar a fenómenos concomitantes:

Un mismo actor es a menudo portador de usos diferentes: un agricultor también puede ser cazador, o defensor de la naturaleza; un industrial puede practicar la el paseo por el bosque; un residente puede entregarse, en el marco de su actividad profesional, a una actividad productiva contaminante...

A su vez, el mismo actor va a presentar facetas diferentes en el seno de diferentes grupos sociales o profesionales. Su comportamiento y su compromiso van entonces a variar según que se encuentra en tren de discutir de sus intereses en el seno de una asociación de defensa del entorno o en actividad plena y productiva en el seno de su empresa o en el seno de su explotación agrícola;

Los actores que pertenecen a categorías "homogéneas" van a presentar comportamientos y a tener reacciones diferentes a solicitudes o a acontecimientos que les afectan. Todos los "nuevos rurales" procuran no desarrollar los servicios en el campo; una parte de ellos prefiere una naturaleza o pueblos santuarios. Todos los 
habitantes "antiguos" de las campañas no son reacios a la instalación de nuevas actividades, etc. Por estas razones, los conflictos deben ser tratados entre usuarios y no entre usos (Torre, A et al., 2006).

En definitiva, cada conflicto que se deriva del proceso de periurbanizacion contiene en sí mismo una oportunidad para convertir la debilidad en una fortaleza. Los conflictos en su mayor parte, ligados a la novedad y a la innovación, constituyen momentos particulares pero no excepcionales del proceso de gobernanza territorial, que revelan las diferencias de poder y las posiciones en el espacio de los actores, y que aportan el cambio, en particular las reglas y las regulaciones locales.

\subsection{Periurbano en diferentes países}

La globalización actúa en favor de una homogeneización de las dinámicas espaciales en el conjunto del planeta, y debilita la especificidad de los lugares y de la dinámica que los crean. Así, en Europa occidental, la tradicional oposición entre las dos "civilizaciones" urbanas, la anglosajona y la mediterránea o latina, tiende a desaparecer (Banzo, M 2001).

Las tradiciones urbanas y políticas de cada sociedad, al mismo tiempo que las estructuras de poblamiento heredadas o la capacidad de cada sociedad para desarrollar sus propias potencialidades y superar sus retos urbanos van a dar lugar a una evolución diferenciada del espacio periurbano (Abad, L 2013).

Tradicionalmente el modelo de ciudad compacta mediterránea se opone el modelo de ciudad difusa anglosajona. El proceso de integración del campo cercano a la lógica urbana es más antiguo en el sur de Europa que en el norte.

En el mediterráneo tradicional, la ciudad física hasta el final del siglo XIX no se expande mucho más allá de las viejas murallas, mientras que la sociedad urbana 
"civitas" colonizaba el campo circundante en un vasto radio y transformaba su paisaje que seguía siendo rural.

En los países anglosajones el periurbano se ha constituido usualmente como el lugar de residencia elegido por las clases acomodadas, con una configuración condicionada en un modelo ciudad-jardín ${ }^{24}$ (Garay, 2001), con unas determinadas pautas de panificación.

La diferencia norte-sur viene también del desfase cronológico que existe en los procesos de difusión urbana. Mientras los países del norte de Europa estaban experimentando el éxodo urbano, los del sur estaban enfrentando un intenso éxodo rural.

En el siglo XX, cuando las grandes ciudades mediterráneas inician también su expansión incontrolada, mantienen la tipología formal de la vivienda en altura y por consiguiente, la gran densidad de edificios y de población de los viejos centros (Dematteis, 1998).

Hubo que esperar hasta mitad de los años setenta en Francia y hasta los ochenta-noventa en España y Portugal, para que apareciera un movimiento de difusión urbana, diferente del que presentaban hasta entonces los suburbios, que se les calificaba de periurbano.

Así Roux y Varnier (2008), explican como en los países de la Europa Meridional hay una ausencia de definiciones estadísticas o aproximaciones políticas de los espacios periurbanos respecto a los países del norte, que se derivaría de una tradición industrial más tardía, así como el peso del medio rural existente en esos países.

\footnotetext{
${ }^{24}$ El modelo de ciudad-jardín es un modelo urbano de principio de $\mathrm{s}$. XX que propone la síntesis entre la vida en la ciudad y en el campo.
} 
En los países latinos, la ocupación del suelo en las áreas periféricas generalmente se realiza de una manera no planificada, constituyendo un espacio de gran heterogeneidad y crecimiento acelerado donde pueden aparecer problemas sociales y ambientales (Puebla, 2003).

Valenzuela (1986), señala que para el caso español los procesos de dispersión residencial iniciados en torno a las grandes ciudades desde fines de los setenta hasta mediados de los años ochenta, se debieron al desarrollo de segundas residencias, y no al inicio de un proceso estructural ligado a transformaciones sociales y económicas.

Para concluir este apartado podríamos decir que actualmente existe una convergencia en los modelos latinos y anglosajón, ya que este proceso no escapa a la globalización, por no hablar de la desaparición de fronteras, la política comunitaria, como factores que contribuyen a la homogeneización (Beauregard, 2001). 
CAPITULO 5: PROGRAMA DE DESARROLLO RURAL DE CASTILLA LA MANCHA 2007-2013 


\section{CAPITULO 5: PROGRAMA DE DESARROLLO RURAL DE CASTILLA LA MANCHA 2007-2013}

\subsection{Características Generales de Castilla la Mancha}

Antes de analizar el Programa de Desarrollo Rural de Castilla la Mancha vamos a realizar una síntesis de las características más significativas de esta región, que nos servirán para situarnos en el contexto a analizar, y que a veces suponen condicionantes fundamentales para la ejecución de un planteamiento de desarrollo rural consecuente y adaptado a las características que presenta la región. Además intentaremos, comparar sus datos socioeconómicos con los de España, para ver si evolucionan en la misma dirección.

Castilla la Mancha tiene la consideración de unidad territorial de nivel 2, según la nomenclatura de unidades estadísticas (NUTS 2). ${ }^{25}$

\section{- Características Geográfícas}

La Comunidad Autónoma de Castilla la Mancha es una comunidad interior, situada en al submeseta sur de la Península lbérica y que limita con otras siete Comunidades Autónomas, constituyendo un enclave estratégico para las comunicaciones con el sureste y sur de España, las Regiones Centro y Extremadura, a la vez que tiene una gran cercanía a la Comunidad de Madrid.

Fig. 17: Área Geográfica cubierta por el Programa de Desarrollo Rural.

${ }^{25}$ Definición establecida en el reglamento CE 1059/2003, modificado por el reglamento CE 159/2007. 


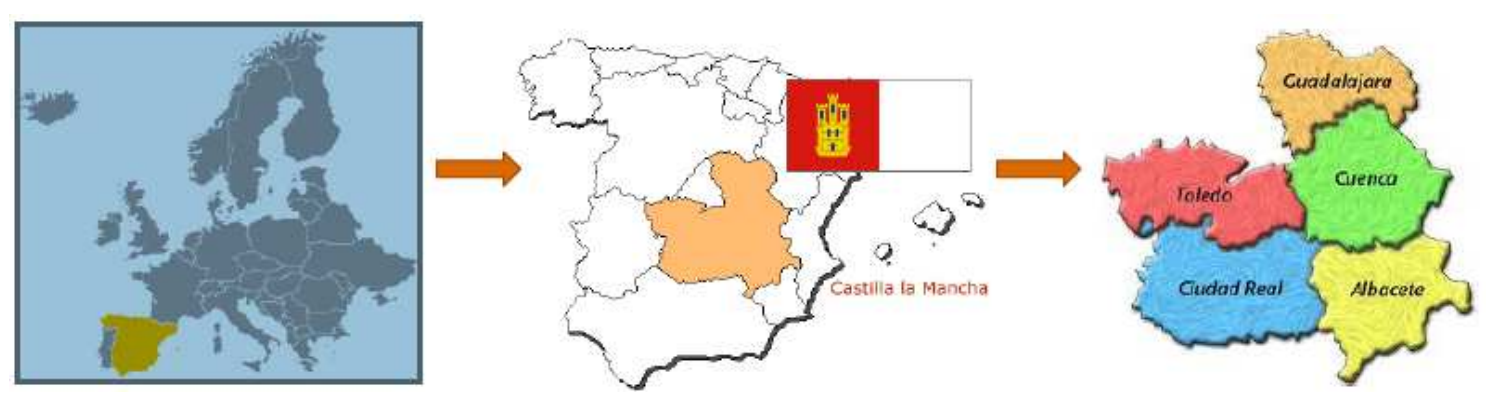

Fuente: PDR Castilla la Mancha 2014-2020

Por su extensión, 79.461 km2, representa el 15,7\% del territorio nacional, lo que la hace ser la tercera región más extensa de España. Engloba a 5 provincias: Albacete, Ciudad Real, Cuenca, Guadalajara y Toledo y 919 municipios, un 11,3\% de los municipios de España.

\section{- Características Climatológicas}

Está asentada en una meseta de elevada altitud media, el $87,44 \%$ de su extensión está a más de 600 m de latitud.

El clima corresponde al prototipo del Mediterráneo Occidental, con degradación continental. En general, la ubicación de la región en el ámbito meridional de la zona templada del Oeste, en el Sur de la Meseta castellana y a Barlovento de los flujos húmedos del Atlántico, implica un régimen térmico bastante moderado, aunque continentalizado por su elevada altitud media (600 m.), su alejamiento de los mares periféricos, unos totales pluviométricos moderadamente bajos (400 mm), con una distribución estacional desequilibrada de las escasas lluvias, y una alternancia térmica, diaria y estacional, bastante contrastada. El mes más cálido es julio, con temperaturas máximas absolutas de hasta $45^{\circ} \mathrm{C}$, que se alcanzan en el Sur de la zona central. Respecto a las temperaturas mínimas absolutas, se suelen alcanzar en 
el mes de enero. Valores inferiores a $-6{ }^{\circ} \mathrm{C}$ pueden aparecer en la zona central de la región desde octubre a marzo.

\section{- Características Orográficas}

Castilla-La Mancha contiene la mayor llanura de la Península Ibérica, se encuentra delimitada por bordes montañosos, elementos que forman parte del sistema central al norte, sistema ibérico al noreste, sierras sub- béticas al sur- este, y Sierra Morena al sur.

Todo el territorio está situado por encima de los $200 \mathrm{~m}$. de altitud sobre el nivel del mar aunque cabe destacar que la mayor parte, el 66,81\% - equivalente a $53.091 \mathrm{~km}^{2}$ - se encuentra entre 600 y 1.000 metros de altitud.

Estas características, han conformado una distribución socio-demográfica propia y característica, que también influye en los aprovechamientos agrícolas y ganaderos de las diferentes unidades de relieve.

\section{- Características Hidrológicas}

La escasez de agua ha sido y continúa siendo una de las características más específicas de las regiones semiáridas, como es el caso de Castilla-La Mancha. La distribución anual de las precipitaciones y sus máximas pluviométricas siguen un esquema propio de climas templados mediterráneos.

De junio a septiembre, se suelen recoger cantidades que oscilan entre el 10 y el 15\% de la precipitación anual en toda la región. La estación lluviosa se centra en la primavera, presentando un máximo secundario en otoño, aunque en los altos 
relieves orográficos de Castilla-La Mancha, donde existe influencia de los temporales atlánticos, el máximo pluviométrico es invernal.

\section{- Características Demográficas}

La población de Castilla la Mancha ${ }^{26}$ es de 2.121.888 habitantes, lo que supone una densidad de población de 26 hab/km2, muy inferior a los 92 hab/km2 del conjunto de España y a los 116,9 de la UE.

El $77 \%$ de esta población se concentra en 3 provincias: Toledo (34\%), Ciudad Real (25\%) y Albacete (19\%).

El peso de la población menor de 15 años en la región 15\% es exactamente igual al del conjunto de España (15\%) y un poco por debajo de la UE(16\%), mientras que el de la población de más de 64 años (17,8\%) es exactamente igual al de la UE y un poco superior al de España (este hecho podría indicar que con una población envejecida el empleo sea menor).

De los 919 municipios que la componen, 743 tienen poblaciones inferiores a 2.000 habitantes,(17,96\% de la población regional). En contrapartida, sólo existen 31 municipios con población superior a los 10.000 habitantes, representado los mismos el $51,37 \%$ de la población regional. El modelo territorial regional, por tanto, se caracteriza por su acentuado componente rural.

${ }^{26}$ INE 2012 
Fig. 18: Densidad de población por municipios Castilla la Mancha.

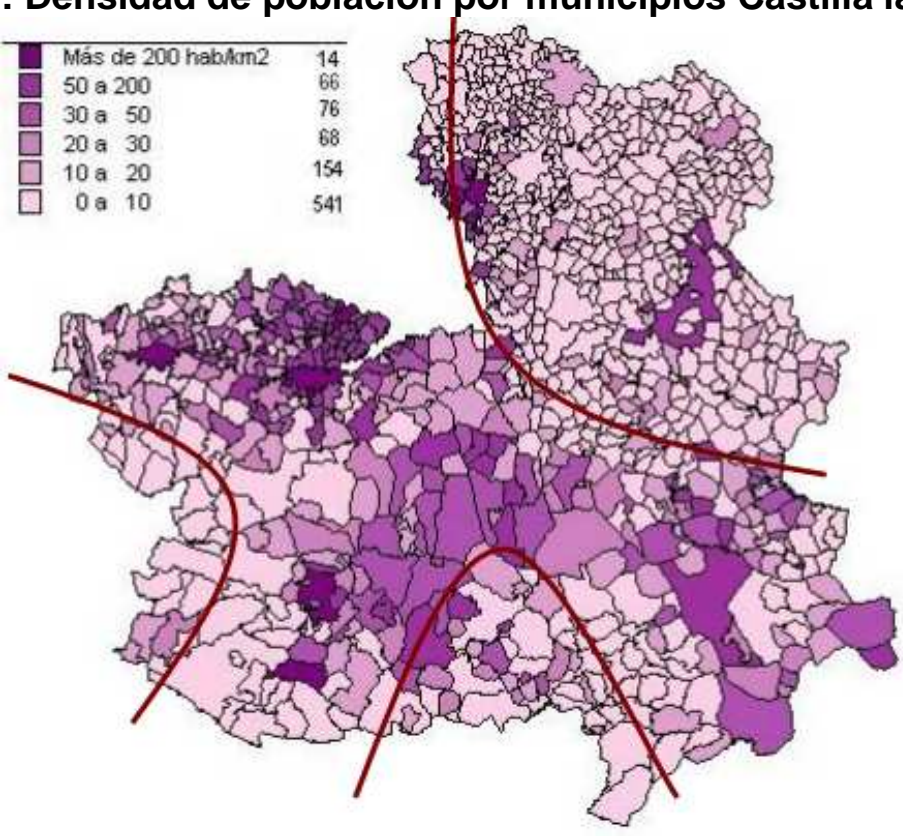

Fuente: PDR 2007-2013 a partir datos INE 2006.

Con carácter general, el éxodo rural en España, explica la baja densidad poblacional, siendo este hecho patente en Castilla la Mancha, con un 0,08\% de éxodo rural frente al 0,04\% nacional.

Como mencionábamos en el capítulo 2, La Ley para el Desarrollo Sostenible del Medio Rural define el medio rural como el espacio geográfico formado por la agregación de municipios o entidades locales menores que posean una población inferior a 30.000 habitantes y una densidad inferior a 100 hab./ km2.

De acuerdo con esta definición, Castilla- La Mancha tiene 910 municipios por debajo de esa cifra, un $99 \%$ de los municipios que conforman la región, por lo que circunscribirnos a este único estrato poblacional significaría ofrecer datos que poco aportan acerca de la realidad de nuestra Comunidad Autónoma.

Es por ello, que se realizó una calificación y delimitación de las zonas rurales, atendiendo a los criterios recogidos en el artículo 10.1 de la Ley para el Desarrollo 
Sostenible del Medio Rural, particularizando los tres tipos de zona que establece en virtud de las particularidades regionales.

El objetivo central perseguido con la zonificación a escala local es detectar características homogéneas que articulen los espacios comarcales en aras a una actuación diferenciada en materia de desarrollo rural, propiciando estrategias que, en función de su diversidad y adecuación, permitan alcanzar un mayor grado de eficiencia en el resultado de las actuaciones públicas articuladas en torno a políticas de desarrollo territorial (PDSMRCLM, 2007)

Se ha procedido a clasificar los núcleos de población excluyendo los de población superior a 30.000 habitantes, considerándolos en su entorno comarcal y analizando la caracterización demográfica más allá de la población total o la densidad de población. Así, elementos tales como la altitud del municipio, la distancia a la capital o la superficie municipal conformarían una primera tipología que podría ofrecer un acercamiento muy aproximado a la realidad que presenta la Región.

Por otra parte, para realizar la clasificación por zonas se ha considerado como ámbito geográfico más apropiado el área de los Grupos de Desarrollo Rural durante el periodo 2000-2006; si bien su superficie no se ajusta en todos los casos a lo que podrían considerarse comarcas naturales, presentan rasgos comunes que les permiten un tratamiento diferenciado y adaptado a la realidad que presentan todos y cada uno de los municipios y núcleos de población que los componen.

La concepción de cada una de las zonas viene determinada por una serie de elementos que, en conjunto, ofrecen un acercamiento a las condiciones zonales con un alto grado de correlación. Por ello los factores que se han tenido en cuenta para valorar la caracterización de cada una de las comarcas regionales han sido los siguientes:

- Población 
- Altitud

- Superficie municipal

- Densidad de población: relación de habitantes por kilometro cuadrado

- Distancia a la capital

- Distribución de la población por estratos de edad, y en concreto los menores de 14 años y mayores de 65 anos.

- Tasa de reemplazo: población de 0 a 14 años en relación con la población superior a 65 anos. Si la tasa es superior a 1, el crecimiento de la población está asegurado.

- Caracterización productiva. Porcentaje de población dedicado a labores del sector primario, secundario y/o terciario.

- La adscripción de cada una de las comarcas a una zona u otra no viene determinada, por tanto, por un único factor, sino que son varios los elementos determinantes que confirman la pertenencia a un ámbito concreto.

En consonancia con la Ley, se crea una tipología en tres zonas bien diferenciadas: zonas rurales a revitalizar, zonas rurales intermedias y zonas rurales periurbanas:

- Las zonas rurales a revitalizar son aquellas con escasa densidad de población, elevada significación de la actividad agraria, y un importante aislamiento geográfico o con dificultades de vertebración territorial (déficit importante de infraestructuras de comunicación).

- $\quad$ Las zonas rurales intermedias son aquellas que presentan una baja o media densidad de población, con un empleo diversificado entre el sector primario, secundario y terciario y distantes del área de influencia directa de los grandes núcleos urbanos. 
- $\quad$ Las zonas rurales periurbanas son las que presentan un ritmo creciente de la población que las conforman, con un predominio claro de empleos del sector terciario y situadas en el entorno de las áreas urbanas o densamente pobladas. 
Tabla 6. Principales características de las 3 tipologías de zonas rurales CM.

\begin{tabular}{|c|c|c|c|c|c|}
\hline \multicolumn{3}{|c|}{ Valores Medios } & $\begin{array}{l}\text { Zonas Rurales a } \\
\text { Revitalizar }\end{array}$ & $\begin{array}{c}\text { Zonas Rurales } \\
\text { Intermedias }\end{array}$ & $\begin{array}{c}\text { Zonas Rurales } \\
\text { Periurbanas }\end{array}$ \\
\hline \multicolumn{3}{|c|}{ Densidad hab/km² (2005) } & 7,32 & 15,02 & 34,49 \\
\hline \multicolumn{3}{|l|}{ Altitud (m) } & 936,19 & 758,50 & 671,63 \\
\hline \multicolumn{3}{|c|}{ Distancia a la capital (km) } & 78,88 & 71,66 & 35,34 \\
\hline \multirow{4}{*}{ Población 2005} & \multicolumn{2}{|c|}{ Total } & 609,92 & 1175,98 & 2025,05 \\
\hline & \multicolumn{2}{|c|}{ Menores de 16 años } & 78,03 & 169,12 & 351,80 \\
\hline & \multicolumn{2}{|c|}{ Mayores de 65 años } & 174,50 & 285,86 & 330,34 \\
\hline & \multicolumn{2}{|c|}{ Tasa de sustitución } & 0,45 & 0,59 & 1,06 \\
\hline \multicolumn{3}{|c|}{ Variación \% Pob. (2001/2005) } & $0,28 \%$ & $3,77 \%$ & $17,70 \%$ \\
\hline \multicolumn{3}{|c|}{ Nivel Económico (de municipios $>1000$ hab) ${ }^{*}$} & 3,23 & 3,60 & 3,67 \\
\hline \multirow{3}{*}{\multicolumn{2}{|c|}{$\begin{array}{l}\text { \% de Ocupados (en el } \\
\text { total de la zona, sep } \\
\text { 06) }\end{array}$}} & Agricultura & $19,43 \%$ & $21,73 \%$ & $7,12 \%$ \\
\hline & & Construcción e Industria & $41,42 \%$ & $40,07 \%$ & $50,23 \%$ \\
\hline & & Servicios & $39,15 \%$ & $38,20 \%$ & $42,65 \%$ \\
\hline
\end{tabular}

Fuente: PDR 2007, con datos INE 2005.

Fig. 19: Tipología de Zonas Rurales en Castilla-la Mancha: Rurales a revitalizar, rurales intermedias, Rurales periurbanas.

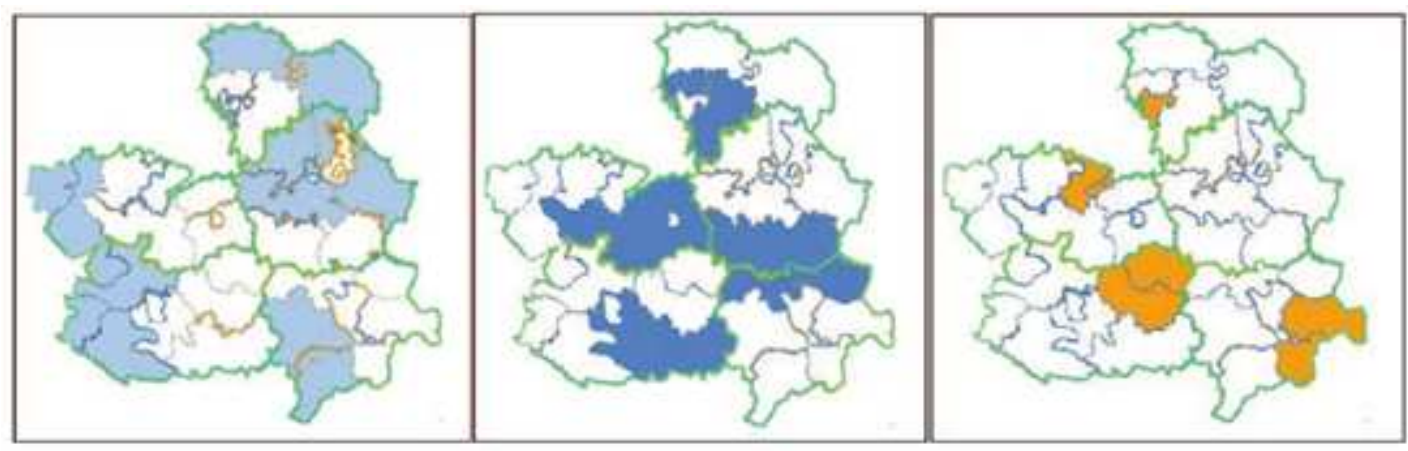

Fuente: Programa de Desarrollo Rural de Castilla-La Mancha, (2007)

Nuestro caso de estudio es la "Comarca de Torrijos", que ya viene definida como una zona periurbana en 2006 junto con la "Comarca de la Sagra". En el capítulo 6, la analizaremos en particular y constataremos ese paso de zona rural agraria a rural periurbana, viendo sus características particulares. 


\section{- Características medioambientales}

Castilla la Mancha cuenta con una gran biodiversidad caracterizada por una elevada variedad de ecosistemas. Además la actividad agraria ha fomentado la creación de extensas llanuras que constituyen otra importante unidad paisajística de la región.

Los ecosistemas agrarios están muy ligados al tipo de cultivo, tipo de explotación y a prácticas agrarias tradicionales, por lo que la desaparición de las mismas supone una amenaza para los ecosistemas.

El 31,8\% de la superficie de la región está catalogada como zona protegida, bien como espacio natural, bien dentro de la Red Natura 2000 (71 Lugares de Interés Comunitario y 38 zonas de especial protección de Aves).

El territorio de Castilla la Mancha está estructurado en 7 cuencas hidrográficas, aunque la mayor parte del territorio está ocupado por las cuencas del Tajo, Guadiana y Júcar. Tiene una elevada presencia de recursos hídricos subterráneos, y más de 90 embalses.

En esta región hay una alta dependencia de las fuentes de energía primaria ${ }^{27 .}$ Entre estas, destacan la eólica y la hidráulica que generan un $14 \%$ del total de la energía eléctrica primaria, muy por debajo de la media nacional situada en torno al $25 \%$.

Para finalizar, y al estar ligado al medio ambiente cabe destacar que la producción agrícola ecológica ocupa un 17\% del número total de hectáreas a nivel nacional, 307.611 ha según el Censo Agrario de 2011, lo que la sitúa como la

\footnotetext{
${ }^{27}$ Según la Comisión Nacional de la Energía se denomina "energía primaria a los recursos naturales disponibles en forma directa (energía hidráulica, biomasa, leña, eólica y solar) o indirecta 8despues de atravesar un proceso) para su uso energético, sin necesidad de someterlos a un proceso de transformación".
} 
segunda Comunidad Autónoma con más superficie destinada a la producción ecológica a nivel nacional (un $7,21 \%$ de la SAU).

Vemos cómo la modernización agraria a través de distintas etapas, bien prima un cultivo, una economía, o un determinado sistema agrario, dando lugar a contradicciones entre lo que se considera modernidad y lo que se considera retraso.

Por ejemplo el sistema agrario de las dehesas, que a principios del s. $\mathrm{XX}$ fueron transformadas para ser cultivadas de cereal siendo consideradas como un sistema obsoleto, en la actualidad y gracias a las políticas agroambientales se transforma en un sistema moderno, como explica en su Tesis Doctoral Ana Velasco (1999).

Es el caso de Castilla la Mancha, a lo largo de los años 70 fue perdiendo importancia en la actualidad vuelve a retomarla, tal como se confirma en el eje 2 del Programa de Desarrollo Rural 2007-2013 de Castilla la Mancha.

\section{- Características económicas}

La evolución de las principales magnitudes económicas indica una evolución hacia la convergencia con respecto a la media de la UE-27, que le ha llevado a superar el 75\% de la renta per cápita europea, (en 2010 alcanzó el 79\%), si bien ésta progresión está siendo más lenta que la de otras regiones españolas.

Según el análisis realizado por EUROSTAT (2012), revela que uno de los factores explicativos más relevantes de los menores niveles de renta per cápita en la región es su débil productividad aparente del trabajo, que se sitúa en torno a 7-8 puntos porcentuales por debajo del nivel medio español tanto si se toman como referencia para su cálculo el número de empleados, como las horas trabajadas. Así, 
mientras que en España la cifra es de 18,7 euros por hora, en Castilla-La Mancha es de $17,2 € /$ hora.

Durante la anualidad 2014 se observa que a nivel mundial y europeo la senda de crecimiento del PIB a precios constantes mantiene un crecimiento moderado mientras que en España se muestran crecimientos mucho más acusados.

El crecimiento del PIB español en el cuarto trimestre de 2014 ha sido mayor que el registrado tanto en la zona euro de forma que la economía española consolidó el proceso de recuperación iniciado a mediados de 2013. En este proceso, resultan especialmente relevantes tanto el dinamismo del consumo privado como la mejora en la inversión en construcción, en un contexto de afianzamiento en la creación de empleo y moderación de los precios.

A nivel autonómico, la tasa de crecimiento interanual del PIB en 2014, vuelve a descender notablemente hasta alcanzar el $-0.6 \%$, acumulando cuatro anualidades consecutivas con valores negativos. Si se tienen en cuenta las ramas de actividad se observa que la actividad agraria es la que mayor descenso registra, alcanzando el 12,4\%. Entre las actividades que registran tasas de variación interanuales positivas se encuentran las del comercio al por mayor y al por menor, las actividades financieras y de seguros, las inmobiliarias, las profesionales, científicas y técnicas; actividades administrativas y servicios auxiliares.

La producción de la región descendió en el período 2008-2012 (-7,73\%), debido sobre todo a la actividad del sector de la construcción, siendo este descenso mayor que el ocurrido en el conjunto de España (-5,37\%).

La tasa de actividad femenina en Castilla-La Mancha es inferior a la de España, así, mientras que el ratio de la tasa de actividad femenina respecto a la masculina es del 58,41\% en la Región, en España asciende al 67,47\%. Esto explica 
la menor tasa de actividad total, que alcanza el 67,7\%, mientras que en España es un $69,7 \%$ y en la UE-25 un 70,1\%, de acuerdo con los datos de Eurostat (2012).

Así en 2013 , la población desempleada se sitúa en un 28,98\%, es decir un $3 \%$ por encima de la nacional. Los sectores en los que se ha creado empleo en la región en 2013 fueron el sector servicios y el sector agrario. Este último se vio favorecido por una campaña agrícola excepcional cuyos efectos duraron hasta el primer trimestre de 2014.

En sentido contrario, la industria y la construcción continuaron destruyendo empleo en 2013 y en el primer trimestre de 2014 en términos de variación anual, aunque en el segundo trimestre parece que el sector industrial cambia de tendencia a la vez que la ocupación en la construcción atenúa su caída.

La desigual evolución de los diferentes sectores y ramas de actividad está produciendo notables cambios en la estructura productiva regional con respecto a la de hace cinco años. Así, desde 2008 se ha incrementado la participación en la producción de los sectores de agricultura y de industria y energía mientras que la construcción y la Administración pública han perdido protagonismo en términos relativos. 


\section{Gráfico 1: Estructura productiva en 2013.}

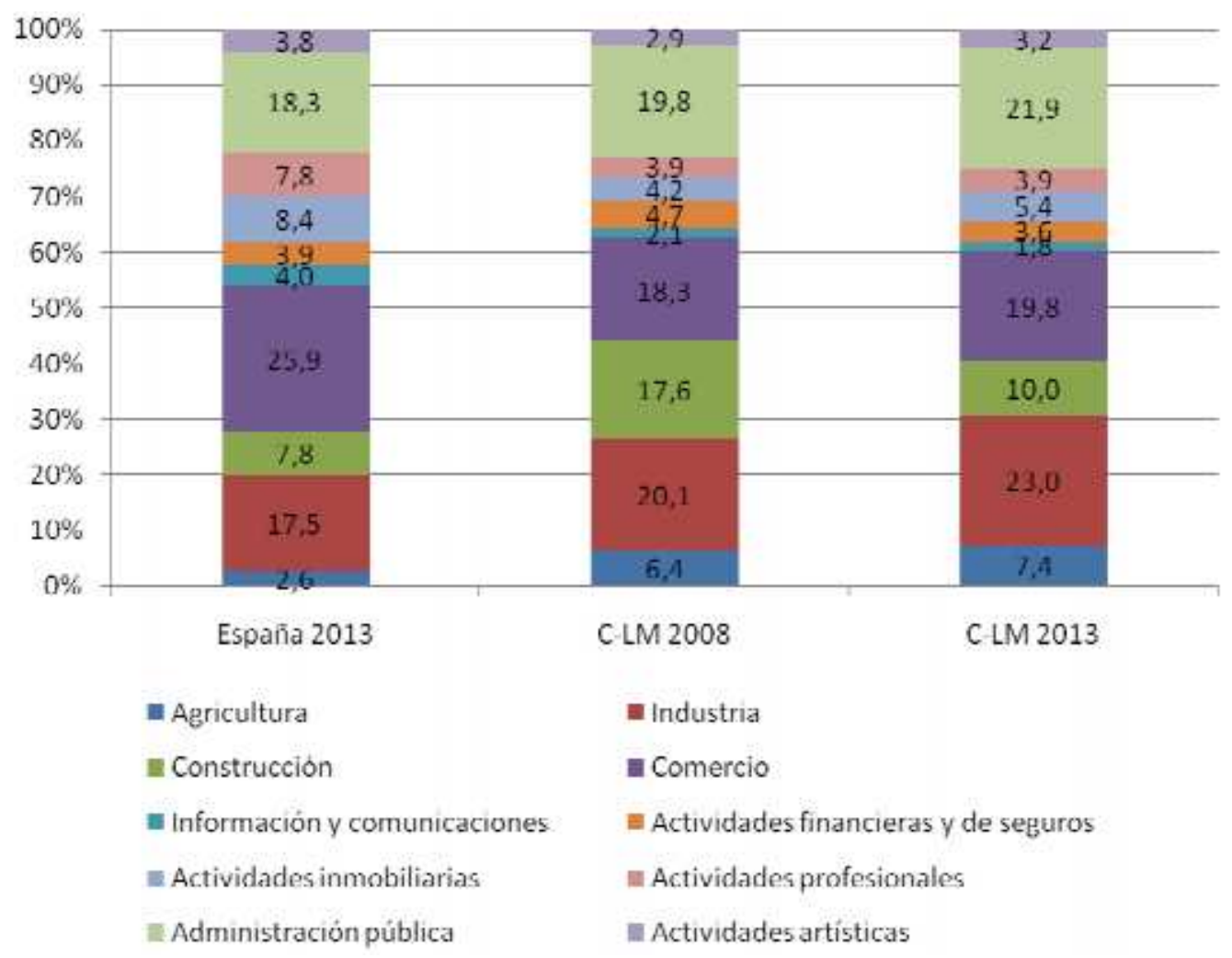

Fuente: JCCM, (2014).

Vemos según este cuadro, que la estructura productiva es la propia de una economía desarrollada, con un mayor peso de los servicios (67\%), seguido de la industria (26\%) y un menor peso del sector primario (7\%), si bien el peso de éstos dos es mayor que en el conjunto de España.

La SAU es de 4.091 .440 ha, con un $88 \%$ en secano, según el Censo agrario de 2009. Si medimos el beneficio agrícola en el año 2010, Castilla la Mancha presenta una cifra menor a la nacional, 16.762€/Unidades de Trabajo Anuales (UTA), frente a los $23.034 € /$ (UTA) de España. La actividad agraria sigue siendo de carácter familiar, suponiendo el $66,86 \%$ de las UTAS registradas.

En la década 1995-2004, la cabaña ganadera castellano-manchega ha experimentado un crecimiento significativo de algo menos de 1 millón de animales. 
Esta tendencia ha estado liderada por el crecimiento en el número de aves y en el número de cabezas de porcino en menor medida. A pesar de esta evolución, el ganado ovino sigue siendo la producción ganadera más importante en la región con efectivos que doblan a la cabaña porcina. 
Tabla 7: Distribución de cabezas de ganado según especie y peso en el total nacional.

\begin{tabular}{|l|c|c|c|c|c|c|}
\hline $\begin{array}{c}\text { TOTAL } \\
\text { ANIMALES }\end{array}$ & 1995 & $\begin{array}{c}\text { \% sobre total } \\
\text { nacional }\end{array}$ & $\mathbf{1 9 9 9}$ & $\begin{array}{c}\text { \% sobre total } \\
\text { nacional }\end{array}$ & $\mathbf{2 0 0 4}$ & $\begin{array}{c}\text { \% sobre total } \\
\text { nacional }\end{array}$ \\
\hline BOVINO & 209.550 & 3,80 & 355.974 & 5,66 & 311.556 & 4,68 \\
\hline OVINO & 3.205 .802 & 15,03 & 3.741 .212 & 15,61 & 3.376 .548 & 14,85 \\
\hline CAPRINO & 406.133 & 15,59 & 356.676 & 13,57 & 397.915 & 14,04 \\
\hline PORCINO & 1.011 .077 & 5,57 & 1.626 .723 & 7,26 & 1.679 .085 & 6,74 \\
\hline AVICOLA & 6.574 & 16,14 & 7.795 & 20,58 & 10.634 & 20,25 \\
\hline TOTAL & 4.839 .136 & & 6.088 .380 & & 5.775 .738 & \\
\hline
\end{tabular}

Fuente: Anuarios M.A.P.A

Destacar la aportación que tiene la actividad cinegética a la estructura productiva de la región, ya que genera 6.500 puestos de trabajo fijos directos (unos 600 Millones de $€$ de facturación) Esta actividad se desarrolla en más del $85 \%$ de la superficie de Castilla la Mancha.

El tejido empresarial lo forman 127.632 empresas, de la cuales 91.575 pertenecen al sector servicios, 22.930 al sector de la construcción y 13.127 al sector de la industria (CNAE, 2011).

De enero a julio de 2014 Castilla-La Mancha ha exportado productos por valor de 2.949,4 millones de euros, con un incremento del 9,7\% interanual, muy superior al 1,6\% registrado en el conjunto del país. Continúa así la tendencia de 2013 donde las exportaciones de Castilla-La Mancha alcanzaron la cifra récord de 5.324,1 millones de euros, lo que supuso un aumento de un $22,18 \%$ respecto al año anterior, es decir, cuatro veces más que en el conjunto del país (ICEX;2014).

El sector agroalimentario de Castilla-La Mancha, en relación al sector industrial participa con el $26 \%$ del empleo y con el $35,5 \%$ de las ventas del producto que alcanzan los 7.537 millones de euros sobre un total de 21.220 millones según datos del último informe sobre Industrias agroalimentarias 2013-2014 publicado por el MAGRAMA. 
Por otro lado, la comunidad autónoma participa, sobre el total nacional, con el $8,24 \%$ de las ventas de la industria alimentaria, el $8,54 \%$ del consumo de materias primas, el $13,62 \%$ en inversiones en activos materiales y el $6,55 \%$ en número de personas ocupadas.

A nivel empresarial, el volumen de empresas dedicadas a la industria alimentaria representa el $1,9 \%$ del total de empresas castellano manchegas y el $8,3 \%$ del total nacional.

Por lo que respecta al volumen de ventas por sectores, este se concentra en las industrias cárnicas con 2.135 millones de euros y el 28,3\% del total de la industria alimentaria, seguido por el sector del vino con 1.416 millones y un $18,8 \%$.

Dada la relevancia del sector agroalimentario, desde la Consejería de Agricultura entre otras actuaciones se creó el Plan de Industrias Agroalimentarias con el objeto de impulsar el tejido agroindustrial de Castilla-La Mancha mediante acciones de desarrollo, innovación, modernización y mejora de tecnologías, productos y procesos

Además en la región este sector está muy impulsado gracias al cooperativismo, ya que buena parte de sus trabajadores participa en alguna entidad asociativa, puesto que después de Andalucía, Castilla La Mancha es la comunidad con el mayor porcentaje de cooperativas agroalimentarias (417). Éstas representan alrededor del $22 \%$ del total de la industria agroalimentaria de la región y un $7 \%$ del total nacional.

Destacar la importancia que el turismo rural significa en la economía de la región, en el año 2012 recibió el 6,36\% de los viajeros de turismo rural d España, situándose ligeramente por encima de la media de todas las regiones españolas $(5,88 \%)$. Además, es la tercera región de España con un mayor número de alojamientos rurales (superada por Castilla y León y Cataluña). 


\subsection{PDR: Castilla la Mancha 2007-2013}

\subsubsection{Antecedentes}

La política de desarrollo rural europea plantea un nuevo período de programación en torno a un nuevo instrumento financiero, el FEADER y en dirección a unas líneas estratégicas que aúnan nuevos elementos cualitativos con la consolidación de los aspectos más exitosos de la experiencia adquirida.

Así, el Consejo de la UE, en Decisión del 16 de Febrero de 2006, ha planteado unas directrices estratégicas para determinar las áreas de intervención más importantes en torno a los objetivos de desarrollo comunitario.

Por su parte, nuestro país, España ha señalado, a través del M.A.P.A. unas líneas básicas y estratégicas para el desarrollo rural en todas las regiones definidas por el Plan Estratégico Nacional y el Marco Nacional de Desarrollo Rural, los cuales inciden en las dimensiones comunitarias que tienen más relaciones específicas con la realidad nacional.

Las directrices estratégicas vienen reflejadas en el gráfico siguiente:

Fig. 20: Resumen de las directrices estratégicas de Desarrollo Rural. 


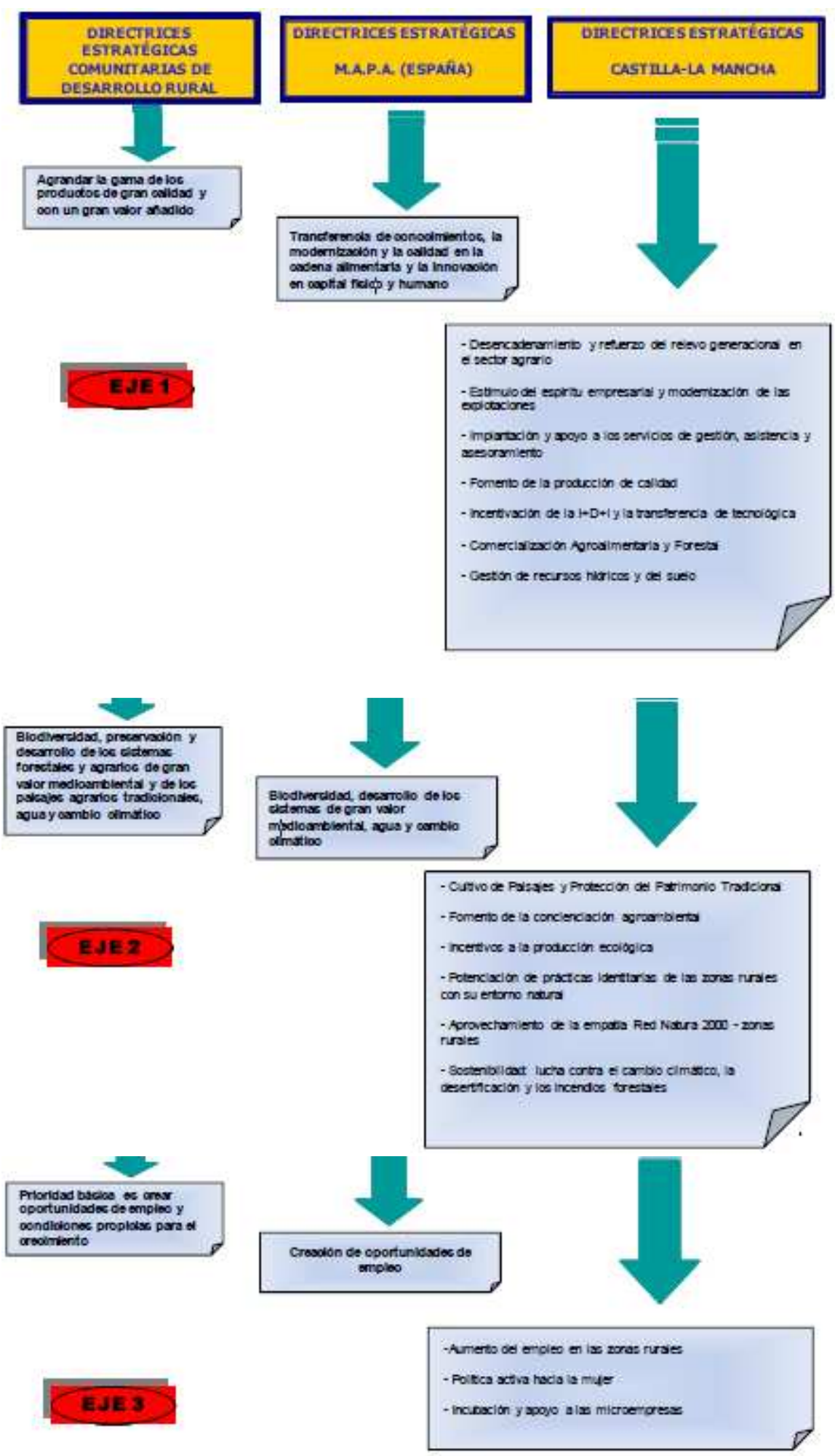




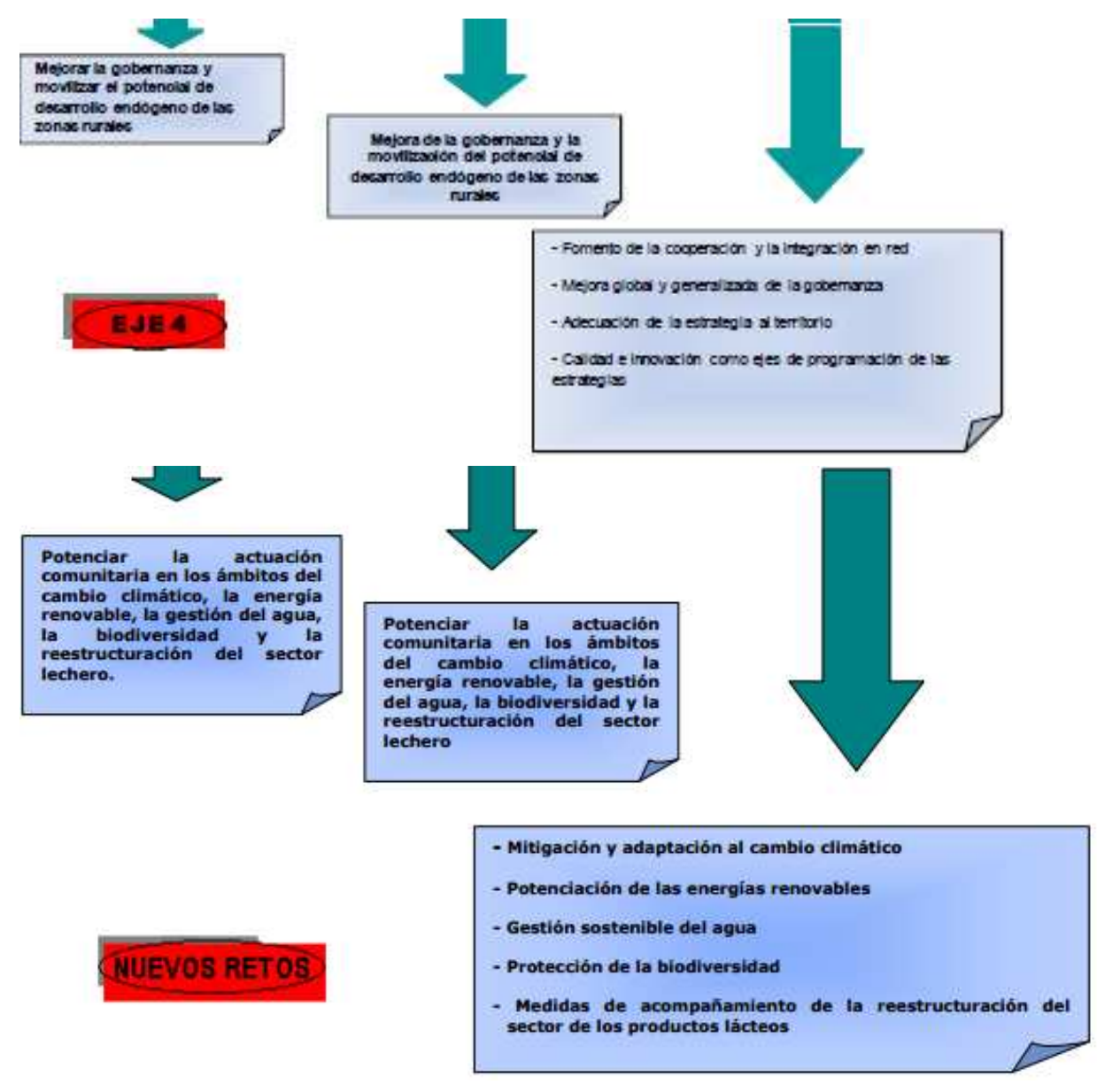

Fuente: PDR 2007-2013

\subsubsection{Descripción del Programa}

El Programa de Desarrollo Rural de Castilla-La Mancha fue presentado a la Comisión Europea el día 18 de octubre de 2007 y aprobado por Decisión de la Comisión Europea C(2008) 3832, de 16 de julio. Es la respuesta al Reglamento 1698/2005 relativo a la ayuda al desarrollo rural a través del FEADER, donde se establece la necesidad de que ésta guarde coherencia con los siguientes elementos de la política europea y nacional: 
En el ámbito europeo:

- En primer lugar, la estrategia de Lisboa y Gotemburgo (mejora de la competitividad, la creación de empleo y la sostenibilidad) constituyen el marco para articular el desarrollo económico, social y medioambiental de los Estados Miembros y sus regiones.

- La Política Agrícola Común (PAC) comparte escenario con las actuaciones del FEADER, constituyéndose como primer y segundo pilar de la política agrícola (reforzar el sector agrícola y forestal, proteger el medio ambiente y el patrimonio rural europeo con medidas agroambientales, aumentar la competitividad del campo)

- Las Directrices Estratégicas Comunitarias de Desarrollo Rural plasman las principales referencias de las políticas europeas en una política de desarrollo rural homogénea para todos los Estados Miembros.

- La Política de Cohesión, a través de sus instrumentos FEDER y FSE, así como el instrumento específico para el desarrollo del sector pesquero, el Fondo Europeo para la Pesca, mantiene sinergias con las actuaciones cofinanciadas por el FEADER.

En el ámbito nacional:

- En relación a la política de cohesión, el Marco Estratégico Nacional de Referencia (MENR) traslada las directrices comunitarias sobre la Política de Cohesión a la realidad nacional, orientando sobre la programación del gasto estructural a través del FEDER y el FSE. 
- El Plan Estratégico Nacional (PEN) de Desarrollo Rural 2007-2013 traduce las Directrices europeas sobre política rural al contexto español y actúa como referente en la elaboración de los PDRs regionales.

- El Marco Nacional de Desarrollo Rural 2007-2013 articula aquellos elementos determinados en el Plan Estratégico que deben ser horizontales y comunes a todos los PDR regionales.

La Región de Castilla la Mancha es un territorio eminentemente rural, como hemos descrito en el apartado anterior. Es por ello, que los aspectos vinculados al desarrollo rural, en su caracterización más amplia, y al desarrollo de determinados sectores económicos, como el agrario y el forestal, mantiene una importancia notable tanto desde el punto de vista social, económico como medioambiental.

\section{- PDR y su vinculación con la estrategia de Lisboa y Gotemburgo}

La Agenda de Lisboa marca el objetivo para la Unión de "Convertirse en la economía basada en el conocimiento más competitiva y dinámica del mundo, capaz de crecer económicamente de manera sostenible con más y mejores empleos y con mayor cohesión social". A su vez la Estrategia de Gotemburgo incorpora el concepto de desarrollo sostenible a este objetivo.

Además, vinculado a ellas, las Directrices Integradas para el Crecimiento y el Empleo 2005-2008 reúnen en un texto único, las recomendaciones de la Comisión sobre las Orientaciones Generales de Política Económica (OGPE) ${ }^{28}$ y las directrices comunitarias en materia de empleo para el periodo 2005-2008, constituyendo el

28 Recomendación 2005/601/CE del Consejo, de 12 de julio de 2005, relativa a las orientaciones generales de las políticas económicas de los Estados miembros y la Comunidad (2005-2008) (Diario Oficial L 205 de 6.8.2005). 
instrumento político principal para el desarrollo y la aplicación de la Estrategia de Lisboa.

Las prioridades seleccionadas en el PDR de Castilla la Mancha contribuyen a alcanzar los objetivos formulados en las estrategias de Lisboa y Gotemburgo relativas a la mejora de la competitividad, la creación de empleo y la sostenibilidad mediante los siguientes elementos:

La mejora de la competitividad del sector agrario y forestal contribuirá de forma decisiva a elevar la competitividad de la UE, así como el apoyo a la industria agroalimentaria y el fomento de la diversificación de actividades económicas en las zonas rurales

El Consejo de Gotemburgo hizo de la sostenibilidad una pieza central del desarrollo europeo. La aportación de las zonas rurales es básica para avanzar por esta senda, dado que ellas atesoran gran parte de la biodiversidad

La diversificación económica de las zonas rurales, mediante la potenciación del desarrollo endógeno, persigue crear nuevos nichos de actividad y empleo que permita a sus habitantes diversificar sus riesgos e incrementar sus oportunidades de desarrollo y empleo.

\section{- PDR y su vinculación con la PAC}

Como recordábamos en el capítulo 3, la renovación de la PAC se ha realizado bajo las siguientes líneas:

- La competitividad debe garantizarse mediante un descenso de los precios que impulse el crecimiento de las salidas interiores y una mayor participación en el mercado mundial. 
- El reparto de tareas entre la Comisión y los Estados miembros debe revisarse en lo relativo a la compensación con ayudas directas y a las medidas de desarrollo rural enmarcadas en una programación global.

- El desarrollo rural debe convertirse en el segundo pilar de la PAC.

Por tanto, una de las principales consecuencias de la reforma de la PAC es la nueva dimensión que adquiere la política rural. Apoyada en:

- Reforzar el sector agrícola y forestal fomentando unos productos agrícolas de calidad, dotando al sector de unos servicios de asesoramiento de calidad y una oferta formativa adecuada.

- Proteger el medio ambiente y el patrimonio rural europeo con medidas agroambientales tales como la agricultura ecológica. Además, para impulsar la integración en la PAC de las exigencias medioambientales, se prevé también ampliar los pagos compensatorios (reservados tradicionalmente a las regiones menos favorecidas) a las zonas donde la agricultura se vea limitada por obstáculos naturales específicos.

- Aumentar la competitividad del campo con el fin primordial de mejorar la calidad de vida de la comunidad rural y de abrir nuevas fuentes de ingresos para los agricultores y sus familias.

El Programa de Desarrollo Rural de Castilla-La Mancha supone, en gran parte, la articulación del segundo pilar de la PAC en la región, por medio de actuaciones que complementen la política de ayuda al mercado y a los ingresos aplicada en el marco de la política agrícola común y la política de cohesión. 


\section{- EI PDR y su vinculación con las Directrices Estratégicas Comunitarias de Desarrollo Rural}

En estas directrices estratégicas, el Consejo determina las prioridades de la UE en el marco del Fondo Europeo Agrícola de Desarrollo Rural (FEADER). Establece el vínculo con los objetivos de Gotemburgo y Lisboa, plasmándolos en la política de desarrollo rural.

Así la política de desarrollo rural definida en estas tres directrices, se centra en tres ámbitos fundamentales: la economía agroalimentaria y silvícola, que abarca el ciclo completo agrícola y forestal, desde la producción hasta la comercialización; el medio ambiente, que se revela crecientemente como un factor económico decisivo en diversificar las economías rurales, además de contribuir a la conservación de la biodiversidad; y la economía y poblaciones rurales en un sentido amplio

Los tres ámbitos descritos con anterioridad se articulan entorno a 4 Ejes:

EJE 1: Aumento de la competitividad del sector agrícola y forestal

EJE 2: Mejora del medio ambiente y entorno rural

EJE 3: Calidad de vida en las zonas rurales y diversificación de la economía rural

EJE 4: el LEADER

EI PDR de Castilla-La Mancha plantea por ello una línea estratégica de programación centrada en aquellos aspectos más relevantes/prioritarios de la región, como son: la necesaria apuesta por la calidad en la producción del sector primario; el sustento de las políticas de inversión en la industria alimentaria como sector estratégico para la comunidad y, principalmente, en su ámbito rural; el desarrollo de 
actuaciones que mejoren los principales ejes que vertebran la mejora del medio ambiente en la región (es decir, el agua, la biodiversidad y la lucha contra el cambio climático) y, finalmente; la apuesta por el desarrollo endógeno como elemento generador de empleo y desarrollo en las áreas rurales (PDR, 2007).

Las Directrices Estratégicas Comunitarias establecían inicialmente seis directrices, las cuatro primeras se identifican con las áreas definidas por los ejes, mientras las dos últimas se refieren al conjunto de la programación.

A través de la Decisión del Consejo del 19 de enero de 2009 (2009/61/CE), las Directrices Estratégicas Comunitarias de desarrollo rural han sido modificadas, incluyendo una quinta directriz que afecta a las cuatro anteriores. La cual establece como nuevas prioridades el cambio climático, las energías renovables, la gestión del agua, la biodiversidad, la reestructuración del sector lechero y la innovación, vinculada esta última a las cuatro anteriores.

A continuación se establece como las prioridades y medidas del PDR contribuyen a estas seis Directrices:

\section{Prioridad 1: Mejora de la competitividad de los sectores agrarios y silvícola.}

EI PDR contiene medidas orientadas a fortalecer el sector agrario y forestal, así como reforzar la importancia de la industria alimentaria para la economía castellano-manchega y, especialmente, sus zonas rurales. En este sentido, las actuaciones del programa se han definido en base a objetivos intermedios como:

- Reforzamiento del apoyo al relevo generacional en el sector agrario, para lo cual se han definido las medidas de "fomento a la instalación de jóvenes agricultores (112) 
- Jubilación anticipada de agricultores y ganaderos agrícolas (113) que tenderán a complementarse con el fin de contribuir, de manera directa, sobre el rejuvenecimiento de las personas vinculadas al trabajo agrario.

- Estímulo del espíritu empresarial y a la modernización de las explotaciones, elementos claves para incidir en una continúa inversión en capital físico (medida 121) y humano (medida 111) que permita dinamizar las estructuras productivas y alcanzar con ello la mejora en la competitividad de las mismas.

- Implantación y apoyo a los servicios de gestión, asistencia y asesoramiento, como fundamento y refuerzo del desarrollo sostenible de la actividad agraria, colaborando en la adopción de nuevas técnicas de producción que, además de contribuir a lograr una agricultura competitiva y económicamente viable, sean más respetuosas con el medio ambiente, la salud pública, la sanidad animal y vegetal y el bienestar de los animales (medidas 114 y 115).

- Fomento de la producción de calidad diferenciada, como elemento integrador de las actuaciones a desarrollar en el ámbito agropecuario. Para ello el programa ha establecido una serie de actuaciones destinadas a fomentar la participación de los agricultores en programas relativos a la calidad de los alimentos (132) y de apoyo a las agrupaciones de productores en actividades de información y promoción en programas de calidad (133).

- Incentivación de la I+D+i y la transferencia tecnológica, como un elemento clave para la mejora de la competitividad de la producción en el sector primario y en la industria alimentaria. Se apoyarán proyectos de investigación que desarrollen las empresas, las inversiones derivadas de la aplicación de nuevas tecnologías, las inversiones para la elaboración de nuevos productos y la aplicación de nuevos proceso y tecnologías, el fomento del uso de nuevas Tecnologías de la Información y Comunicación en las empresas agroalimentarias 
(123). Con un enfoque similar, serán subvencionables los gastos derivados de la incorporación de nuevas tecnologías en las explotaciones como un elemento determinante de la modernización de explotaciones (121).

- Apoyo a la comercialización de la producción agroalimentaria y forestal, por medio de la continua mejora del sector de la industria alimentaria de la región. Este apoyo se destinará al aumento del valor añadido de los productos agrícolas y forestales (123) y, en menor medida, a generar estructuras de cooperación para el desarrollo de nuevos procesos, productos y tecnologías (124).

- Gestión sostenible de los recursos hídricos y el suelo, como un elemento dinamizador de la oportunidades de desarrollo de las zonas rurales por medio del mejor aprovechamiento de los recursos hídricos y de infraestructuras de apoyo. Por ello, el programa ha definido una medida destinada a disponer de infraestructuras relacionadas con la evolución y adaptación de la agricultura y selvicultura (125).

\section{Prioridad 2: Mejora del medio ambiente y del entorno natural}

- Cultivo de paisajes y protección del patrimonio tradicional como elemento de valorización económica de los mismos. En el programa no existe una medida propiamente destinada a tal fin, aunque pueden destacarse las medidas agroambientales (214) como elementos que contribuirán decisivamente a dicho objetivo intermedio.

- Fomento de la concienciación agroambiental. Tampoco existe un conjunto de medidas directamente vinculadas a dicho objetivo, aunque si varias que incidirán de manera positiva sobre dicho objetivo intermedio: la Indemnización 
compensatoria a zonas desfavorecidas (211 y 212) y los pagos agroambientales (214)

- Incentivos a la producción ecológica como un tipo de producción en la que confluyen tanto criterios ambientales como una buena rentabilidad en el mercado de los productos. Para el fomento de dichas actuaciones se han definido una serie de medidas agroambientales (214) que contribuirán a la sustitución de cultivos tradicionales por otros de producción ecológica.

- Potenciación de prácticas identitarias de las zonas rurales con su entorno natural, como un elemento añadido a la actividad agropecuaria que permita favorecer el paisaje, el patrimonio cultural y etnográfico, etc., elementos que suelen tener una incidencia importante sobre la atracción de turismo sobre las distintas zonas rurales. Dichas actuaciones se vincularán en gran medida a las actuaciones a desarrollar dentro de las medidas agroambientales (214) y, en menor medida, de la indemnización compensatoria a zonas con dificultades (211 y 212).

- Aprovechamiento de la empatía Red Natura - zona rural, para lo que se tiene previsto una ayuda a los titulares de explotaciones agropecuarias cuyas explotaciones mantengan restricciones especiales al situarse dentro de una zona de Red Natura 2000, dadas las limitaciones productivas que se generan. En este sentido, el programa ha definido dos medidas destinadas a dicho fin como son algunas actuaciones de las Ayudas Agroambientales (214) y algunas actuaciones vinculadas a ayudas para inversiones no productivas destinadas a zonas Red Natura forestal (227).

- Sostenibilidad: lucha contra el cambio climático, la desertificación y los incendios forestales. En este sentido, el programa ha definido actuaciones vinculadas, en gran medida al desarrollo y mantenimiento de las masas forestales en la región, 
por medio de la forestación de tierras agrícolas (221), las ayudas a la recuperación del potencial forestal 226) y las ayudas para inversiones no productivas con este fin (227).

Prioridad 3: Mejora de la calidad de vida en las zonas rurales y fomento de la diversificación de la economía rural.

El PDR atiende esta prioridad con dos grupos de actuaciones muy relacionadas y un elemento más de carácter transversal.

- El primero refiere directamente a la creación de oportunidades de empleo en las zonas rurales. Dicho objetivo se presenta como un elemento esencial dados los problemas de envejecimiento y despoblación que afectan a una parte de las zonas rurales castellano manchegas. Por ello, el mantenimiento de oportunidades de empleo y la creación de nuevas en sectores diversificados se considera un elemento esencial al que contribuirán todas las medidas del eje 3.

- El segundo ámbito es más particular, y puede considerarse vinculado al anterior, dado que el fomento de las microempresas y el empleo autónomo se ha revelado, en el pasado reciente, como una fuente importante de desarrollo económico y social en las zonas rurales de esta región. En este sentido, cabe destacar el papel que pueden jugar principalmente las actuaciones vinculadas a las medidas de ayudas a la creación y desarrollo de microempresas y el fomento de actividades turísticas como ayudas para el desarrollo de estas empresas en las zonas rurales.

- la mejora de la calidad de vida de las zonas rurales se plantea como un objetivo que debe incluir a todos los residentes en las zonas rurales, e incluso aquellos otros con intenciones de dirigirse a ellas. En este sentido, el programa 
buscará ofrecer un papel preponderante al colectivo de mujeres por medio de actuaciones de fomento del empleo de dicho grupo poblacional, incluso por medio de la priorización de actuaciones sobre el mismo.

\section{Prioridad 4: Desarrollar la capacidad local de creación de empleo y diversificación.}

Los Grupos de Desarrollo Rural (GDR), a través de estrategias integradas, fomentan la diversificación y la mejora de la calidad de vida en el medio rural, eje 3, como base principal de sus actuaciones. Además, actuarán como unidades de gestión de proyectos con un impacto directo en el ámbito local.

\section{Prioridad 5: Nuevos retos.}

EI PDR de Castilla-La Mancha pretende incrementar los esfuerzos con relación a las prioridades de la Comunidad en los ámbitos siguientes:

- Mitigación y adaptación al cambio climático. El mantenimiento de las masas forestales ofrece importantes posibilidades para contrarrestar los efectos desfavorables ligados al cambio climático. En este sentido se pretende por apoyar la formación y utilización de los servicios de asesoramiento para los productores agrícolas sobre el cambio climático mediante la programación de la submedida 114.2 (Utilización de servicios de asesoramiento para la gestión forestal sostenible).

- Potenciación de las energías renovables. La utilización de este tipo de energías ofrece unas perspectivas de desarrollo muy interesantes a la vez que actúa de manera favorable en referencia al cambio climático. Para potenciar la utilización 
de dicho tipo de energías en Castilla-La Mancha, se opta por subvencionar las instalaciones e infraestructuras para la producción de energías renovables a través de las submedidas 125.1 (Infraestructuras de gestión de recursos hídricos) y 125.3 (Optimización y uso eficiente de recursos hídricos).

Por otro lado la medida 123 (Aumento del valor añadido de los productos agrícolas y forestales) de inversiones relacionadas con la transformación de biomasa para la producción de energías renovables, forman parte del plan de actuaciones a desarrollar en este sentido.

- Gestión sostenible del agua. Se plantea desarrollar tecnologías para ahorrar agua mediante planes mejora de explotaciones agrícolas (121.1), inversiones en explotaciones intensivas (121.3), infraestructuras de gestión de recursos hídricos (125.1) y optimización y uso eficiente de los mismos (125.3).

La implementación de instalaciones para el tratamiento de aguas residuales en las granjas y en los procesos de elaboración y comercialización, es otra de las cuestiones a llevar a cabo, mediante la medida 123 (Aumento del valor añadido de los productos agrícolas y forestales). Por otro lado, es importante incentivar el asesoramiento para la optimización de la gestión del agua mediante la submedida 115.2 (Ayudas para la implantación de servicios de asesoramiento para la optimización de la gestión del agua).

- Protección de la biodiversidad. Para lograr esto se puede actuar desde dos ámbitos: Por un lado desde las ayudas agroambientales que fomenten la producción ecológica y la extensificación de las prácticas ganaderas, mediante la creación de una ayuda agroambiental específica para explotaciones de ovinocaprino en extensivo; y por otro lado, a través de la información y divulgación de conocimientos sobre la biodiversidad mediante la creación de la submedida 
(111.2): Información y divulgación de conocimientos sobre fauna y flora silvestre y su aprovechamiento sostenible.

- Medidas de acompañamiento de la reestructuración del sector de los productos lácteos: Con objeto de paliar la situación de crisis que afecta al sector del vacuno de carme se plantea una reestructuración enfocada principalmente a la realización de una serie de medidas de acompañamiento en materia de ayudas a la inversión vinculada a la producción lechera y la mejora de la transformación y comercialización con el sector lechero. Dichas operaciones se llevarán a cabo dentro de los denominados planes de mejora y de la medida (Aumento del valor añadido de los productos agrarios y forestales).

\section{Prioridad 6: Garantizar la coherencia de la programación.}

El presente PDR garantiza la coherencia de la programación en dos niveles: Internamente, el programa, de acuerdo con el análisis de la evaluación previa muestra una gran solidez. Externamente, los respectivos análisis en la evaluación previa ponen de manifiesto la alineación de la programación con los referentes estratégicos comunitarios y nacionales.

\section{Prioridad 7: Complementariedad entre los instrumentos comunitarios.}

La Estrategia de Lisboa definía objetivos comunes a todas las políticas de la UE, para "convertir Europa en la Economía más competitiva del mundo en el año 2010". Por su parte, la programación de los instrumentos financieros para el periodo 2007-2013 tiene un carácter más estratégico, más centrado en objetivos que en medidas, que en gran medida deben responder a contribuir al objetivo fijado por la 
Estrategia de Lisboa. Así, la complementariedad y coherencia adquiere una mayor relevancia para cumplir con las directrices de la UE.

En este sentido, el Reglamento General 1083/2006 de los Fondos Estructurales, el Reglamento 1198/2006 del FEP y el Reglamento 1698/2005 del FEADER coinciden en señalar la necesaria complementariedad entre los diferentes instrumentos financieros y evitar duplicidades en la concesión de ayudas, debiendo articular actuaciones con dicho fin.

\section{- Complementariedad con FEAGA}

EI FEAGA financia, en gestión compartida entre los Estados miembros y la Comisión:

- las restituciones fijadas por exportación de productos agrícolas a terceros países

- las intervenciones destinadas a la regularización de los mercados agrarios.

- los pagos directos a los agricultores establecidos en el ámbito de la política agrícola común

- algunas medidas de información y promoción de los productos agrícolas en el mercado interior de la Comunidad y en los terceros países realizadas por los Estados miembros.

EI FEADER financia la Política de Desarrollo Rural (segundo pilar), que debe acompañar y completar las políticas de ayuda al mercado y a los ingresos (primer pilar) aplicadas en el marco de la PAC.

\section{- Complementariedad con FEDER.}

La Programación del FEDER en Castilla-La Mancha para el periodo 2007-2013 se articula en torno a los siguientes ejes y actuaciones: 
- Desarrollo de la economía del conocimiento.

- Desarrollo e Innovación empresarial

- Medio ambiente, entorno natural, recursos hídricos y prevención de riesgos

- Transporte y energía

- Desarrollo local y urbano

- Inversión en infraestructuras sociales

- Asistencia técnica y refuerzo de la capacidad institucional

- Complementariedad con FSE

Los ejes prioritarios del Programa Operativo del FSE de Castilla-La Mancha son:

Eje 1: Fomento del espíritu empresarial y mejora de la adaptabilidad de trabajadores, empresas y empresarios.

Eje 2: Fomentar la empleabilidad, la inclusión social y la igualdad entre hombres y mujeres.

Eje 3. Aumento y mejora del capital humano.

Eje 4. Promover la cooperación transnacional e interregional.

Eje 5.- Asistencia técnica.

El sector agrario es el principal elemento en el que incide la programación de desarrollo rural en Castilla-La Mancha, enmarcando las diferentes actuaciones dirigidas hacia el mantenimiento de la población y la mejora de la calidad de vida del conjunto del medio rural. En todos los ejes de la programación se tendrá en cuenta la igualdad de oportunidades, considerando con un enfoque transversal, el efecto de las medidas sobre las mujeres. 


\subsubsection{Ejes y Medidas del PDR}

\section{Eje 1: Aumento de la competitividad del sector agrícola y forestal}

- Medida 111: Acciones relativas a la información y la formación profesional

- Medida 112: Instalación de Jóvenes agricultores

- Medida 113: Jubilación anticipada de los agricultores y trabajadores agrícolas

- Medida 114: Utilización de servicios de asesoramiento

- Medida 115: Implantación de servicio de gestión, sustitución y asesoramiento de las explotaciones agrícolas y forestales

- Medida 121: Modernización de las explotaciones agrícolas

- Medida 123: Aumento del valor añadido de los productos agrícolas y forestales

- Medida 124: Cooperación para el desarrollo de nuevos productos, procesos y tecnologías en el sector agrícola y alimentario y en el sector forestal

- Medida 125: Infraestructuras relacionadas con la evolución y adaptación de la agricultura y la silvicultura

- Medida 126: Reconstitución del potencial de producción agrícola dañado por catástrofes naturales e implantación de medidas preventivas adecuadas

- Medida 132: Participación de los agricultores en programas relativos a la calidad de los alimentos

- Medida 133: Apoyo a las agrupaciones de productores en actividades de información y promoción en programas de calidad 


\section{Eje 2: Mejora del Medio Ambiente y del Entorno Rural}

- Medida 211: Ayudas destinadas a indemnizar a los agricultores por las dificultades naturales en las zonas de montaña

- Medida 212: Ayudas destinadas a indemnizar a los agricultores por las dificultades naturales en las zonas distintas a las de montaña

- Medida 214: Ayudas agroambientales

- Medida 221: Primera forestación en tierras agrícolas

- Medida 226: Ayudas a la recuperación del potencial forestal e implantación de medidas preventivas

- Medida 227: Ayudas para inversiones no productivas

Eje 3: Calidad de vida en las zonas rurales y diversificación de la economía rural

- Medida 311: Diversificación hacia actividades no agrícolas

- Medida 312: Ayudas a la creación y el desarrollo de microempresas

- Medida 313: Fomento de Actividades turísticas

- Medida 321: Servicios Básicos para la Economía y la Población rural

- Medida 322: Renovación y desarrollo de poblaciones rurales

- Medida 323: Conservación y mejora del patrimonio rural

- Medida 331: Formación e Información

- Medida 341: Adquisición de capacidades, promoción y aplicación de estrategias de desarrollo local

\section{Eje 4: Aplicación del enfoque LEADER}

- Medida 41 (413): Estrategia de Desarrollo Local

- Medida 421: Cooperación interterritorial y transnacional 
- Medida 431: Funcionamiento del grupo de desarrollo rural, adquisición de capacidades y promoción territorial.

Cabe destacar que algunas medidas del eje 3, se desarrollan mediante el enfoque LEADER a través de la medida 413. En concreto son: $311,312,313,321$, $322,323,331,341$.

Tabla 8: Árbol de objetivos del PDR Castilla la Mancha.

\begin{tabular}{|c|c|c|}
\hline $\begin{array}{l}\text { OBNEIINOS } \\
\text { ESTRATÉEICOS }\end{array}$ & OBUETWOS IKIERUEDWS & MEDIDAS \\
\hline \multirow{14}{*}{$\begin{array}{l}\text { 1. Mejora de ta } \\
\text { competividad de } \\
\text { bs sectores } \\
\text { apraiosy } \\
\text { sitricola }\end{array}$} & \multirow{2}{*}{$\begin{array}{l}\text { 1. A Reforzmiento del apoyo al relevo } \\
\text { generacional en el sector agrario }\end{array}$} & Medida 112 instalación de jóvenes agricultares \\
\hline & & $\begin{array}{l}\text { Medida } 113 \text { suoviación anvicioada de los aqricultores } y \text { trabajaclores } \\
\text { agricolas }\end{array}$ \\
\hline & \multirow{3}{*}{$\begin{array}{l}1.8 \text { Estimulo del espintu empresarial y } \\
\text { la modernizacion de las explotaciones }\end{array}$} & Medida 111 Formación profesional y actividades de intomación \\
\hline & & Medida 121 Modernización de las Explotaciones agrarias \\
\hline & & $\begin{array}{l}\text { Medida } 123 \text { Aumento oer valor ariacido de los productos acricolas y } \\
\text { forestales }\end{array}$ \\
\hline & $\begin{array}{l}\text { 1.C Implantación y apoyo a los servicios } \\
\text { de gestion, asistencia y asesoramiento }\end{array}$ & $\begin{array}{l}\text { Medida } 114 \text { Utilzación de servicios de asesoramiento } \\
\text { Medide } 115 \text { implantación de servicias de gestión, sustiución y } \\
\text { asesoramiento }\end{array}$ \\
\hline & \multirow{3}{*}{$\begin{array}{l}\text { 1.D Fomento de la pooducción de } \\
\text { calisad diterenciada }\end{array}$} & $\begin{array}{l}\text { Medida } 131 \text { Cumaimiento de las nomas establecidas en la nomativa } \\
\text { comunitaria }\end{array}$ \\
\hline & & $\begin{array}{l}\text { Medioa } 192 \text { Participación de los agyicutares en programas relativos a } \\
\text { la caiclas de ias alimentos }\end{array}$ \\
\hline & & $\begin{array}{l}\text { Medioa } 133 \text { Actividades de infomacion de productos en el marto del } \\
\text { programa de calicad de alimentos }\end{array}$ \\
\hline & \multirow[b]{2}{*}{$\begin{array}{l}\text { 1.E incentivación de la I + D + i y la } \\
\text { transferencia tecnológica }\end{array}$} & Medida 121 Modernización oe las Explotaciones agranias \\
\hline & & $\begin{array}{l}\text { Medida } 123 \text { Aumento oel vaior añadiolo de los productos agricolas y } \\
\text { forestales }\end{array}$ \\
\hline & \multirow{2}{*}{$\begin{array}{l}\text { 1. F Comercialización de la producción } \\
\text { agroalimentaria y forestal }\end{array}$} & $\begin{array}{l}\text { Medida } 123 \text { Aumento del valor ariadió de los productos agricolas y } \\
\text { forestales }\end{array}$ \\
\hline & & $\begin{array}{l}\text { Medida } 124 \text { Cooperación para ef desarmolo de nuevos productos, } \\
\text { procesos y temologias }\end{array}$ \\
\hline & $\begin{array}{l}1.6 \text { Gestion sostenible de los recursos } \\
\text { hidricos y suelo }\end{array}$ & Medida 126 intaestructuras para agricutura y siticumura \\
\hline
\end{tabular}




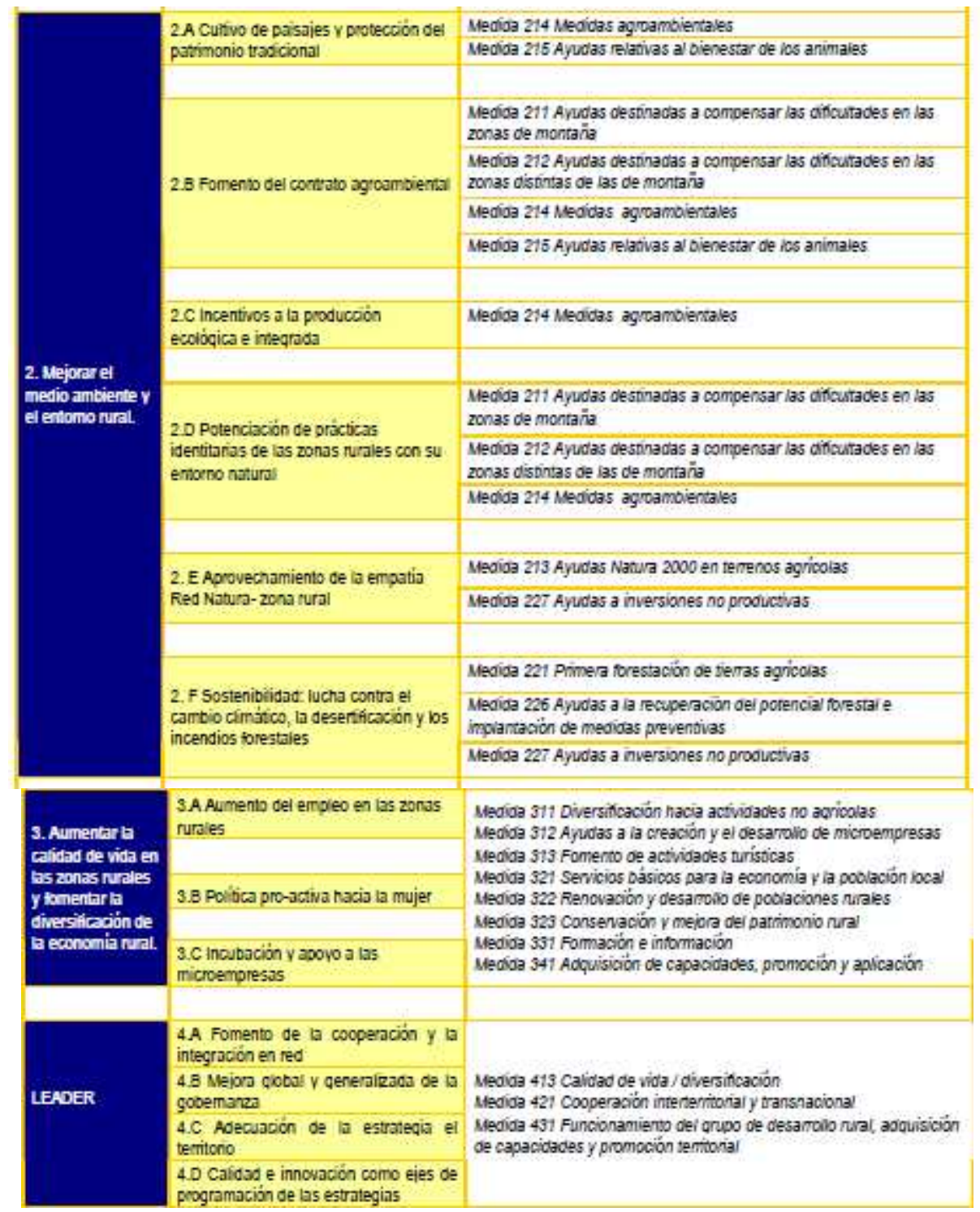

Fuente: PDR 2007

\subsubsection{Cuadro Financiero del Programa}

A continuación se presenta el Gasto Público Total declarado en el año 2014, así como el gasto acumulado desde la puesta en marcha del programa, conforme a lo establecido en el anexo VII del Reglamento (CE) no 1974/2006, de 15 de diciembre de 2006 por el que se establecen disposiciones de aplicación del Reglamento (CE) oㅜ $1698 / 2005$ y sus modificaciones posteriores. 
Tabla 9: Cuadro financiero del PDR a 31de diciembre de 2014.

\begin{tabular}{|c|c|c|c|c|c|c|c|c|c|}
\hline \multirow{2}{*}{$\begin{array}{l}\text { Medida } \\
\text { Eje }\end{array}$} & \multicolumn{2}{|c|}{ Plan financiero del PDR CLM } & \multicolumn{3}{|l|}{ Ejecución 2014} & \multicolumn{4}{|c|}{ Total ejecución 2007-2014 } \\
\hline & Gasto FEADER & $\begin{array}{l}\text { Total Gasto } \\
\text { publico }\end{array}$ & FEADER & TOTAL & \%Ejec. & FEADER & TOTAL & \%Ejec & $\begin{array}{l}\text { GASTOS } \\
\text { transitorios }\end{array}$ \\
\hline 111 & 4.519 .423 & 6.677 .983 & $746.774,03$ & $990.853,09$ & 14,8 & 3.885.455,39 & $5.856 .618,23$ & 87,70 & 0 \\
\hline 112 & 51.005 .000 & 73.485 .382 & $9.028 .879,64$ & $12.038 .506,18$ & 16,4 & $39.085 .981,84$ & $57.883 .501,61$ & 78,77 & $16.694 .593,14$ \\
\hline 113 & 24.960 .000 & 37.758 .418 & 1.815.417,05 & $2.418 .589,06$ & 6,41 & $23.780 .953,12$ & $36.161 .974,66$ & 95,77 & 22.229 .791 \\
\hline 114 & 5.066 .000 & 6.998 .984 & 1.114.431,89 & 1.485.909,18 & 21,2 & $2.609 .645,53$ & 3.705.941,84 & 52,95 & 0 \\
\hline 115 & 1.583 .341 & 1.869 .484 & $125.780,15$ & $153.293,25$ & 8,2 & $464.660,88$ & $571.492,82$ & 30,57 & 0 \\
\hline 121 & 108.272 .365 & 160.957 .821 & $4.457 .598,06$ & 5.887.121,40 & 3,66 & $88.819 .661,69$ & $134.347 .903,43$ & 83,47 & $51.340 .342,18$ \\
\hline 123 & 189.188.081 & 273.142 .689 & $15.968 .074,80$ & $20.610 .090,29$ & 7,55 & $128.260 .799,52$ & 190.524.410,11 & 69,00 & 71.648 .593 \\
\hline 124 & 425.000 & 653.141 & $10.800,00$ & 14.400 & 2 & 10.800 & 14.400 & 2,20 & 0 \\
\hline 125 & 36.737 .892 & 54.765 .116 & $1.585 .781,38$ & 2.114.375,17 & 3,86 & $31.697 .052,01$ & $48.593 .802,88$ & 88,73 & $12.677 .570,00$ \\
\hline 126 & 0 & 0 & 0 & 0 & 0 & 0 & 0 & 0,00 & 0 \\
\hline 132 & 6.006.059 & \begin{tabular}{|l}
8.797 .368 \\
\end{tabular} & 749.693 & 999.590 & 11,36 & 5.698.424 & \begin{tabular}{|l}
8.331 .399 \\
\end{tabular} & 94,70 & 0 \\
\hline 133 & 4.819 .554 & 6.976.719 & 692.098,61 & $922.798,14$ & 13,23 & $3.304 .474,50$ & 4.844.401,50 & 69,44 & \\
\hline T. EJE 1 & 432.582 .715 & 632.083.105 & \begin{tabular}{|l|}
$36.295 .328,37$ \\
\end{tabular} & $47.635 .526,10$ & 7,54 & $327.617 .908,73$ & $490.835 .846,20$ & 77,7 & $174.590 .889,32$ \\
\hline 211 & 19.928.571 & 33.093 .649 & $3.590 .710,24$ & $4.446 .759,55$ & 13,44 & 15.586.739,99 & $25.409 .029,52$ & 97,41 & 257.255 \\
\hline 212 & 62.546 .414 & 97.331.390 & 10.123.239,51 & $12.351 .553,92$ & 12,69 & 48.828.289,99 & $81.361 .338,21$ & 76,58 & \\
\hline 214 & 290.253 .609 & 423.446 .586 & 72.619.857,82 & 89.971.399,94 & 21,25 & 264.994.854,41 & $390.421 .145,87$ & 92,20 & 99.898 .896 \\
\hline 221 & 90.784 .921 & 160.271 .900 & $11.487 .255,49$ & $14.329 .792,55$ & 8,94 & $91.811 .569,48$ & $153.443 .452,48$ & 95,74 & 143.587 .224 \\
\hline 226 & 60.187 .502 & 85.875 .200 & 19.764.336,83 & $24.705 .325,58$ & 28,77 & $34.988 .468,80$ & $49.792 .366,75$ & 57,98 & 0 \\
\hline 227 & 43.588 .325 & 66.007 .527 & $974.936,17$ & $1.212 .757,82$ & 1,84 & $23.890 .535,82$ & $40.050 .269,19$ & 60,68 & $4.641 .722,00$ \\
\hline T. EJE 2 & 567.289 .342 & 866.026 .252 & $118.560 .336,06$ & $147.017 .589,36$ & 16,98 & $480.100 .458,49$ & \begin{tabular}{|l|l}
$740.477 .602,02$ \\
\end{tabular} & 85,50 & $248.385 .097,00$ \\
\hline 313 & 3.153 .874 & 4.205 .166 & 0,00 & 0,00 & 0,00 & 0,00 & 0,00 & 0,00 & \\
\hline 321 & 10.846 .180 & $14.461 .573,00$ & $1.088 .881,84$ & $1.451 .842,45$ & 10,04 & $1.088 .881,84$ & $1.451 .842,45$ & 10,04 & \\
\hline 323 & 4.249 .823 & 5.701.159,00 & 685.644,01 & 914.192,01 & 4,16 & $2.730 .919,74$ & 3.665.230,45 & 64,29 & \\
\hline T. EJE 3 & \begin{tabular}{|l|}
18.249 .877 \\
\end{tabular} & 24.367.898 & $1.774 .525,85$ & $2.366 .034,46$ & 9,71 & $3.819 .801,58$ & 5.117.072,90 & 21,00 & 0 \\
\hline 413 & 97.277 .562 & 123.647 .864 & $18.479 .886,53$ & 23.096.728,97 & 18,68 & 61.358.284,91 & $78.864 .008,32$ & 63,78 & \\
\hline 421 & 2.772 .420 & $3.495 .113,00$ & $116.356,96$ & $145.446,20$ & 4,16 & $192.554,46$ & $240.693,07$ & 6,89 & \\
\hline 431 & 23.110 .058 & $30.061 .614,00$ & $1.999 .349,86$ & $2.499 .187,33$ & 8,31 & $18.156 .857,94$ & $23.865 .838,58$ & 79,39 & \\
\hline T. EJE 4 & 123.160 .040 & 157.204.591 & 20.595.593,35 & 25.741.362,50 & 16,4 & \begin{tabular}{|l}
$79.707 .697,31$ \\
\end{tabular} & $102.970 .539,97$ & 65,5 & 0 \\
\hline 511 & 1.856 .250 & 3.267 .678 & $317.875,27$ & $423.833,69$ & 13 & $1.250 .890,77$ & $2.350 .934,56$ & 72 & \\
\hline T. EJE 5 & 1.856 .250 & 3.267 .678 & $317.875,27$ & $423.833,69$ & 13 & $1.250 .890,77$ & $2.350 .934,56$ & 72 & 0 \\
\hline TOTAL & 1.143.138.224 & 1.682 .949 .524 & $177.543 .658,9$ & 223.184.346,11 & 13,3 & $892.496 .756,88$ & $1.341 .751 .995,65$ & 79,7 & $422.975 .986,32$ \\
\hline
\end{tabular}

Fuente: Elaboración propia partir datos de la Consejería de Agricultura, Medio Ambiente y Desarrollo Rural Castilla la Mancha.

Tabla 10: Ejecución financiera de las operaciones relacionadas con nuevos retos a 31 de diciembre de 2014. 


\begin{tabular}{|l|l|l|}
\hline Medida/Eje & $\begin{array}{l}\text { FEADER } \\
\text { programado }\end{array}$ & $\begin{array}{l}\text { FEADER } \\
\text { acumulado }\end{array}$ \\
\hline 111 & 90.000 & $32.182,76$ \\
\hline 114 & 360.000 & 0 \\
\hline 115 & 1.350 .000 & $303.814,07$ \\
\hline 121 & 10.980 .000 & $2.807 .111,98$ \\
\hline 123 & 5.220 .000 & $2.060 .113,43$ \\
\hline 125 & 4.950 .000 & $238.989,17$ \\
\hline T. EJE 1 & $\mathbf{2 2 . 9 5 0 . 0 0 0}$ & $\mathbf{5 . 4 4 2 . 2 1 1 , 4 1}$ \\
\hline 214 & 47.402 .874 & $43.102 .293,20$ \\
\hline T. EJE 2 & $\mathbf{4 7 . 4 0 2 . 8 7 4}$ & $\mathbf{4 3 . 1 0 2 . 2 9 3}$ \\
\hline TOTAL & $\mathbf{7 0 . 3 5 2 . 8 7 4}$ & $\mathbf{4 8 . 5 4 4 . 5 0 4 , 6 1}$ \\
\hline
\end{tabular}

Fuente: Elaboración propia a partir datos la Consejería de Agricultura, Medio Ambiente y Desarrollo Rural Castilla la Mancha.

Además, tendremos que dar cumplimiento a regla $n+2^{29}$. En caso de liberación automática, el importe correspondiente a la liberación se deducirá, para el año en cuestión, de la participación del FEADER en el Programa de Desarrollo Rural. El Estado miembro elaborará un plan de financiación revisado con el fin de distribuir el importe de la reducción de la ayuda entre los ejes del programa. De no hacerlo así, la Comisión reducirá proporcionalmente los importes asignados a cada eje prioritario.

En este sentido, aquellos créditos del ejercicio 2012 que no se hayan utilizado a 31 de diciembre de 2014 deberán ser liberados automáticamente. El gasto FEADER comprometido en 2012 asciende a un total de 185.064.799 euros.

${ }^{29}$ El Reglamento (CE) № 1290/2005 sobre la financiación de la política agrícola común establece en su artículo 29, "la Comisión liberará automáticamente la parte del compromiso presupuestario de un programa de desarrollo rural que no se haya utilizado para el pago de la prefinanciación o para pagos intermedios o por la cual no se le haya presentado, a más tardar el 31 de diciembre del segundo año siguiente al del compromiso presupuestario, ninguna declaración de gastos que reúna las condiciones establecidas en el artículo 26, apartado 3, en concepto de gastos realizados". 
Como puede verse en la Tabla adjunta, el programa de desarrollo rural de Castilla-La Mancha cumple con la regla $n+2$ puesto que los gastos declarados hasta el 31 de diciembre de 2014 superan los compromisos de gasto establecidos en 2012.

Tabla 11: Análisis del cumplimiento de la regla $\mathbf{n}+2$.

\begin{tabular}{|c|c|c|c|c|c|c|}
\hline AN̂́o & $\begin{array}{l}\text { GASTO FEADER } \\
\text { PROGRAMADO } \\
\text { ACUMULADO }\end{array}$ & ANTICIPO & $\begin{array}{c}\text { GASTO } \\
\text { FEADER } \\
\text { DECLARADO }\end{array}$ & $\begin{array}{l}\text { GASTO FEADER } \\
\text { DECLARADO } \\
\text { ACUMULADO }\end{array}$ & $\begin{array}{c}\text { ANTICIPO } \\
\text { +GASTO } \\
\text { DECLARADO } \\
\text { ACUMULADO }\end{array}$ & $\begin{array}{l}\text { GASTO MLYMMO } \\
\text { A DECLARAR } \\
\text { (REGLA N+2) }\end{array}$ \\
\hline 2007 & 0,00 & 0,00 & 0,00 & 0,00 & 0,00 & \\
\hline 2008 & $176.219 .219,00$ & $64.711 .767,32$ & $86.423 .742,75$ & $86.423 .742,75$ & $151.205 .510,07$ & \\
\hline 2009 & $366.596 .813,00$ & 0,00 & 98.258.151,28 & 185.451 .894 .73 & $250.163 .862,05$ & \\
\hline 2010 & $578.184 .197,00$ & 0,00 & $131.388 .022,53$ & $316.849 .917,26$ & $381.561 .684,58$ & $176.219 .219,00$ \\
\hline 2011 & $763.248 .996,00$ & 0,00 & $127.731 .944,88$ & $444.581 .862,24$ & $509.283 .629,56$ & $366.586 .813,00$ \\
\hline 2012 & $851.487 .358,00$ & 0,00 & $83.244 .549,45$ & $527.826 .411,69$ & $592.538 .179,01$ & $578.184 .197,00$ \\
\hline 2013 & $1.143 .138 .224,00$ & 0,00 & $187.127 .046,37$ & $714.853 .070,94$ & $779.684 .838,26$ & $763.248 .996,00$ \\
\hline 2014 & 0,00 & 0,00 & $177.543 .658,86$ & $892.496 .729,80$ & $957.208 .497,12$ & $851.487 .358,00$ \\
\hline 2015 & 0,00 & 0,00 & 0,00 & 0,00 & 0,00 & $1.143 .138 .224,00$ \\
\hline
\end{tabular}

Fuente: Informe facilitado por la Consejería de Agricultura, Medio Ambiente y Desarrollo Rural.

\subsubsection{Ejecución del PDR}

El grado de ejecución del PDR a 31 de diciembre de 2014 es del 79,73\% sobre el total de gasto público programado y del $78,07 \%$ si se considera la ejecución del gasto FEADER.

\section{Gráfico 2: Evolución por trimestres y años del Gasto FEADER.1}

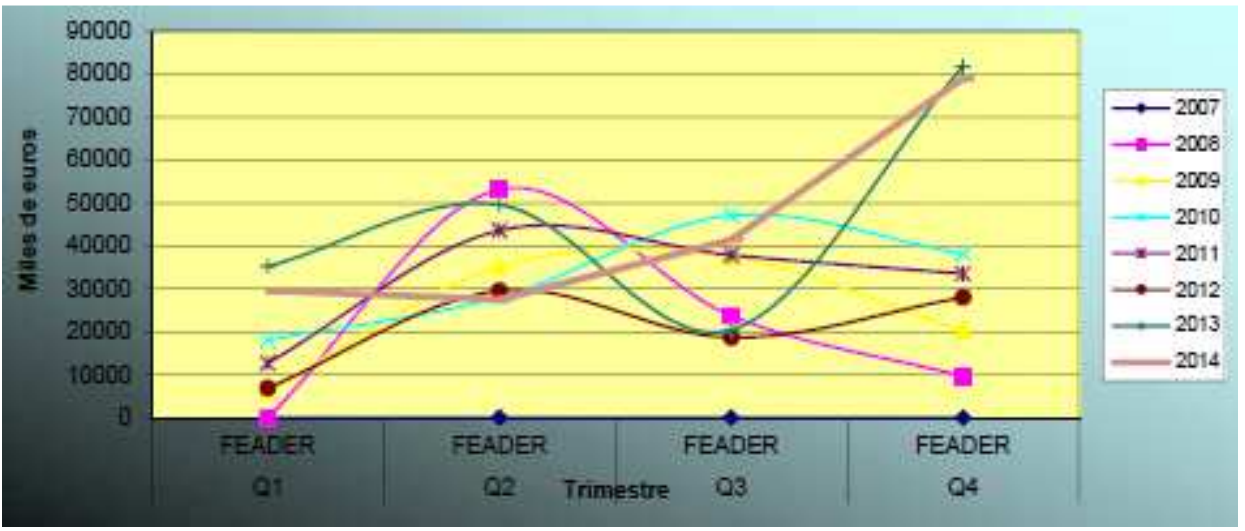

Fuente: Informe Intermedio Anual JCCM, 2014. 
Ahora trataremos de analizar cuál ha sido el comportamiento del PDR según los ejes que contiene:

\section{Gráfico 3: Distribución del gasto público ejecutado para todo el PDR en valores acumulados 2007-2014.}

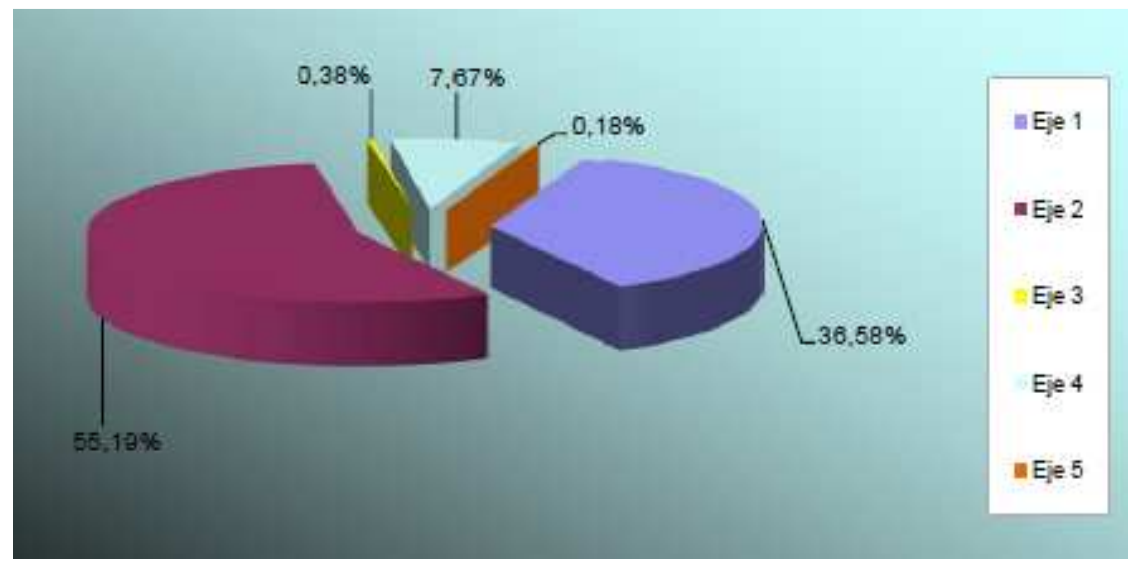

Fuente: Informe Intermedio Anual JCCM, 2014.

La ejecución financiera por ejes, incluyendo tanto las operaciones convencionales como aquellas derivadas de la consideración de nuevos retos, destaca la ejecución del eje 2, relativo a la conservación y mejora del medio ambiente, con un 55,19\% del gasto, seguido por el eje 1 , relativo a medidas cuyo objetivo es el aumento de la competitividad del sector agrícola y forestal, con un $36,58 \%$. A continuación a gran distancia se encuentra el eje 4, que representa el 7,67\%, respecto al gasto público total acumulado. Finalmente, el gasto realizado en el eje 3 supone el $0,38 \%$ del total acumulado y la asistencia técnica el 0,18\%. 


\section{Grafico 4: Grado de ejecución del gasto público, valores acumulados} 2007-2014.

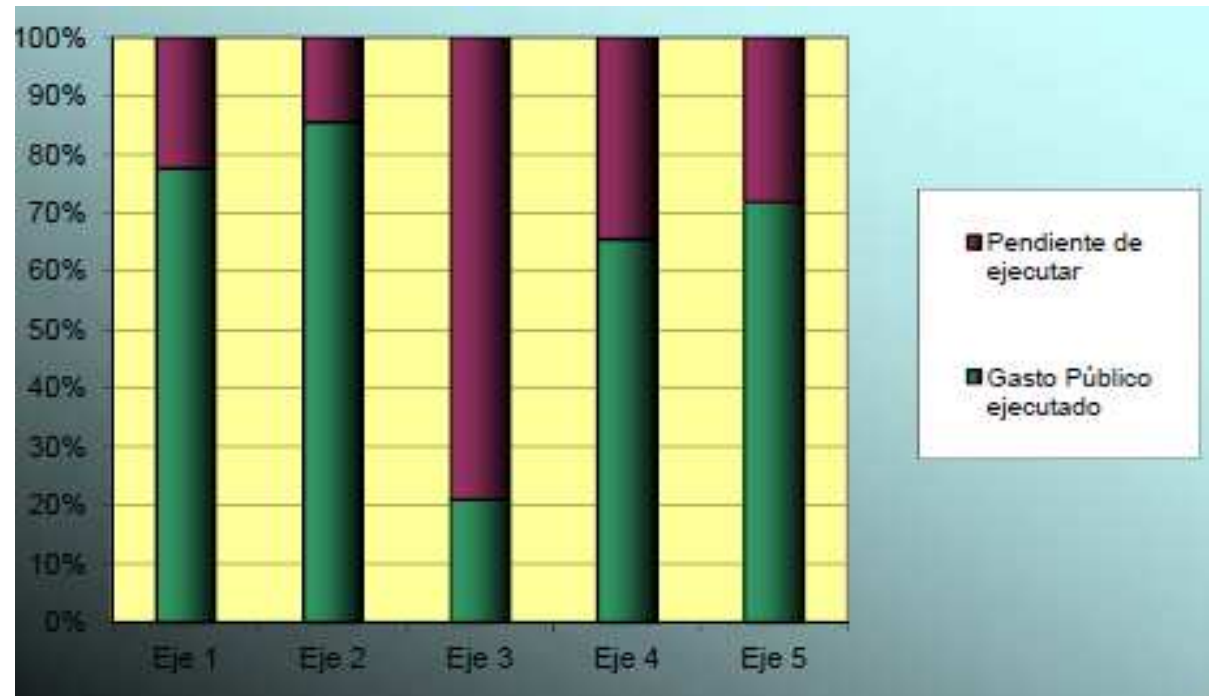

Fuente: Informe Intermedio Anual JCCM, 2014.

De la observación del gráfico se desprende que la mayor ejecución la presenta el eje 2 con el 85,50\%,seguido muy de cerca por el eje 1, con un $77,65 \%$ y el eje 5 , con el 71,95\% del total previsto. A continuación se encuentra el eje 4 , con el $65,50 \%$ del total programado y, en último lugar, con el menor valor, el eje 3 , con una ejecución del $21 \%$ del total previsto.

Una vez visto la distribución de gasto por ejes, vamos a ver la distribución de cada eje en sus correspondientes medidas. 


\section{Gráfico 5: Distribución del gasto del eje 1 por medidas.}

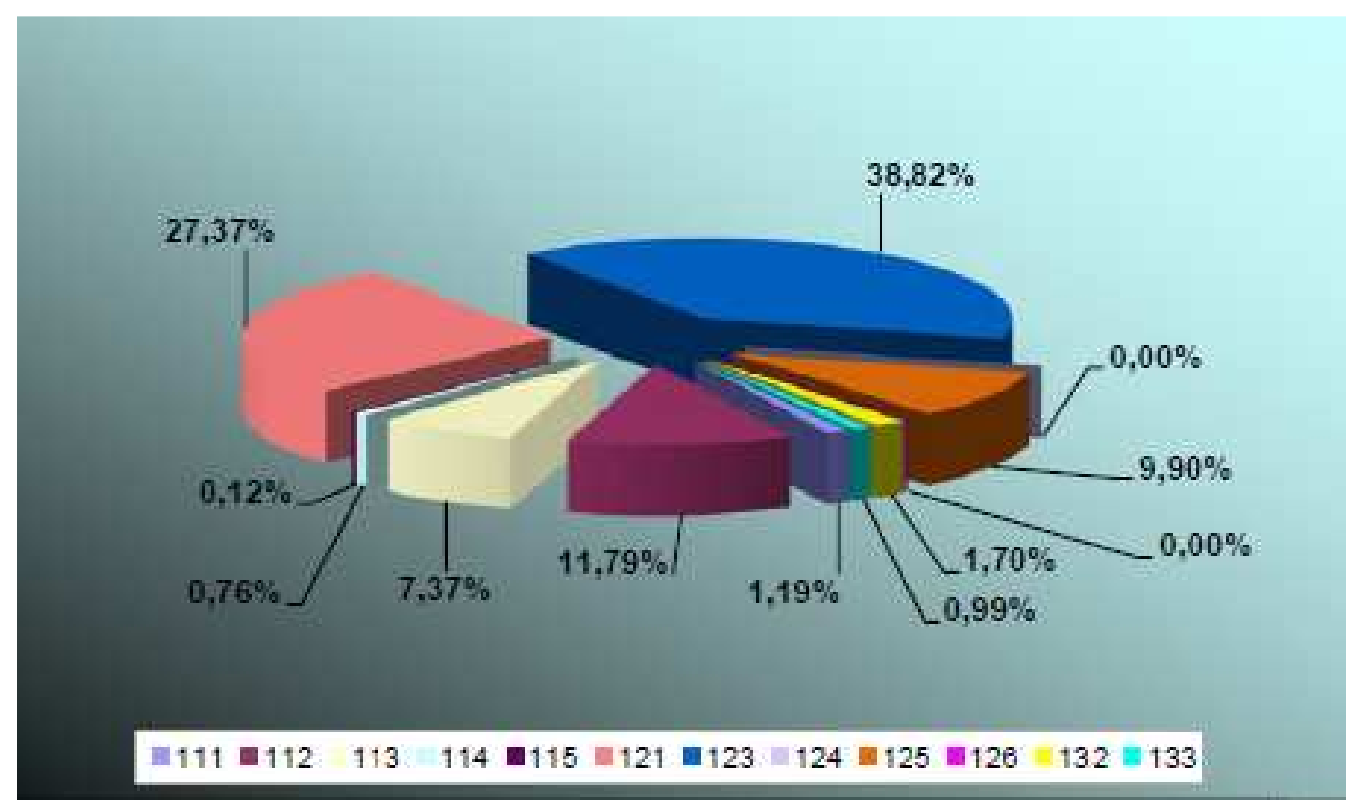

Fuente: Informe Intermedio Anual JCCM, 2014.

Se observa que las medidas 123 y 121 son las que más fondos han recibido a lo largo de este período.

\section{Gráfico 6: Distribución del gasto del Eje 2 por medidas.}

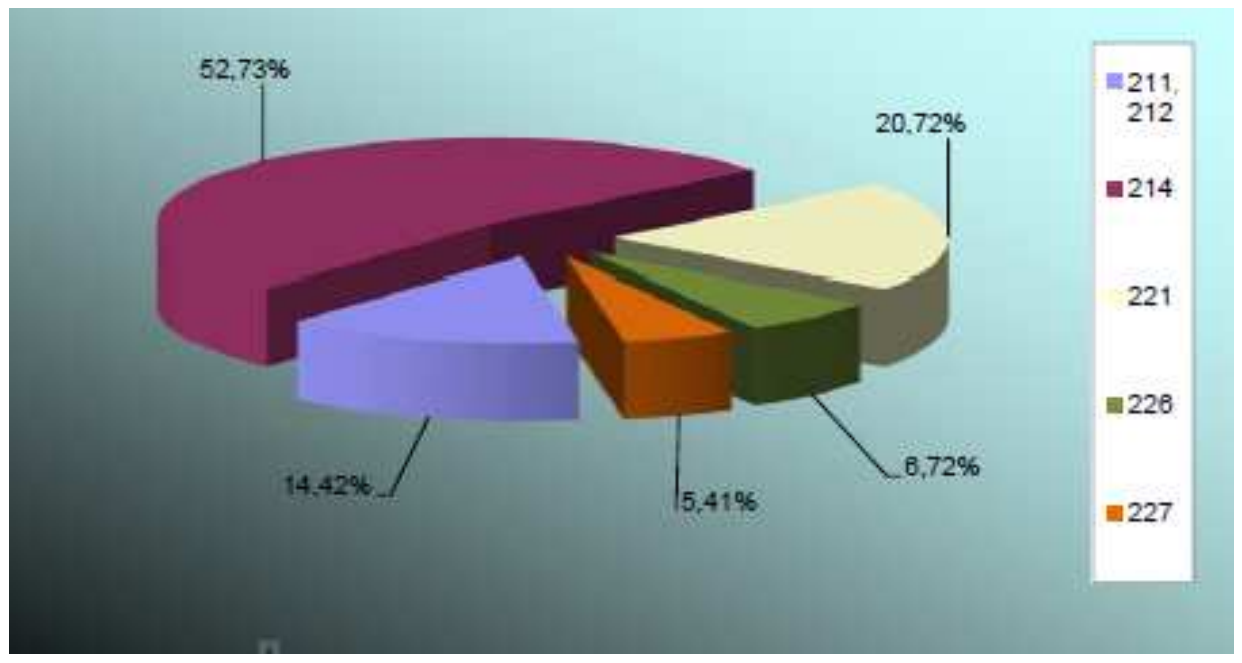

Fuente: Informe Intermedio Anual JCCM, 2014. 
En relación al Eje 2, la medida 214 es la que más recursos económicos ha distribuido en ayudas, seguida de las medidas 221 y las medidas relativas a la indemnización compensatoria, medidas 211 y 212.

Con respecto al Eje 3, en 2014 se han efectuado los primeros pagos en la medida 321, aunque el mayor gasto ejecutado sigue correspondiendo a la 323 , que acumula el 71,63 del gasto total efectuado en el eje.

\section{Gráfico 7: Distribución del gasto del Eje 4 por medidas.}

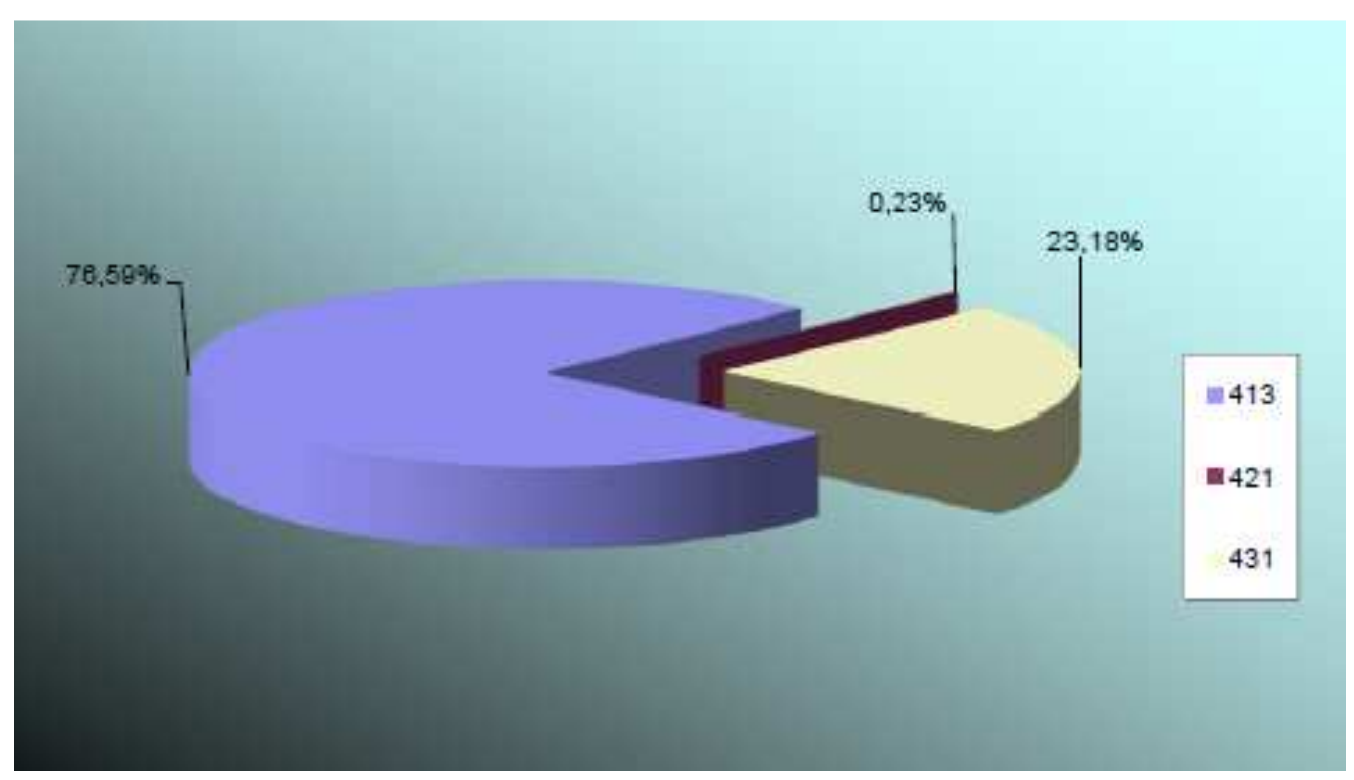

Fuente: Informe Intermedio Anual JCCM, 2014.

El presupuesto ejecutado en relación a las medidas del eje 4 corresponde, sobre todo, a la medida 413, con un 76,59\%, como vemos en el gráfico ํㅜ․

Analizando la ejecución de las operaciones consideradas como nuevos retos por medidas es preciso indicar que la medida 214 es la que presenta la mayor ejecución acumulada, con un 90,93\% del total previsto para el período de programación. Hay que tener presente que en la programación de esta medida se ha destinado el $88,79 \%$ del total de fondos disponibles para los nuevos retos. Tras ella, 
se encuentra la medida 123 , con un $39,47 \%$ de ejecución respecto al objetivo previsto para todo el período, aunque esta medida tan sólo aglutina el $4,24 \%$ del total previsto para nuevos retos. La medida 111 ha experimentado un incremento notable de ejecución en esta anualidad, aunque no llega a superar el $36 \%$ del total previsto en el periodo de programación. En las medidas 115 y 121, la última anualidad ha llevado su ejecución a un 22,50\% y 25,57\%, respectivamente. Por último, la medida 125 es la que menor ejecución presenta, con un 4,83\% de los objetivos previstos, no habiéndose efectuado pagos en 2014.

Gráfico 8: Porcentaje de ejecución de Nuevos Retos 2007-2014.

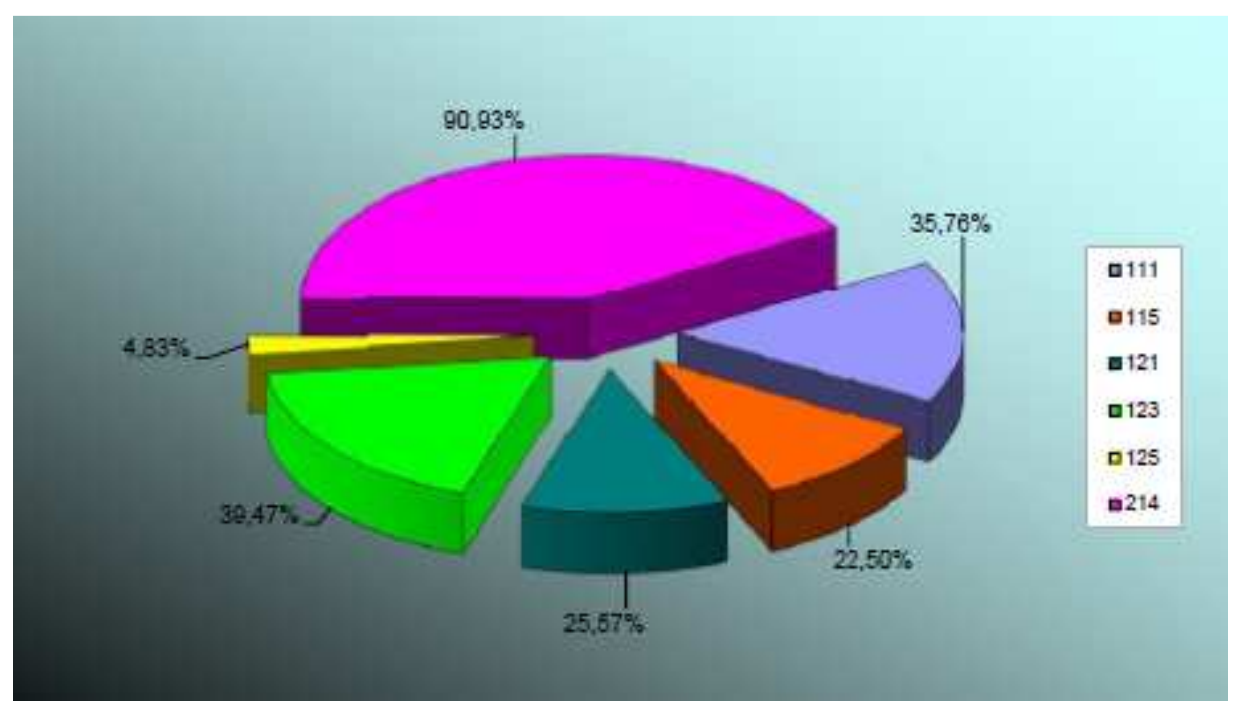

Fuente: Informe Intermedio Anual JCCM 2014.

Vista la situación global del PDR por ejes, vamos a intentar analizar las medidas independientemente: 


\section{- Medida 111: Acciones relativas a la información y formación profesional.}

Las actuaciones de formación e información incluidas han sido programadas a través de dos grupos de actividades o enfoques diferenciados, coincidentes con las dos submedidas programadas, financiando acciones de formación dirigidas a los profesionales del sector agroalimentario y del mundo rural (submedida 111.1) y acciones de información y divulgación de conocimientos sobre fauna y flora silvestre y su aprovechamiento sostenible (submedida 111.2).

Por otra parte, durante la anualidad 2014 se ha ejecutado un $17 \%$ del gasto público acumulado para toda la medida, que asciende a 5.856.618 euros, de los que 3.885.456 euros corresponden a FEADER, de forma que se ha alcanzado un elevado grado de cumplimiento del objetivo programado al ascender al 87,7\% del mismo, gracias por un lado a la destacada ejecución del gasto durante la anualidad 2014 y por otro a la reducción del gasto programado para la medida en la versión 7aㅗ (vigente) del Programa de Desarrollo Rural, de Noviembre de 2014.

En el gráfico siguiente, se muestra la evolución de la ejecución financiera para toda la medida desde su puesta en marcha en 2008 hasta el 31 de diciembre de 2014. Se aprecia la tendencia creciente del gasto, con un menor ritmo de crecimiento a partir del año 2010, más limitado aún durante 2013 debido a un cambio en el procedimiento de pagos y a la publicación de la nueva convocatoria, pero una vez superada esa desaceleración, durante la última anualidad se ha incrementado el gasto hasta encontrarse muy próximo al objetivo programado. 
Gráfico 9: Evolución del gasto público total acumulado 20072014.Medida 111.

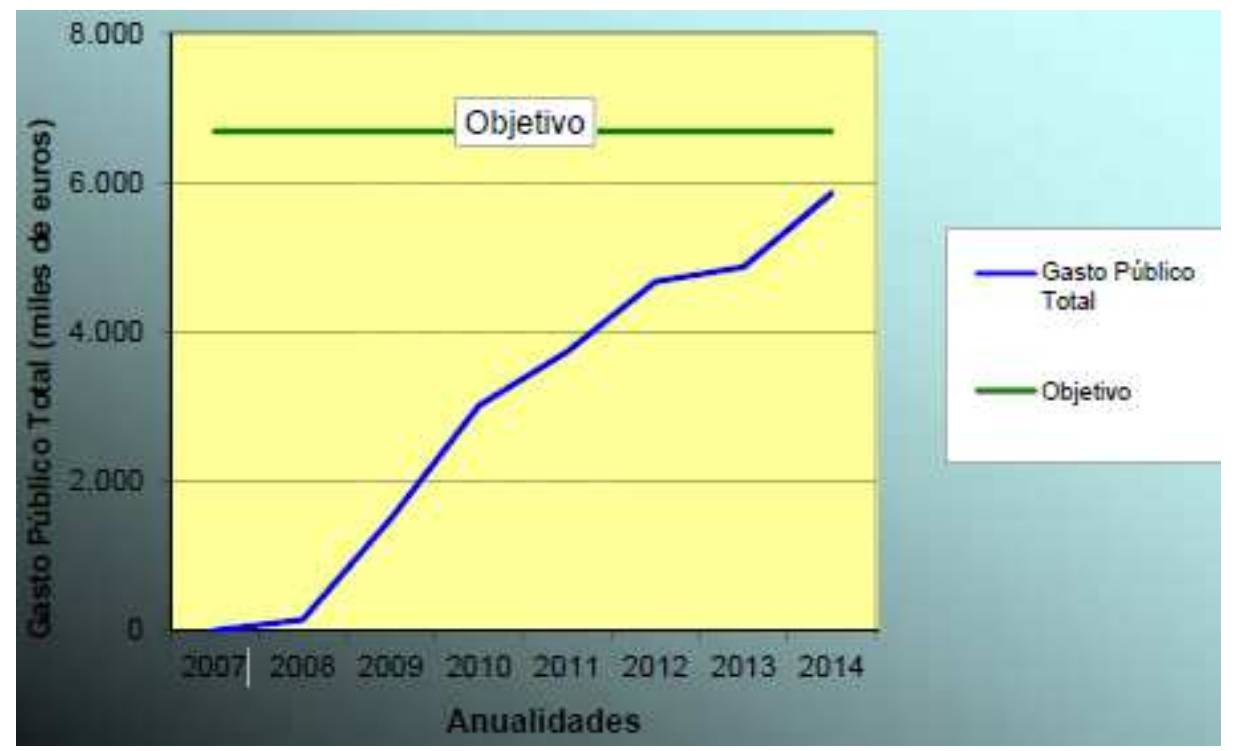

Fuente: Informe Intermedio Anual JCCM 2014.

\section{- Medida 112: Instalación jóvenes agricultores}

Se han beneficiado de esta medida 1189 jóvenes, de los que $79,23 \%$ son hombres mientras que el $20,77 \%$ son mujeres. 


\section{Gráfico 10: Evolución del número de jóvenes agricultores beneficiarios} 2007-2014.

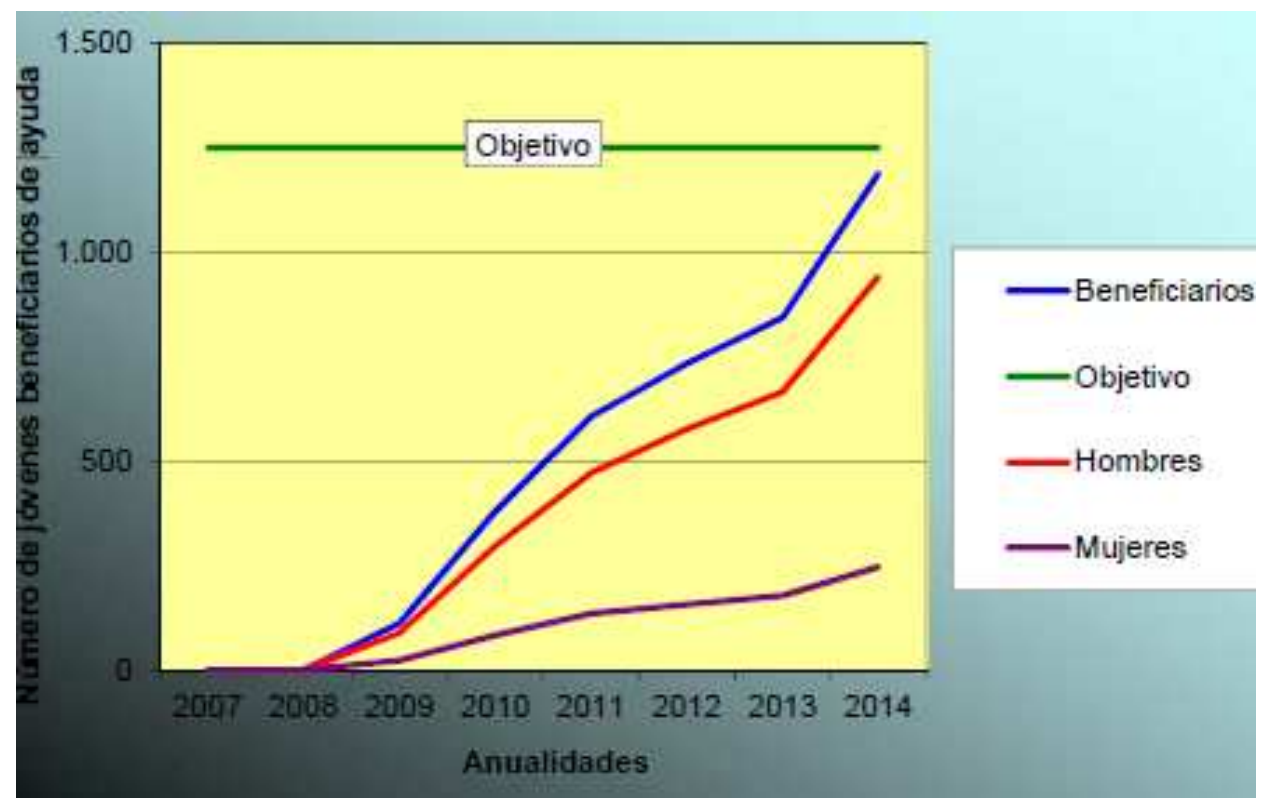

Fuente: Informe Intermedio Anual JCCM 2014.

Como puede apreciarse en el gráfico, a pesar de ciertas dificultades que encuentran las mujeres en su incorporación a la actividad agraria, su número continúa creciendo año a año. En cuanto al total de beneficiarios de ambos sexos, se está muy próximo al objetivo, incluso a falta de la anualidad 2015, gracias a la buena ejecución de 2014 y a la reducción efectuada en dicho objetivo en la última versión del PDR. Desde el servicio gestor se ha estimado la ejecución para la siguiente anualidad de 2015, en un total de 1.059 solicitudes aprobadas y 1.095 jóvenes agricultores beneficiarios de ayuda. 
Gráfico 11: Evolución del volumen de la inversión. 2007-2014.

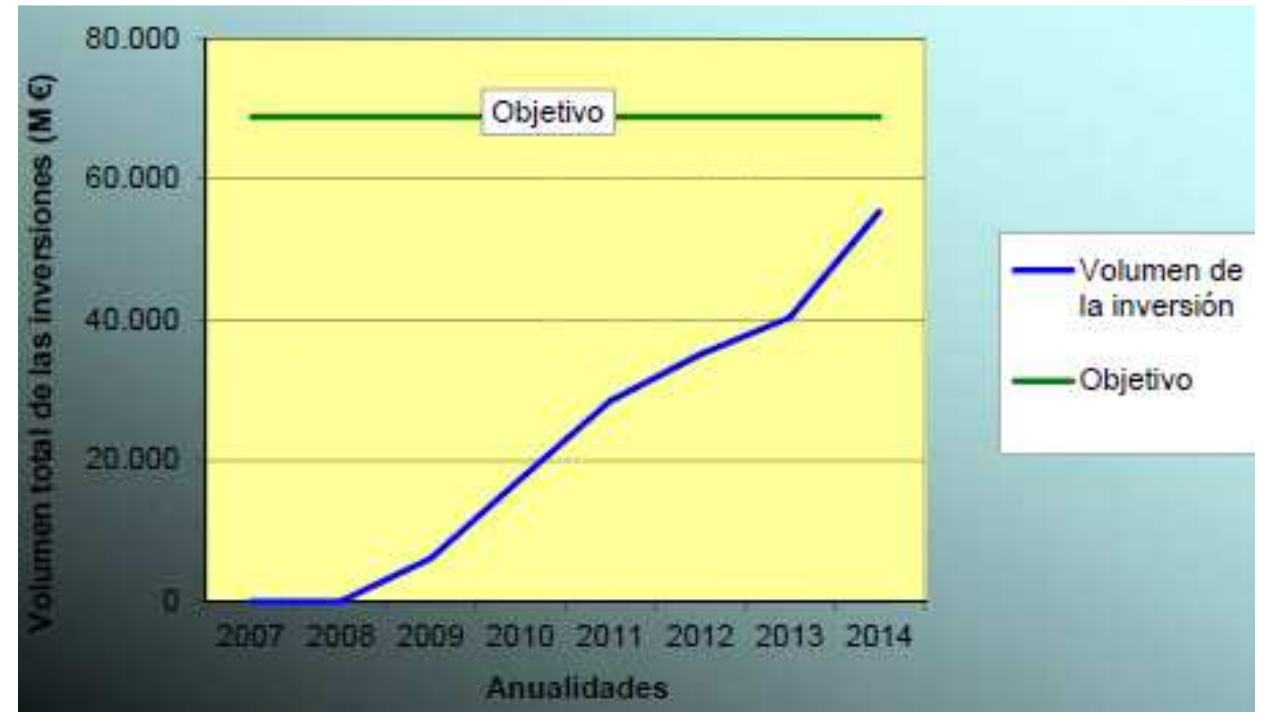

Fuente: Informe Intermedio Anual JCCM 2014.

El valor acumulado, considerando toda la inversión realizada desde que la medida fuera implementada asciende a 55.448 .794 euros, el $80,59 \%$ de los objetivos previstos para todo el periodo de programación.

La ejecución es alta no sólo es por la buena contribución de la anualidad 2014, sino también ha resultado fundamental la acusada reducción del objetivo fijado en el PDR, que se ha adaptado al contexto económico y ejecución existente y se ha alejado del optimismo que había cuando se programó inicialmente la medida en base al periodo anterior

Si comparamos este gráfico con la evolución del número de beneficiarios, se produce un ligero desfase entre los grados de ejecución logrados en ambo sindicadores. Así, el nivel de avance hacia su objetivo es menor en el volumen de las inversiones debido a que la ejecución de esta medida está condicionada a la obtención de financiación y dado el contexto económico, los problemas para la 
consecución de préstamos financieros ralentizan la inversión que tiene que hacer el joven agricultor para instalarse.

Al analizar las solicitudes aprobadas, vemos en el grafico inferior que hay un predominio en la instalación de explotaciones con cultivos en campo labrados, seguido, casi al mismo nivel, por el ganado herbívoro y la vitivinicultura con un 19\% y $18 \%$ respectivamente y, a mayor distancia, se encuentran los cultivos permanentes, la horticultura, el sector mixto, otros tipos de sectores, las aves de corral, la producción láctea y el ganado porcino, todos con una representación inferior al 10\%.

\section{Gráfico 12: Distribución de las solicitudes aprobadas según sector agrícola del joven agricultor 2007-2014.}

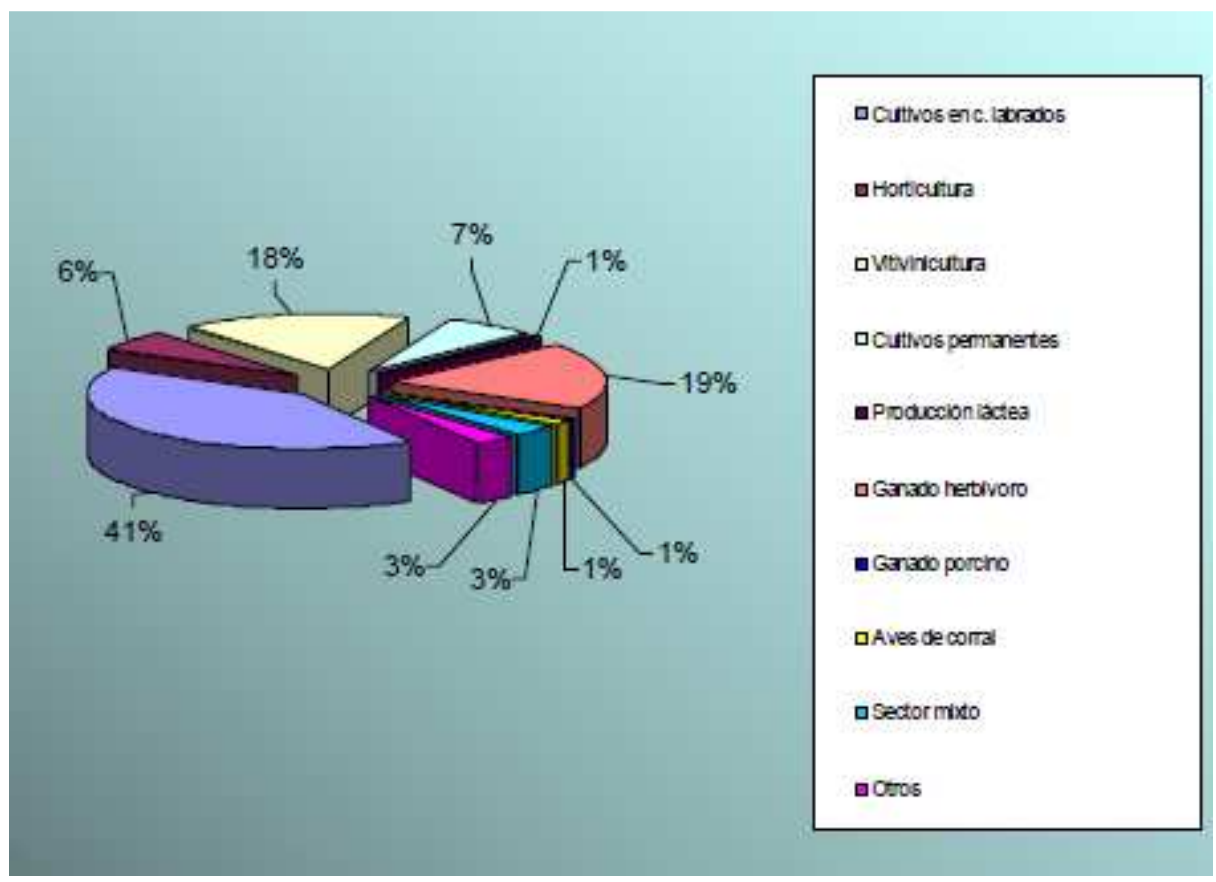

Fuente: Informe Intermedio Anual JCCM 2014.

Importante destacar el hecho, que el $11,82 \%$ de las solicitudes aprobadas está asociado a jubilaciones anticipadas. 
El gasto público total ejecutado desde que la medida fuera implementada asciende a 57.883 .502 euros alcanzado un grado de ejecución del 78,77\%. Señalar también que en esta medida, teníamos un gasto acumulado de programaciones anteriores de 16.694.593.

Gráfico 13: Evolución del gasto público total 2007-2014.

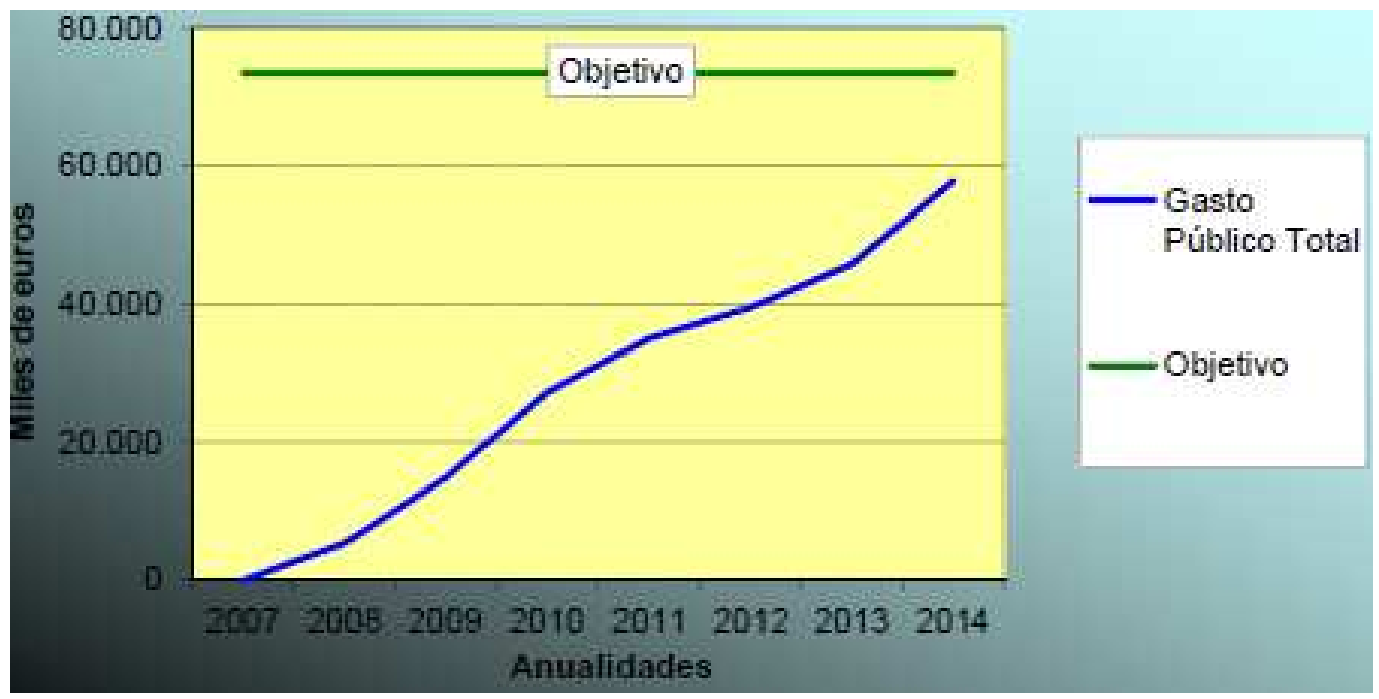

Fuente: Informe Intermedio Anual JCCM 2014.

Resumiendo y a la vista del gráfico siguiente, vemos como la situación económica actual ha generado un aumento del número de solicitudes presentadas por los potenciales beneficiarios de esta línea de ayudas como consecuencia del trasvase de trabajadores de otros sectores al agrario, mientras que el contexto de crisis económica ha provocado a su vez una disminución del importe de las inversiones unitarias solicitadas, posiblemente ocasionada por la dificultad de obtención de financiación para llevarlas a cabo.

El análisis de este hecho será muy importante al estudiar la comarca de Torrijos. 


\section{Gráfico 14: Resumen evolución de los principales indicadores de ejecución 2007-2013.}

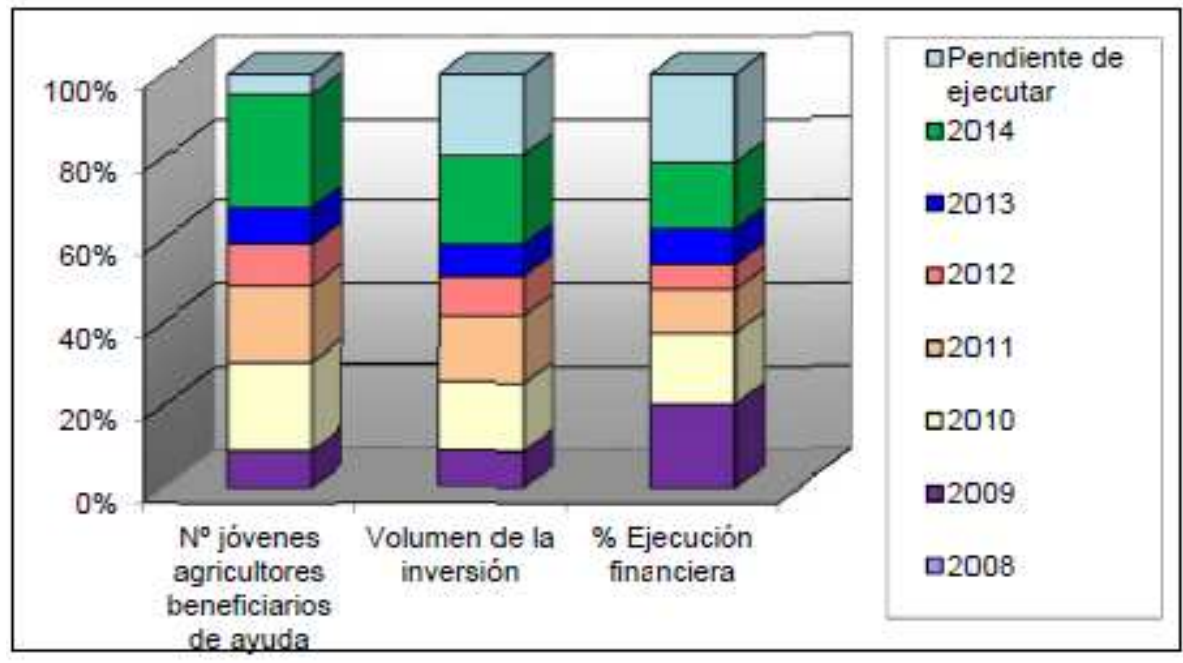

Fuente: Informe Intermedio Anual JCCM 2014.

- Medida 113: Jubilación anticipada de los agricultores y trabajadores agrícolas

En lo que respecta al número de beneficiarios, en 2014 no se han tramitado pagos en favor de nuevos beneficiarios en el programa de cese anticipado, por lo que el acumulado de jubilaciones anticipadas desde que fuera puesta en marcha la medida, asciende a 226 beneficiarios. Esto representa el $88,63 \%$ del objetivo previsto para todo el periodo, quedando del actual periodo un expediente que percibirá pagos hasta diciembre de 2019.

El siguiente grafico refleja la evolución del indicador a lo largo de todo el período, mostrando el ritmo en el que se ha realizado el primer pago a las solicitudes resueltas para las dos convocatorias de ayuda efectuadas, la primera en 2007, resuelta a lo largo de 2008 y 2009 y la segunda y última durante la campaña 2009 resuelta principalmente en los años 2010, 2011 y 2012. 
Gráfico 15: Evolución del número de beneficiarios 2007-2014.

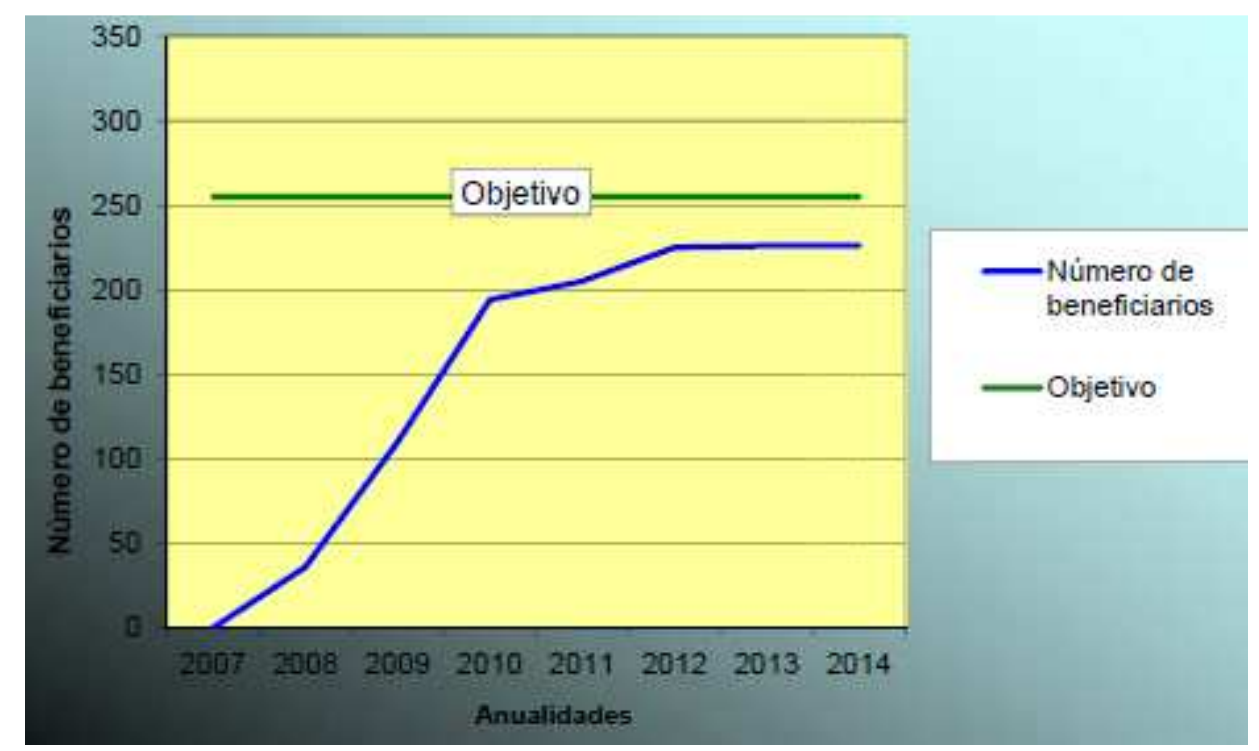

Fuente: Informe Intermedio Anual JCCM 2014.

Se trata en el $100 \%$ de los casos de jubilación de agricultores, no habiéndose registrado ningún beneficiario en la categoría de trabajadores agrícolas. Por otro lado, el $93,36 \%$ de todos los beneficiarios de esta ayuda son hombres, con edades comprendidas entre los 55 y 64 años.

Si analizamos el número de hectáreas liberadas de las explotaciones de los agricultores beneficiarios de esta ayuda, hasta el 31 de diciembre de 2014 se ha liberado un total de 17.471,84 hectáreas. Por consiguiente, se ha alcanzado el objetivo previsto para todo el periodo de 17.200 hectáreas

Vemos por tanto, que el tamaño de las explotaciones de los beneficiarios acogidos a la ayuda es superior al previsto, liberándose mayor cantidad de superficie media por beneficiario.

En cuanto a la ejecución financiera, se han pagado $36.171 .975 €$, lo que se corresponde con una ejecución del 95,77\%. Señalar que también en esta medida se tenían compromisos de periodos anteriores por valor de 22.220.291€, suponen que 
el $38,53 \%$ de los pagos corresponden a expedientes del actual periodo de programación y un $61,47 \%$ a compromisos establecidos en periodos de programación anteriores.

Si analizamos el grafico inferior, la ejecución del gasto mantiene una tendencia de crecimiento constante a lo largo del periodo, no siguiendo la evolución de los beneficiarios ya que los compromisos de pago son plurianuales, lo que hace que se incremente el gasto progresivamente para los beneficiarios inicialmente reconocidos. Por tanto, el grado de ejecución física se alcanzará ya que los pagos van a continuar en los próximos años, al existir expedientes con compromisos de pago hasta el año 2019.

Gráfico 16: Evolución del gasto público total 2007-2014

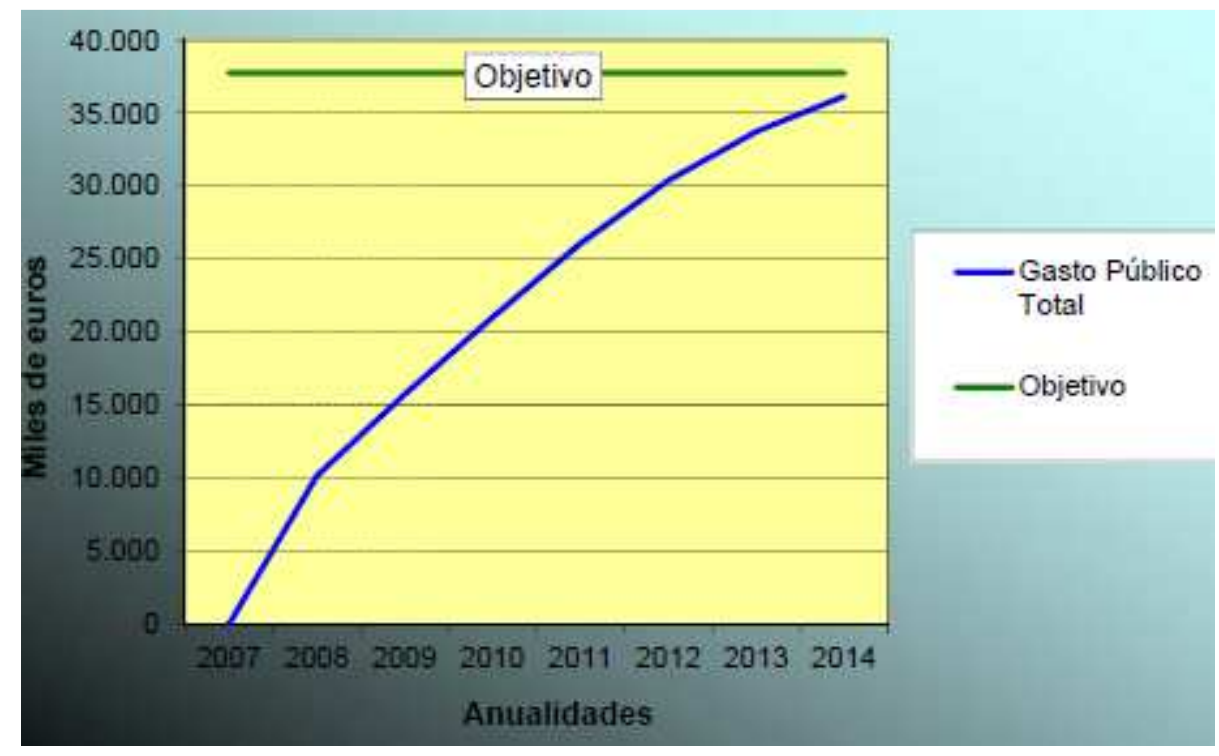

Fuente: Informe Intermedio Anual JCCM 2014. 


\section{- Medida 114: Utilización de servicios de asesoramiento}

Las actuaciones de esta medida se ejecutan a través de dos submedidas, mediante las que se conceden ayudas para la utilización de servicios de asesoramiento a explotaciones agrícolas (114.1) y para la gestión forestal sostenible (114.2).

En total se han beneficiado de esta medida 5.284 agricultores y ningún silvicultor (en lo que va de 2015 se han presentado 12 expedientes).

En cuanto a la ejecución financiera, en 2013 de un 19,62\%, se ha elevado hasta un $52,95 \%$ gracias a la reducción del gasto programado para esta medida en la versión 7 del PDR de Noviembre de 2014, ascendiendo a 3.705.942€.

Ha sido una medida no con mucho éxito entre los agricultores, debida a la creencia en muchos casos, por parte del agricultor, de que no tiene necesidad de asesoramiento, al margen del agronómico, para gestionar su explotación. Aunque las ayudas de la PAC supongan más del $30 \%$ de sus ingresos, se sigue obviando la importancia de conocer el funcionamiento de las subvenciones agrarias y los compromisos que conllevan.

Esta ayuda al asesoramiento subvenciona el $80 \%$ de la inversión realizada en asesoramiento, el importe máximo que puede percibir un titular es de $1.500 €$ cada tres años, por lo que esta ayuda es considerada secundaria en comparación de otras líneas más dotadas. 


\section{- Medida 115: Implantación de servicios de gestión, sustitución y asesoramiento de las explotaciones agrícolas y forestales}

Las actuaciones de esta medida se ejecutan a través de dos submedidas, la 115.1 relativa a la implantación de servicios de asesoramiento y la 115.2 de implantación de servicios de asesoramiento en materia de gestión del agua.

En cuanto a la ejecución financiera, a 31 de diciembre de 2014, ésta se encuentra en el 30,57\%, con un montante de $571.492 €$.

Por submedidas, la 115.1 , ha alcanzado los $233.922 €$, es decir el objetivo está lejos de ser alcanzado, por lo que se redujo significativamente el gasto programado en la última versión del PDR, pasando de 1,73M€ a 369.000€.

Pudiera ser que la crisis económica dificulte la puesta en marcha de las entidades de asesoramiento, dado el elevado coste económico que se precisa y la necesaria contención de gastos a practicar.

La submedida 115.2, surge para la consecución de los nuevos retos inició su implementación en el segundo semestre de 2010 publicándose la normativa reguladora en mayo de 2011, año en que se resolvieron 4 expedientes, siendo por tanto reconocidas 4 entidades de asesoramiento (de estas 4, 2 han perdido el derecho al cobro de la ayuda por no haber ejecutado ninguna de las actuaciones contempladas en la resolución), siendo el importe concedido de 337.571€.

Teniendo en cuenta que el objetivo previsto en esta submedida para todo el período de programación asciende a 1.500 .000 euros, la ejecución financiera alcanza un $22,50 \%$, valor muy bajo para esta medida de nuevos retos y notablemente inferior al registrado en la submedida 115.1 (la cual sí ajustó su presupuesto a la baja en la modificación 7 del PDR). 


\section{- Medida 121: Modernización de las explotaciones agrícolas}

La medida 121 se ejecuta a través de 4 submedidas:

- $\quad$ Submedida 121.1: Planes de mejora de explotaciones agrícolas

- $\quad$ Submedida 121.2: Fomento y desarrollo de sectores ganaderos

- $\quad$ Submedida 121.3: Inversiones en explotaciones intensivas

- $\quad$ Submedida 121.4: Producción de cultivos para la obtención de biomasa

Desde 2007 se han aprobado un total de 4.927 solicitudes de ayuda, de los cuales 3.738 corresponden a compromisos contraídos en el periodo 2007-2013 y 1.189 a expedientes de transición. Así mismo se han realizado pagos a 3.112 beneficiarios, alcanzando de este modo el $68,46 \%$ del objetivo establecido para todo el periodo. Destacar que del total de nuevos compromisos, el $4,60 \%$ de las solicitudes se destinan a actuaciones ecológicas.

Gráfico 17: Distribución de las solicitudes de ayuda aprobadas en relación al tipo sector agrícola 2007-2014.

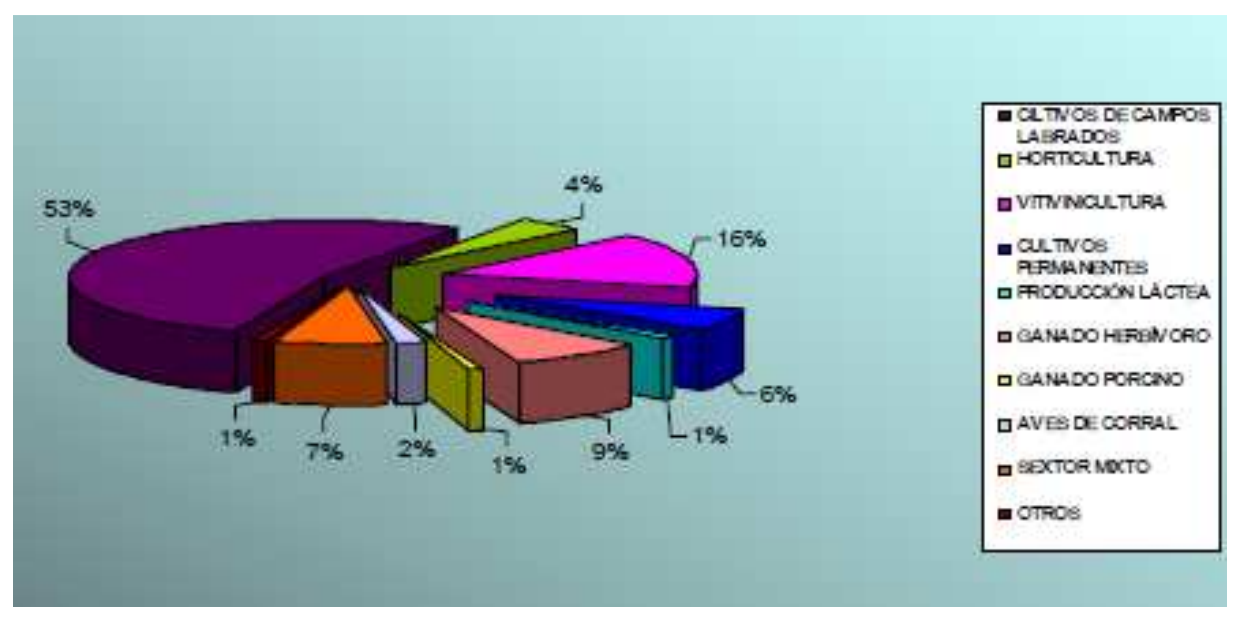

Fuente: Informe Intermedio Anual JCCM 2014. 
Como podemos ver en le grafico anterior, el 53\% corresponde a expedientes cuyas explotaciones se dedican a cultivos en campos labrados (tierras arables), seguido del $16 \%$ para vitivinicultura, el $9 \%$ son para el sector de ganado herbívoro (excluido el destinado a la producción láctea), el 7\% al sector mixto (agricultura y ganadería), el 6\% para los cultivos permanentes, el $4 \%$ a la horticultura y con menor representatividad se encuentran las destinadas a las aves de corral, ganado porcino, producción láctea y otros sectores.

La ejecución financiera alcanza el 83,47\% del total previsto del PDR, con un importe de gasto público acumulado de134.347.904€. De este importe total, el 62\% corresponde a compromisos de este periodo y el $38 \%$ restante a los derivados de períodos anteriores.

Señalar que el objetivo financiero se ha incrementado en 10 millones en la última versión del PDR de noviembre de 2014, para hacer frente a la convocatoria realizada en 2014 y que se resolverá a lo largo de 2015.

Así mismo, es importante destacar que no todas las submedidas han contribuido del mismo modo al total de la medida. El gasto público total ejecutado está repartido entre la submedida 121.1, que acumula la casi totalidad de los importes de gasto público con un $89 \%$, la 121.3 con aproximadamente un $11 \%$ y la 121.2 con un peso sobre el total que no llega al 1\% En cuanto la submedida 121.4, no se han registrado pagos en este período de programación, pudiera ser que los potenciales beneficiarios renunciaron a las ayudas al dejar de ser primada esta energía a través del Ministerio de Industria, Energía y Turismo.

Respecto a la tipología de proyectos ejecutados en la submedida $121.1, \mathrm{si}$ bien comprende actuaciones relacionadas con los nuevos retos relacionados con las prioridades de "Energías renovables", "Gestión del agua" y "Medidas de acompañamiento de la reestructuración del sector de los productos lácteos", 
"Producción de biogás utilizando residuos orgánicos", "Transformación de biomasa agrícola o forestal para la producción de energías renovables”, "Tecnologías para ahorrar agua" y "Ayuda a la inversión vinculada a la producción lechera", predominan los asociados a la modernización de explotaciones a través de inversiones en maquinaria y naves para alojarla.

En el grafico inferior, reflejamos la evolución del gasto público, y como los pagos comenzaron en 2008 con los compromisos del período anterior, incrementándose notablemente en 2009 con el comienzo del pago del período actual y ralentizándose a partir de 2011 por el contexto de crisis económica, apreciándose una ligera recuperación en 2013.

Gráfico 18: Evolución del gasto público total 2007-2014.

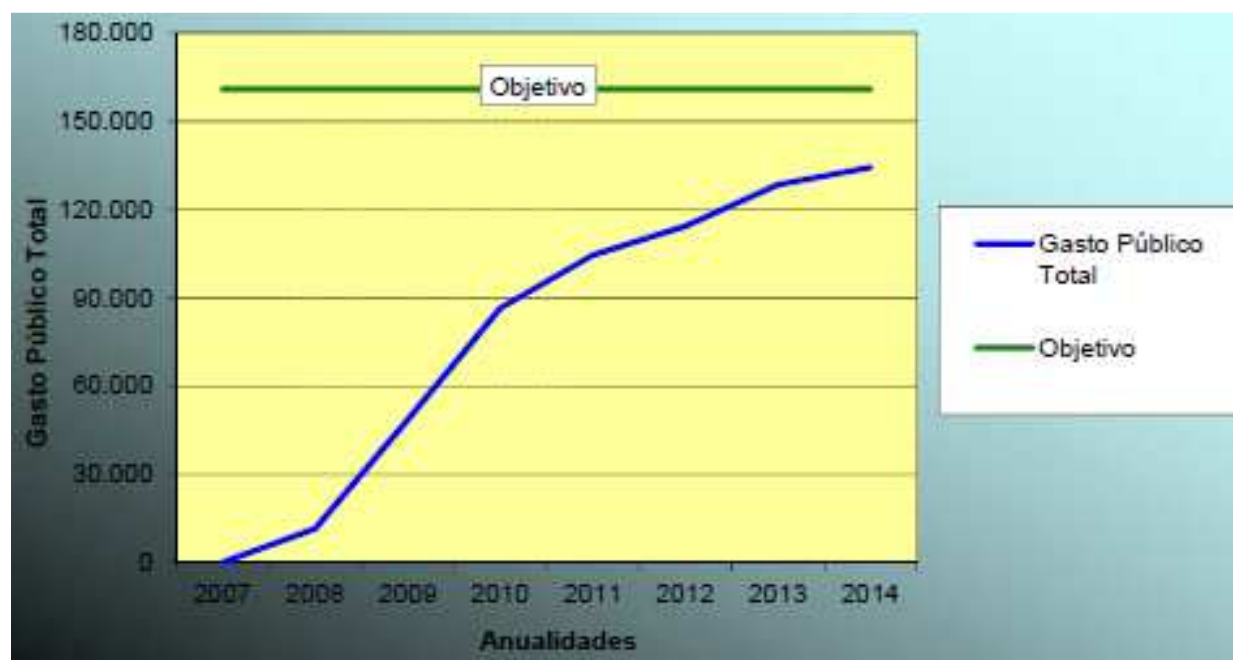

Fuente: Informe Intermedio Anual JCCM 2014. 
- Medida 123: Aumento del valor añadido de los productos agrícolas y forestales

Tradicionalmente conocida como FOCAL, se han concedido 190.524.410€ en el período 2007-2014, y 71.648.593€ del período anterior., representado un 69,75 el porcentaje de ejecución financiera.

El número de empresas beneficiadas ha sido de 1.592, de las cuales el $81,34 \%$ está, relacionadas con la transformación y comercialización y el 18,66\% restante con acciones de desarrollo de nuevos productos, procesos y tecnologías.

En relación con el tipo de empresa, del total acumulado durante todo el periodo, 501 (86,98\%) corresponden a micro y pequeñas empresas, 49 (8,51\%) a empresas medianas y $26,(4,51 \%)$ a medianas-grandes empresas.

La tipología predominante de proyectos en la Comunidad Autónoma está asociada al sector de los mostos, vinos y derivados vínicos, en particular a la elaboración y crianza de vinos.

Gráfico 19: Evolución del Gasto Público 2007-2013.

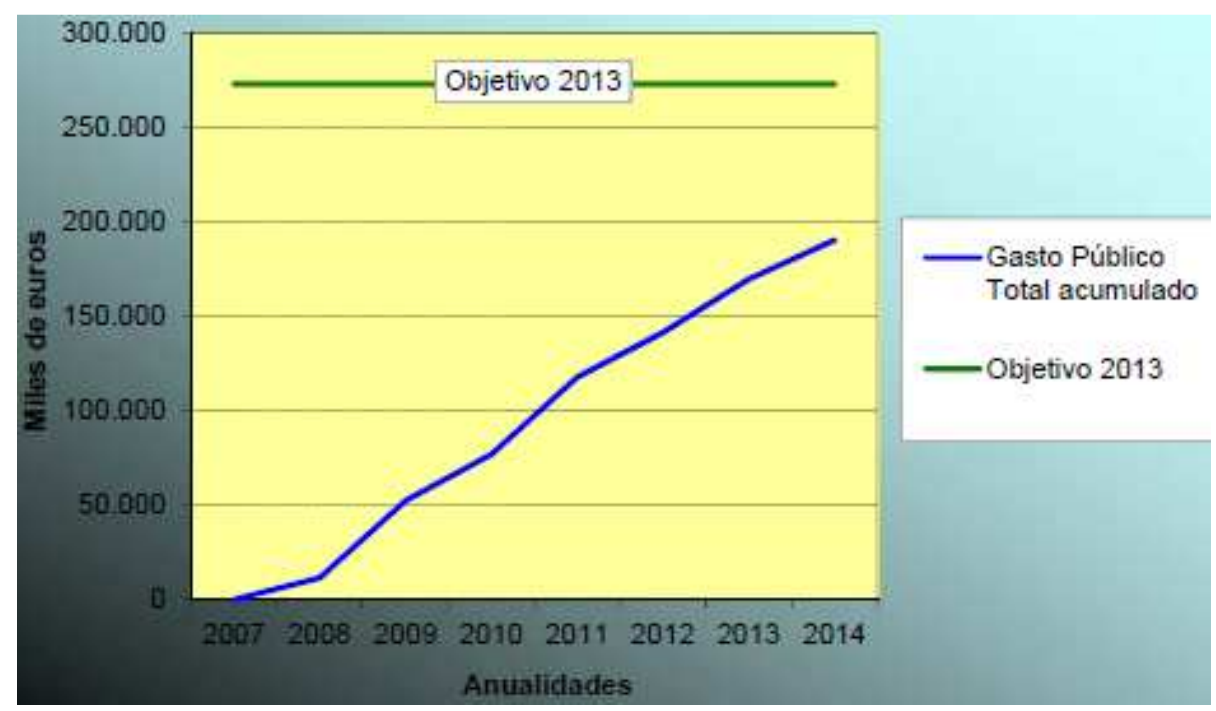

Fuente: Informe Intermedio Anual JCCM 2014. 
Como puede apreciarse, los años 2009 y 2011 tuvieron incrementos del gasto público similares, mientras que durante las anualidades 2010 y 2012 se produce un crecimiento menos acentuado, recuperándose un mayor ritmo de crecimiento con la ejecución de 2013,que no se mantiene en 2014, al haberse movilizado un gasto algo inferior.

Para 2015 existe una previsión de pagos elevada, de 68.952 .925 euros, lo que permitiría elevar la ejecución financiera hasta un 95\%, alcanzándose prácticamente el objetivo previsto en el PDR (273M€).

En el Programa de Desarrollo Rural de Castilla-La Mancha se indicó un VAB de partida de 350.000 euros/empresa en base a datos del período 2000-2006, y el objetivo a alcanzar al finalizar el periodo ascendía a 440.000 euros/empresa. Con los datos obtenidos a 31 de diciembre de 2014, el VAB medio de las empresas beneficiarias de las ayudas para el aumento del valor añadido de los productos agrícolas se ha situado en 467.853 euros por empresa beneficiaria.

En el grafico inferior vemos un resumen de la situación, viendo que hay un ligero desequilibrio entre la eficacia conseguida en el número de empresas beneficiarias y el volumen total de las inversiones. Hay que recordar que en el PDR, la inversión media prevista para las empresas que se acogieran a la ayuda estaba cuantificada en $882.535 €$ y la media ha sido de $723.548 €$. 
Gráfico 20: Resumen de la medida 123.

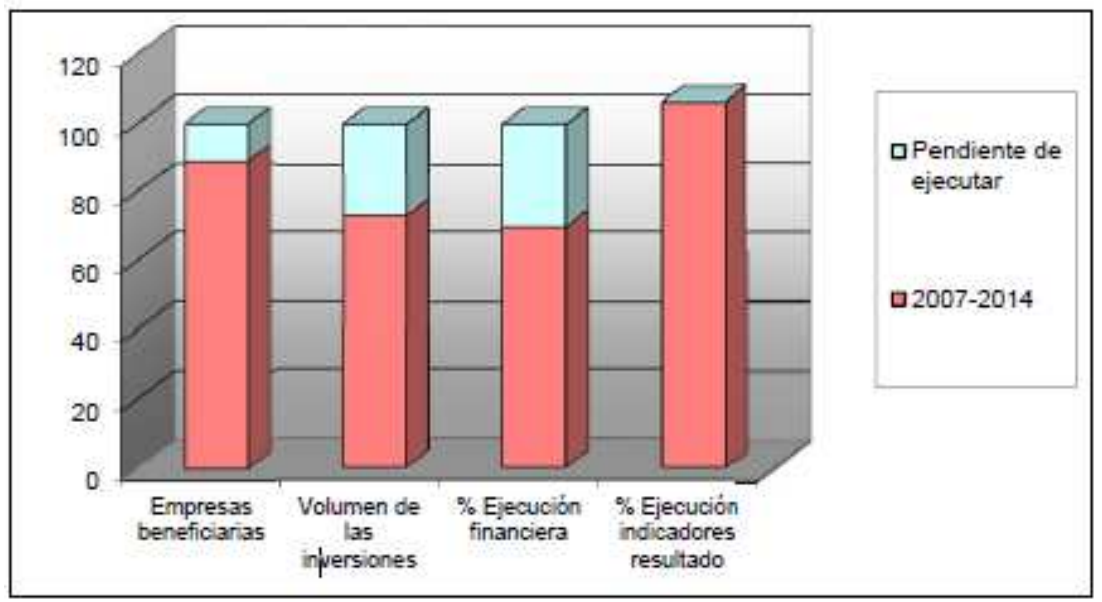

Fuente: Informe Intermedio Anual JCCM 2014.

- Medida 124: Cooperación para el desarrollo de nuevos productos, procesos y tecnologías en el sector agrícola y alimentario y en el sector forestal

Se inició con la convocatoria de ayudas 2010 y que se aprobaron sólo 3 proyectos de cooperación, de entre las 11 solicitudes presentadas. De los 3 proyectos sólo se ha pagado en 2014 la ayuda de uno de ellos, mientras que los otros 2 proyectos han finalizado sin percibir ayuda alguna (renuncia y ausencia de solicitud de pago).

Se han abonado $14.400 €$, correspondiente con un 2,2\% de ejecución.

El escaso éxito de las convocatorias publicadas puede deberse a varias razones, entre las que destaca en primer lugar la dificultad para encontrar líneas de investigación en el sector agroalimentario que resulten realmente innovadoras y novedosas, así como los obstáculos que surgen a la hora de coordinar agentes de distintos ámbitos (industria transformadora-productor primario-centro de investigación) en el desarrollo y puesta en marcha de la idea innovadora. 
Por otro lado, la situación económica actual afecta al número de solicitudes, volumen de inversión y número de empresas participantes en los proyectos de cooperación. En concreto, las dificultades para obtener la financiación necesaria para acometer cualquier inversión de mejora en las industrias, reduce el número de proyectos propuestos, destinándose los escasos recursos a mejoras prácticas en las empresas, antes que a desarrollar nuevas ideas que conllevan incertidumbre de éxito y que, en definitiva, suponen un riesgo que el sector no está dispuesto a asumir en tiempos de crisis.

\section{- Medida 125: Infraestructuras relacionadas con la evolución y adaptación de la agricultura y la silvicultura}

La medida 125 se ejecuta a través de 4 submedidas, de tal modo que las actuaciones puestas en marcha se centren en la mejora de los distintos aspectos clave en relación a la producción de las explotaciones para respaldar sus procesos productivos:

- Submedida 125.1: Infraestructuras de gestión de recursos hídricos

- Submedida 125.2: Otras infraestructuras agrarias

- Submedida 125.3: Optimización y uso eficiente de recursos hídricos

- Submedida 125.4: Infraestructuras ganaderas

El gasto para este período en esta medida ha sido de 48.593.804€, alcanzando un $88,73 \%$ de ejecución financiera, siendo el 26,09\% (12.677.570€) correspondiente compromisos de períodos de programación anteriores.

La evolución del gasto en las diferentes medidas es la que aparece en el gráfico inferior: 


\section{Gráfico 21: Evolución gasto público total 2007-2014. Medida 125 y submedidas.}

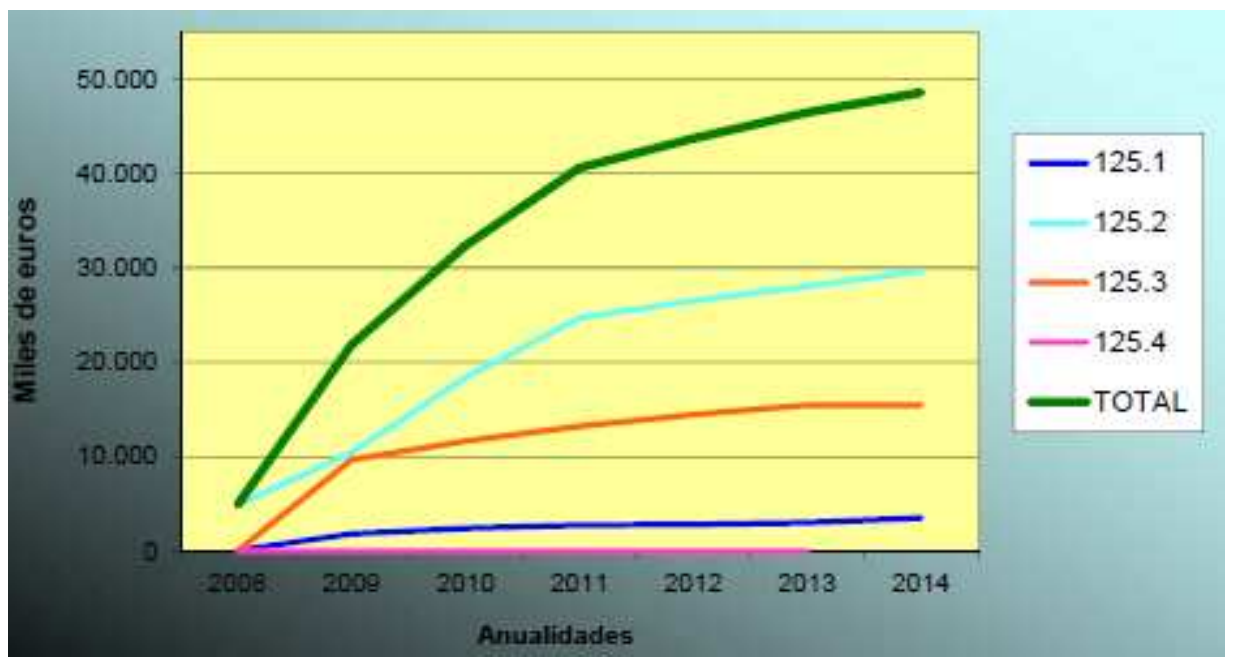

Fuente: Informe Intermedio Anual JCCM 2014.

En relación a la representatividad de cada submedida teniendo en cuenta el cómputo del gasto público total ejecutado en el conjunto de la medida desde el inicio del periodo hasta el 31 de diciembre de 2014, la submedida 125.2 representa el $61,04 \%$, seguida del gasto de la submedida 125.3 , que representa el $31,80 \%$. En último lugar se encuentra la submedida 125.1 con el $7,16 \%$ del gasto público ejecutado.

Destacar que esta ha sido otra de las medidas a modificar su cuantía en la última versión del PDR. Es posible que la situación económica atravesada haya disminuido el interés de los inversores, fruto de la incertidumbre reinante.

- Medida 132: Participación de los agricultores en programas relativos a la calidad de los alimentos 
Se han resuelto favorablemente 119.905 solicitudes desde que la medida fuera puesta en marcha. De este total, el $71,48 \%$ de las mismas están relacionadas con la participación en programas comunitarios frente al 28,52\% que corresponden a solicitudes relativas a programas nacionales.

El gasto público acumulado desde que la medida fuera implantada asciende 8.331.399€, alcanzándose el 94,70\% del gasto programado para todo el período, por lo que una vez finalizada la ejecución de la medida, podría considerarse que prácticamente se ha alcanzado el objetivo financiero.

\section{Gráfico 22: Distribución de las explotaciones beneficiarias según la categoría de su producción 2007-2014.}

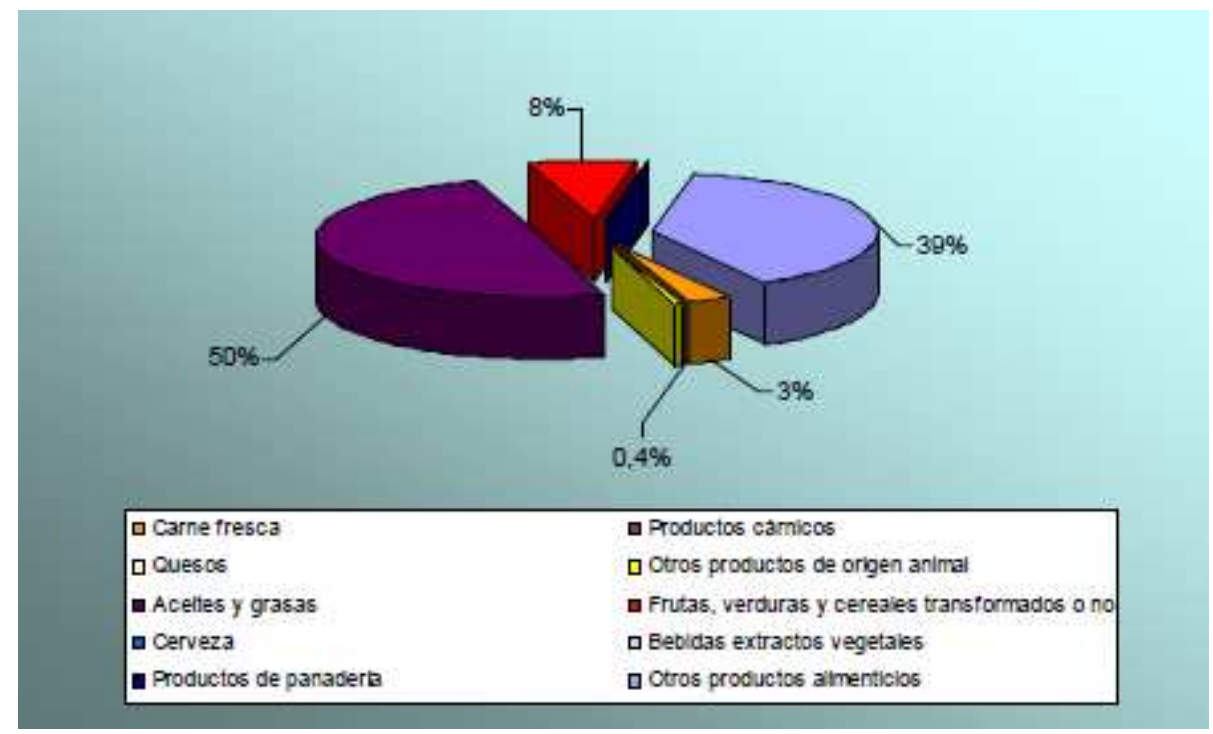

Fuente: Informe Intermedio Anual JCCM 2014.

En relación a la categoría de producto que caracteriza a las explotaciones perceptoras de ayuda destaca la vinculada a la de aceites y grasas que representa el $49,47 \%$, seguido de las explotaciones correspondientes a otros productos alimenticios, representando el 39,08\%. Las explotaciones vinculadas a la producción de frutas, verduras y cereales transformados o no, representan el $7,63 \%$, las 
vinculadas a carne fresca el 3,37\% y a la categoría de otros productos de origen animal con el $0,46 \%$.

- Medida 133: Apoyo a las agrupaciones de productores en actividades de información y promoción de programas de calidad

El gasto público acumulado desde que la medida fuera implementada asciende a 4.844.402€. El grado de ejecución financiera es por tanto del $69,44 \%$ sobre el objetivo programado.

Como muestra el gráfico posterior, en relación a la categoría de productos que caracterizan las solicitudes aprobadas, el $47,40 \%$ del total acumulado corresponde a otros productos alimenticios, entre los que se incluye el vino, y el $19,65 \%$ a la categoría de aceites y grasas. A la categoría relativa a las frutas, verduras y cereales transformados pertenecen el $16,76 \%$ de las solicitudes aprobadas mientras que a la relativa a la carne fresca corresponden el 8,09\%, el $6,94 \%$ del total corresponden a la categoría denominada otros productos de origen animal y en último lugar, la categoría relativa a los quesos cuenta con el 1,16\% de las solicitudes. 
Gráfico 23: Distribución solicitudes ayuda presentadas según categoría producto sobre el que se realiza la actuación 2007-2014

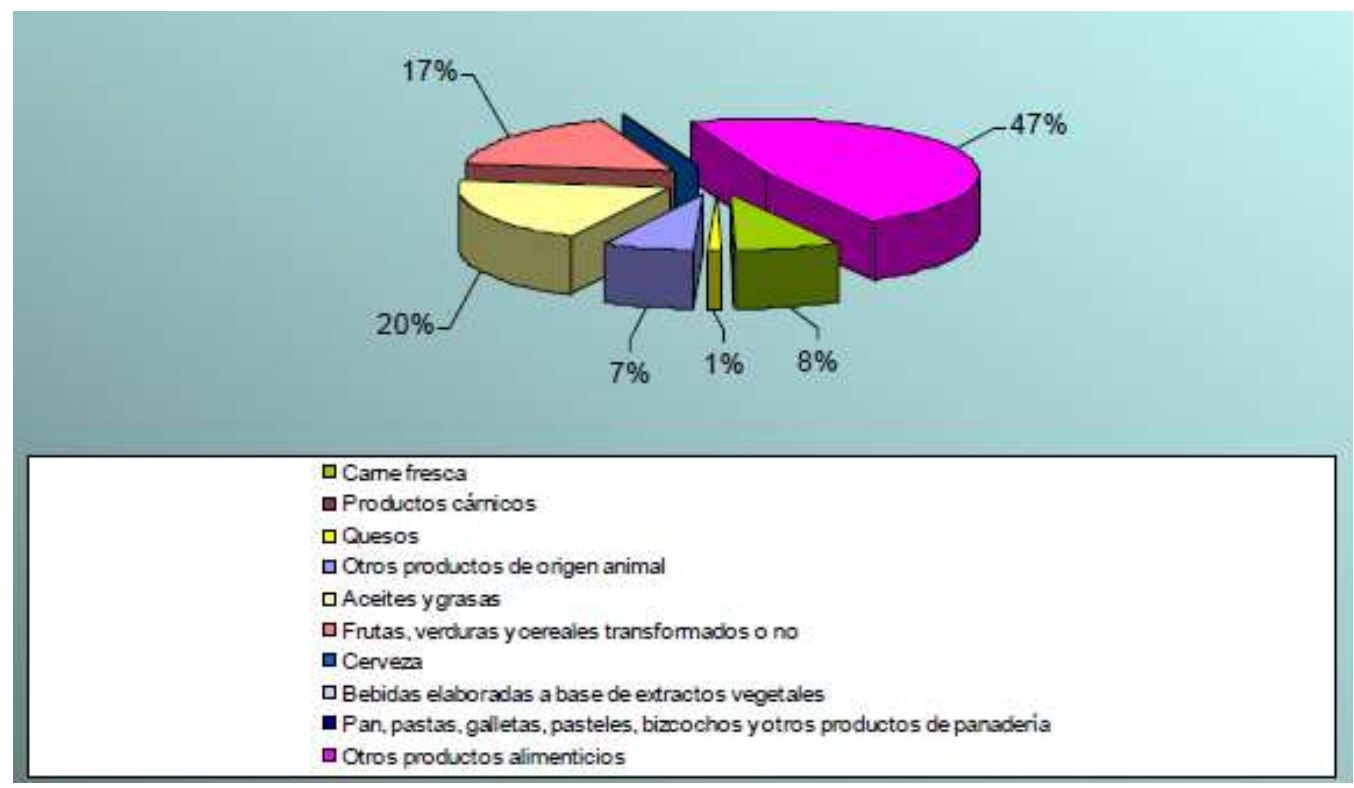

Fuente: Informe Intermedio Anual JCCM 2014.

- Medidas 211 y 212: Ayudas destinadas a indemnizar a los agricultores por las dificultades naturales en las zonas de montaña y en otras zonas distintas de las de montaña

Se han pagado ayudas en relación a estas medidas en una superficie de 428.054 has, de las que 32.427 has se encuentran dentro de la Red Natura 2000, 11.868 has corresponden a la medida 211 mientras que 20.558has corresponden a la medida 212.

El gasto público acumulado desde que las medidas fueran puestas en marcha asciende a $106.770 .368 €$. De este gasto, 25.409.030 euros corresponden a la medida 211 y 81.361 .338 euros a la 212. Por tanto, el grado de ejecución financiera para ambas medidas se sitúa en un $81,86 \%$. 
Se estima pagar durante la anualidad 2015, a 15.714 beneficiarios por un importe de 22M€, lo que supondrá alcanzar el 99\% del objetivo financiero.

\section{- Medida 214: Ayudas agroambientales}

Se han abonado un total de 390.421.146€, desde el inicio del programa, con un grado de ejecución del $92,2 \%$. De este gasto público total acumulado de la medida, el $74,41 \%$ se corresponde con compromisos adquiridos en el actual periodo con un total acumulado de 290.522.247 euros de gasto público y el 25,59\% con compromisos de periodos anteriores con un total acumulado de 99.898 .899 euros.

Las ayudas agroambientales se dividen en:

\section{Grafico 24: distribución del número de explotaciones por submedidas.}

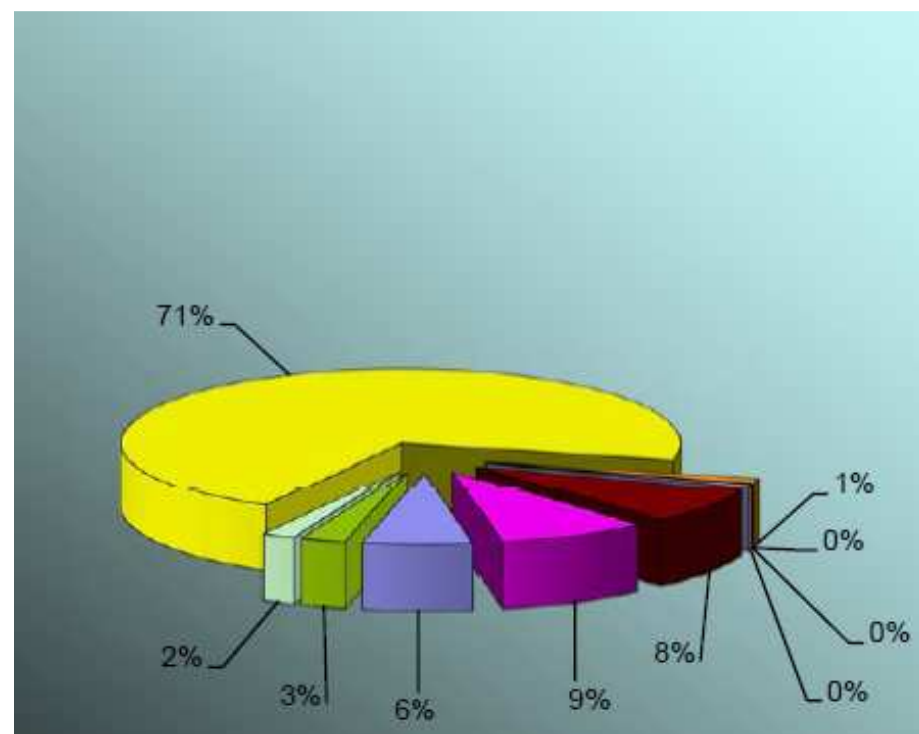

Q214.1 Agrosistemas extensivos de secano

- 214.2 Apicultura para la mejora de la biodiversidad en zonas naturales

口214.3 Ganaderia ecológica

口214. 4 Agricultura ecológica

-214.5 Razas autóctonas en peligro de extinción

ם214.6 Conservación de la dehesa

घ214.11 Lucha contra la erosión en cultivos leñosos

ם214.12 Intearación del cultivo de viñedo de secano

-214.13 Fomento de prácticas de pastoreo en las explotaciones de ovino-caprino

Q214.14 Cultivo de girasol de secano

Fuente: Informe Intermedio Anual JCCM 2014. 
Como se puede observar, el $71 \%$ de las explotaciones con compromisos en la medida 214 corresponden a la submedida 214.4 de agricultura ecológica, seguida a gran distancia por la submedida 214.14 de prácticas agroambientales en cultivo de girasol de secano con un $9 \%$, le sigue la 214.3 ayuda para el incremento de la extensificación mediante el fomento de prácticas de pastoreo en las explotaciones de ovino-caprino, con un $8 \%$, y la 214.1 agrosistemas intensivos de secano con un $6 \%$, el resto de submedidas tiene pesos relativos inferiores al $5 \%$.

Desde el inicio del período se han percibido ayudas en una superficie de 509.035 has.

Si analizamos el gasto ejecutado, el $85 \%$ corresponde al submedida 214.4 agricultura ecológica, seguida con el 6\% por la submedida 214.13 ayuda agroambiental para el incremento de la extensificación mediante el fomento de prácticas de pastoreo en las explotaciones de ovino-caprino.

Analizando con más detalle la submedida 214.4 para ver qué cultivos se han puesto en ecológico, viendo que en olivar la superficie acogida es de 60.000 has, seguido del viñedo vinificación de 44.800 has. Desde el comienzo del programa se ha abonado un importe de 249.593.060€.

\section{- $\quad$ Medida 221: Primera forestación de tierras agrícolas}

La superficie forestada desde el inicio del programa es de 297.716 has, con 5.619 beneficiarios, y un gasto publico de 153.443.452€, con un grado de ejecución del $95,74 \%$.

- Medida 226: Ayudas a la recuperación del potencial forestal e implantación de medidas preventivas 
Las actuaciones de esta medida se ejecutan mediante dos submedidas las cuales conceden ayudas a la recuperación del potencial forestal e implantación de medidas preventivas a través de la lucha contra incendios en la submedida 226.10 bien con otras medidas preventivas en la submedida 226.2.

Se ha contabilizado, para el indicador del número de solicitudes aprobadas, un total de 1.211 expedientes. La ejecución financiera acumulada asciende a 49.792.366 euros, por lo tanto, el grado de ejecución es del 57,98\% con respecto al objetivo previsto hasta el fin del período.

En la submedida 226.1, el gasto ejecutado acumulado desde el inicio de período es de $48.201 .334 €$, con un a ejecución de un 59,69\%, bastante baja que podría ser debida al hecho de que los beneficiarios tienen que adelantar el pago de los trabajos realizados.

\section{- $\quad$ Medida 227: Ayudas para inversiones no productivas.}

Las actividades desarrolladas dentro de las inversiones no productivas se engloban en dos submedidas en función de la zona donde se realicen aquellas.

Con este enfoque en el diseño del PDR, las inversiones consideradas no productivas que se realicen en zona Red Natura 2000 están incluidas en la submedida 227.1, por el contrario, cuando estas inversiones se produzcan fuera de esta zona, pueden ser llevadas a cabo a través de la submedida 227.2.

Se han contabilizado un total de 3.717 expedientes con resolución favorable de ayuda desde que la medida fuera puesta en marcha incluyendo la anualidad 2014. Esto ha supuesto atender a 2.090 silvicultores alcanzando así el 90,87\% de las previsiones actuales efectuadas para todo el periodo de programación. 
Por otra parte, la ejecución financiera acumulada asciende a 40.050.269 euros, por lo tanto, el grado de ejecución es del 60,68\% con respecto al objetivo previsto hasta el fin del periodo.

Por submedidas, la 227.1 ha tenido un gasto público total desde que fuera puesta en marcha la submedida se eleva a 15.356.517 euros de los cuales el $94 \%$, 14.430.821 euros, corresponde a compromisos del periodo 2007-2013 y el 6\% restante, 925.696 euros, a compromisos establecidos en períodos de programación anteriores, alcanzando una ejecución financiera del 63,84\%.

La baja ejecución pudiera ser debida a que el importe concedido como ayuda a los beneficiarios se recibe de forma posterior a la ejecución y justificación de los trabajos. De esta forma, los beneficiarios tienen que adelantar el pago de los trabajos realizados. Así mismo, la actual falta de liquidez y la dificultad de acceso al crédito provocan en muchos casos situaciones muy difíciles hasta que se produce el pago. La demora en el pago, fruto de las dificultades para cofinanciar y de la complejidad en la gestión de los expedientes, así como la solicitud de líneas de crédito con altos intereses que implican un mayor coste económico (pago de intereses, comisiones de apertura y cancelación) hacen que pierda interés la realización de inversiones.

En la submedida 227.2, se han aprobado 2.758 solicitudes en el acumulado del período, con una inversión de 21.063.387€, que se corresponde con un grado de ejecución del 50,47\%, y una superficie forestal subvencionada de 22.002 has.

Tal y como sucede con la submedida 227.1, durante el año 2015 se espera se paguen expedientes correspondientes a la convocatoria 2013 y sucesivas, mejorando el porcentaje de ejecución financiera.

\section{- Medida 313: Fomento de actividades turísticas}


La Submedida 313.3, Fomento de actividades turísticas cinegéticas, no se han aprobado solicitudes y no se han realizado pagos. En la anualidad 2015 se están preparando los expedientes para enviar a Intervención las propuestas finales y remitir las resoluciones aprobatorias definitivas, para finalmente efectuar los pagos correspondientes.

\section{- Medida 321: Servicios básicos para la economía y la población rural}

Submedida 321.2: Servicios básicos para la economía y la población rural

En el año 2014 se han realizado los primeros pagos por un valor de 1.451 .842 euros de los que 1.088.882 euros, con un grado de ejecución es del 10,04\% del objetivo previsto para todo el período.

En este caso no parece que vaya a ejecutarse todo el presupuesto programado para la medida. La situación económica de los últimos años ha tratado de alcanzar una consolidación fiscal y la mejora de la competitividad, para lo cual se ha intentado reducir el déficit público con el fin de garantizar la estabilidad financiera. En este contexto se han adoptado medidas que han llevado a la contención del gasto. Dadas las circunstancias, las inversiones en infraestructuras como regadíos, caminos y concentraciones se han visto mermadas.

\section{- Medida 323: Conservación y mejora del patrimonio rural}

Submedida 323.2: Conservación y mejora del patrimonio rural

Desde que la submedida fuera puesta en marcha se han ejecutado 3.665 .230 euros, de los que 2.730.920 euros corresponden a FEADER. El grado de ejecución es, por tanto, del $64,29 \%$ del presupuesto previsto para esta submedida para todo el periodo. 
En cuanto a la previsión de pagos para 2015, ésta se ha cifrado en 646.869,98 euros, lo que elevaría la ejecución financiera a un 75,63\%. El siguiente gráfico refleja la evolución del volumen de la inversión:

Gráfico 25: Evolución del volumen total de la inversión 2007-2014.

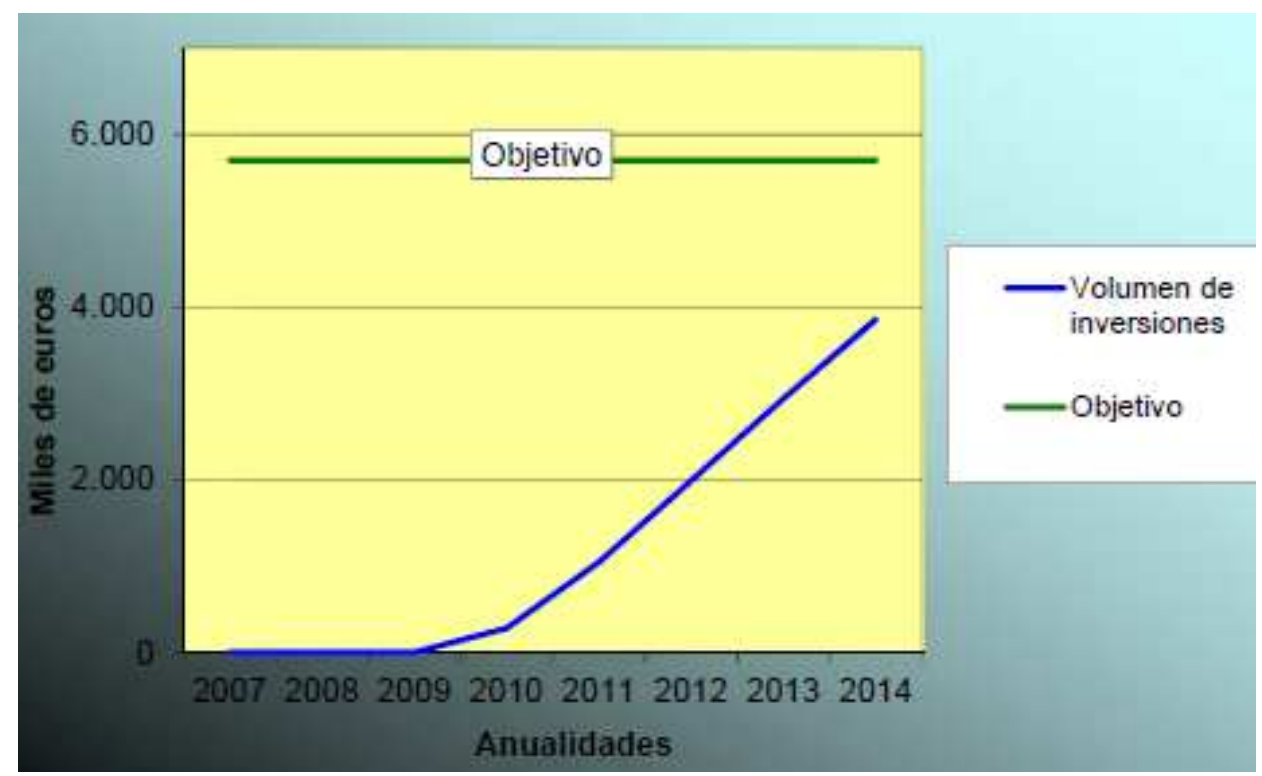

Fuente: Informe Intermedio Anual JCCM 2014.

En el gráfico anterior puede observarse que el grado de ejecución resulta medio-alto. Analizando tales resultados podemos concluir que se han llevado a cabo más acciones beneficiarias de las previstas, pero con un volumen medio de inversión considerablemente inferior al programado, como consecuencia del contexto de crisis económica que ha condicionado a todas las medidas de inversión.

\section{- Medida 413: Estrategias de Desarrollo Local. Calidad de vida y diversificación}

EI PDR de Castilla-La Mancha incluye entre sus objetivos la mejora de la calidad de vida y la diversificación económica de las zonas rurales. En este sentido, 
incide en la mejora de la gobernanza y la movilización del potencial de desarrollo endógeno con el apoyo de los Grupos de Desarrollo Rural (GDR), fomentando el enfoque ascendente para el logro de la competitividad y la mejora del medio ambiente así como posibilitando la diversificación de actividades en el medio rural y el bienestar de su población mediante la aplicación de enfoques innovadores.

La consecución de estos objetivos del PDR de Castilla-La Mancha se alcanza a través de la gestión de las medidas del eje 3 ejecutadas mediante el eje 4 LEADER, en concreto, a través de la medida 413.

Es preciso señalar el hecho de que determinadas inversiones son ejecutadas directamente por la Administración como son las submedidas 313.2, 313.3, 321.2 y 323.2, que han sido descritas con anterioridad.

Así como viene sucediendo a lo largo de todo el periodo, la implementación de esta medida ha tenido lugar a través de la gestión de los 29 Grupos de Desarrollo Rural (GDR) que representan el $100 \%$ de los grupos previstos, con una superficie cubierta de $73.881,67 \mathrm{~km} 2$, y una población beneficiaria potencial de 1.205.220 personas

El gasto público total ejecutado desde que la medida fuera implantada asciende a 78.864.008 euros, de los que 61.358.285 euros corresponden a FEADER. El grado de ejecución es por tanto del $63,78 \%$ de todo el gasto previsto para el período. En cuanto a la previsión para la anualidad restante, se prevé pagar en 2015 un total de 31.523.076 euros, lo que elevaría la ejecución financiera a un 89,28\%.

Ese nivel medio de ejecución se debe principalmente a los siguientes motivos:

- Tardía puesta en marcha del programa LEADER que no comenzó a funcionar hasta el último trimestre de 2009.

- Limitación de los recursos de fondos propios de la Administración Regional en 2012. 
- Problemas financieros de los GDR para conseguir crédito con el que financiar sus pólizas de crédito. Esto repercute directamente en problemas de ejecución, $\quad$ ya que no pueden adelantar el crédito a los promotores finales.

- Dificultades socioeconómicas para los promotores privados que no pueden acceder a la financiación para realizar los proyectos.

En respuesta a esta situación, el servicio de desarrollo rural ha optado por permitir la utilización de certificaciones parciales, de forma que se puedan ir abonando parcialmente proyectos de cierta dimensión económica, facilitando de esta forma el acceso al crédito del promotor y mejorando la situación de las pólizas de crédito del grupo.

Si analizamos la distribución del gasto en función de las medidas, tendríamos la gráfica siguiente:

Gráfico 26: Distribución del gasto público total según la medida.

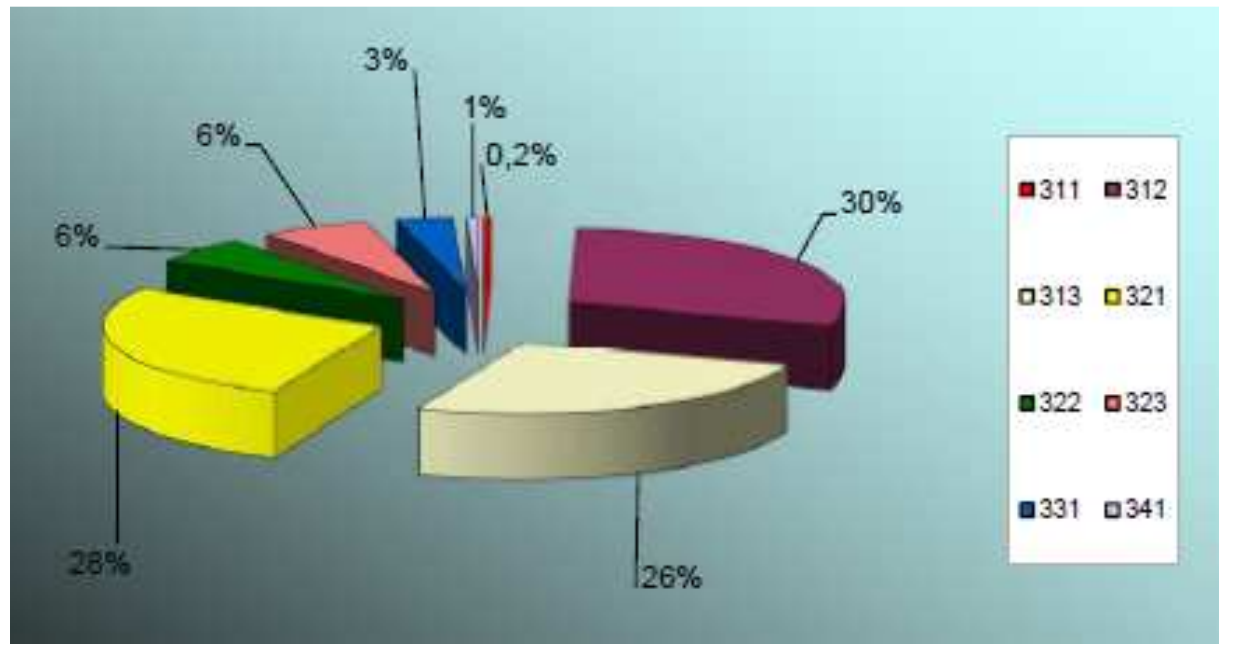

Fuente: Informe Intermedio Anual JCCM 2014.

Vemos que las submedidas 312 y 313 (en torno al 30\%) han mejorado en su ejecución, posiblemente derivadas de un mayor número de promotores, consecuencia de parados de larga duración que no encuentran empleo y deciden 
iniciar su propio negocio. La disminución de los requisitos de empleo a generar en municipios de más de 10.000 habitantes, ligados a los proyectos de las medidas 312 , 313 y 321, que fue incorporada en la versión 7 del PDR, también ha contribuido a mejorar la ejecución al adaptar esas medidas a la actual situación de crisis económica y desempleo.

Por el contrario, existe una baja ejecución de la submedida 311 "Diversificación hacia actividades no agrícolas", ya que son pocos los agricultores que disponen de capital suficiente y/o que desean diversificar en otros sectores, ya sea fuera o dentro de su explotación agropecuaria.

A nivel social, el elevado número de parados con el que cuenta la región actualmente, está limitando el número de promotores que pueden realizar inversiones. Gran parte de esta población estaría dispuesta a emprender actividades a través del eje LEADER, siempre que contase con financiación y crédito de las entidades bancarias.

La distribución de los proyectos financiados por los GDR por medidas sería:

\section{Gráfico 27: Distribución proyectos financiados por los GDR en función de las medidas.}

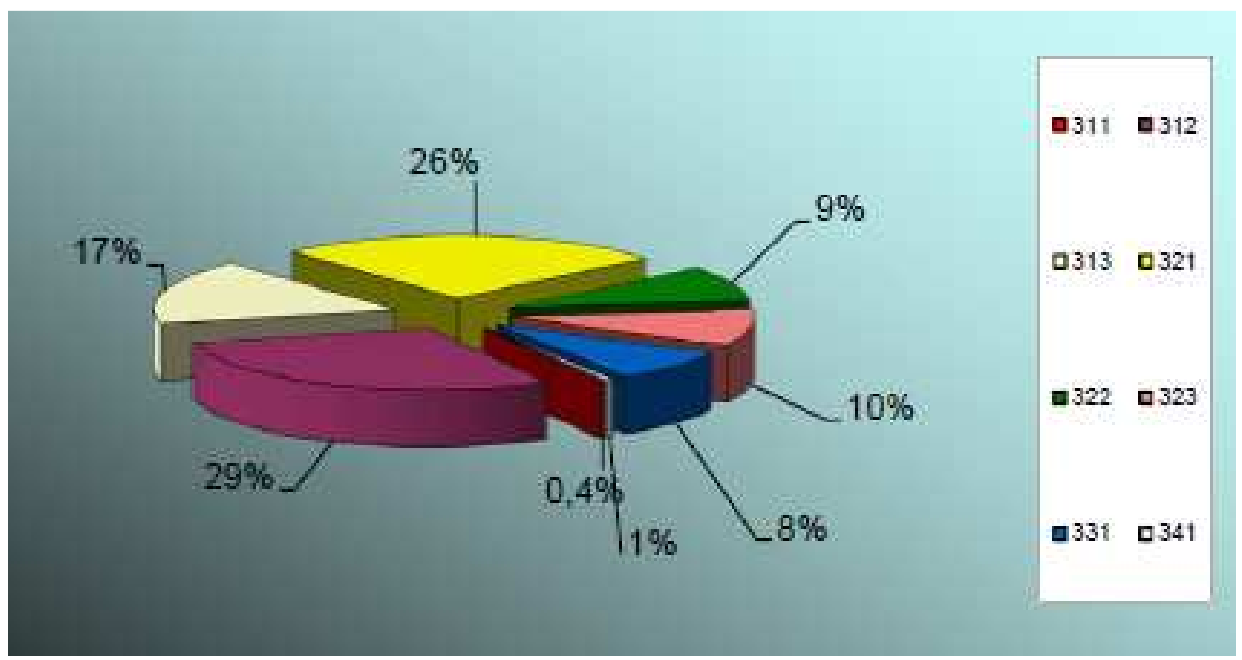

Fuente: Informe Intermedio Anual JCCM 2014. 
Podemos ver que las medidas 312,321 y 313 son las que más proyectos financiados aglutinan, más del $72 \%$.

$\mathrm{Si}$ analizamos quienes han sido los beneficiarios de estos proyectos, tendríamos la siguiente gráfica:

\section{Gráfico 28: Distribución beneficiarios en función del tipo de propiedad y medida.}

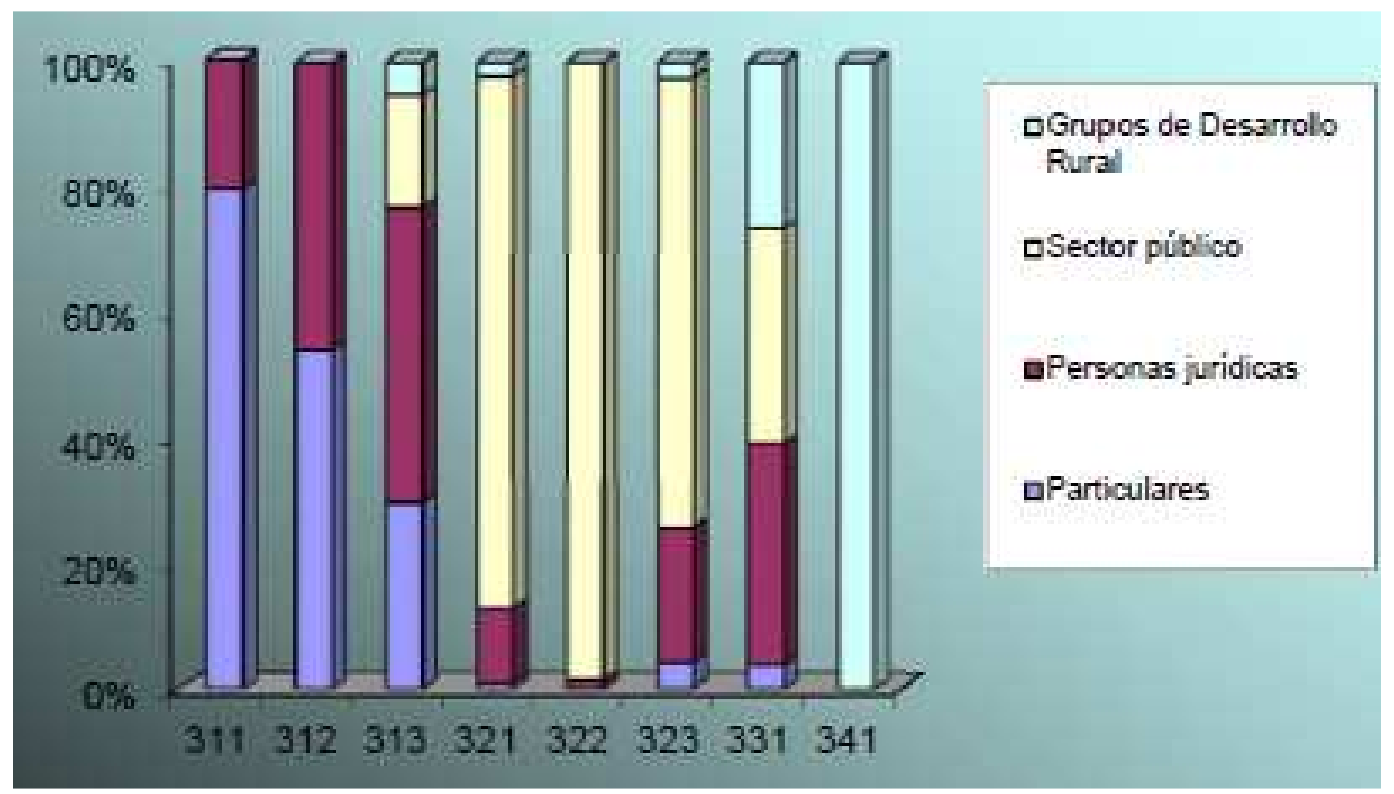

Fuente: Informe Intermedio Anual JCCM 2014.

Vemos que el sector público es el beneficiado mayoritario en las medidas 321,322 y 323 , de marcado carácter social, mientras que el sector privado lo es de las medidas 311,312 y 313 . Los GDR son el único tipo de beneficiario en la medida 341 , mientras que en la medida 331 representa un reparto equilibrado ente el sector público y el privado.

Si analizamos como se ha repartido las subvenciones a lo largo de los años, tendremos el siguiente gráfico: 


\section{Gráfico 29: Resumen de la evolución de los principales indicadores de ejecución.}

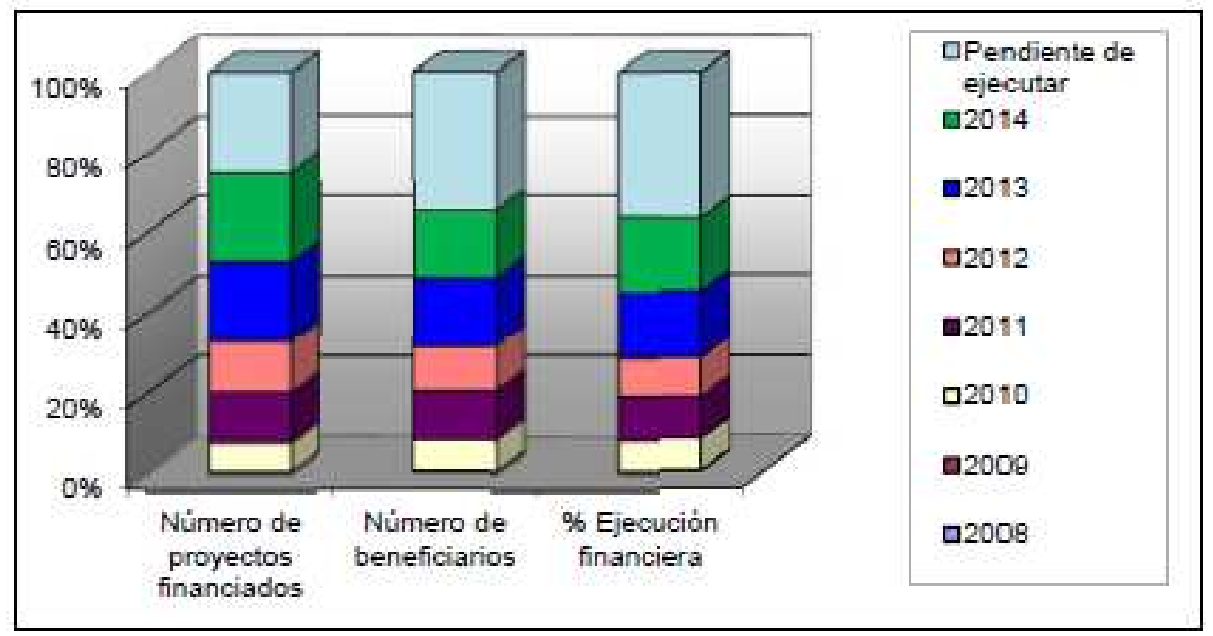

Fuente: Informe Intermedio Anual JCCM 2014.

Hay que tener en cuenta que la medida no comenzó su ejecución hasta el año 2009, momento en el que se suscribieron los convenios con cada uno de los GDR, y pese a que las estrategias no fueron implementadas hasta 2010, el ritmo creciente en todos los indicadores en los últimos años se muestra fuerte y constante, con una gran contribución de la anualidad 2013, superad incluso por la 2014.con la ejecución de la anualidad 2015se espera alcanzar los objetivos o por lo menos quedar muy cerca de los mismos.

\section{- Medida 421: Cooperación internacional o transnacional}

Desde que fuera puesta en marcha esta medida se han presentado 15 proyectos de los cuales se aprobaron 14, previendo un máximo de 17 para 2015, que han sido realizados por 13 GDR, es decir un $44,83 \%$ del total.

Esta medida hasta el 31 de diciembre de 2014, había dispuesto de 240.693€, lo que supone un grado de ejecución del 6,89\%. 
El grado de ejecución actual es muy bajo, se debe a un procedimiento de gestión que puede alargarse en el tiempo a causa de la resolución de incidencias detectadas en los controles, no ayudando la falta de personal o la ausencia de una aplicación informática más desarrollada.

Por todo ello y para aprovechar los recursos financieros no comprometidos en esta medida, se prevé modificar los cuadros financieros de los 13 Grupos en esta situación.

- Medida 431: Funcionamiento del grupo de desarrollo rural, adquisición de capacidades y promoción territorial

En cuanto al gasto público acumulado desde que la medida fuera puesta en marcha, a 31 de diciembre de 2014 se alcanzan los 23.865 .838 euros, de los que 18.156.858 euros corresponden a FEADER, lo que equivale a un grado de ejecución financiera del 79,39\%. El índice de ejecución alcanzado se debe al hecho de que para cada GDR se computa una única acción por año de ejecución en relación a sus gastos de funcionamiento.

Actualmente en 11 de los GDR se ha iniciado el procedimiento de compensación del anticipo y en 8 ya se ha liberado el aval. 


\subsubsection{Marco Legal}

En este apartado está resumida la normativa aplicable para el año 2014, en cada medida o submedida de los ejes del PDR.

\section{- Medida 111: Acciones relativas a la información y formación profesional}

\section{Submedida 111.1: Actividades formativas dirigidas a los profesionales del sector agroalimentario y del mundo rural}

- Orden de 08/03/2011, de la Consejería de Agricultura y Medio Ambiente, por la que se establecen las bases reguladoras para la concesión de ayudas para la realización de actividades formativas dirigidas a los profesionales del sector agroalimentario y del medio rural.

- Resolución de 08/03/2011, de la Dirección General de Desarrollo Rural, por la que se convocan para 2011 ayudas para la realización de actividades formativas dirigidas a los profesionales del sector agroalimentario y del medio rural.

- Orden de 22/04/2013, de la Consejería de Agricultura, por la que se establecen las bases reguladoras para la concesión de ayudas para la realización de actividades formativas dirigidas a los profesionales del sector agroalimentario y del medio rural.

- Resolución de 22/04/2013, de la Dirección General de Infraestructuras y Desarrollo Rural, por la que se convocan para el curso 2013 ayudas para la realización de actividades formativas dirigidas a los profesionales del sector agroalimentario y del medio rural. 


\section{Submedida 111.2: Información y divulgación de conocimientos sobre fauna y flora silvestre y su aprovechamiento sostenible}

Las actuaciones contempladas en esta submedida están relacionadas con el nuevo reto de biodiversidad y, en concreto, están incluidas dentro del tipo de operación "información y divulgación de conocimientos sobre la biodiversidad", de conformidad con el Anexo del Reglamento (CE) ํㅜ 74/2009 del Consejo, por el que se modifica el Reglamento (CE) ํo 1698/2005.

Esta submedida se gestiona mediante ejecución directa por parte de la Administración, por lo que no se publica convocatoria de ayudas.

\section{- Medida 112: Instalación de jóvenes agricultores}

- Orden de 26 de julio de 2010, de la Dirección General de Mejora de Explotaciones Agrarias, por la que se establecen las bases reguladoras de las ayudas a la modernización de explotaciones agrarias, a la primera instalación de jóvenes agricultores y a las actuaciones en materia de regadíos.

- Orden de 27 de diciembre de 2011, de la Consejería de Agricultura, por la que se establecen las bases reguladoras de las ayudas a la modernización de explotaciones agrarias, a la primera instalación de jóvenes agricultores y a las actuaciones en materia de regadíos.

- Orden de 6 de marzo de 2012, de la Consejería de Agricultura, por la que se modifica la Orden de 27 de diciembre de 2011, por la que se establecen las bases reguladoras de las ayudas a la modernización de explotaciones agrarias, a la primera instalación de jóvenes agricultores y a las actuaciones en materia de regadíos.

- Resolución de 6 de marzo de 2012, de la Dirección General de Infraestructuras y Desarrollo Rural, por la que se convocan para el año 2012 las 
ayudas a la primera instalación de jóvenes agricultores y a la modernización de explotaciones agrarias ligadas a estas incorporaciones.

- Orden de 28/05/2013, de la Consejería de Agricultura, por la que se modifica la Orden de 27/12/2011, por la que se establecen las bases reguladoras de las ayudas a la modernización de explotaciones agrarias, a la primera instalación de jóvenes agricultores y a las actuaciones en materia de regadíos.

- Orden de 11/06/2014, de la Consejería de Agricultura, por la que se establecen las bases reguladoras de las ayudas a la modernización de explotaciones agrarias, a la primera instalación de jóvenes agricultores y a las actuaciones en materia de regadíos y se efectúa su convocatoria para 2014.

- Medida 113: Jubilación anticipada de los agricultores y trabajadores agrícolas

- Orden de 29 de mayo de 2009, de la Consejería de Agricultura y Desarrollo Rural, por la que se establece la normativa reguladora de las ayudas destinadas a fomentar la jubilación anticipada de agricultores y trabajadores agrícolas, en el marco del Programa de Desarrollo Rural de Castilla-La Mancha 2007-2013 y se convocan dichas ayudas para el año 2009.

- Medida 114: Utilización de servicios de asesoramiento

Submedida 114.1: Utilización de servicios de asesoramiento a las explotaciones agrícolas

- Orden de 10/03/2011, de la Consejería de Agricultura y Medio Ambiente, por la que se establece el procedimiento para el reconocimiento de las entidades que presten servicios de asesoramiento a las explotaciones agrarias, se regula su 
Registro Regional de Castilla-La Mancha y se establece el régimen de concesión de ayudas a su implantación y utilización.

- Resolución de 15/02/2012, de la Dirección General de Infraestructuras y Desarrollo Rural, por la que se convocan las ayudas para el año 2012 para la implantación y utilización de los servicios de asesoramiento a las explotaciones agrarias.

- Corrección de errores de la Resolución de 15/02/2012, de la Dirección General de Infraestructuras y Desarrollo Rural, por la que se convocan las ayudas para el año 2012 para la implantación y utilización de los servicios de asesoramiento a las explotaciones agrarias

\section{Submedida 114.2: Utilización de servicios de asesoramiento para la gestión forestal sostenible.}

- Orden de 26/12/2012, de la Consejería de Agricultura, por la que se establece el procedimiento para el reconocimiento de las entidades que prestan servicios de asesoramiento para la gestión forestal sostenible, y las bases reguladoras de las ayudas a la utilización de dichos servicios en el marco del Programa de Desarrollo Rural de Castilla-La Mancha 2007-2013, y se efectúa su convocatoria para el año 2013.

- Medida 115: Implantación de servicios de gestión, sustitución y asesoramiento de las explotaciones agrícolas y forestales.

\section{Submedida 115.1: Implantación de servicios de asesoramiento}

- Orden de 26/02/2007, de la Consejería de Agricultura y Desarrollo Rural, por la que se establece el procedimiento para el reconocimiento de las entidades que presten servicios de asesoramiento a las explotaciones agrarias, se precisa el régimen de concesión de ayudas para su creación, adaptación y utilización de 
conformidad con lo previsto en el Real Decreto 520/2006, de 28 de abril y se crea el Registro Regional de Castilla La Mancha de entidades que prestan servicios de asesoramiento.

- Resolución de 21/04/2008, de la Dirección General de Mejora de Explotaciones Agrarias, por la que se publica la convocatoria del año 2008 de las ayudas establecidas en la Orden de 26/02/2007 de la Consejería de Agricultura, por la que se establece el procedimiento para el reconocimiento de las entidades que presten servicios de asesoramiento a las explotaciones agrarias, se precisa el régimen de concesión de ayudas a su creación, adaptación y utilización, de conformidad con lo previsto en el Real Decreto 520/2006, de 28 de abril, y se crea el Registro Regional de Castilla-La Mancha de entidades que prestan servicios de asesoramiento.

- Orden de 21/04/2008, de la Consejería de Agricultura, por la que se modifica la Orden 26/02/2007 de la Consejería de Agricultura y Desarrollo Rural, por la que se establece el procedimiento para el reconocimiento de las entidades que presten servicios de asesoramiento a las explotaciones agrarias, se precisa el régimen de concesión de ayudas para su creación, adaptación y utilización de conformidad con lo previsto en el Real Decreto 520/2006, de 28 de abril, y se crea el Registro Regional de Castilla-La Mancha de entidades que prestan servicios de asesoramiento.

- Orden de 23/02/2010, de la Consejería de Agricultura y Desarrollo Rural, por la que se establece el procedimiento para el reconocimiento de las entidades, sin ánimo de lucro, que presten servicios de asesoramiento a las explotaciones agrarias, se regula su Registro Regional de Castilla-La Mancha y se establece el régimen de concesión de ayudas a su implantación, adaptación y utilización. 
- Resolución de 23/02/2010, de la Dirección General de Mejora de Explotaciones Agrarias, por la que se convocan las ayudas para el año 2010 para la implantación, adaptación y utilización de los servicios de asesoramiento a las explotaciones agrarias.

- Orden de 14/09/2010, de la Consejería de Agricultura y Medio Ambiente, que modifica la Orden de 23/02/2010, de la Consejería de Agricultura y Desarrollo Rural, por la que se establece el procedimiento para el reconocimiento de las entidades, sin ánimo de lucro, que prestan servicios de asesoramiento a las explotaciones agrarias, se regula su Registro Regional de Castilla-La Mancha y se establece el régimen de concesión de ayudas a su implantación, adaptación y utilización.

- Corrección de errores a la orden de 23/02/2010, de la Consejería de Agricultura y Desarrollo Rural, por la que se establece el procedimiento para el reconocimiento de las entidades, sin ánimo de lucro, que prestan servicios de asesoramiento a las explotaciones agrarias, se regula su Registro Regional de Castilla-La Mancha y se establece el régimen de concesión de ayudas a su implantación, adaptación y utilización.

- Orden de 10/03/2011, de la Consejería de Agricultura y Medio Ambiente, por la que se establece el procedimiento para el reconocimiento de las entidades que presten servicios de asesoramiento a las explotaciones agrarias, se regula su Registro Regional de Castilla-La Mancha y se establece el régimen de concesión de ayudas a su implantación y utilización.

- Resolución de 10/03/2011, de la Dirección General de Mejora de Explotaciones Agrarias, por la que se convocan las ayudas para el año 2011 para la implantación y utilización de los servicios de asesoramiento a las explotaciones agrarias. 
- Resolución de 15/02/2012, de la Dirección General de Infraestructuras y Desarrollo Rural, por la que se convocan las ayudas para el año 2012 para la implantación y utilización de los servicios de asesoramiento a las explotaciones agrarias.

- Corrección de errores de la Resolución de 15/02/2012, de la Dirección General de Infraestructuras y Desarrollo Rural, por la que se convocan las ayudas para el año 2012 para la implantación y utilización de los servicios de asesoramiento a las explotaciones agrarias.

- Resolución de 06/06/2013, de la Dirección General de Infraestructuras y Desarrollo Rural, por la que se establece el procedimiento de renovación del reconocimiento de entidades que prestan servicios de asesoramiento a las explotaciones agrarias en Castilla-La Mancha.

\section{Submedida 115.2: Implantación de servicios de asesoramiento en materia de gestión del agua.}

Orden del 2 de mayo de 2011, de la Consejería de agricultura y Medio ambiente, por la que se establecen las bases reguladoras de las ayudas destinadas a la implantación de servicios de asesoramiento en materia de gestión del agua y se convocan dichas ayudas para el año 2011.

\section{- Medida 121: Modernización de las explotaciones agrícolas}

\section{Submedida 121.1: Planes de mejora de explotaciones agrícolas}

- Orden de 26/07/2010, de la Consejería de Agricultura y Medio Ambiente, por la que se establecen las bases reguladoras de las ayudas a la modernización de explotaciones agrarias, a la primera instalación de jóvenes agricultores y a las actuaciones en materia de regadíos. 
- Orden de 27/12/2011, de la Consejería de Agricultura, por la que se establecen las bases reguladoras de las ayudas a la modernización de explotaciones agrarias, a la primera instalación de jóvenes agricultores y a las actuaciones en materia de regadíos.

- Orden de 06/03/2012, de la Consejería de Agricultura, por la que se modifica la Orden de 27/12/2011, por la que se establecen las bases reguladoras de las ayudas a la modernización de explotaciones agrarias, a la primera instalación de jóvenes agricultores y a las actuaciones en materia de regadíos.

- Resolución de 06/03/2012, de la Dirección General de Infraestructuras y Desarrollo Rural, por la que se convocan para el año 2012 las ayudas a la primera instalación de jóvenes agricultores y a la modernización de explotaciones agrarias ligadas a estas incorporaciones.

- Orden de 28/05/2013, de la Consejería de Agricultura, por la que se modifica la Orden de 27/12/2011, por la que se establecen las bases reguladoras de las ayudas a la modernización de explotaciones agrarias, a la primera instalación de jóvenes agricultores y a las actuaciones en materia de regadíos.

- Orden de 11/06/2014, de la Consejería de Agricultura, por la que se establecen las bases reguladoras de las ayudas a la modernización de explotaciones agrarias, a la primera instalación de jóvenes agricultores y a las actuaciones en materia de regadíos y se efectúa su convocatoria para 2014.

\section{Submedida 121.2: Fomento y desarrollo de sectores ganaderos}

- Orden de 01/07/2008 de la Consejería de Agricultura, por la que se establecen ayudas para el traslado de explotaciones ganaderas fuera de los cascos urbanos y se efectúa su convocatoria para 2008. 
Resolución de 10/08/2010, de la Dirección General de Producción Agropecuaria, por la que se publica el incremento de los créditos disponibles para la ayuda destinada al traslado de explotaciones ganaderas fuera de los cascos urbanos para el ejercicio 2008, en base a la Orden de 01/07/2008 de la Consejería de Agricultura, por la que se establecen ayudas para el traslado de explotaciones ganaderas fuera de los cascos urbanos y se efectúa su convocatoria para 2008.

\section{Submedida 121.3: Inversiones en explotaciones intensivas}

- Orden de 26/07/2010, de la Consejería de Agricultura y Medio Ambiente, por la que se establecen las bases reguladoras de las ayudas a la modernización de explotaciones agrarias, a la primera instalación de jóvenes agricultores y a las actuaciones en materia de regadíos.

- Corrección de errores a la Orden de 26/07/2010, de la Consejería de Agricultura y Medio Ambiente, por la que se establecen las bases reguladoras de las ayudas a la modernización de explotaciones agrarias, a la primera instalación de jóvenes agricultores y a las actuaciones en materia de regadíos.

- Resolución de 15/10/2010, de la Dirección General de Mejora de Explotaciones Agrarias, por la que se convocan para el año 2010 las ayudas a la modernización de explotaciones agrarias, a la primera instalación de jóvenes agricultores y a las actuaciones en materia de regadíos.

- Orden de 11/06/2014, de la Consejería de Agricultura, por la que se establecen las bases reguladoras de las ayudas a la modernización de explotaciones agrarias, a la primera instalación de jóvenes agricultores y a las actuaciones en materia de regadíos y se efectúa su convocatoria para 2014.

\section{Submedida 121.4: Producción de cultivos para la obtención de biomasa}


- Orden de 02/03/2012, de la Consejería de Agricultura, por la que se establecen las bases reguladoras de las ayudas a la producción de cultivos forestales para la obtención de biomasa en el marco del Programa de Desarrollo Rural de Castilla-La Mancha 2007-2013 y se efectúa su convocatoria para el año 2012.

- Medida 123: Aumento del valor añadido de los productos agrícolas y forestales

- Orden de 23 de julio de 2009, de la Consejería de Agricultura y Desarrollo Rural, por la que se establecen las bases reguladoras de las ayudas para el aumento del valor añadido de los productos agrícolas y el fomento de la calidad agroalimentaria (FOCAL).

- Resolución de 23 de julio de 2009, de la Dirección General de Desarrollo Rural, por la que se convocan, para el año 2009, las ayudas para el aumento del valor añadido de los productos agrícolas y el fomento de la calidad agroalimentaria (FOCAL) en la Comunidad Autónoma de Castilla-La Mancha.

- Orden de 31 de agosto de 2010, de la Consejería de Agricultura y Medio Ambiente, por la que se modifica la Orden de 23 de julio de 2009, de la Consejería de Agricultura y Desarrollo Rural, por la que se establecen las bases reguladoras de las ayudas para el aumento del valor añadido de los productos agrícolas y el fomento de la calidad agroalimentaria (FOCAL).

- Resolución de 31 de agosto de 2010, de la Dirección General de Desarrollo Rural, por la que se convocan, para el año 2010, las ayudas para el aumento del valor añadido de los productos agrícolas y el fomento de la calidad agroalimentaria (FOCAL) en la Comunidad Autónoma de Castilla-La Mancha. 
- Orden de 7 de octubre de 2010, de la Consejería de Agricultura y Medio Ambiente, por la que se modifica la Orden de 23 de julio de 2009, de la Consejería de Agricultura y Desarrollo Rural, por la que se establecen las bases reguladoras de las ayudas para el aumento del valor añadido de los productos agrícolas y el fomento de la calidad agroalimentaria (FOCAL).

- Resolución de 7 de octubre de 2010, de la Dirección General de Desarrollo Rural, por la que se modifica la Resolución de 31 de agosto de 2010, de la Dirección General de Desarrollo Rural, por la que se convocan, para el año 2010, las ayudas para el aumento del valor añadido de los productos agrícolas y el fomento de la calidad agroalimentaria (FOCAL) en la Comunidad Autónoma de Castilla-La Mancha.

- Orden de 13 de diciembre de 2011, por la que se modifica la Orden de 23/07/2009, de la Consejería de Agricultura y Desarrollo Rural, por la que se establecen las bases reguladoras de las ayudas para el aumento del valor añadido de los productos agrícolas y el fomento de la calidad agroalimentaria (FOCAL).

- Resolución de 14 de diciembre de 2011, por la que se convocan, para el año 2011, las ayudas para el aumento del valor añadido de los productos agrícolas y el fomento de la calidad agroalimentaria (FOCAL) en la Comunidad Autónoma de Castilla-La Mancha.

- Corrección de errores de la Resolución de 14 de diciembre de 2011, de la Dirección General de Infraestructuras y Desarrollo Rural, por la que se convocan, para el año 2011, las ayudas para el aumento del valor añadido de los productos agrícolas y el fomento de la calidad agroalimentaria (FOCAL) en la Comunidad Autónoma de Castilla-La Mancha.

- Orden de 20/02/2013, de la Consejería de Agricultura, por la que se modifica la Orden de 23/07/2009, de la Consejería de Agricultura y Desarrollo Rural, por la 
que se establecen las bases reguladoras de las ayudas para el aumento del valor añadido de los productos agrícolas y el fomento de la calidad agroalimentaria (Focal).

-Resolución de 20/02/2013, de la Dirección General de Infraestructuras y Desarrollo Rural, por la que se convocan, para el año 2013, las ayudas para el aumento del valor añadido de los productos agrícolas y el fomento de la calidad agroalimentaria (Focal) en la Comunidad Autónoma de Castilla-La Mancha.

- Orden de 14/04/2014, de la Consejería de Agricultura, por la que se modifica la Orden de 23/07/2009, de la Consejería de Agricultura y Desarrollo Rural, por la que se establecen las bases reguladoras de las ayudas para el aumento del valor añadido de los productos agrícolas y el fomento de la calidad agroalimentaria (Focal).

- Resolución de 14/04/2014, de la Dirección General de Infraestructuras y Desarrollo Rural, por la que se convocan, para el año 2014, las ayudas para el aumento del valor añadido de los productos agrícolas y el fomento de la calidad agroalimentaria (Focal) en la Comunidad Autónoma de Castilla-La Mancha.

- Medida 124: Cooperación para el desarrollo de nuevos productos, procesos y tecnologías en el sector agrícola y alimentario y en el sector forestal

- Orden de 15 de septiembre de 2010, de la Consejería de Agricultura y Medio Ambiente, por la que se establecen las bases reguladoras de las ayudas en materia de cooperación para el desarrollo de nuevos productos, procesos y tecnologías en el sector agrícola y alimentario, en el marco del Programa de Desarrollo Rural de Castilla-La Mancha para el período 2007-2013.

- Resolución de 15 de septiembre de 2010, de la Dirección General de Desarrollo Rural, por la que se convocan, para el año 2010, las ayudas en materia de cooperación para el desarrollo de nuevos productos, procesos y tecnologías en el 
sector agrícola y alimentario, en el marco del Programa de Desarrollo Rural de Castilla-La Mancha para el período 2007-2013.

- Orden de 20 de mayo de 2011, de la Consejería de Agricultura y Medio Ambiente, por la que se modifica la Orden de 15 de septiembre de 2010, por la que se establecen las bases reguladoras de las ayudas en materia de cooperación para el desarrollo de nuevos productos, procesos y tecnologías en el sector agrícola y alimentario, en el marco del Programa de Desarrollo Rural de Castilla-La Mancha para el período 2007-2013.

- Corrección de errores a la Resolución de 15 de septiembre de 2010, de la Dirección General de Desarrollo Rural, por la que se convocan, para el año 2010, las ayudas en materia de cooperación para el desarrollo de nuevos productos, procesos y tecnologías en el sector agrícola y alimentario, en el marco del Programa de Desarrollo Rural de Castilla-La Mancha para el período 2007-2013.

- Orden de 23/04/2013, de la Consejería de Agricultura, por la que se modifica la Orden de 15/09/2010, de la Consejería de Agricultura y Medio Ambiente, por la que se establecen las bases reguladoras de las ayudas en materia de cooperación para el desarrollo de nuevos productos, procesos y tecnologías en el sector agrícola y alimentario, en el marco del Programa de Desarrollo Rural de Castilla-La Mancha para el período 2007-2013.

- Resolución de 23/04/2013, de la Dirección General de Infraestructuras y Desarrollo Rural, por la que se convocan, para el año 2013, las ayudas en materia de cooperación para el desarrollo de nuevos productos, procesos y tecnologías en el sector agrícola y alimentario, en el marco del Programa de Desarrollo Rural de Castilla-La Mancha para el período 2007-2013. 


\section{- Medida 125: Infraestructuras relacionadas con la evolución y adaptación de la agricultura y la silvicultura}

\section{Submedida 125.1: Infraestructuras de gestión de recursos hídricos.}

- Orden de 26/07/2010, de la Consejería de Agricultura y Medio Ambiente, por la que se establecen las bases reguladoras de las ayudas a la modernización de explotaciones agrarias, a la primera instalación de jóvenes agricultores y a las actuaciones en materia de regadíos.

- Corrección de errores a la Orden de 26/07/2010, de la Consejería de Agricultura y Medio Ambiente, por la que se establecen las bases reguladoras de las ayudas a la modernización de explotaciones agrarias, a la primera instalación de jóvenes agricultores y a las actuaciones en materia de regadíos.

- Resolución de 15/10/2010, de la Dirección General de Mejora de Explotaciones Agrarias, por la que se convocan las ayudas para el año 2010 a la modernización de explotaciones agrarias, a la primera instalación de jóvenes agricultores y a las actuaciones en materia de regadíos.

- Orden de 28/05/2013, de la Consejería de Agricultura, por la que se modifica la Orden de 27/12/2011, por la que se establecen las bases reguladoras de las ayudas a la modernización de explotaciones agrarias, a la primera instalación de jóvenes agricultores y a las actuaciones en materia de regadíos.

\section{Submedida 125.2: Otras Infraestructuras agrarias}

- Decreto 215/2001, de 18 de diciembre, por el que se establecen los procedimientos reguladores de las Concentraciones Parcelarias de carácter privado en el ámbito de Castilla-La Mancha.

- Orden de 13 de marzo de 2002, de la Consejería de Agricultura y Medio Ambiente, que desarrolla el Decreto 215/2001, de 18 de diciembre. 
- Orden de 16 de agosto de 2012, de la Consejería de Agricultura, por la que se deroga la Orden de 13 de marzo de 2002, de la Consejería de Agricultura y Medio Ambiente, relativa a concentraciones parcelarias de carácter privado en el ámbito de Castilla-La Mancha.

\section{Submedida 125.3: Optimización y uso eficiente de recursos Hídricos}

-.Orden de 26/07/2010, de la Consejería de Agricultura y Medio Ambiente, por la que se establecen las bases reguladoras de las ayudas a la modernización de explotaciones agrarias, a la primera instalación de jóvenes agricultores y a las actuaciones en materia de regadíos.

- Corrección de errores a la Orden de 26/07/2010, de la Consejería de Agricultura y Medio Ambiente, por la que se establecen las bases reguladoras de las ayudas a la modernización de explotaciones agrarias, a la primera instalación de jóvenes agricultores y a las actuaciones en materia de regadíos.

- Resolución de 15/10/2010, de la Dirección General de Mejora de Explotaciones Agrarias, por la que se convocan las ayudas para el año 2010 a la modernización de explotaciones agrarias, a la primera instalación de jóvenes agricultores y a las actuaciones en materia de regadíos.

- Orden de 28/05/2013, de la Consejería de Agricultura, por la que se modifica la Orden de 27/12/2011, por la que se establecen las bases reguladoras de las ayudas a la modernización de explotaciones agrarias, a la primera instalación de jóvenes agricultores y a las actuaciones en materia de regadíos.

\section{Submedida 125.4: Infraestructuras ganaderas}

- Orden de 01/08/2008, de la Consejería de Agricultura, por la que se establecen las bases reguladoras de las ayudas para la instalación o mejora de 
centros de limpieza y desinfección de los vehículos destinados al transporte de ganado y se efectúa su convocatoria para el año 2008.

- Resolución de 22/10/2010, de la Dirección General de Producción Agropecuaria, por la que se publica el incremento de los créditos disponibles para la Orden 01/07/2008 de la Consejería de Agricultura, por la que se establecen las bases reguladoras de las ayudas para la instalación o mejora de centros de limpieza y desinfección de los vehículos destinados al transporte de ganado y se efectúa su convocatoria para el año 2008.

- Medida 132: Participación de los agricultores en programasrelativos a la calidad de los alimentos

- Orden de 21/12/2007, de la Consejería de Agricultura, por la que se establecen las bases reguladoras para la concesión de las subvenciones para fomentar la producción y comercialización de productos agroalimentarios de calidad diferenciada, y se realiza su convocatoria para el año 2008.

- Orden de 10/04/2008, de la Consejería de Agricultura, por la que se modifica el plazo de presentación de solicitudes de ayudas establecido en la Orden de 21/ 12/2007, por la que se establecen las bases reguladoras para la concesión de las subvenciones para fomentar la producción y comercialización de productos agroalimentarios de calidad diferenciada, y se realiza su convocatoria para el año 2008.

- Orden de 08/10/2008, de la Consejería de Agricultura y Desarrollo Rural, por la que se modifica la Orden de 21/12/2007, de la Consejería de Agricultura, por la que se establecen las bases reguladoras para la concesión de las subvenciones para fomentar la producción y comercialización de productos agroalimentarios de calidad diferenciada, y se realiza su convocatoria para el año 2008. 
- Resolución de 28/01/2009, de la Dirección General de Desarrollo Rural, por la que se convocan, para el año 2009, las ayudas para fomentar la producción y comercialización de productos agroalimentarios de calidad diferenciada.

- Resolución de 15/12/2009, de la Dirección General de Desarrollo Rural, por la que se convocan, para el año 2010, las ayudas para fomentar la producción y comercialización de productos agroalimentarios de calidad diferenciada.

- Resolución de 19/05/2010, de la Dirección General de Desarrollo Rural, por la que se modifica la Resolución de 15/12/2009, por la que se convocan para el año 2010, las ayudas para fomentar la producción y comercialización de productos agroalimentarios de calidad diferenciada.

- Resolución de 09/12/2010, de la Dirección General de Desarrollo Rural, por la que se convocan, para el año 2011, las ayudas para fomentar la producción y comercialización de productos agroalimentarios de programas relativos a la calidad diferenciada incluidos en el Programa de Desarrollo Rural (PDR).

- Resolución de 23/12/2011, de la Dirección General de Infraestructuras y Desarrollo Rural, por la que se convocan, para el año 2012, las ayudas para fomentar la producción y comercialización de productos agroalimentarios de programas relativos a la calidad diferenciada incluidos en el Plan de Desarrollo Rural.

- Resolución de 11/12/2012, de la Dirección General de Infraestructuras y Desarrollo Rural, por la que se convocan, para el año 2013, las ayudas para fomentar la producción y comercialización de productos agroalimentarios de programas relativos a la calidad diferenciada incluidos en el Programa de Desarrollo Rural.

- Medida 133: Apoyo a las agrupaciones de productores en actividades de información y promoción de programas de calidad 
-.Orden de 21/12/2007, de la Consejería de Agricultura, por la que se establecen las bases reguladoras para la concesión de las subvenciones para fomentar la producción y comercialización de productos agroalimentarios de calidad diferenciada, y se realiza su convocatoria para el año 2008.

- Orden de 10/04/2008, de la Consejería de Agricultura, por la que se modifica el plazo de presentación de solicitudes de ayudas establecido en la Orden de 21/12/2007, por la que se establecen las bases reguladoras para la concesión de las subvenciones para fomentar la producción y comercialización de productos agroalimentarios de calidad diferenciada, y se realiza su convocatoria para el año 2008.

- Orden de 08/10/2008, de la Consejería de Agricultura y Desarrollo Rural, por la que se modifica la Orden de 21/12/2007, de la Consejería de Agricultura, por la que se establecen las bases reguladoras para la concesión de las subvenciones para fomentar la producción y comercialización de productos agroalimentarios de calidad diferenciada, y se realiza su convocatoria para el año 2008.

- Resolución de 28/01/2009, de la Dirección General de Desarrollo Rural, por la que se convocan, para el año 2009, las ayudas para fomentar la producción y comercialización de productos agroalimentarios de calidad diferenciada.

- Resolución de 15/12/2009, de la Dirección General de Desarrollo Rural, por la que se convocan, para el año 2010, las ayudas para fomentar la producción y comercialización de productos agroalimentarios de calidad diferenciada.

- Resolución de 19/05/2010, de la Dirección General de Desarrollo Rural, por la que se modifica la Resolución de 15/12/2009, por la que se convocan para el año 2010, las ayudas para fomentar la producción y comercialización de productos agroalimentarios de calidad diferenciada. 
- Resolución de 09/12/2010, de la Dirección General de Desarrollo Rural, por la que se convocan, para el año 2011, las ayudas para fomentar la producción y comercialización de productos agroalimentarios de programas relativos a la calidad diferenciada incluidos en el Programa de Desarrollo Rural (PDR).

- Resolución de 23/12/2011, de la Dirección General de Infraestructuras y Desarrollo Rural, por la que se convocan, para el año 2012, las ayudas para fomentar la producción y comercialización de productos agroalimentarios de programas relativos a la calidad diferenciada incluidos en el Plan de Desarrollo Rural.

- Resolución de 11/12/2012, de la Dirección General de Infraestructuras y Desarrollo Rural, por la que se convocan, para el año 2013, las ayudas para fomentar la producción y comercialización de productos agroalimentarios de programas relativos a la calidad diferenciada incluidos en el Programa de Desarrollo Rural.

- Resolución de 27/05/2014, de la Dirección General de Infraestructuras y Desarrollo Rural, por la que se convocan, para el año 2014, las ayudas para fomentar la producción y comercialización de productos agroalimentarios de programas relativos a la calidad diferenciada incluidos en el Plan de Desarrollo Rural de Castilla-La Mancha 2007/2013 (PDR).

- Medidas 211 y 212: Ayudas destinadas a indemnizar a los agricultores por las dificultades naturales en las zonas de montaña y en otras zonas distintas de las de montaña

- Orden de 01/02/2007, de la Consejería de Agricultura y Desarrollo Rural, por la que se establecen disposiciones de aplicación del régimen comunitario de ayuda a las zonas desfavorecidas y a las zonas con limitaciones medioambientales específicas en Castilla-La Mancha en la campaña 2007. 
- Orden de 03/03/2008, de la Consejería de Agricultura y Desarrollo Rural, por la que se establecen disposiciones de aplicación del régimen comunitario de ayuda a las zonas desfavorecidas y a las zonas con limitaciones medioambientales específicas en Castilla-La Mancha en la campaña 2008.

- Orden de 29/01/2009, de la Consejería de Agricultura y Desarrollo Rural, por la que se establecen disposiciones de aplicación del régimen comunitario de ayuda a las zonas desfavorecidas y a las zonas con limitaciones medioambientales específicas en Castilla-La Mancha en la campaña 2009.

- Orden de 23/02/2010, de la Consejería de Agricultura y Desarrollo Rural, por la que se establecen disposiciones de aplicación del régimen comunitario de las ayudas destinadas a compensar las dificultades naturales en zonas de montaña y en otras zonas con dificultades en Castilla-La Mancha en la campaña 2010.

- Corrección de errores de 16/03/2010, de la Consejería de Agricultura y Desarrollo Rural, a la Orden de 23/02/2010, por la que se establecen disposiciones de aplicación del régimen comunitario de las ayudas destinadas a compensar las dificultades naturales en zonas de montaña y en otras zonas con dificultades en Castilla La Mancha en la campaña 2010.

- Orden de 10/03/2011, de la Consejería de Agricultura y Medio Ambiente, por la que se establecen disposiciones de aplicación del régimen comunitario de las ayudas destinadas a compensar las dificultades naturales en zonas de montaña y en otras zonas con dificultades en Castilla-La Mancha en la campaña 2011.

- Orden de 15/02/2012, de la Consejería de Agricultura, por la que se establecen disposiciones de aplicación del régimen comunitario de las ayudas destinadas a compensar las dificultades naturales en zonas de montaña y en otras zonas con dificultades en Castilla-La Mancha en la campaña 2012. 
- Orden de 16/04/2014, de la Consejería de Agricultura, por la que se establecen disposiciones de aplicación del régimen comunitario de las ayudas destinadas a compensar las dificultades naturales en zonas de montaña y en otras zonas con dificultades en Castilla-La Mancha en la campaña 2014.

\section{- Medida 214: Ayudas agroambientales}

- Orden de 10/01/08 de la Consejería de Agricultura, por la que se establecen las bases reguladoras de la concesión de ayudas en materia de medidas agroambientales en el marco del programa de Desarrollo Rural para Castilla-La Mancha 2007-2013.

- Orden de 24/01/08, de la Consejería de Agricultura, por la que se convocan las ayudas en materia de ayudas agroambientales para 2008.

- Orden de 29/01/2009, de la Consejería de Agricultura y Desarrollo Rural, de bases reguladoras y convocatoria de ayudas para 2009, para la concesión de subvenciones para la aplicación de las medidas agroambientales en el marco del programa de Desarrollo Rural para Castilla-La Mancha 2007-2013.

- Orden de 20/05/2009, de la Consejería de Agricultura y Desarrollo Rural, por la que se modifica la Orden de 29/01/2009, por la que se establecen las bases reguladoras y se convocan para 2009 las ayudas en materia de medidas agroambientales en el marco de los programas de desarrollo rural 2000-2006 y 20072013 en Castilla-La Mancha 2007-2013.

- Orden de 16/02/2010, de la Consejería de Agricultura y Desarrollo Rural, de bases reguladoras para la concesión de subvenciones para la aplicación de las medidas agroambientales en el marco del Programa de Desarrollo Rural para Castilla-La Mancha 2007/2013. 
- Orden de 16/02/2010, de la Consejería de Agricultura y Desarrollo Rural, por la que se convocan para 2010 varias ayudas en materia de medidas agroambientales en el marco de los programas de desarrollo rural 2000/2006 y 2007/2013 en CastillaLa Mancha.

- Orden de 19/02/2010, de la Consejería de Agricultura y Desarrollo Rural, por la que se establecen las bases reguladoras de la ayuda agroambiental para el incremento de la extensificación mediante el fomento de prácticas de pastoreo en las explotaciones de ovino-caprino de Castilla-La Mancha.

- Resolución de 19/02/2010, de la Dirección General de Producción Agropecuaria, por la que se realiza la convocatoria para 2010 de la ayuda agroambiental para el incremento de la extensificación mediante el fomento de prácticas de pastoreo en las explotaciones de ovino-caprino, en el marco del Programa de Desarrollo Rural 2007/2013 en Castilla-La Mancha.

- Corrección de errores de la Orden de 19/02/2010, por la que se establecen las bases reguladoras de la ayuda agroambiental para el incremento de la extensificación mediante el fomento de prácticas de pastoreo en las explotaciones de ovino-caprino de Castilla-La Mancha.

- Resolución de 10/03/2011, de la Dirección General de Producción Agropecuaria, por la que se realiza la convocatoria, en 2011, para renovar los compromisos de la ayuda agroambiental para el incremento de la extensificación mediante el fomento de prácticas de pastoreo en las explotaciones de ovino-caprino, en el marco del programa de desarrollo rural 2007-2013 en Castilla-La Mancha.

- Orden de 10/03/2011, de la Consejería de Agricultura y Medio Ambiente, por la que se convocan para 2011 ayudas en materia de medidas agroambientales en el marco de los programas de desarrollo rural 2000-2006 y 2007-2013 en Castilla-La Mancha. 
- Orden de 14/04/2011, de la Consejería de Agricultura y Medio Ambiente, por la que se modifica la Orden de 16/02/2010, de bases reguladoras para la concesión de subvenciones para la aplicación de las medidas agroambientales en el marco del programa de desarrollo rural para Castilla-La Mancha 2007/2013.

- Orden de 14/04/2011, de la Consejería de Agricultura y Medio Ambiente, por la que se modifica la Orden de 10/03/2011, por la que se convocan para 2011 ayudas en materia de medidas agroambientales en el marco de los programas de desarrollo rural 2000-2006 y 2007-2013 en Castilla-La Mancha.

- Orden de 15/02/2012, de la Consejería de Agricultura, de bases reguladoras para la concesión de subvenciones para la aplicación de las medidas agroambientales en el marco del Programa de Desarrollo Rural para Castilla-La Mancha 2007/2013.

- Resolución de 15/02/2012, de la Dirección General de Infraestructuras y Desarrollo Rural, por la que se realiza la convocatoria en 2012, para renovar los compromisos de las ayudas en materia de medidas agroambientales, en el marco de los programas de desarrollo rural 2000-2006 y 2007-2013 en Castilla-La Mancha.

- Orden de 28/02/2012, de corrección de errores de la Orden de 10/03/2011, de la Consejería de Agricultura y Medio Ambiente, por la que se convocan para 2011 ayudas en materia de medidas agroambientales en el marco de los programas de desarrollo rural 2000-2006 y 2007-2013 en Castilla-La Mancha.

- Orden de 21/02/2013, de la Consejería de Agricultura, por la que se modifica la Orden de 19/02/2010, de la Consejería de Agricultura y Desarrollo Rural, por la que se establecen las bases reguladoras de la ayuda agroambiental para el incremento de la extensificación mediante el fomento de prácticas de pastoreo en las explotaciones de ovino-caprino de Castilla-La Mancha. 
- Resolución de 21/02/2013, de la Dirección General de Infraestructuras y Desarrollo Rural, por la que se realiza la convocatoria, en 2013, para renovar los compromisos de la ayuda agroambiental para el incremento de la extensificación mediante el fomento de prácticas de pastoreo en las explotaciones de ovino-caprino, en el marco del Programa de Desarrollo Rural 2007-2013 en Castilla-La Mancha.

- Orden de 21/02/2013, de la Consejería de Agricultura, por la que se modifica la Orden de 15/02/2012, de bases reguladoras para la concesión de subvenciones para la aplicación de las medidas agroambientales en el marco del Programa de Desarrollo Rural para Castilla-La Mancha 2007-2013.

- Resolución de 21/02/2013, de la Dirección General de Infraestructuras y Desarrollo Rural, por la que se realiza la convocatoria en 2013, para renovar los compromisos de las ayudas en materia de medidas agroambientales en el marco de los Programas de Desarrollo Rural 2000-2006 y 2007-2013 en Castilla-La Mancha.

- Resolución de 10/02/2014 de la Dirección General de Infraestructuras y Desarrollo Rural, por la que se realiza la convocatoria en 2014, para renovar los compromisos de las ayudas en materia de medidas agroambientales en el marco de los programas de desarrollo rural 2000-2006 y 2007-2013 en Castilla- La Mancha.

- Resolución de 10/02/2014 de la Dirección General de Infraestructuras y Desarrollo Rural, por la que se realiza la convocatoria en 2014, para renovar los compromisos de la de la ayuda agroambiental para el incremento de la extensificación mediante el fomento de prácticas de pastoreo en las explotaciones de ovino-caprino, en el marco del Programa de Desarrollo Rural 2007/2013 en CastillaLa Mancha

- Orden de 23/12/2014, de la Consejería de Agricultura, por la que se reconoce la aplicación de medidas excepcionales al cumplimiento de las ayudas agroambientales al olivar ecológico derivadas de las condiciones meteorológicas 
adversas en el cultivo del olivar de Castilla-La Mancha para la campaña 2014 (cosecha 2014-2015).

\section{- Medida 221: Primera forestación de tierras agrícolas}

- Orden de 15 de mayo de 2008, de la Consejería de Medio Ambiente y Desarrollo Rural, por la que se regulan las ayudas para fomentar la primera forestación de tierras agrícolas.

- Orden de 29 de enero de 2009, de la Consejería de Agricultura y Desarrollo Rural, por la que se modifica la Orden de 15 de mayo de 2008, de la Consejería de Medio Ambiente y Desarrollo Rural, por la que se regulan las ayudas para fomentar la primera forestación de tierras agrícolas.

- Orden de 25 marzo de 2009, de la Consejería de Agricultura y Desarrollo Rural, por la que se establece un plazo extraordinario para solicitar ayudas para fomentar la primera forestación de tierras agrícolas.

-Orden de 22 de febrero de 2010, de la Consejería de Agricultura y Desarrollo Rural, por la que se modifica la Orden de 15 de mayo de 2008, de la Consejería de Medio Ambiente y Desarrollo Rural, por la que se regulan las ayudas para fomentar la primera forestación de tierras agrícolas.

- Orden de 21/02/2013, de la Consejería de Agricultura, por la que se modifica la Orden de 15/05/2008, de la Consejería de Medio Ambiente y Desarrollo Rural, por la que se regulan las ayudas para fomentar la primera forestación de tierras agrícolas.

- Resolución de 10/12/2013, de la Consejería de Agricultura, por la que se modifica la Orden de 15/05/2008, de la Consejería de Medio Ambiente y Desarrollo Rural, por la que se regulan las ayudas para fomentar la primera forestación de tierras agrícolas. 
- Medida 226: Ayudas a la recuperación del potencial forestal e implantación de medidas preventivas

\section{Submedida 226.1: Ayudas a la recuperación del potencial forestal e implantación de medidas preventivas (lucha contra incendios)}

- Orden de 1/7/2009 de la Consejería de Agricultura y Desarrollo Rural, por la que se establecen las bases reguladoras y el plazo de las convocatorias de las ayudas a la implantación de medidas preventivas de lucha contra incendios forestales en el marco del programa de desarrollo rural de Castilla-La Mancha 20072013.

- Orden de 20/10/10, de la Consejería de Agricultura y Medio Ambiente, por la que se regula la tramitación para hacer efectiva la cesión del derecho de cobro de subvenciones cuyo pago compete al Organismo pagador de Castilla-La Mancha.

- Orden de 29/12/2010, de la Consejería de Agricultura y Medio Ambiente, por la que se establecen las bases reguladoras de las ayudas forestales para la implantación de medidas preventivas de lucha contra incendios forestales y para inversiones no productivas en bosques y terrenos forestales en el marco del Programa de Desarrollo Rural de Castilla-La Mancha 2007-2013 y se efectúa su convocatoria para el año 2011.

- Corrección de errores de la Orden de 29/12/2010, por la que se establecen las bases reguladoras de las ayudas forestales para la implantación de medidas preventivas de lucha contra incendios forestales y para inversiones no productivas en bosques y terrenos forestales en el marco del Programa de Desarrollo Rural de Castilla-La Mancha 2007-2013.

- Resolución de 30/11/2011, de la Dirección General de Montes y Espacios Naturales, por la que se delegan competencias en materia de resoluciones de carácter denegatorio en los Coordinadores Provinciales de la Consejería de Agricultura, en relación con los expedientes acogidos a la Orden de 29/12/2010, de la 
Consejería de Agricultura y Medio Ambiente, por la que se establecen las bases reguladoras de las ayudas forestales para la implantación de medidas preventivas de lucha contra incendios forestales y para inversiones no productivas en bosques y terrenos forestales, y a la Orden de 15/05/2008, de la Consejería de Medio Ambiente y Desarrollo Rural, por la que se regulan las ayudas para fomentar la primera forestación de tierras agrarias en el marco del Programa de Desarrollo Rural de Castilla-La Mancha 2007-2013.

- Resolución de 22/02/2012, de la Dirección General de Montes y Espacios Naturales, por la que se delegan competencias en materia de resoluciones de carácter denegatorio en los Coordinadores Provinciales de la Consejería de Agricultura, en relación con los expedientes acogidos a la Orden de 15/05/2008, de la Consejería de Medio y Desarrollo Rural, por la que se regulan las ayudas para inversiones no productivas en bosques y terrenos forestales, y a la Orden de 01/07/2009, de la Consejería de Agricultura y Desarrollo Rural, por la que se establecen las bases reguladoras y el plazo de las convocatorias de las ayudas a la implantación de medidas preventivas de lucha contra incendios forestales en el marco del Programa de Desarrollo Rural de Castilla-La Mancha 2007-2013.

- Orden de 26/12/2013, de la Consejería de Agricultura, por la que se establecen las bases reguladoras de ayudas a la implantación de medidas preventivas de lucha contra incendios forestales en el marco del programa de desarrollo rural de Castilla-La Mancha 2007-2013 y se efectúa su convocatoria para el año 2014. 


\section{Submedida 226.2: Ayudas a la recuperación del potencial forestal e implantación de medidas preventivas (otras medidas preventivas)}

No se han publicado convocatorias de ayuda en relación a esta submedida, habiéndose formalizado en 2014 una encomienda de gestión con una empresa pública para la realización de una serie de trabajos de prevención de incendios.

- Medida 227: Ayudas para inversiones no productivas

\section{Submedida 227.1: Ayudas para inversiones no productivas (Red Natura 2000 forestal)}

- Orden de 31/10/2001, de la Consejería de Agricultura y Medio Ambiente, por la que se regulan las ayudas al desarrollo y ordenación de los bosques en zonas rurales.

- Orden de 29/12/2006, por la que se modifica la orden de 31/01/2001, de la Consejería de Agricultura y Medio ambiente, reguladora de las ayudas para fomentar la forestación de tierras agrícolas y la orden de 31/10/2001 reguladora de las ayudas para acciones de desarrollo y ordenación de los bosques en zonas rurales.

- Orden de 15/05/2008, de la Consejería de Medio Ambiente y Desarrollo Rural, por la que se regulan las ayudas para inversiones no productivas en bosques y terrenos forestales.

- Orden de 07/07/2008, de la Consejería de Medio Ambiente y Desarrollo Rural, por la que se modifica la Orden de 15/05/2008.

- Orden de 29/12/2010, de la Consejería de Agricultura y Medio Ambiente, por la que se establecen las bases reguladoras de las ayudas forestales para la implantación de medidas preventivas de lucha contra incendios forestales y para inversiones no productivas en bosques y terrenos forestales en el marco del Programa de Desarrollo Rural de Castilla-La Mancha 2007-2013 y se efectúa su convocatoria para el año 2011. 
- Corrección de errores de la Orden de 29/12/2010, por la que se establecen las bases reguladoras de las ayudas forestales para la implantación de medidas preventivas de lucha contra incendios forestales y para inversiones no productivas en bosques y terrenos forestales en el marco del Programa de Desarrollo Rural de Castilla-La Mancha 2007-2013.

- Orden de 26/12/2013, de la Consejería de Agricultura, por la que se establecen las bases reguladoras de las ayudas para la elaboración de revisiones de instrumentos de gestión forestal conforme a los postulados de la Gestión Forestal Sostenible y para la ejecución de tratamientos silvícolas en el marco del programa de desarrollo rural de Castilla-La Mancha 2007-2013 y se efectúa su convocatoria para el año 2014.

\section{Submedida 227.2. Ayudas para inversiones no productivas}

- Orden de 31/10/2011, de la consejería de agricultura y Medio ambiente, por la que se regulan las ayudas al desarrollo y ordenación de los bosques en zonas rurales.

- Orden de 29/12/2006, por la que se modifica la orden de 31/01/2001, de la Consejería de Agricultura y Medio ambiente, reguladora de las ayudas para fomentar la forestación de tierras agrícolas y la orden de 31/10/2001 reguladora de las ayudas para acciones de desarrollo y ordenación de los bosques en zonas rurales.

- Orden de 15/05/2008, de la Consejería de Medio Ambiente y Desarrollo Rural, por la que se regulan las ayudas para inversiones no productivas en bosques y terrenos forestales.

- Orden de 07/07/2008, de la Consejería de Medio Ambiente y Desarrollo Rural, por la que se modifica la Orden de 15/05/2008. 
- Orden de 29/12/2010, de la Consejería de Agricultura y Medio Ambiente, por laque se establecen las bases reguladoras de las ayudas forestales para la implantación de medidas preventivas de lucha contra incendios forestales y para inversiones no productivas en bosques y terrenos forestales en el marco del Programa de Desarrollo Rural de Castilla-La Mancha 2007-2013 y se efectúa su convocatoria para el año 2011.

- Corrección de errores de la Orden de 29/12/2010, por la que se establecen las bases reguladoras de las ayudas forestales para la implantación de medidas preventivas de lucha contra incendios forestales y para inversiones no productivas en bosques y terrenos forestales en el marco del Programa de Desarrollo Rural de Castilla-La Mancha 2007-2013.

- Orden de 26/12/2013, de la Consejería de Agricultura, por la que se establecen las bases reguladoras de las ayudas para la elaboración de revisiones de instrumentos de gestión forestal conforme a los postulados de la Gestión Forestal Sostenible y para la ejecución de tratamientos silvícolas en el marco del programa de desarrollo rural de Castilla-La Mancha 2007-2013 y se efectúa su convocatoria para el año 2014.

\section{- Medida 313: Fomento de actividades turísticas}

\section{Submedida 313.3: Fomento de actividades turísticas cinegéticas}

- Orden de 21/11/2013, de la Consejería de Agricultura, por la que se establecen las bases reguladoras de las ayudas para potenciar el aprovechamiento sostenible de los cotos privados de caza y el turismo cinegético, en el marco del programa de desarrollo rural de Castilla-La Mancha 2007-2013 y se convocan para el año 2013. 
- Medida 321: Servicios básicos para la economía y la población rural Submedida 321.2: Servicios básicos para la economía y la población rural

- Decreto 118/1973 de 12 de enero por el que se desarrolla el texto de la Ley de Reforma Agraria.

- Decreto 215/2001, de 18 de diciembre, por el que se establecen los procedimientos reguladores de las Concentraciones Parcelarias de carácter privado en el ámbito de Castilla-La Mancha.

- Orden de 13 de marzo de 2002, de la Consejería de Agricultura y Medio Ambiente, que desarrolla el Decreto 215/2001, de 18 de diciembre y se establece una línea de ayudas para subvencionar las asistencias técnicas necesarias. (Sólo vigente para concentraciones privadas ya autorizadas, derogadas para nuevas solicitudes).

- Normas jurídicas que se incardinan en la gestión administrativa de los expedientes, en especial el RDL 2/2000 de 16 de junio que desarrolla el Texto Refundido de la Ley de Contratos de las Administraciones Públicas.

- Orden de 16/08/2012 de la Consejería de Agricultura por la que se deroga la Orden de 13 de marzo de 2002, de la Consejería de Agricultura y Medio Ambiente, que desarrolla el Decreto 215/2001, de 18 de diciembre aconsejando no autorizar nuevas actuaciones para evitar inoportunos incumplimientos económicos.

- Medida 323: Conservación y mejora del patrimonio rural

\section{Submedida 323.2: Conservación y mejora del patrimonio rural}

Normativa comunitaria aplicable:

- Directiva 92/43/CEE, relativa a la Conservación de los Hábitat Naturales y la Flora y la Fauna Silvestres. 
- Directiva 2009/147/CEE, relativa a la Conservación de las Aves Silvestres.

Normativa estatal aplicable:

- Ley 3/1995, de 23 de marzo, de Vías Pecuarias.

- Ley 42/2007, del Patrimonio Natural y la Biodiversidad.

- Ley 11/2012, de 19 de diciembre, de medidas urgentes en materia de medio ambiente.

Normativa regional aplicable:

- Ley 9/2003, de Vías Pecuarias de Castilla-La Mancha.

- Ley 3/2008, de Montes y Gestión Forestal Sostenible de Castilla-La Mancha.

- Decreto 63/2003, de 16 de mayo, del uso recreativo, la acampada y la circulación de vehículos a motor en el medio natural.

- Ley 9/1999, de Conservación de la Naturaleza de Castilla-La Mancha

Resolución de la Consejera de Agricultura para la iniciación del expediente de: "Asistencia técnica para la elaboración del plan director y de los planes de gestión de los espacios de la Red Natura 2000 en Castilla-La Mancha." (21-6- 2012).

- Acuerdo entre la Consejería de Agricultura y la empresa pública para la encomienda de gestión de la asistencia técnica citada (7-8-2012).

- Resolución de aprobación de la reprogramación presupuestaria y prórroga de la propuesta de Asistencia técnica mencionada (23-12-2014).

\section{- Medida 413: Estrategias de Desarrollo Local. Calidad de vida y Diversificación}

- Orden de 15/05/2007, de la Consejería de Medio Ambiente y Desarrollo Rural, por la que se establecen medidas para la financiación de proyectos de inversión a través del Fondo Europeo Agrícola de Desarrollo Rural (FEADER), en el marco del Programa de Desarrollo Rural de Castilla-La Mancha 2007/2013. 
- Orden de 06/06/2008, de la Consejería de Medio Ambiente y Desarrollo Rural, por la que se establecen el procedimiento de selección de territorios y las disposiciones de aplicación del Eje LEADER en el marco del Programa de Desarrollo Rural de Castilla-La Mancha 2007/2013.

- Orden de 07/07/2008, de la Consejería de Medio Ambiente y Desarrollo Rural, por la que se modifica la Orden de 06-06-2008, por la que se establecen el procedimiento de selección de territorios y las disposiciones de aplicación del Eje LEADER en el marco del Programa de Desarrollo Rural de Castilla-La Mancha 2007/2013.

- Resolución de 24/06/2009, de la Dirección General de Desarrollo Rural, por la que se procede a la publicación del manual de procedimiento en el que se establece el procedimiento de gestión de las ayudas del eje 4 LEADER en el marco del Programa de Desarrollo Rural de Castilla-La Mancha 2007/2013

- Orden de 25/11/2009, de la Consejería de Agricultura y Desarrollo Rural, por la que se modifica la Orden de 06/06/2008 de la Consejería de Medio Ambiente y Desarrollo Rural, por la que se establecen el procedimiento de selección de territorios y las disposiciones de aplicación del Eje LEADER en el marco del Programa de Desarrollo Rural de Castilla-La Mancha 2007/2013.

- Resolución de 30/06/2010, de la Dirección General de Desarrollo Rural, mediante la que se determinan los parámetros de calificación de Proyectos de Interés Regional y su tramitación.

- Orden de 17/12/2012, de la Consejería de Agricultura, por la que se modifica la Orden de 06/06/2008 de la Consejería de Medio Ambiente y Desarrollo Rural, por la que se establece el procedimiento de selección de territorios y las disposiciones de aplicación del Eje LEADER en el marco del programa de Desarrollo Rural de CastillaLa Mancha 2007/2013. 
- Orden de 23/07/2014, de la Consejería de Agricultura, por la que se modifica la Orden de 06/06/2008 de la Consejería de Medio Ambiente y Desarrollo Rural, por la que se establecen el procedimiento de selección de territorios y las disposiciones de aplicación del Eje Leader en el marco del Programa de Desarrollo Rural de Castilla-La Mancha 2007/2013.

\section{- Medida 421: Cooperación internacional o transnacional}

- Orden de 15/05/2007, de la Consejería de Medio Ambiente y Desarrollo Rural, por la que se establecen medidas para la financiación de proyectos de inversión a través del Fondo Europeo Agrícola de Desarrollo Rural (FEADER), en el marco del Programa de Desarrollo Rural de Castilla-La Mancha 2007/2013.

- Orden de 06/06/2008, de la Consejería de Medio Ambiente y Desarrollo Rural, por la que se establecen el procedimiento de selección de territorios y las disposiciones de aplicación del Eje LEADER en el marco del Programa de Desarrollo Rural de Castilla-La Mancha 2007/2013.

- Orden de 07/07/2008, de la Consejería de Medio Ambiente y Desarrollo Rural, por la que se modifica la Orden de 06/06/2008, por la que se establecen el procedimiento de selección de territorios y las disposiciones de aplicación del Eje LEADER en el marco del Programa de Desarrollo Rural de Castilla-La Mancha $2007 / 2013$.

- Orden de 25/11/2009, de la Consejería de Agricultura y Desarrollo Rural, por la que se modifica la Orden de 06/06/2008 de la Consejería de Medio Ambiente y Desarrollo Rural, por la que se establecen el procedimiento de selección de territorios y las disposiciones de aplicación del Eje LEADER en el marco del Programa de Desarrollo Rural de Castilla-La Mancha 2007/2013. 
- Orden de 17/12/2012, de la Consejería de Agricultura, por la que se modifica la Orden de 06/06/2008 de la Consejería de Medio Ambiente y Desarrollo Rural, por la que se establece el procedimiento de selección de territorios y las disposiciones de aplicación del Eje LEADER en el marco del programa de Desarrollo Rural de CastillaLa Mancha 2007/2013.

- Orden de 23/07/2014, de la Consejería de Agricultura, por la que se modifica la Orden de 06/06/2008 de la Consejería de Medio Ambiente y Desarrollo Rural, por la que se establecen el procedimiento de selección de territorios y las disposiciones de aplicación del Eje Leader en el marco del Programa de Desarrollo Rural de Castilla-La Mancha 2007/2013.

\section{Medida 431: Funcionamiento del grupo de desarrollo rural, adquisición de capacidades y promoción territorial}

-.Orden de 15/05/2007, de la Consejería de Medio Ambiente y Desarrollo Rural, por la que se establecen medidas para la financiación de proyectos de inversión a través del Fondo Europeo Agrícola de Desarrollo Rural (FEADER), en el marco del Programa de Desarrollo Rural de Castilla-La Mancha 2007/2013.

- Orden de 06/06/2008, de la Consejería de Medio Ambiente y Desarrollo Rural, por la que se establecen el procedimiento de selección de territorios y las disposiciones de aplicación del Eje LEADER en el marco del Programa de Desarrollo Rural de Castilla-La Mancha 2007/2013.

- Orden de 07/07/2008, de la Consejería de Medio Ambiente y Desarrollo Rural, por la que se modifica la Orden de 06-06-2008, por la que se establecen el procedimiento de selección de territorios y las disposiciones de aplicación del Eje LEADER en el marco del Programa de Desarrollo Rural de Castilla-La Mancha $2007 / 2013$. 
- Orden de 25/11/2009, de la Consejería de Agricultura y Desarrollo Rural, por la que se modifica la Orden de 06/06/2008 de la Consejería de Medio Ambiente y Desarrollo Rural, por la que se establecen el procedimiento de selección de territorios y las disposiciones de aplicación del Eje LEADER en el marco del Programa de Desarrollo Rural de Castilla-La Mancha 2007/2013.

- Resolución de 30/06/2010, de la Dirección General de Desarrollo Rural, mediante la que se determinan los parámetros de calificación de Proyectos de Interés Regional y su tramitación.

- Orden de 17/12/2012, de la Consejería de Agricultura, por la que se modifica la Orden de 06/06/2008 de la Consejería de Medio Ambiente y Desarrollo Rural, por la que se establece el procedimiento de selección de territorios y las disposiciones de aplicación del Eje LEADER en el marco del programa de Desarrollo Rural de CastillaLa Mancha 2007/2013. 


\section{CAPITULO 6: COMARCA DE TORRIJOS}




\section{CAPITULO 6: COMARCA DE TORRIJOS}

\subsection{Caracterización de la comarca.}

Vamos a describir el territorio de nuestra actuación, la comarca de Torrijos, en primer lugar vamos a describir el territorio desde el punto de vista del medio físico, para lugar analizar la población y la actividad realizando una comparación entre el año 1989 y el 2009, para ver cómo ha evolucionado.

\section{- Características Geográficas}

La Comarca de Torrijos es una de las diez comarcas en las que está dividida la provincia de Toledo, limítrofe y equidistante con las dos principales ciudades de la provincia: Toledo y Talavera de la Reina.

Tiene una extensión de 1.918,37 Km², y 87.272 hab $^{30}$, es decir una densidad de población de $45 \mathrm{hab} / \mathrm{km}^{2}$.

Los límites son con el río Guadarrama y la comarca de la Sagra en la zona oriental; al norte con la Comunidad de Madrid; al sur la limita el río Tajo, y al oeste por la comarca de Talavera de la Reina y la sierra de San Vicente.

${ }^{30}$ Datos INE 2011 
Fig. 21: Distribución por comarcas de la provincia de Toledo.

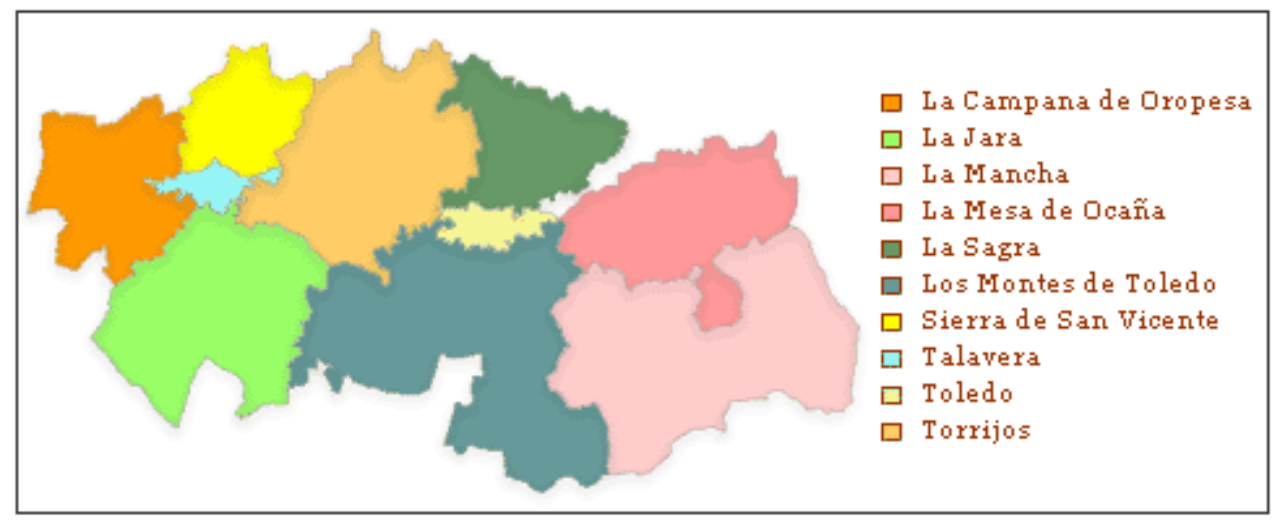

Fuente: Diputación de Toledo, 2011

\section{- Características Climatológicas}

Las características climáticas de la zona se corresponden con las de un tipo mediterráneo de matiz continental: inviernos fríos y veranos cortos, secos y calurosos; las diferencias térmicas entre temperaturas máximas y mínimas dentro de cada estación son importantes con un régimen de lluvias escaso.

Por lo general la temperatura media anual oscila en torno a los $12,5-17,5 \stackrel{\circ}{ } \mathrm{C}$. En invierno las temperaturas medias no son extremadamente frías ( $6 \stackrel{\circ}{\mathrm{C}}$ en enero), sin embargo las mínimas son bajas y muchos días se registran temperaturas por debajo de $0 \stackrel{\circ}{\circ}$ e incluso $-5 \stackrel{\circ}{\circ}$ (de 40 a 90 días con registros inferiores a $0^{\circ} \mathrm{C}$ ). El valle medio del Tajo se caracteriza por un clima más cálido que la zona norte del valle del Alberche, registrándose temperaturas máximas absolutas en verano de 40 ․ C. Las heladas y nieblas en invierno son frecuentes sobre todo en el valle del Tajo.

Las precipitaciones son escasas (400-600 mm), con valores medios de 534,5 $\mathrm{mm}$ en el valle del Alberche y los escasos $376 \mathrm{~mm}$ de precipitación media anual que registra el observatorio de Toledo, caracterizando al valle medio del Tajo como una de las zonas más secas de la región. En cuanto a su distribución a lo largo del año corresponden a los meses de noviembre y diciembre los de mayor precipitación, 
frente a la acusada sequía estival, caracterizada por unos meses de julio y agosto muy secos.

La coincidencia de los máximos térmicos estivales con los mínimos pluviométricos determina unos elevados índices de aridez en una zona muy apta para el cultivo, con prolongados periodos de sequía.

\section{- Características Orográficas e Hidrológicas}

La comarca de Torrijos, está enclavada en la denominada Cuenca sedimentaria del Tajo, de suave llanura con una altitud media entorno a los $500 \mathrm{~m}^{31}$ y una pendiente media del $3 \%$.

Se corresponde con una zona de lomas y amplios valles modelados sobre arenas y arcosas miocenas de la cuenca del Tajo, ocupando el $88 \%$ de la superficie de la comarca, y una pequeña zona de suelos aluviales, coluviales transformados por el riego en los cursos fluviales, como podemos ver a continuación en el mapa litológico.

Las arcosas constituyen los terrenos típicamente cerealistas de Toledo, se consideran unos suelos, en conjunto semipermeables, con abundancia de "aguas colgadas", acuíferos a profundidades mayores de $5 \mathrm{~m}$ en estos terrenos.

\footnotetext{
${ }^{31}$ Ver Mapa Hipsométrico en página siguiente.
} 
Fig. 22: Mapa Litológico Comarca Torrijos.

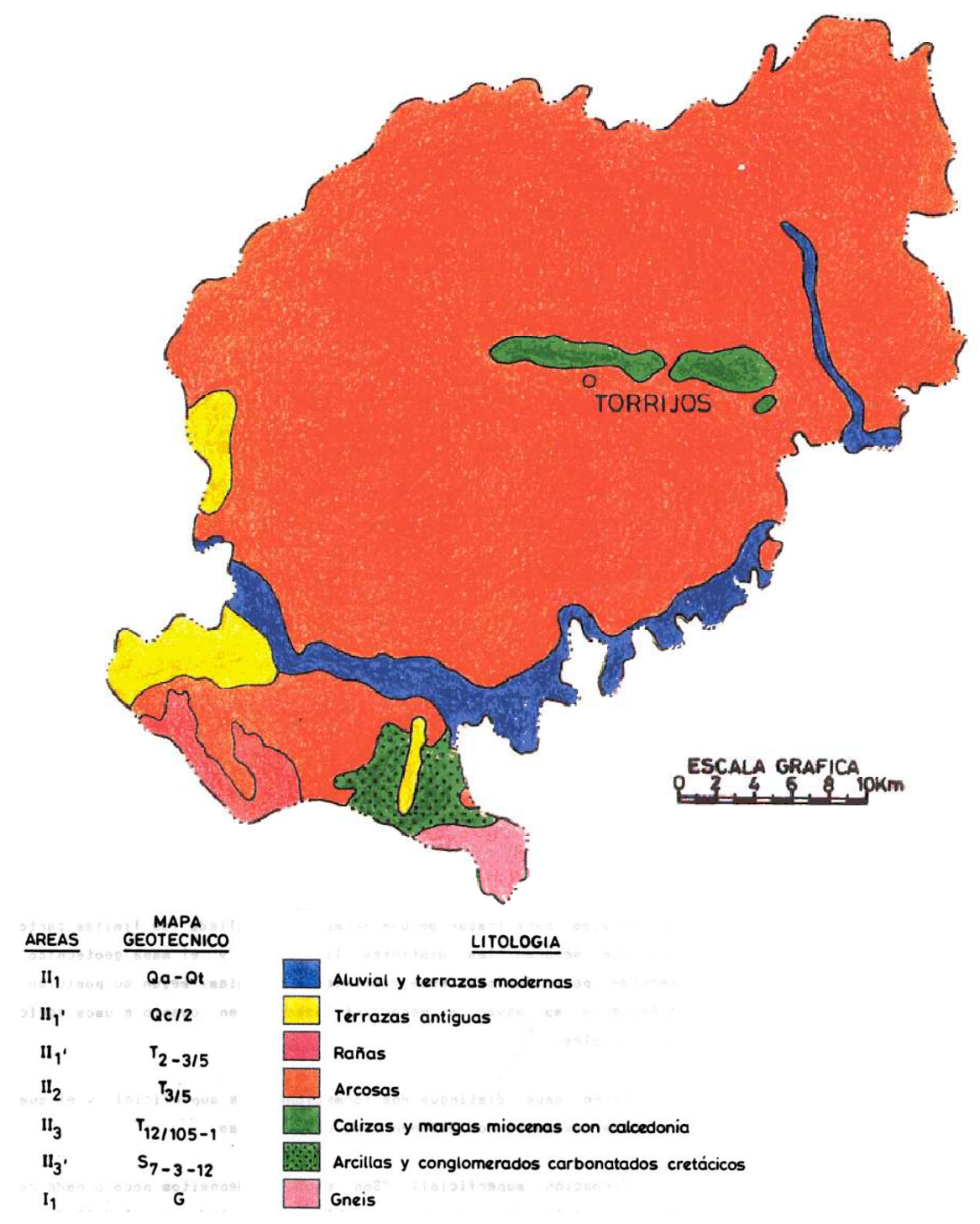

Fuente: Fuente: de la Horra, 1992

El sistema hídrico de la comarca pertenece a la Cuenca Hidrográfica del Tajo. El sur de la comarca es atravesado por el río Tajo, la ribera media del Tajo, dando lugar a los terrenos más ricos desde el punto de vista agrario. De norte a sur la atraviesan el río Alberche por el noroeste y el Guadarrama desde el nordeste, como afluentes principales del Tajo. Una red de arroyos y embalses (Embalse de Castrejón-El Carpio y Embalse de Castrejón) completan la red fluvial. 
Fig. 23: Mapa Hipsométrico de la comarca de Torrijos.

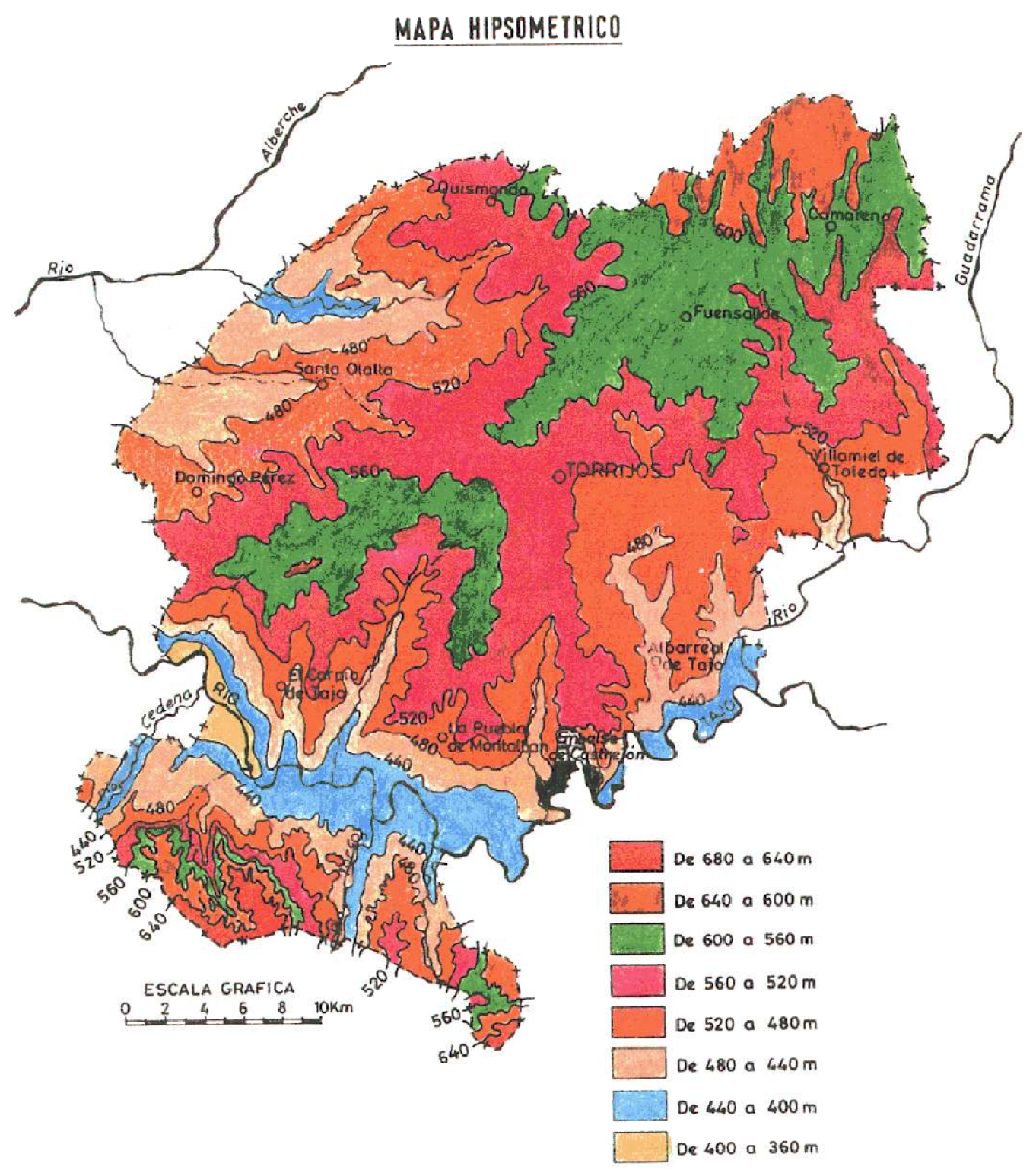

Fuente: de la Horra, 1992. 


\section{- Patrimonio natural}

De la vegetación primigenia, correspondiente a la zona, de encinares tipo carrasca de Quercus rotundifolia queda poco o nada. Actualmente la vegetación natural autóctona aparece únicamente en determinados lugares representativos, allí donde la topografía es más agreste.

La acción del hombre ha dado lugar a una profunda transformación paisajística con la introducción de cultivos, principalmente de la llamada "trilogía mediterránea" cereal, vid y olivo. Las zonas en las que todavía existe vegetación natural las encontramos hacia el noroeste con dehesas de encinas (Quercus ilex. Subsp. rotundifolia) bien conservadas y en el valle del Alberche con restos de vegetación de ribera. La ribera del Tajo se encuentra prácticamente roturada por cultivos con una vegetación ripícola ${ }^{32}$ bastante alterada; el matorral tipo mediterráneo de porte arbustivo o subarbustivo, resultado de la degradación del bosque primigenio, es lo que encontramos en el interior de la comarca.

En el entorno inmediato a Castrejón existen formaciones de encinares y coscojares, bien conservadas, y de monte bajo con cultivos de secano, que constituyen los mejores hábitat de alimentación y dispersión de especies en peligro como el águila imperial ibérica o el buitre negro.

En el entorno de Torrijos destacan las extensas zonas esteparias que quedan al norte del río Tajo, donde en armonía con las prácticas agrarias tradicionales conviven especies como la avutarda, la ortega, el sisón, el aguilucho cenizo o el cernícalo primilla.

\footnotetext{
${ }^{32}$ Vegetación asociada a las riberas y vegas de un río.
} 
Los recursos cinegéticos y piscícolas son importantes en la comarca. Como toda la tierra toledana, la comarca de Torrijos es rica en caza menor, ocupando lugar preferente la perdiz que se caza según el método del ojeo; también liebre, que permite el deporte de la caza con galgo, y conejo, en mano y con perro. Destacamos también la codorniz y las torcaces. En cuanto a la pesca, el Tajo, sus afluentes y sus embalses permiten la captura de bogas, barbos, carpas comunes y reales, lucios, etc.

Mencionar los 3 espacios protegidos de la comarca LIC y ZEPA, incluidos en la Red Natura $2000^{33}$ :

- ZEPA ES0000435: Área esteparia del Margen derecha del río Guadarrama

- ZEPA ES0000169, LICES0000169: Río Tajo en Castrejón. Islas de Malpica y Azután.

- ZEPA ES 0000391: Pinar de Almorox

${ }^{33}$ Toda la información que aparece a continuación es de la JCCM 2006. 
Fig. 24: Área esteparia del Margen derecha del río Guadarrama.

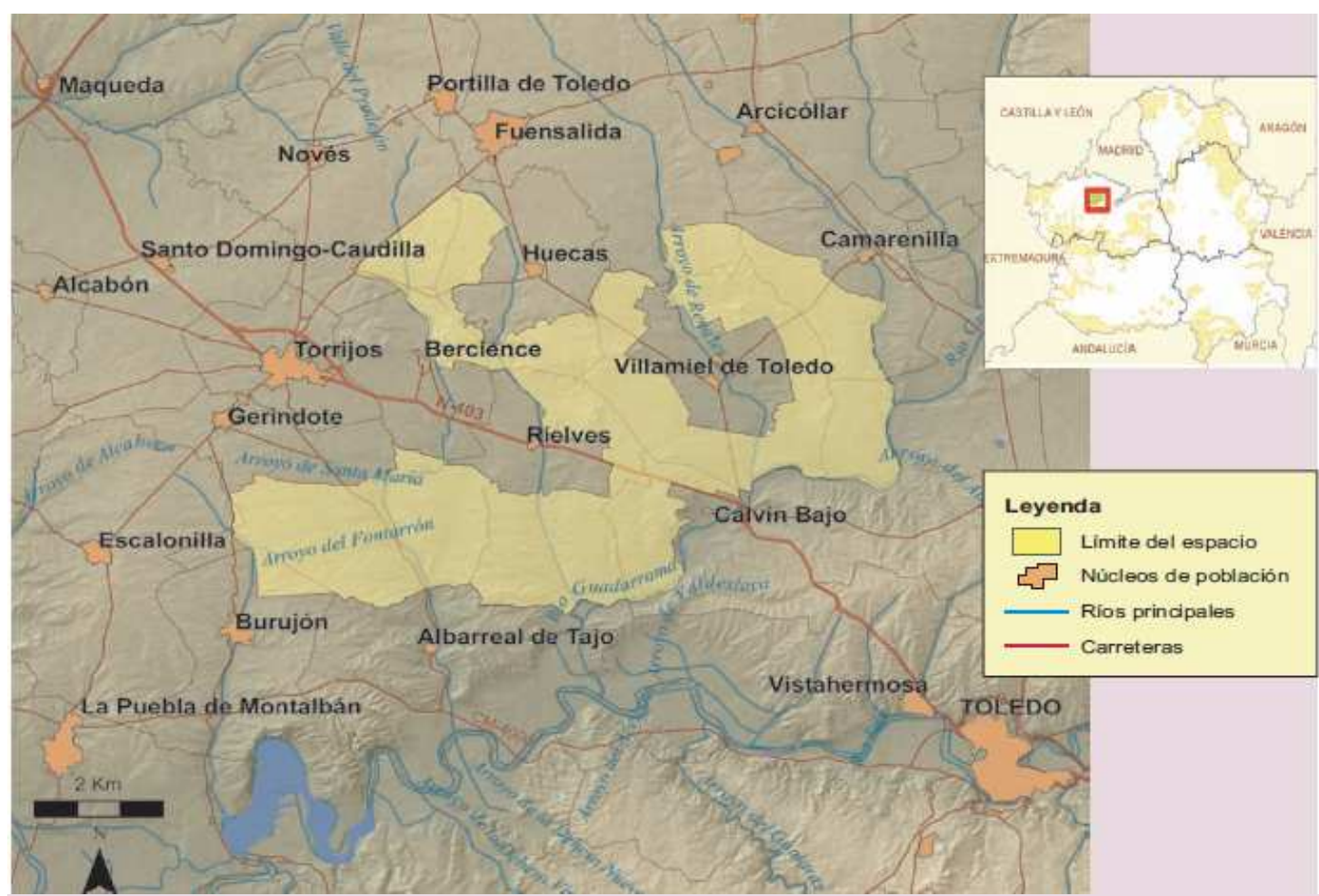

\section{FICHA TÉCNICA RESUMEN}

Código RN 2000: ES0000435. Nombre: Área Esteparia de la Margen Derecha del río Guadarrama. Provincia: Toledo. Extensión: 12.703 ha.

Términos Municipales: Barcience, Bargas, Burujón, Camarenilla, Escalonilla, Fuensalida, Gerindote, Huecas, Novés, Rielves y Villamiel de Toledo.

Hábitat característicos: ambientes esteparios y subesteparios en general, como llanuras cerealistas, cultivos de secano, pastizales anuales, olivares, viñedos, tomillares, etc. Presencia de muestras pequeñas de encinar y restos de comunidades de bosque ymatorral ripario.

Valores sobresalientes y especies más representativas y singulares: importantes pobladiones de avutarda, ganga, ortega, sisóny cernicalo primilla.

Otras figuras de protección: noexisten.

Época aconsejada de visita y otras recomendaciones: primavera y otoño. Acceso principal desde Toledo capital, o desde Torrijosy Fuensalida. 


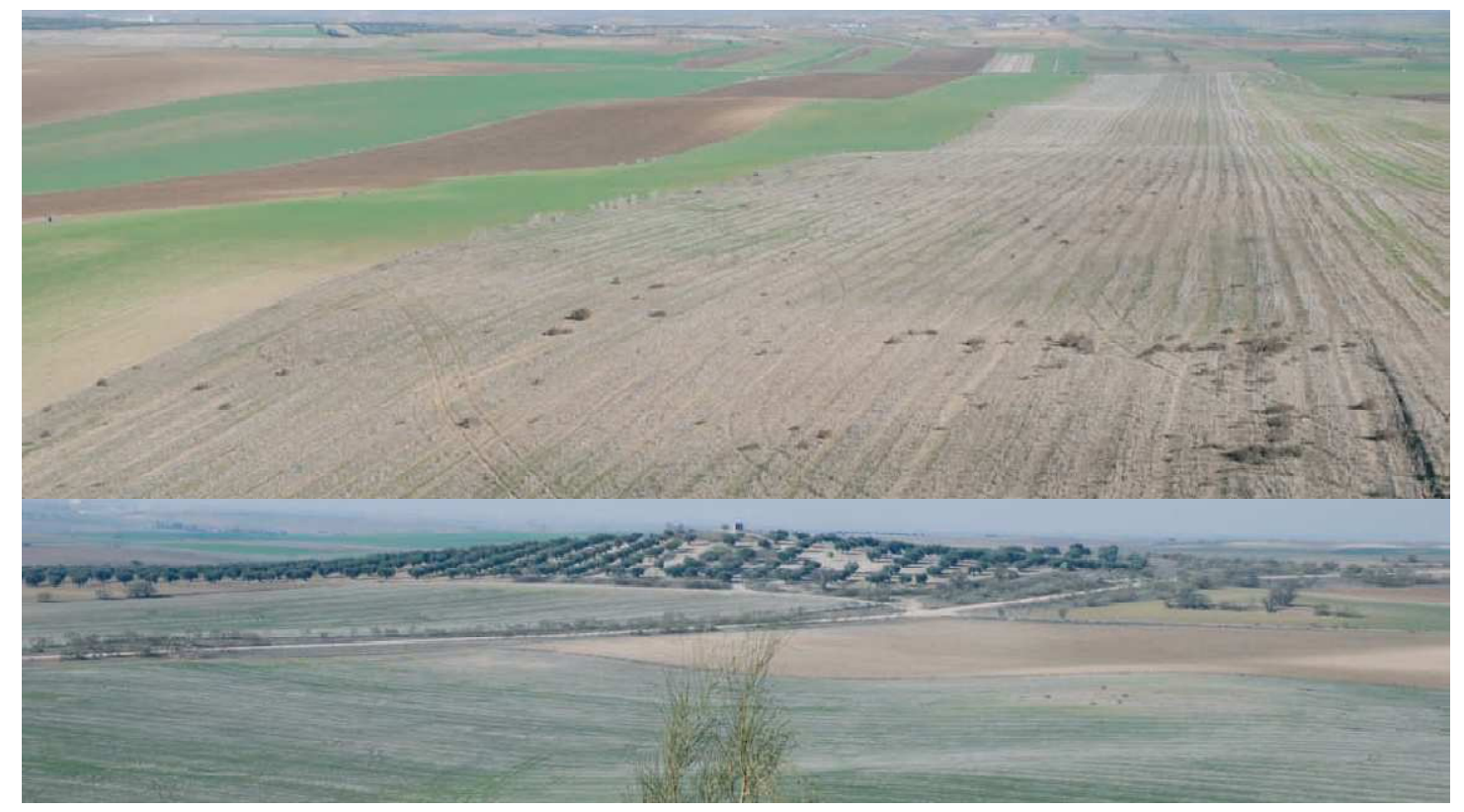

Podemos observar un mosaico de cultivos y barbechos, y un paisaje alomado de olivares y retamares 
Fig. 25: Río Tajo en Castrejón.

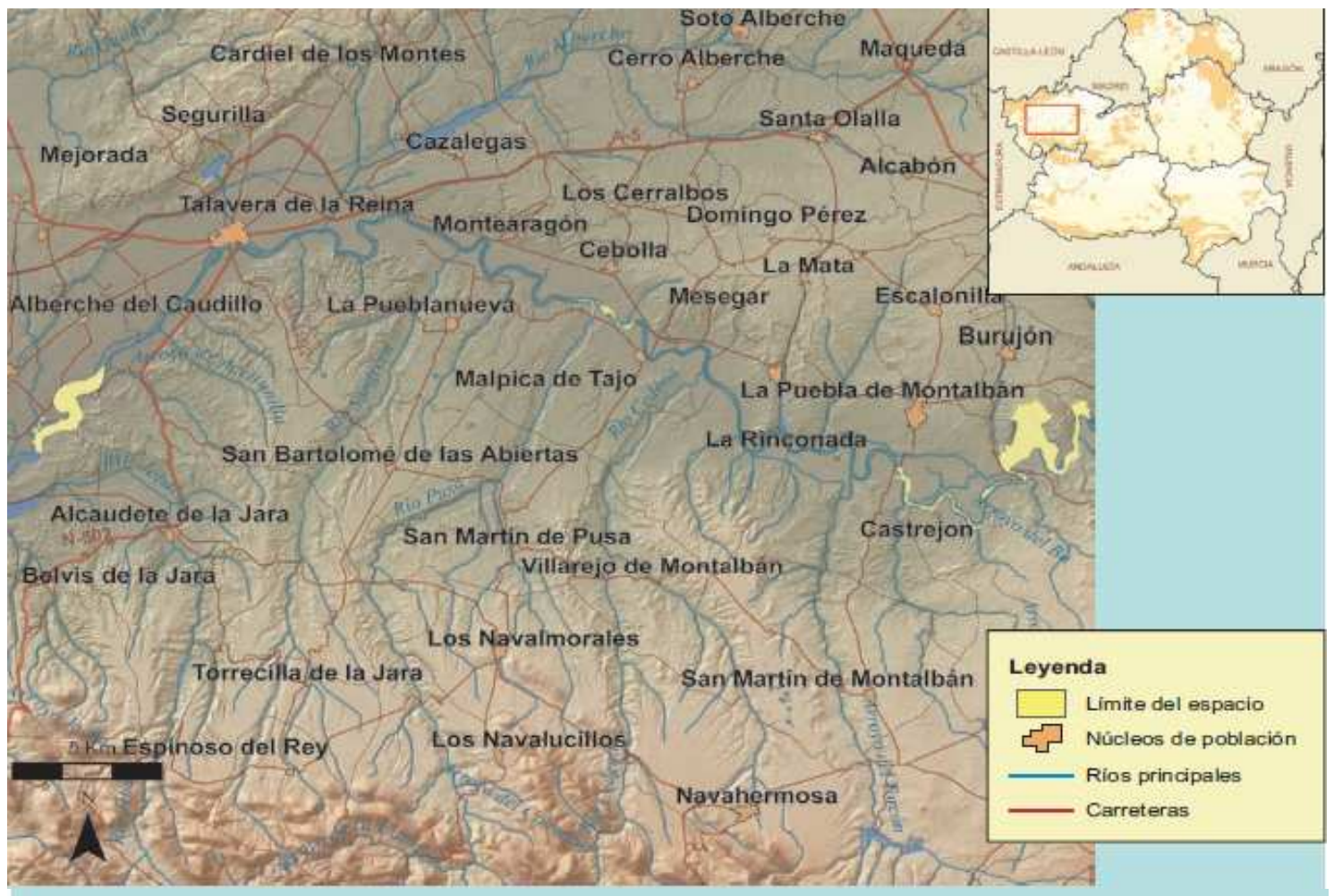

\section{FICHA TÉCNICA RESUMEN}

Código RN 2000ZEPA y LIC: ES0000 I69. Nombre: Rio Tajo en Castrejón, Islas de Malpica de Tajoy Azután.

Provincia: Toledo. Extensión: 1.972 ha.

Términos Municipales: Albarreal de Tajo, Belvis de la jara, Burujón, Calera y Chozas, Cebolla, Las Herencias, Malpica de Tajo, Polán, La Puebla de Montalbán.

Hábitat caracteristicos: embalse, islas, riberas, terrazas y cortados fluviales. Bosque de ribera: alamedas, fresnedas, tarayales, saucedas, juncales y vegetacion palustre de eneas y carrizos. Bosquetes y dehesas deencina.

Valores sobresalientes y especies más representativas y singulares: hábitat palustres bien conservados que sustentan importantes colonias de nidificadón de aves acuáticas, con dormideros y zonas de invernada. Presencia de especies amenazadas como el calamón, d avetorillo y el avetoro. Sustenta las colonias de ardeidas más importantes del interior penin sular. Los cortados son hábitat idóneo para rapaces rupicolas, como águila perdicera. Poblaciones de aves esteparias, especialmente avutarda, sisón, ganga y ortega. Mamiferos: nutria. Reptiles: galápago leproso. Ciprinidos: boga de rio, calandino y bar bo comizo.

Otras figuras de protección: induye los Refugios de Fauna delos Embalses de Castrejóny Azután.

Época aconsejada de visita y otras recomenda ciones: todo el año para observación de aves; primavera para la observación de flora y vegetación. Talavera de La Reina y La Puebla de Montalbán son las localidades más adecuadas como base para la visita.

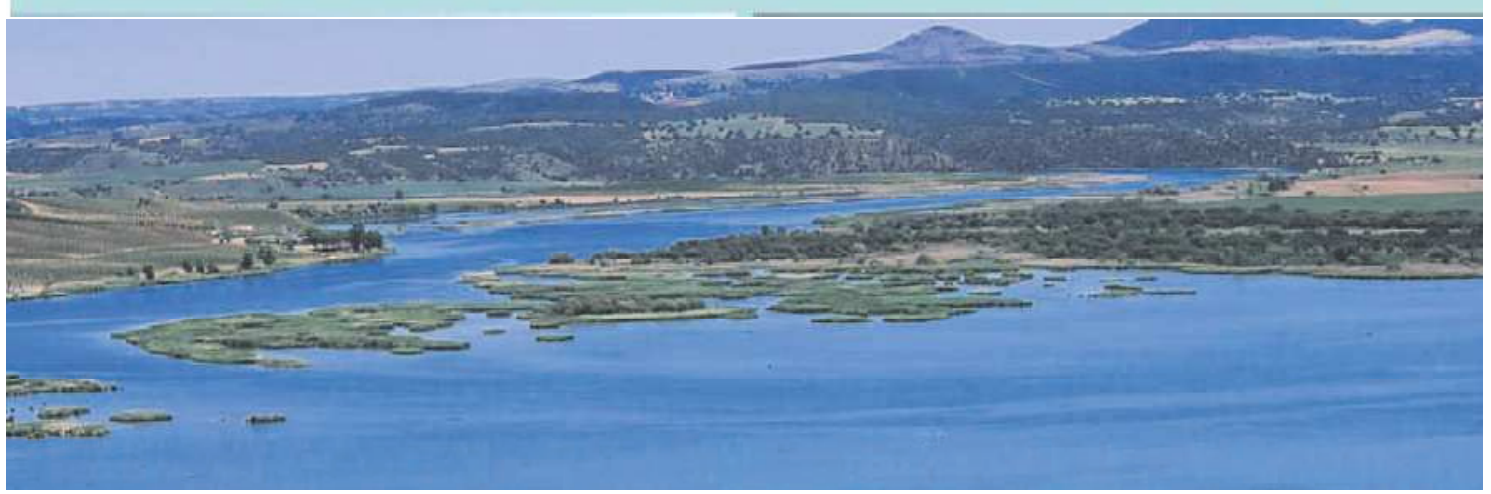

Fuente: JCCM, 2006. 
Fig. 26: Pinar de Almorox.

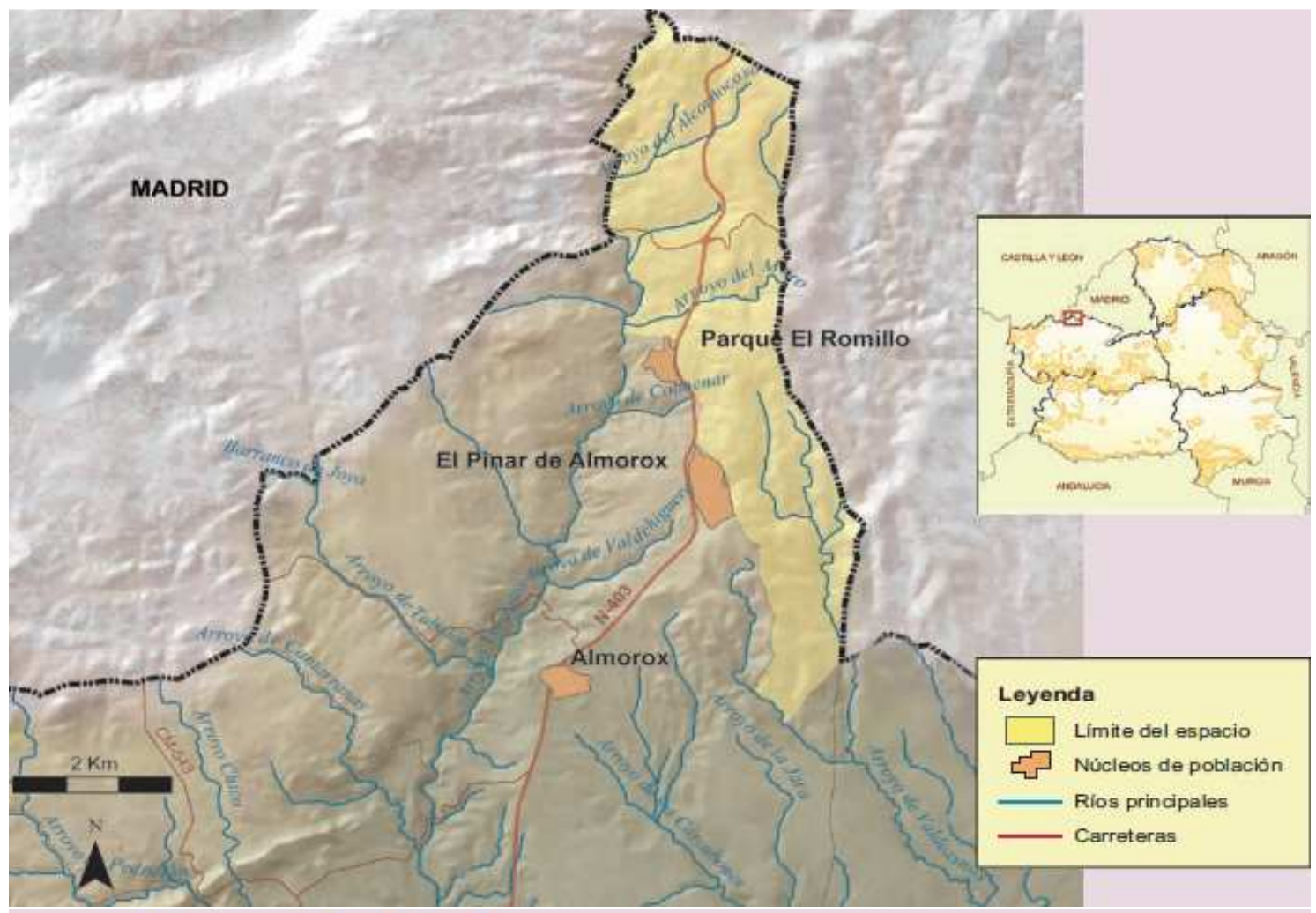

\section{FICHA TÉCNICA RESUMEN}

Código RN 2000: ES0000391. Nombre: Pinar de Almorox. Provincia: Toledo. Extensión: 1.479 ha.

Términos Municipales: Amorox.

Hábitat caracteris ticos: pinar de piñonero (Ainus pinea) sobre berrocal, arenas con matorral de cistáceas y romeral. Encinar (Quercus ilex), bosque mixto, retamar yenebral. Pequeños arroyosestadionales.

Valores sobresalientes y especies más representativas y singulares: pinar maduro, con ejemplares notables. Valores estéticos y recreativos. Rapaces de interés, principalmente águila imperial ibérica. Además otras muchas especies de aves de carácter forestal.

Otras figuras de protección: área critica de águila imperial ibérica, cigüeña negra y buitre negro, designada en los planes de conservación de estas especies.

Época aconsejada de visita y otras recomendaciones: acceso desde el cruce de la carretera Toledo-Ávila conla de Madrid-

Cenicientos. Existen instalaciones de uso recreativo.

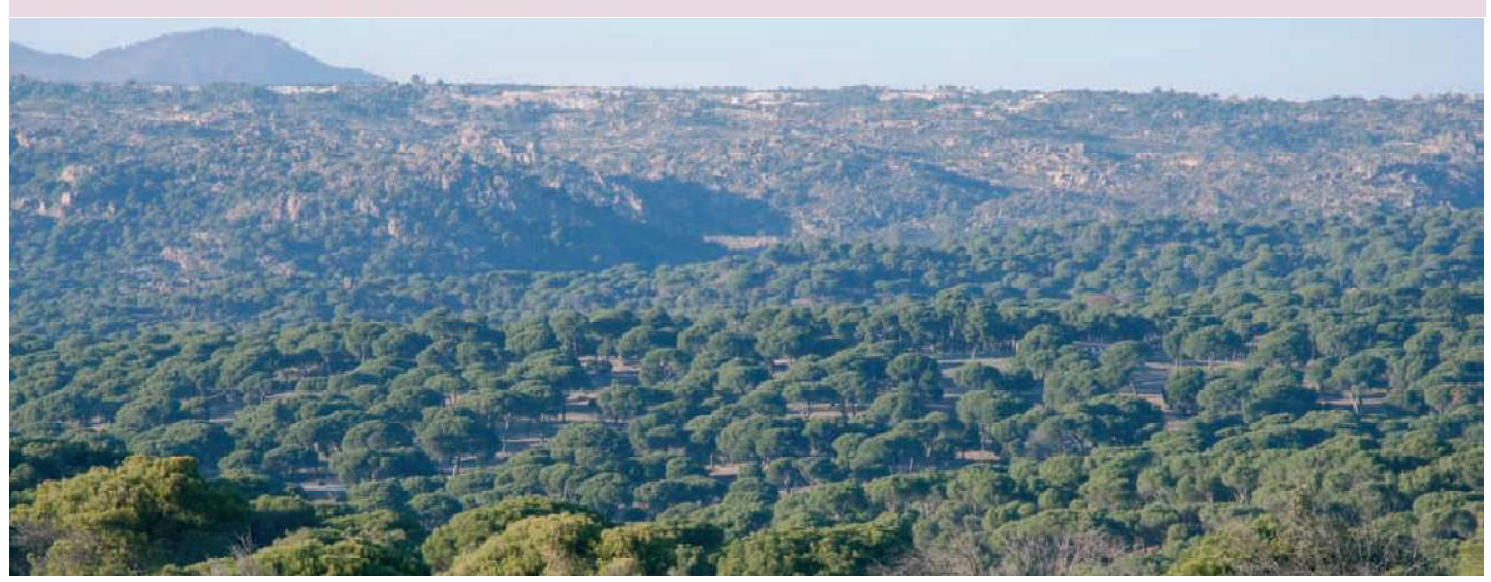

Fuente: JCCM, 2006. 


\section{- Infraestructuras}

Las vías de comunicación más importantes son la $\mathrm{N}-\mathrm{V}$ que cruza la comarca de noreste a este, la N-403 que cruza la comarca de norte a sureste. Además hay una autopista R-5 de peaje que acerca aún más la comarca a Madrid.

Se observa que los poblamientos más importantes están localizados en las áreas de influencia de dichas vías de comunicación.

En los últimos años se ha producido una sustancial mejora de la red de transportes y comunicaciones que une los pueblos de la comarca entre sí, así como en los ejes de comunicación de ámbito regional y nacional que la atraviesan. De este modo, aunque la lógica de trazados no responde a las necesidades comarcales, puede afirmarse que los factores de localización y comunicación de la comarca constituyen un importante recurso a tener en cuenta de cara a su desarrollo, especialmente con relación a la proximidad de grandes mercados.

A pesar de dichas mejoras, persisten algunas deficiencias, como por ejemplo, la pobre conexión entre Fuensalida y Torrijos (por una carretera local), los dos mayores núcleos de la comarca. 
Fig. 27: Mapa carreteras de la comarca.

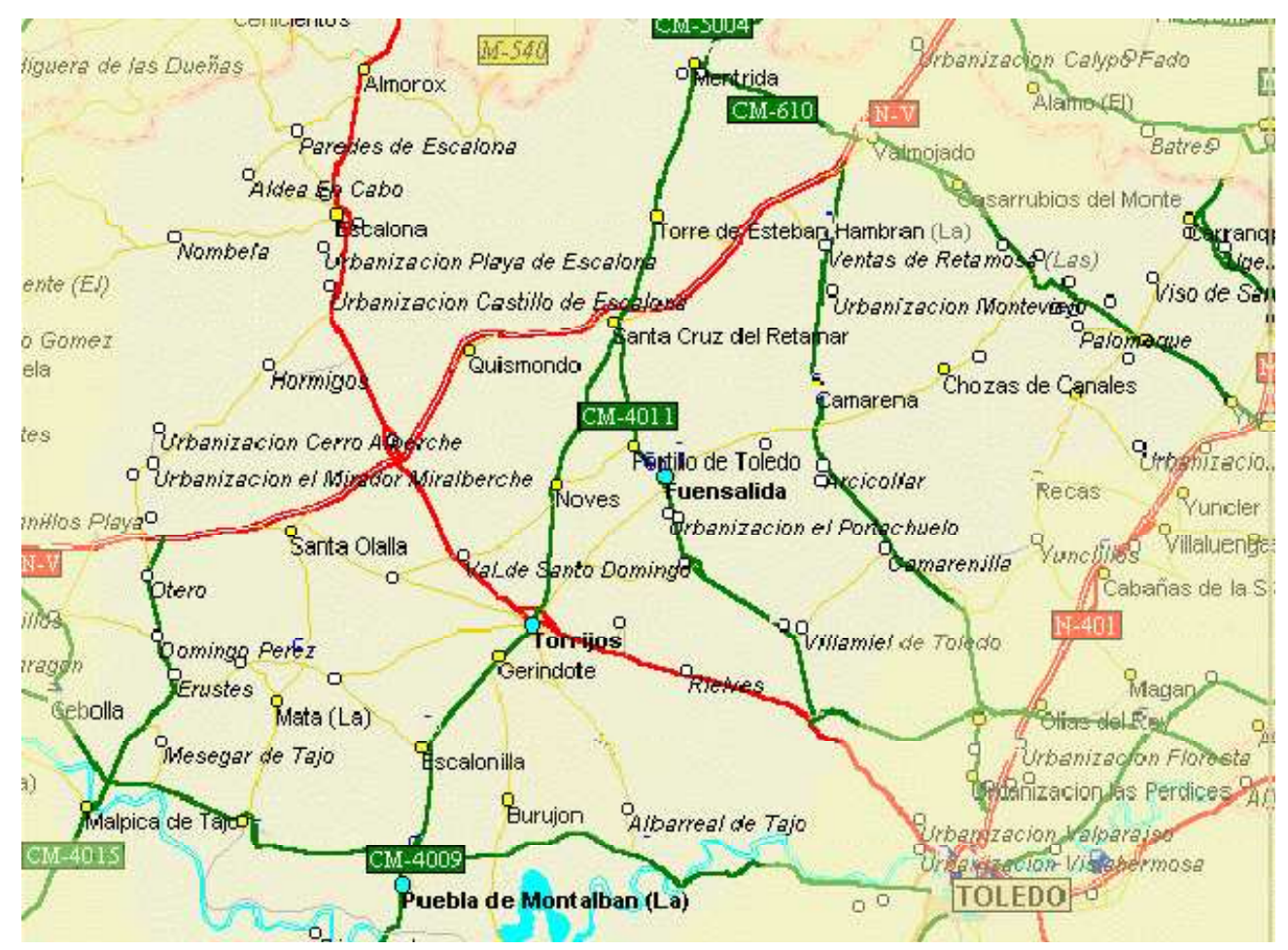

Fuente: Diputación de Toledo, 2009.

El transporte público urbano intra y extra comarcal está bastante bien dotado en cuanto a frecuencias, calidad del servicio, itinerarios etc.

El ferrocarril cruza la comarca de este a oeste por la zona centro, pasando por Torrijos.

Se puede observar la existencia de un flujo de población de los municipios de menor tamaño a los de mayor, que en la mayoría de los casos es diario, dado que la distancia a recorrer es pequeña y las vías de comunicación favorecen que el trayecto se realice en un corto período de tiempo. A parte de estos movimientos locales, se constata movimientos extra comarcales, siendo cada vez más abundantes hacia Madrid.

Los equipamientos sociales presentan un nivel satisfactorio en el conjunto de la comarca. Una de las principales fuentes de problemas se encuentra en la situación 
de algunos municipios que tienen una gran presencia de residentes no empadronados, antiguos residentes secundarios que se instalan en las urbanizaciones con carácter permanente. Estos "inmigrantes invisibles" demandan servicios municipales que las corporaciones no pueden financiar, a la vez que impiden que las mismas corporaciones accedan a financiación para ofrecer servicios nuevos.

\section{- Urbanismo y vivienda}

Según los datos de la Diputación provincial de Toledo, a 31 de diciembre de 2009 , el $26,5 \%$ de los municipios de la comarca carecía de cualquier clase de figura de planeamiento propio (Plan General, Normas Subsidiarias o Delimitación de Suelo Urbano), utilizando las Normas Subsidiarias Provinciales. Esta ausencia, no obstante, sólo afecta al 16,6\% de la población: son los municipios, por tanto, con menor número de habitantes.

El planeamiento existente, además, es ya veterano, con una media de antigüedad de 11 años desde la fecha de aprobación definitiva. De hecho, casi el $20 \%$ de la población vive en municipios con planeamiento cuya vigencia tiene más de 16 años: estos municipios son sólo el $12,2 \%$ del total.

Es evidente que se produce una inadecuación entre las actuales necesidades y la realidad para la que se redactó la planificación territorial en una buena parte de la comarca. Por otra parte, los municipios que han redactado recientemente sus documentos de planeamiento no lo han planteado desde una óptica comarcal, y no se han establecido mecanismos de cooperación: son frecuentes las interrupciones en clasificación y calificación de terrenos por los límites de término municipal o la diferente denominación para elementos con idéntica categoría, sobre todo en el suelo no urbanizable. 
La oferta de suelo residencial, en muchos casos, viene determinada por el resultado de las presiones y negociaciones entre Ayuntamientos, constructores y propietarios de terrenos para determinar sobre quiénes debe repercutirse el coste de la urbanización.

Por su parte, la población tiende a abandonar algunos cascos urbanos, por las dificultades de edificabilidad que pueden marcar las normas, o bien porque el patrón dominante de la demanda obedece al modelo de vivienda unifamiliar con patio o jardín, modelo que sólo puede ofertarse en las nuevas promociones que se realizan en las nuevas áreas de intervención o planes parciales, y no en los cascos urbanos de las localidades.

Por otra parte, la demanda de viviendas tanto de primera como de segunda residencia después de un período de expansión y parada, vuelve a resurgir aunque a otro ritmo. Resulta complicado establecer en la actualidad el resultado de equilibrio, considerando además el fuerte componente especulativo del pasado, de una parte de esa demanda: en la comarca es notorio el caso de las urbanizaciones de segunda residencia (ya de primera en algunos casos lindantes con la Comunidad de Madrid).

Al mirar el incremento de población en estos 20 años (lo veremos más detalladamente en el apartado de características demográficas), vemos que aparte de los grandes municipios como Torrijos, Fuensalida, la Puebla de Montalbán, ha habido un crecimiento importante en los núcleos diseminados, entendiendo por estos urbanizaciones.

Las urbanizaciones se concentran en dos ámbitos, el área periférica de Madrid y la vega del Alberche: la conjunción de accesibilidad y parámetros de calidad del medio determinan la existencia de doce urbanizaciones en Méntrida, once en Escalona, nueve en El Casar de Escalona, cinco en Ugena, cuatro en Otero, Cedillo del Condado, Carranque y Almorox y tres en El Viso de San Juan, Santa Cruz de 
Retamar, Lominchar y Chozas de Canales. Las urbanizaciones colindantes con la Comunidad de Madrid son las que han protagonizado el empadronamiento de personas en la rectificación padronal de 2009, en un proceso de conversión de segunda en primera residencia.

Si analizamos la superficie catastral de la comarca, según su naturaleza, vemos que de las 192.274 ha, 185.914 ha son rústicas y 6.360 ha urbanas.

La evolución de la superficie rústica es la que refleja la gráfica inferior:

\section{Gráfico 30: Evolución superficie.}

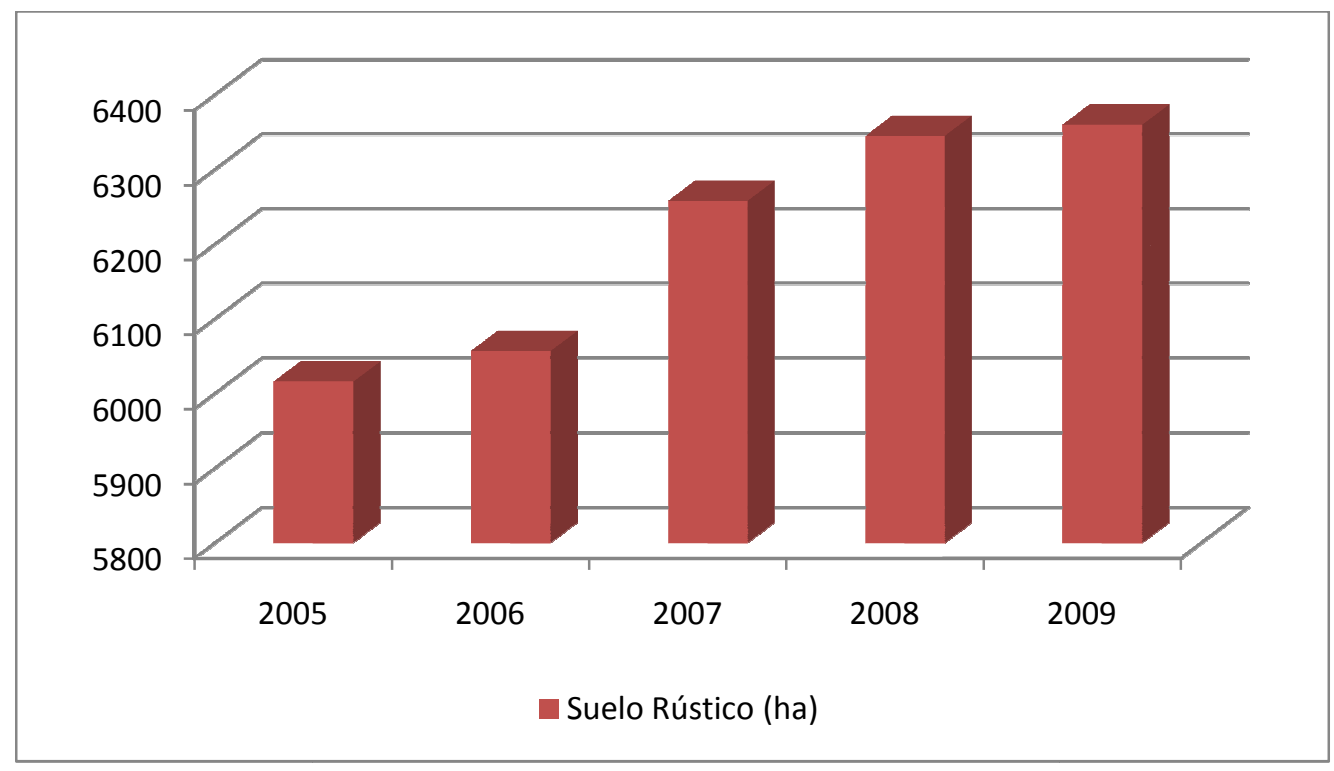

Fuente: Elaboración propia a partir datos JCCM, 2009.

\section{- Patrimonio histórico y cultural}

La comarca dispone de una notable riqueza patrimonial, siendo especialmente significativos los castillos (que dan nombre al GDR de la comarca), de los cuales la mayor parte son de los siglos XIII y XIV. Este recurso cultural constituye un indudable potencial turístico. El estado de conservación de este patrimonio 
requiere de intervención en toda la comarca, pero su coste hace que ni la Administración Local ni los propietarios privados hayan podido acometer hasta el momento de forma generalizada trabajos de restauración.

Por otra parte, el legado cultural del castellano como lengua está muy ligado a la comarca, pues el Infante don Juan Manuel (sobrino de Alfonso X) era de Escalona, mientras que Fernando de Rojas era de La Puebla de Montalbán.

En la comarca sobresalen:

- Barcience (Castillo, siglo XIV, planta cuadrangular).

- Erustes (Iglesia de la Asunción.

- Escalona (Castillo y convento).

- Malpica (Castillo, siglo XIV).

- Maqueda (Castillo y Convento).

- Novés (Castillo de San Silvestre).

- Puebla de Montalbán: Palacio de los Condes de Montalbán (siglo XV), Ermita de Nuestra Señora de la Soledad (siglo XVIII), Torre de San Miguel (siglo XVI), Convento de Concepcionistas y Franciscanos (siglo XVI), Hospital de la Caridad (siglo XVI).

- Torrijos: Colegiata del Santísimo Sacramento (gótica), Hospital del Cristo de la Sangre (siglo XVI), Palacio de Pedro I de Castilla (siglos XI-XVI, actual Ayuntamiento). 


\subsection{Sistema Económico-Social: Recursos Humanos y Actividades}

\subsubsection{Características Demográficas}

Durante la primera parte del siglo XX la población aumenta paulatinamente, iniciándose en los años 60 un descenso progresivo a lo largo de esta década con motivo de la emigración a las grandes ciudades que afectó a los sectores más dinámicos y menos arraigados al medio rural.

A partir de los años 70 , la evolución de la población en la comarca va aumentando (en casi todos los municipios), pasando de una población en 1.989 de 57.517 habitantes a una población 20 años después de 87.272 habitantes, pasando la densidad de población de 30,01 hab/ $\mathrm{km}^{2}$ a $45 \mathrm{hab} / \mathrm{km}^{2}$.

De los 42 municipios que componen la comarca, destacan Torrijos con una densidad de población de 791,4 hab/km², Fuensalida con 164,5 hab/km², y Portillo de Toledo con $96,37 \mathrm{hab} / \mathrm{km}^{2}$

Estos municipios ya en el año 1.989 tenían densidades de población muy por encima de la comarca, pero el crecimiento de los 13 municipios más poblados de la comarca que acogen en la actualidad al $71 \%$ de los habitantes de este territorio, no han tenido un crecimiento paralelo. 
Tabla 12: Variación de la población en los 11 pueblos de mayor población comarcal.

\begin{tabular}{|l|r|r|r|}
\hline & Año 1989 & Año 2009 & \\
\hline Municipios & habitantes & habitantes & $\%$ \\
\hline Torrijos & 9.359 & 13.117 & 40,2 \\
\hline Fuensalida & 6.877 & 10.967 & 59,5 \\
\hline Puebla de Montalbán & 6.218 & 8.431 & 35,6 \\
\hline Carpio de Tajo & 2.375 & 2.202 & - \\
\hline Santa Olalla & 2.269 & 3.465 & 52,7 \\
\hline Almorox & 2.182 & 2.410 & 10,4 \\
\hline Camarena & 1.998 & 3.520 & 76,2 \\
\hline Portillo & 1.910 & 2.211 & 15,8 \\
\hline Escalona & 1.825 & 3.521 & 92,9 \\
\hline Gerindote & 1.700 & 2.439 & 43,5 \\
\hline Novés & 1.521 & 2.712 & 78,3 \\
\hline Méntrida & 1.500 & 4.599 & 206,6 \\
\hline Santa Cruz & 1.442 & 2.972 & 106,1 \\
\hline
\end{tabular}

Fuente: Elaboración propia, datos INE 1989, y 2009

Así podemos ver como los municipios de Torrijos, Fuensalida y la Puebla de Montalbán, siguen siendo los más poblados y con un crecimiento medio de un $45,1 \%$ de población a lo largo de estos años.

Si ordenamos los municipios más poblados en el orden actual de mayor población, en la tabla inferior, podemos observar, el gran crecimiento de los municipios de Méntrida (206,6\%), de Santa Cruz de Retamar (106,61\%), Escalona (92,9\%), Novés $(78,3 \%)$, y Camarena $(76,2 \%)$, cambiando el orden de los municipios de mayor número de población. 
Tabla 13: Municipios de mayor población de la comarca.

\begin{tabular}{|l|c|}
\hline Año 2009 & \\
\hline Municipios & Habitantes \\
\hline Torrijos & 13.117 \\
\hline Fuensalida & 10.967 \\
\hline Puebla de Montalbán & 8.431 \\
\hline Méntrida & 4.599 \\
\hline Escalona & 3.521 \\
\hline Camarena & 3.520 \\
\hline Santa Olalla & 3.465 \\
\hline Santa Cruz & 2.972 \\
\hline Novés & 2.712 \\
\hline Gerindote & 2.439 \\
\hline Almorox & 2.410 \\
\hline Portillo & 2.211 \\
\hline Carpio de Tajo & 2.202 \\
\hline
\end{tabular}

Fuente: Elaboración propia, datos INE 1989, y 2009

Si analizamos la pirámide de población de la comarca, a continuación, vemos por un lado el mayor porcentaje de población masculina $(51,4 \%)$ sobre la femenina (48,6\%), y si comparamos a nivel nacional (raya negra), vemos que el un comportamiento de la pirámide es parecido, con un menor número de población femenina en la franja de 15-64años.

Vamos analizar las tasas demográficas de dependencia, envejecimiento y reemplazo. 


\section{Gráfico 31: Pirámide de población de la comarca de Torrijos.}

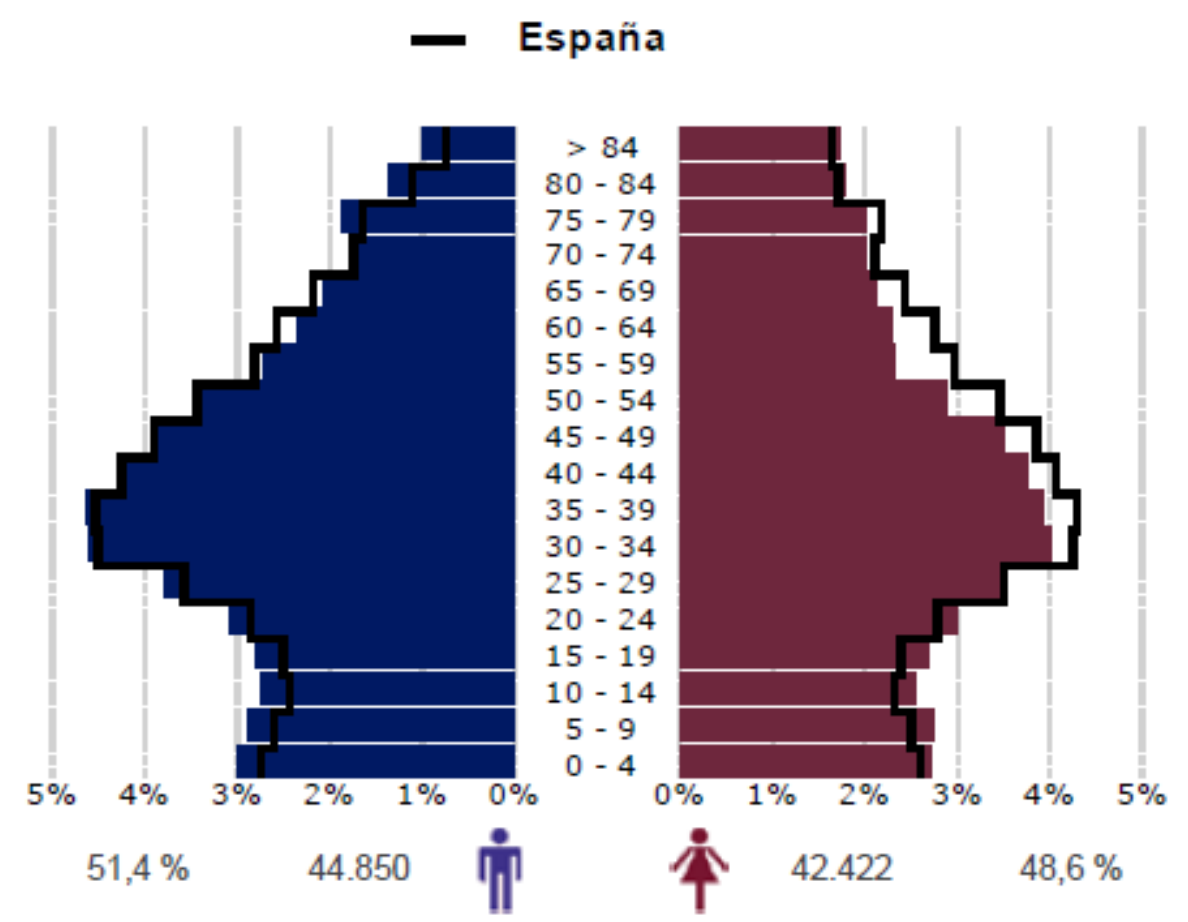

Fuente: Caja España, 2011.

Recordemos que:

Dependencia $=($ Población $<15+$ Población $>64) /$ Pob.de 15 a 64*100

Envejecimiento=Población $>64$ / Población total ${ }^{\star} 100$

Reemplazo=Población de 20 a 29 / Población de 55 a 64

Tabla 14: Tasas demográficas de la comarca 2009.1

\begin{tabular}{|l|l|l|l|}
\hline \multicolumn{4}{|l|}{ Tasas demográficas } \\
\hline & Comarca & Comunidad & España \\
\hline Dependencia & $51 \%$ & $49,3 \%$ & $47,1 \%$ \\
\hline Envejecimiento & $17,4 \%$ & $17,6 \%$ & $17,2 \%$ \\
\hline Reemplazo & 1,38 & 1,40 & 1,14 \\
\hline
\end{tabular}

Fuente: Elaboración propia, INE 2009. 
Si analizamos la tasa de dependencia, que tiene un claro significado económico, al representar la media relativa de la población potencialmente inactiva sobre la potencialmente activa, vemos que es mayor en la comarca que a nivel autonómico y español, pero si tenemos en cuenta que esta tasa en el año 1989 era de un $67 \%$ en la comarca y de un $61 \%$ en al región, ha mejorado sustancialmente.

Al analizar la tasa de reemplazo o sustitución, que sería 1 si se produjese un reemplazo estricto, en la comarca es de 1,38 bastante mejor que la habida en 1.989 de 0,94 para la comarca y similar para la región que era de 1,39.

De los 42 municipios que la componen, podemos definir tres grandes grupos:

- Municipios con una población superior o rondando los 10.000 habitantes: Torrijos, Fuensalida y la Puebla de Montalbán, que entre los 3 albergan el 37,7\% de la población.

- Municipios entre 2.000 y 5.000habitantes, Méntrida, Escalona, Camarena, Santa Olalla, Santa Cruz, Novés, Gerindote, Almorox, Portillo, y Carpio de Tajo, que albergan entre los 10 el 31,02\% de la población comarcal.

- Municipios menores de 1.000 habitantes, el resto de los 30 municipios, donde vive el 31,71 de la población de la comarca.

La población extranjera en 2009 , es de 11.514 personas, un $13,2 \%$ de la población total de la comarca (6.219 hombres y 5.295 mujeres), de los que un $33,1 \%$ son africanos del norte (mayoritariamente marroquíes), un $31 \%$ son rumanos, y un 24,6 americanos del sur.

En la comarca de Torrijos la población de 16 y más años de edad era ligeramente superior a la media española en 1989. La población activa es (en relación con la población total) tres puntos porcentuales inferior a la media española, por tanto, similar a los valores de provincia y región. Los 23.274 activos de la 
comarca en 1989 eran casi el 46\% de las personas con 16 y más años de edad, pero esta relación era del $50 \%$ en España. La tasa de paro era inferior a la mitad en la comarca que en España, lo que se traduce en una menor relación ocupados/ activos.

Se repite una tónica general de la provincia de Toledo y de Castilla la Mancha: la desproporción existente entre los valores masculinos y femeninos. En concreto, la relación entre actividad masculina y femenina para las personas de 16 y más años es de 2,3 activos masculinos por cada activo femenina en la comarca, de 2,7 en la provincia, de 2,8 en la región y de 2 en España. Estos bajos niveles de actividad femenina (6.936 mujeres frente 16.338 hombres) son los que determinan gran parte de la situación comarcal.

Además, esta desproporción también acontece en el paro, siendo asimismo desfavorable a la mujer: la relación entre desempleo femenino y masculino es de 2,5 mujeres por cada hombre en la comarca y en la provincia, de 2,1 en la región y de 1,8 en España. El paro masculino comarcal $(8,46 \%)$ no llegaba a la mitad del masculino español en 1989, mientras que el paro femenino comarcal era del $21,54 \%$, siendo el paro global comarcal del $12,05 \%$.

Si analizamos la tabla inferior vemos como ha evolucionado la situación:

Tabla 15: Población en edad de trabajar y paro en la comarca.

\begin{tabular}{|l|c|c|c|}
\hline Mercado de Trabajo Año 2011 & \multicolumn{3}{l|}{} \\
\hline & Comarca & Comunidad & España \\
\hline Población 15-64 años & 57.807 & 1.417 .032 & 32.082 .758 \\
\hline Pob 15-64 /Pob total*100 & $66,2 \%$ & $67 \%$ & $68 \%$ \\
\hline Paro registrado (31/3/2011) & 9.385 & 217.745 & 4.333 .669 \\
\hline Paro reg/Pob 15-64*100 & $16,2 \%$ & $13,4 \%$ & $13,5 \%$ \\
\hline
\end{tabular}

Fuente. Elaboración propia a partir datos SEPE 2011. 
De la tabla superior vemos que en 2011, el paro en la comarca es superior a la región y al conjunto de España, y se sigue manteniendo la diferencia entre el paro femenino y masculino, con una relación de 2 mujeres por cada hombre en paro.

Para valorar la población como fuerza de trabajo, es muy interesante ver el grado de formación de la población de la comarca, y ver si en estos 20 años han cambiado las tendencias.

En el año 1989, los jóvenes en su mayoría terminaban los estudios obligatorios y después se incorporaban al mundo laboral, solo un $3 \%$ cursaba estudios superiores para lo que se trasladaban a otros municipios mayores como Madrid o Toledo.

Se ha conseguido aumentar el número de estudiantes que aceden a una formación profesional en un 4\%, así como el porcentaje de población que cursa estudios superiores un $6,5 \%$, pero inferior al porcentaje provincial.

Visto como es la edad de población y las tendencias, vamos a analizar el sistema productivo por sectores.

\subsubsection{Sector primario}

El sector agropecuario en 1989, tenía una población activa del 15,47\% de la población total. El municipio con menos población activa en el sector agropecuario es precisamente la capital Torrijos, en el otro extremo nos encontramos con el municipio de Hormigos que posee una tasa de actividad en el sector del $26 \%$.

Analizamos la distribución por edades en el sector y vemos el siguiente cuadro: 


\section{Tabla 16: Distribución de la población sector primario en años 1989 y 2009.2}

\begin{tabular}{|l|l|l|}
\hline EDAD & $\begin{array}{l}\% \\
1989\end{array}$ & $\begin{array}{l}\% \\
2009\end{array}$ \\
\hline Hasta 35 años & $3,94 \%$ & $4,24 \%$ \\
\hline De 35 a 54 años & $31,53 \%$ & $16,96 \%$ \\
\hline De 55 a 64 años & $31,19 \%$ & $38,72 \%$ \\
\hline De más de 65 años & $33,32 \%$ & $40,08 \%$ \\
\hline
\end{tabular}

Fuente: Elaboración propia a partir Censos Agrarios, 1989 y 2009.

Se puede observar que la distribución por edades en el sector, no se encuentra equilibrada, con un claro envejecimiento de la población agrícola, con un pequeño aumento en la franja hasta 35 años.

Otro de los hechos que constatamos en el año 1989 era que la tendencia al asociacionismo entre los agricultores es muy baja, no forman cooperativas para comercializar sus productos, sino que delegan en intermediarios que se encargan de almacenarlos y venderlos. Sin embargo, si son importantes el numero de cooperativas que existen para productos que necesitan transformación, como son la producción del vino y aceite y su posterior envasado.

De los datos obtenidos a partir de las entrevistas realizadas este año, son varios los entrevistados que manifiestan la falta de comercialización de los productos como un punto importante a tener en cuenta, pero que el número de cooperativas sobre todo de vino es elevado. Se da la paradoja, de la existencia en municipios como Camarena o la Torre de Esteban Hambrán, varias cooperativas que están teniendo que agruparse ante el riesgo de quiebra.

En este sentido, señalar que muchas veces los conflictos entre los propios habitantes de un municipio, les llevan a no formar parte de la misma cooperativa, e incluso a un mismo agricultor a pertenecer a varias, una situación insostenible desde el punto de vista de la rentabilidad económica. 
Vamos a analizar ahora la distribución de la superficie agrícola de la comarca, del total de la superficie de la comarca, las tierras labradas en el año 1989 eran 121.294 ha, que representan el $63,28 \%$ de la superficie total de toda la comarca, en el año 2009 las tierras labradas son 110.740ha, que representan el 57,77\%, es decir ha disminuido un $8,70 \%$.

Sin embargo, como podemos ver en el cuadro siguiente, la SAU ha disminuido en un 6,28 \%. Es decir, al no haber disminuido en la misma proporción, la SAU y las tierras labradas, quiere decir que esa diferencia del $2,42 \%$ es el aumento de los pastos, en definitiva retirada de tierras para barbechos.

Tabla 17: Distribución tierras labradas y la SAU en los años 1989 y 2009.

\begin{tabular}{|l|l|l|l|}
\hline & 1989 & 2009 & Variación \% \\
\hline Tierras labradas (Ha) & 121.294 & 110.740 & 8,70 \\
\hline № Explotaciones & 8.129 & 4.179 & 48,59 \\
\hline SAU (Ha) & 132.777 & 124.441 & 6,28 \\
\hline
\end{tabular}

Fuente: Elaboración propia, Censo agrario INE1989 y 2009

Otro dato a destacar es el descenso del número de explotaciones, no en el mismo porcentaje que el descenso de tierras labradas.

Vamos a estudiar la evolución de las tierras labradas en estos 20 años. Viendo el cuadro inferior observamos que los cultivos herbáceos han disminuido un $4,95 \%$, lo frutales han aumentado un $64 \%$, el olivar también ha aumentado un $28,42 \%$ y el viñedo se ha reducido un $49 \%$, debido a que durante estos años en Castilla La Mancha se ha procedido al arranque de viñedos para reestructurar un mercado que estaba estancado y en claro declive. 
Tabla 18: Distribución de cultivos en las tierras labradas años 1989 y 2009.

\begin{tabular}{|c|c|c|c|c|c|c|c|c|c|c|}
\hline \multirow{3}{*}{$\begin{array}{l}\text { EXPLOT.SEGUN SUPERFICIE } \\
\text { TOTAL EN ha AÑO } 1989\end{array}$} & \multicolumn{2}{|c|}{ T. LABRADAS } & \multicolumn{8}{|c|}{ CULTIVOS } \\
\hline & \multirow{2}{*}{ № $\mathrm{EX}$} & \multirow{2}{*}{ ha } & \multicolumn{2}{|c|}{ HERBACEOS } & \multicolumn{2}{|c|}{ FRUTAL } & \multicolumn{2}{|c|}{ OLIVAR } & \multicolumn{2}{|c|}{ VIÑEDO } \\
\hline & & & №EX & ha & №EX & ha & NoEX & ha & №EX & ha \\
\hline N TIERR & 29 & 1.294 & 5.324 & 95.9 & 463 & 774 & 3.629 & 7.480 & 4.556 & 17.061 \\
\hline \multirow{2}{*}{$\begin{array}{l}\text { EXPLOT.SEGUN SUPERFICIE } \\
\text { TOTAL EN ha AÑO } 2009\end{array}$} & \multirow{2}{*}{ № $\mathrm{EX}$} & \multirow{2}{*}{ h } & \multicolumn{2}{|c|}{ HERBACEOS } & \multicolumn{2}{|c|}{ FRUTAL } & \multicolumn{2}{|c|}{ OLIVAR } & \multicolumn{2}{|c|}{ VIÑEDO } \\
\hline & & & №EX & ha & №EX & ha & NoEXX & ha & №EX & ha \\
\hline EXPLOTAC. CON TIERRAS & 4.038 & 110.740 & 2.595 & 91.220 & 338 & 1.271 & 2.407 & 9.606 & 1.533 & 8.643 \\
\hline
\end{tabular}

Fuente: Elaboración propia, a partir datos Censo Agrario INE1989 y 2009.

Gráfico 32: Distribución de las tierras labradas en al año 1989.2

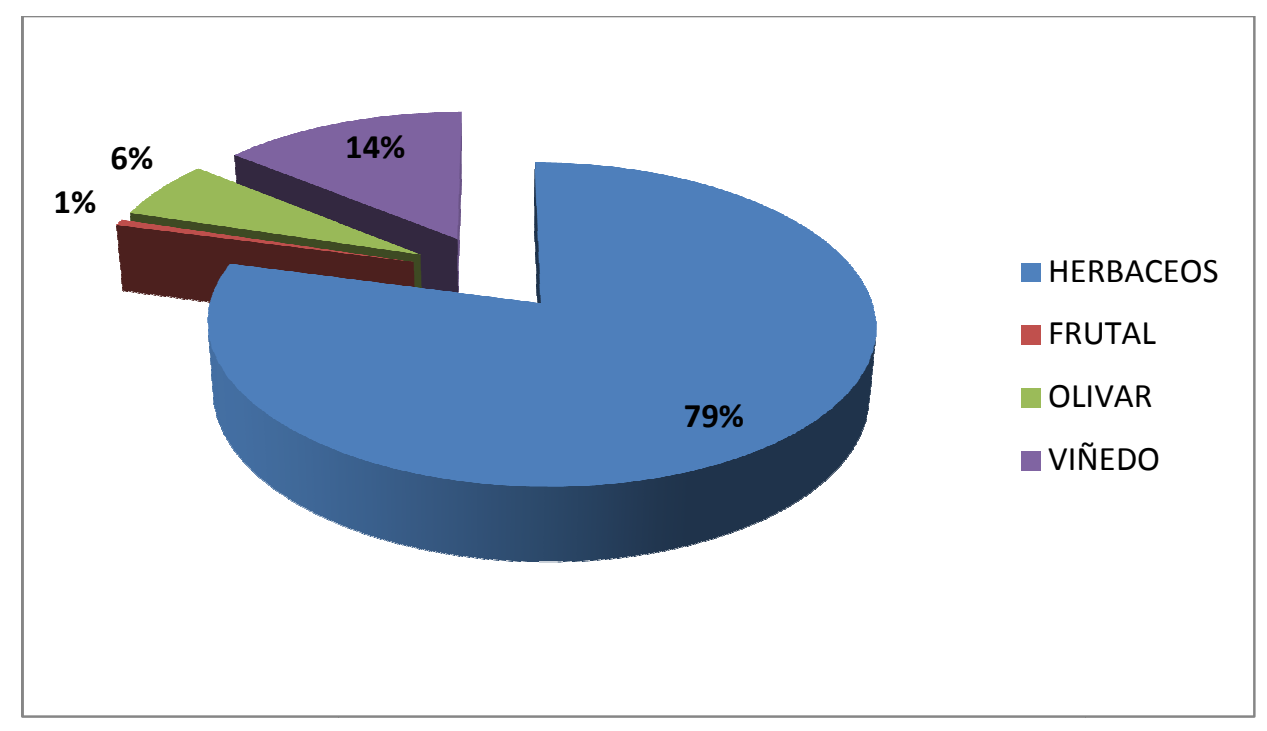

Fuente: Elaboración propia, a partir datos Censo Agrario INE1989.

El descenso de los cultivos herbáceos de 95.979 ha a 91.220 , es posible que sea debido a la superficie que se ha reforestado con las ayudas de la PAC, con frondosas, encinas, y pinos. 


\section{Gráfico 33: Distribución de las tierras labradas en al año 2009.}

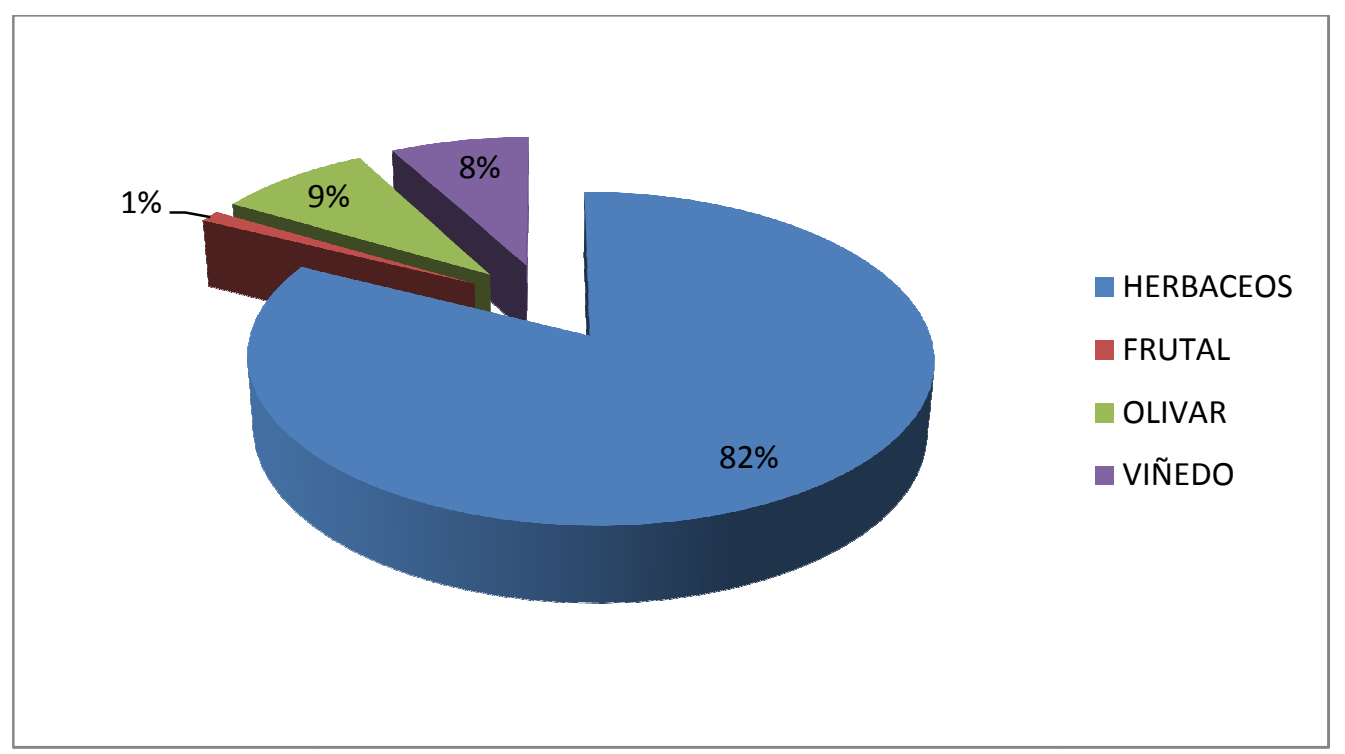

Fuente: Elaboración propia, a partir datos Censo Agrario INE 2009.

Dentro de los cultivos herbáceos, el $80 \%$ es cereal que según los tipos de suelos cambia, pero predominando la cebada, trigo, avena, centeno y triticale.

Los cultivos hortícolas se realizan sobre todo en los municipios de la Puebla de Montalbán y el Carpio de Tajo, representan el 1,5\% de todos los cultivos herbáceos. Los cultivos hortícolas a destacar son la sandía y el melón.

Reflejar también que el $12 \%$ de estos cultivos herbáceos son de regadío, sobre todo para el cultivo de alfalfa y maíz, no habiendo aumentado su superficie en estos años y utilizando el sistema de riego de aspersión mayoritariamente.

En cuanto a los cultivos leñosos, los más abundantes son olivar y viñedo. Los viñedos en secano tienen una gran importancia, sobre todo en Fuensalida, Camarena y la Torre de Esteban Hambrán.

Además, el arranque de viñedos ha tenido efectos positivos, en el caso de los arranques definitivos, supone un importante ingreso para el agricultor y en el caso 
del reordenamiento, permite introducir cepas de mayor calidad y nuevas técnicas de cultivo en el área cubierta por la denominación de origen.

Además, fuera de éste área, favorece el crecimiento de superficie dedicada al olivo que, dadas las tendencias del mercado, cabe pensar que su rentabilidad pueda ser mayor.

Hay también frutales como melocotoneros e higueras, en Almorox, La Puebla de Montalbán y Mesegar.

Con respecto al tamaño de las explotaciones, si bien el número de estas se ha reducido, el tamaño medio de éstas ha aumentado, pasando de un tamaño medio de 17 ha a 21 ha. Importante es señalar, que el tipo de explotación más común en la comarca de Torrijos es la extensión inferior a 5 ha con un 44\% explotaciones.

Por otro lado cabe destacar, que las explotaciones mayores de 200ha, solo representan el $1 \%$ pero ocupan el $36 \%$ de la superficie agraria, es decir gran parte de la comarca está formando parte de este tipo de latifundios.

Si analizamos el grado de parcelación de las explotaciones, hay una media de 8 parcelas por explotación, que ha aumentado en estos años. Es un dato importante para el análisis de las zonas periurbanas, donde la gente no vende las parcelas por pequeñas que sean a la espera de un aumento de su valor con la expansión de algunos municipios.

En lo referente al régimen de tenencia, si bien en 1989 el régimen de tenencia en propiedad era del $77 \%$, ha pasado a un $67,25 \%$, el arrendamiento ha pasado de un $18 \%$ en 1989 a un $26,2 \%$ en 2009 , y la aparcería y otro regímenes de un $4 \%$ a un $6,6 \%$.

Habrá que incidir en el aumento del tamaño de la propiedad, y el hecho de la fragmentación de las explotaciones en parcelas, como factores para modernizar las explotaciones. 
Es importante la constatación de un hecho obtenido a partir del trabajo de campo, ya que en el censo agrario no aparece reflejado como tal, y es que la mayoría de los agricultores con superficies menores de 40-50 ha se dedican a la agricultura a tiempo parcial.

La crisis del sector de la construcción ha hecho que muchos de sus trabajadores, cultiven las tierras de su familia en fines de semana e incluso, a la vez que reciben la prestación del subsidio de desempleo.

Con respecto a la cabaña ganadera, en la comarca predominan las explotaciones de porcino y aves en régimen intensivo. El ganado bovino ocupa un papel secundario al igual que el caprino.

Como se parecía el la tabla inferior, predominas las explotaciones de porcino y aves en régimen de intensivo, y que además han aumentado su número en estos años, representado un porcentaje importante, $20 \%$ en aves y $17 \%$ en porcino respecto al número de cabezas de la provincia de Toledo.

\section{Tabla 19: Evolución de la cabaña ganadera en la comarca de Torrijos.}

\begin{tabular}{|c|l|l|l|l|l|}
\hline & Porcino & Ovino & Bovino & Aves & Caprino \\
\hline Año 1989 (Ud) & 110.653 & 78.846 & 17.854 & 721.068 & 15.108 \\
\hline Año 2009 (Ud) & 195.253 & 56.636 & 15.860 & 1.107 .500 & 5.588 \\
\hline$\%$ & 43,33 & $-39,22$ & $-12,57$ & 34,89 & $-170,37$ \\
\hline
\end{tabular}

Fuente: Elaboración propia, a partir datos Censo Agrario INE 1989 y 2009.

El ganado ovino, ha descendido un $39,22 \%$, abundan la raza manchega para la elaboración de quesos. El ganado bovino ocupa un papel secundario al igual que el caprino.

Los municipios con mayores explotaciones de porcino son la Puebla de Montalbán y Burujón, los de ovino son la Puebla de Montalbán, y Carpio de Tajo, y los de aves Portillo de Toledo, Burujón, Camarena y Gerindote. 
Durante estos años los alojamientos para el ganado, causantes de malos olores que se encontraban en la zona urbana de los municipios se han ido trasladando hacia las zonas exteriores del municipio.

\subsubsection{Sector Secundario y Terciario}

Si bien el sector primario no tiene un peso elevado $(6,8 \%)$, si es cierto que marca considerablemente la actividad económica, pues genera muchos servicios a su alrededor, así como una importante actividad agroalimentaria.

En el año 1989, la actividad industrial tiene una importancia media en relación al resto de las comarcas del provincia de Toledo. Había un predominio del sector agroalimentario y textil, concretamente de la industria del calzado, y dos empresas manufactureras en constante crecimiento. También tenía relevancia con respecto a la provincia, la construcción y la fabricación de muebles, puertas, tarimas etc.

La actividad industrial se encuentra agrupada por sectores, según su proximidad a las materias primas y vías de comunicación. En torno a la autovía de Extremadura (N-V) aparece una importante concentración de industrias agrícolas. Así como en el eje de la carretera Toledo-Ávila y alrededor de los núcleos más poblados, Torrijos, La Puebla de Montalbán y Fuensalida que junto con el municipio de Portillo de Toledo, forman el núcleo importante de la industria del calzado.

Los núcleos industriales más importantes son .Torrijos, Fuensalida, La Puebla de Montalbán, el Carpio de Tajo. Es muy interesante señalar, la disminución acusada de la actividad industrial, conforme aumenta la distancia a Toledo y Madrid.

La situación de la población activa en la comarca en el año 1989, era la reflejada en el gráfico inferior:

Fig. 28: Ocupados por sector de actividad año 1989. 
Ocupados por sectores de actividad

\begin{tabular}{lrrrr}
\hline & Agric./activos & \multicolumn{1}{c}{ Ind./activos } & Const/activos & Serv./activos \\
\hline Comarca & $17,38 \%$ & $34,61 \%$ & $16,92 \%$ & $31,08 \%$ \\
Castilla La Mancha & $16,30 \%$ & $22,70 \%$ & $14,20 \%$ & $46,80 \%$ \\
España & $10,20 \%$ & $21,30 \%$ & $10,10 \%$ & $51,80 \%$
\end{tabular}

Fuente: Memoria GDR, Castillos de Medio Tajo, 2000 con datos INE 1989.

La población dedicada al sector primario es similar en la comarca de Torrijos y en la región, pero es 1,7 veces el porcentaje de España. La tasa de ocupados comarcales en la industria es superior a la regional y española en vez y media. Igual circunstancia acontece en la construcción: un poco superior a las tasas de Castilla la Mancha y casi 1,7 veces superiores a las nacionales. Sin embargo, las diferencias más notorias acontecen en el sector servicios: los 31 de cada 100 trabajadores comarcales que estaban empleados en 1989 en este sector son el $60 \%$ de los que en ese mismo año censal trabajaban en el sector terciario tanto en la región como en España.

En el cuadro inferior vemos las industrias existentes en la comarca en 1989, según clasificación CNAE:

Tabla 20: Industrias de la comarca de Torrijos año 1989.

\begin{tabular}{|l|l|l|l|}
\hline & SECTORES INDUSTRIALES & NUMERO & $\%$ \\
\hline 1 & Industria manufacturera & 809 & 58,16 \\
\hline 2 & Producción y distribución de energía & 12 & 0,86 \\
\hline 3 & Construcción & 396 & 28,47 \\
\hline 4 & Comercio, talleres y servicios & 159 & 11,43 \\
\hline 5 & Otras actividades & 13 & 0,93 \\
\hline 6 & Extracción y minería & 2 & 0,14 \\
\hline
\end{tabular}

Fuente: Elaboración propia, INE1988.

Destacar en el tipo de actividad de la industria manufacturera, el núcleo Fuensalida- Portillo de Toledo, con 136 empresas dedicadas a la industria del 
calzado, y los municipios de Torrijos en textil, fabricación de muebles, materiales de construcción y la Puebla de Montalbán en textil y fabricación de muebles.

Dentro de este mismo epígrafe, están las industrias de alimentación y bebidas, siendo Torrijos, El Carpio de Tajo y la Puebla de Montalbán los municipios líderes en este sector. Destaca este último municipio por sus productos hortofrutícolas y sus fábricas de conservas con gran número de empleados.

Señalar también que las características del propio mercado de trabajo en algunos sectores cono la confección de prendas y calzado, favorecieron el surgimiento del fenómeno de una economía sumergida, eran muchos los trabajadores que realizaban pequeñas tareas artesanales en sus propios hogares para estas industrias, tales como bordados, cordonería, cosidos etc

Si analizamos los datos del año 2009: en la comarca de Torrijos, del gráfico inferior, vemos que tanto la industria como la construcción, han derivado parte de sus activos hacia el sector servicios.

Gráfico 34: Trabajadores por sector de actividad 2009.

TRABAJADORES POR SECTOR DE ACTIVIDAD

\begin{tabular}{lrrr}
\hline Agricultura & 1.619 & $\ldots \ldots$ & 6,8 \\
Industria & 6.092 & $\ldots \ldots$ & 25,6 \\
Construcción & 5.585 & $\ldots \ldots$ & 23,5 \\
Servicios & 10.487 & $\ldots \ldots$ & 44,1 \\
No Consta & 0 & $\ldots .$. & 0 \\
Total & 23.783 & $\ldots \ldots$ & 100 \\
\hline - Autónomos & & 7.101 & \\
- Por cuenta ajena & & 16.682 &
\end{tabular}

Fuente: Informe Caja España 2011 
En el gráfico inferior vemos la distribución de las empresas por sector de actividad en el año 2009, destacando las empresas de servicios como las mayoritarias de la comarca.

Gráfico 35: Empresas por sector de actividad 2009.

EMPRESAS POR SECTOR DE ACTIVIDAD

\begin{tabular}{lrlr}
\hline Agricultura & 268 & $\ldots .$. & 7,9 \\
Industria & 527 & $\ldots .$. & 15,5 \\
Construcción & 851 & $\ldots .$. & 25,1 \\
Servicios & 1.746 & $\ldots .$. & 51,5 \\
No Consta & 0 & $\ldots .$. & 0 \\
$\quad$ Total & 3.392 & $\ldots .$. & 100 \\
\hline
\end{tabular}

Fuente: Informe Caja España 2011

El sector turístico en la comarca es uno de los grandes potenciales que tiene y a nuestro juicio poco explotado. La actividad hostelera de cierto nivel está vinculada a las carreteras, e incluso así es muy escasa.

En la comarca son varias las posibilidades turísticas que ofrece, desde un turismo cultural con el gran patrimonio histórico- artístico existente (descrito con anterioridad en la descripción del territorio), turismo de naturaleza (senderismo, parajes naturales,..), gastronómico con una cocina rural de tierra adentro, logrando altas cotas de exquisitez con platos sencillos, turismo enológico tan de moda en estos tiempos, cinegético (caza menor de perdiz, conejo, tórtola, y liebre), etc.

Si bien es cierto que ha mejorado con la ceración de algún alojamiento de turismo rural, apoyado por el GDR Castillos de Medio Tajo, la oferta sigue siendo insuficiente. 


\subsection{Diagnóstico del territorio}

\subsubsection{Matriz DAFO}

\section{DEBILIDADES}

$\rightarrow$ Desequilibrio entre los muncipios en cuanto a nivel de desarrollo económico

$\rightarrow \quad$ Poco reconocimiento por parte de la población del valor que tienen los diferentes recursos de la comarca

$\rightarrow$ Nulo sentimiento de pertenencia al territorio Agricultores con escasa cultura empresarial

$\rightarrow$ (minifundismo empresarial). Dificultad integración en cooperativas para transformación o comercialización. Estructura de la propiedad de la tierra en grandes propietarios, y dificultades para realizar concentración parcelaria

Predominio absoluto del secano sobre regadío, en cultivos leñosos (vid y olivo) y herbáceos (cereal y leguminosas)

$\rightarrow \quad$ Endeudamiento municipal

Dificultades para acceder a incentivos y ayudas de la administración

$\rightarrow \quad$ Escaso nivel de formación población joven

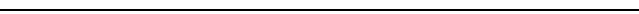

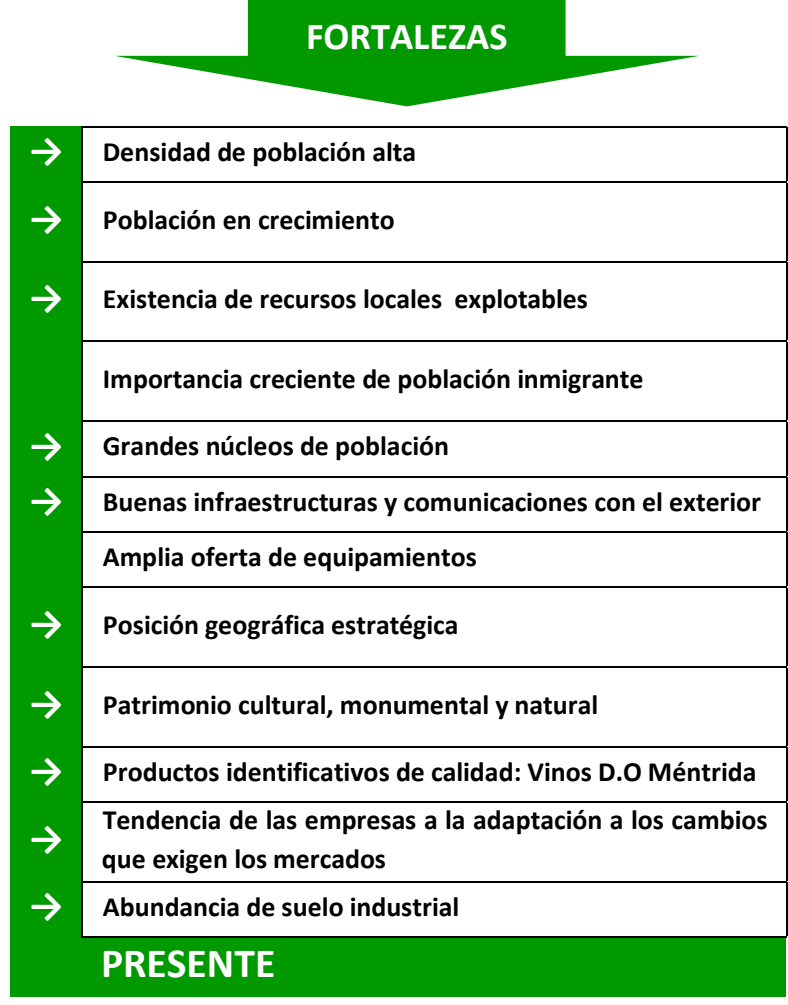

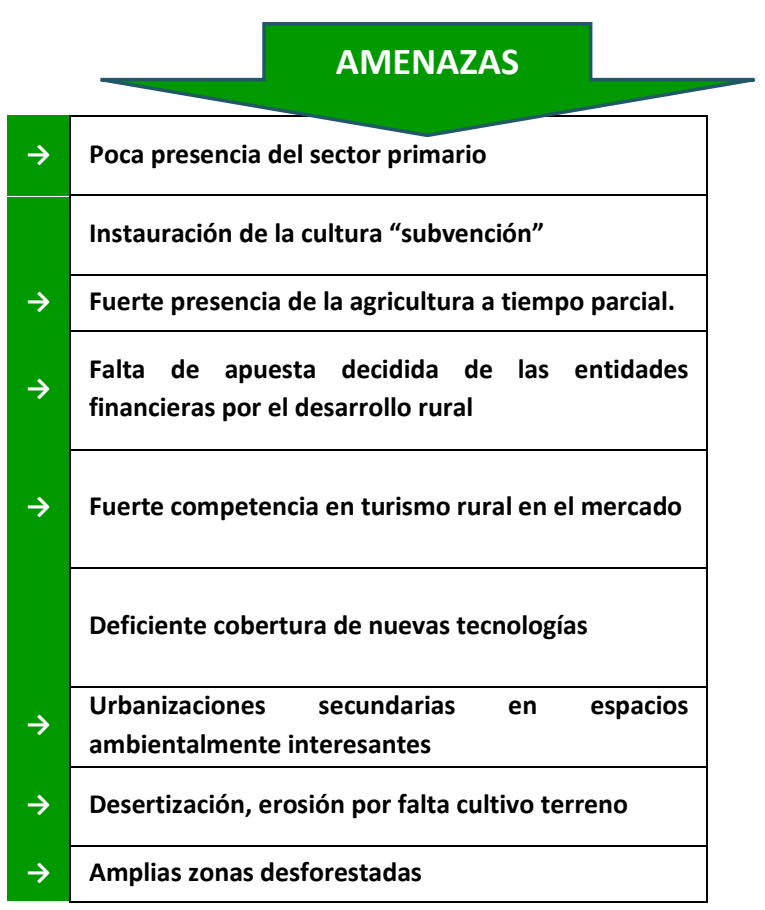

\section{OPORTUNIDADES}

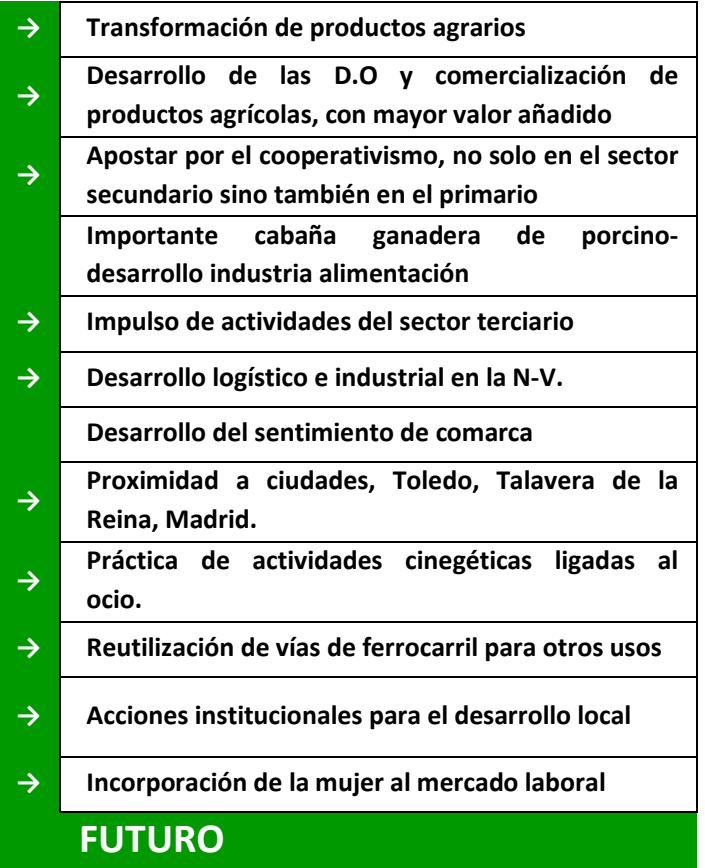




\subsection{Desarrollo rural y local dentro del proceso de cambio}

\subsubsection{PDR}

Dada la complejidad del análisis del PDR a nivel comarcal, ya que no están desagregados los resultados por comarcas, vamos a estudiar aquellas que dado su importe y naturaleza son más representativas en nuestro territorio:

\section{EJE 1}

\section{Medida 112: Instalación de jóvenes agricultores}

De los 1.189 jóvenes que sean incorporado en toda la región, 47 han sido de nuestra comarca, 34 hombres y 13 mujeres La inversión en esta medida ha sido de $2.051 .873,81 €$ y la ayuda prestada de $1.706 .735,47 €$.

Medida 113: Jubilación anticipada de los agricultores y trabajadores agrícolas En el $100 \%$ de los casos son jubilación de agricultores, no habiéndose registrado ningún beneficiario en la categoría de trabajador agrícola. La ayuda prestada ha sido de $1.413 .000 €$.

\section{Medida 121: Modernización de las explotaciones agrícolas}

La inversión en esta medida ha sido de 2.374.153 € y la ayuda prestada de $1.190 .900 €$.

Medida 123: Aumento del valor añadido de los productos agrícolas y forestales La ayuda prestada ha sido de 5.453.458,09 €, a 41 empresas, muchas de las cuales han tenido ayuda en cada ejercicio presupuestario.

Medida 124: Cooperación para el desarrollo de nuevos productos, procesos y tecnologías en el sector agrícola y alimentario y en el sector forestal

Teniendo en cuenta que en toda la región se han abonado ayudas por valor de $14.400 €$, la aportación a la comarca es insignificante.

\section{EJE 2}




\section{Medida 214: Ayudas agroambientales}

Dentro de la submedidas que tenía este epígrafe, en nuestra comarca se refleja la trayectoria seguida a nivel regional en el reparto de las ayudas. El $70 \%$ de las explotaciones con compromisos en la medida 214 corresponden a la submedida 214.4 agricultura ecológica para la que se ha destinado una ayuda de 5.320,646€.

Medida 221: Primera forestación de tierras agrícolas

En nuestra comarca se han presentado 87 expedientes. Consiguiendo reforestar 1.018ha.

\section{EJE 3}

Medida 313: Fomento de actividades turísticas

No ha tenido ninguna solicitud en toda la región.

Medida 312: Ayudas a la creación y desarrollo de microempresas

La veremos en el GDR

Medida 321: Servicios básicos para la economía y la población rural La 321.1 aparece en le GDR.

La 321.2 se ejecuta a través de la consejería ha tenido muy poca inversión, dada a situación económica de estos últimos años, se ha contenido el gasto.

Medida 322: Renovación y desarrollo de poblaciones rurales

La veremos en el GDR

Medida 323: Conservación y mejora del patrimonio rural

La veremos en el GDR

Medida 331: Formación e información

La veremos en el GDR

Medida 341: Adquisición de capacidades, promoción y aplicación de estrategias de desarrollo local 
La veremos en el GDR

\section{EJE 4 .Todas aparecen en el análisis del GDR.}

Medida 413: Aplicación de estrategia de desarrollo local. Calidad de vida/diversificación

Medida 42: Ejecución de proyectos de cooperación

Medida 43: Funcionamiento del grupo de acción local, adquisición de capacidades y promoción territorial.

\subsubsection{GDR Castillos del Medio Tajo}

Vamos a analizar a nuestro Grupo de Acción Local y su trayectoria en estos años de trabajo en la comarca.

El Grupo de Acción Local Castillos del Medio Tajo, está constituido como una Asociación Comarcal en el año 2000, formalizándose su inscripción el 28 de septiembre del año 2000.

Es una asociación sin fines de lucro, con unos estatutos que regulan las funciones y responsabilidades de la misma, determinando el marco normativo para la actuación del Grupo de acción Local y que se responsabiliza de la gestión de los diferentes programas de desarrollo rural en la comarca de Torrijos.

Contemplan la posibilidad de constituir diferentes grupos de trabajo para regular y agilizar las diferentes tareas que el grupo de acción Local debe asumir para garantizar la gestión.

La asamblea general es el órgano de máxima decisión de la asociación en tanto que la Junta Directiva es el órgano de gobierno, gestión y representación.

De acuerdo con los estatutos, la Junta Directiva está facultada para crear Comisiones a fin de delegar en ellos cuantas facultades concretas considere 
oportuno o encomendar tareas específicas cuando las necesidades lo aconsejen. En este marco, la Junta Directiva constituirá un órgano de gestión cuyo fin principal será gestionar el Programa de Desarrollo Rural a través del Centro de Desarrollo Rural (CEDER), que será el instrumento técnico y administrativo para su ejecución y regulación.

El organigrama del Órgano de Gestión para la planificación y realización del

Programa de Desarrollo Rural Integrado de la Comarca de Torrijos, da cabida a tres tipos de representantes: Agentes Públicos (3 miembros), Agentes Privados (3 miembros) y Asesores (2 miembros). Los dos primeros forman parte del órgano de gestión con voz y voto, en tanto que los últimos asisten con voz, pero sin voto. Este órgano, a su vez, se dota de dos instrumentos, uno de carácter técnico, el CEDER, y otro de carácter consultivo y de decisión política, las Mesas Sectoriales.

EI CEDER se encargará específicamente de la realización del Programa de Desarrollo Rural, asumiendo también funciones de soporte técnico para reforzar las decisiones de la Junta Directiva. Contratación de los técnicos del CEDER: transparencia, igualdad de oportunidades, atención a la idoneidad (perfil del puesto), difusión.

Gráfico 36: Esquema de funcionamiento Grupo de Acción Local Castillos de Medio Tajo. 


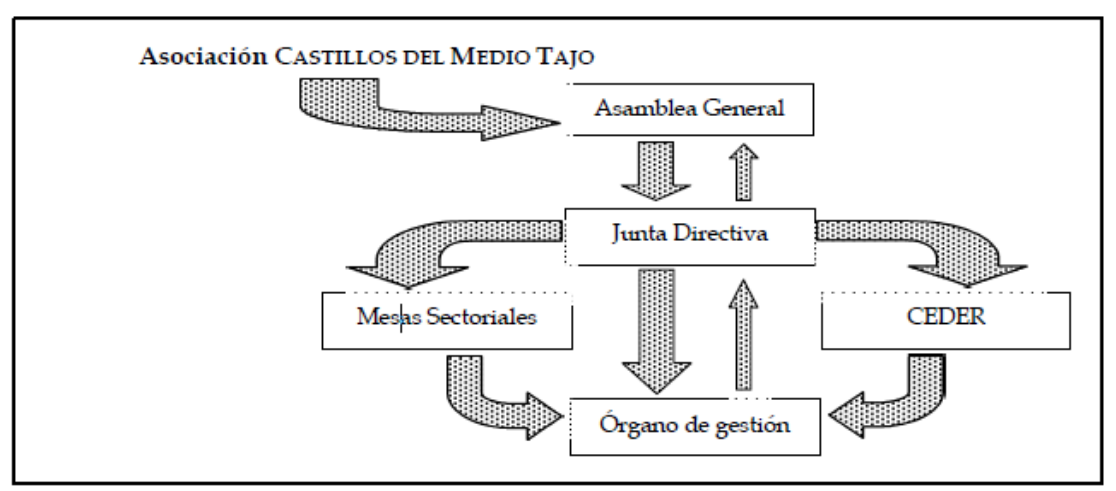

Fuente: Memoria del Grupo de Desarrollo Rural Castillos de Medio Tajo.

Son de destacar las relaciones que el equipo técnico del Grupo de Acción Local ha generado con el tejido económico, social y cultural de la Comarca de Torrijos .El objeto principal de estas relaciones se sitúa tanto en el ámbito de dar a conocer la existencia y contenido de los Programas de Desarrollo Rural, como en las funciones de transmisión de información y generación de confianza para motivar la inversión. Todo ello, en la doble vertiente de las demandas públicas y privadas planteadas y con el cuidado de no generar falsas expectativas en los sectores, empresarios y colectivos a quienes iba destinada la información.

Por otra parte, la Asociación Comarcal CASTILLOS DEL MEDIO TAJO se ha integrado en la red de Centros de Desarrollo Rural de Castilla La Mancha CEDERCAM, con el fin de conectarse a las redes españolas y europeas de desarrollo rural, aspecto este esencial para compartir experiencias y fomentar la cooperación interterritorial.

Recordemos que estos Grupos de Acción Local tienen por objeto la dinamización rural del territorio en el que actúan, en nuestro caso la comarca de Torrijos, conforme a un programa Comarcal (LEADER o PRODER), en nuestro caso se iniciaron con PRODER, que el propio grupo diseña y que luego es aprobado por el Organismo Intermedio mediante la firma de un convenio de colaboración. En este 
convenio se fija un cuadro financiero por medidas de actuación para las estrategias planteadas.

Las estrategias de Castillos de Medio Tajo se definen en su programa como sigue:

- Promover el desarrollo comarcal a corto, medio y largo plazo, primando estrategias de desarrollo sostenible y participación ciudadana.

- Implementar los recursos locales existentes para definir una articulación regional más beneficiosa para la población, compatible con la planificación del desarrollo y las diferentes políticas de ámbito europeo, nacional y autonómico

- $\quad$ Establecer una estrategia de desarrollo comarcal de largo plazo, cuya meta final sea el autosostenimiento de las políticas de desarrollo local y la reducción de la dependencia de recursos externos para la obtención de los objetivos que se planteen.

Además, su estrategia identifica las siguientes áreas estratégicas, cuyo objetivo final no es otro que llegar a definir para la comarca un modelo operativo de gestión territorializada de políticas públicas, coordinadas y concertadas con la iniciativa privada y los agentes sociales:

Área estratégica 1. Articulación del territorio.

Área estratégica 2. Dinamización social.

Área estratégica 3. Dinamización económica

Se establecieron una serie de medidas para poder realizar la estrategia planteada, así tenemos: 
- Medida 1. Gastos de gestión, funcionamiento administrativo y asistencia técnica

- Medida 2. Servicios a la población

- Medida 3. Patrimonio natural

- Medida 4. Valoración de productos agrarios locales

- Medida 5. PYMES y servicios

- Medida 6. Valoración del patrimonio cultural y arquitectónico

- Medida 7. Turismo

- Medida 8. Otras inversiones

- Medida 9. Formación y empleo

Además, con la filosofía que subyace en la acción de la UE, y de la que PRODER 2 es heredero, requiere la cooperación entre territorios con problemas similares, o con intereses convergentes, incorporándose 2 ejes de cooperación, interterritorial y transnacional.

Este Grupo de Desarrollo Rural, dentro de la iniciativa PRODER 2 para el período 2000-2006, ha contado con un presupuesto de 4.674.215€.

Vamos ahora a analizar el Grupo de Acción Local, a partir del Programa de Desarrollo Rural de Castilla la Mancha 2007-2013, para empezar se cambia de nombre y en vez de GAL se denomina GDR.

EI PDR de Castilla-La Mancha incluye entre sus objetivos la mejora de la calidad de vida y la diversificación económica de las zonas rurales. En este sentido, incide en la mejora de la gobernanza y la movilización del potencial de desarrollo endógeno con el apoyo de los Grupos de Desarrollo Rural (GDR), fomentando el enfoque ascendente para el logro de la competitividad y la mejora del medio 
ambiente así como posibilitando la diversificación de actividades en el medio rural y el bienestar de su población mediante la aplicación de enfoques innovadores.

La consecución de estos objetivos del PDR de Castilla-La Mancha se alcanza a través de la gestión de las medidas del eje 3 ejecutadas mediante el eje 4 LEADER, en concreto, a través de la medida 413.

Es importante mencionar que la puesta en marcha del programa, ha sido tardía, no comenzando a funcionar hasta el último trimestre de 2009. Por un lado ha influido en su ejecución la limitación de los recursos de fondos propios de la Administración Regional en 2012 y por otro los problemas financieros del GDR para conseguir crédito con el que financiar sus pólizas de crédito. Esto repercute directamente en problemas de ejecución, ya que no pueden adelantar el crédito a los promotores finales.

Además recordemos las dificultades socioeconómicas para los promotores privados que no pueden acceder a la financiación para realizar los proyectos.

En el año 2010, la situación era la siguiente: 
Fig. 29: Peso de las medidas del eje 3 ejecutadas a través del eje LEADER en relación al presupuesto, el gasto y la relación con la ejecución física de la medida 413.

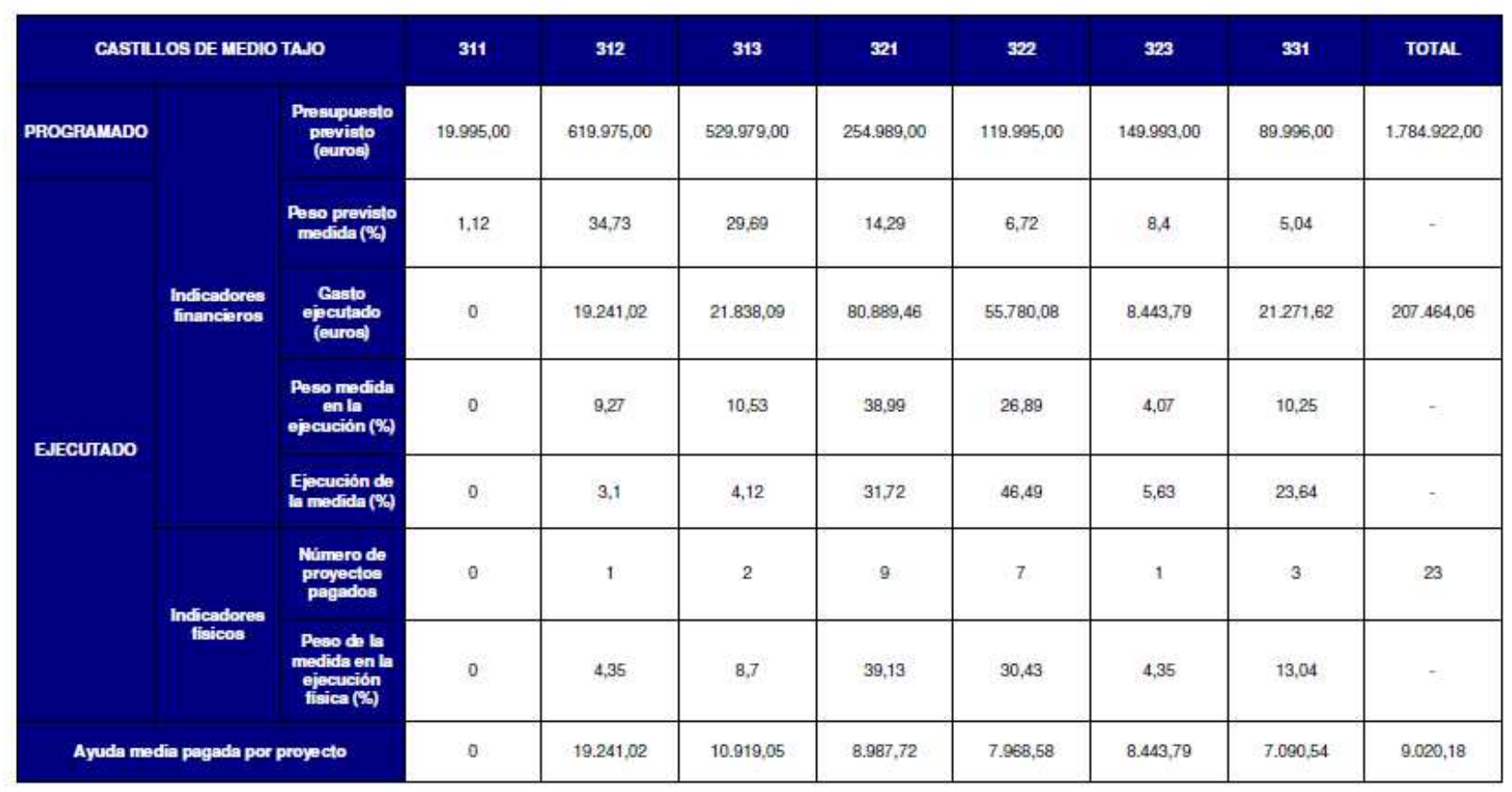

Fuente: JCCM, 2011.

Siendo:

Presupuesto Previsto: importes previstos en el periodo de programación 2007-2013, para las medidas del eje 3 ejecutadas a través del eje LEADER, tras la modificación aprobada en 2010.

Gasto ejecutado: pagos declarados a la Comisión de la medida a $31 / 12 / 2011$.

Peso de la medida: peso del importe de la medida del eje 3 en el total de la 413 (previsto y ejecutado).

Como se desprende de la tabla, las medidas con mayor peso en el presupuesto previsto son la 312, relativa a la Creación de microempresas, que supone el $34,73 \%$ de toda la dotación, seguida de la 313 , de Fomento de las 
actividades turísticas, con el $29,69 \%$ del presupuesto. Con valores relativos inferiores al $15 \%$ se encuentran las medidas 321 de Prestación de servicios básicos para la economía y la población rural, la 323 de Conservación y mejora del patrimonio rural y la 322 de Renovación y desarrollo de poblaciones rurales.

Por otro lado, las medidas menos priorizadas en este sentido son la 311 , de Diversificación hacia actividades no agrícolas, con el 1,12\% y la 331 de Formación e información con el 5,04\%. En cuanto a la medida 341 de Adquisición de capacidades, ésta no ha sido programada en el grupo Castillos de Medio Tajo.

Si se tiene en consideración la distribución del gasto ejecutado entre las distintas medidas se pueden observar las notables diferencias en esta escala de priorización. En la gráfica siguiente se muestran, de forma comparada, los pesos relativos de los importes previstos y ejecutados de las medidas del eje 3 gestionadas a través del eje LEADER enmarcadas en la medida 413. 
Gráfico 37: Comparación de los pesos previstos y ejecutados de las medidas del eje 3 gestionadas a través del eje LEADER por nuestro GDR.

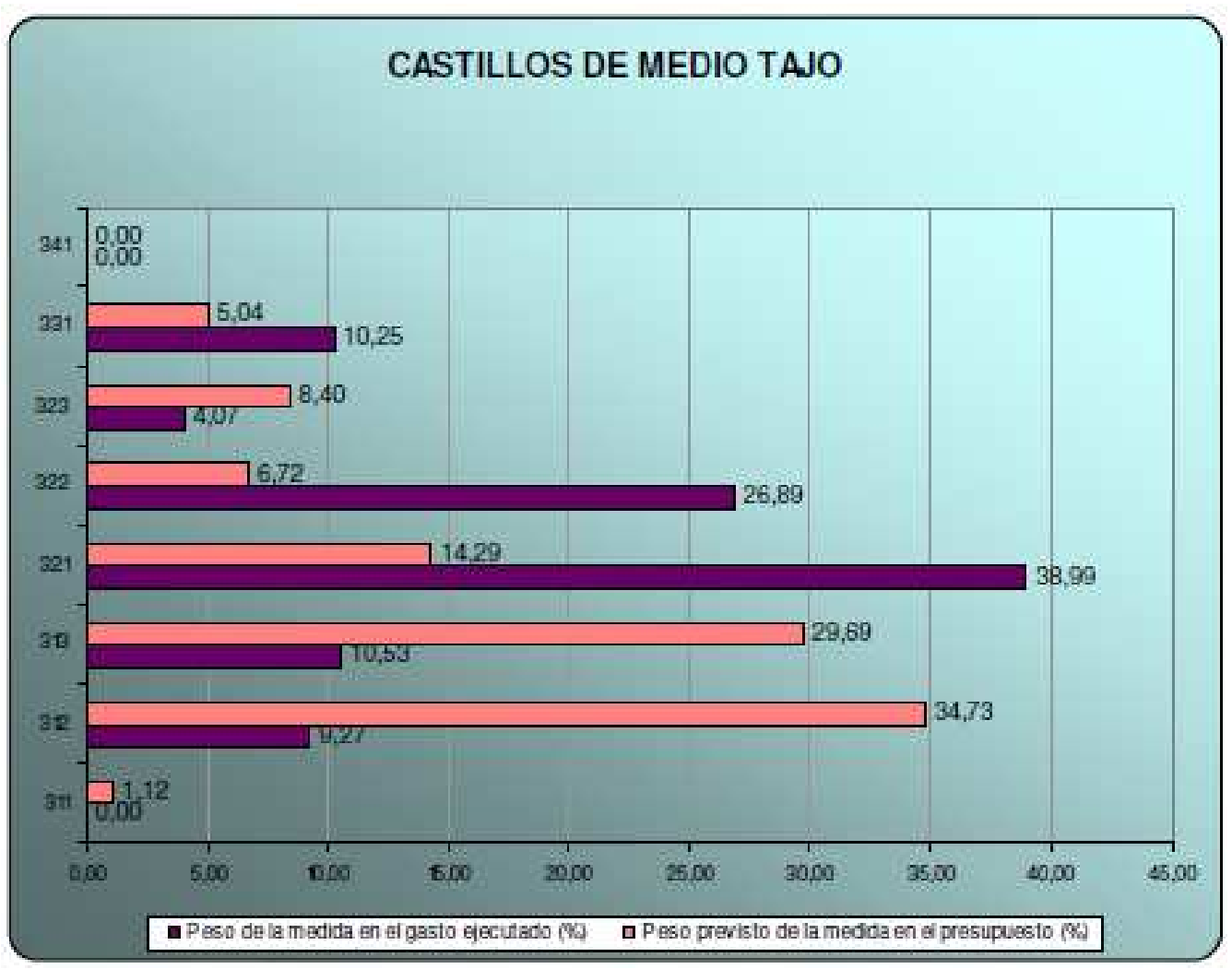

Fuente: JCCM, 2011

Al comparar los objetivos previstos con lo realmente ejecutado se observa que a 31 de diciembre de 2011 se han priorizado, muy por encima de lo previsto, las medidas 321 de Prestación de servicios básicos para la economía y la población rural y la 322 de Renovación y desarrollo de poblaciones rurales, mientras que la medida 331 de Formación e información presenta una ejecución algo mayor a la prevista. Por el contrario, las medidas menos priorizadas las cuales presentan mucha menos ejecución de lo que cabría esperar son la 312 de Creación y desarrollo de empresas y la 313 de Fomento de actividades turísticas, mientras que la medida 323 de Conservación y mejora del patrimonio rural presenta una ejecución algo menor a la esperada. Además, no se ha ejecutado la medida 311 de Diversificación hacia 
actividades no agrícolas y la 341 de Adquisición de capacidades no ha sido programada.

Existen dos grupos diferenciados, las medidas más relacionadas con la diversificación de la economía rural, como son la 312 y 313 que son las que cuentan con mayor presupuesto en el grupo pero con menor ejecución y proyectos financiados. Por este motivo y por la tipología de estos proyectos suelen tratarse de inversiones elevadas que necesitan movilizar porcentajes menores de subvención para ser llevadas a cabo. Por el contrario, las medidas más directamente relacionadas con la mejora de la calidad de vida de las zonas rurales, como son la $321,322,323$ y 331 , contribuyen a sus proyectos financiados con subvenciones que representan entre el $73 \%$ y el $100 \%$ del coste elegible.

Por otro lado, si se analiza la tipología del solicitante que pide al Grupo la subvención para realizar un proyecto determinado como puede observarse en el siguiente gráfico, existe una clara predominancia de las corporaciones locales, que representan el $74 \%$ del total de peticionarios. Lejos quedan las asociaciones con un $17 \%$ y las sociedades de responsabilidad limitada con un peso relativo del $9 \%$.

Si analizamos el tipo de peticionario de la inversión y la medida en la que se enmarcan, en las medidas más destinadas a la diversificación de la economía rural, como la medida 312 Creación y desarrollo de empresas y la 313 Fomento de actividades turísticas, el tipo de solicitante más habitual son sociedades de responsabilidad limitada. Por otro lado, los solicitantes de las medidas más destinadas a la mejora de la calidad de vida en la zona son corporaciones locales en las medidas 321 Prestación de servicios básicos para la economía y la población rural, 322 Renovación y desarrollo de poblaciones rurales y 323 Conservación y mejora del patrimonio rural, mientras que en la medida 331 Formación e información los peticionarios son asociaciones. 
El análisis del detalle de los proyectos que son objeto de ayuda complementado con los detalles de las áreas estratégicas identificadas por Castillos de Medio Tajo permite obtener resultados de los aspectos previstos que finalmente se están abordando tras la ejecución de los proyectos.

Para ello, se ha realizado una clasificación de los proyectos financiados relacionándolos con las actuaciones planteadas, intentando plasmar la estrategia prevista del grupo al objeto de extraer conclusiones sobre la relación entre la estrategia planteada y la ejecución real de ésta.

Recordemos, que el GDR tenía una estrategia planteada y unas áreas estratégicas definidas al principio de este apartado.

Dentro de estas áreas estratégicas se detallan una serie de actuaciones a desarrollar en el ámbito del programa de desarrollo rural.

En la siguiente tabla, se muestra el número de proyectos financiados por área estratégica y por tipo de actuación propuesta. Como puede extraerse de la misma, en la relación realizada de los proyectos con los detalles de la estrategia todas las actuaciones se han enmarcado en las áreas estratégicas programadas 1, 2 y 3.

Fig. 30: Proyectos ejecutados por el grupo en relación a su estrategia.

\begin{tabular}{|l|l|c|}
\hline \multicolumn{1}{|c|}{ Áreas estratégicas } & \multicolumn{1}{c|}{ Actuaciones propuestas } & Total \\
\hline \multirow{3}{*}{ 1. Articulación del territorio } & Aprovechamiento de la biodiversidad como recurso económico & 4 \\
\cline { 2 - 3 } & Revalorización del patrimonio rural & 13 \\
\cline { 2 - 3 } & Total área 1 & 17 \\
\hline \multirow{2}{*}{ 2. Dinamización económica } & Apoyo a la comercialización turística comarcal & 2 \\
\cline { 2 - 3 } & Total área 2 & 2 \\
\hline \multirow{2}{*}{ 3. Dinamización social } & Comunicación en la comarca & 1 \\
\cline { 2 - 3 } & Dinamización social en TIC & 3 \\
\cline { 2 - 3 } & Total área 3 & 23 \\
\hline Total general & & 2 \\
\hline
\end{tabular}

Fuente: JCCM, 2011 
Como se desprende de la tabla, la estrategia se ha centrado en el área estratégica 1 Articulación del territorio que integra a 17 proyectos, el 73,91\% del total. En cuanto a las actuaciones que agrupan más proyectos se encuentran las que persiguen la revalorización del patrimonio rural, con 13 proyectos, seguida de las encaminadas al aprovechamiento de la biodiversidad como recurso económico, que cuenta con 4 proyectos.

Atendiendo a la ejecución realizada por el grupo, la siguiente área estratégica con más protagonismo por número de proyectos es la número 3 Dinamización social que cuenta con 4 proyectos, un 17,39\% del total ejecutado por el grupo Castillos de Medio Tajo. Aquí destaca la actuación de dinamización social en TIC, que agrupa a 3 proyectos, mientras que un proyecto está dedicado a la comunicación en la comarca. Finalmente, el área estratégica número 2 Dinamización económica participa en la estrategia con 2 proyectos orientados a las actuaciones de apoyo a la comercialización turística comarcal.

Vamos a ver la situación en los siguientes años:

El año 2011 debería haber sido un año de consolidación del programa, año en el que los proyectos debían haber fructificado e iniciado el funcionamiento ya sea en creación de nuevas actividades o en ampliación de existentes. Sin embargo la situación económica tanto comarcal, regional como nacional, han marcado de forma negativa tanto la tramitación de expedientes como la resolución, certificación y pago de proyectos subvencionados. Con estas circunstancias el número de promotores, irremediablemente ha caído y por ende tanto el número de proyectos como de expedientes. Aún así desde el GDR se ha procurado tanto dinamizar como apoyar cuantas nuevas iniciativas se han presentado. 
La aplicación informática, ya consolidada como instrumento de trabajo en años anteriores ha sufrido pequeñas modificaciones enfocadas a un mejor control sobre los expedientes y sobre los datos a tratar.

El Procedimiento de Gestión para la aplicación de LEADER sigue depurándose, tanto para adecuarse a nuevos aspectos propuestos por la Dirección General de Desarrollo Rural, como para subsanar criterios propios. Así en Junta Directiva de 27 de Diciembre de 2011 se aprobó por unanimidad la modificación de varios puntos de nuestro Procedimiento de Gestión del GDR, concretamente:

- Supresión de la baremación correspondiente al uso de recursos endógenos.

- Introducción de un criterio de cálculo de la ruralidad de los expedientes de los proyectos de índole comarcal.

Durante el presente ejercicio se ha dado un impulso considerable a los Proyectos de Cooperación, por un lado se ha seguido trabajando en los proyectos de Cooperación de la Red Rural Nacional y junto con los GDR de ADECOR y Tierras de Talavera se ha iniciado el Proyecto de Cooperación Regional "ITÍNERE, Camino Real de Madrid a Guadalupe por Castilla la Mancha". Durante el transcurso del año se han tenido hasta cinco reuniones de coordinación del Proyecto entre los distintos grupos, dando como resultado una serie de acciones a poner en marcha que han quedado recogidas en el Proyecto de Cooperación, del que se entregó el correspondiente borrador a la Consejería para su chequeo y validación. De esta forma, una vez aprobado dicho proyecto, se pondrán en marcha las medidas en él contempladas de modo que a lo largo del año 2012 se realice dicho Proyecto.

También se han planteado la segunda modificación del Cuadro Financiero LEADER, solicitada en fecha 28 de febrero de 2011 y que fue aceptada mediante la suscripción del correspondiente Modificado de Convenio en fecha 21 de Diciembre. El motivo de dicha modificación del cuadro fue para ir adecuando el mismo en 
función de la demanda que hemos tenido de proyectos para las distintas medidas de subvención.

Así el cuadro financiero aprobado es el siguiente:

Tabla 21: Cuadro financiero 2011 GDR Castillos del Medio Tajo.

\begin{tabular}{|c|c|c|c|c|}
\hline \multicolumn{5}{|c|}{ CUADRO FINANCIERO POR EJES, MEDIDAS Y FUENTES DE FINANCIACION } \\
\hline & TOTAL & FEADER & AGE & JCCM \\
\hline $\begin{array}{l}\text { 311Diversificación } \\
\text { actividades no agrícolas }\end{array}$ & 119.995 & 88.796 & 16.799 & 14.400 \\
\hline $\begin{array}{l}\text { 312Creación y el desarrollo de } \\
\text { microempresas }\end{array}$ & 569.975 & 421.782 & 79.797 & 68.396 \\
\hline \begin{tabular}{|l|l}
313 Fomento de Actividades \\
Turísticas
\end{tabular} & 479.979 & 355.184 & 67.197 & 57.598 \\
\hline $\begin{array}{l}\text { 321Servicios básicos para la } \\
\text { economía y la población rural }\end{array}$ & 179.992 & 133.194 & 25.199 & 21.599 \\
\hline $\begin{array}{l}322 \text { Renovación y desarrollo de } \\
\text { población rural }\end{array}$ & 119.995 & 88.796 & 16.799 & 14.400 \\
\hline $\begin{array}{l}323 \text { Conservación y mejora del } \\
\text { patrimonio }\end{array}$ & 149.993 & 110.995 & 20.999 & 17.999 \\
\hline 331Formación e Información & 89.996 & 66.597 & 12.599 & 10.800 \\
\hline $\begin{array}{l}341 \text { Adquisición de capacidades, } \\
\text { promoción y aplicación }\end{array}$ & 74.997 & 55.498 & 10.500 & 8.999 \\
\hline 421 Cooperación & 55.006 & 40.704 & 7.701 & 6.601 \\
\hline 431 Gastos de funcionamiento & 459.983 & 340.387 & 64.398 & 55.198 \\
\hline TOTAL & 2.299.911 & 1.701 .933 & 321.988 & 275.990 \\
\hline
\end{tabular}

Fuente: Elaboración propia a partir datos memoria Castillos de Medio Tajo.

Durante el año 2011 se ha grabado un total de 39 solicitudes de nuevos expedientes de subvención. En cuanto al número de expedientes resueltos, y de los que se ha firmado el contrato han sido un total de 25 Proyectos. En cuanto a los Expedientes Certificados durante el año han sido un total de 20 Proyectos, de los que se han pagado un total de 19 Proyectos. 
El importe total en Subvenciones firmadas y con Contrato durante el año 2011 ha sido de 732.526,98 €. En cuanto al importe total de Expedientes pagados asciende a la cantidad de 263.045,56 €.

De los expedientes resueltos y que se han pagado, promovidos por iniciativa tanto privada como pública, han supuesto una inversión total realizada de 321.139,28 $€$, mientras que de todos los expedientes resueltos y con subvención concedida, la inversión total tanto privada como pública asciende a la cantidad de 3.556.802,32 €.

De las cifras anteriormente expuestas, se puede sacar como conclusión que aun habiendo una situación económica a nivel nacional ciertamente complicada, durante el pasado año se han iniciado números expedientes con un cuantía de inversión considerable, lo que hace afrontar el año 2012 con una buenas expectativas en cuanto a la reactivación económica de la comarca.

En cuanto a los expedientes certificados y pagados a 31 de diciembre de 2011, tenemos un total de 19 expedientes, siendo 1 de promotor privado, 13 públicos, 4 expedientes propios del grupo y 1 expediente destinado a sufragar los gastos de funcionamiento y estructurales.

Los expedientes de proyectos a fecha de 31 de diciembre de 2011 pagados a los promotores, han sido los siguientes:

L4504.1.0313.014 “Casas de San Antón” siendo el promotor Agropecuaria Finca de San Antón S.L, con un pago recibido de 16.018,19€.

L4504.0.321.006 “Suministro e Instalación de Pavimento Deportivo”. Excmo. Ayuntamiento de La Puebla de Montalbán, con un pago recibido de 18.529,42 €.

L4504.0.321.024 "Reforma antiguo Ayuntamiento para sede de la Policía Local”. Excmo. Ayuntamiento de El Viso de San Juan, con un pago recibido de 10.080,00€. 
L4504.0.321.026 “Circuito Biosaludable” Excmo. Ayuntamiento de Aldea en Cabo, con un pago recibido de $6.340,68 €$.

L4504.0.321.028 “Adaptación Gimnasio Residencia de Mayores” Excmo. Ayuntamiento de Carpio de Tajo, con un pago recibido de 9.515,92 €.

L4504.0.321.033 “Acondicionamiento Zona verde Cañada” Excmo. Ayuntamiento de Gerindote, con un pago recibido de 8.662,76€.

L4504.0.321.045 “Parque de Máquinas Biosaludables” Excmo. Ayuntamiento de Hormigos, con un pago recibido de 7.125,00 €.

L4504.0.321.057 “Acondicionamiento de Parque municipal” Excmo. Ayuntamiento de Carriches, con un pago recibido de 6.517,31€.

L4504.0.322.017 “Adaptación y mejora de Parque infantil” Excmo. Ayuntamiento de Maqueda, con un pago recibido de 6.900,67 €.

L4504.0.322.025 “Adquisición de Mobiliario Urbano” Excmo. Ayuntamiento de Paredes de Escalona, con un pago recibido de 5.170,00 €.

L4504.0.322.027 “Ornamentación de Rotonda Acceso Sur” Excmo. Ayuntamiento de Camarena, con un pago recibido de 10.086,12€.

L4504.0.322.032 “Zona Recreativa Nueva Escalona” Excmo. Ayuntamiento de Escalona, con un pago recibido de $9.651,83 €$.

L4504.0.322.037 “Construcción de Parque Biosaludable” Excmo. Ayuntamiento de Portillo, con un pago recibido de 9.178,92 €.

L4504.0.322.040 “Acondicionamiento de Plaza de la Constitución” Excmo. Ayuntamiento de Alcabón, con un pago recibido de 7.178,03 €.

L4504.0.331.003 "Asistencia a Feria de Talavera, Comarca y Territorio" Asociación Comarcal Castillos de Medio Tajo con un pago recibido de $1.230 €$.

L4504.0.331.039 “Curso de Postproducción Avanzada en VFX" Asociación Comarcal Castillos de Medio Tajo con un pago recibido de 14.482,00 €. 
L4504.0.331.041 "Talleres de Guiones de Cine" Asociación Comarcal Castillos de Medio Tajo con un pago recibido de 5.559,22 €.

L4504.0.313.053 “Naturcam, Feria de Turismo Rural e Interior” Asociación Comarcal Castillos de Medio Tajo con un pago recibido de 6.125,08 €.

L4504.0.431.036 "Gastos de Funcionamiento de anualidad 2011” Asociación Comarcal Castillos de Medio Tajo con un pago recibido de 105.000,00 €.

En el 2011, de todos los expedientes resueltos y con contrato firmado, ha habido una baja, concretamente el Expte. L 4504.0.331.051, cuyo promotor fue Castillos del Medio Tajo, relativo al "Plan de Acción Comarcal", motivado por un cambio en la estrategia de dinamización.

\section{Año 2012:}

El año 2012 ha sido un año en el que se ha dado un importante avance en el cumplimiento de los objetivos del programa, tanto a nivel de nuevos proyectos como de proyectos en ejecución y certificados.

No obstante, la situación económica y sobre todo financiera continúan siendo un pesado lastre, tanto a la hora de poner en marcha nuevas iniciativas emprendedoras y empresariales como a la hora de que fructifiquen dichas iniciativas en verdaderos proyectos empresariales. El número de promotores ha ido creciendo, a un ritmo bueno, de modo que la situación tanto a la hora de ejecución del programa como de certificación de proyectos subvencionados ha pegado un importante ascenso respecto a los años inmediatamente anteriores.

La dinamización realizada, tanto en grandes eventos o charlas, la difusión y promoción a través de las nuevas tecnologías así como por la redes sociales, han ayudado a fomentar y difundir a un público mucho más amplio la realidad de las 
ayudas e incentivación a emprendedores. Esta circunstancia junto con el "boca a boca", han supuesto un considerable aumento tanto en el número de nuevos promotores, como en el número de expedientes o solicitudes recibidas así como no, en cuanto al número de expedientes certificados y pagados.

Dentro de las distintas acciones en cuanto a dinamización, el buscar la complicidad de los regidores municipales, así como de los concejales de promoción económica y/o industrial, han ayudado a que incluso a promotores a los que nos es imposible llegar debido a las dificultades que se plantean en el grupo (hemos de recordar que es uno de los de mayor número de municipios y población, para unos recursos realmente escasos) hayan supuesto un importante granero de nuevos promotores y/o proyectos.

La aplicación informática, ya consolidada como instrumento de trabajo en años anteriores, aún hoy por hoy deja mucho que desear, pudiéndose en un futuro no demasiado lejano replantear para su mejora de cara a la mayor funcionalidad. Esta circunstancia, junto con la adaptación de la aplicación a los proyectos de cooperación debiera ser prioritaria.

El Procedimiento de Gestión propio para el Grupo, también se va adaptando a las nuevas circunstancias, la modificación del mismo para adecuarse a nuevos aspectos propuestos por la Dirección General de Desarrollo Rural, o para subsanar criterios propios que se van detectando, se produce de forma ágil y no traumática. De este modo, a requerimiento de los Servicios Periféricos de la Consejería, en Junta Directiva de 25 de Octubre de 2012 se aprobó por unanimidad la modificación de varios puntos de nuestro Procedimiento de Gestión del GDR, concretamente:

- Mecanismo de Control de Pagos a Beneficiarios

- Creación del Órgano Competente. 
En este periodo se han planteado la modificaciones del Cuadro Financiero LEADER, para flexibilizar el mismo y favoreciendo el trasvase de fondos desde las medidas excedentes a las deficitarias. Esta circunstancia, junto a la proximidad de la finalización del periodo de firma de nuevos contratos (Diciembre de 2013), ha propiciado irremediablemente nuevas modificaciones de Cuadro Financiero, con el fin de que toda la consignación del mismo sea empleada y no exista remante devuelto.

Dichas modificaciones de Cuadro Financiero, al igual que ocurre con las modificaciones presupuestarias de las entidades locales, son necesarias y constituyen una herramienta necesaria en algo vivo como es propiamente el programa de desarrollo rural. No resulta sin embargo ágil la forma de aprobarlas por parte de la entidad competencial, lo que supone una rémora en el trabajo del día a día. Por este motivo, desde los Servicios centrales debieran priorizarse dichas aprobaciones de modificados de los Cuadros Financieros, de cara a facilitar la labor a todos los grupos.

Durante el pasado año, se consiguió la resolución favorable por parte del comité de evaluación en cuanto al Proyecto de Cooperación Itínere "Camino Real a Guadalupe". No obstante y debido a que dicho proyecto comprendía una fuerte inversión tanto en recursos humanos como económicos y dadas las circunstancias económicas que hacían peligrar la subsistencia de los GDR más allá del horizonte de 2012, se optó por congelar la realización del mismo hasta tener la certeza que al menos existiría consignación presupuestaria para la anualidad de 2013.

No obstante el proyecto a nivel nacional ha continuado, se ha procedido a la señalización de paneles informativos a la entrada de los municipios por los que discurre el camino. También se han colocado señalización vertical y se ha finalizado parte de la señalización horizontal que contemplaba el proyecto nacional. Hemos 
asistido a las reuniones que se nos ha requerido en el que además de intercambiar posturas con los otros grupos participantes se han formulado propuestas y acciones de dinamización.

El Convenio entre la Consejería de Agricultura y Desarrollo Rural de la Junta de Comunidades de Castilla-La Mancha, y el Grupo "Asociación Comarcal Castillos de Medio Tajo", para la aplicación del eje 4-LEADER del Programa de Desarrollo Rural de Castilla-La Mancha 2007/2013, establece para este programa la subvención total concedida para la ejecución del programa territorial hasta el 31 de diciembre de 2.012 es de 2.299.911 €. Este importe corresponde a la primera asignación establecida en el artículo 18.4 de la Orden.

El cuadro financiero modificado para este ejercicio es el siguiente: 
Tabla 22: Cuadro financiero 2012 GDR Castillos del Medio Tajo.

\begin{tabular}{|c|c|c|c|c|}
\hline \multicolumn{5}{|c|}{ CUADRO FINANCIERO POR EJES, MEDIDAS Y FUENTES DE FINANCIACION } \\
\hline & TOTAL & FEADER & AGE & JCCM \\
\hline $\begin{array}{l}\text { 311Diversificación hacia actividades no } \\
\text { agrícolas }\end{array}$ & 19.995 & 15.117 & 2.599 & 2.279 \\
\hline $\begin{array}{l}\text { 312Creación y el desarrollo de } \\
\text { microempresas }\end{array}$ & 619.975 & 468.393 & 80.789 & 70.793 \\
\hline 313Fomento de Actividades Turísticas & 529.979 & 400.664 & 68.897 & 60.418 \\
\hline $\begin{array}{l}\text { 321Servicios básicos para la economía y } \\
\text { la población rural }\end{array}$ & 344.989 & 260.586 & 44.990 & 39.413 \\
\hline $\begin{array}{l}322 \text { Renovación y desarrollo de } \\
\text { población rural }\end{array}$ & 99.995 & 75.475 & 13.075 & 11.445 \\
\hline $\begin{array}{l}323 \text { Conservación y mejora del } \\
\text { patrimonio }\end{array}$ & 79.993 & 60.339 & 10.484 & 9.170 \\
\hline 331Formación e Información & 89.996 & 68.037 & 11.699 & 10.260 \\
\hline $\begin{array}{l}341 \text { Adquisición de capacidades, } \\
\text { promoción y aplicación }\end{array}$ & 0 & 0 & 0 & 0 \\
\hline 421 Cooperación & 55.006 & 41.584 & 7.371 & 6.051 \\
\hline 431Gastos de funcionamiento & 459.983 & 342.247 & 64.049 & 53.687 \\
\hline TOTAL & 2.299.911 & 1.732 .442 & 303.953 & 263.516 \\
\hline
\end{tabular}

Fuente: Elaboración propia a partir datos memoria Castillos de Medio Tajo

Durante el año 2012 se han certificado un total de 29 Proyectos, de los cuales, por medidas:

Medida 312: 10 Proyectos.

Medida 313: 4 Proyectos.

Medida 321: 8 Proyectos.

Medida 322: 3 Proyectos.

Medida 323: 2 Proyectos.

Medida 331: 2 Proyectos. 
En cuanto a los nuevos expedientes grabados, en el periodo de 2012 nos han entrado un total de 65 solicitudes de Nuevos expedientes de subvención, de los que por medidas:

Medida 312: 37 Nuevas solicitudes.

Medida 313: 13 Nuevas solicitudes.

Medida 321: 12 Nuevas solicitudes.

Medida 322: 3 Nuevas solicitudes.

Medida 323: 1 Nuevas solicitud.

Medida 331: 1 Nuevas solicitud.

El Importe total de Subvenciones pagadas en el presente periodo ha sido de $322.651,27 €$, en un total de 23 Expedientes.

De las cifras anteriormente expuestas, se puede sacar como conclusión que aun habiendo una situación económica a nivel nacional ciertamente complicada, durante el pasado año se han iniciado números expedientes con un cuantía de inversión considerable, que junto con el ritmo de entrada de nuevas solicitudes nos hacen pensar que el 2013 será muy bueno en cuanto a resultados y cumplimiento de la Senda Financiera.

Así mismo, ese buen ritmo en cuanto a nuevos expedientes generan buenas expectativas en cuanto a la reactivación económica de la comarca durante el presente ejercicio. Hemos de considerar igualmente 1 expediente de Grupo destinado a sufragar los gastos de funcionamiento y estructurales.

Los expedientes de proyectos a fecha de 31 de diciembre de 2012 pagados a los promotores, han sido los siguientes: 
L4504.1.0312.071 “Obrador de Pan y bollería artesana” siendo el promotor Productos Artesanos el Quijote S.L, con un pago recibido de 32.094,18 €.

L4504.1.312.072 “Can Villamiel”. Promotor: Can Villamiel S.L. con un pago recibido de $4.978,01 €$.

L4504.1.312.084 “Centro de Estética”. Promotor: Ma․ Soledad Rodríguez Rodríguez, con un pago recibido de 15.575,88 €.

L4504.1.312.088 “Túnel de Congelación”. Promotor: Antoliano García Frontelo, con un pago recibido de $6.432,71 €$.

L4504.1.312.091 “Establecimiento de alimentación y Bebidas” Promotor: Ma․ Almudena Rodríguez Ordóñez, con un pago recibido de 5.635,09 €.

L4504.1.312.107 “Gimnasio Fitness Hispania” Promotor: Domingo Sánchez Serrano, con un pago recibido de 7.198,81€.

L4504.1.313.007 “Casa Rural Al-Qabu” Promotor: Mª . Del Rosario Saavedra Pérez, con un pago recibido de $76.831,38 €$.

L4504.1.313.016 “Centro de Ocio y Turismo Activo Sostenible” Promotor: Bernuy Aventuras Sociedad Cooperativa CLM, con un pago recibido de 40.901,80€.

L4504.1.313.034 “Taberna Restaurante Galán” Promotor: Félix Galán del Castillo con un pago recibido de $12.238,54 €$.

L4504.1.313.114 "Café Bar Arena” Promotor: Julio Garoz Mora con un pago recibido de $2.234,04 €$.

L4504.0.321.022 "Parque Biosaludable para mayores" Excmo. Ayuntamiento de Cedillo del Condado, con un pago recibido de 7.402,85€.

L4504.0.321.023 "Parque Biosaludable en Rielves" Excmo. Ayuntamiento de Rielves, con un pago recibido de 7.096,94 €.

L4504.0.321.042 "Equipamiento e Instalación de aparatos biosaludables" Excmo. Ayuntamiento de El Casar de Escalona, con un pago recibido de 9.066,10€. 
L4504.0.321.043 “Equipamiento para parque Biosaludable” Excmo. Ayuntamiento de Erustes, con un pago recibido de 5.782,98 €.

L4504.0.321.047 "Parque saludable” Excmo. Ayuntamiento de Mesegar de Tajo, con un pago recibido de 5.950,56€.

L4504.0.321.054 “Parque infantil Municipal” Excmo. Ayuntamiento de Santa Olalla, con un pago recibido de $11.283,00 €$.

L4504.0.321.067 “Innovación Tecnológica en instalaciones deportivas” Excmo. Ayuntamiento de Fuensalida, con un pago recibido de 21.597,00 €.

L4504.0.322.020 “Acondicionamiento de Parque municipal” Excmo. Ayuntamiento de La Mata, con un pago recibido de 7.564,00 €.

L4504.0.322.049 “Embellecimiento de Rotonda del Cementerio" Excmo. Ayuntamiento de Malpica de Tajo, con un pago recibido de 9.327,97 €.

L4504.0.323.073 “Conservación de Fuente del Pilar” Excmo. Ayuntamiento de La Huecas, con un pago recibido de $6.880,41 €$.

L4504.0.323.074 “Arreglo de cubierta Centro Cultural El Convento" Excmo. Ayuntamiento de La Torre de Esteban, con un pago recibido de 6.954,47 €.

L4504.0.331.044 “I Foro de la Industria del Ocio Interactivo Digital” Excmo. Ayuntamiento de Torrijos, con un pago recibido de $11.589,60 €$.

L4504.0.331.070 “Talleres del Festival del Cine y la Palabra” Asociación Cultural El Viento de la Luna, con un pago recibido de 8.035,05 €.

L4504.0.431.082 "Gastos de Funcionamiento de anualidad 2012” Asociación Comarcal Castillos de Medio Tajo con un pago recibido de 70.184,69 €.

El año 2013 ha sido un año en el que se ha dado un gran avance en el cumplimiento de los objetivos del programa, tanto a nivel de nuevos proyectos como de proyectos en ejecución y certificados. 
La situación económica y sobre todo financiera siguen incidiendo notablemente en los promotores y proyectos, aunque paulatinamente se va aclarando un incierto futuro y se van solventando los problemas que hasta hace meses eran un pesado lastre, tanto a la hora de poner en marcha nuevas iniciativas emprendedoras y empresariales como a la hora de que fructifiquen dichas iniciativas en verdaderos proyectos empresariales. El número de promotores ha ido creciendo, a un ritmo bueno, de modo que la situación tanto a la hora de ejecución del programa como de certificación de proyectos subvencionados ha pegado un importante ascenso respecto a los años inmediatamente anteriores.

En este período se han planteado modificaciones del Cuadro Financiero LEADER, para flexibilizar el mismo y favoreciendo el trasvase de fondos desde las medidas excedentes a las deficitarias, sobre todo a raíz de la firma de la adenda correspondiente a la $2^{\underline{a}}$ asignación de fondos que se materializó el pasado mes de abril de 2013. Esta circunstancia, junto a la proximidad de la finalización del periodo de firma de nuevos contratos, que se prorrogó de Diciembre de 2013 a septiembre de 2014, así como la situación actual en la que tenemos más de una medida agotada y la posibilidad de una nueva asignación económica extraordinaria, propiciarán irremediablemente nuevas modificaciones de Cuadro Financiero, con el fin de que toda la consignación del mismo sea empleada y no exista remante devuelto.

También parece que ha mejorado sustancialmente la agilidad por parte de la entidad competencial que es la encargada de resolver estas modificaciones de cuadro financiero, por lo que dado que en un pasado reciente se vertieron ciertas críticas al respecto, hemos de decir que a día de hoy, la situación ha mejorado ostensiblemente y así hemos de reconocerlo. Esta agilidad ha facilitado en gran medida el trabajo del GDR y de su personal técnico. 
Durante el pasado año, se consiguió la resolución favorable por parte del comité de evaluación en cuanto al Proyecto de Cooperación Itínere "Camino Real a Guadalupe". A día de hoy y tras casi dos años de su aprobación, el proyecto está más en entredicho que nunca, entre otros motivos porque hay algún grupo socio que desea gastar sus fondos de cooperación en otras medidas, por lo que hasta que los servicios centrales no se pronuncien en cuanto a la modificación de esos fondos, no sabemos a ciencia cierta si finalmente podremos desarrollar el proyecto.

El cuadro financiero para el año 2013, es el siguiente:

Tabla 23: Cuadro financiero 2013 GDR Castillos del Medio Tajo.

\begin{tabular}{|c|c|c|c|c|}
\hline \multicolumn{5}{|c|}{ CUADRO FINANCIERO POR EJES, MEDIDAS Y FUENTES DE FINANCIACION } \\
\hline & TOTAL & FEADER & AGE & JCCM \\
\hline $\begin{array}{l}\text { 311Diversificación hacia actividades no } \\
\text { agrícolas }\end{array}$ & 0 & 0 & 0 & 0 \\
\hline $\begin{array}{l}\begin{array}{l}312 \text { Creación y el desarrollo de } \\
\text { microempresas }\end{array} \\
\end{array}$ & 926.347 & 717.941 & 108.395 & 100.011 \\
\hline 313Fomento de Actividades Turísticas & 558.905 & 424.906 & 71.039 & 62.960 \\
\hline $\begin{array}{l}\text { 321Servicios básicos para la economía y } \\
\text { la población rural }\end{array}$ & 588.942 & 449.759 & 73.466 & 65.717 \\
\hline $\begin{array}{l}322 \text { Renovación y desarrollo de } \\
\text { población rural }\end{array}$ & 160.754 & 124.082 & 19.151 & 17.521 \\
\hline $\begin{array}{l}323 \text { Conservación y mejora del } \\
\text { patrimonio }\end{array}$ & 148.934 & 115.492 & 17.378 & 16.064 \\
\hline 331Formación e Información & 152.573 & 117.658 & 18.257 & 16.658 \\
\hline $\begin{array}{l}341 \text { Adquisición de capacidades, } \\
\text { promoción y aplicación }\end{array}$ & 0 & 0 & 0 & 0 \\
\hline 421 Cooperación & 55.006 & 41.584 & 7.371 & 6.051 \\
\hline 431Gastos de funcionamiento & 647.866 & 492.553 & 82.837 & 72.475 \\
\hline TOTAL & 3.239.327 & 2.483.975 & 397.894 & 357.457 \\
\hline
\end{tabular}

Fuente: Elaboración propia a partir datos memoria Castillos de Medio Tajo 
El programa en el año 2013 se ha desarrollado según las previsiones planteadas para el cumplimiento de los objetivos de la senda financiera. Se ha superado el nivel exigido del $60 \%$ de certificación, habiéndose llegado al 71,45\%.

El nivel de compromiso se encuentra el niveles elevados previéndose realizar un compromiso total en el primer cuatrimestre del año siguiente.

Se han agotado dos medidas, la medida 312 y 313 quedando un nivel de compromiso de $92 \%$ sobre el total del cuadro y una disponibilidad de fondos del $8 \%$. En este año se han pagado expedientes por encima de la disponibilidad de fondos inicial, se ha certificado un porcentaje del $52 \%$ sobre la estrategia. 
CAPITULO 7: DISCUSIÓN Y CONTRASTACIÓN DE HIPÓTESIS 


\section{CAPITULO 7: DISCUSIÓN Y CONTRASTACIÓN DE HIPÓTESIS}

Antes de concluir esta investigación, vamos a presentar la contestación de hipótesis planteadas.

HIPOTESIS 1: Como hipótesis principal formulamos que los Programas de Desarrollo Rural son herramientas que han servido a orientar el desarrollo de la Comarca de Torrijos en el ámbito del rural agrario, no así en el rural periurbano.

RESPUESTA HIPOTESIS 1: Sí se cumple la hipótesis planteada. Se demuestra que hay una falta de cohesión a nivel territorial entre el desarrollo rural y el desarrollo periurbano. Es decir, el PDR no llega a entretejer estos dos espacios de un mismo territorio, tal como aparece en el capítulo 2 de este documento.

Este supuesto se acompaña de tres hipótesis específicas:

HIPOTESIS 2: Que las actuaciones de los Programas de Desarrollo Rural para Castilla La Mancha y consecuentemente para la Comarca de Torrijos han buscado fijar población y crear un entorno más sostenible incorporando una red de relaciones multidisciplinares en la coordinación de las acciones a realizar.

RESPUESTA HIPOTESIS 2: Sí se cumple la hipótesis planteada, sin embargo para ser más efectivas, las acciones que provienen de los PDR de manera descendente, deberían converger con los movimientos ascendentes procedentes de los GDR, pensando las acciones no tanto de manera individualizada sino insertadas en un proyecto global para el territorio que se va redefiniendo. 
HIPOTESIS 3: Los Grupos de Desarrollo Rural lideran iniciativas que responden a una realidad de proximidad inserta en la concepción tradicional de las políticas públicas.

RESPUESTA HIPOTESIS 3: No se cumple en su totalidad, puesto que se han quedado en una concepción bastante tradicional del territorio, sin captar las sinergias que llegan del flujo de actividades periurbano, industria de calzado, industria manufacturas productos asociados a la construcción (puertas, mobiliario de cocina), servicios logísticos etc. El GDR de nuestra comarca se ha concentrado en sectores tradicionales como comercios, bares y restaurantes.

HIPOTESIS 4: Los Programas de Desarrollo rural son atemporales a los resultados que se pretenden alcanzar, se van mostrando unas tendencias sin resultados finales.

RESPUESTA HIPOTESIS 4: Sí se cumple la hipótesis planteada. El PDR 20072013, a 31de diciembre de 2014 ha ejecutado un 79,73\%, es decir el gasto que no está ejecutado se va a pagar en los años venideros solapándose con el nuevo período de programación. Resultando que de las medidas que se están diseñando en la actualidad los resultados esperados no aparecerán hasta pasados unos años. Además ocurre que una medida diseñada para un PDR desaparezca en el siguiente, dejando los proyectos sin concluir, cayendo así en las fisuras tantas veces enunciadas en los tratados de Desarrollo.

Con respecto al GDR las Conclusiones generales sobre ejecución de la estrategia: 
- Se detecta una mayor priorización en la ejecución respecto a lo previsto en términos financieros, especialmente elevada en las medidas 321 y 322 , y menos acentuada en la medida 331.

- Se observa una menor priorización en la ejecución respecto a lo previsto inicialmente, siendo ésta muy acusada en la medida 312, también en la 313, y menos resaltada en la medida 323.

- Las medidas con mayor dotación presupuestaria prevista en la estrategia del grupo, la 312 y 313 , son las que registran la mayor ayuda media por proyecto.

- Existe un claro dominio de los proyectos catalogados como no productivos frente a los productivos, aunque en la estrategia del grupo no se priorizaban según esta tipología.

- Se registra una predominancia de proyectos realizados por corporaciones locales. Aun así, no se prioriza ninguna tipología de solicitante en la estrategia prevista.

- A través de la ejecución de los proyectos se detecta que se está contribuyendo a las tres áreas definidas en el Programa Territorial del grupo, siendo especialmente favorecida el área estratégica número 1. Dentro de esta área de Articulación del territorio las actuaciones de la estrategia más ejecutadas son las ayudas destinadas a la revalorización del patrimonio rural. Esto resulta coherente con la elevada ejecución que registran las medidas 321 y 322 cuyos objetivos definidos en el PDR y en la estrategia se encuentran en esa misma línea de actuación.

- Se observa coherencia entre la ejecución real de los proyectos gestionados por el grupo Castillos de Medio Tajo y las áreas estratégicas y actuaciones propuestas en su Programa Territorial. No obstante, es interesante resaltar que en este grupo, a diferencia de otros, el nivel de detalle de las actuaciones 
propuestas en la estrategia no es alto, pudiendo acogerse a cada área una gran variedad de proyectos, no siendo tan particularizada la correspondencia entre la ejecución de los proyectos y las actuaciones definidas en la estrategia

- De las cifras anteriormente expuestas, se puede sacar como conclusión que aun habiendo una situación económica a nivel nacional ciertamente complicada, durante los pasados años se han iniciado numerosos expedientes con un cuantía de inversión considerable, que junto con el ritmo de entrada de nuevas solicitudes nos hacen pensar que en el 2015 puedan finalizar el $100 \%$ del Cuadro financiero y por lo tanto podremos cerrar el programa y estar en disposición de arrancar el nuevo programa.

En cuanto a los PDR, mencionar que una vez aprobados los Programas de Desarrollo rural para el período 2014-2020, en el conjunto de España se reduce el gasto público en 3.145 millones de euros, y concretamente Castilla la Mancha, se reduce un $10 \%$, pasando de un presupuesto 2007-2013 inicial de 1.641.309.696 € a 1.477.755.584€.

Si bien el sistema de envío de fondos de la UE es bastante flexible, puesto que permite que los fondos se usen hasta dos años después de que el presupuesto comunitario los consigna (regla " $n+2$ "), pero si no se usan en este plazo se pierden.

El enfoque descendente de unos programas y el de abajo arriba de la política local, no son coincidentes. Las políticas de Desarrollo rural que se proyectan desde los despachos de Bruselas, dada la diversidad del territorio espacial, raramente puede coincidir con la realidad.

Esta es una de las razones por las que se propone el plan de cohesión, para corregir ese desequilibrio con el FEADER, y sin embargo no se ha corregido. 
De ahí una reflexión, es necesario profundizar en la línea de cómo podría imbricarse la política del PDR diseñada de arriba abajo, con una política de desarrollo local liderada por los GDR de abajo a arriba, para hacer coincidir esta falta de coherencia con la realidad del territorio.

A partir de este Marco Teórico es evidente que no hay una visión sobre qué es lo rural, puesto que depende del tipo de territorio y de diversos indicadores, densidad, $\mathrm{n}^{\circ}$ de habitantes, sector de actividad en porcentaje etc, en cualquier caso las definiciones siempre se quedan algo incompletas, al estudiar una cuestión demográfica, y no socioeconómica, como la movilidad de la gente en el territorio.

En el propio concepto de ruralidad, habría que utilizar más indicadores y más diversos que lo que hasta ahora se han utilizado, desde la concepción propiamente estadística que define lo rural por habitantes y densidades de población, hasta conseguir la definición antropológica que considera muchos otros parámetros cualitativos para alcanzar una construcción social como concepto, hay una pluralidad de modalidades. En efecto, "rural", no es una noción inmutable, y en los programas de desarrollo rural, se atiende a políticas administrativas.

La clasificación de la OCDE es crítica, porque se adapta mal al prototipo de la península ibérica, no son zonas muy pobladas ni muy densas. Esta respuesta heterogénea, hace que en ocasiones se adapte a las propias condiciones territoriales de cada comunidad, haciendo un uso discrecional. Sin embargo, estas decisiones están influyendo decisivamente en la ejecución de los PDR. Es decir, el enfoque territorial podría resentirse de no haber acertado e impactar de modo no deseable en esa cohesión que desde los PDR, se busca para los territorios rurales (Sancho,J et Reinoso, D 2012) 
Al mismo tiempo, en cuanto al poder de las palabras existe el siguiente aspecto a destacar, no se ve bien que a una capital de provincia se le clasifique como rural, lo cual sigue hablando no solo de la propia ambigüedad en la definición o de la falta de indicadores más cualitativos para poder aceptar mejor la clasificación de la OCDE, y su representación lo que condiciona.

Tanto la ruralidad como la periurbanización son graduaciones relacionadas con la manera en la que se apropia un espacio, se representan las prácticas sociales o se producen normas.

Los instrumentos de desarrollo rural deberían llevar alguna medida para crear sinergias a través de ese continuo rural-urbano, del valor agregado que se crea por ambas partes. 


\section{CAPITULO 8: CONCLUSIONES}




\section{CAPITULO 8: CONCLUSIONES}

Castilla la Mancha se caracteriza, entre otras cosas, por ser una región desigual en cuanto a distribución poblacional se refiere. En los últimos años se ha producido un despoblamiento de la zona rural y un envejecimiento considerable de población agrícola que ha llevado a la concentración de población en otras zonas de la región, entre las que se encuentra la Comarca de Torrijos.

En los últimos años, la Comarca de Torrijos se ha convertido en una de las demarcaciones más activas y de mayor crecimiento, también poblacional, de la región castellano manchega. Su situación estratégica, bajo la influencia que ejerce el gran perímetro urbano de Madrid le ha otorgado unas vías de comunicación e infraestructuras cada vez más desarrolladas que han facilitado las interrelaciones con otros municipios y regiones colindantes.

EI PDR de Castilla-La Mancha incluye entre sus objetivos la mejora de la calidad de vida y la diversificación económica de las zonas rurales, lo que no ha sido fácil de asumir en la última década ante una situación económica a nivel nacional ciertamente complicada, sin embargo en su ejecución se han iniciado numerosos expedientes con cuantías de inversión considerables, pudiendo afrontar el periodo 2007 -2013 con buenas expectativas en cuanto a la reactivación económica de la comarca.

En la ejecución financiera de este PDR por ejes, incluyendo tanto las operaciones convencionales como aquellas derivadas de la consideración de nuevos retos, destaca la ejecución del eje 2 , relativo a la conservación y mejora del medio ambiente, con un 55,2\% del gasto, seguido del eje 1 , relativo al fomento de la competitividad del sector agrícola y forestal, con un 36,6\% principalmente. A gran distancia se encuentra el eje 4, aplicación del enfoque Leader que representa el 
$7,67 \%$ respecto al gasto público total acumulado. Finalmente, el gasto realizado en el eje 3, calidad de vida y diversificación de la economía rural, apenas supone el 0,38\% del total acumulado y la asistencia técnica el $0,18 \%$. Constatando que las políticas de este Programa siguen priorizando un desarrollo rural agrario y además poco diversificado, manteniendo una posición conservadora sin apertura al cambio socioeconómico presente en el territorio y procedente de la periurbanización.

Aunque la dinamización social y económica que promueven los distintos Grupos de Desarrollo Rural de Castilla la Mancha se ha venido considerando de manera positiva en las distintas evaluaciones realizadas, en líneas generales, los efectos sobre el empleo han sido poco tangibles.

Los GDR son instrumentos de participación local en los territorios rurales. El Grupo de Desarrollo Rural (GDR) Castillos de Medio Tajo ha priorizado la medida de servicios básicos para la economía y la población rural (la medida 321) y la renovación y desarrollo de la población rural (la 322), que han sido principalmente absorbidas por los Ayuntamientos para la realización de parques "biosaludables", parques infantiles, rehabilitación de edificios históricos, instalaciones deportivas. En menor medida el GDR ha fomentado la creación de microempresas (medida 312) y las actividades turísticas (la 313) debido en parte a la falta de financiación de los promotores. La medida 311, de diversificación de las actividades no agrícolas ha ido perdiendo dotación presupuestaria a lo largo del tiempo, no se ha apostado por ella. Sin embargo una parte de la población estaría dispuesta a emprender actividades a través del eje LEADER, siempre que contase con financiación y crédito de las entidades bancarias.

A través de la ejecución de los proyectos de este GDR también se observa que ha prevalecido la primera de las áreas estratégicas definidas en su Programa Territorial, a saber la Articulación del Territorio frente a la dinamización económica y 
la dinamización social. Lo que se ha traducido en ayudas destinadas a la revalorización del patrimonio rural. Es interesante resaltar que este grupo, a diferencia de otros, no es exigente en el nivel de detalle de las actuaciones propuestas, pudiendo acoger en cada área estratégica una gran variedad de proyectos.

Si bien los proyectos asociados a estas estrategias del GDR no se han priorizado según la naturaleza de los mismos, productivos o no productivos, sí se ha observado un claro dominio de los proyectos catalogados como no productivos.

Al observar las iniciativas apoyadas por las políticas de acción local vemos que se ha mantenido una mirada estanca en el desarrollo de actividades y servicios tradicionales, perdiendo oportunidades ofrecidas por el posicionamiento del territorio. No se trata de ir ejecutando sistemáticamente el cuadro financiero, sino de analizar las sinergias y los cambios que se están produciendo y adaptarlo a las nuevas oportunidades.

El análisis de las políticas locales pone en evidencia la siguiente contradicción: las medidas insisten en fijar empleo en el sector agrario cuando los agricultores quieren salir de esta actividad primaria y acercarse a una actividad de servicios, las actuaciones del grupo de acción local desaprovecha la potencialidad que le ofrece en términos de oportunidad las nuevas actividades surgidas de la cercanía a la gran ciudad para crear mayor innovación y fijar población.

En el ámbito del rural agrario destacan tres tipos de agricultores: por un lado, agricultores a tiempo completo que tienen la agricultura como actividad principal, que están expandiendo sus explotaciones con la finalidad de obtener unas rentabilidades competitivas y que siguen invirtiendo apoyándose en las subvenciones de la PAC para la mejora y modernización de sus explotaciones; por otro lado, agricultores pluriactivos que realizan esta actividad a tiempo parcial, teniendo su actividad 
principal en el sector de la construcción o en el de servicios; y un tercer tipo que son los "agricultores pensionistas" que no han cedido sus tierras y que a decir de los jóvenes "siguen mandando" en la propiedad de la tierra.

En cuanto a la incorporación de nuevos agricultores a la actividad agraria se ha visto que el total de beneficiarios de ambos sexos está próximo a cumplir el objetivo, incluso a falta de la anualidad 2015, gracias a la buena ejecución de 2014 y a la reducción efectuada en dicho objetivo en la última versión del PDR. Destacar en este sentido que $11,8 \%$ de las solicitudes aprobadas están asociadas a jubilaciones anticipadas. A pesar de ciertas dificultades que encuentran las mujeres en su incorporación a la actividad agraria, su número continúa creciendo año a año.

En el sector agroalimentario se observa que falta voluntad de asociacionismo, no solo en la compartimentación de tareas y labores, o en el uso de la maquinaria, también a la hora de buscar mejorar sus estrategias para poner en valor el producto o comercializar; en este sentido las cooperativas no están siendo innovadoras, manteniendo estructuras tradicionales y conflictos entre ellas. Se producen hechos como la pertenencia de un mismo agricultor a varias cooperativas de vino para evitar enfrentamientos o conflictos vecinales, y es que a veces las relaciones familiares, vecinales o incluso ideológicas van por delante de los intereses económicos dificultando la cultura empresarial y la integración entre cooperativas, en este caso.

Por otro lado, hay una industria agroalimentaria en emergencia, relacionada con las explotaciones de porcino en intensivo que está en crecimiento constante.

En este proceso de traslación de lo rural agrario a periurbano, vemos también que anteriormente a la crisis nuevos residentes venían a esta zona ocupando una segunda residencia, que en muchos de los casos se ha convertido en la actualidad en su vivienda principal porque mejora su calidad de vida, es más económico y al 
tener unas buenas comunicaciones con Madrid, les merece la pena ese cambio de emplazamiento.

Estos nuevos residentes tardan en integrar las reglas de sociabilidad local y los mecanismos tradicionales bajo los que operan las economías locales, la cohesión entre la sociedad autóctona y los nuevos habitantes requiere de procesos de articulación interna considerables, lo que aún está por lograr ya que éstos no han suscitado un sentido de pertenencia e identidad al territorio, generándose, en este proceso, conflictos poblacionales. Así, los recién llegados no siempre se han integrado en la sociedad local ni están empadronados, su interés en las políticas locales de ordenamiento territorial está relacionado con la revalorización de sus propiedades. Sin embargo el interés de los habitantes locales, en particular de algunos agricultores, está justamente en la reducción del precio del suelo.

El gran auge (boom) inmobiliario en Madrid y su periferia, han dado lugar a la creación de empresas auxiliares a la construcción, junto a un desarrollo de industrias manufactureras derivadas de este sector: fábricas de puertas, muebles de cocina, etc, además de fábricas de calzado, apósitos, y de una industria agroalimentaria que ya gozaban de un cierto esplendor a principios de los años 90, pero que fueron altamente perjudicadas por la crisis y que se han consolidado y arraigado en estos últimos años.

Actualmente existe un flujo comercial procedente de Madrid y su periferia que está interesado en comprar estos productos locales (zapatos, cocinas, puertas, etc.) sin embargo esta oportunidad que viene de la mano de empresas de manufacturas no está siendo suficientemente aprovechada por el sector de la restauración para ofrecer un complemento a estas visitas, y para hacer intervenir la gastronomía, la oferta culinaria, las visitas enológicas en un viaje de comercio y así dar a conocer la comarca desde otras miradas. Se echa en falta una mirada innovadora, que integre 
la diversidad de recursos que tiene el territorio y aprovechar ese acercamiento existente de la gran ciudad.

Si bien se han hecho algunos establecimientos de turismo rural gracias a las medidas que contempla el PDR, éstos no ponen a disposición del visitante el atractivo de la comarca. Tampoco se ofrecen alternativas diferenciadas que generen dinamismo económico asociado a creación de empleo y fijación de la población.

Por otro lado los encargados de emerger el cambio en la realidad social, como son los Grupos de desarrollo rural no lo están haciendo, no son transmisores de estos cambios. Quizás por no comprender que el espacio social y de actividades está cambiando y en consecuencia no están abiertos a las potencialidades de este flujo. Existe una falta de creatividad, se debería fortalecer la movilidad, y analizar qué se hace en otros lugares y así forjar nuevas ideas.

Desde la estructura de los GDR están demasiado preocupados en cumplir el cuadro financiero, por las propias exigencias administrativas, y no proyectan iniciativas acordes con la realidad del cambio que se está generando en la comarca.

Además, los cambios de representantes públicos en el seno de los GAL tras los cambios políticos en los ayuntamientos, es un aspecto que afecta negativamente en tanto en cuanto constituye un elemento de inestabilidad y, sobre todo, de posible pérdida de eficacia en los órganos de decisión, así como en una ralentización en el funcionamiento del programa. Mencionar que estos cambios suelen obligar a los equipos técnicos a intensificar su labor de asesoramiento e instrucción a los miembros de los órganos de decisión.

Hasta el momento el intento de definir metas comunes para el desarrollo de la comarca se ha impuesto sobre cualquier otro debate que pudiera enfrentar a alcaldes o concejales de distinto signo político, lo que favorece a la implementación de cualquier programa de ámbito comarcal. 
Señalar también que para la población, todo lo proveniente de Europa sigue resultando lejano y difícil de comprender de cara a la vida cotidiana, salvo contadas excepciones. Las acciones llevadas a cabo hasta la fecha han obedecido a la capacidad de gestión de los diferentes equipos municipales, más que a una estrategia consolidada.

Por otro lado, se plantea una cuestión en relación a los agentes que diseñan el PDR, y es que no están en el proceso de cambio, siguen dirigiendo sus políticas hacia un sector que está en declive, perdiendo la oportunidad de ir hacia otros sectores más novedosos que podrían ser más interesantes para el territorio.

Los agentes que mejor se están percatando de esta dinámica de cambio son los ayuntamientos, así ante esta demanda por parte de unos sectores procedentes de lo urbano, los ayuntamientos ofertan suelo a muy bajo precio, cedido a veces por 50 años para que se instalen industrias en sus municipios..

En una región tan extensa como Castilla la Mancha con realidades tan diversas la aplicación de las medidas de los diferentes ejes de los programas quedan demasiado encorsetadas y no son capaces de llegar al nivel más local, ver comarcal, donde entran en juego componentes y actividades que no están contemplados en la estructura de los programas tal y como están diseñados.

En este sentido el PDR es poco flexible en sus medidas para avanzar sobre una rural periurbano, la realidad social va por delante de las medidas administrativas. EI PDR no está recogiendo el cambio hacia una sociedad periurbana procedente del desarrollo de la industria de manufactura y de servicios, que llegan de la amplitud del perímetro de la ciudad.

EI PDR persigue con la zonificación de la región de Castilla la Mancha, detectar características homogéneas que articulen las comarcas en aras a una 
actuación diferenciada en materia de desarrollo rural, sin embargo no se ha planteado definir diferentes medidas en función de esa zonificación.

En consecuencia la política rural no está avanzando a la realidad socioeconómica de la comarca, respondiendo así al hecho de que el PDR no ha creado oportunidades para el flujo socioeconómico procedente de este cambio periurbano.

Esta investigación viene a confirmar la complejidad del espacio periurbano, un espacio donde en función del territorio y de su sociedad se producen diferentes realidades que nos dan idea de lo heterogéneo que es hablar de la ruralidad en sus diversas modalidades.

A partir de esta investigación, se podría plantear como hipótesis que un primer paso hacia un rural periurbano es la pluriactividad de los agricultores, es decir tener otra actividad como principal y la agricultura en complemento de una renta. Un segundo paso sería la penetración de otra actividad que pueda acoger una mano de obra no cualificada y un tercer paso las residencias secundarias.

Esta comarca está ante un proceso que no ha finalizado y están emergiendo una serie de paradojas, contradicciones y conflictos que hemos podido captar pero que merecerían un análisis más profundo en una investigación futura.

Otra apertura a esta investigación, es profundizar sobre el impacto de la urbanificación en el medio rural y explorar conexiones y condiciones endógenas favorables a las nuevas ruralidades. 


\section{CAPITULO 9: BIBLIOGRAFIA}




\section{CAPITULO 9: BIBLIOGRAFIA}

ABAD, L (2010): "Patrimonio y desarrollo territorial". Ed. De Re Metallica, no 15. Madrid

ALDHUY, J (2009): “Au-delá territoire, la territorialité?".disponible en http://hal.archives-ouvertes.fr/docs/oo/27/86/69/PDF/aldhuy-2008-au dela-T-Tly.pdf

AVILA, H (2004)."La agricultura en las ciudades y su periferia: un enfoque desde la geografía”. Investigaciones Geográficas, ㄲ53. UNAM, pp.:98-121.

ARNALTE, E (2012):" Lecciones de política rural: la política rural de la Unión Europea y su aplicación en España”. Editorial de la Universidad Politécnica de Valencia.

ATANCE, I, TIÓ, C (2000):"La multifuncionalidad de la agricultura: Aspectos económicos e implicaciones sobre la política agraria". Estudios Agrosociales y

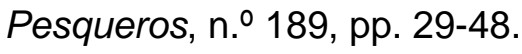

BANZO,M (2005) :»Del espacio al modo de vida». la cuestión periurbana en Europa Occidental », en H, Avila (coord), Lo urbano es rural ¿nuevas expresiones territoriales ? UNAM, pp. 207-241.

BANZO, M. (2001: «Territoires de protection environnementale. Les parcs naturels de la Région Autonome de Madrid». En: Guichard, F. Articulation des territoires dans la Péninsule ibérique. Burdeos, Maison des Pays lbériques. pp.101-110.

BARDAJI, I.; RAMOS, E. \& RAMOS F. (2008): "Los Nuevos Espacios Rurales". Papeles de Economía Español. N.ำ117, pp.: 13-29 , 181-191

BARSKY,A (2005): «El periurbano productivo, un espacio en constante transformación ». Scripta Nova, 194 (36). Buenos aires. 
BAUER,G., ROUX, JM (1976):»La rurbanisation ou la ville éparpilleé ». Ed.Seuil. París.

BELTRÀN, M (2003) : »Estrategias de aprendizaje». Revista de Educación, ㄲo332, pp.55-73

BOISIER, S (2001). «Teorias y metáforas sobre el desarrollo territorial », en Revista Austral de Ciencias Sociales nำ2, pp. 5-18

BRUGUÉ, Q., GOMÁ, R.y SUBIRATS, J (2002): “Conclusiones. La gobernabilidad de las ciudades y los territorios en la sociedad de las redes", en Subirats, J (coord.) Redes, territorios y Gobierno. Nuevas respuestas locales a los retos de la globalización. Diputación de Barcelona. Colección Territorio y gobierno; visiones ㄲọ, Barcelona.

BRYANT, C. R; RUSSWURM et Al (1982): "The city, countryside land and its mangement in the rural urban frince». Longman, Great Britain.

CAMPAGNE, P ET BERNARD PECQUEUR,(2014):»Le développement territorial. Une réponse émergente à la mondialisation».Éd. Charles Léopold Mayer. (pp268284).

CAPEL, H (1994). "Las periferias urbanas y la geografía. Reflexiones para arquitectos". En CAPEL, H (Dir).La geografía hoy. Textos, historia y documentación. Anthropos. Barcelona.

CARMONA, F,J (2013): "Análisis Territorial de los efectos de los programas de desarrollo rural LEADER + y PRODER II en Castilla la Mancha.. Tesis Doctoral. Departamento de Producción Vegetal y Tecnología Agraria. Universidad de Castilla la Mancha. 
CARMONA, F.J; MONTERO, F; CASTILLO J.S.(Dir.); BRASA, A.(Dir.).El "efecto llamada" de la concentración de población en la distribución territorial de proyectos del programa LEADER PLUS y PRODER 2, en Castilla La Mancha. En: Actas VIII Coloquio Ibérico de Estudios Rurales. (Cáceres 21-23 de octubre de 2010).

CARUSO, G. (2002) « Figures de la périurbanisation en Europe » in Perrier-Cornet, P. (dir.) Repenser les campagnes, Datar, Aube, p.67-99.

CASTELLS, M (2001): La era de la información. Vol. 1: La sociedad red. Alianza Editorial, Madrid. $(2001,171)$

CASTILLO, J.S (Dir.) y GARCÍA Mạ C. (2011) "Los distritos rurales: un nuevo concepto de desarrollo territorial. Modelos Centro-Periferia en Castilla-La Mancha". Estudios de economía aplicada. Vol. 29 - 1 2011, págs. 1-24.

CAZORLA, A et AL. (1994): "Experiencias de Desarrollo Rural en una iniciativa LEADER”. Dirección general de agricultura y alimentación. Comunidad de Madrid.

CEÑA, (1994): "Planteamientos económicos del desarrollo rural". Revista de Estudios Agrosociales no 169 , pp 11-52

CEÑA, F (1992):"Transformaciones del mundo rural y políticas agrarias". Revista de Estudios Agrosociales, ํㅜ162.pp 11-35. MAPA.

CERTU-INRETS (2007): Le periurbain. Quelle connaisance? Quelle aproches?. En la web: www.observation-urbaine.certu.equipement.gouv.fr

CONSEJERÍA DE AGRICULTURA Y DESARROLLO RURAL DE LA JUNTA DE COMUNIDADES DE CASTILLA LA MANCHA (2007) Programa de Desarrollo Rural de Castilla-La Mancha (2007-2013). http://www.jccm.es 
CONSEJERÍA DE AGRICULTURA Y DESARROLLO RURAL DE LA JUNTA DE COMUNIDADES DE CASTILLA LA MANCHA (2007) Informe de Sostenibilidad Ambiental del Programa de Desarrollo Rural de Castilla-La Mancha (2007-2013). http://www.jccm.es

COMISIÓN EUROPEA (1988). Informe 1988 sobre medio rural

COMISIÓN EUROPEA (2006): «El enfoque Leader». Fact sheet.

COMISIÓN EUROPEA (2009) Desarrollo Rural en la Unión Europea - información estadística y económica - Informe 2008. Dirección General de Agricultura y Desarrollo Rural.

COMISIÓN EUROPEA (2011). Rural Development in the European Union - Statistical and Economic Information- Report 2011. Bruselas.

DELORME, HELENE (DIR.) (2004): «La politique agricole commune. Anatomie d'une transformation», Presses de Sciences Po, París.

DEMATTEIS,G (1998): "Suburbanización y periurbanización. Ciudades anglosajonas y ciudades latinas". Ed. Monclús. Barcelona.

DONADIEU, P. (1998). Campagnes urbaines, Actes Sud/Ecole Nationale Supérieure du Paysage.

DROGUETT,J.G (2001). Bases semióticas de un nuevo método para las ciencias humanas. En http:/www.unav.es/gep/Drogurtt.pdf

ESCRIBANO, S (2011), Análisis Rural y Socioeconómico de la Comarca Mancha de la provincia de Toledo, Visión Libros 
ESPARCIA, J y NOGUERA, J. (1999): Reflexiones en torno al territorio y al desarrollo rural. En: El desarrollo rural en la Agenda 2000. Coord. Eduardo Ramos Real. MAPA. Madrid.

ESPARCIA, J y ESCRIBANO, J. (2012): La dimensión territorial en la programación comunitaria y el nuevo marco de políticas públicas: desarrollo rural territorial, reforma de la PAC y nuevo LEADER. Anales de Geografía 2012, vol. 32, núm. 2 pp. 227-252 ETXERRARRETA, M (1988):"Desarrollo rural Integrado". Serie Estudios del MAPA. Madrid.

\section{EUROPEAN NETWORK OF RURAL DEVELOPMENT.}

http://enrd.ec.europa.eu/leader_en.cfm..

FLEURY, A. Y P. MOUSTIER (1999) : "L'agriculture périurbaine, infrastructure de la ville durable". Cahiers Agricultures, núm. 8. pp. 281-287.

FORO IESA sobre la Cohesión de los Territorios Rurales (2009), Del desarrollo rural al desarrollo territorial, Reflexiones sobre el caso español. IESA-CSIC

FOURNY, M.C (1995):"Identités territoriales et strategies d'amenagement. Les reseaux de villes en Rhône. Alpes”, dans IEspace Géographique. Ed. Reclus, Montpellier, no4, pp. 329-340.

GALLARDO, R et Al (2014): «Reflexiones en torno a laPAC». Cajamar.

GAROFOLI, G (1986): «Modelos locales de desarrollo», en Estudios Territoriales, nำ2, pp157-168. 
GARAY, A (2001).”Dimensión territorial del desarrollo local”. Módulo 2. Buenos aires: Curso de Posgrado "Desarrollo local en áreas metropolitanas". Universidad Nacional de General Sarmiento.

GARCíA AZCÁRATE, T. (2009) "Apuntes sobre la Política Agraria Común de la próxima década". Colección Mediterráneo Económico, №15, pp. 353-374.

GARRIDO FERNÁNDEZ, F., MOYANO ESTRADA, E., (2013), "Sostenibilidad agraria, desarrollo rural y cohesión territorial", Sostenibilidad de la agricultura española. Cátedra Cajamar pp. 203-232.

GÓMEZ MENDOZA, J (2001)."Las nuevas funciones socio-económicas y medioambientales en los espacios rurales", en García Pascual, F (coord.): el mundo rural en la era de la globalización: incertidumbres y potencialidades. MAPA. Madrid.

GÓMEZ OREA, D (2001). Ordenación Territorial. Ediciones Agrícola Española, S.A. y Mundi Prensa. Madrid.

GÓMEZ OREA, D. (2002) Ordenación Territorial. Ediciones Mundiprensa. Editorial Agrícola Española SA. Madrid.

GONZALEZ CANALES, F (2005). «El enfoque LEADER en la nueva política de Desarrollo rural de la ». Informe socio économico de la Agricultura Familiar de España. Fundación Estudios rurales. Madrid.

HERVIEU, B (2002): 'La multifonctionnalité de l'agriculture. Genèse et fondements d'une nouvelle approche conceptuelle de l'activité agricole". Agricultures: cahier d'études et de recherches", nํ6, volumen 11, pp. 415-419

HERVIEU, B (1995): «El espacio rural europeo entre la ruptura y el desarrollo». En hacia un sistema rural. Serie estudios $n^{\circ} 99$ MAPA. 
JANSMA, D.J et AL. (1981): "Rural development. A review of conceptual and empiric studies".Ed. Martin. Economics of Welfare, rural development and natural resources in agriculture, 1940`s to 1970's. University of Minnesota Press. Minneapolis.

KAYSER, B (1990): «La Renaissance Rurale, sociologie des campagnes du monde», Édition Armand Colin, Paris.

KAYSER, B (1994, Dir.):»Pour une ruralité choisie, Éditions de l'Aube.París.

KOOLMAN J (1993), Modern governance, London, Sage

LAJARGE, R (2012) Territorialités en développement, contribution aux sciences territoriales, tome 1, HDR Soutenue à l'université Joseph Fourier, Grenoble.

LE BERRE M., 1992, “Territoires”, dans Encyclopédie de géographie. Paris. Ed. Economica, pp620-621.

LEVY,J., Lussault, M., (2003) : Dictionnaire de la géographie et de l'èspace des sociétés. París, Ed. Bellin

LEWIS, G. J. Y D. L. MAUND (1976): «The Urbanization of the Countryside: A Framework for Analysis», Geografi ska Annaler, 58 (1): 17-27. Citado por García Docampo, M, Otero Enríquez, R (2012), Transición territorial: modelo teórico y contraste con el caso español Territorial, Reis 139, julio-septiembre 2012, pp. 133162

LAMO DE ESPINOSA, J (2004). "Transformación y modernización de la agricultura española". Revista del Instituto de estudios Económicos, nำ-3

LARRUBIA, R (1998): Los espacios rurales” en R. Puyol Geografía Humana Baetíca. Estudios de Arte, Geografía e Historia, 20 ,pp. 77-95. 
LAURENT DAVEZIES (2008):"Economie residentielle: atout ou contrainte pour les territoires ruraux". POUR. ํo 199 pp 200

LOPEZ DE SOUZA, MARCELO (1995) "O territorio: sobre espaco e poder, autonomía e desenvolvimento", en De Castro, I., da Costa Gómez, P. y Lobato Correa, R. Geografía: conceitos e temas, Bertrand Edit, Río de Janeiro

LOWE, Ph MURDOCH, J, WARD, N(1997): "Redes en el desarrollo rural: más allá de los modelos exógenos y endógenos”, en Agricultura y Sociedad nำ 82, pp 13-43.

MANZANAL, M (2007). "La coparticipación de impuestos en Argentina. ¿un dilema para las actuales propuestas de desarrollo territorial?", en Realidad Económica 225, IADE, Buenos Aires, enero-febrero 2007, pp. 47-71.

MARM (2010). Evaluación Intermedia del Programa de Desarrollo Rural de CastillaLa Mancha (2007-2013). Disponible en http://ec.europa.eu/agriculture/rurdev/countries/es/mte-rep-es-castilla-la- mancha_es. MARM (2011), Leader en España (1991-2011): Una contribución activa al desarrollo rural. Dirección General de Desarrollo Sostenible del Medio Rural.

MARTÍNEZ DE ANGUITA, P. (2006): Desarrollo Rural Sostenible. Mc GrawHill/Interamericana de España, S.A.U. Madrid.

MASSOT, A. (2009): España ante la refundación del la Política Agrícola Común de 2013. Real Instituto Elcano. Documento de Trabajo 35/2009.

MASSOT, A. (2000): «La PAC entre la Agenda 2000 y la Ronda del Milenio: ¿A la búsqueda de una política en defensa de la multifuncionalidad agraria?», Revista Española de Estudios Agrosociales y Pesqueros, 188, pp. 9-66. 
MATHIEU, N. (1998). «La notion de rural et les rapports ville/campagne en France: les années quatre-vingt-dix». Economie Rurale, núm. 247. pp.11-20.

MAZOYER, M y LAURENCE,R. (1998): "Histoire des agricultures du monde .du néolithique á la crise contemporaine". Seuil, Paris

MENDES, A (1997): "La implicación de las regiones en el desarrollo local”. Direççao Regional agricultura Porto. Portugal.

MOLINERO, F (1999). Caracterización y perspectivas de los espacios rurales españoles. Dpto de Geografía. Universidad de Valladolid. En: El desarrollo rural en la Agenda 2000, coord. por Eduardo Ramos Real. Serie Estudios. MAPA.

MOYANO y GARRIDO (2007). La multifuncionalidad en la agricultura, Madrid, Eumedia, pp. 59-78.

NELSON, J (2011) en revista Equidad y Desarrollo n¹6

NIETO, A. (2007). El Desarrollo Rural en Extremadura: Las Políticas Europeas y el Impacto de los Programas Leader y Proder. Tesis Doctoral. Departamento de Arte y Ciencias del Territorio. Universidad de Extremadura.

OCDE. Creating rural Indicators for Shaping Territorial Policy, Paris, 1994

PAHL R. (1968), The Rural-Urban Continuum. In: Pahl R. (ed.), Readings in Urban Sociology. Pergamon, London, pp. 263-297

PLAN EStRAtÉGico DE DESARROLlO SOSTENIBLE DE CASTILLA LA MANCHA. Consejería de Agricultura y Desarrollo rural. Junta de Comunidades de Castilla La Mancha (2007), http://www.jccm.es 
PECQUEUR, B. (2001): "Qualité et développement territorial: I'hypothèse du panier de biens et de services territorialisés". Economie Rurale, N. 261, pp.: 37-49.

PECQUEUR, B. (1995): "La logique de la proximité ». En Sciences Humaines, Hors Series no 8, pp. 43-44

PECQUEUR, B. (1989): "Le développement local». Ed. Syros. Alternatives Economiques. Paris.

PEREIRA, D et Al (2004) : »Las zonas rurales en España: Un diagnóstico desde la perspectiva de las desigualdades territoriales y los cambios sociales y económicos ». Fundación FOESSA. Madrid.

PEÑA, A.(2004): «Las disparidades económicas interregionales en Andalucía ». Universidad de Cádiz.

POULOT, M (2008): « Les territoires périurbains : « fin de partie » pour la géographie rurale ou nouvelles perspectives ? ", Géocarrefour [Vol. 83/4 | 2008: http://geocarrefour.revues.org/7045

PROST, B. (2001): "Quel périurbain aujourd'hui?". Géocarrefour vol. 76, núm. 4. pp.283-288.

PROST B: "Du rural au péri-urbain : conflit de territoire et requalification de l'espace / Territorial conflict and spatial change : the rural - peri-urban transformation. In: Revue de géographie de Lyon. Vol. 66 n2, 1991. Mutations économiques et requalifications territoriales. pp. 96-102.

PUEBLA, G (2004). «Aproximaciones al concepto del periurbano ». Cátedra de Gestión Local, Universidad Nacional de Tres de Febrero. Buenos Aires. 
RAMOS, E. (2004) "Hacia un nuevo papel del medio rural europeo: la multifuncionalidad entre la PAC y la OMC". En: E. Pérez y M. A. Farah (Coords.): Desarrollo Rural y Nueva Ruralidad en América Latina y la Unión Europea. CIRAD (Montpellier) y Pontificia Universidad Javeriana (Bogotá), pp. 109 - 127.

RAMOS, E. (2004) "Hacia un nuevo papel del medio rural europeo: la multifuncionalidad entre la PAC y la OMC". En: E. Pérez y M. A. Farah (Coords.): Desarrollo Rural y Nueva Ruralidad en América Latina y la Unión Europea. CIRAD (Montpellier) y Pontificia Universidad Javeriana (Bogotá), pp. 109 - 127.

RAMOS, E., GARRIDO, D (2010); La reforma de la política rural de la Unión Europea. En: Agricultura familiar en España 2010. Fundación de Estudios Rurales. UPA en colaboración con el MARM. Madrid.

RAFFESTIN C., (1986): "Ecogènese territoriale et territorialité", Espaces, jeux et enjeux, AURIAC F., BRUNET R. (dir), Paris, Fayard, pp173-185.

REDFIELD, R (1941):"The folk culture of Yucatán". University of Chicago.

REGIDOR, J.G, Política de Desarrollo Rural en España. En: Desarrollo Rural Sostenible: Un Nuevo Desafío. Coord. Jesús G. Regidor. Centro de Publicaciones. MARM. Madrid 2008.

ROUX, E Y VARNIER, M (2008): »La périurbanisation .problématiques et perspectives». DIACT. La documentation Française. Collection :Travaux, nํㅇ.

RUBIO, M.A. (2011) : La Red Natura 2000 en Castilla-La Mancha. Revista Foresta nos 47-48 Especial Castilla La Mancha. pp.190-193. 
SANCHO COMINS, J et Al : (2012): "La delimitación del ámbito rural: una cuestión clave en los programas de desarrollo rural", en Revista de Estudios Geográficos LXXIII, 273, pp.599-624

SANCHO COMINS, J et Al : (2002):"Población y poblamiento rural en España: un primer análisis a la luz del censo 2001». Universidad de Alcalá. Madrid.

SANCHO MARTÍ, J. (1989):"El espacio periurbano de Zaragoza». Zaragoza, Ayuntamiento de Zaragoza

SASSEN, S (2013) "When Territory Deborders Territoriality". Territory, Politics, Governance, Vol.1, pp. 21-45.

SOROKIN, P.A, ZIMMERMAN, CC,. (1929): «Principes of rural urban sociology ». Ed. Henry Holt.New York.

STEINBERG, J (2001). «La periurbanisation en Europe». bulletin de L'assotiation de géographes Françaises, vol 78,nำ1, pp 49-50.

STEINBERG, J. (1993). “Le périurbain: définition, délimitation et spécificités”. Cahiers du CREPIF, núm. 42. pp.9-17.

SUMPSI, J (1994):«La política agraria y el futuro del mundo rural». Revista de Estudios Agrosociales, ํo 169, 3/1994.

TCHEKEMIAN, A. (2008). L'impact d'une politique publique agricole européenne sur les acteurs et les territoires ruraux français Etude de l'application du programme français de développement rural dans six territoires ruraux. Thèse Doctoral. Université Joseph Fourier Grenoble I Institut de Géographie Alpine. Ecole doctorale 454 « Sciences de l'Homme, du Politique et du Territoire » Discipline : Géographie. 
TOLON BECERRA, A (2007): «Evolución del Desarrollo Rural en Europa y España. Las áreas rurales de metodología Leader». M+A. Revista electrónica de medio ambiente, $\mathrm{n} \div 4$.

VALCÁRCEL-RESALTS (1992) :"Planes estratégicos de Desarrollo Local”, en Valcarcel-Resalt et al. Desarrollo Local, Turismo y Medio Ambiente. Diputación de Cuenca.

VALCARCEL-RESALT, G. y TROITIÑO, M.A.(1992) .Local y Medio Ambiente en Zonas Desfavorecidas. MOPT. Colección Monografías. Madrid VÁZQUEZ BARQUERO, A. (1996), "Desarrollos Recientes de la Política Regional. La Experiencia Europea”. Revista Eure, Vol. XXII, núm. 65, pp. 101-116

VALENZUELA, M (1986): «Los espacios periurbanos». IX Coloquio de Geógrafos Españoles. Actas, discursos, ponencias y mesas redondas. Murcia 16 de diciembre de 1985.

VANIER, M. (2001). "Le tiers espace, acte II de la périurbanisation”. Pouvoirs Locaux, núm. 48. pp.59-63.

VELASCO, ANA (2002), Les contradictions de la modernisation en agriculture. Paris, l'Harmattan.

VELASCO, ANA (1999): Du mythe du «retard» au mythe de la «modernisation» ou I'adaptation des agriculteurs du sud de l'Europe à la PAC: le cas de l'Extremadure Espagnole, 492 p. Thèse Doctorale Université de París X Nantérre.

WHYTE, WILLIAM (1961): Street Corner Society, Chicago, the University of Chicago Press (e.o de 1937). 


\section{ANEXOS}




\section{ANEXO I: MARCO LEGAL}




\section{ANEXO I: MARCO LEGAL}

En este Anexo figuran las principales Normas que influyen en:

- Desarrollo Rural

- Planificación Territorial

- Medio Ambiente

Estas Normas se estructuran siguiendo primero un orden descendente de ámbito institucional: Unión Europea, España y Castilla-La Mancha y, segundo, un orden cronológico también descendente.

\section{UNIÓN EUROPEA}

\subsection{Desarrollo Rural}

\subsubsection{Reglamentos y Marcos}

Regulaciones para 2014-2020

Esta sección ofrece enlaces a los textos legales que son relevantes para el FEADER y la implementación de PDR en 2014-2020:

Reglamento (UE) no 1303/2013 del Parlamento Europeo y el Consejo estableciendo las disposiciones comunes sobre el Fondo europeo de desarrollo regional, el fondo social europeo, el fondo de cohesión, el fondo europeo agrícola de desarrollo rural y el fondo europeo marítimo y de pesca cubiertos por el Marco estratégico común y estableciendo las disposiciones generales sobre los fondos europeos regionales, el fondo europeo social y el fondo de cohesión abrogando el reglamento (CE) № 1083/2006. La regulación de provisiones comunes ofrece una 
serie común de normas básicas que aplican a todos los instrumentos estructurales incluso el FEADER.

Reglamento (UE) no 1305/2013 del Parlamento Europeo y el Consejo sobre el apoyo al desarrollo rural por el Fondo europeo agrícola de desarrollo rural (FEADER) .Esta es la ley básica que establece normas concretas relacionadas con el FEADER para la programación de desarrollo rural.

Reglamento (UE) no 1306 / 2013 del Parlamento Europeo y el Consejo sobre financiación, gestión y seguimiento de la política agrícola común La denominada Regulación horizontal PAC ofrece normas de gestión financiera para los dos fondos de la PAC, el Fondo europeo agrícola de garantía (FEAGA) que financia el mercado de finanzas y los pagos directos y el FEADER que apoya el financiamiento del desarrollo rural. Reúne las normas sobre condicionalidad, servicios de asesoramiento agrícola y seguimiento y evaluación de la PAC.

Regulación (UE) no 1310/2013 del Parlamento Europeo y el Consejo que establece ciertas provisiones transitorias para el desarrollo rural por el Fondo agrícola europeo de desarrollo rural (FEADER). Esta regulación define las normas transitorias para cerrar la brecha entre dos periodos de programación de varios años. Reglamento (UE) $\mathbf{n}{ }^{\circ} \mathbf{6 5 / 2 0 1 1}$ de la Comisión, de 27 de enero de 2011, por el que se establecen disposiciones de aplicación del Reglamento (CE) n 1698/2005 del Consejo en lo que respecta a la aplicación de los procedimientos de control y la condicionalidad en relación con las medidas de ayuda al desarrollo rural [Diario Oficial L 25 de 28.1.2011].

Este Reglamento establece las disposiciones de aplicación del Reglamento (CE) nº $1698 / 2005$ en lo que concierne a los principios y normas generales aplicables al apoyo al desarrollo rural, las disposiciones comunes y particulares aplicables a las medidas de desarrollo rural y las disposiciones en materia de admisibilidad y de 
gestión administrativa.

Reglamento (CE) n 800/2008 de la Comisión, de 6 de agosto de 2008 por el que se declaran determinadas categorías de ayuda compatibles con el mercado común en aplicación de los artículos 87 y 88 del Tratado (Reglamento general de exención por categorías).

Reglamento (CE) no 1320/2006 de la Comisión, de 5 de septiembre de 2006, por el que se establecen normas para la transición a la ayuda al desarrollo rural establecida en el Reglamento (CE) № 1698/2005 del Consejo.

Reglamento (CE) no 1974/2006 de la Comisión, de 15 de diciembre de 2006, por el que se establecen disposiciones de aplicación del Reglamento (CE) 꾸 1698/2005 del Consejo relativo a la ayuda al desarrollo rural a través del Fondo Europeo Agrícola de Desarrollo Rural (FEADER).

Reglamento (CE) no 1975/2006 de la Comisión, de 7 de diciembre de 2006, por el que se establecen disposiciones de aplicación del Reglamento (CE) n o 1698/2005 del Consejo en lo que respecta a la aplicación de los procedimientos de control y la condicionalidad en relación con las medidas de ayuda al desarrollo rural [Diario Oficial L 368 de 23.12.2006].

Este Reglamento establece las disposiciones de aplicación del Reglamento (CE) no 1698/2005 en lo que respecta a la aplicación de los procedimientos de control y la condicionalidad en relación con las medidas de ayuda al desarrollo rural.

\section{Marco Comunitario de Apoyo 2000/2006}

Los Marcos Comunitarios de Apoyo (MCA) son documentos de programación que aprueba la Comisión Europea, una vez analizados los planes de desarrollo que presentan los Estados miembros para cada objetivo prioritario. En dichos documentos se describen la estrategia de desarrollo y las prioridades de actuación a cofinanciar con los recursos comunitarios, sus objetivos específicos, la participación 
de los Fondos Estructurales y los demás recursos financieros a aplicar. El Marco Comunitario de Apoyo para las regiones españolas del Objetivo № 1 constituye el instrumento financiero de ayudas estructurales más amplio e importante para el período 2000-2006.

Reglamento (CE) 1698/2005 del Consejo, de 20 de septiembre de 2005, relativo a la ayuda al desarrollo rural a través del Fondo Europeo Agrícola de Desarrollo Rural (FEADER) Es el Reglamento comunitario del que derivan el Plan Estratégico Nacional de Desarrollo Rural para el período 2007-2013, integrado por los 17 Programas de Desarrollo Rural Autonómicos (PDR).

Reglamento (CE) 70/2001 de 12-01-2001, sobre ayudas de PYME.

Reglamento (CE) 68/2001 de 12-01-2001, sobre ayudas de formación.

Reglamento (CE) 994/1998 de 07-05-1998, sobre ayudas de Estado.

Reglamento (CE) 1685/2000, de 28-07-00, por el que se establecen disposiciones de aplicación del Reglamento (CE) 1260/1999 en lo relativo a la financiación de gastos de operaciones cofinanciadas por los fondos estructurales.

Reglamento (CE) 1159/2000, de 30-05-00, sobre actividades de información y publicidad que deben llevar a cabo los Estados miembros en relación con las intervenciones de los fondos estructurales.

Reglamento (CE) 1257/1999 del Consejo, de 17 de mayo de 1999 sobre la ayuda al desarrollo rural a cargo del Fondo Europeo de Orientación y de Garantía Agrícola (FEOGA) y por el que se modifican y derogan determinados Reglamentos.

Reglamento (CE) 2603/1999, de 08-12-99, por el que se establecen disposiciones transitorias para la ayuda al desarrollo rural previsto por el Reglamento (CE) $1257 / 1999$

Reglamento (CE) 1750/1999, de 23 de julio, por el que se establecen disposiciones generales de aplicación del Reglamento (CE) 1257/1999. 
Reglamento (CE) 1784/1999, de 12-07-99, relativo al FSE.

Reglamento (CE) 1261/1999, de 21-06-99, relativo al FEDER.

Reglamento (CE) 1260 /1999, del Consejo, de 21 de junio, por el que se establecen disposiciones generales sobre los fondos estructurales.

Reglamento (CE) 1257/1999, de 17 de mayo, sobre la ayuda al desarrollo rural a cargo del Fondo Europeo de Orientación y Garantía Agrario (FEOGA).

Es el Reglamento comunitario del que derivan LEADER + y PRODER II Rural para el período 2000-2006.

\subsubsection{Comunicaciones, Decisiones y Directrices}

Decisión del Consejo 2008/168/CE, de 20 de febrero de 2008, por la que se establece la estructura organizativa de la red europea de desarrollo rural [Diario Oficial L 56 de 29.2.2008].

La red europea de desarrollo rural se compone de un comité de coordinación, un grupo de trabajo temático, un subcomité LEADER y un Comité de expertos encargados de la evaluación. Estos órganos cumplen las normas fijadas en la presente Decisión.

Decisión de la Comisión 2006/636/CE, de 12 de septiembre de 2006, por la que se fija el desglose anual por Estado miembro de la ayuda comunitaria al desarrollo rural en el período comprendido entre el 1 de enero de 2007 y el 31 de diciembre de 2013 [Diario Oficial L 261 de 22.9.2006].

Decisión del Consejo 2006/493/CE, de 19 de junio de 2006, por la que se establece el importe de la ayuda comunitaria al desarrollo rural para el período comprendido entre el 1 de enero de 2007 y el 31 de diciembre de 2013, su desglose anual y el importe mínimo destinado a regiones subvencionables por el objetivo de 
convergencia [Diario Oficial L 195 de 15.7.2006].

Esta decisión fija el importe de los créditos de compromiso en favor del desarrollo rural para el período 2007-2013.

Decisión del Consejo de 19 de junio de 2006 establece el importe de la ayuda comunitaria al desarrollo rural para el período comprendido entre el 1 de enero de 2007 y el 31 de diciembre de 2013, su desglose anual y el importe mínimo destinado a regiones subvencionables por el objetivo de convergencia (2006/493/CE).

Decisión del Consejo de 20 de febrero de 2006 sobre las directrices estratégicas comunitarias de desarrollo rural (período de programación 2007-2013) (2006/144/CE).

Directrices sobre las ayudas de Estado de finalidad regional para el período 2007-2013 Mapa de ayudas regionales: España (Texto pertinente a efectos del EEE) (2007/C 35/03) N 626/06 ESPAÑA Mapa nacional de ayudas regionales 1.1.200731.12.2013 (Aprobado por la Comisión el 20.12.2006).

Decisión del Consejo 2006/144/CE de 20 de febrero de 2006 sobre las directrices estratégicas comunitarias de desarrollo rural para el periodo de programación 20072013

Decisión no C (2005) 305, de 2 de febrero, que modifica la Decisión no C(2001) 1245, de 18 de mayo, sobre el régimen de ayudas para la aplicación de la iniciativa comunitaria Leader Plus.

Directrices sobre ayudas al empleo (95/C334/04).

Decisión no C (2001) 2066, de 31 de julio, por la que se aprueba el "Programa Regional para la aplicación de la iniciativa comunitaria "Leader Plus" en Castilla-La Mancha.

Decisión no $\mathbf{C}(\mathbf{2 0 0 1 )}$ 1245, de 18 de mayo, sobre el régimen de ayudas para la aplicación de la iniciativa comunitaria Leader +. 
Decisión no C (2001) 525, de 13 de marzo, por la que se aprueba el Programa Operativo Integrado de Castilla La Mancha.

Comunicación 2000/C 139/05, de la Comisión, a los Estados miembros, sobre orientaciones, objetivos, ámbito y modalidades de aplicación de la iniciativa comunitaria de desarrollo rural "Leader +".

\subsection{Planificación y Ordenación del Territorio}

Comisión Europea (2011a): Agenda Territorial de la Unión Europea 2020. Hacia una Europa integradora, inteligente y sostenible de regiones diversas. Reunión de Ministros responsables de ordenación del territorio y desarrollo territorial. Gödölló (Hungría), 19-05-2011.

Comité de las Regiones (2010): Primer Informe de Seguimiento del CDR sobre la Estrategia Europa 2020, 126를 Reunión de la Mesa del Comité de las Regiones. 28 p. Comisión Europea (2010a): Europa 2020: Una Estrategia para un crecimiento inteligente, sostenible e integrador. $\operatorname{COM}(2010) 2020$, Bruselas, 42 p.

Comisión Europea (2010d): La PAC en el horizonte de 2020: Responder a los retos futuros en el ámbito territorial, de los recursos naturales y alimentarios. Comunicación de la Comisión al Parlamento Europeo, al Consejo, al Comité Económico y Social Europeo y al Comité de las Regiones. Brussels, COM (2010) 672/5. $17 \mathrm{p}$.

Comisión Europea (2008a): Libro Verde sobre la cohesión territorial. Convertir la diversidad territorial en un punto fuerte. SEC (2008)2550, Bruselas, 14 p.

Comisión Europea (2007): Agenda Territorial de la Unión Europea. Hacia una Europa más competitiva y sostenible de regiones diversas, Leizpig, 24-25 de mayo, 2007, 8 p. 
Directrices Comunitarias Estratégicas de Cohesión 2007-13 (2006) De estas directrices derivan los Marcos Estratégicos Nacionales de Referencia

Estrategia Europea de Desarrollo Sostenible (2001).

Estrategia Territorial Europea ETE (Potsdam 1999) Para un desarrollo equilibrado y sostenible del territorio de la UE

\subsection{Medio Ambiente}

Directiva 2009/147/CE del Parlamento Europeo y del Consejo de 30 de noviembre de 2009 relativa a la conservación de las aves silvestres, Directiva "Aves". Diario Oficial № $L 20$ de 26/1/2010)

Directiva 92/43/CEE del Consejo, de 21 de mayo de 1992, relativa a la conservación de los hábitats naturales y de la fauna y flora silvestres (Diario Oficial $n^{\circ} L 206$ de 22/07/1992).

\section{España: Legislación Nacional e Instrumentos de Aplicación}

\subsection{Desarrollo Rural}

Marco Nacional de Desarrollo Rural 2007-2013

Plan Estratégico Nacional de Desarrollo Rural 2007-2013

Ley 45/2007, de 13 de diciembre, de Desarrollo Sostenible del medio rural.

Esta Ley estatal clasifica el territorio en distintas zonas rurales según sus características físicas y socioeconómicas: zonas a revitalizar, intermedias y periurbanas, fijando las prioridades para actuar, con el denominador común de la sostenibilidad. 
Real Decreto 394/2006, de 31 de enero, por el que se modifica el Real Decreto, 2/2002, de 11 de enero, por el que se regula la aplicación de la iniciativa comunitaria "Leader Plus" y los programas de desarrollo endógeno de grupos de acción local incluidos en los Programas Operativos de Desarrollo Rural (PRODER).

Real Decreto, 2/2002, de 11 de enero, por el que se regula la aplicación de la iniciativa comunitaria "Leader Plus" y los programas de desarrollo endógeno de grupos de acción local incluidos en los Programas Operativos de Desarrollo Rural (PRODER).

\subsection{Planificación y Ordenación del Territorio}

Real Decreto Legislativo 2/2008, de 20/06/2008, por el que se aprueba el Texto Refundido de la Ley de Suelo.

\section{Marco Estratégico Nacional de Referencia sobre Cohesión 2007-13} (2006)

Real Decreto Legislativo 1/2001 por el que se aprueba el texto refundido de la Ley de Aguas. La Administración y el Control del dominio público hidráulico (ríos, cauces, acuíferos, embalses, lagunas y sus vasos) mediante los Planes Hidrológicos.de cuenca determinan el aprovechamiento del recurso básico, natural y renovable que es el agua.

\subsection{Medio Ambiente}

Ley 6/2010, de 24 de marzo, de modificación del texto refundido de la Ley de Evaluación de Impacto Ambiental de proyectos, aprobado por el Real Decreto Legislativo 1/2008, de 11 de enero

Real Decreto Legislativo 1/2008, de 11/01/2008, se aprueba el texto refundido de la Ley de Evaluación del Impacto Ambiental de proyectos (BOE ํㅜ 23, de 26/01/2008). 
Ley 42/2007, de 13 de diciembre, del Patrimonio Natural y de la Biodiversidad.

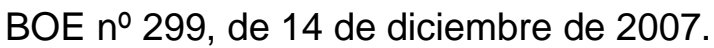

Ley 43/2003, de 21 de noviembre, de Montes. BOE núm. 280, de 22 noviembre 2003.

\section{CASTILLA-LAMANCHA: LEGISLACIÓN AUTONÓMCAEINSTRUMENTOSDEAPLCACIÓN}

\subsection{Desarrollo Rural}

\subsubsection{Planes y Programas}

Programa de Desarrollo Rural de Castilla-La Mancha 2007-2013, aprobado por Decisión de la Comisión Europea C (2008) 3832, de 16 de julio de 2008.

Es el documento programático en el que se recogen todas las actuaciones cofinanciadas con cargo al Fondo Europeo Agrícola de Desarrollo Rural (FEADER) que, en materia de desarrollo rural, se van a llevar a cabo en Castilla-La Mancha en el periodo 2007-2013. Posteriormente, el programa ha sido modificado mediante la Decisión C(2010) 1229, de 8 de marzo de 2010, la Decisión C(2010) 7656, de 5 de noviembre de 2010 y la Decisión C(2012) 9505, de 11 de diciembre de 2012.

Plan Estratégico de Desarrollo Sostenible del Medio Rural de Castilla-La Mancha 2007-2013.

Se trata de un documento acompañante del PDR, no vinculante, que contiene directrices básicas para el desarrollo rural de Castilla- La Mancha.

Programa Regional 2000-2006 para la aplicación de la iniciativa comunitaria "Leader +" en Castilla-La Mancha, aprobado por la Decisión no C (2001) 2066, de 31 de julio.

Programa Operativo Integrado de Castilla-La Mancha 2000-2006 aprobado por Decisión de la Comisión Europea C(2001) 525, de 13 de marzo de 2001. 


\subsection{2 Órdenes}

Orden de 17/12/2012, de la Consejería de Agricultura, por la que se modifica la Orden de 06/06/2008 de la Consejería de Medio Ambiente y Desarrollo Rural, por la que se establece el procedimiento de selección de territorios y las disposiciones de aplicación del Eje Leader en el marco del programa de Desarrollo Rural de CastillaLa Mancha 2007/2013. [2012/17279].

Orden de 25/11/2009, de la Consejería de Agricultura y Desarrollo Rural, por la que se modifica la Orden de 06/06/2008 de la Consejería de Medio Ambiente y Desarrollo Rural, por la que se establecen el procedimiento de selección de territorios y las disposiciones de aplicación del Eje LEADER en el marco del Programa de Desarrollo Rural de Castilla-La Mancha 2007/2013.D.O.C.M № 233, 27-11-2009.

Orden de 06/06/2008 de la Consejería de Medio Ambiente y Desarrollo Rural, por la que se establece el procedimiento de selección de territorios y las disposiciones de aplicación del Eje LEADER en el marco del programa de Desarrollo Rural de Castilla-La Mancha 2007/2013. D.O.C.M. № 126 de 18- 06-2008.

Orden de 15-05-2007, de la Consejería de Medio Ambiente y Desarrollo Rural, por la que se establecen medidas para la financiación de proyectos de inversión a través del Fondo Europeo Agrícola de desarrollo Rural (FEADER), en el marco del Programa de Desarrollo Rural de Castilla-La Mancha 2007/2013. D.O.C.M. № 110 de 25-05-2007.

Orden de 18-10-2001, de la Consejería de Agricultura y Medio Ambiente, por la que se establecen las normas de presentación, selección y aplicación de programas de desarrollo rural con ámbito regional en Castilla La Mancha, en el marco de la iniciativa comunitaria "Leader Plus" y el programa de desarrollo endógeno en zonas rurales Proder- 2. D.O.C.M. № 116 de 2-11-2001. 


\subsection{Planificación y Ordenación del Territorio}

Decreto Legislativo $\mathbf{1 / 2 0 1 0}$, de 18 de mayo, por el que se aprueba el texto refundido de la Ley de Ordenación del Territorio y de la Actividad Urbanística. (DOCM 21.05.2010).

Este Decreto tiene como objetivo la organización y control de la ocupación y utilización del suelo, así como de la transformación de éste mediante la urbanización y la edificación. Clasifica los tipos de suelos en urbano, urbanizable y rústico con distintos requisitos y condiciones para la urbanización.

\section{Plan de Ordenación del Territorio de Castilla-La Mancha (POT Castilla-La Mancha)}

Decreto 248/2004, de 14/09/2004, por el que se aprueba el Reglamento de Planeamiento de la Ley 2/1998, de 4 de junio, de Ordenación del Territorio y de la Actividad Urbanística. (DOCM nº 179, de 28/09/2004).

Decreto Legislativo 1/2004, de 28/12/2004, Se aprueba el Texto Refundido de la Ley de Ordenación del Territorio y de la Actividad Urbanística. (DOCM no 13, de 19/01/2005).

Ley Autonómica 7/2005, de 07/07/2005, de modificación del Decreto Legislativo 1/2004, de 28 de diciembre, por el que se aprueba el texto refundido de la Ley de Ordenación del Territorio y de la Actividad Urbanística de Castilla-La Mancha. (DOCM no 141, de 15/07/2005).

Ley Autonómica 12/2005, de 27/12/2005, de modificación del Decreto Legislativo 1/2004, de 28 de diciembre, por el que se aprueba el texto refundido de la Ley de Ordenación del Territorio y de la Actividad Urbanística de Castilla-La Mancha. (DOCM no 264, de 31/12/2005).

Ley 9/1990, de 28 de diciembre, de Carreteras y Caminos de Castilla-La Mancha. 
Las carreteras son la parte más importante del sistema conectivo de poblaciones en Castilla-La Mancha y su número, tipo y distribución influyen notablemente en las posibilidades de desarrollo de una zona.

\subsection{Medio Ambiente}

Ley 9/99 de Conservación de la Naturaleza de Castilla-La Mancha. BOE núm 179, de 28-07-1999, DOCM núm. 40, de 12-06-1999 y modificaciones posteriores: Ley 11/2011, de 21 de marzo, de modificación de la Ley 9/1999, de 26 de mayo, de Conservación de la Naturaleza; Ley 8/2007, de 15 de marzo, de modificación de la Ley 9/1999, de 26 de mayo, de Conservación de la Naturaleza.

Esta Ley tiene una incidencia clara en la gestión de los espacios protegidos de la Red Natura 2000 y de las actividades permitidas dentro de los mismos con el objeto de procurar su conservación.

Ley 9/2003, de Vías Pecuarias de Castilla-La Mancha. D.O.C.M. ํㅜ 50, de 08-042003. Los corredores para la trashumancia de ganado, cañadas reales, cordeles y veredas, forman una red de dominio público que supera los $10.000 \mathrm{~km}$ de longitud y que sirve de pasillo ecológico para conectar ecosistemas en un sistema relacional de la naturaleza. Están calificadas como Suelo Rústico Protegido.

Ley 4/2007, de 8 de marzo, de Evaluación Ambiental en Castilla La Mancha. DOCM, 20 de marzo de 2007.

En esta Ley se clasifican los distintos tipos de proyectos que se someten al filtro de la evaluación ambiental para que sean compatibles con el medio ambiente, estableciendo condiciones y regulando el procedimiento administrativo a seguir.

Ley 3/2008, de 12 de junio, de Montes y Gestión Forestal Sostenible de CastillaLa- Mancha. DOCM, № 130, de 26 de junio de 2008.

"Castilla-La Mancha tiene una superficie forestal algo superior a 3.500 .000 
hectáreas, equivalente al 44 por ciento de su territorio, correspondiendo aproximadamente las tres cuartas partes a monte arbolado".

"La importancia de los montes de la región no solo se pone de manifiesto por la extensión que ocupan, lo que se traduce en numerosos e inestimables beneficios medioambientales para la sociedad, sino también por el destacado papel que están llamados a desempeñar en el desarrollo del medio rural, pudiendo constituir, adecuadamente gestionados, un importante factor de estabilidad de su población, al ser fuente generadora de riqueza y empleo el aprovechamiento de los recursos renovables que atesoran". 
ANEXO II: ENTREVISTAS 


\section{ANEXO II: ENTREVISTAS}

En este anexo se describen las propias entrevistas realizadas para cada "actor" del territorio:

ENTREVISTA №1: CONSEJERO DE AGRICULTURA Y MEDIO AMBIENTE JCCLM, Sr. D. Francisco Martínez Arroyo.

\section{Globalmente ¿Qué opinión tiene de los proyectos LEADER?}

La metodología LEADER, es aquella en la que los habitantes del territorio rural deciden las políticas que se tienen que poner en marcha en sus pueblos, deciden cómo quieren que sea el desarrollo de sus propios territorios.

El medio rural nos tiene que ayudar a generar actividad económica, a crear empleo y a hacer de nuestra comunidad autónoma una comunidad mucho más vertebrada. Desde el Gobierno Regional estamos trabajando de la mano de los Grupos de Acción Local y de su red regional, RECAMDER, y debe ser, lo es ya, nuestra referencia para la diversificación de la actividad económica y para la aplicación de la metodología Leader. Es el enfoque ascendente de esta metodología lo que permite que los propios actores y los propios habitantes del medio rural decidan cómo quieren que sea el desarrollo de sus territorios.

\section{En cuanto a los Grupos de Desarrollo Rural o de Acción Local (GAL)} ¿según Ud que papel han tenido y como han contribuido al desarrollo rural regional?

No han sido años fáciles para cuadrar esta última programación de DR. Los grupos de desarrollo rural han servido para llegar donde nadie más lo hacía, han servido para financiar proyectos y para creer en la gente de nuestros pueblos, en sus 
ideas en sus negocios y así lo pone de manifiesto la cantidad de ilusiones materializadas y el empleo que se ha generado gracias a ellos.

Estoy convencido de la necesidad de su trabajo, no siempre es fácil, puesto que no cuentan en muchos casos con la financiación suficiente, y en ocasiones realizan una labor invisible que no se corresponde con el enorme esfuerzo que proyectan los hombres y mujeres que están involucrados en esta tarea.

En estos momentos estamos elaborando el borrador para la selección de los grupos de Acción Local y las estrategias de desarrollo local participativo y queremos consensuarlo con todos los agentes implicados. Se nos abre un horizonte de aquí al 2020 que debemos aprovechar y gestionar entre todos, administración pública, grupos de acción local, sociedad civil en su conjunto, en aras de mejorar la calidad de vida de quienes son de aquí y quieren seguir siéndolo, de quienes sienten y aman su tierra y no quieren irse a ningún otro lugar.

En la nueva programación los grupos van a poder financiar proyectos de la industria agroalimentaria proyectos que no lleguen a los 100.000 euros de inversión, y esto se hace porque apostamos por la decisión de los grupos, apostamos porque estas decisiones se tomen desde los territorios. Esta es una forma de demostrar la confianza en el medio rural.

\section{Estos grupos como conocedores del territorio, ¿deberían ser más activos?} ¿Habría que redefinir a estos grupos? ¿Más autonomía?

Somos críticos por cómo han funcionado los grupos en los últimos 4 años en Castilla-La Mancha, creemos que no se han hecho las cosas bien, claro que hay que darles mucha más autonomía ya que son ellos los que deben decidir las cosas que hay que hacer, es decir, en este tipo de políticas, que tienen que ver con el desarrollo 
del territorio como casas rurales o espacios comunes, no se deben decidir desde Toledo sino desde donde se ejerce esa estrategia territorial.

\section{4. ¿Cuál es su percepción del PDR 2007-2013 de Castilla la Mancha?}

El Gobierno anterior, en funciones (mayo-junio de 2015) decidió publicar tres convocatorias de ayuda: una para la reconversión del sector lácteo, otra para la incorporación de jóvenes agricultores y otra para la mejora de explotaciones agrarias. Sin duda, las tres medidas muy importantes, las tres apoyadas en los nuevos retos de la PAC, las tres apoyadas en la transferencia de fondos que se produjo a mitad de período del primer pilar al segundo pilar de la PAC. Transferencia, que se produjo a mitad del periodo 2007-2013 pero las convocatorias salieron en Castilla-La Mancha en mayo y junio del 2015.

Evidentemente, al llegar al Gobierno regional tuvimos que ampliar los plazos para que los agricultores y ganaderos pudieran hacer sus inversiones. Las convocatorias del mes de junio para poder pagarse en el mes de diciembre de este año exigían, según la perspectiva, en su caso, del Gobierno anterior, que esas actuaciones se ejecutaran durante los meses de verano. Cualquiera que conozca un poco la agricultura y la ganadería sabrá que en verano en Castilla-La Mancha no se puede plantar nada. Estamos hablando de almendro, de pistacho, estamos hablando de olivar, evidentemente no se podía hacer en verano. Lo que hicimos fue recoger el interés del sector para que estas ayudas se pudieran retrasar en lo que tiene que ver con la ejecución de las actuaciones y, por lo tanto, estamos en ese momento, haciendo frente a esos compromisos que se generaron, en el mes de junio del 2015, después de ocho años de aplicación del PDR 2007-2013.

Hemos tenido que enviar el Programa de Desarrollo Rural (PDR) 2014-2020 a Bruselas en un tiempo récord porque cuando este equipo llegó a la Consejería, el 
PDR estaba todavía encima de la mesa y sin negociar con la Comisión Europea. Dar respuesta y cumplimentar todas las correcciones enviadas por la propia Comisión con mucho esfuerzo y hemos conseguido que finalmente se aprobara el 30 de octubre.

Tengo que señalar, que la aportación del Gobierno Central es inferior al periodo 2007-2013. En concreto, el MAGRAMA se ha comprometido a aportar el $30 \%$ de la cofinanciación nacional calculada ésta con los porcentajes máximos de aportación FEADER. EN Castilla-La Mancha este porcentaje representa 101,02 M€ para todo el periodo, 305,84 M€ menos que en 2007-2013; una reducción de más del 75\%. Este Plan no podíamos retrasarlo más pero la intención es modificarlo. Así, a lo largo de 2016, revisaremos el programa para adaptarlo a los objetivos prioritarios de jóvenes, agricultores profesionales e integración de cooperativas.

\section{5. ¿Son suficientes las Políticas de Desarrollo Rural europeas para conseguir el desarrollo del medio rural?}

Más de un $90 \%$ del territorio de la UE es rural y más del $56 \%$ de la población reside en él por lo que cualquier medida, apoyo, estrategia o política que venga a poner en valor el territorio es bienvenida.

Creo que se han hecho y se siguen haciendo esfuerzos "para" y "con" el medio rural, no obstante sería necesario más inyección económica para poder realizar inversiones importantes y transformar el espacio en aras de asentar a la población y poder invertir la pirámide de población así como la conservación del patrimonio a favor del turismo o el acercamiento de los servicios para la calidad de vida de sus habitantes. 


\section{6. ¿Cuál es el problema en la falta de estimulación en la incorporación de jóvenes a la agricultura?}

Dependiendo de las zonas, estamos observando que en los últimos años cada vez son más jóvenes preparados los que están gestionando las empresas agrícolas familiares y haciendo más profesional aún, este oficio. Probablemente esta motivación subyace por un lado del conocimiento de que es un sector en alza y absolutamente necesario y por otro, un nicho de trabajo importante.

Bien es cierto que se trata de un sector duro como probablemente ninguno, y sujeto a unas condiciones que ningún ser humano puede controlar como es el tiempo, no obstante, desde el gobierno regional y desde la Consejería de agricultura, medio ambiente y desarrollo rural vamos a hacer esfuerzos titánicos para que ningún joven de nuestra región que quiera incorporarse a la agricultura quede fuera. Pero no solo eso, queremos que se hable de agricultura, que se muestre en primera fila del debate regional y nacional y se ponga en valor lo que tanto aporta a la economía y a la sociedad.

7. ¿Por qué resulta tan complicado que los agricultores, empresarios agrícolas, etc consigan asociarse bien en cooperativas o en otro tipo de estructuras para aumentar su competitividad como ocurre en otros países cercanos?

Castilla la Mancha tiene una fuerte presencia de entidades asociativas agroalimentarias (EAAS) (cooperativas agrarias, sociedades agrarias de transformación y cooperativas de explotación comunitaria de la tierra) tenemos censadas un total de 897. 
Sin embargo, una parte importante de estas entidades son de muy reducida dimensión y normalmente creadas para estructurar explotaciones de ámbito familiar. Por ello, podríamos considerar que solo una parte de esas EAAS tienen relevancia social por aglutinar a un número importante de socios (más de 25 socios) y/o por tener una facturación relevante que vaya más allá de las explotaciones domésticas (se ha fijado un rango de facturación mínimo de 500.000 euros). Con ambos filtros (número de socios y facturación mínimos) podemos considerar que el tejido cooperativo regional se cuantifica en un total de 447 EAAS de relevancia social.

Promocionar las figuras de calidad será una de las prioridades del nuevo programa (2015-2020) y supondrá una inyección de 1.500 millones de euros para la región.

Desde la Administración vamos a apoyar la promoción pero lógicamente es necesario también un compromiso por parte de los agricultores y ganaderos de Castilla-La Mancha por nuestras figuras de calidad.

\section{Punto de vista sobre el futuro de la agricultura y las actividades agroindustriales en la región.}

El gran objetivo de esta legislatura es la apuesta del Gobierno regional por los agricultores profesionales, queremos apoyar a quienes realmente viven de esto en todas sus concepciones (en el acceso al agua, en el acceso a las ayudas de la PAC, en el acceso a las líneas de ayudas de Desarrollo Rural...) todo irá encaminado a esa figura del agricultor profesional, que es la clave de nuestro sector agrario, del agroalimentario y de la actividad económica de la mayor parte de nuestro territorio. 
La industria agroalimentaria supone solo en exportación el $30 \%$ del total de la industria en Castilla-La Mancha, y un valor en el mes de septiembre pasado de alrededor de 170 millones de euros.

Estos datos avalan la importancia de la industria agroalimentaria y tienen también una dimensión social, sin este tipo de industria no podríamos poner en el mercado los excelentes productos agrícolas y ganaderos que producimos en CastillaLa Mancha. Es necesaria la integración comercial de cooperativas puesto que la concentración de la oferta es un elemento básico e indispensable para la mejora de la eficiencia, la ordenación de la producción y la mejora de las rentas de los productores.

ENTREVISTA №2: GERENTE DEL GDR CASTILLOS DEL MEDIO TAJO.

\section{1. ¿Cuáles son los elementos que han contribuido a este cambio del rural agrario? ¿Por qué? ¿A qué se debe?}

A ver, la Comarca uno de los grandes potenciales que tiene precisamente es la cercanía que existe a la capital, a Madrid, y eso ha generado unas circunstanciales particulares. De alguna manera también se atosigó con el tema de la crisis sobre todo del ladrillo y demás, la consecuencia que tuvo pues que gran parte de la población sufrió en sus carnes lo que fue la crisis del boom inmobiliario de la construcción. Con lo cual, de alguna manera todas los servicios y sobretodo empresas que se habían creado bajo el impulso de la construcción directamente o bien de servicios próximos a la construcción, pues ahí sí se han resentido y sufrido un poco lo que fue precisamente esta crisis. 


\section{2. ¿Qué tipo de proyectos se han subvencionado desde el GDR Castillos del Medio Tajo?}

En cuanto al tipo de proyectos que nosotros hemos subvencionado aquí, son muy variados, pero también hemos de decir que no hemos podido o no hemos tenido opciones de ser demasiado rigurosos con las exigencias administrativas, ya que debido a la crisis económica ha sido difícil buscar financiación.

De esos proyectos, a nosotros con el cuadro financiero que tenemos nos obliga a tener un cumplimiento de senda financiera cada año, tenemos que ir teniendo un porcentaje ejecutado de lo que sería ese cuadro financiero y si no lo cumples te penalizan, con lo cual yo creo que prácticamente ningún grupo de la región ha podido ser riguroso o selectivo en cuanto a los proyectos a subvencionar, entre otras cosas porque se tenía que subvencionar si o sí para que los números salieran ¿vale?, a lo mejor en otros programas o grupos sí que se ha podido hacer esa criba o esa selección de proyectos. En ese caso se puede elegir un determinado proyecto y decir le voy a subvencionar bien porque se genera mucho empleo o bien porque es una ciudad numerosa o bien porque es una actividad que de alguna manera va a servir para la mejora de ciertos aspectos de la comarca. Pero en nuestra programación lo cierto es que la mayoría de los grupos de desarrollo rural hemos tenido que subvencionar prácticamente lo que nos entraba, precisamente para cumplir objetivos. No obstante, en los últimos dos años sí que se ha notado una mejoría aunque no llegue esa mejoría al ciudadano o a gran parte de la masa de gente que está todavía en desempleo.

\section{3. ¿En qué se han traducido?}

Lo cierto es que de dos años a esta parte, sí que estamos notando un incremento bastante notable de actividad, sobretodo en el número de gente, de 
promotores que están interesándose por las subvenciones, no tanto de nuevas empresas sino sobretodo de empresas ya existentes que durante una serie de años han plegado velas y se han limitado a mantener lo que tenían y que ahora, sobre todo en el último año y en el anterior y actualmente, lo que están haciendo es preocuparse por la inversión, bien en maquinaria, bien en modernización, bien en mejora de instalaciones o en algunos casos en la ampliación del negocio. Por ejemplo tenemos gente que se tiene que trasladar de donde está porque está empezando a crecer o han abierto nuevas líneas de negocio y con eso pues tienen que irse de donde están y coger una nave más grande etc.

4. ¿Con la implementación del nuevo período de programación del PDR (2007-2013) se han generado nuevos empleos en el sector? ¿De qué manera ha afectado la difícil situación económica y principalmente, cuáles han sido las alternativas llevadas a cabo para solventar?

En definitiva se está notando activación ¿vale?. También ha habido gran cantidad de proyectos que se han subvencionado, han sido a gente que en su día trabajaron por cuenta ajena, que fueron despedidos de su trabajo, entraron a formar parte de las listas del desempleo y su objetivo fundamental era conseguir otro trabajo. Después de llevar en paro un tiempo se dieron cuenta que no les iban a llamar y que tenían que buscar algo antes de que se les acabara lo prestación por desempleo.

Ha habido mucha gente que ha puesto su propio negocio, unos han funcionado otros no, pero lo cierto es que ha habido mucha gente que se ha hecho autónomo y ha montado una pequeña empresita y algunos están funcionando. 


\section{5. ¿En qué medida has apreciado un cambio o traslado de gente del sector primario al sector servicios o terciario?}

Nosotros ese dato realmente no lo tenemos, si que te puedo decir que bastante gente se ha interesado por ejemplo por montar un tema de cría de pollos, el tema de huevos también, que aunque no es objeto de subvención por nuestra parte lo que hemos hecho nosotros con esa gente que venía preguntando y que en muchas ocasiones iban a su ayuntamiento y le comentaban al alcalde o al concejal de promoción económica: "oye mira quiero poner una granja de engorde de pollo o quiero montar, yo que sé, ternera o incluso cerdos, pues entonces para el alcalde lo más fácil era derivarlo hacia nosotros, nosotros cuando nos entraban le hemos derivado a su vez a Agricultura y en algunas ocasiones sí que era susceptible de recibir ayuda, si eran jóvenes agricultores o jóvenes ganaderos, en otros casos no.

También, nos hemos encontrado con empresas o con gente que tenía una primera actividad que se dedican que te digo yo, al sector de la construcción, y se planteaban como complemento a ese sector el montar precisamente una actividad relacionada directamente con el sector primario, pero esos no eran susceptibles de obtener la ayuda porque no eran agricultores a título principal, con lo cual en ese caso no han conseguido subvención, ¿Que hacíamos nosotros? Los poníamos en contacto directamente con la Junta, a través de una serie de programas, ya sea del Focal o como incorporación de jóvenes agricultores y les han tramitado directamente esas subvenciones.

\section{Debido a la influencia del programa, ¿Se ha mantenido población rural} en los municipios, o se ha producido un incremento, descenso? 
En cuanto al tema de población, nuestra comarca es también un poco peculiar ¿vale? porque si bien es cierto que hemos perdido algo de población, no mucha porque hemos compensado, a lo mejor hemos perdido algo de población en ciertos municipios pero a nivel total en toda la comarca no hemos perdido gran número de población.

Además nuestro grupo también es un poco peculiar, no es significativo de toda la región por la cercanía que tenemos a Madrid, por la cercanía que tenemos a Toledo, y a Talavera, nosotros tenemos 47 municipios de los cuales tenemos 3, que no pertenecen al comarca geográfica de Torrijos. Hubo una serie de pueblos que quedaron ahí en tierra de nadie, pueblos de la comarca de la Sagra que nos los endosaron a nosotros, aunque no es la comarca natural. Todo lo que es la comarca de la Sagra estaba excluida como GAL, todo esto hay que hablar de la situación inicial cuando el programa se empieza a desarrollar, y todos los pueblos de la comarca de la Sagra teóricamente no necesitaban ninguno tipo de incentivo al desarrollo porque estaban prácticamente en las puertas de Madrid. Hoy todos esos pueblos están viviendo el éxodo de los pueblos de la periferia de Madrid llámese, Alcorcón, Parla, Fuenlabrada, Móstoles se da la circunstancia que había gente que tenía su piso o su nave de 150 m en un polígono de Madrid y vendían esa nave, con lo que sacaban con la venta de esa nave podían comprar una nave el doble o el triple de grande en cualquier pueblo de la periferia llámese Illescas, Esquivias, Yuncler, Numancia, Yuncos, etc. Si además vendían su casa en Parla, Fuenlabrada, Móstoles conseguían un adosado en los pueblos de la periferia.

Con lo cual ahí hubo un momento en el que se originó un desplazamiento de población, de hecho hay muchísimos pueblos del corredor de la Sagra que están excluidos (de los programad de desarrollo). Estaban excluidos porque se entendía que esos pueblos no necesitaban incentivos para que se desarrollarán y para ganar 
población. Ahora estamos en la situación contraria, ahora estamos volviendo un poco a que gente joven que en su día se trasladó a estos pueblos ahora están volviendo a esos pueblos de la periferia de Madrid, que refleja un flujo entre el campo y la ciudad.

En cuanto a nuestro grupo, realmente el balance no es negativo en cuanto a población, si qué ocurre que en el balance interno de algunos municipios se están dando cuenta que se está perdiendo población, pero lo están absorbiendo los pueblos más grandes. Por ejemplo yo tengo 3,4, 5 pueblos que sistemáticamente están perdiendo población todos los años pero esa población está siendo absorbida por municipios como Torrijos, como Fuensalida, la Puebla de Montalbán etc, con lo cual realmente nosotros la población real o la población que tenemos es más o menos fija y no estamos perdiendo gran número de población en lo global aunque si te pones a mirar pueblo a pueblo, sí te das cuenta que algunos están sufriendo retroceso de población, hay un aumento de población en los municipios cuya actividad principal no es la agricultura.

\section{7. ¿EI PDR ha generado nuevas oportunidades de empleo en la comarca? ¿Qué sectores productivos son los que han experimentado mayor auge desde la puesta en marcha del PDR?}

Esta gente vive parte del sector primario parte del sector secundario y algo del sector terciario, aunque ya te digo que no podemos decir 33,33,33 a día de hoy en esos municipio tenemos municipios muy pequeñitos muy pequeñitos que por ejemplo Aldea en Cabo, estamos hablando de 160/170 hab, ahí si que el sector primario es el principal ¿vale?, sector secundario no hay y terciario muy poquito: hay algo mejor algún bar, alguna peluquería, pero en esos pueblos tan pequeños por debajo de 500 habitantes la mayoría de la gente vive del sector primario. En pueblos 
entre 500 y 2000 habitantes tienes algo de sector primario y algo de sector secundario y también algo de sector terciario y luego tienes municipios a partir de 2000 habitantes donde el sector primario es residual, sobre todo ahí tendríamos sector secundario y sector terciario.

Por ejemplo Torrijos, sector primario entre 3-4 familias están moviendo la mayoría de la agricultura y la ganadería, pero son 3-4 familias y son grandes propietarios de suelo; pero por ejemplo lo que es Torrijos, Fuensalida, la Puebla de Montalbán tiene mucha importancia el sector terciario y el sector secundario, el sector primario no tiene prácticamente repercusión ni en cuanto al número de puestos de trabajo que genera, ni en cuanto al número de personas que se dedican directamente como propietarios del suelo, son grandes propietarios pero no se pueden considerar terratenientes.

\section{En cuanto a los Grupos de Desarrollo Rural o de Acción Local (GAL) ¿según Ud que papel han tenido y como han contribuido al desarrollo rural regional?}

Han sido puros financiadores de proyectos como decía al principio, sin mucha posibilidad de elección sobre los mismos, ya que la crisis ha mermado en bastantes ocasiones la posibilidad de obtener financiación por parte de los promotores. Si bien se ha tratado de trabajar en la búsqueda de promotores, de ayudarles con los proyectos, y así activar económicamente la comarca, intentando crear empleo a largo plazo. 


\section{ENTREVISTA №3: ALCALDE DE QUISMONDO Y PRESIDENTE DEL GDR}

\section{1. ¿Cuáles son los elementos que han contribuido a este cambio de un rural agrario a un rural periurbano?}

La cercanía Madrid ha hecho una pequeña transformación al mundo agrícola integrando a muchas empresas de servicios. Un caso muy claro es Quismondo, era un pueblo agrícola y ganadero y se ha transformado en un concunto de empresa de servicios hacia Madrid, destacando las empresas que se dedican a montar Parquet, que son las que los últimos 20 años han montado la mayoría de los parquets, esto lo ha hecho con la revolución inmobiliaria en Madrid y provincia. Algunas de ellas se han convertido en fábricas de tarimas dura que está en Noves pero los propietarios son de Quismondo u otra empresa muy importante Deva que se dedica al tema de los barnices.

\section{2. ¿Qué tipo de cambios principales se han producido en el municipio en estos 15-20 años?}

La comarca a nivel agrícola está sufriendo un cambio muy importante, un caso significativo es el caso del vino, antes era un vino que se hacía y se vendía a granel y ahora el $50 \%$ se está vendiendo con su marca con lo cual el valor añadido del producto se está quedando en la zona. Hay pequeñas bodegas que se están instalando con la denominación de vinos de Méntrida esto es muy importante Las explotaciones agrícolas son cada vez mayores, el minifundismo cada vez tiene menos futuro, los agricultores se van agrupando para poder hacer empresas agrícolas cada vez más grandes y poder hacerlas rentables necesitan como mínimo 100 ha. 


\section{Si ha cambiado la agricultura? Ha emigrado mucha gente del pueblo? ¿ha venido mucha gente? ¿en qué actividad?}

En Quismondo en la parte demográfica la gente que trabaja el campo son propietarios principalmente, y empresas que se han constituido de hijos de propietarios de empresas que se han constituido de gente que no vive directamente de la agricultura, pero para fomentar la agricultura tienen una empresa montada y vamos cogiendo tierras de gente que se va jubilando en alquiler y vamos aumentando nuestra explotación.

Esto está pasando en muchos municipios, se alquilan la tierras y se explotan las tierra, se gestionan con la PAC, que la tierra es de quien la produce este es un error muy grande que hay.

Quiero manifestar que el gran cambio de la nueva PAC es que los beneficiarios van a ser los productores de verdad, lo que era ilógico es que te pagaran muchas veces por no producir.

Hasta ahora tienes que manifestar una serie de ingresos para justificar que esa explotación es más o menos rentable o que vives de ella. Se va a evitar que gente jubilada siga cobrando subvenciones del Estado o de Europa y a su vez esté cobrando su jubilación, no está muy bien que digamos.

Los agricultores nos hemos unido y para trabajos de ayuda complementarios como la poda, etc, cada uno lo hace de una manera. En algunas explotaciones a la hora de recoger la aceituna viene gente de fuera con una maquina, igual que en cereal, varios agricultores se unen y traen una cosechadora para hacerlo juntos.

En nuestro caso cerramos todo el ciclo y lo hacemos todo nosotros, hay alguno más que es así.

\section{4. ¿Es un municipio con gente joven, mayor, desempleados?}


Hay una renovación generacional no ha sido todo lo dinámica que tenía que haber sido, hay una parte en torno a los 60-65 años a punto de jubilarse, una parte entorno a los 50 y falta la gente en torno a los 20-30.

Una de las injusticias que cometió el anterior gobierno con el PDR, es que no se podían dar ayudas al sector primario como eran las ayudas a jóvenes agricultores. En el nuevo PDR, que tiene que entrar antes de fines de 2015, tenemos negociado eso es ayudar al sector primario, con un tope en el porcentaje del nivel de las ayudas, para evitar empresas queseras o lácteas que hacen inversiones casi anualmente y absorbieran todo el presupuesto.

Sí, hay emigrantes de varios países, hay rumanos que están en empresas de construcción, la señora en labores de casa limpieza y luego sudamericanos algunos trabajan en las fincas de alrededor.

Quismondo tiene un perímetro cerrado rodeado de varias fincas de alrededor fincas que linda con Escalona, Almorox, Hormigos, Santa Cruz de Retamar y hay mucho extranjero también en el sector de la ganadería en las ovejas y en la vaca de leche.

\section{5. ¿Qué piensa de los proyectos LEADER? ¿conoce los GAL? ¿Qué opina de ellos?}

Es un programa muy válido, si bien es cierto que sectores como la agricultura no estaban incluidos y que se tienen que incluir. Es un dinero que viene de Europa y que sirve para que la población rural se fije en los pueblos.

Tengo casos muy claros, por ejemplo un señor que era ganadero ha puesto una panadería, en la panadería se ha empleado el hijo con las ayudas LEADER, han hecho una buena comercialización del pan y ahí están. Sin esa ayuda, ese hijo no estaría allí, no le gustaban los cerdos y sí la panadería. 
Se ha hecho mucha variedad de ayudas a proyectos: carpinterías, panaderías, centros de ocio, Pint ball, casas rurales, albergues, residencias de mayores, tiendas como peluquerías que son muy importante para el servicio del pueblo ( uno de los que más se ha ayudado).

Hay que tener en cuenta que en el programa LEADER, la mujer siempre tiene y una ayuda especial cuando el puesto trabajo es femenino, en la puntuación se tiene más ayuda y las poblaciones de más de 10.000 habitantes el puesto de trabajo tiene que ser femenino, discriminación positiva.

Tenemos estadísticas que el $98 \%$ de los proyectos que hemos subvencionado están funcionando, siempre hay alguno que falla, pero por lo general luego siguen generando estabilidad empleo y trabajo en la zona.

\section{6. ¿Cuál es tu percepción de trabajo del GDR del que eres Presidente}

\section{¿Han hecho mucho por el desarrollo del Medio Rural?}

El GDR tenía un presupuesto de 3.200.000 € y debido al gran número de proyectos la Consejería de agricultura ha implementado 1.700.000 más que se han trasladado a empresas y a autónomos o cualquier tipo de acción empresarial. La comarca ha demandado esa ayuda, ese dinero ha venido de otros grupos que no han sido capaces de gestionar esa ayuda o que no han tenido empresas que quisieran instalarse en su territorio o que no han tenido proyectos a subvencionar

\section{7. ¿Cuántos agricultores hay? ¿son a tiempo completo? ¿parcial? ¿son} jóvenes? ¿Viven en el pueblo? ¿Las tierras son suyas? ¿Propietarios 0 arrendatarios? 
La mayoría de los agricultores de Quismondo son agricultores que se han asociado y ejercen en tierras de otros. La gente mayor no es que ponga pegas a la cesión de las tierras, la gente mayor es nostálgica. Mi suegro tiene 80 años y continúa con las tierras en momentos puntuales, le ayuda sus nietos pero le sirven de estímulo, mientras que el sistema se lo permite lo siguen haciendo. Cuando ya no lo pueden hacer, lo derivan a algún familiar para que lo trabajen, sobrino hijo etc.

\section{8. ¿Cuál son sus perspectivas personales para la comarca más agraria, más servicios?}

La comarca tiene una zona muy industrial que es la zona de Fuensalida Torrijos, dónde se sitúan uno de los mayores fabricantes de calzado deportivo cómo es Joma, una de las mayores productoras de calzado infantil como es Pablosky, es decir el mundo del zapato está muy representado.

Desde el GDR se han hecho acciones junto con el Ayuntamiento de Fuensalida para dar cursos de formación porque lo que ha pasado estos años es que los jóvenes no están formados, por ejemplo es difícil encontrar un reparador para coser los zapatos, han desaparecido.

Antes se veía de pequeño el trabajo en casa, esto ha desaparecido y no habido una formación profesional y se ha hecho una escuela de formación específica para puestos de trabajo del mundo del calzado.

En Torrijos y Escalonilla son fabricantes de jamón, las mayores fábricas de jamón no están en Guijuelo, están en nuestra comarca, es un jamón blanco.

(El Chato, Navidul, España) son fábricas que exportan a nivel mundial y tienen gran poder económico. 


\section{9. ¿Cómo se ve el futuro del mundo rural agrario?}

Los pueblos pequeños necesitan más claridad de competencias, es muy injusto que un pueblo que no tiene competencias en sanidad, en educación tenga que estar manteniendo la consulta del médico o el colegio, no tenemos ni competencias mi dinero, son servicios de la junta de comunidades y tendrían que habilitar esos dineros pero la financiación no llega. A nosotros esto nos puede costar $50.000 €$ para mantenimiento del colegio, luz, calefacción etc... y si se cae una persiana y te llaman pues hay que ir, aunque sólo hay escuela primaria.

ENTREVISTA №4: JEFE OFICINA COMARCAL DE AGRICULTURA TORRIJOS DE JCCLM.

\section{1. ¿Cuáles son los elementos que han contribuido a este cambio del rural agrario? ¿Por qué? ¿A qué se debe?}

En primer lugar lo que hemos visto es que en la población de los municipios grandes, ha habido un aumento significativo en el número de habitantes, ha habido un crecimiento muy significativo por personas ajenas a la agricultura, inmigrantes principalmente del norte de África, los hispanoamericanos están volviendo a sus países de origen.

La población nuestra ha dejado de ser agrícola hace ya algunos años, al aumentar las industrias y servicios de la comarca, aunque hay municipios eminentemente agrícolas, en todos tienen implantación algo de industria, por ejemplo Novés es un municipio agrícola, con dos grandes industrias INDAS Y TEGOSA, que absorben mucha mano de obra joven. 
Torrijos es un municipio de servicios no tiene prácticamente agricultura, la Puebla de Montalbán es un municipio muy agrícola, se han implantado industrias de transformación como CIDACOS, un gran matadero etc que están absorbiendo población no sólo de la Puebla sino también del entorno.

\section{2. ¿En qué se ha traducido?}

La agricultura la están haciendo fundamentalmente los padres de estos jóvenes, jubilados o prejubilados, y agrupándose en servicios. Antes un agricultor era capaz de labrarse y hacerse toda la tierra él y ahora él hace un poco, da otro poco a un tractorista, la recolección la hacen empresas especializadas tanto para cereal como para el tomate, pimiento.

Para el olivar igual, antes había mano de obra que aunque no era de la zona, había mano de obra para la recogida de aceituna, ahora con los vibradores hay mucha menos demanda, entonces pues la población está disminuyendo en la agricultura de 20 años a esta parte en un 25-30\% de población activa.

Esa población que ha dejado la agricultura que ha ido despareciendo por jubilación o por muerte no se ha repuesto, el que ha entrado ha cogido más superficie, por ejemplo antes un agricultor tenía 25-30 ha como máx, mezclado con un poquito de olivar, un poquito de viña, huerta y ahora un agricultor de los jóvenes que se han incorporado llenan 150-200ha fundamentalmente de secano y con maquinaria grande, llevan algo de olivar.

La huerta no, como necesitan más mano de obra, o bien se ha mecanizado y se ha puesto riego por goteo o permanentes o pivot, la huerta tradicional hay muy poquita la mantienen los jubilados. 
3. Desde la oficina comarcal agraria, que vivís de primera mano las solicitudes de las líneas subvencionables de los PDR, ¿los objetivo para el que se ha creado el PDR, se están cumpliendo?

Sí, y digo si a medias porque lo que es fundamental para el agricultor es ayudarle, pero le estamos ayudando quizás de una forma complicada, porque le estamos dando dinero, pero para darle dinero él antes tiene que hacer inversión y él no dispone de medios económicos para ello, dependen de entidades financieras que le suelen exigir para darle el préstamo o la ayuda más de lo que él puede tener, por eso muchos proyectos se quedan en el camino.

Cuando abrimos los plazos para solicitud de ayudas, las realizan, presentan los proyectos pero a la hora de la verdad muchos de esos proyectos se quedan en el limbo porque no encuentran la manera de conseguir realizar la inversión para más tarde recibir las ayudas que en muchas ocasiones son a fondo perdido.

\section{Dentro de la comarca en los últimos PDR qué ejes se han intentado} priorizar? ¿Por qué esos? ¿cuales han tenido más demanda?

Los 2 ejes fundamentales de solicitudes han sido incorporación de jóvenes y planes de mejora y modernización de explotaciones ya existentes, se ha priorizado mucho más a jóvenes y no ha habido directriz específica para regadío, o para vacuno de carne, o para ovino etc.

Es cierto que había unas prioridades, pero como ha habido presupuesto, todos los que lo han solicitado y han presentado un proyecto viable, se les ha pagado otra cosa es que esos proyectos se puedan certificar, por falta de obtención de la financiación requerida, creo que muchos no se van a poder realizar. 


\section{Importancia de la agricultura a tiempo parcial. ¿Qué \%? ¿Esos agricultores} a que se dedican a tiempo parcial? ¿Han heredado la SAU? ¿Lo hacen los fines de semana?

Esto es una cosa muy propia de esta zona, hay dos grandes grupos los activos y los jubilados, los jubilados evidentemente tienen su jubilación y van con su tractorcito y es su medio de complementar la renta y ayudar a la familia, y digo a la familia porque han estado manteniendo las casas de los hijos en estos años de crisis. $\mathrm{Y}$, por otro lado, tenemos el sector activo que suele ser gente que como consecuencia de la crisis o incluso antes de la crisis trabajan parcialmente en la industria del calzado. Fuensalida absorbe mucha mano de obra a tiempo parcial para el calzado, luego el resto del tiempo están en la agricultura.

También a veces el padre jubilado titular de la explotación lleva la viña, y el hijo va a las grandes labores vendimia, poda, prepoda, tratamientos fitosanitarios, sin embargo es el padre el que está en el día a día de la viña permanentemente, y cuando hay grandes trabajos ayudan los hijos.Luego esa superficie agrícola sigue siendo de su familia, no se pone en el mercado sino que sigue en el entorno familiar en la mayoría de los casos.

\section{Cuál es el problema en la falta de instalación de jóvenes en la agricultura?}

Cuando hay que trabajar hay que hacerlo mucho, independientemente que sea lunes martes o domingo, y los rendimientos económicos no son los esperados, el dinero lo cogen muy a posteriori, por ejemplo en la viña, vendimian en octubre y cobran esa cosecha como muy pronto en septiembre-octubre del año siguiente, que no todos. Una vez metidos en la cadena eso no lo notas, pero para arrancar estás un año en blanco. 
En cereal igual, ellos ven que los pagos hay que hacerlos en efectivo y sin embargo los ingresos vienen diferidos en el tiempo, unos 3 meses, otros 4 meses etc y luego el rendimiento, no tiene sentido que un señor tenga melones y le paguen a 78 céntimos el melón y luego en su pueblo en la frutería el melón valga 80 céntimos, no tiene sentido que la cebada se la lleven sin precio y así sucesivamente.

\section{7. ¿Hay suficientes cooperativas para intervenir en la comercialización?}

Hay cooperativas de viña, de olivar, de cereal para pienso para los ganaderos, pero por ejemplo en la Puebla de Montalbán hay mucho melocotón y mucha fruta de hueso y lo venden $60,70 \%$ en las cajas en la calle, no hay una estrategia de vamos a agruparnos todos y vamos a vender a Mercamadrid, no se lo han planteado, cada uno se defiende como puede. Por ejemplo el tomate, lo hacen a través de contratos con empresas de Murcia, o Extremadura.

El vino, hay muchas bodegas, la D.O Méntrida ha venido muy bien porque ha puesto en valor la garnacha, que hasta entonces nos lo compraban para otras zonas de España (Rioja), se ha intentado agrupar las cooperativas, no tiene sentido que pueblos como Camarena o como la Torre tengan dos Cooperativas, en Camarena se ha conseguido la unión y solo va a comercializar una de ellas, aparte de que hay 4 bodegas más en el mismo municipio.

En la Torre hay 2 cooperativas que elaboran muy poco vino, también hay cooperativas en Portillo, en Novés, en Santa Cruz, que si se agruparan reducirían costes, no es lo mismo salir al mercado una cooperativa con un millón de $\mathrm{Kg}$ que otra con 20 millones de $\mathrm{kg}$.

\section{8. ¿Cuáles son tus perspectivas sobre la comarca?}


La comarca desde el punto de vista agrario tiene dos grandes grupos, la agricultura y la ganadería. La agricultura se va a seguir produciendo probablemente los mismos kilos o quizás más, va dejando la agricultura el pequeño agricultor y lo va cogiendo los que tienen gran maquinaria, si dejamos de ir a "gastar hierro al campo", y se hacen las labores en condiciones se va a mantener. La viña se ha reestructurado mucho, se ha cambiado de vaso a espaldera, se está mecanizando, en vaso era difícil de cosechar. Olivar se ha plantado para hacer cultivo intensivo con un mayor rendimiento, en secano se están trabajando tanto en trigos como en cebadas con otras variedades, por ejemplo el triticale era un producto residual, hoy en día un 15-18\% del cereal es triticale por su resistencia, este año 2015 de mucha sequía ha habido casi cosechas normales con triticale.

La ganadería en municipios como Burujón, Escalonilla, la Puebla de Montalbán, a principios del año 2000 se iban cerrando granjas de cerdos y ahora se están abriendo con integración, con grandes empresas, el ganadero pone la mano de obra y las instalaciones ( contractualización). Se producen similares cantidades de kg de carne de cerdo pero con explotaciones más grandes con menos ganaderos.

En vacuno es parecido menos ganaderos con más explotaciones, si la media hace 20 años era 50 terneros por explotación ahora son 200 terneros.

La oveja se ha concentrado con una media de 500 ovejas en vez de 180, se ha cambiado la raza para leche, en definitiva hay menos ganaderos con mayor número de cabañas, especializados y estabulados.

El problema sin duda es la comercialización, tú produces y sabes producir, pero venden a coste, por debajo de coste, imagino que esto pasa aquí, en Segovia y en otras ciudades; el agricultor si tiene que trabajar trabaja, pero por ejemplo siembras patatas que te pagan a 3 céntimos, pero te está costando 5 producirlas, los invernaderos les cuesta poner un kilo de lo que pongan porque no tiene suficiente 
agua y no tiene que hacer perforaciones; la energía eléctrica es carísima pero eso es la parte de producción. Ahora vamos a vender me ha costado 5 producirlo ahora lo vamos a vender a 6 , pero no el precio de compra es 4 (bajos precios a la producción). Cómo pues realmente no lo sé, pero quien lo sepa se va hacer de oro, pero en esta comarca el campo demanda comercialización, gente que sea capaz de vender los productos que se están produciendo a un precio que le sea rentable y ventajoso.

ENTREVISTA №5: ALCALDE DE ARCICOLLAR

1. ¿Cuáles son los elementos que han contribuido a este cambio de un rural agrario a un rural periurbano?

Sin duda alguna la cercanía a Madrid, en nuestro municipio hay varias urbanizaciones de los años 80 y 90, que eran utilizadas como segundas residencias, como "El camorro" y con la crisis se han convertido en lugares de residencia habituales.

Es más, eran tantas las expectativas creadas, que en Arcicollar hay una urbanización cuasi fantasma construida en los años 2000, hoy día está en manos de los bancos pero se podría decir que está habitada a un $20 \%$, y estoy siendo generoso.

2. ¿Qué tipo de cambios principales se han producido en el municipio en estos 15-20 años? 
En nuestro municipio ha aumentado la población, pero esta población es una población que en su mayoría no trabaja en la zona, es decir los nuevos vecinos trabajan en Toledo, en Madrid o incluso en Talavera.

Se han realizado grandes infraestructuras de parques, polideportivos, piscinas etc cuando teníamos una economía municipal mejor, y ahora conservarlos y mantenerlos es difícil y muy costoso, necesitamos ayuda de las diputaciones para poder gestionarlos.

\section{Si ha cambiado la agricultura? Ha emigrado mucha gente del pueblo? ¿ha venido mucha gente? ¿en qué actividad?}

La gente que trabaja el campo son propietarios principalmente, y empresas que se han constituido de hijos de propietarios que han arrendado mas hectáreas para aumentar los rendimientos agrícolas, ya que tienen buenas maquinarias para poder llevar más hectáreas.

Como decía antes, si ha venido gente, buscan viviendas más económicas que en las capitales, al estar bien comunicados llegan fácilmente a sus trabajos.

\section{4. ¿Es un municipio con gente joven, mayor, desempleados?}

Sí, hay emigrantes de varios países, pero bastante menos que Fuensalida, Recas etc. Es cierto que la vivienda que se ofertaba aunque están vacios, tienen un precio mayor que en municipios más grandes y con más ofertas laborales, por lo que los inmigrantes no eligen nuestro municipio a priori. 
5. ¿Qué piensa de los proyectos LEADER? ¿conoce los GAL? ¿Qué opina de ellos?

He oído hablar de ellos, en nuestro municipio desde el ayuntamiento no se han realizado peticiones en este sentido, pero me consta que otros compañeros míos han hecho algunas mejoras de parques, reparación de iglesias etc con financiación proveniente de estos Grupos.

6. ¿Cuál es tu percepción de trabajo del GDR ¿Han hecho mucho por el desarrollo del Medio Rural?

No conozco a fondo en que han dedicado sus esfuerzos, pero toda la ayuda que recibamos los municipios de nuestro entorno, bienvenida sea, no solo por la ayuda económica que también, sino por iniciativas que puedan sugerir para ayudar al medio rural.

7. ¿Cuántos agricultores hay? ¿son a tiempo completo? ¿parcial? ¿son jóvenes? ¿Viven en el pueblo? ¿Las tierras son suyas? ¿Propietarios o arrendatarios?

La mayoría de los agricultores de Arcicollar son agricultores que labran lo suyo, aunque hay dos empresas (socios) que también llevan las tierras de otros.

Por otro lado, está la gente mayor que siga subida al tractor realizando sus trabajillos como buenamente puede.

8. ¿Cuál son sus perspectivas personales para la comarca más agraria, más servicios? 
La comarca tiene una zona muy industrial que es la zona de Fuensalida Torrijos, con industria del calzado, y en Torrijos hay bastantes cárnicas.

Luego está la zona de la Puebla de Montalbán, zona agrícola muy buena y la zona norte donde estamos nosotros, zona agrícolamente con tierras peores, lo que implica peores rendimientos.

Yo creo que las perspectivas de la comarca son diversas en función de los distintos municipios, porque cosas se están haciendo, y hay cierta ilusión en invertir, en crear, etc, en nuestro municipio se ha instalado un restaurante solo para los fines de semana, ya estaba en otro municipio cercano pero por problemas familiares, han dejado digamos la explotación familiar y han comprado sus propias infraestructuras que han remodelado e inaugurado esta pasada Semana Santa, tienen bastante demanda.

Se hacen cosas, pero hay que dar con aquello que funcione que no siempre es fácil.

ENTREVISTA №6: EMPRESARIO DE LA COMARCA SECTOR CONSTRUCCIÓN

\section{1. ¿Cuáles son los elementos que han contribuido a este cambio del rural agrario a rural periurbano?}

La presión urbanística sobre el suelo rústico, generando atractivo laboral a la población rural diferente al agrario.

\section{2. ¿Por qué? ¿A qué se debe? ¿En qué se ha traducido?}

Se ha traducido en que la población dedicada a la agricultura se dedica a labores en otro sector, abandonando la agricultura. 
El por qué, pues debido al poco atractivo de las labores agrícolas, debido a la baja proyección económica que genera la agricultura.

3. Importancia de la agricultura a tiempo parcial. ¿Qué \%? ¿Esos agricultores a que se dedican a tiempo parcial? ¿Han heredado la SAU? ¿Lo hacen los fines de semana?

En mi opinión poca gente se dedica a tiempo parcial a la agricultura, el que es agricultor está en la agricultura, otra cosa son los jubilados que a su vez labran sus tierras y pocas veces las ceden a otros.

Puede ser que familiares, sea hijos, cuñados etc, ayuden al agricultor principal ocasionalmente y puntualmente, vendimia, recolección pero yo creo que no es lo más habitual.

4. Dentro de la comarca en los últimos PDR qué ejes se han intentado priorizar? ¿Por qué esos?

Creo que lo que más se necesitan son ayudas a la mecanización agraria y modernización de las explotaciones, puesto que con los beneficios obtenidos no se puede hacer si no es con ayudas.

5. ¿Cuál es el problema en la falta de instalación de jóvenes en la agricultura?

La poca perspectiva de ingresos económicos a obtener vía agraria, mucho riesgo, inversiones a priori, rentabilidad escasa.

6. Hay continuidad? Si no existe continuidad por qué, a qué se debe? 
El campo de nuestra comarca no es capaz de generar expectativas de trabajo para todos, los que se quedan tienen que estar especializados, y con explotaciones modernas, tienen que asociarse para poder competir en el mercado actual.

\section{7. ¿Son suficientes las Políticas de Desarrollo Rural europeas para conseguir el desarrollo del medio rural?}

No, no son suficientes. No están enfocadas a fijar población, sino a mitigar la diferencia entre ingresos y gastos de la misma actividad. Se mantienen a los agricultores como "cuidadores del campo", al fin y al cabo alguien se tendrá que ocupar del campo y nadie quiere.

8. Dado que este territorio se está acercando a un rural periurbano ¿piensan que las medidas o iniciativas de los programas responden a esta realidad? ¿habría que cambiar algún aspecto para ello

Los programas son genéricos, creo que pocas veces se particulariza para cada tipo de comarca, es por ello que debían adaptarse más a cada realidad rural, ya que cada rural es diferente, lo que funciona en una comarca no tiene por que ocurrir de igual manera en una comarca de Castilla y León.

\section{9. ¿Cuáles son tus perspectivas sobre la comarca?}

Como empresario de la zona creo que es una comarca de oportunidades, pero no en el mundo agrícola. Nosotros hacemos sobre todo obra industrial, y en algunos casos tenemos que contratar para incrementar plantilla a gente de la zona, y es complicado. Los más jóvenes exigen unos salarios no acordes a su aportación a la empresa. Esto no ocurre en otras zonas, nos es más fácil "conseguir gente", por ejemplo en la zona de Talavera que aquí. 
Yo creo que en parte es debido a que la presencia de industrias de calzado y de otro tipo, han generado colocaciones rápidas, con buenos salarios sin grandes esfuerzos y en el sector de la construcción las condiciones son más duras, no más que en el campo. Hay una generación entre 35 y 45 años, cuya capacidad de empleabilidad es complicada, no quieren ser agricultores, no quieren trabajar en la construcción, y no tienen estudios, lo que no se han dado cuenta es que trabajar requiere esfuerzo sea donde sea, están mal acostumbrados.

\section{ENTREVISTA №7: JOVEN AGRICULTOR LA PUEBLA DE MONTALBÁN}

Me comentabas que ahora este territorio está cambiando, que cada día está más urbanizado.

\section{1. ¿Cuáles son los elementos que han contribuido a este cambio del rural agrario?}

Yo un joven agricultor con una superficie de cultivo de 225ha, cereal secano, y olivo que llevo junto con mis dos hermanos. Me diplomé en relaciones laborales, pero al final el campo pudo más. Me gusta esta profesión, lo conozco desde chaval.

Está claro que la cercanía a la ciudad de Madrid, ha hecho cambiar esta comarca. Puedo decir que el hecho de haber tenido mucha industria del calzado hace años, hizo que compañeros míos del colegio, que simultaneaban los estudios con algunos trabajillos relacionados con trabajos del calzado, no vieran la necesidad de estudiar. Ahora algunos de ellos, están intentando volver al campo, pero no es fácil. 


\section{2. ¿Por qué? ¿A qué se debe? ¿En qué se ha traducido?}

Pues en que hay una franja de edad, algo mayores que yo (yo tengo 33 años), que no estudiaron, no tienen trabajo de continuo y no tienen interés en el campo. El campo te gusta o no, es un trabajo poco reconocido y muy sacrificado.

También en las épocas buenas de la construcción, la gente buscó trabajo allí y con la crisis se quedaron sin él.

3. Importancia de la agricultura a tiempo parcial. ¿Qué \%? ¿Esos agricultores a que se dedican a tiempo parcial? ¿Han heredado la SAU? ¿Lo hacen los fines de semana?

En la Puebla, como en otros lugares de por aquí hay dos tipos de agricultores, el que es agricultor de toda la vida con tradición familiar, y los que simultanean la agricultura con otras actividades, bien trabajando en despieces de pollos, en el ramo de restaurantes y bares, .... la gente se busca la vida.

4. Dentro de la comarca en los últimos PDR qué ejes se han intentado priorizar? ¿Por qué esos?

Conozco poco sobre los Planes de Desarrollo Rural, ya me cuesta entender la PAC y eso que tengo estudios.

Los funcionarios a veces no se dan cuenta que para un agricultor es tarea imposible tramitar, enterarse de ayudas etc, a veces nos enteramos por ASAJA y otras cuándo ya se ha paso el plazo.

5. ¿Cuál es el problema en la falta de instalación de jóvenes en la agricultura?

Es una profesión muy sacrificada, muy bonita pero a veces decepcionante. Tienes por ejemplo unas cosechas estupendas y en unas horas te cae un pedrisco, y 
adiós muy buenas. Las jornadas en plena campaña son duras, todo trabajo y un poco de tiempo para los hijos.

\section{Hay continuidad? Si no existe continuidad por qué, a qué se debe?}

Uno de los principales problemas que tiene el sector son los precios de los cultivos, son parecidos a los de hace 20 años y los costos se han triplicado en el mejor de los casos.

Como decía antes, la agricultura es una profesión preciosa, pero es muy dificultosa, y no te digo nada si tienes que comenzar de cero, es casi imposible.

\section{7. ¿Cómo ves tú el futuro de la comarca?}

Yo, que soy joven tengo que aportar optimismo y esperanza a la situación., pero es cierto que la agricultura va para abajo. Si es cierto que parece que las industrias que hay van bien o por lo menos, se ven obras nuevas lo cual indica actividad, puestos de trabajo, en definitiva activación de la economía.

El futuro es un tanto incierto pero somos nosotros los jóvenes los que tenemos la llave, hay que remar conjuntamente y a veces es cierto que en los pueblos es complicado ponerse de acuerdo ni siquiera a veces para realizar alguna mejora en el campo que beneficie a todos. Habrá que intentarlo. 


\section{ENTREVISTA №8: GERENTE DE EXPLOTACION, E INGENIERO AGRONOMO EX} FUNCIONARIO DE LA JCCLM

Primero me presento diciendo que soy Antonio Cubillo Saavedra, ya jubilado desde hace unos años, he sido ingeniero agrónomo especializado en los temas de leche y agricultura y estoy titulado por España y por Francia.

Yo vengo de la empresa privada a la agricultura, por motivos familiares, esta explotación familiar la llevaba el hermano mayor y hubo un momento en el año 85 que no estaba a la altura, digamos técnica, en producción, para poder mantener una familia. Entonces la explotación agropecuaria de aproximadamente 1000 ha se dividió entre los tres hermanos. Yo en este momento llevo dos partes, 600 ha, está situada en la zona de el Norte de Toledo, comarca de Torrijos, vulgarmente llamado "tierras de Madrid" esa vulgaridad es porque las tierras de esta zona son tierras muy arenosas, franco -arenosas de poca arcilla, de poco humus y de poca materia orgánica y por eso se llaman tierras de Madrid.

\section{1. ¿qué cambios ha observados a nivel territorial en las últimas dos décadas?}

Esta comarca está cambiando en sus actividades, hábitos y sobre todo en su agricultura, cada día con menor peso.

\section{2. ¿Cuáles son los elementos que han contribuido a este cambio en la ruralidad? ¿Por qué? ¿A qué se debe?}

Una explicación es que hay que darse cuenta que de la comarca de Torrijos hay un $50 \%$ de zona Madrid, es decir un lugar periurbano altamente influenciado por Madrid, razón ésta de la proximidad que por un lado aporta algo de turismo madrileño, pero que por otro lado ha originado (gracias también a las buenas 
comunicaciones existentes con Madrid), una oferta de viviendas en nuestros municipios agrícolas, atrayendo "madrileños" a nuestros campos, no para realizar actividades agrícolas sino por motivos de búsqueda de residencia más económica, y de mayor tamaño que en la capital.

Esta comarca ha pasado de ser una comarca 100 por 100 agraria, ya en los años 60 se empezó a mover mucho la construcción en Madrid el desarrollo en aquellos momentos del año 65 fue inmejorable, respecto lo que había antes se empezaron hacer muchos barrios de extrarradio en Madrid y se nos fue parte de la mano de obra de esta zona.

Al estar próximo a Madrid hizo que en los años fuertes de la construcción, muchos agricultores o empleados agrícolas se fueran a este sector, ¿qué pasa en este momento? Pués que en la construcción ha bajado enormemente con respecto a hace años, han ganado tantísimo dinero los nacionales que no se colocan si no es al mismo sueldo que estaban ganando cuando la burbuja inmobiliaria estaba en su momento álgido y ganaban un dineral, que ellos han ahorrado y viven con eso, y pueden vivir hasta el final de sus vidas, la vida en el campo es más económica.

Como ahora de la agricultura no pueden sacar los mismos salarios pues siguen en paro, no trabajan, así vemos como los pueblos de aquí alrededor de entre Camarenilla, Camarena, Vargas, Chozas, Fuensalida, Recas etc en esos pueblos hay personal nacional que están en sus casas con su televisión.

\section{3. ¿En qué se han traducido estos cambios?}

Hoy en día es muy complicado encontrar gente para los trabajos agrícolas. En mi caso, trabajo con una familia de empleados extranjeros fijos compuesta por cuatro personas, dos estudiantes que algunas veces echan una mano, los sábados y alguna tarde que tienen libre, y la mujer del empleado que se ocupa de las cosas menores. 
Cuando no corre prisa las cuestiones agrarias lo dedica al mantenimiento de los edificios, tarea a la que empleamos bastantes horas, al ser, una explotación antigua tiene muchos edificios antiguos que sería una pena dejarlos derruir puesto que es la estructura inicial y la tradición de la finca.

Personal nacional no se encuentra para vivir en el campo, yo vivo en el campo pero unas veces sigo ejerciendo mi profesión libro de ingeniero y tengo que salir y tengo que tener aquí una persona fija. No he encontrado nunca una familia Nacional de españoles que quieran vivir en el campo, igual que antes se decía que el más tonto de la familia era pastor, el más tonto de la familia se metía agricultor.

Es una pena, aquí se considera que el que se mete en el campo es el más tonto del pueblo y por eso solamente en las fincas tenemos extranjeros. Extranjeros que el que sale bueno es magnífico y el que es malo hay que echarlo al día siguiente porque no ha captado que si se vienen a España no es para recibir algún dinero fácil, sino para trabajar. El dinero fácil lo han estado ganando todos los inmigrantes, poniendo malamente ladrillos o poniendo malamente alicatados en una casa que como no importaba los gastos porque se vendían a nueve veces su coste, pues allí han estado.

Los municipios aquí son relativamente pequeños, con una carga de administración absurda, con unos gastos absurdos por qué los apoyos que daban eran para mejorar estructuras innecesarios, porque por ejemplo hay pueblos que tienen piscinas que no se utilizan, hay pueblos que tienen pistas de pádel que tampoco se utilizan porque las personas autóctonas de pueblo no saben jugar ni van a saber jugar al padel etc y así como muchas construcciones de ese tipo que son innecesarias. Esto ha provocado también, que haya unos gastos que han repercutido en que el Ayuntamiento ha tenido que subir los IBIs que ha tenido que poner tasas 
nuevas por recogida de basuras y muchos impuestos de este tipo para poder completar su presupuesto municipal.

4. Importancia de la agricultura a tiempo parcial. ¿Qué \%? ¿Esos agricultores a que se dedican a tiempo parcial? ¿Han heredado la SAU? ¿Lo hacen los fines de semana?

Sí, es cierto que hay agricultores que compaginan la actividad agraria, con trabajillos en la construcción en pequeños negocios familiares, comercio etc.

En mi opinión suelen ser propietarios de la superficie y a veces también hacen las labores en fin de semana como complemento, o llevan las tierras entre varios familiares etc, pero este tipo de agricultores no suelen cultivar grandes superficies, la agricultura es un complemento de su renta.

\section{Dentro de la comarca en los últimos PDR qué ejes se han intentado priorizar? ¿Por qué esos?}

Como decía al principio, las tierras no son de calidad, salvo que podamos seguir con la forestación si es que hemos llegado al tope o no hemos llegado a ese tope que nos exige el acuerdo de Tokio de hace 15 años, que exigía a cada país tener un mínimo de hectáreas forestadas para mejorar el ambiente y si no es por ese camino, toda esta zona se convertirá en una zona improductiva por los altos costes de producción actuales.

Creo que se ha acertado la aplicación de políticas de reforestación, en mi caso he de decir que Bruselas nos ha dado la oportunidad de cambiar las tierras arables por forestación, en este momento todo lo que produce menos de $1.800 \mathrm{~kg} / \mathrm{ha}$ no es rentable y en mi caso, en el $50 \%$ de las superficie así ocurre (mala calidad de tierras arenosas, 0 de materia orgánica y 0,5 de arcilla) por lo que he forestado con pinos, encinas y acebuches unas 170 has. 
Las primas compensatorias son una ayuda muy grande porque estas tierras nunca hubieran dado esa cantidad de dinero de cereales, durante 20 años lo estarán pagando y después de 20 años, si se cumple la Ley las podremos transformar en dehesas. Cosa curiosa que esta finca se llama Dehesa de Buzarabajo en el año cinco del siglo XX estuvo siendo dehesa de ganado y hubo un antepasado que la transformó en finca agropecuaria con cereales y cultivos. Estas forestaciones están apoyadas por Bruselas de una forma muy curiosa las tierras arables se apoyan para forestarlas, pero por otro lado nos estamos dando cuenta también de que esto le conviene mucho a Europa porque de alguna forma dejamos de producir cereales, para que cuando a nosotros nos falte ellos tengan un buen mercado de donde vender lo suyo.

La cuestión es forestar España para que se pueda decir que España está forestada en una cantidad importante y esa cantidad importante, es la que nosotros incluso podemos presumir de que estamos protegiendo el medio ambiente desde la comarca de Torrijos

Mencionar que la comarca de Torrijos es muy diversa, tiene municipios como Maqueda, la Mata, Gerindote de tierras arcillosas muy productivas que no se parecen a tierras como las mías, este es otro clima, con una media de lluvia que si en la comarca es de 350, $375 \mathrm{~mm}$ aquí es de $250 \mathrm{~mm}$.

Esta zona salvo determinados municipios, es una zona de dificultades de producción de olivo, porque tenemos unas heladas que no tienen en la zona sur, tenemos una grana con una polinización muy difícil en el mes de mayo-junio, porque se nos caen unas aguas y no se polinizan correctamente y porque también seguimos con árboles antiguos que para vibrarlos con elementos mecánicos es mucho más difícil que las plantaciones modernas de que se están haciendo en líneas. Son marcos antiguos de 80-90 olivos por hectárea, cuando en este momento en una plantación de línea están 
metiendo 1000 plantas por hectárea, y que dificultan su recolección incrementado el coste de la misma.

Destacar también las ayudas que se han dado para cultivos en ecológico como en el olivar, obteniendo producciones parecidas pero con mayores primas.

Yo he estado en la administración, en el año 95 hice un estudio para mandarlo a Bruselas desde la asociación de jóvenes agricultores, jóvenes dentro lo que cabe que el $80 \%$ pasamos de los 50 años, luego jóvenes agricultores hay un $20 \%$ nos llamamos así porque nos hace ilusión, pero no por otra cosa. Es un estudio que se mandó a Bruselas donde se demostró claramente que el $30 \%$ en general de la provincia de Toledo pasaba a gastos de las primas compensatorias, es decir que los costes de producción sobrepasaban las ventas y un 30\% de la prima compensatoria pasaba a gastos, luego nos quedaba de las primas compensatorias un $70 \%$ para la familia. Este dinero que hay que declararlo en el impuesto de la renta las personas físicas y un agricultor medio esta en un 18 20\%, luego de $70 \%$ tiene que revertir hacienda un $20 \%$.

\section{6. ¿Cuál es el problema en la falta de instalación de jóvenes en la agricultura?}

Es curioso, se encuentran fácilmente gente joven que pueda trabajar en la construcción, no hay ni un joven que quieran venir al campo, y que quieran cultivar las viñas de sus abuelos o parientes entonces echa cuentas y dicen ¿qué voy a ganar yo sí hecho tres o cuatro días en la viña o en el Olivar o en la tierra de mi padre? si el sueldo de un joven agrícola está entre los $65 €$ dependiendo de lo que estén trabajando eso no le compensa en tanto el estaba ganando con la burbuja del ladrillo 80,90,100 o $120 €$ normalmente o algunas veces hasta $150 €$ al día.

Es una cuestión de educación. El agricultor tiene que ser respetado. Yo he visto otras naciones europeas en las que el agricultor no sólo es respetado sino 
también adorado. ¿qué quiere decir adorado? Que le tienen realmente donde hay que tenerle, es decir él es el que nos da de comer, él es el que produce los alimentos que nosotros compramos en los supermercados, porque en el supermercado no vienen de la fábrica, vienen de una materia prima producida en el campo. Mientras no den una educación a esa juventud, que el ser agricultor es ser una persona considerada tanto o más que un funcionario, tanto o más que un administrativo tanto o más que un albañil, mientras no tenga una educación inicial no vendrá la juventud al campo. ¿cómo puede venir la juventud al campo? pues en vez de hacer tanta educación del ciudadano y tanta educación de otros tipos que son totalmente de corte político, a esos niños hay que hacerles que visiten granjas rurales, que visiten explotaciones agrícolas, que hagan estancias en esas explotaciones agrícolas y que vayan amando y queriendo al campo. Esto se debe hacer desde jóvenes mientras esto no se empiece a tener en cuenta en España la juventud, no vendrán.

Si está ocurriendo que hijos de agricultores se están aprovechando y hacen bien. Muchos son hijos de los agricultores, no un agricultor nuevo sino un joven hijo de agricultor y su padre que le ayuda y que le dice tú te apuntas como joven agricultor lo dejo la agricultura yo te inicio, yo te apoyo, yo te ayudo y a lo mejor están con ellos hasta su vejez se ha jubilado a los 65 años han dejado el patrimonio para que lo lleven sus hijos y lo gestionen y encima tiene un apoyo que esto es muy efectivo.

Pero no hay una gran cantidad porque hay muchos que no aran las tierras porque no les merecen la pena y no se agregarán al sector agrario nunca. Estos jóvenes agricultores si tenemos en cuenta y nos pusiésemos a hacer una encuesta son todos hijos de agricultores que están por encima de las 100 ha. Para que sea rentable una explotación en esta zona de la comarca de Torrijos hace falta que sea una explotación de entre 150 y 100 ha por lo menos. Aunque en las buenas tierras 
de Torrijos, de Maqueda, de Gerindote como acabo de decir tampoco se puede decir que con 100 ha aquí un agricultor puede vivir tampoco, ya que tiene que alimentar a su familia y dar estudio a su familia que sería lo más importante que se pueda hacer en esta vida es dar a un hijo una educación y que realmente esté preparado para cualquier cosa que le venga el día de mañana sea agricultor o sea de cualquier otra profesión.

\section{7. ¿Hay continuidad? Si no existe continuidad ¿por qué, a qué se debe?}

El futuro se ve desde aquí hasta Madrid que hay $68 \mathrm{~km}$ yo diría que el $50 \%$ de las fincas que se ven están abandonadas, antiguo viñedo abandonado, antiguas tierra de cereales poco productivas abandonadas, tierras pequeñas que no se pueden labrar porque no son rentables, la unión de agricultores para que trabajasen las tierras en conjunto es inviable, porque somos muy personalistas y yo quiero juntarme con el vecino porque mi tierra es mejor que la del vecino y a lo mejor si hay alguien que me la quiere llevar o arrendar pues me tendría que pagar a mí el doble que el vecino y como no es verdad porque las tierras que están una al lado de otra son iguales pero cada uno cree que su tierra es mejor que la de los demás.

¿Qué ocurre? pues que hay incluso propietarios que ceden su tierra gratuitamente a ciertos agricultores que tienen sobra de maquinaria para que no sea un perdido, donde nos nazca más que cardos, malas hierbas, zarzas o se inunde de arbustos.

El futuro está en educar a una nueva generación de jóvenes amantes del campo, como pasa en Europa. En Europa ya los hay, pero eso lleva tiempo y a nadie se le ha ocurrido empezar a mover esa idea en España.

\section{8. ¿Cómo ves tú el futuro de la comarca?}


En viñedo ese futuro próximo ha llegado no ahora, si no hace unos 10-15 años, ya que como el consumo se ha reducido muchísimo y la producción se ha aumentado indiscriminadamente, porque desde Bruselas se ha considerado que es un cultivo social y es cierto que lo es, pero aparte de eso no se pueden hacer barbaridades como estar produciendo casi el doble en este momento de lo que se producía en el año 54 cuando el consumo en ese mismo año era hasta de 75 I per cápita. En este momento estamos en 7-8 I per cápita y produce un desarreglo en el en el comercio y en la venta de vino que quiere decir que el $90 \%$ del vino producido tiene que pasar a alcohol con las pérdidas que supone para un estado el tener que pasar un vino a alcohol.

¿Que se exporta algo? muy poco y a bajos precios, pero hay que abrir mercados y bueno es que se exporte.

El problema de la aceituna se va a plantear de aquí a pocos años, porque antes era la cuenca y la rivera del Mediterráneo, Turquía, Grecia, Italia, España y el norte de África producíamos aceite. Ahora ya no, ahora hay una cultura de aceite en Chile tan importante como la hay en España, en Sudáfrica también tan importante como la hay en España, en Australia tan importante como la puede haber en España y se conoce que la India tiene un programa de 4 a 5 años de 450.000 ha para poner de Olivar.

¿Qué está pasando con el aceite de oliva? pues lo mismo que con la uva, años que se produce tal cantidad que los precios bajan por debajo de los costes de producción y años que no hay producción por que son muy veceros, queremos decir en el campo año produce y otro año no según viene la climatología y el año que no producen los aceites suben. Este año han subido hasta cuatro euros el kilo de consumo y 60 y tantos cts. el kilo en cooperativa, ¿por que hablo de cooperativas? antes las olivas de se iban a almazaras particulares, porque la economía era una 
economía muy escasa si necesitabas dinero sobre la marcha si necesitaba dinero inmediatamente y no se podía esperar a la liquidación de la cooperativa que normalmente tarda un año. Las cooperativas están esperando a obtener los mejores precios, unas veces lo sostienen esperando otras veces no pero normalmente si tienen mejores precios esperando.

El resultado vemos que es más efectivo, aunque se tarde más tiempo en cobrar. Las necesidades de cobrar no es que sean menores que antes, pero se tiene digamos una organización de poco gasto para que no nos falte el dinero inmediato. Los agricultores tenemos o tendrán que ser capaces de organizarse, asociarse si queremos aumentar la productividad.

En este momento yo creo que el mayor tiempo que emplea un agricultor es en programar bien su siembra, sus ciclos de cultivo para conseguir las mayores primas de compensación de tierras arables y productivas digo primas de compensación en contra de todos los que llaman subvención, porque de subvención esto no tiene nada, esto son primas compesatorias.

Es una prima para que nosotros un trigo una cebada un cereal que cuesta por ejemplo $0,45 €$ su producción, solamente lo podemos vender a $0,20 €$ o $0,25 €$ porque el pan de mi señora o la suya o de cualquier familia española tiene que comprar la barra a $0,67 €$, porque si la pusiéramos a $1,30 €$ no comprarían pan.

No es solamente España, es Europa entera la que tienen establecidas estas primas compensatorias, repito que no volveré a hablar de subvenciones por que en Europa se hace porque en el mundo entero se hace la agricultura si no es apoyada no tiene futuro alguno por los costos de producción.

Hay una constatación ahora de que hay una media de agricultores de entre 5056 años que bien porque sus padres han sido agricultores, han seguido el mismo 
camino, pero si no hay una regeneración por parte del personal para que se pueda volver al campo, lo primero es una cuestión de educación.

Hemos pasado una serie de años que como se ganaba mucho en la construcción, hay niños que han dejado a los 14 años sus estudios para ponerse a remar ladrillos o a arrimar cemento o a poner ladrillos cuando incluso ni sabían ponerlos por lo tanto es una cosa de tiempo, pero que ahí nos sacan mucho de adelanto los países europeos.

ENTREVISTA №9: AGRICULTOR: MIGUEL AGUDO FERRERO

\section{1. ¿Cuáles son los elementos que han contribuido a este cambio del rural agrario?}

Lo primero se debe a que estamos cerca de Madrid, lo segundo el campo no da para vivir a no ser tengas mucha superficie con lo cual eso es un problema, lo tercero que en el producto no mandas todo el mundo te manda en ti todo el mundo te manda en el precio. En la agricultura todos los productos suben lo que tú compras y lo que tú vendes sigue como hace 40 años. Mi padre también ha sido agricultor, mi abuelo también y mi padre vendía la cebada a 25 pts que es como está ahora entonces no se puede, competir cómo se compite? Pues con mucha superficie trabajando muchas horas y no hay más, ahorrando mirando el precio mirando para acá y para allá. No hay otra manera, sino no sobrevives, no puedes sobrevivir porque es que no hay solución.

\section{2. ¿Por qué? ¿A qué se debe? ¿En qué se ha traducido?}


Esta comarca que era una comarca tradicionalmente agrícola de cereal, olivar y viñedo y Arcicollar más porque siempre ha sido de ganadería y agricultura Ahora mismo Arcicóllar, se gestiona entre nosotros (yo mi hermano), Jaime y luego hay dos o tres más pequeños que llevan entre los 3,150 ha.

Soy socio de una comunidad de bienes, somos dos hermanos y llevamos una explotación juntos desde 2009, labramos 500 hectáreas tenemos cereal, olivar y viña es lo que más tenemos. Lo hacemos todo nosotros. 100 ha son nuestras, el resto son arrendadas, lo que es arrendamiento puro arrendamiento puro, yo alquilo la hectárea a tanto dinero y ya me ocupo yo de ella para la subvención para el trabajo para mí todo yo pago solamente la renta.

3. Importancia de la agricultura a tiempo parcial. ¿Qué \%? ¿Esos agricultores a que se dedican a tiempo parcial? ¿Han heredado la SAU? ¿Lo hacen los fines de semana?

Aquí en Arcicóllar a tiempo parcial hay poco, solo un señor que tiene un taller, y los fines de semana trabajan como hobby pero nada más. Algún mayor jubilado que va en su tractorcito, pero nada más.

\section{Dentro de la comarca en los últimos PDR qué ejes se han intentado priorizar? ¿Por qué esos?}

Sé que aquí hay un Grupo de Acción local que está en Torrijos, no lo conozco mucho. Cómo no te muevas tú no te enteras de nada, hay ayudas pero hay desconocimiento de ellos hay gran falta de información, si hubiese más información la mejor la gente joven se enteraría las cosas.

Las ayudas como la PAC, son el $80 \%$ de la renta agraria, es decir cuando la PAC se quite pues se acabo, el campo se queda abandonado. La administración debe ayudar y no poner zancadillas, que nos ayuden para que la gente se incentive. 
Yo por ejemplo tengo un hijo de 20 años y no lo quiero en el campo, está estudiando pero no le quiero en el campo porque tiene mal futuro y eso que yo estoy comprando maquinaria y me gustaría que estuviese en el campo, pero no lo quiero aquí. esto es como los toreros o toreas o te retiran con lo que no te queda más remedio que invertir en el campo si no te pones al día no hay nada que hacer, tractores nuevos cosechadoras .

\section{5. ¿Cuál es el problema en la falta de instalación de jóvenes en la agricultura?}

Para incentivarla ellos tienen que ver un beneficio, porque yo conozco gente que por ejemplo sus padres se van a jubilar y ponen viñas y dice el hijo por mí no pongas viñas que yo no quiero tener viñas y estar trabajando todo el año, ir a cobrar la uva que me la pagan al año y así no puedo vivir. Ellos llevan razón prefieren un sueldo de $1000 €$ que saben que van a tener seguro y que de la otra manera no, porque si se dedican a viña no viven porque las cooperativas, te pagan tarde mal y nunca y así no se puede vivir.

Y es verdad, esto de las cooperativas también pasa con las cooperativas de cereal al final todas cooperativas pagan tarde y tienes que hacer un poco de caja con anterioridad y es caro y tú no tienes suficiente dinero como para vivir de eso. Quizás si a lo mejor la administración fuese asegurando un poco la producción, porque no puedes estar pidiendo préstamos y préstamos y préstamos o adelantos de la PAC etc. porque no ganas para los bancos.

\section{Hay continuidad? Si no existe continuidad por qué, a qué se debe?}

Por ejemplo en Fuensalida hay mucha gente árabe y esta gente se dedica a vivir, no quiero trabajar. Muchas veces les ofreces compartir parte del beneficio de la renta y te contestan que no, a mí dame los $50 €$ de jornal que no quiero. 
Por ejemplo en Camarena este año he cogido las tierras de una mujer que han partido los hermanos. Esta señora tiene viñas y no he querido cogerlas porque yo puedo tener viña pero no puedo tener mucha porque no tengo tiempo, ni personas que me ayuden, entonces digo bueno pues se lo damos a alguien y que lo labre pero es que no hay gente que lo quiera hacer. No quieren arriesgar a ser ellos mismos agricultores. El problema es que como luego cuando van a cobrar tardan mucho en pagar y no quieren arriesgar y hacer ellos mismos de agricultores.

A lo mejor, si la administración pudiese financiar esto, adelantando dinero....

Yo creo que es un problema para los jóvenes, no se llegan incorporar no se renueva el capital productivo. Yo tengo 49 años, llegará un momento que esta generación desaparezca, va a pasar que por ejemplo Arcicóllar lo lleve uno, Fuensalida entre dos o tres, y así. En Fuensalida está pasando esto, como hay mucha viña pues lo llevan entre mucha gente, hay una generación de gente con 40 años que sus padres tenían viña y están poniendo ellos también, mientras no tengan otra oportunidad están en el paro y mientras que no sale otra cosa va manteniendo pero vamos sin ilusión, si el día de mañana viene otra vez la construcción o los zapatos pues lo dejarán.

El gran problema que hay es un problema del precio del producto final del cereal. antes con 5 I de gasóleo le pagabas con un kilo de cebada ahora necesitas cinco kilos de cebada para pagar 1 I de gasoi,I así no se puede mantener se mantiene a base de horas, de días, domingo, es decir de no computar las horas de trabajo es decir si yo computase mis horas de trabajo cuánto ganaría yo al día que estoy 17 horas.

\section{7. ¿Cómo ves tú el futuro de la comarca?}


Mal, si la gente mayor que se dedicaba a la agricultura fallece, la gente joven no se quiere incorporar el campo, el cual lo que está haciendo es llevándolo entre varios y desde la administración no somos capaces de hacerles ver que hay una oportunidad para el futuro.

Se necesita lo primero apoyo de las administraciones, por ejemplo aquí zona ZEPA no te dejan hacer nada de nada, llega un poquito Fuensalida, Huecas Villamiel yo por ejemplo esparramo basura tengo que pedir permiso para hacerlo no es químico pero como no me dejan enseguida como te pillen te sancionan entonces no lo hago, porque me sancionan y pierdo la ganancia. $Y$ si pides un permiso no te lo darían pues si a base de mucho tiempo yo por ejemplo tengo dos fincas pegadas al arroyo, se me están metiendo las cañas y no las puedo tocar ipero si lo único que quiero es limpiar mi tierra!, si yo no voy a coger nada que no sea mío, si yo no me voy a meter el arroyo, pues al final es el que no quiero problemas la administración es muy lenta y pone muchos problemas.

Yo por ejemplo he arrancado una viña se me ha metido al arroyo, se ha hecho un retamar allí y me quita por lo menos media hectárea, si quito el retamar primero te denuncian y luego demuéstralo y te pasas con ese tema un año y porque tengo que estar un año si esto es mío entonces lo haces con miedo el fin de semana para que no te vea y así no se puede vivir.

Por ejemplo a mí las aceitunas me cuestan dinero llevo casi 2000 olivas y me cuestan dinero y por qué las llevo, pues porque están dentro de mismo paquete como llevo las tierras me tengo que quedar con el Olivar, pero me cuesta dinero. Llegas a la almazara a cómo me vas a pagar las olivas a 50 Pts es que me gusta coger la 40, poda trata y las almazaras están funcionando mal.

Al igual que las cooperativas de vino, funcionan mal, mucho gasto en vez de reducir gastos, no se ha especializado es decir si tiene que haber cuatro personas y hay 5 
pues quita uno, pero estamos en un ámbito tan pequeño que no se mira por el negocio, es mayor el enfado que el beneficio económico.

En Fuensalida, en una de las cooperativas, el secretario que es economista se va a tener que ir, porque las medidas que el propone nadie las quiere aplicar y discute con todo el mundo. $Y$ en cuanto al cereal, interesa a veces guardarlo en la nave y esperar a ver los precios.

ENTREVISTA №10: AGRICULTOR, ECONOMISTA Y PRESIDENTE DE COOPERATIVA VINICOLA: ALBERTO BENAYAS

\section{1. ¿Cuáles son los elementos que han contribuido a este cambio del rural agrario?}

Sin duda alguna la realidad geográfica de la cercanía a Madrid ha influido mucho en este cambio hacía una comarca de servicios. Existen unas vías con buena comunicación que han hecho que las ciudades próximas como Madrid y Toledo ejerzan su acción sobre los pueblos de nuestra comarca.

\section{2. ¿Por qué? ¿A qué se debe? ¿En qué se ha traducido?}

En mi caso que soy agricultor también soy economista tengo una explotación 430 ha de cereal y viñedo de regadío, tenemos viñedo unas 15 ha y el resto secano y cereal todo está en el término municipal de Maqueda y la Torre de Esteban Hambrán, de unos años a esta parte es complicado conseguir mano de obra para las distintas labores a realizar en el campo. Es decir, prefieren hacer pequeños trabajos en otros sectores, bien sea la construcción o el sector servicios que buscar empleo en el campo. 


\section{Importancia de la agricultura a tiempo parcial. ¿Qué \%? ¿Esos agricultores} a que se dedican a tiempo parcial? ¿Han heredado la SAU? ¿Lo hacen los fines de semana?

No sé decirte, creo que hay mucho agricultor que está dedicado a otras actividades. En mi caso yo tengo una persona fija todo el año completo y luego pues depende, el tema de la vendimia pues viene gente de fuera de la zona. Mi vendimia necesita personal, pues tengo mucha espaldera pero también tengo mucha cepa baja, mi cuadrilla de vendimia son 24 personas, son gitanos portugueses llevan conmigo 24 años juntar a veintitantos payos es complicado. ¿Qué regañan? Junta tú 24-25 personas y veremos a ver si discuten o no. Tema de la poda pues la mayoría de la gente es de la zona, desde hace un par de años vienen dos matrimonios de Sevilla y el tema el personal lo tengo más o menos cubierto con eso.

\section{4. ¿Cuál es el problema en la falta de instalación de jóvenes en la agricultura?}

Lo que se ve es que hay unos jóvenes que están en la zona y que no quieren trabajar en la agricultura es una realidad. Ahora se nota mucho la mano de obra local que se ha venido ofrecer por el tema de la crisis, pero no son tan jóvenes. Los conozco yo y es gente que estaba trabajando en la construcción y que se ha quedado sin trabajo y se han tenido que venir aquí al campo, pero lo que quieren es trabajar a días y compaginar con chapucillas de aquí y allá.

En la Consejería también me lo dicen, los funcionarios que imparten los cursos de incorporación de agricultores dicen que antes venían a las formación las mujeres con las uñas pintadas se veían que no eran de las del campo ahora no, ahora la gente que viene a recibir esos cursos es gente del campo. 


\section{5. ¿Las ayudas recibidas del PDR han afectado de alguna forma al nivel de ingresos de los beneficiarios de las ayudas?}

No sé decirte las del PDR más en concreto, pero las ayudas de la PAC en mi caso ha sido sin imprescindibles casi han supuesto una cuarta parte de los ingresos y esperemos que sigan así. Ahora creo que el PDR subvenciona el ecológico, también he estado 10 años en ecológico, en algunas parcelas diseminadas de la Torre y me salí de ecológico porque las tierras eran flojas y cortas y los rendimientos bajaban mucho tenía unas 15 ha.

Se está haciendo un gran esfuerzo, dicen los altos cargos que van a ir a mejor con la nueva PAC, creo que hay bastante lío con la transferencia de derechos, yo en mi caso espero no tener ningún problema, sin estas ayudas muchas parcelas estarían abandonadas.

\section{Como Presidente de cooperativa vinícola, ¿Cuáles son los grandes retos a los que se enfrentan las cooperativas?}

Aquí hay un problema muy grande con las cooperativas, está excesivamente atomizado hay cooperativas con $500000 \mathrm{~kg}$, yo creo que la que más tiene tiene alrededor de 5.000.0000 de kilos y eso es inviable si han intentado fusionar, se han hecho muchos esfuerzos pero es imposible por la idisionsicrasia que tienen.

Yo por ejemplo soy socio de cuatro cooperativas, soy Presidente de otra cooperativa que tenía 500.000 kilos, lo primero que hemos decidido es que no podía ser, eso asi no puede seguir y hemos firmado un acuerdo inter cooperativo con otras cooperativas mucho más grandes para juntarnos, no para fusionarnos sino para elaborar allí porque nosotros no podemos ahorrar costes. Esto es un problema sobre todo en el tema del viñedo y del vino y además yo noto un poco descoordinación por parte de la Consejería en el sentido de que por ejemplo en el tema de los planes de 
restructuración de viñedo se han hecho un poco para mi gusto a lo loco, empezaron el año 99 por ejemplo la zona de Méntrida que es a la zona a la que pertenezco yo la variedad autóctona es la garnacha.

La garnacha se prohibió ponerla, te financiaban cualquiera menos la garnacha, entonces mucha gente como era la que no te financiaba pues puso otra variedades. Esas variedades ahora ya pasados 15 años se han dado cuenta desde la administración también porque he hablado con algunos técnicos y me han dicho que es un fracaso porque no se adapta al terreno. Aparte de eso, para mí el más grave el problema es que no se han establecido una paridad a la hora de reestructurar hectáreas viejas hectáreas nuevas, en el sentido de que por ejemplo tú arrancabas que una parcela que te producía 1000 kilos por hectárea para luego poner una que te producía 20.000 kilos por hectárea. Hay un exceso de oferta ahora mismo, no sabemos que va pasar porque yo creo que de aquí a tres o cuatro años la administración tendrá que tomar cartas en el asunto porque toda la explotación que están poniendo ahora y ya le digo que de una parcela vieja a una nueva te multiplica por 20 la producción y el consumo de vino a nivel nacional está disminuyendo.

Por otro lado dicen que las exportaciones aumentan, y yo les respondo ¿cuánto vale eso que se exporta? tiene un muy escaso valor añadido, entonces claro a mí eso no me sirve entonces nos queda más remedio que regalar el vino por exceso de producción que vamos a tener y para mí eso si subiera establecido una paridad como por ejemplo por cada 3 ha viejas una nueva o dos, se hubiera regulado bastante el tema de los mercados.

Hay un claro problema de promoción de los vinos de Méntrida,. a mí se me abren las carnes cuando digo mira que la Comunidad de Madrid tiene más fama los vinos de la Comunidad de Madrid que los de Méntrida, ipero si no tienen viñas!. Se ha hecho un plan de marketing, se ha sabido mover mejor pero ha sido desde la 
administración se ha tomado eso como un impulso, y la marca M de Madrid que es algo desde hace dos o tres años se ha fomentado.

A mí por ejemplo que me gusta el vino y tal me gusta probar vinos y tal es que hablo con gente, compro vinos en tiendas especializadas y Méntrida no se conoce sólo algunos sí pero están muy metido en ello.

Tenemos una atomización excesiva te lo he comentado antes de hecho. Ahí, si que la Administración ha hecho un gran esfuerzo porque he ido a varias reuniones que nos juntemos, que nos juntemos pero no habido forma de juntarnos. Yo creo también que al final las fusiones van a venir solas, porque van a quebrar entonces que hacemos aquí vámonos a otro lado como ha pasado en Santa Cruz de Retamar que hacemos aquí con instalaciones totalmente obsoletas cerrada que ha pasado en Santa Cruz pues que tenía muy poquitos kilos y ha dicho que hacemos aquí pues vamos a Fuensalida.

Hace tiempo ya 3-4años que ya hablamos por ejemplo en La Torre de Esteban Hambrán que hay 2 cooperativas pequeñas que cada una no cogen ni 2 millones de kilos, no somos capaces de juntarnos, fíjate yo soy de las dos pero no somos capaces. Hace tres o cuatro años dijimos vamos a juntarnos las dos la torre, Santa Cruz y Méntrida y no hubo forma yo dije al final caerán y mira Santa Cruz ya caído hecho un acuerdo intercooperativa con Fuensalida para elaborar el vino conjuntamente. El futuro pues van a ir por ahí las cosas de aquí a 3-4 años cuando empiecen a producir todas nuevas plantaciones que se han puesto ahora ya veremos qué pasa.

Hay un departamento en la Consejería que se llama regulación de mercados se lo he dicho a ellos y me dicen que es complicado, por ejemplo en la mancha va pasar lo mismo, se están poniendo miles de cepas arrancando viejas poniendo regadío en espaldera en intensivo y vamos a ver qué pasa. 
Hace poco venía en el periódico un artículo de las exportaciones a nivel de vino de España mundial, España la que más volumen exportaba y la que menos valor añadido tenía, y eso es malo para todos.

\section{Cómo ves el futuro de la comarca?}

Yo creo que acabarse creo que no, esperemos que no. Lo que cambiará de manos El típico señor que se jubila los hijos dicen que no lo quieren cultivar, pero lo cojo otro agricultor se lo dan en renta y tal y cual y por lo menos se va manteniendo. Una cosa que hizo buena la Consejería hace 4-5 años cuando subvencionó los arranques de viñedo, que obligaban a tener las tierras subvencionadas labradas , hay tierras por ahí que dan pena Santa Cruz, Portillo, da pena ver el campo abandonado.

El tema del relevo generacional yo lo veo complicado. Los jóvenes que hay muy pocos seguirán supongo ir haciéndose con las tierras que vayan dejando. Hay empresitas que son de 4-5 y que van cogiendo volumen de explotación, por eso creo que desaparecer no desaparecerá, cambiará la estructura.

Hay que incidir en la comercialización, las cooperativas vendemos muchas veces a gente de España que yo sé que luego ellos lo exportan y sacarán más que nosotros lo cual es una pena. Se está mejorando mucho la calidad de los vinos, se está invirtiendo mucho y para mi gusto se ha invertido demasiado en activos fijos, se invirtió mucho cooperativas se han hecho a loco pensando que iba a ir mejor y yo creo que poco a poco van a ir cayendo. Las que no crezcan acabarán desapareciendo. 